\title{
Numerical Modeling of Trinity River Shoaling below Wallisville, Texas
}

Joseph V. Letter, Jr., Gary L. Brown, Robert McAdory,

February 2015 and Thad C. Pratt

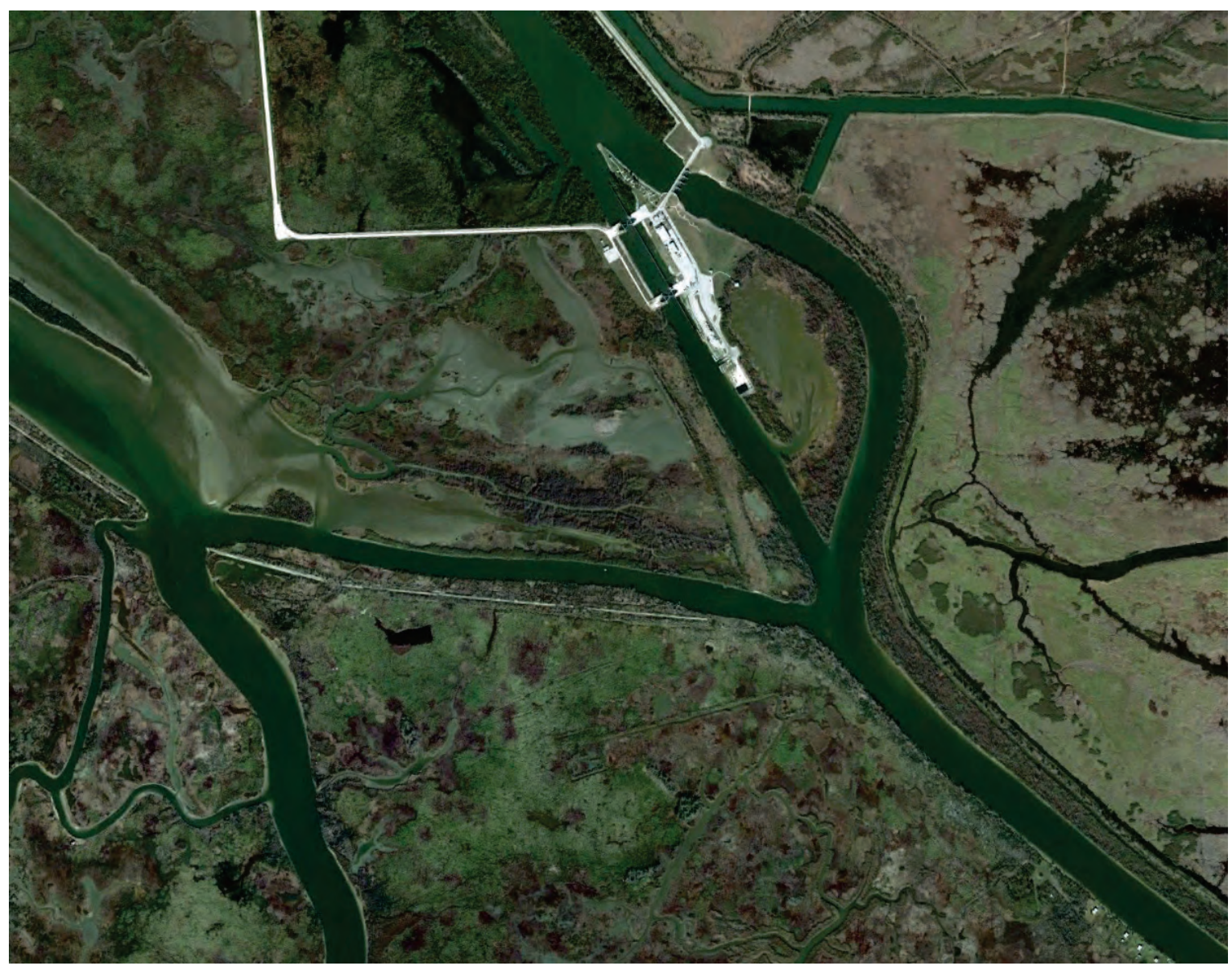


The US Army Engineer Research and Development Center (ERDC) solves the nation's toughest engineering and environmental challenges. ERDC develops innovative solutions in civil and military engineering, geospatial sciences, water resources, and environmental sciences for the Army, the Department of Defense, civilian agencies, and our nation's public good. Find out more at www.erdc.usace.army.mil.

To search for other technical reports published by ERDC, visit the ERDC online library at http://acwc.sdp.sirsi.net/client/default. 


\section{Numerical Modeling of Trinity River Shoaling below Wallisville, Texas}

Joseph V. Letter, Jr., Gary L. Brown, Robert McAdory, and Thad C. Pratt

Coastal and Hydraulics Laboratory

U.S. Army Engineer Research and Development Center 3909 Halls Ferry Road

Vicksburg, MS 39180-6199

Final report

Approved for public release; distribution is unlimited. 


\section{Abstract}

The Trinity River below the navigation lock and salinity control structure at Wallisville, TX, has experienced significant shoaling in recent years. The location of the shoal is immediately downstream of the confluence with the Old River Cut Off channel (ORCO), which has been enlarging and progressively carrying a greater fraction of the discharge at the expense of the Trinity River. The reduction in flow in the Trinity River below the ORCO has resulted in reduced sediment transport capacity which created the shoaling problem. This report presents the results of a numerical model study to evaluate alternatives for potential mitigation of the shoaling problem. The alternatives include dredging the shoal and placing the material into the ORCO, damming the ORCO, and creating partial closure of the ORCO. The model results illustrate the basic problem of an elongated navigation channel with numerous distributary pathways for water and sediment within a deltaic system. The routing of all flow down the Trinity River will result in erosion of the current shoal, but shoaling will then occur below the next bayou that extracts flow from the river.

DISCLAIMER: The contents of this report are not to be used for advertising, publication, or promotional purposes. Citation of trade names does not constitute an official endorsement or approval of the use of such commercial products. All product names and trademarks cited are the property of their respective owners. The findings of this report are not to be construed as an official Department of the Army position unless so designated by other authorized documents. 


\section{Contents}

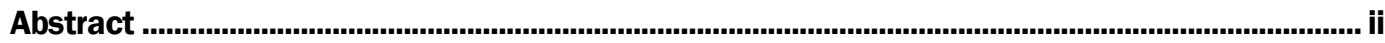

Figures and Tables..................................................................................................................vi

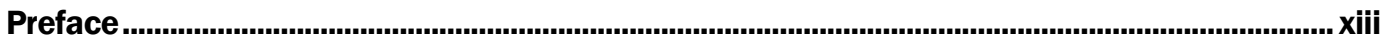

Unit Conversion Factors ..................................................................................................................xiv

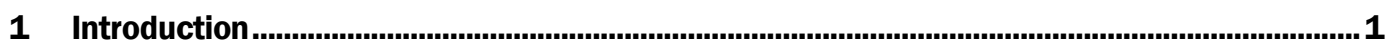

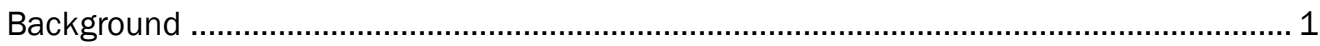

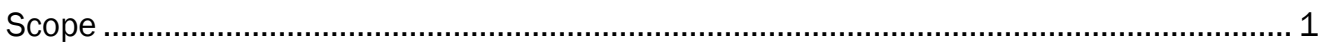

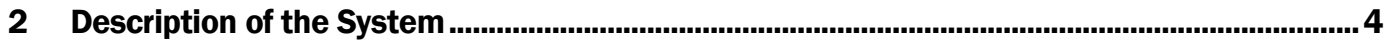

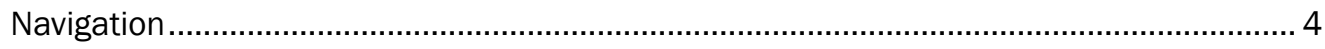

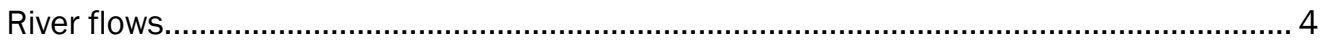

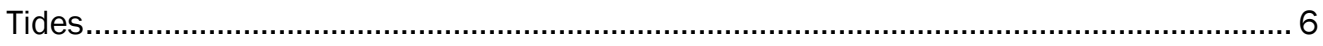

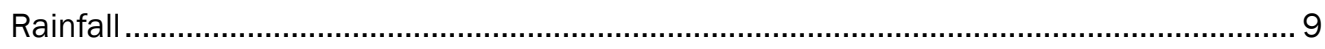

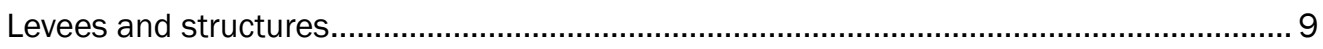

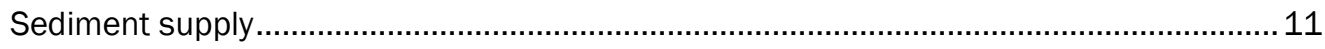

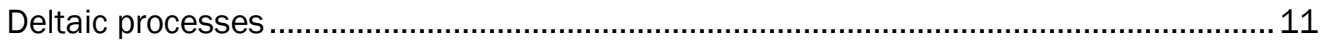

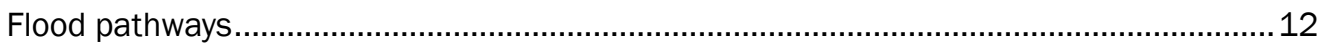

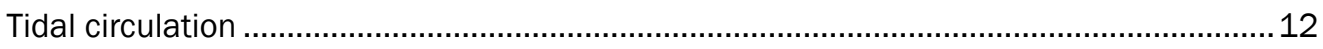

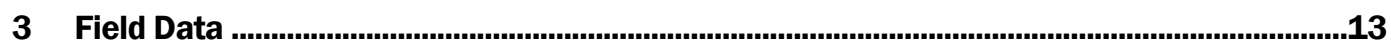

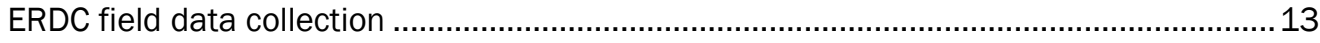

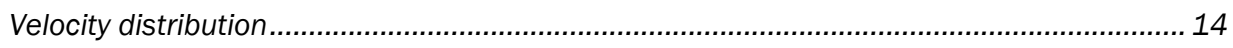

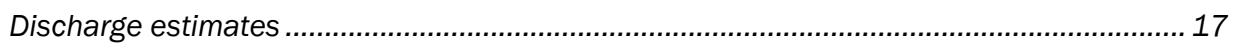

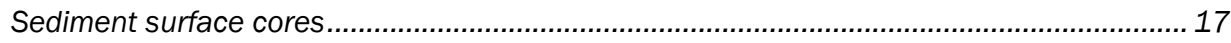

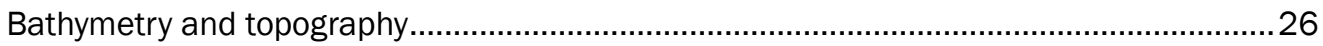

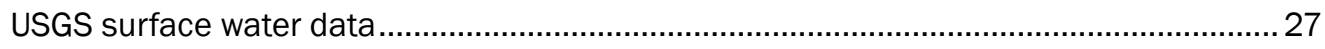

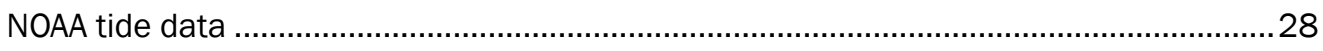

CESWG data and support provided ............................................................................. 30

Rating curves for the salt-barrier tainter gates ................................................................... 30

Operational log for salt barrier and navigation lock......................................................... 30

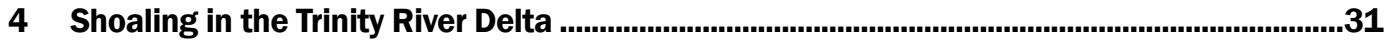

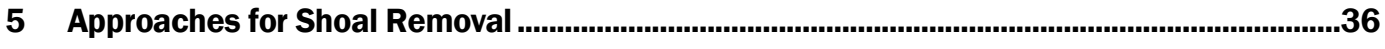

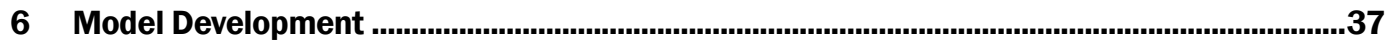

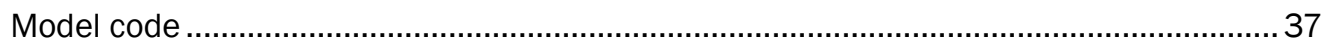

Model domain ........................................................................................................... 37

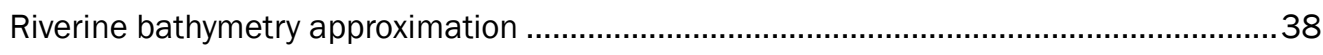

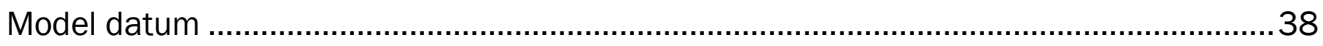




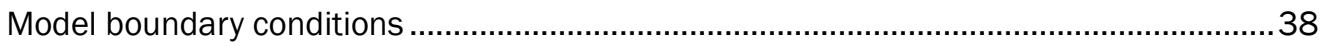

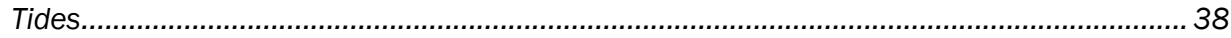

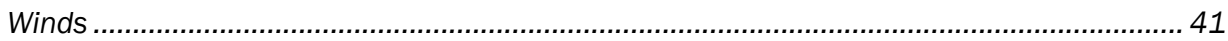

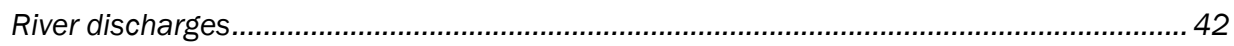

Coastal Water Authority (CWA) canal withdrawals ........................................................... 43

Boundary condition inflow uncertainties .......................................................................... 43

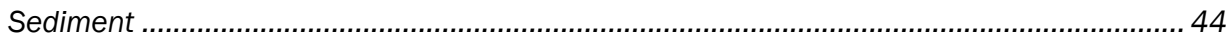

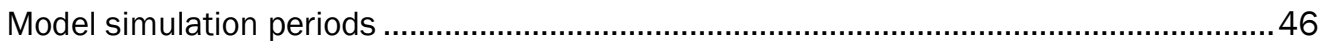

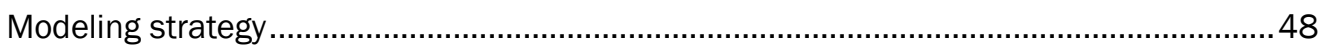

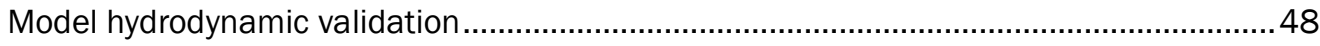

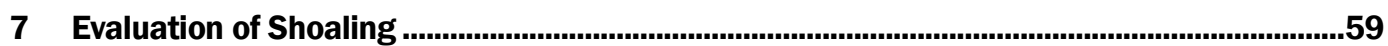

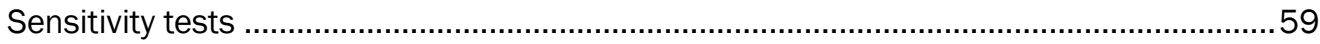

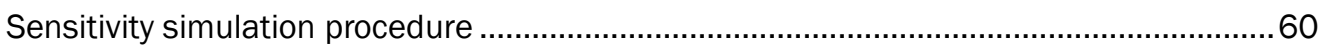

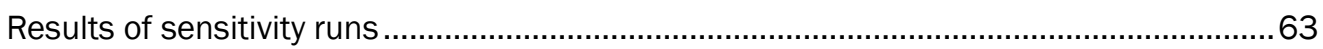

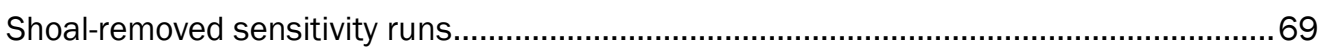

Differences in erosion/deposition with and without the shoal..........................................69

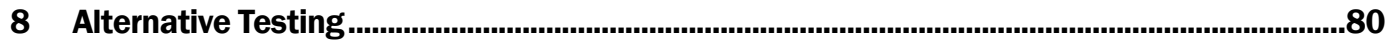

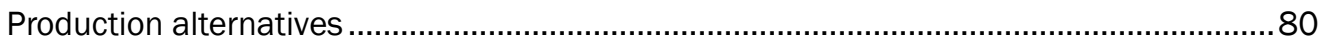

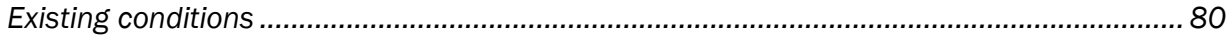

Dredging of the shoal and placing material into ORCO ……........................................... 80

Closure of ORCO by 20\% of the cross-sectional area ……………………………........... 82

Closure of ORCO by $40 \%$ of the cross-sectional area …………………................................ 82

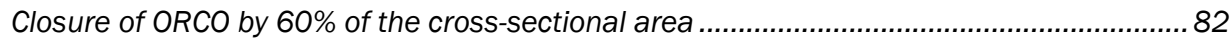

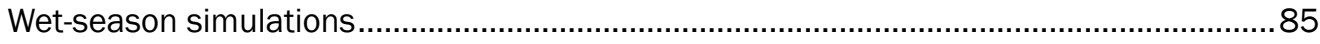

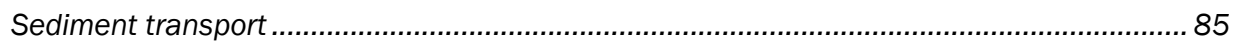

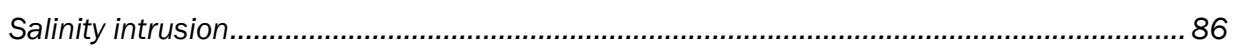

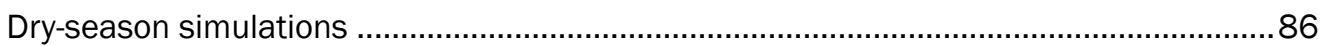

Estimation of flow through partially open salt barrier for the dry-season simulations .......... 88

Estimation of flow through lock during operations for the dry-season simulations ............... 91

Sediment run initialization for dry-season simulations........................................................92

Salinity modeling ......................................................................................................... 93

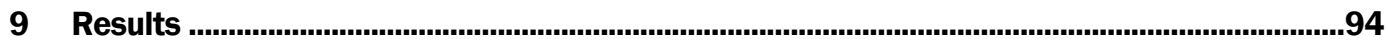

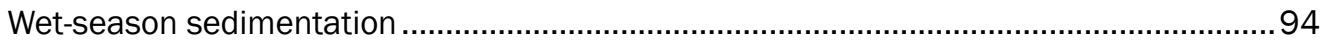

Existing conditions .................................................................................................... 94

Dredging the shoal and placing material into ORCO ……................................................... 95

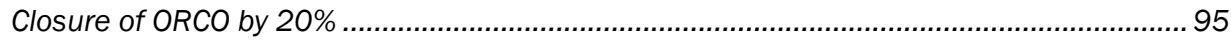

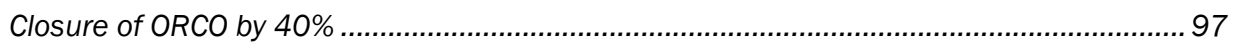

Closure of $\mathrm{ORCO}$ by $60 \%$........................................................................................ 99

Closure of ORCO by 100\%

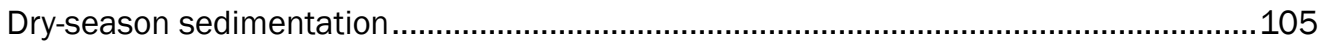

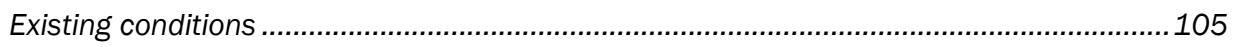

Dredging the shoal and placing material into ORCO .................................................... 107

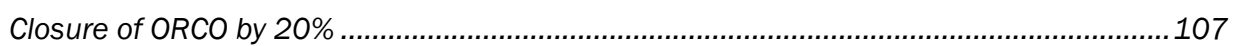

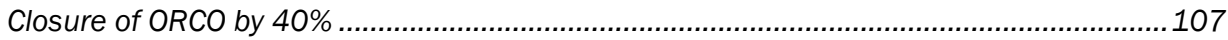




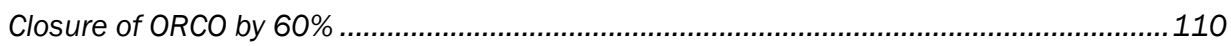

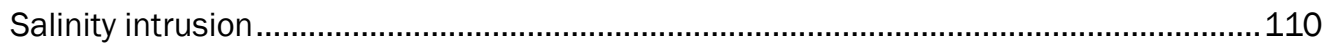

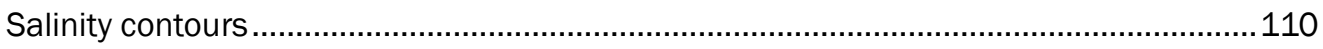

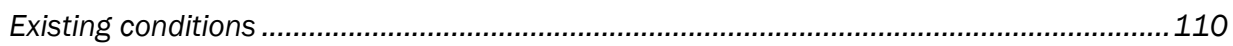

Dredging the shoal and placing material into ORCO ........................................................ 112

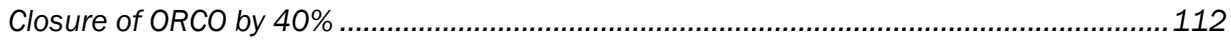

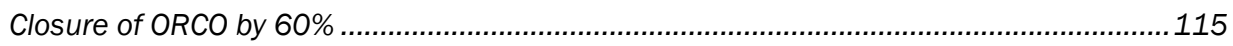

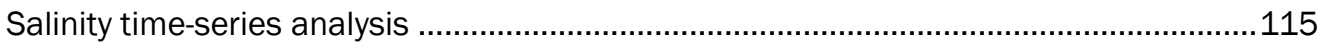

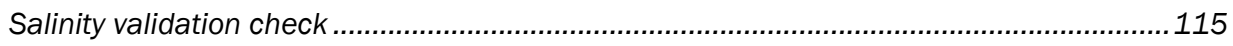

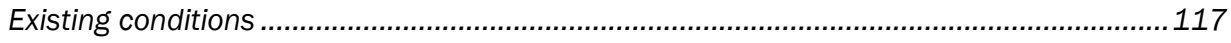

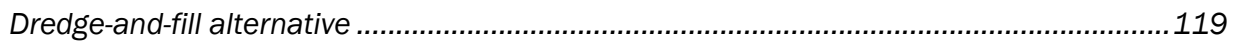

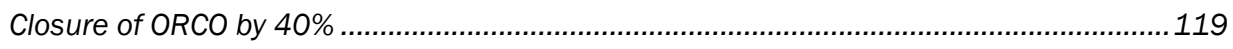

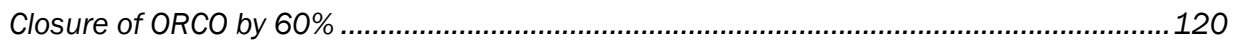

Comparison of responses at the west end of ORCO ........................................................120

Comparison of responses at Port Anahuac ......................................................................... 122

Comparison of responses at the confluence................................................................... 122

Response time for salinity intrusion........................................................................ 123

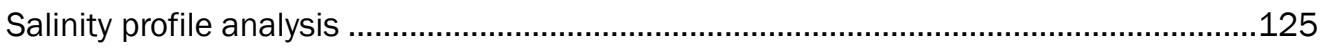

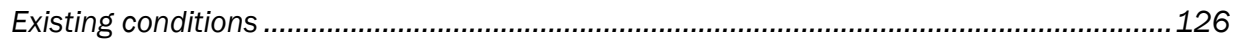

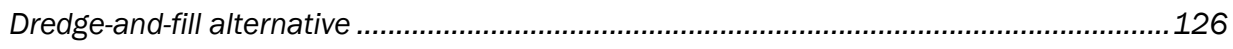

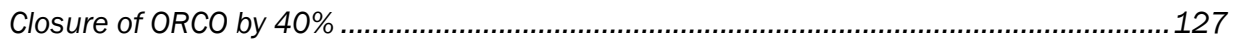

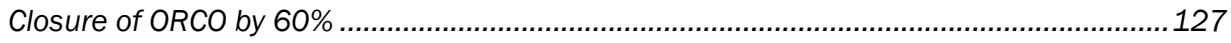

Comparisons at end of the wet-season simulation ..............................................................129

Comparisons at end of dry simulation period 1 ................................................................... 129

Comparisons at end of dry simulation period 2 .............................................................. 130

Comparisons at end of dry simulation period 3 ................................................................. 130

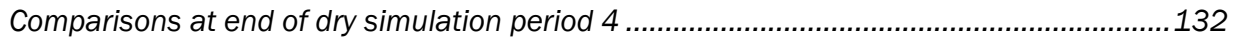

Comparisons at end of dry simulation period 5 ..............................................................132

Comparisons at end of dry simulation period 6 ................................................................... 132

Comparisons at end of dry simulation period 7 ................................................................ 134

10 Conclusions...............................................................................................................................1 135

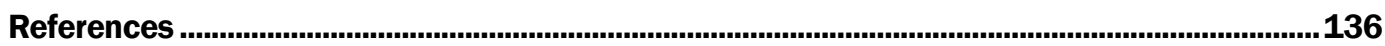

Appendix A: Aerial Photographs of Trinity River Delta Evolution ............................................ 137

Appendix B: Development of Upper River Bathymetry..........................................................149

\section{Report Documentation Page}




\section{Figures and Tables}

\section{Figures}

Figure 1-1. Project location (after Dellapenna et al. 2006)...............................................................

Figure 1-2. Details of the study area and location of the problem shoal. ............................................

Figure 2-1. Trinity River and Tributaries, TX, navigation project. …………………………………....... 5

Figure 2-2. Drainage basin for the Trinity River. ........................................................................ 6

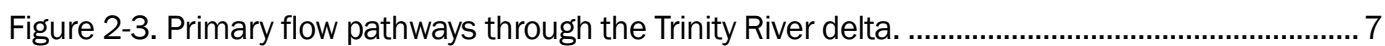

Figure 2-4. Tidal signal at Morgan Point in Galveston Bay; predicted values are astronomical tides

Figure 2-5 Mean tide range in meters at locations in Galveston Bay (data from National

Ocean Service 2006).....................................................................................................................

Figure 2-6 Relative times (in hours) of high water (HW) and low water (LW) (HW/LW) referenced to times of high and low water at Galveston Pier 21 Bay (data from National Ocean Service 2006).

Figure 2-7 Model domain and location of structures...................................................................10

Figure 2-8 Structure A looking downstream toward Old River. ........................................................11

Figure 3-1 Location of ADCP transect cross sections for May 2012 field exercise.............................13

Figure 3-2 Depth-averaged velocity distribution at ADCP transects. Contour range is 0 to 1.22 meters per second (mps)

Figure 3-3 Details of ADCP depth-averaged velocities at the salt-barrier channel transect..............15

Figure 3-4 Details of ADCP depth-averaged velocities at the lock channel transect.

Contour range is $1.22 \mathrm{mps}$.

Figure 3-5 Details of ADCP depth-averaged velocities at the ORCO transect. Contour range is 0 to $1.22 \mathrm{mps}$

Figure 3-6 Details of ADCP depth-averaged velocities at the lower Trinity River transect. 16

Figure 3-7 Flow distribution measurements at the confluence of the Trinity River, lock channel, and ORCO.

Figure 3-8 Location of ERDC bottom cores sampled 10 May 2012.

Figure 3-9 Grain-size distribution curves for bottom surficial core samples 1 through 4 . Sample 1 is on the south bank on the eastern end of ORCO. Sample 3 is on the west bank of the Trinity River adjacent the shoal.

Figure 3-10 Grain-size distribution curves for bottom surficial core samples 5 through 7 . The surface and bottom sample locations refer to the location within the core samples, not the water COLUMN.

Figure 3-11 Grain-size distribution curves for bottom surficial core samples 8 through 12............21

Figure 3-12 Grain-size distribution curves for bottom surficial core samples 13 through 16..................22

Figure 3-13 Grain-size distribution curves for bottom surficial core samples 17 through 21....................22

Figure 3-14 Grain-size distribution curves for bottom surficial core samples 22 through 30 ...................23

Figure 3-15 Grain-size distribution curves for bottom surficial core samples 31 through 35..............23

Figure 3-16 Trinity River profile of field-sample sediment class percentages. 
Figure 3-17 ORCO profile of field-sample sediment class percentages.

Figure 3-18 Trinity River profile of percent finer fractions of surficial sediments. …….....................25

Figure 3-19 TNRIS 10 m LIDAR Data. Elevations are in meters above MLLW...................................26

Figure 3-20 NOAA Estuarine Bathymetry (30 m horizontal resolution) in meters above MLLW.

Figure 3-21 ERDC ADCP profiling and cross-section measurements..............................................28

Figure 3-22 Details of ERDC ADCP bathymetric profiling and cross sections; elevations are in meters above NAVD88.

Figure 3-23 USGS NWIS surface-water elevation data for the verification period.............................29

Figure 4-1 1970 aerial photograph. .........................................................................................32

Figure 4-2 2011 aerial photograph. ................................................................................................32

Figure 4-3 1970 aerial photograph. …………………….........................................................

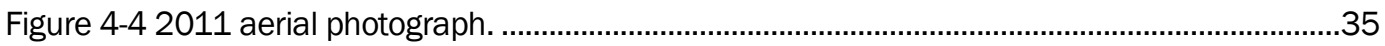

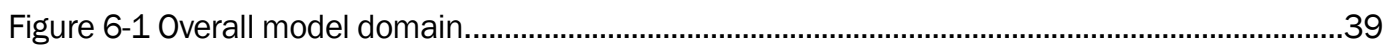

Figure 6-2 Bathymetry of the numerical model; elevations are in meters above NAVD88. ..............40

Figure 6-3 Example of the estimation of point bars along the upper meandering Trinity

River. Red indicates shallow areas; blue indicates deep areas. See Appendix B for details............. 41

Figure 6-4 Filtered wind components for the wet-season simulation period......................................42

Figure 6-5 Filtered wind components for the dry-season simulation period. .....................................43

Figure 6-6. Approximated river discharges for the Trinity River at Liberty, TX..................................44

Figure 6-7 Historical exceedance frequency for Trinity River discharge at Liberty, TX

(National Weather Service, NOAA, Advanced Hydrologic Prediction Service:

http://water.weather.gov).

Figure 6-8 Historical exceedance frequency for the Trinity River stage at Liberty, TX (National Weather Service, NOAA, Advanced Hydrologic Prediction Service: http://water.weather.gov ).

Figure 6-9 Simulation periods for wet and dry seasons based on river inflows.

Figure 6-10 Wet-season simulation period; observed tidal signals upstream and downstream of the salt barrier. The barrier open flag (right vertical axis) is equal to 1 when the barrier is open and 0 when closed.

Figure 6-11 Selection of simulation period for dry season. Vertical axis is truncated so details of lower flows can be seen.

Figure 6-12 Locations of observed water surface elevation data for model validation.

Figure 6-13 Model overall response in water surface elevation during the wet-season validation.

Figure 6-14 Wet-season water surface elevation validation at the downstream side of the salt barrier at Wallisville, TX.

Figure 6-15 Wet-season water surface elevation validation at the upstream side of the salt barrier at Wallisville, TX.

Figure 6-16 Wet-season water surface elevation validation at Lake Charlotte.

Figure 6-17 Wet-season water surface elevation validation at the downstream side of The Cutoff tide gate near Moss Bluff, TX.

Figure 6-18 Wet-season water surface elevation validation at the upstream side of the tide gate in The Cutoff near Moss Bluff, TX. 
Figure 6-19 Wet-season water surface elevation validation at the Trinity River at Moss Bluff, TX

Figure 6-20 Wet-season water surface elevation validation at the Trinity River at Liberty, TX...............54

Figure 6-21 Dry-season water surface elevation validation at the downstream side of the salt barrier at Wallisville, TX

Figure 6-22 Dry-season water surface elevation validation at the upstream side of the salt barrier at Wallisville, TX. 55

Figure 6-23 Dry-season water surface elevation validation at Lake Charlotte.

Figure 6-24 Dry-season water surface elevation validation at the downstream side of the tide gate (Structure A) in the Cut Off that runs south from Mark's Bend on the Trinity River near Moss Bluff, TX.

Figure 6-25 Dry-season water surface elevation validation at the upstream side of the tide gate (Structure A) in the Cut Off that runs south from Mark's Bend on the Trinity River near Moss Bluff, TX.

Figure 6-26 Dry-season water surface elevation validation at the Trinity River at Moss Bluff, TX. 57

Figure 6-27 Dry-season water surface elevation validation at the Trinity River at Liberty, TX................58

Figure 6-28 Validation of discharges at the confluence..................................................................58

Figure 7-1 Model initial sediment size distribution compared to field sample distributions.............60

Figure 7-2 Bed initialization results: active layer $\mathrm{D}_{50}$ grain size. 61

Figure 7-3 Profile of $D_{50}$ size after model bed initialization simulation compared to field sediment data

Figure 7-4 Original bathymetric elevations (-4, $0 \mathrm{~m}$ contour range).

Figure 7-5 Thickness of sediment removed for sediment sensitivity testing $(0,2 \mathrm{~m}$ contour range). Volume removed was $65,891 \mathrm{~m}^{3}\left(86,116 \mathrm{yd}^{3}\right)$.

Figure 7-6 Deepened elevations for sediment sensitivity testing ( -4 to $0 \mathrm{~m}$ contour range)....................64

Figure 7-7 Deposition and erosion for sediment sensitivity run LOBOCO with existing depths..................65

Figure 7-8 Deposition and erosion for sediment sensitivity run LXBOCO with existing depths. .................66

Figure 7-9 Deposition and erosion for sediment sensitivity run LOBXCO with existing depths...................66

Figure 7-10 Deposition and erosion for sediment sensitivity run LOBOCX with existing depths. ..............67

Figure 7-11 Deposition and erosion for sediment sensitivity run LXBOCX with existing depths. ...............68

Figure 7-12 Deposition and erosion for sediment sensitivity run LOBXCX with existing depths................68

Figure 7-13 Deposition and erosion for sediment sensitivity run LOBOCO with shoal removed...............69

Figure 7-14 Deposition and erosion for sediment sensitivity run LXBOCO with shoal removed. ...............70

Figure 7-15 Deposition and erosion for sediment sensitivity run LOBXCO with shoal removed................70

Figure 7-16 Deposition and erosion for sediment sensitivity run LOBOCX with shoal removed. ...............71

Figure 7-17 Deposition and erosion for sediment sensitivity run LXBOCX with shoal removed.................71

Figure 7-18 Deposition and erosion for sediment sensitivity run LOBXCX with shoal removed...............72

Figure 7-19 Difference in deposition/erosion for sediment sensitivity run LOBOCO (shoal removed-existing)

Figure 7-20 Difference in deposition/erosion for sediment sensitivity run LXBOCO (shoal removed-existing).

Figure 7-21 Difference in deposition/erosion for sediment sensitivity run LOBXCO (shoal removed-existing). 
Figure 7-22 Difference in deposition/erosion for sediment sensitivity run LOBOCX (shoal removed-existing)

Figure 7-23 Difference in deposition/erosion for sediment sensitivity run LXBOCX (shoal removed-existing)

Figure 7-24 Difference in deposition/erosion for sediment sensitivity run LOBXCX (shoal removed-existing)

Figure 7-25 Deposition/erosion comparison of existing bathymetry vs. dredged condition for LOBOCO.

Figure 7-26 Deposition/erosion comparison of existing bathymetry vs. dredged condition for LXBOCO.

Figure 7-27 Deposition/erosion comparison of existing bathymetry vs. dredged condition for LOBXCO.

Figure 7-28 Deposition/erosion comparison of existing bathymetry vs. dredged condition for LOBOCX.

Figure 7-29 Deposition/erosion comparison of existing bathymetry vs. dredged condition for LXBOCX.

Figure 7-30 Deposition/erosion comparison of existing bathymetry vs. dredged condition for LOBXCX.

Figure 8-1 Bathymetry of existing conditions.

Figure 8-2 Bed changes as a result of dredging Trinity River shoal and placing the material in ORCO.

Figure 8-3 Bathymetry after the dredge-and-placement alternative.

Figure 8-4 Mesh configuration for $20 \%$ reduction in ORCO cross section (top) and bathymetry (bottom).

Figure $8-5$ Mesh configuration for $40 \%$ reduction in ORCO cross section (top) and bathymetry (bottom).

Figure 8-6 Mesh configuration for 60\% reduction in ORCO cross section (top) and bathymetry (bottom).

Figure 8-7 Initial salinities for wet-season salinity simulation. Red is $30 \mathrm{psu}$ and blue is $0 \mathrm{psu}$...............86

Figure 8-8 Definition sketch for tainter gate in open-channel flow.

Figure 8-9. Flow through the salt-barrier structure estimated by Equation 8-3.

Figure 8-10. The time series of equivalent net flow through the Wallisville lock.

Figure 9-1 Deposition and erosion for the wet season for existing conditions in the vicinity of the primary channel confluence.

Figure 9-2 Deposition and erosion over the Trinity River delta for the wet season for existing conditions

Figure 9-3 Deposition and erosion for the wet season for dredging the Trinity River and placing the material uniformly into ORCO in the vicinity of the primary channel confluence.

Figure 9-4 Deposition and erosion over the Trinity River delta for the wet season for dredging the Trinity River and placing the material uniformly into ORCO.

Figure 9-5 Deposition and erosion for the wet season for $20 \%$ closure of ORCO in the vicinity of the primary channel confluence.

Figure 9-6 Deposition and erosion over the Trinity River delta for the wet season for $20 \%$ closure of ORCO. 
Figure 9-7 Deposition and erosion for the wet season for $40 \%$ closure of ORCO in the vicinity of the primary channel confluence.

Figure 9-8 Deposition and erosion over the Trinity River delta for the wet season for $40 \%$ closure of ORCO. 102

Figure 9-9 Deposition and erosion for the wet season for $60 \%$ closure of ORCO in the vicinity of the primary channel confluence.

Figure 9-10 Deposition and erosion over the Trinity River delta for the wet season for $60 \%$ closure of ORCO. 104

Figure 9-11 Deposition and erosion for the wet season for $100 \%$ closure of ORCO in the vicinity of the primary channel confluence. 105

Figure 9-12 Deposition and erosion over the Trinity River delta for the wet season for $100 \%$ closure of ORCO. 106

Figure 9-13 Dry-season erosion and deposition for existing conditions. 107

Figure 9-14 Dry-season erosion and deposition for dredge-and-fill conditions............................... 108

Figure 9-15 System-wide, dry-season erosion and deposition for dredge-and-fill........................... 108

Figure 9-16 Dry-season erosion and deposition for 20\% closure of ORCO. .................................... 109

Figure 9-17 Dry-season erosion and deposition for 40\% closure of ORCO. .................................... 109

Figure 9-18 Dry-season erosion and deposition for 60\% closure of ORCO. .................................. 110

Figure 9-19 Salinity contours for existing conditions at the end of each simulation period segment.

Figure 9-20 Salinity contours for dredging the shoal and placing the material into ORCO at the end of each simulation period segment.

Figure 9-21 Salinity contours for $40 \%$ closure of ORCO at the end of each simulation period segment.

Figure 9-22 Salinity contours for $60 \%$ closure of ORCO at the end of each simulation period segment.

Figure 9-23 Location of stations for salinity time-series analysis......................................................117

Figure 9-24 Validation of salinity response................................................................................ 118

Figure 9-25 Time series of salinity at analysis stations for existing-conditions results.................. 118

Figure 9-26 Time series of salinity at analysis stations for the alternative of dredging the shoal and placing the material into ORCO.

Figure 9-27 Time series of salinity at analysis stations for results of 40\% closure of ORCO. ........ 120

Figure 9-28 Time series of salinity at analysis stations for results of 60\% closure of ORCO. ........ 121

Figure 9-29 Time series of salinity at analysis stations for all alternatives at the west end of ORCO.

Figure 9-30 Time series of salinity at analysis stations for all alternatives at Port Anahuac. ........ 122

Figure 9-31 Time series of salinity at analysis stations for all alternatives at the confluence of the Trinity River and the downstream lock channel.

Figure 9-32 Comparison of the salinity response time between alternatives as a function of the threshold salinity level.

Figure 9-33 Salinity profile alignment for analysis.

Figure 9-34 Salinity profile for existing conditions at the end of the wet season and all dryseason simulation periods. 
Figure 9-35 Salinity profiles for the dredge-and-fill alternative at the end of the wet season and all dry-season simulation periods.

Figure 9-36 Salinity profile for 40\% closure of ORCO condition at the end of the wet

season and all dry-season simulation periods. 128

Figure 9-37 Salinity profile for $60 \%$ closure of ORCO condition at the end of the wet season and all dry-season simulation periods. 128

Figure 9-38 Salinity profile for all alternatives at the end of the wet season. 129

Figure 9-39 Salinity profile for all alternatives at the end of the dry season period 1. 130

Figure 9-40 Salinity profile for all alternatives at the end of the dry season period 2. 131

Figure 9-41 Salinity profile for all alternatives at the end of the dry season period 3. 131

Figure 9-42 Salinity profile for all alternatives at the end of the dry season period 4. 132

Figure 9-43 Salinity profile for all alternatives at the end of the dry season period 5. ................... 133

Figure 9-44 Salinity profile for all alternatives at the end of the dry season period 6. ................... 133

Figure 9-45 Salinity profile for all alternatives at the end of the dry season period 7.................... 134

Figure B-1 Example bendway on the lower Trinity River below Liberty, TX................................... 149

Figure B-2 Distortion of the parabolic cross section for increasing values of $\alpha$ greater than 1.......... 151

Figure B-3 Effect of the distortion exponent on the ratio of maximum water depths. .................... 152

Figure B-4 Illustration of depth sensitivity for point-bar emergence. ............................................. 153

Figure B-5 Locations of ADCP cross sections....................................................................... 155

Figure B-6 Fit of Equation B-9 to ADCP cross section 1........................................................... 155

Figure B-7 Fit of Equation B-9 to ADCP cross section 2 …............................................................ 156

Figure B-8 Fit of Equation B-9 to ADCP cross section 3........................................................ 156

Figure B-9 Fit of Equation B-9 to ADCP cross section 4 ……................................................... 157

Figure B-10 Fit of Equation B-9 to ADCP cross section 5 .......................................................... 157

Figure B-11 Fit of Equation B-9 to ADCP cross section 6. ........................................................ 158

Figure B-12 Fit of Equation B-9 to ADCP cross section 7.......................................................... 158

Figure B-13 Fit of Equation B-9 to ADCP cross section 8 .......................................................... 159

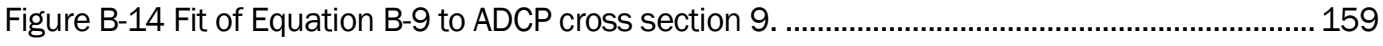

Figure B-15 Fit of Equation B-9 to ADCP cross section 10.......................................................... 160

Figure B-16 Fit of Equation B-9 to ADCP cross section 11........................................................... 160

Figure B-17 Fit of Equation B-9 to ADCP cross section 12 ......................................................... 161

Figure B-18 Fit of Equation B-9 to ADCP cross section 13............................................................ 161

Figure B-19 Fit of Equation B-9 to ADCP cross section 14......................................................... 162

Figure B-20 Fit of Equation B-9 to ADCP cross section 15......................................................... 162

Figure B-21 Fit of Equation B-9 to ADCP cross section 16. ……................................................ 163

Figure B-22 Fit of Equation B-9 to ADCP cross section 17......................................................... 163

Figure B-23 Fit of Equation B-9 to ADCP cross section 18 ......................................................... 164

Figure B-24 AdH model mesh development in the vicinity of the observed Trinity River bendway. The division of the river channel into segments for the application of the analytical bathymetric bendway distortion is illustrated.

Figure B-25 Methodology for the application of the cross-section distortion above I-10.

Cross sections were generated at vertices along the shoreline arcs. 165 
Figure B-26 Overall extent of river segments with analytically generated bathymetry using the bendway distortion methodology. 166

Figure B-27 Example of the analytically developed bathymetry in the numerical model.

\section{Tables}

Table 3-1 Sediment core sampling depths and field notations...........................................................19

Table 3-2 Summary of ADCP discharge estimates.....................................................................20

Table 7-1 Sediment transport sensitivity simulation run configurations.............................................59

Table 7-2 Sediment model grain size initial specification. ................................................................60

Table 8-1 All possible combinations of configurations for the lock (L), salt barrier $(B)$, and Structure A (A), open (O) and closed (X). Only the configurations shaded blue were used in the dry-season simulation.

Table 8-2 Simulation segments for the dry-season simulation period. The gray shading identifies common mesh configurations.

Table 9-1. Summary of salinity response....................................................................................... 124

Table B-1 Point-bar encroachment into cross section..................................................................... 154 


\section{Preface}

This report presents the results of numerical modeling and analyses performed by the U.S. Army Engineer Research and Development Center (ERDC), Coastal and Hydraulics Laboratory (CHL), Estuarine Engineering Branch (HFE), at the request of the U.S. Army Engineer District, Galveston (CESWG), to evaluate alternatives for mitigation of sedimentation problems in the lower Trinity River channel downstream of the Wallisville structures. The work was performed during the period of J uly 2012- May 2013 by Dr. J oseph V. Letter, Jr. (CEERD-HFE-L), in consultation with Gary Brown (CEERD-HFE-S) and Dr. Robert McAdory (CEERD-HFE), under the general supervision of J osé E. Sánchez, Director, CHL. Data were collected by Thad C. Pratt (CEERD-HNF-M). Direct supervision was provided by Dr. Ty Wamsley, Chief, Flood and Storm Protection Division, CEERD-HF, and Dr. Robert McAdory, Chief of the Estuarine Engineering Branch.

COL J effrey R. Eckstein was Commander and Executive Director of ERDC. Dr. J effery P. Holland was Director.

The authors acknowledge the contributions made by Paula Wise, CESWGOD-N, for her efforts in coordinating the logistics of this project at Galveston District and MAJ Gregory Couturier, who was stationed at CESWG at the time this work was performed and who contributed in formulating the plan of the work and the questions, particularly concerning salinity, to be answered by the effort. Richard Long, CESWG-OD-OH, and Charles Scheffler, CESWG-OD-O, coordinated the field data collection and the documentation of the operation of the Wallisville structures and provided information to ERDC for use in the validation of the numerical model. 


\section{Unit Conversion Factors}

\begin{tabular}{|l|c|l|}
\hline Multiply & By & To Obtain \\
\hline cubic feet & 0.02831685 & cubic meters \\
\hline cubic yards & 0.7645549 & cubic meters \\
\hline feet & 0.3048 & meters \\
\hline square feet & 0.09290304 & square meters \\
\hline inches & 25400.30887 & microns \\
\hline cubic meters & 35.31466247 & cubic feet \\
\hline cubic meters & 1.307950547 & cubic yards \\
\hline meters & 3.2808 & feet \\
\hline square meters & 10.76391042 & square feet \\
\hline microns & 0.000039369599997 & inches \\
\hline
\end{tabular}




\section{Introduction}

\section{Background}

In March 2012, the U.S. Army Engineer District, Galveston (CESWG), requested that the U.S. Army Engineer Research and Development Center (ERDC) study the shoal that had formed in the Trinity River just downstream of the confluence of the lock channel and the salt-barrier discharge channel at Wallisville, TX. The study area is at the lower end of the Trinity River on the northeast side of Trinity Bay within the greater Galveston Bay system (Figure 1-1). The subject shoal is located in the navigation channel just south of the Wallisville Lock and Salinity Control Structure (Figure 1-2) and just below the Old River Cut Off (ORCO) channel. The ORCO channel is an important component of the lower river and has been diverting an increasing portion of the total flow in response to geomorphologic flow rerouting within the overall Trinity River delta. A field data collection effort was mobilized by ERDC in May 2012. Subsequently, ERDC was asked to conduct a sediment transport study of the problem to evaluate potential remedial measures.

\section{Scope}

This report documents the numerical modeling and analysis performed by ERDC to evaluate the subject shoal. The goals of the modeling and analysis are to provide greater insight into the causes of the shoaling and the changes associated with historical system modifications and to develop a tool to evaluate various alternatives for mitigating the shoaling. Specifically, the goal of the project is to determine if it is possible, in principle, to remove the Trinity River shoal below the ORCO/Trinity River split by manipulation of the ORCO. 
Figure 1-1. Project location (after Dellapenna et al. 2006).

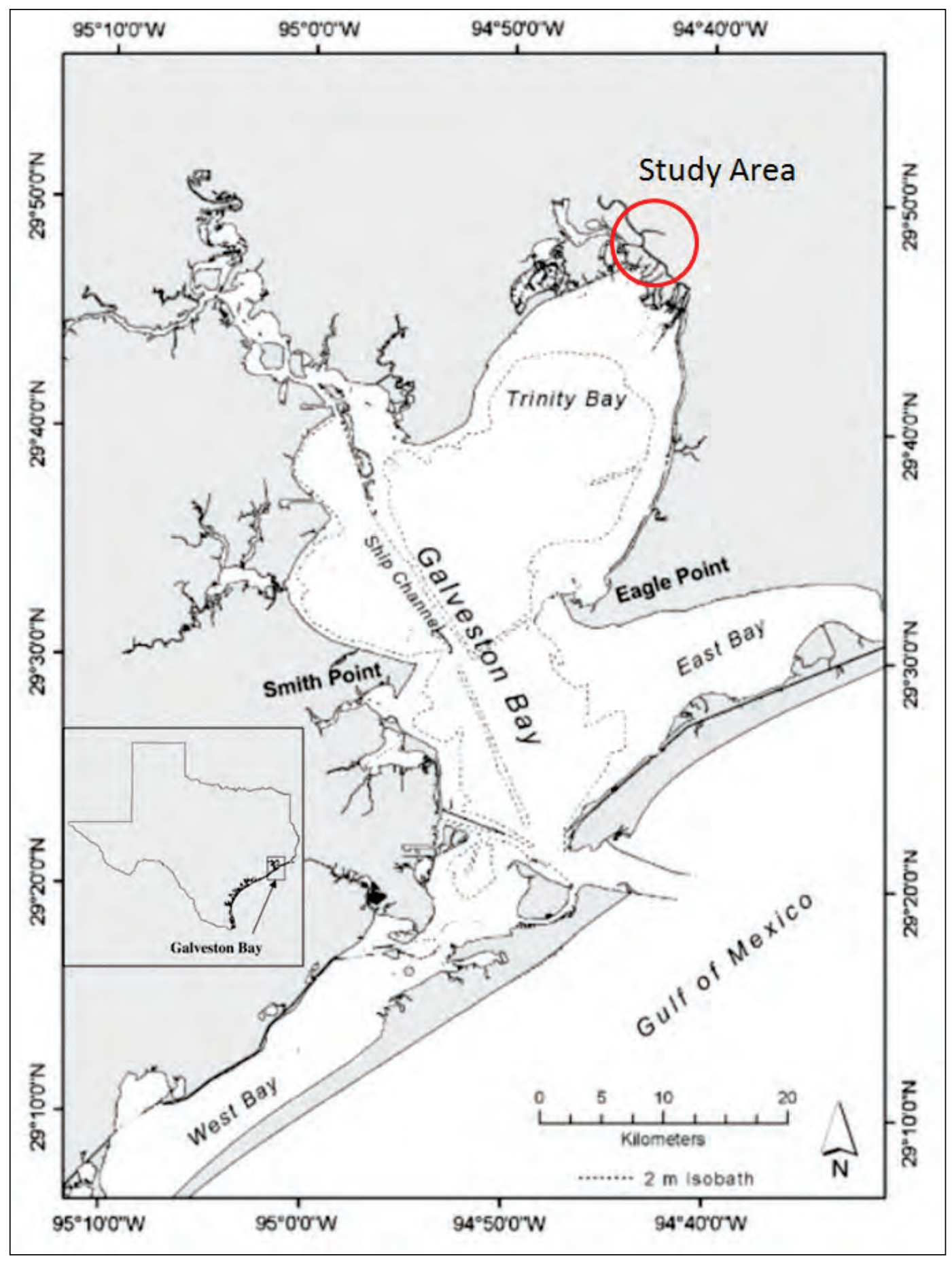


Figure 1-2. Details of the study area and location of the problem shoal.

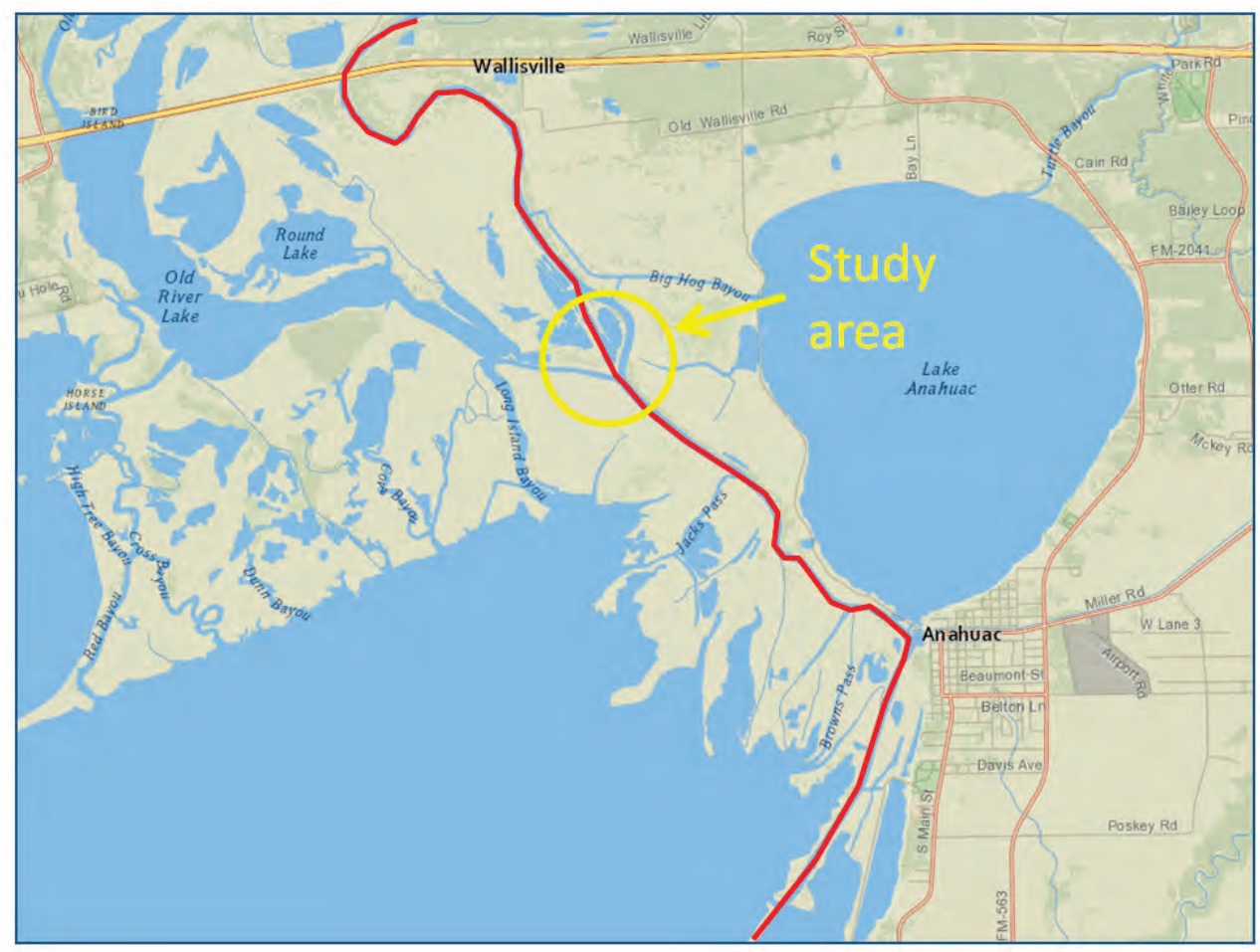

a. General study area.

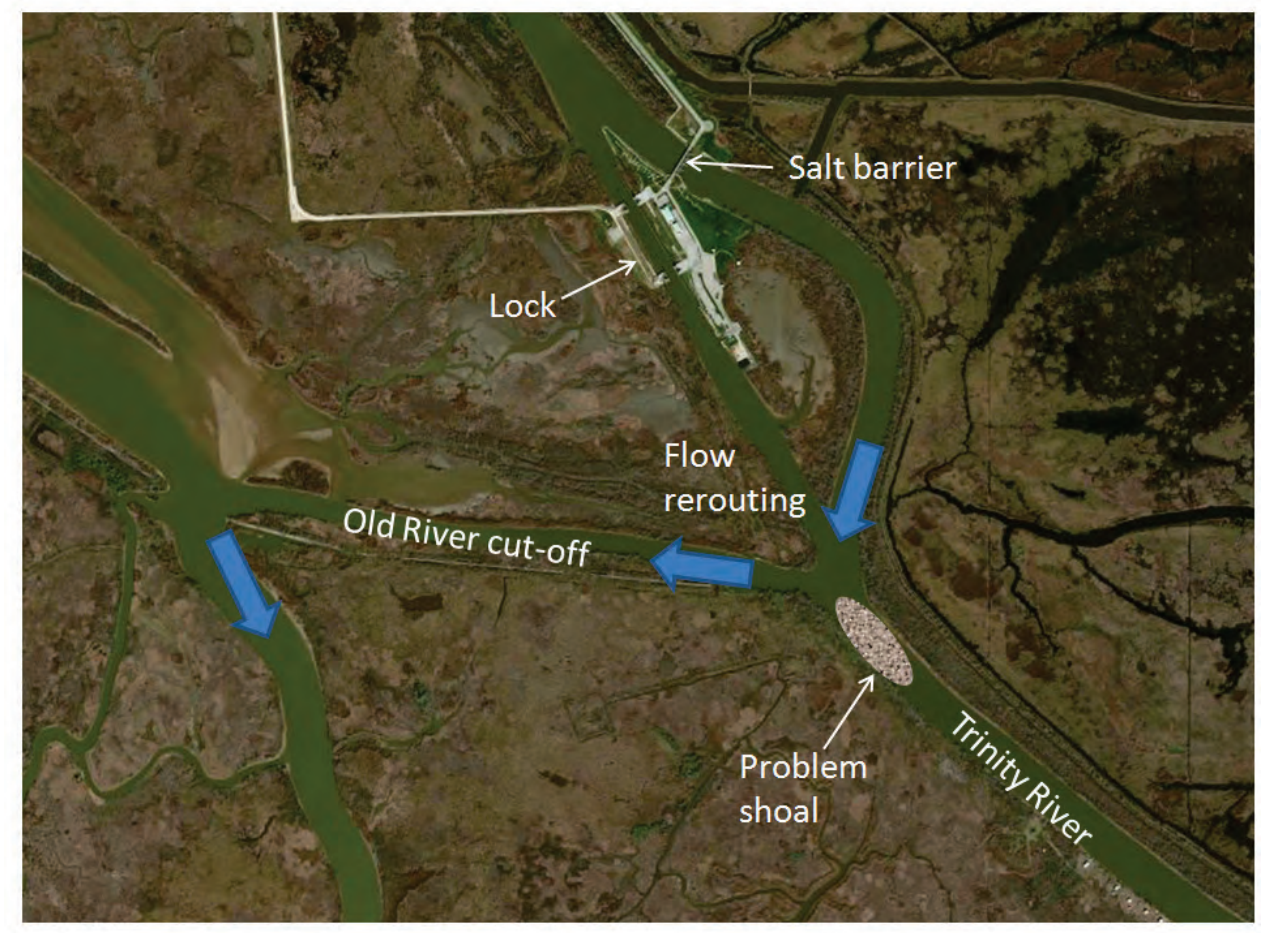

b. Aerial view of structures and location of the shoal. 


\section{Description of the System}

\section{Navigation}

The Trinity River and Tributaries Project is a 76-kilometer ( $\mathrm{km})$, shallowdraft waterway beginning with the Anahuac Channel which extends for $9 \mathrm{~km}$ from the 1.8 meter $(\mathrm{m})$ depth in upper Trinity Bay to the mouth of Trinity River at Anahuac, TX (Figure 2-1). From the mouth of Trinity River, the Channel to Liberty proceeds for $66.6 \mathrm{~km}$ along the meanders of the Trinity River to the Port of Liberty. The project also includes a $2.7 \mathrm{~m}$ depth channel (Channel to Smith Point) extending from the Houston Ship Channel along the east shore of the Trinity Bay to a point $1.6 \mathrm{~km}$ south of Anahuac, TX.

The nonfederal sponsor is the Chambers-Liberty Counties Navigation District. Fiscal Year (FY) 2010 activities included dredging the Anahuac Channel to limited depth and at critical locations. FY 2011 activities included the completion of limited-depth dredging of the Anahuac Channel.

\section{River flows}

The Trinity River basin includes portions of east and north-central Texas (Figure 2-2). The Trinity River begins near the Texas-Oklahoma border, and its watershed encompasses 47,000 square kilometers ( $\mathrm{sq} \mathrm{km}$ ) (7\% of the state's land area), including all or parts of 38 Texas counties (Trinity Waters 2011). Nearly $80 \%$ of water use in the Trinity River basin is necessary to meet municipal demands, and this number is expected to increase as population increases (Trinity Waters 2011).

The Trinity River at Liberty, TX, (U.S. Geological Survey (USGS) station 08067000) has a mean flow of 694 cubic meters per second (cms), median flow of $660 \mathrm{cms}$, a 25 percentile of $453 \mathrm{cms}$, and a 75 percentile of $816 \mathrm{cms}$. The maximum flow over the period of record (1940 to present) was 1,385 cms in 1973. These flows empty into Trinity Bay through the river delta shown in Figure 2-3. 
Figure 2-1. Trinity River and Tributaries, TX, navigation project.

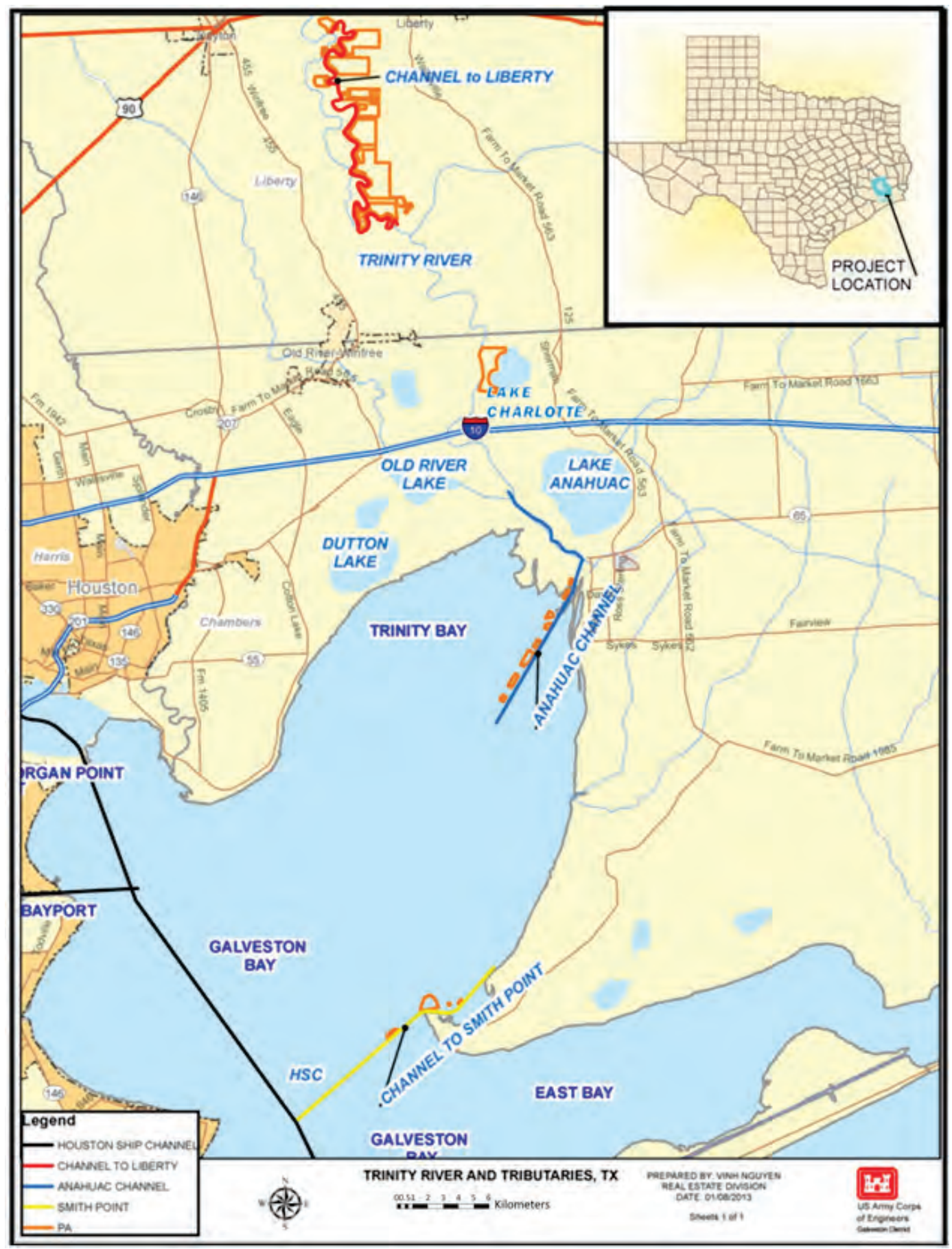


Figure 2-2. Drainage basin for the Trinity River.

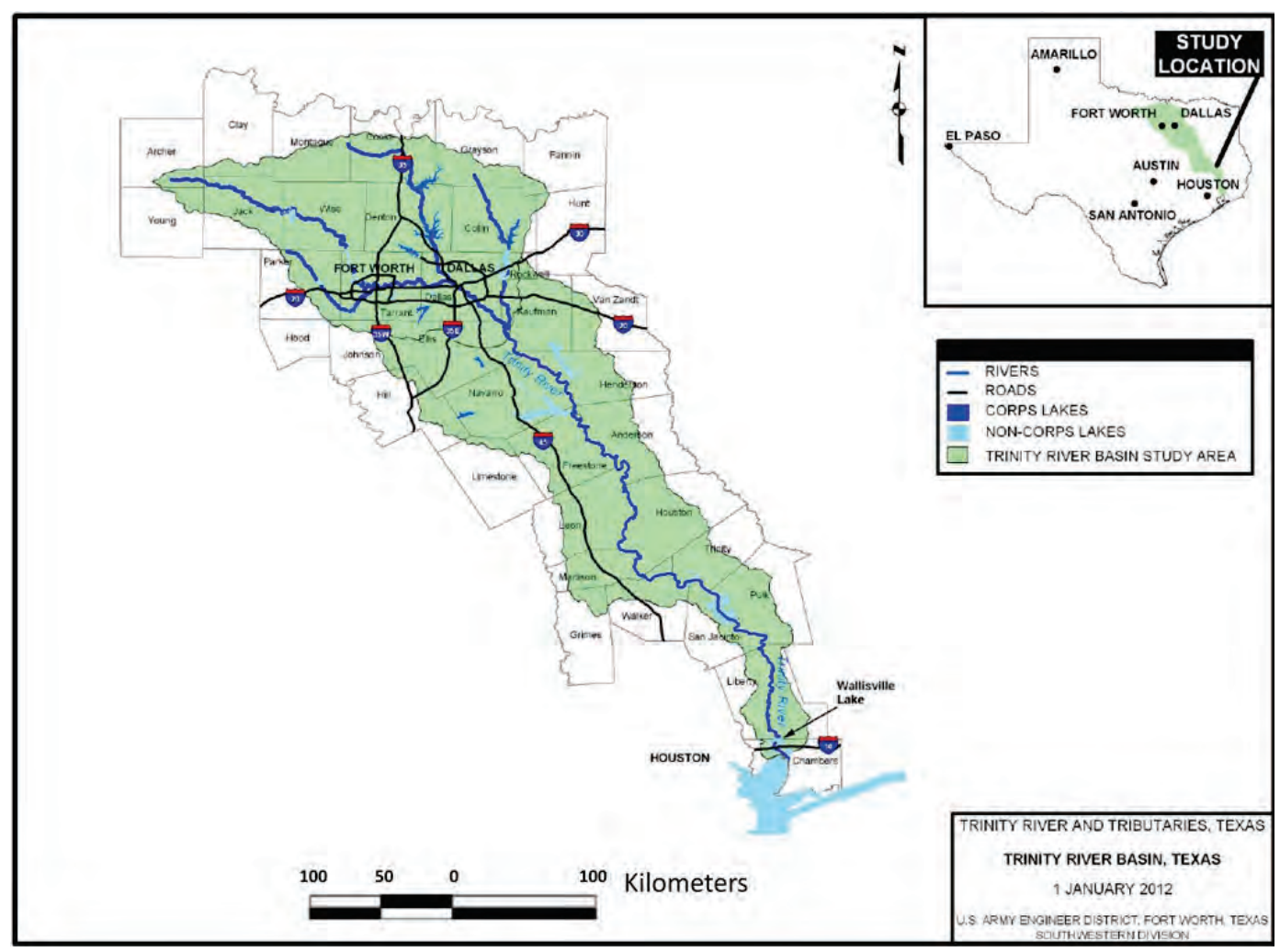

\section{Tides}

The tides in the study area propagate across Trinity Bay from the primary forcing through Bolivar Roads at the coastal inlet entrance to Galveston Bay from the Gulf of Mexico (Figure 2-5). Tides in the bay are diurnal in nature, with the $\mathrm{O} 1$ and $\mathrm{K} 1$ harmonic constituents being dominant. A sample tidal signal for Morgan Point is shown in Figure 2-4. The mean tide range at the entrance to Galveston Bay is approximately $0.43 \mathrm{~m}$. Figure 2-5 presents the variation in mean tide range across Galveston Bay. The tide range diminishes by nearly $50 \%$ before it reaches the Trinity River delta.

The high- and low-water intervals, defined as the average time lag in hours, between the high and low waters relative to the reference tide station at Galveston Pier 21, are presented in Figure 2-6. Notice the very large time lag in high water (HW) for Round Point in Trinity Bay, which shows the effect of the tide propagating against the river flow. The time lag for low water is not as severe as for high water at this location. 
Figure 2-3. Primary flow pathways through the Trinity River delta.

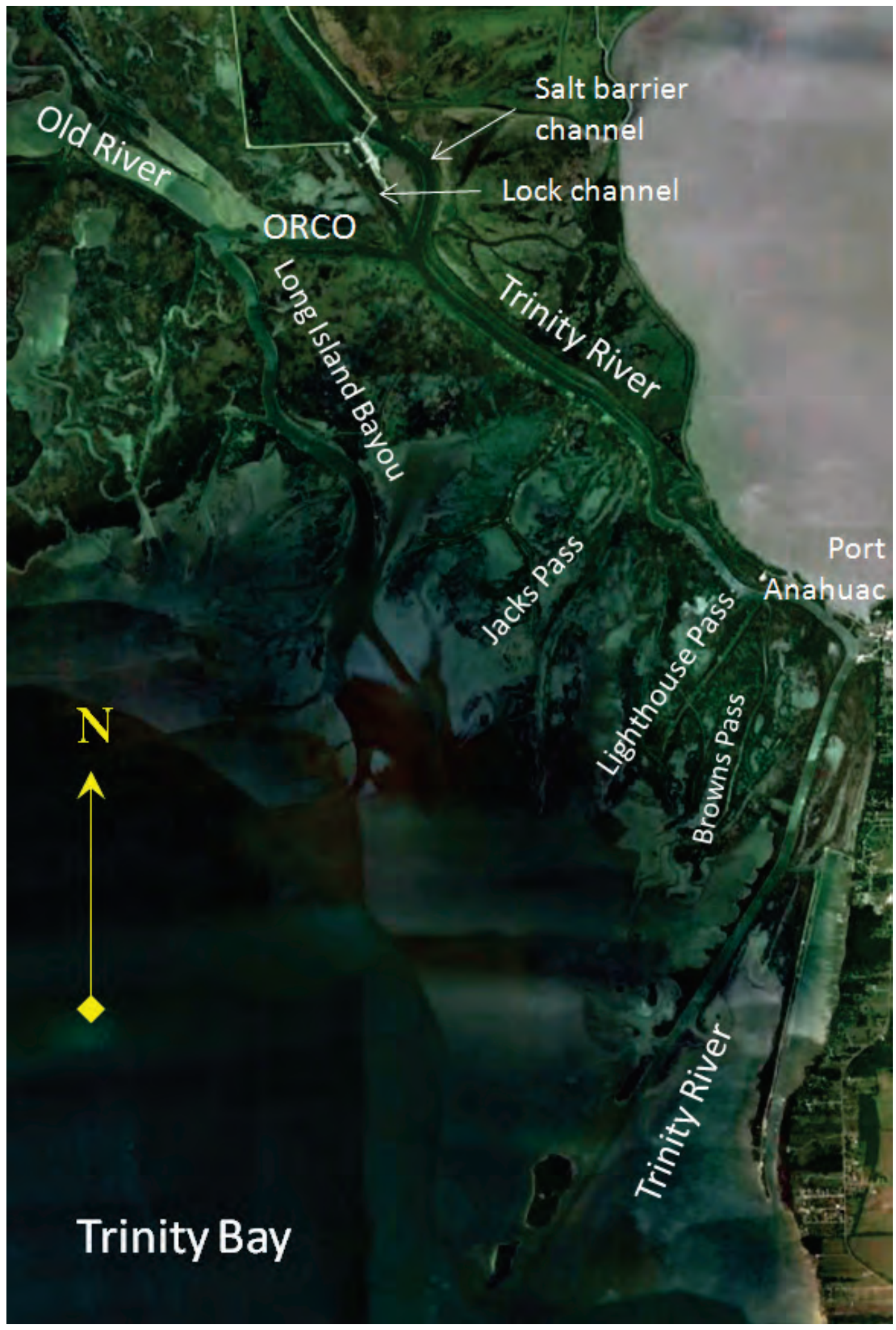


Figure 2-4. Tidal signal at Morgan Point in Galveston Bay; predicted values are astronomical tides.

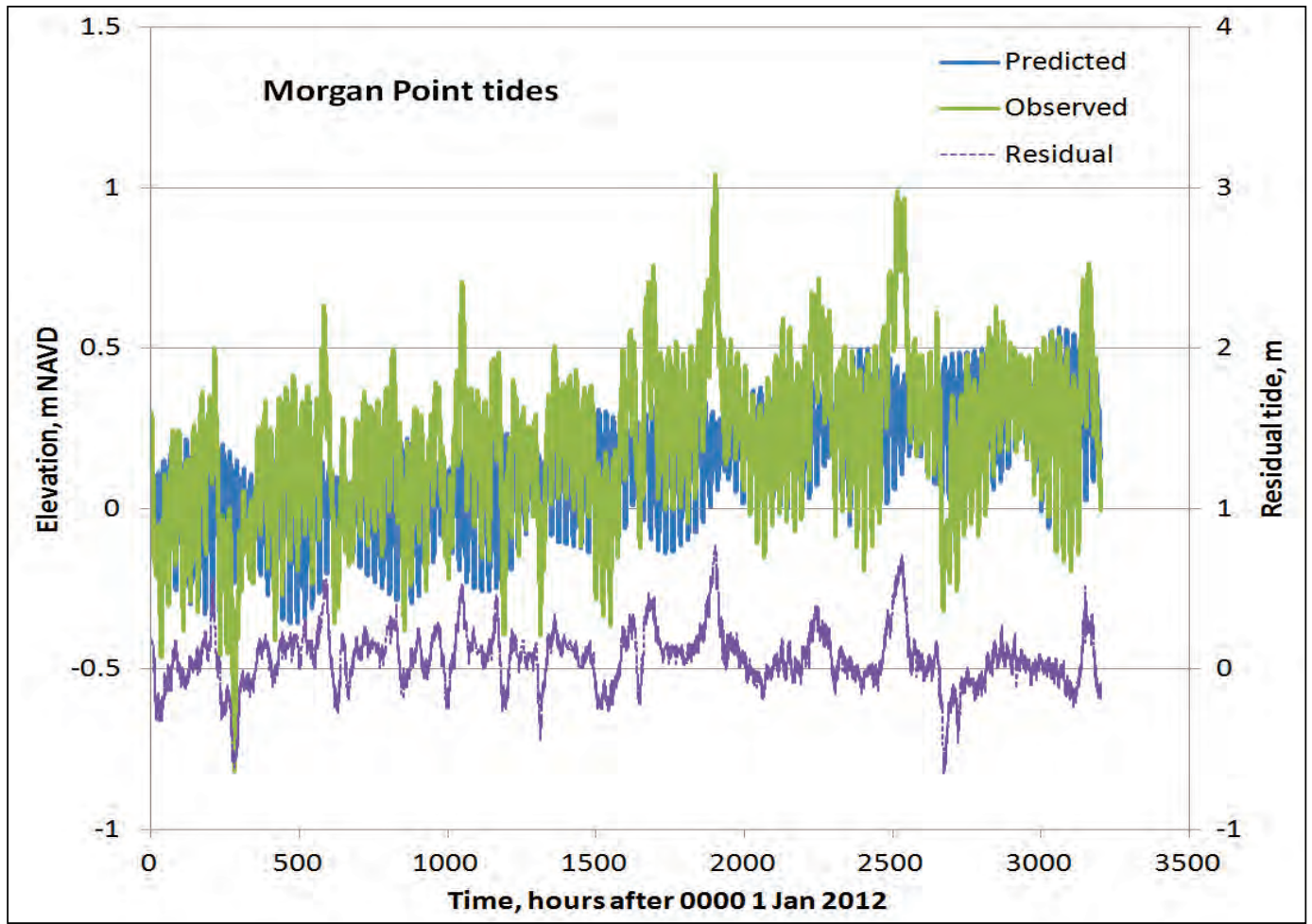

Figure 2-5 Mean tide range in meters at locations in Galveston Bay (data from National Ocean Service 2006).

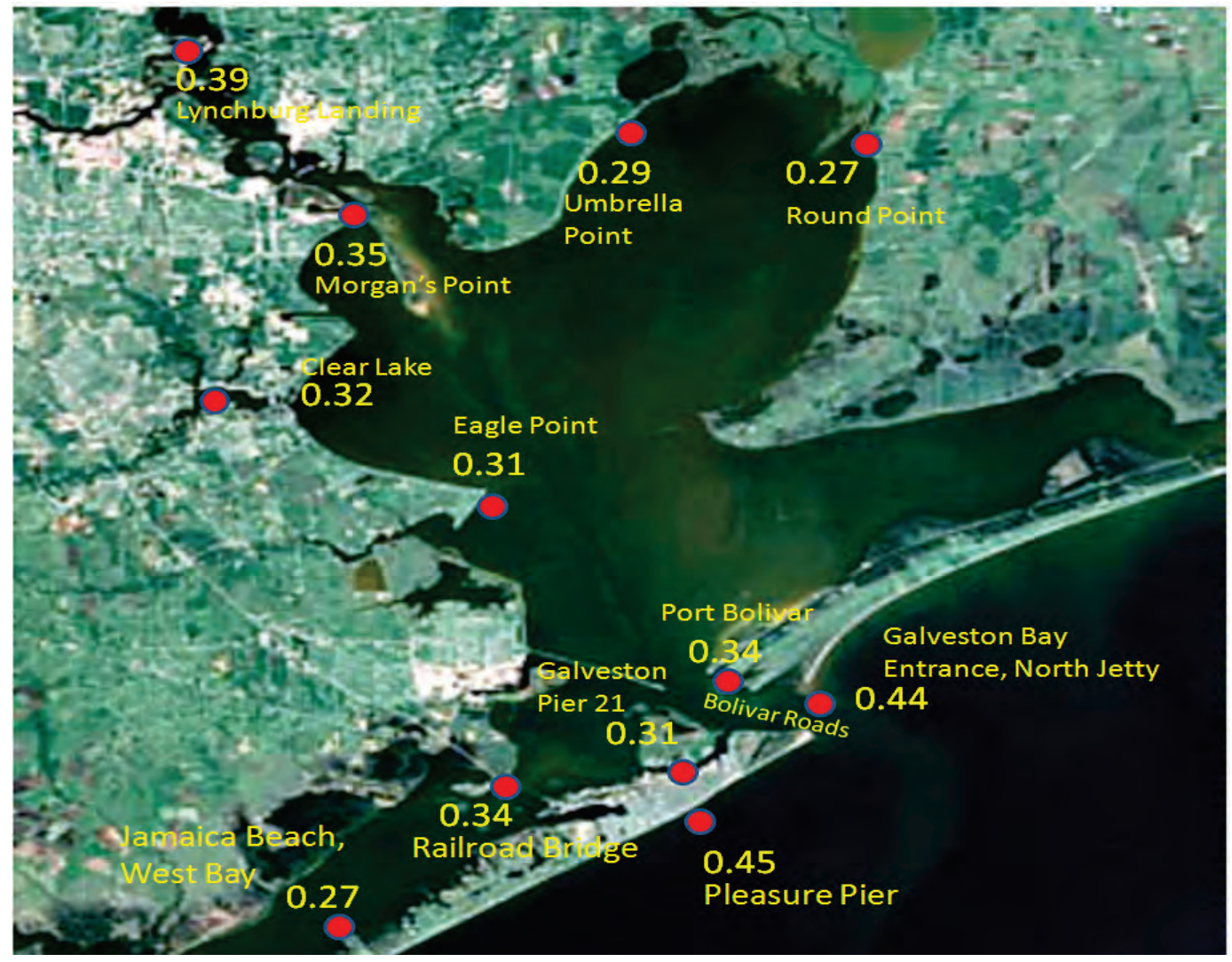


Figure 2-6 Relative times (in hours) of high water (HW) and low water (LW) (HW/LW) referenced to times of high and low water at Galveston Pier 21 Bay (data from National Ocean Service 2006).

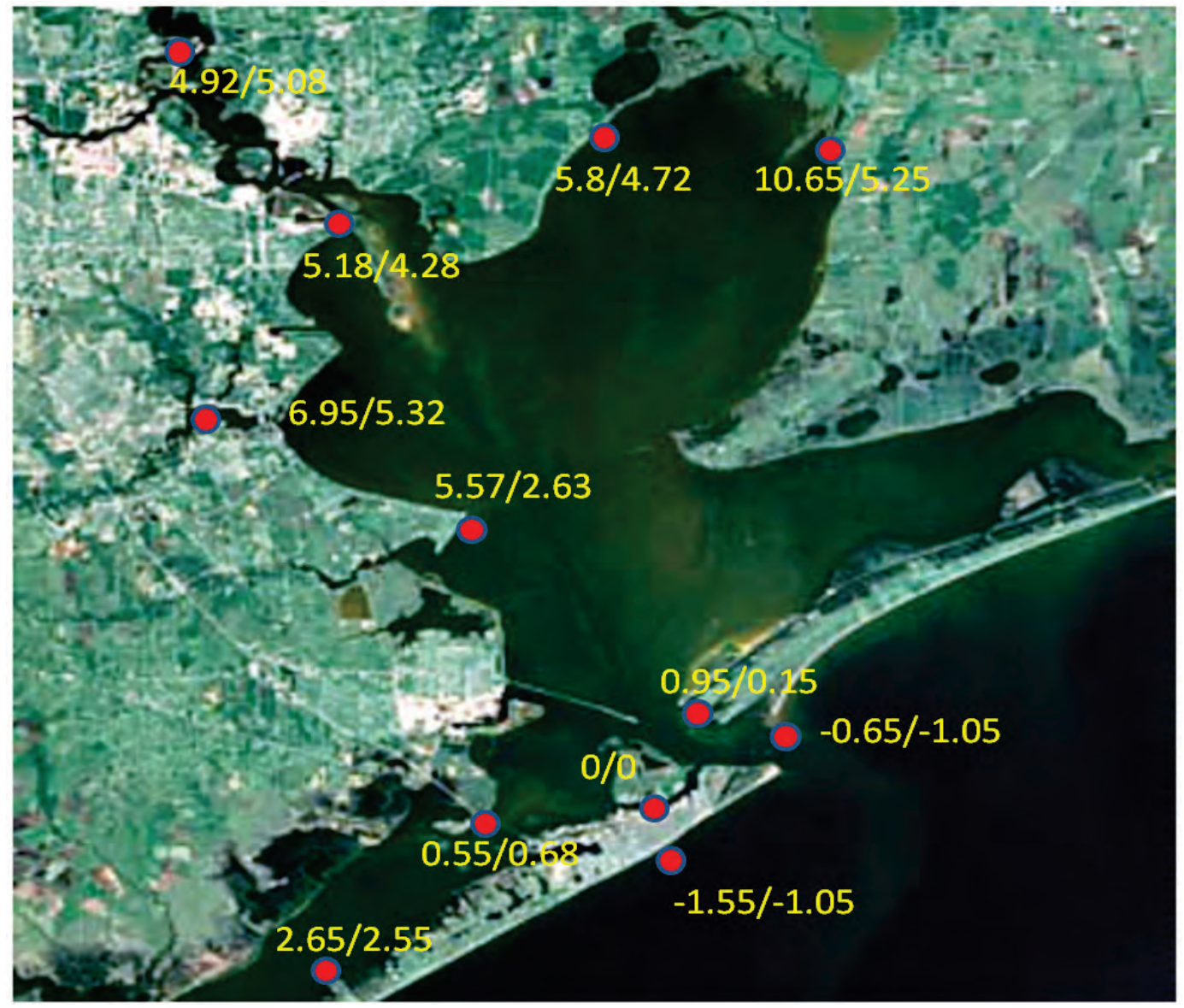

\section{Rainfall}

Annual precipitation ranges from 91 centimeters $(\mathrm{cm})$ at the headwaters up to $132 \mathrm{~cm}$ near the Gulf of Mexico. During the wet season, the Trinity River flows generally overwhelm local rainfall, with the possible exception of rainfall occurring during tropical storms. Therefore, no local rainfall is added to the numerical model for the wet season. During the dry season, the rainfall does not significantly influence the river discharge.

Consequently, no rainfall was included in the numerical model study for either the dry or wet seasons.

\section{Levees and structures}

The lower Trinity River is confined by a series of levees, roads, and other high ridges. There are several large wetlands along the course of the river, separating the main stem of the river from the levees. These wetland flood 
plains vary in overall width between 3 to $5 \mathrm{~km}$ overall laterally and provide significant flood plain storage, offering considerable flood storage and flow attenuation below Liberty, TX.

At Wallisville, TX, there is a navigation lock and a salinity barrier as shown in Figure 1-2. The structures are normally open during flood events to allow flow to pass through the structures. During the dry season the structures are normally closed to control salt water intrusion. The structures are operated periodically in the dry season to maintain desirable water levels in the cypress wetlands and to flush salt water away from the structures. The lock gates are operated daily to prevent sediment accumulation in the lock gate structure that would prevent the locks from closing and as needed for navigation purposes.

A flow-control weir, Structure A, is located on the Old River Cut Off channel near Moss Bluff and diverts flow from the Trinity River into the Old River (Figure 2-7). The structure (Figure 2-8) can operate as a weir at low flows. Additionally, it can be opened for free flow during flood events and at extreme flood levels when the flows come out of banks and completely overtop the structure.

Figure 2-7 Model domain and location of structures.
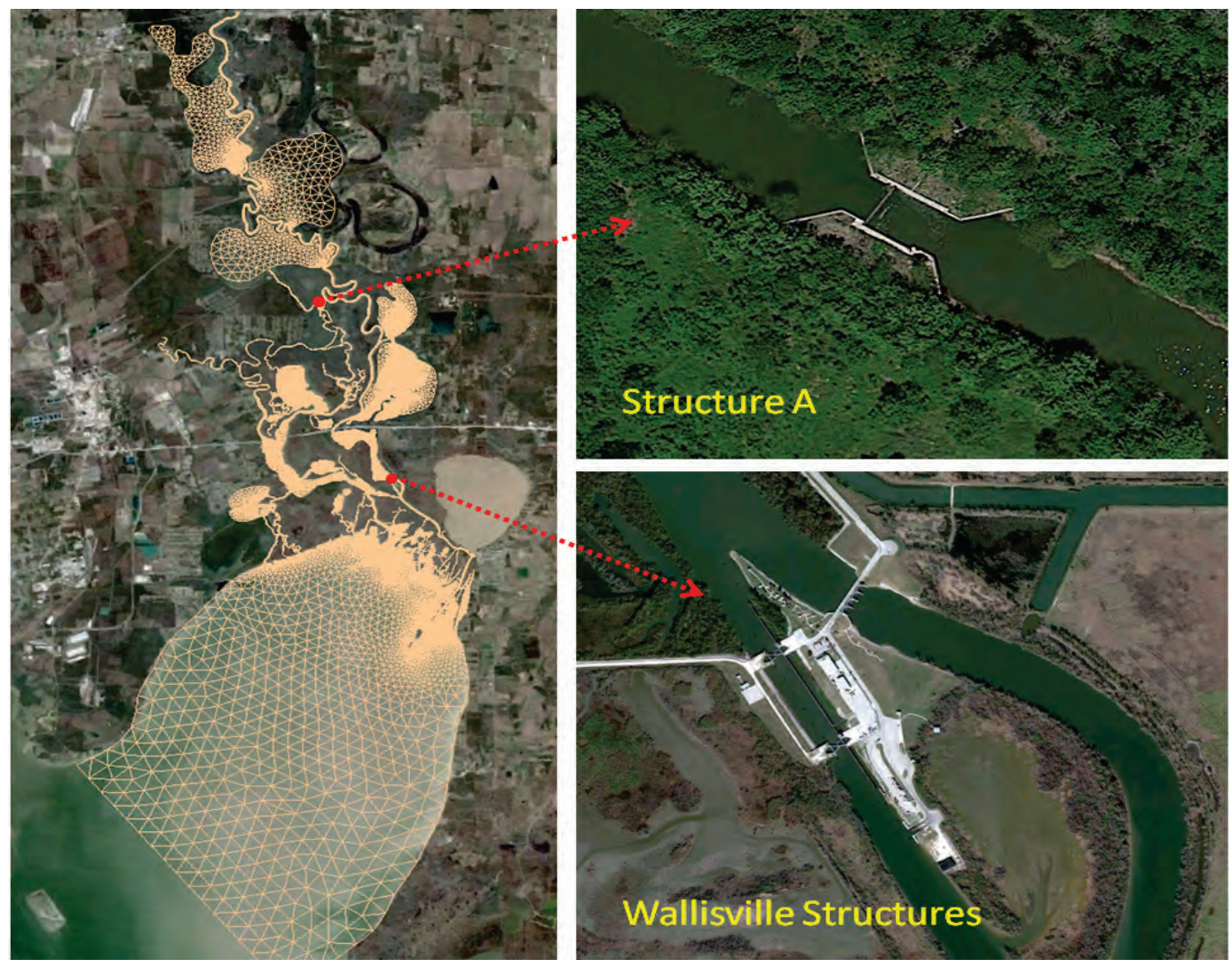
Figure 2-8 Structure A looking downstream toward Old River.

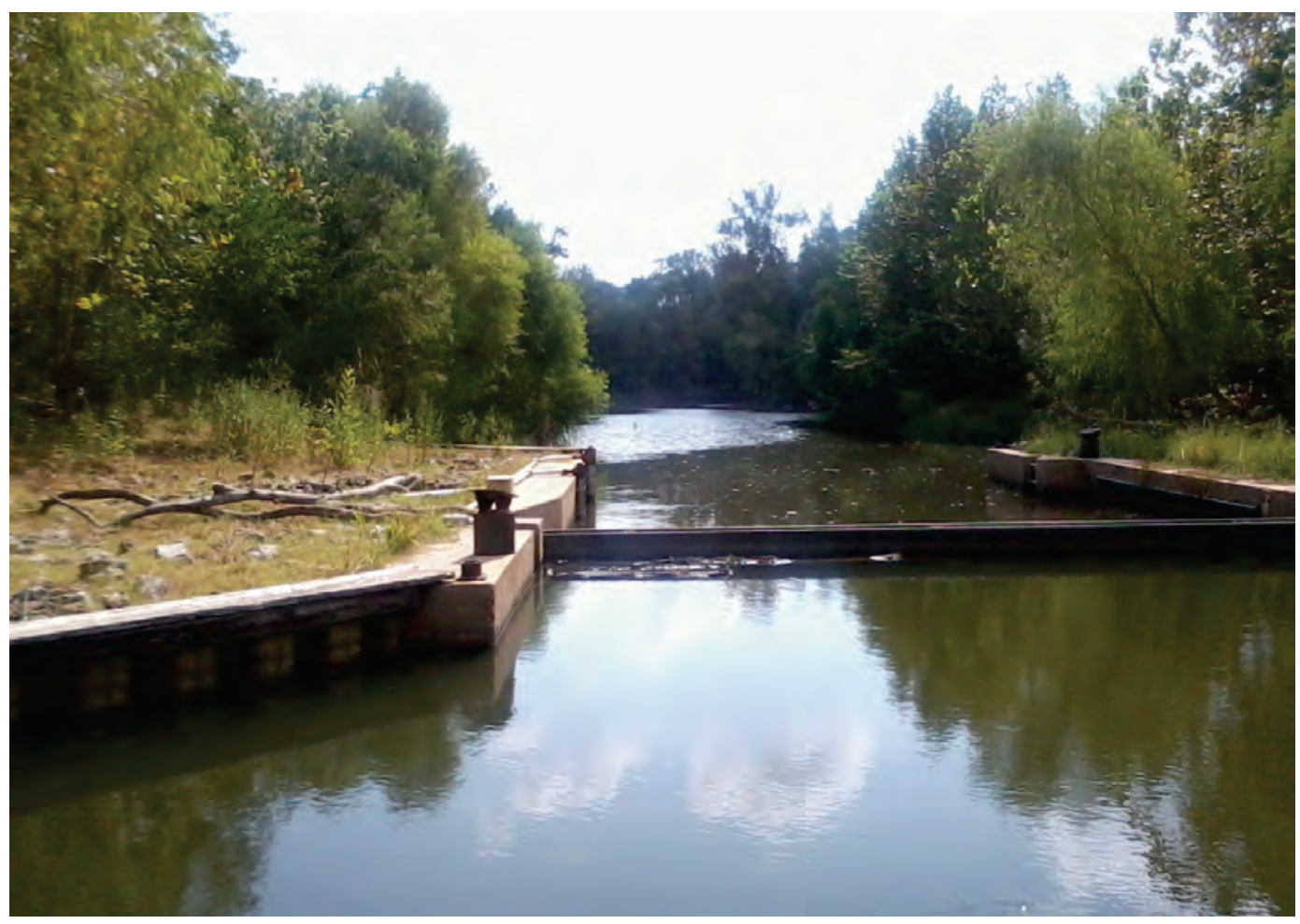

\section{Sediment supply}

Phillips et al. (2004) reported that there is no evidence of a reduction in sediment input (dam-related or otherwise) to the Trinity delta due to changes in the upper Trinity River system. This is because the lowermost reaches of the Trinity River are characterized by a high rate of alluvial sediment storage, thereby creating a bottleneck for sediment delivery to the river mouth. Essentially, the upper Trinity basin and lowermost reaches are decoupled (and have been since pre-impoundment). This sediment storage buffers the Trinity delta from changes in sediment supply and transport upstream.

\section{Deltaic processes}

Although the sediment supply to the Trinity River delta is buffered, there has been progressive delta development at the mouth of the river. The processes of deltaic development appear to be at work within the system, as seen by the dendritic patterns of branching tidal channels through lobes of deposited sediments, and play an important role in the shoaling issue being addressed by this study. Evidence of deltaic formation is seen in Figure 2-3. Phillips et al. (2007) concluded that the transition from 
riverine to low-gradient coastal environment on the Trinity River is also strongly influenced by antecedent landforms and complex delta geometry.

\section{Flood pathways}

The pathways for flood waters to move from Liberty, TX, to Trinity Bay are dynamic on two levels.

First, the river water moves from the upper system to the lower system (i.e., from behind the levees to pathways that flow freely to the bay). These pathways are

- through the Wallisville structures,

- through Structure A, the tide gate on the Cut Off that runs south from Mark's Bend on the Trinity River near Moss Bluff, TX, and

- through the overtopping of levees and natural ridges, which have low spots and channels that have incised from previous floods.

Second, once the flood waters are outside the levees, the hydraulic deltaic process of finding the most efficient pathway to open water controls the flow direction and speed.

Additionally, changes to the downstream head at the Wallisville structures can have an impact upstream of the structures and affect the pathways of flood waters (flow distribution) getting to the lower system.

\section{Tidal circulation}

Tides are dampened considerably, propagating up the Trinity River and other passes to the Wallisville structures. Because the pathway up Long Island Bayou (Figure 2-3) and the ORCO channel is shorter and somewhat deeper, the tides arrive more quickly via that route than the longer pathway up the Trinity River. When the two tidal waves meet, the net effect can be a null point along the path where the tidal current velocities approach zero. It is possible this may be a contributor to the shoaling below the Wallisville structures because the null velocity will cause suspended sediment to fall out of the water column. 


\section{Field Data}

\section{ERDC field data collection}

ERDC conducted a limited field-data-collection effort in May 2012 with the goal of providing information to help evaluate the shoaling questions discussed in this report. The data collection relied, in part, upon a boatmounted Acoustic Doppler Current Profile (ADCP) instrument to measure current velocity distributions and discharges in the channels leading into and out of the confluence of the salt-barrier and lock channels below the Wallisville structures and down the lower Trinity River and westward through the ORCO. The ADCP ranges are shown in Figure 3-1. The ERDC field effort also included sediment sampling and bathymetry measurements.

Figure 3-1 Location of ADCP transect cross sections for May 2012 field exercise.

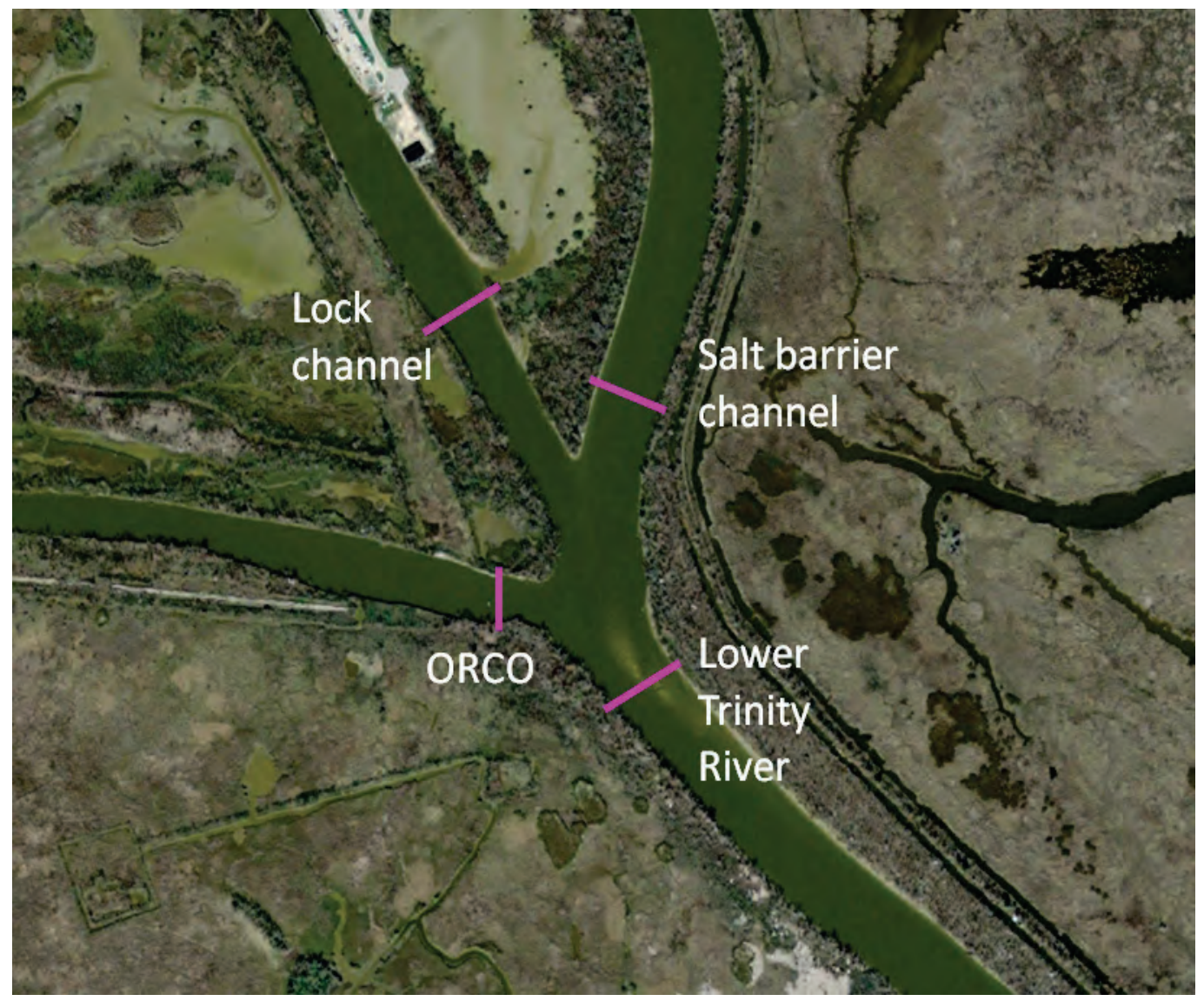




\section{Velocity distribution}

Depth-averaged velocities at the four $\mathrm{ADCP}$ ranges are presented in Figure 3-2, and details of each of the ranges are presented in Figure 3-3 through Figure 3-6. Multiple transects were made at each ADCP range, and these are shown in the figures. The transects in the lower Trinity River were limited to the western side of the channel due to the shallow water depths on the eastern side caused by the shoaling. Therefore, it is expected that the discharge estimate down the lower Trinity River may be underestimated. The highest current velocities were measured in the ORCO, illustrating the problem of flow being diverted to the west.

Figure 3-2 Depth-averaged velocity distribution at ADCP transects. Contour range is 0 to 1.22 meters per second (mps)

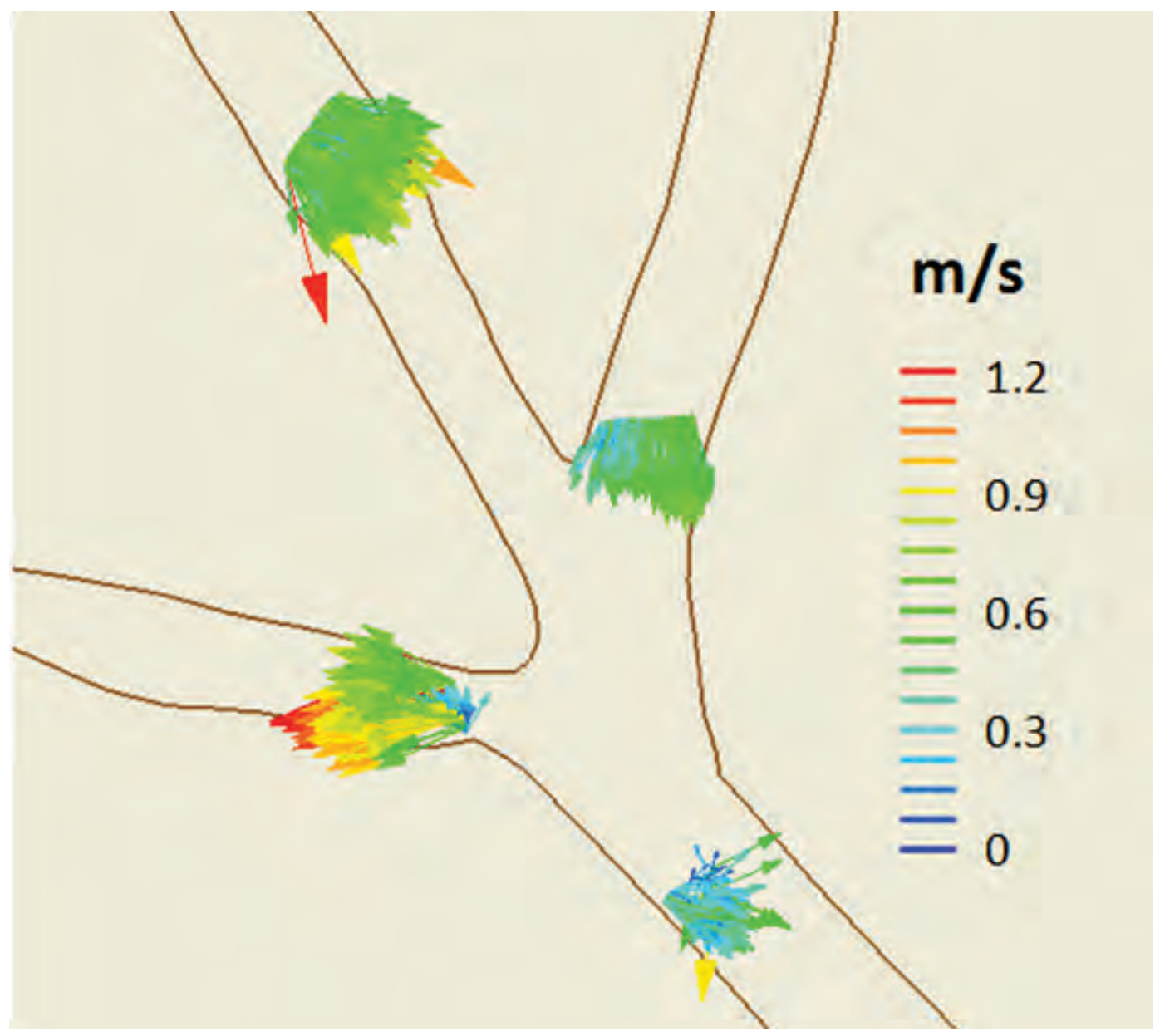


Figure 3-3 Details of ADCP depth-averaged velocities at the salt-barrier channel transect.

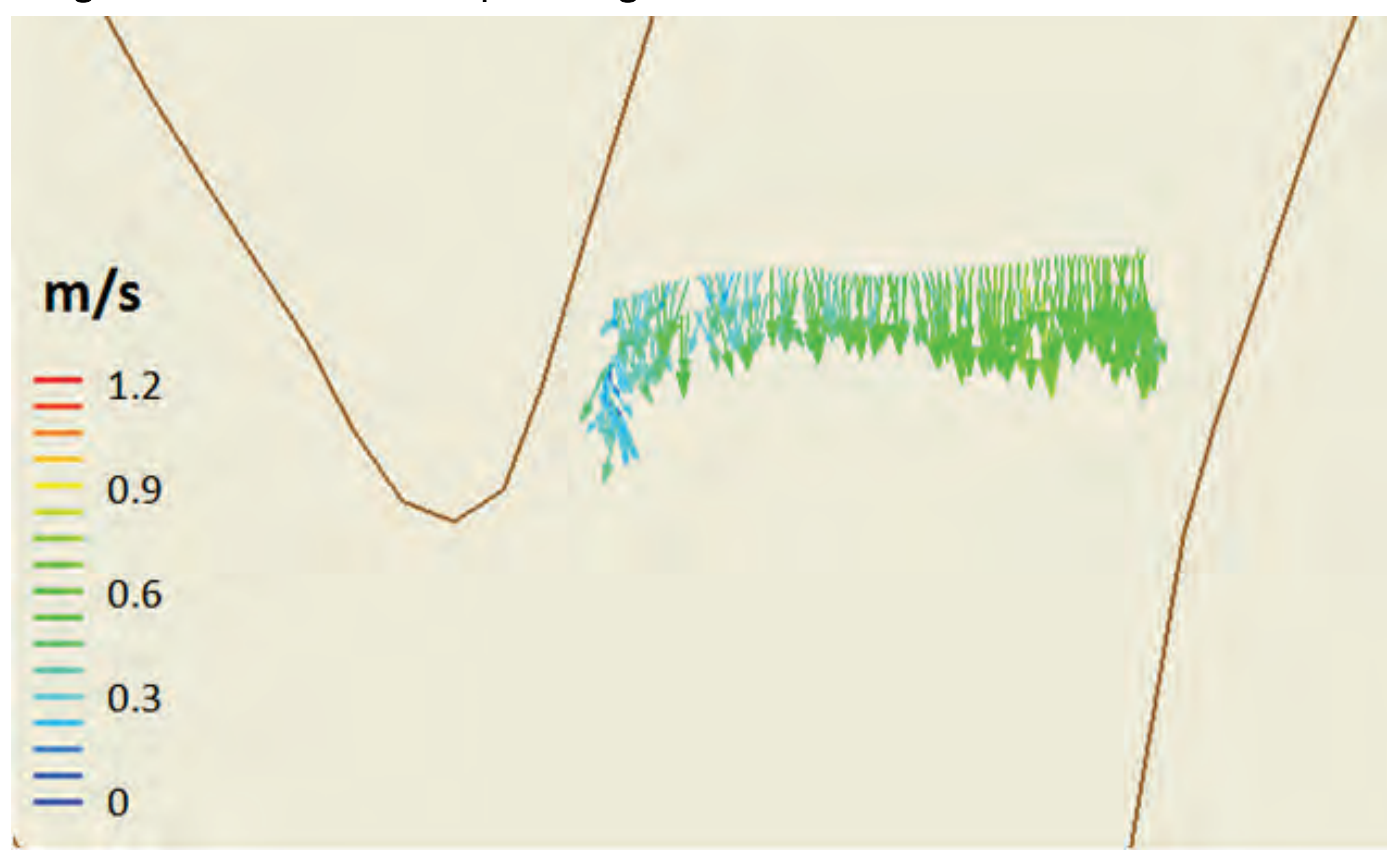

Figure 3-4 Details of ADCP depth-averaged velocities at the lock channel transect. Contour range is $1.22 \mathrm{mps}$.

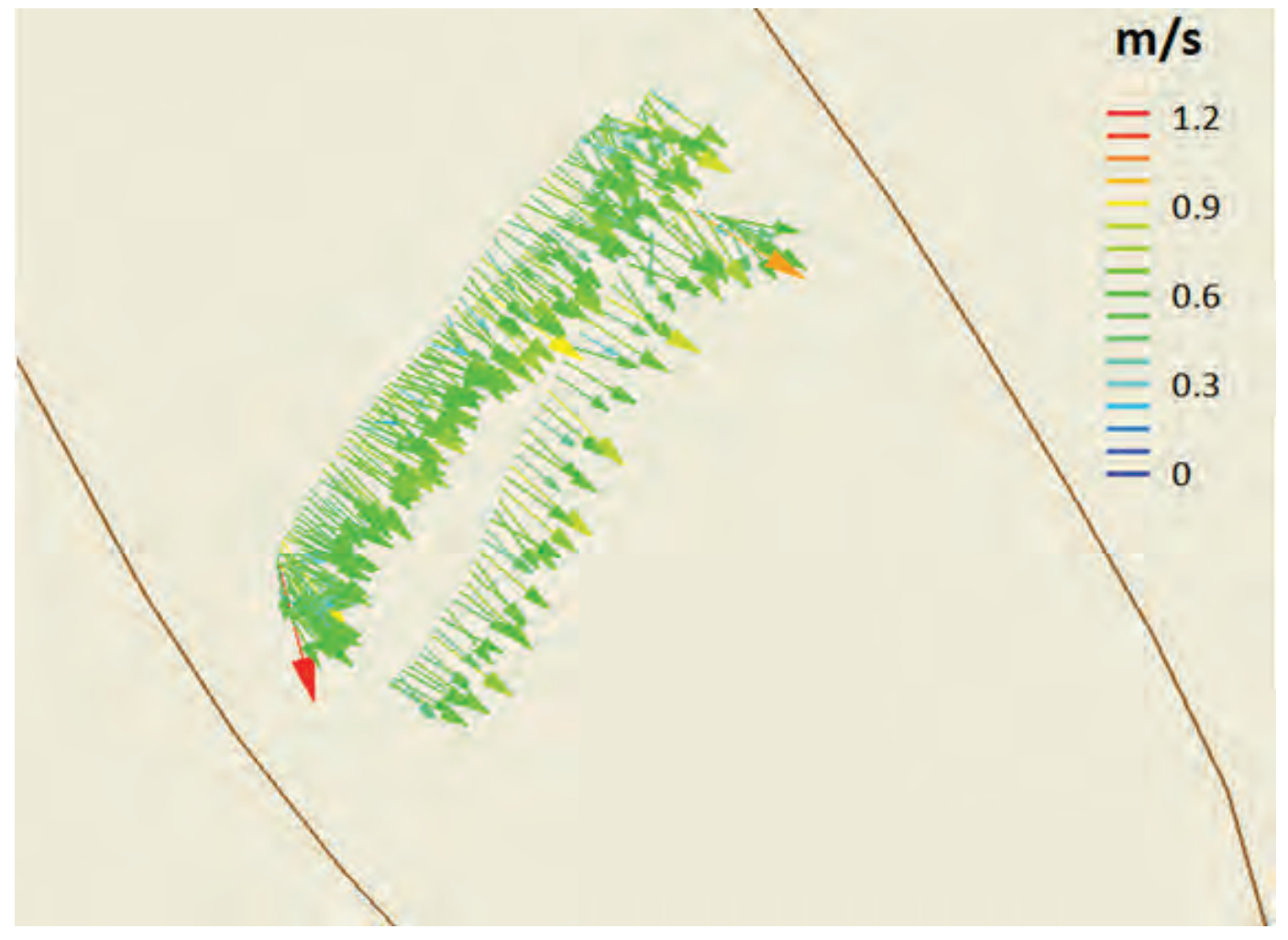


Figure 3-5 Details of ADCP depth-averaged velocities at the ORCO transect. Contour range is 0 to $1.22 \mathrm{mps}$.

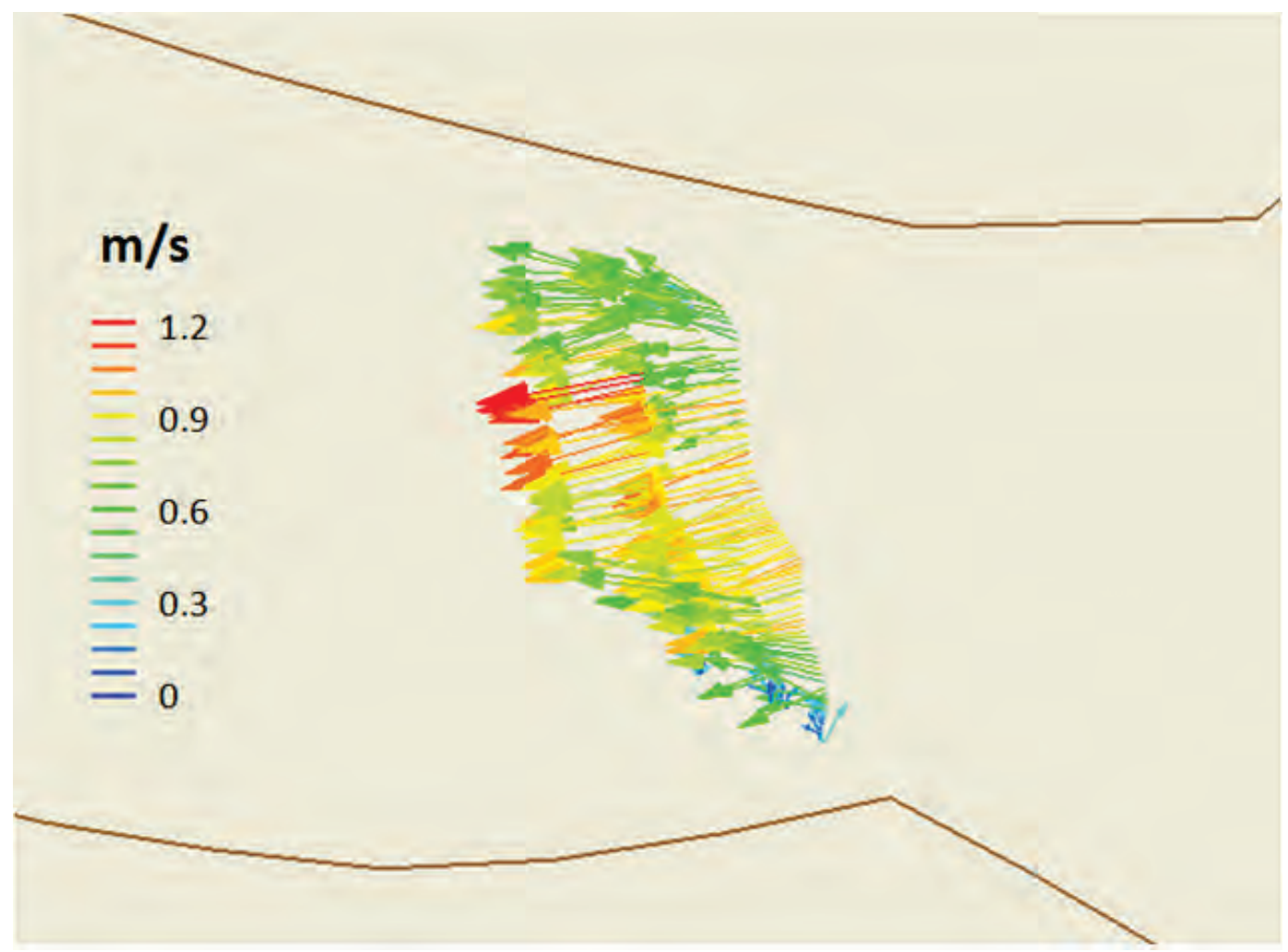

Figure 3-6 Details of ADCP depth-averaged velocities at the lower Trinity River transect.

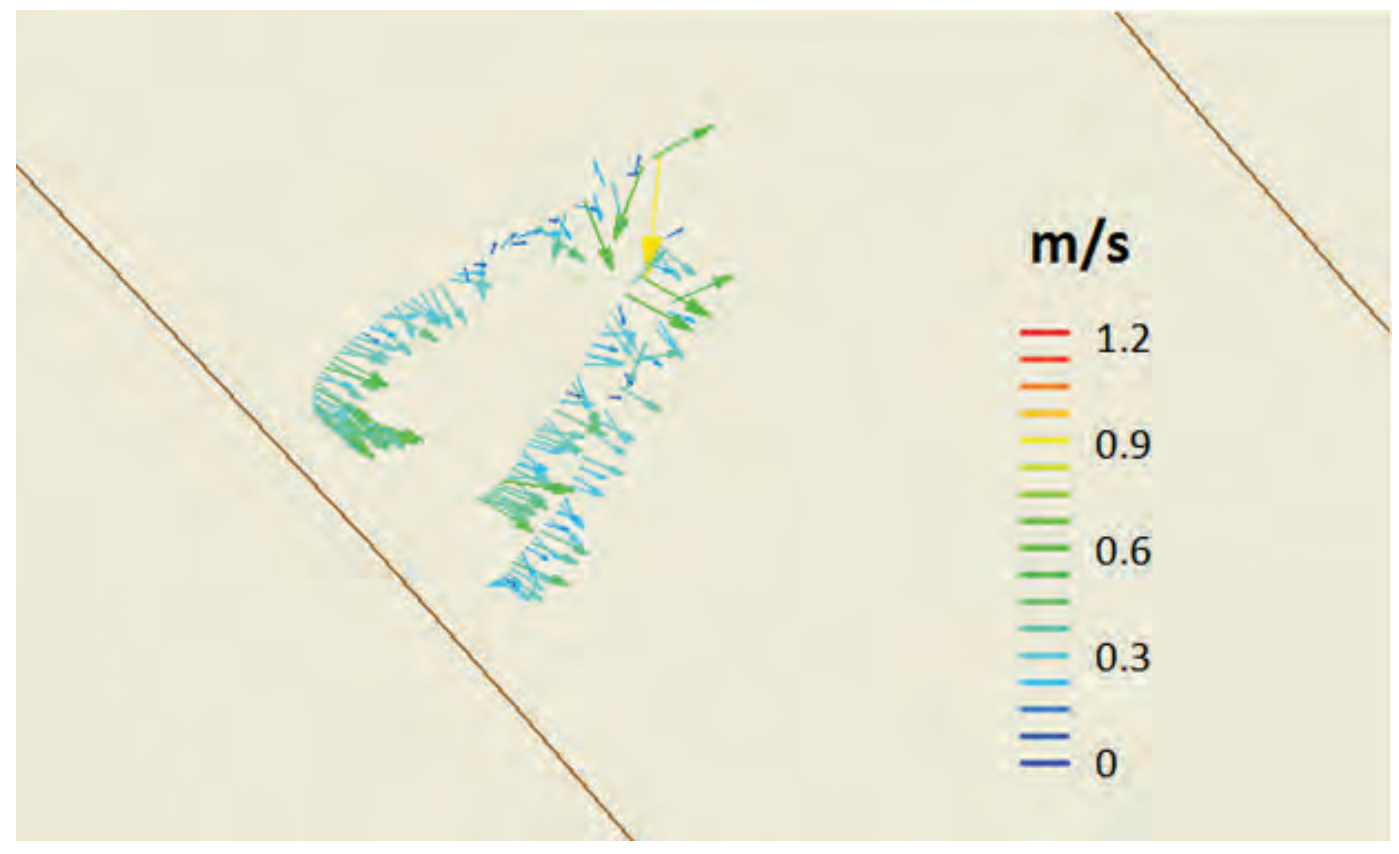




\section{Discharge estimates}

It is of interest to know the flow split at the Trinity River-ORCO divergence. To determine this, the ADCP cross-sectional velocities were integrated to estimate the discharge at each of the monitoring ranges. Each range was transected three times, with the exception of the saltbarrier channel that was only transected twice. Each of these transects provide separate estimates of the discharge. These discharge estimates, along with the average and standard deviation, are presented in Figure 3-7 and Table 3-2. The sum of the average discharges for the lock and saltbarrier channel are $169.8 \mathrm{cms}$, while the sum of the outgoing discharges is $158.9 \mathrm{cms}$, a difference of $10.9 \mathrm{cms}$. This difference results from measurement uncertainty due to several factors that include (1) underestimation of the lower Trinity River discharge due to limited access to the full cross section, (2) difficulties traversing any entire transect due to the finite size of the boat and $\mathrm{ADCP}$, and (3) flow not being strictly constant during the ADCP measurements. The flows were not constant because the discharges measured were primarily the result of releasing the pool stored above the salinity and lock structures at Wallisville specifically for this split measurement during this low-flow period. The most significant uncertainty likely arises from the measurement of the Trinity River flows below ORCO, whose measurement shows, by far, the largest variance. This uncertainty could be narrowed by further flow split measurements at higher flows.

\section{Sediment surface cores}

Surficial sediment cores were collected over a wide area of the project, both upstream and downstream of the Wallisville structures on the Trinity River into Trinity Bay and within ORCO. The locations of the core samples are presented in Figure 3-8. The water depths for each of the core samples along with the field notations are presented in Table 3-1. The resulting grain size distribution of the surface sediments at each sample location are presented in Figure 3-9 through Figure 3-15. Note that the numbering of the samples presented is based on the sample numbering from the field effort. No samples numbered 18 or 26 through 29 were collected. 
Figure 3-7 Flow distribution measurements at the confluence of the Trinity River, lock channel, and ORCO.

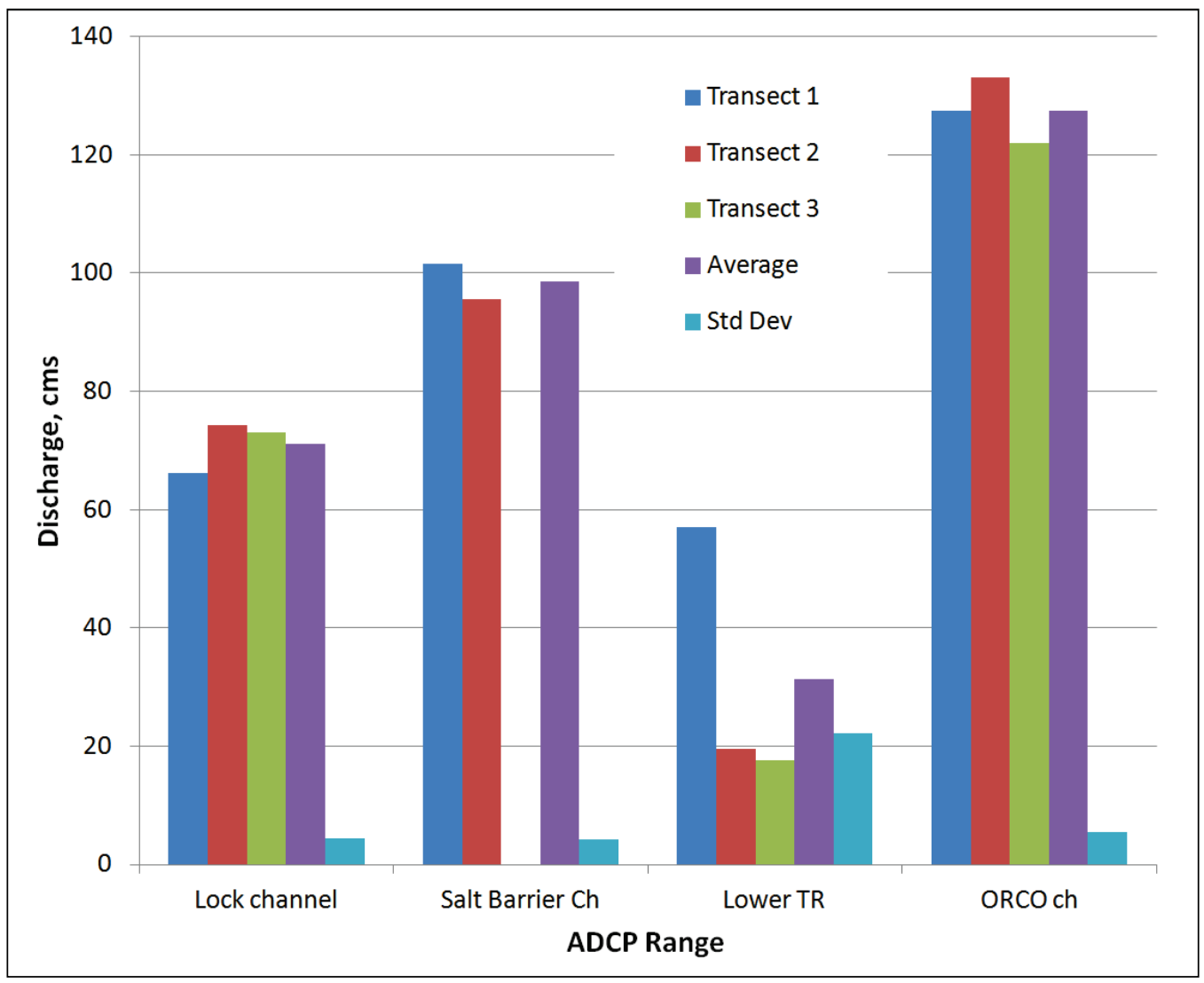

Figure 3-8 Location of ERDC bottom cores sampled 10 May 2012.

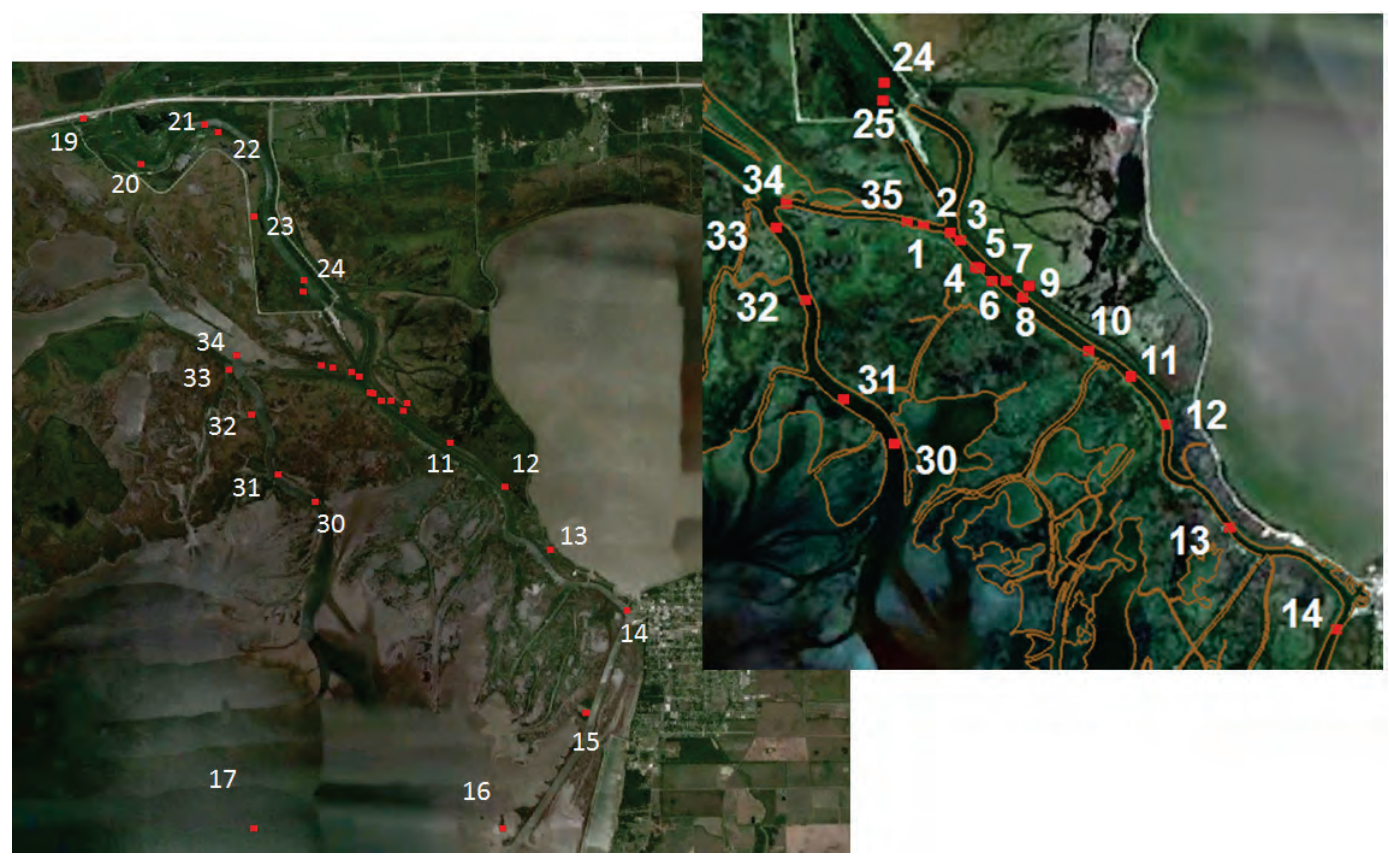


Table 3-1 Sediment core sampling depths and field notations.

\begin{tabular}{|c|c|c|}
\hline Core Sample & Water Depth (m) & Field Notes \\
\hline 1 (bank) & 0.0 & Bank \\
\hline 2 (shoal) & 1.8 & Sand \\
\hline 3 (shoal LB) & 1.1 & Sand \\
\hline 4 (downstream shoal) & 2.7 & Sand \\
\hline 5 (surface) & 1.4 & Sand \\
\hline $5 \mathrm{~A}$ (bottom) & 1.4 & Soft material \\
\hline 6 & 1.5 & Sand \\
\hline 7 (surface) & 1.8 & Sand \\
\hline 7A (bottom) & 1.8 & Soft material \\
\hline 8 & 1.8 & Sand \\
\hline 9 & 1.1 & Sand \\
\hline 10 & 2.6 & Sand \\
\hline 11 & 2.1 & Sand \\
\hline 12 & 2.4 & Sand \\
\hline 13 & 3.0 & Sand \\
\hline 14 & 2.3 & Sand \\
\hline 15 & 2.1 & Soft fines \\
\hline 16 (bottom) & 3.0 & Soft material \\
\hline 16A (surface) & 3.0 & Tan sand \\
\hline 17 (bottom) & 2.1 & Softer material \\
\hline 17A (surface) & 2.1 & Tan sand \\
\hline $19(\mathrm{I}-10)$ & 4.0 & Sand \\
\hline 20 & 6.7 & Sand \\
\hline 21 & 6.4 & Sand \\
\hline 22 & 3.7 & Sand \\
\hline 23 & 4.9 & Sand \\
\hline 24 & 3.4 & Sand \\
\hline 25 & 3.4 & Sand \\
\hline 30 & 4.9 & Fine sand \\
\hline 31 & 4.9 & Fine sand \\
\hline 32 & 5.2 & Sandy \\
\hline 33 & 5.8 & Sandy \\
\hline $34 \mathrm{~A}$ & 6.1 & Sand lens \\
\hline $34 \mathrm{~B}$ & 6.1 & Organics \\
\hline 35 & 3.8 & Sand \\
\hline
\end{tabular}


Table 3-2 Summary of ADCP discharge estimates.

\begin{tabular}{|l|l|l|l|l|}
\hline \multicolumn{5}{|c|}{ Range Discharge (cms) } \\
\hline Transect & Lock channel & Salt-barrier Channel & Lower Trinity River & ORCO channel \\
\hline 1 & 66.1 & 101.6 & 57.1 & 127.4 \\
\hline 2 & 74.3 & 95.7 & 19.6 & 133.1 \\
\hline 3 & 73.1 & & 17.6 & 122.0 \\
\hline Average & 71.2 & 98.6 & 31.4 & 127.5 \\
\hline $\begin{array}{l}\text { Standard } \\
\text { Deviation }\end{array}$ & 4.4 & 4.2 & 22.2 & 5.5 \\
\hline
\end{tabular}

Figure 3-9 Grain-size distribution curves for bottom surficial core samples 1 through 4 . Sample 1 is on the south bank on the eastern end of ORCO. Sample 3 is on the west bank of the Trinity River adjacent the shoal.

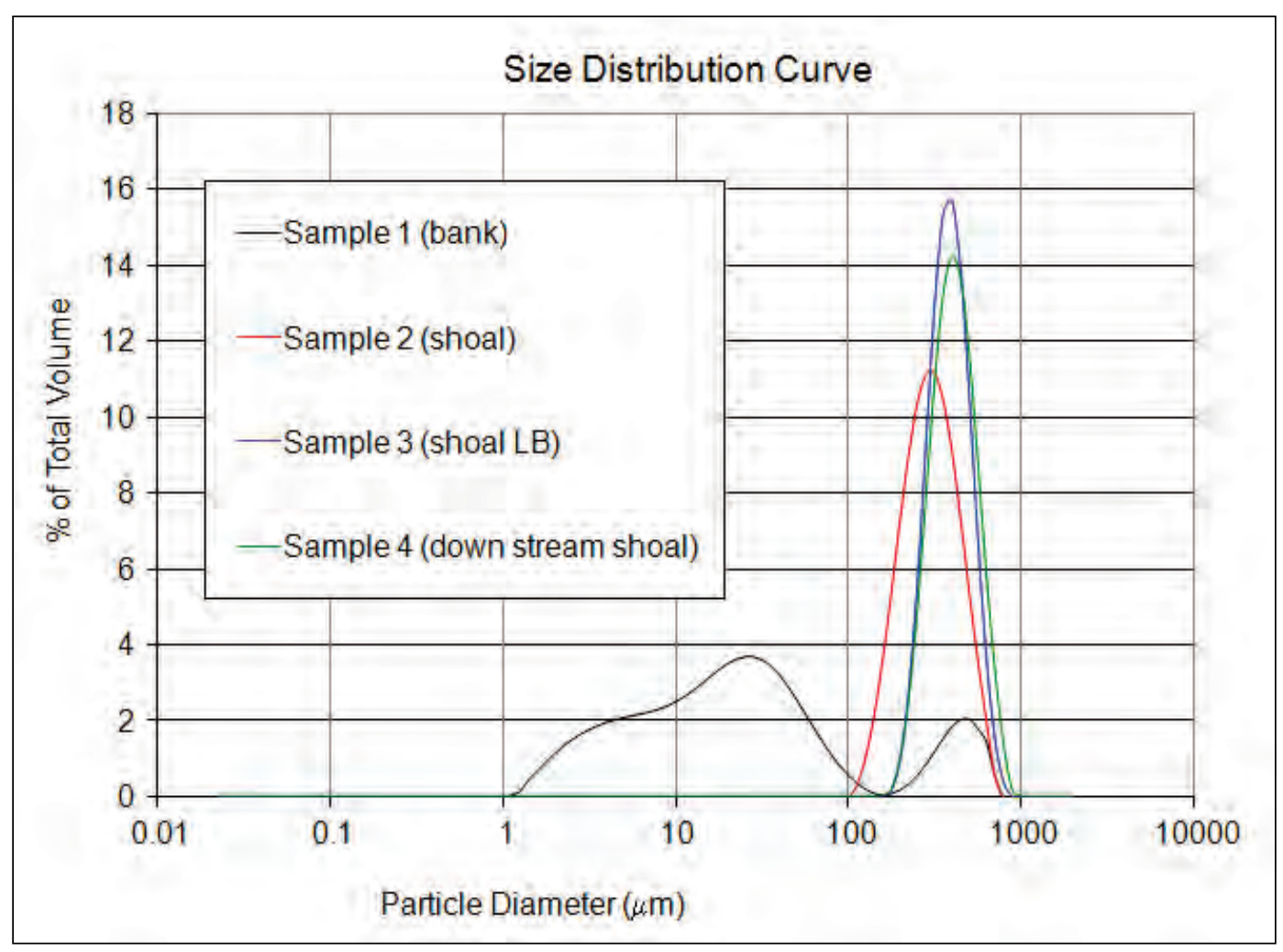


Figure 3-10 Grain-size distribution curves for bottom surficial core samples 5 through 7 . The surface and bottom sample locations refer to the location within the core samples, not the water COLUMN.

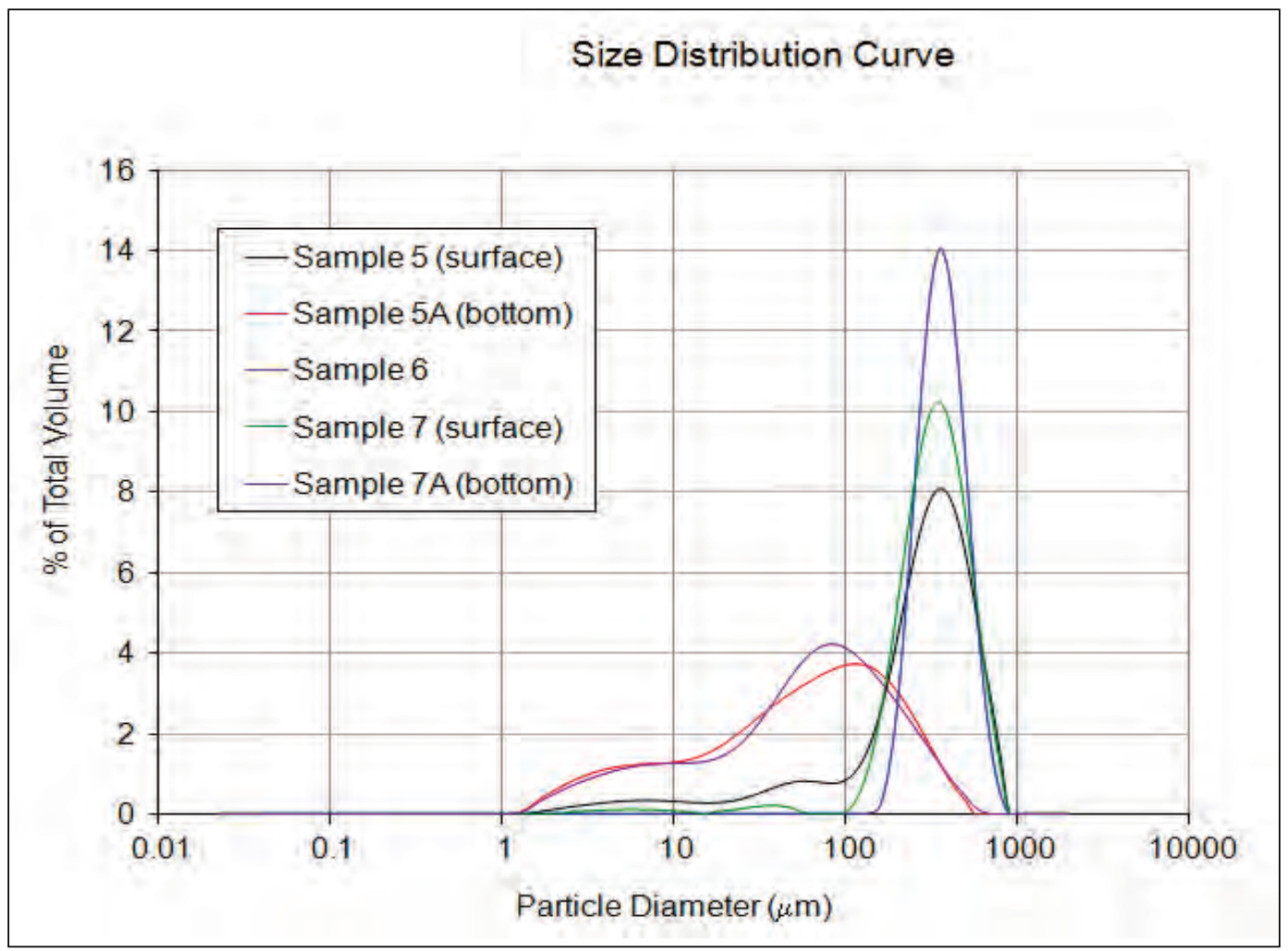

Figure 3-11 Grain-size distribution curves for bottom surficial core samples 8 through 12 .

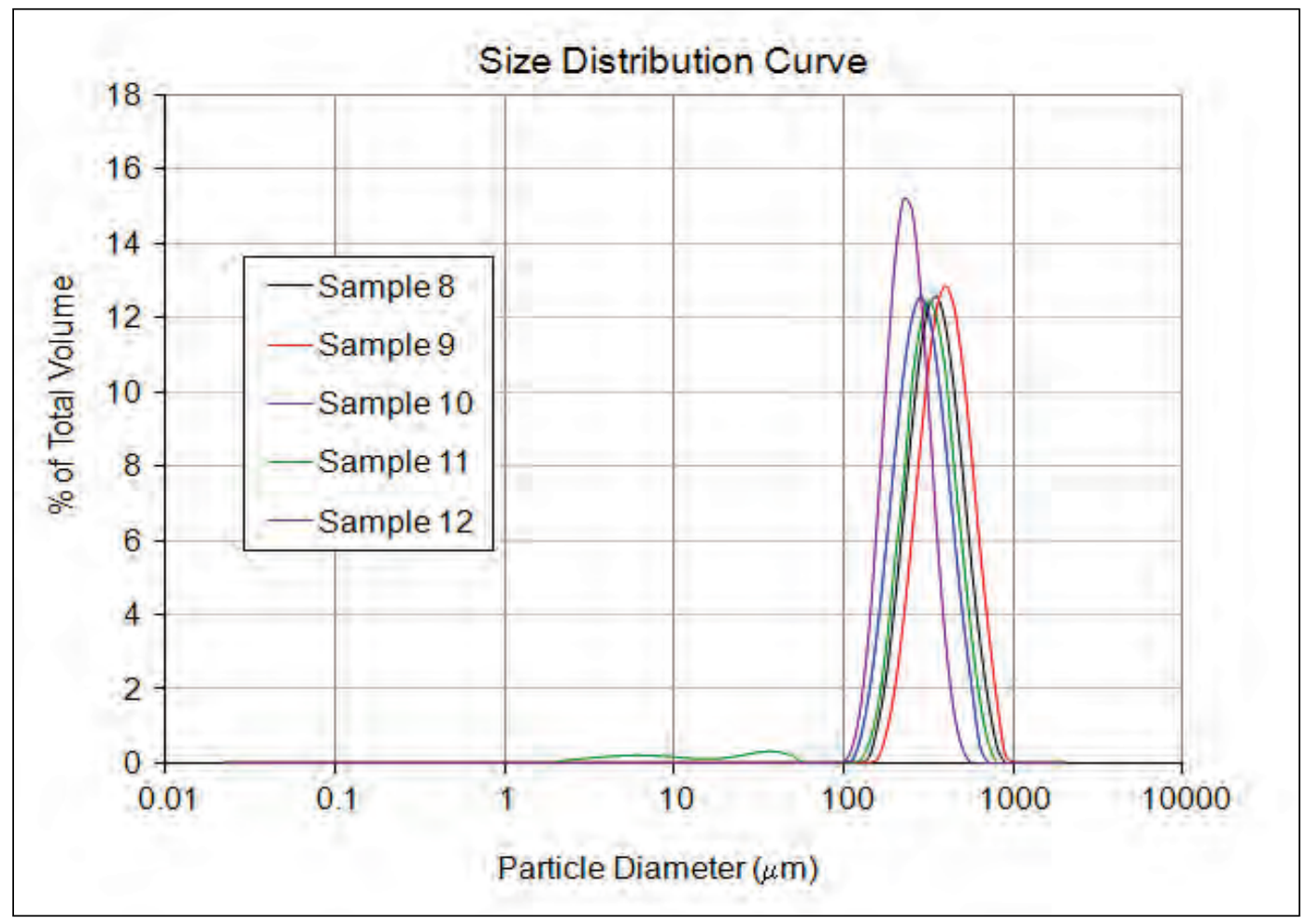


Figure 3-12 Grain-size distribution curves for bottom surficial core samples 13 through 16.

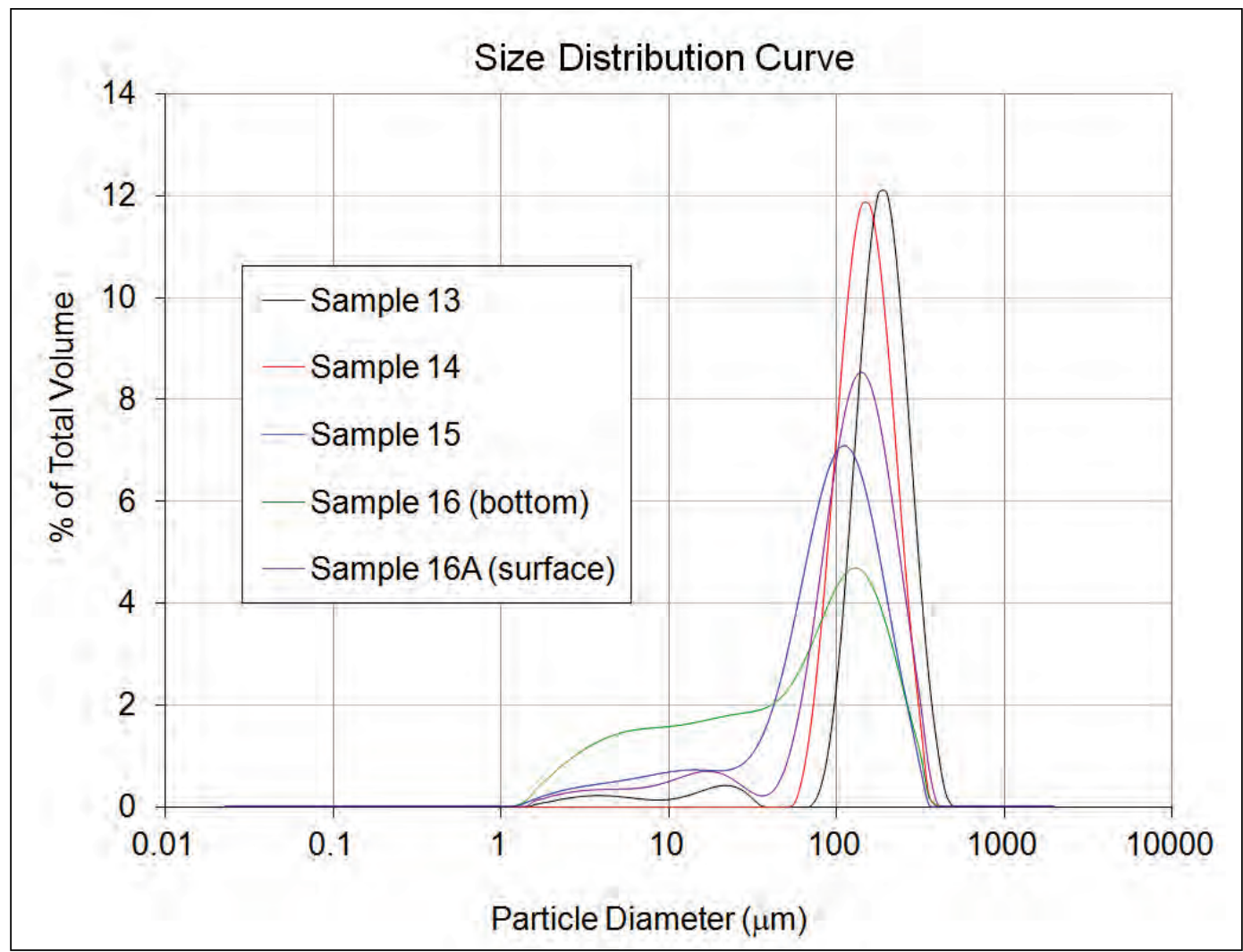

Figure 3-13 Grain-size distribution curves for bottom surficial core samples 17 through 21.

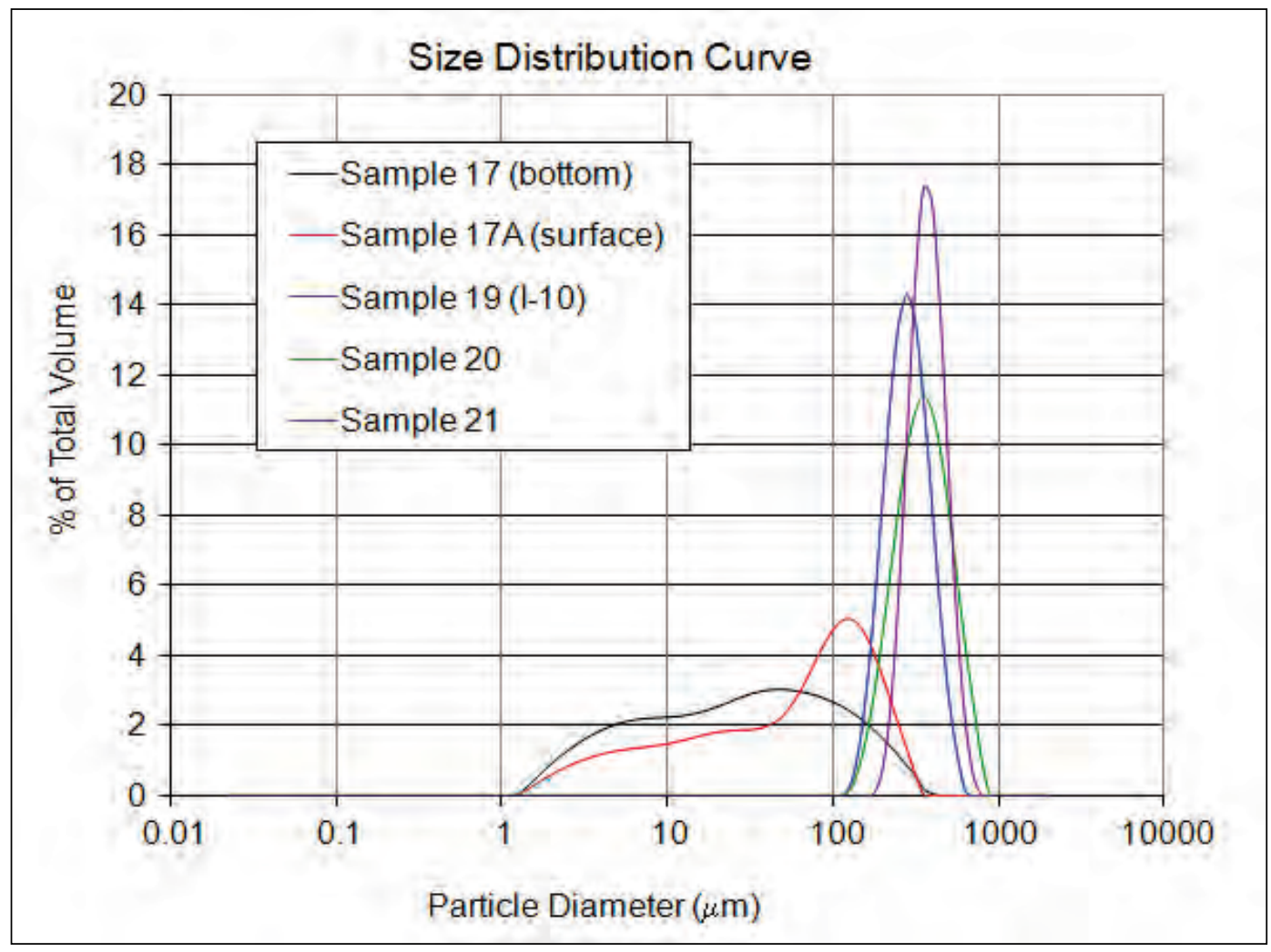


Figure 3-14 Grain-size distribution curves for bottom surficial core samples 22 through 30.

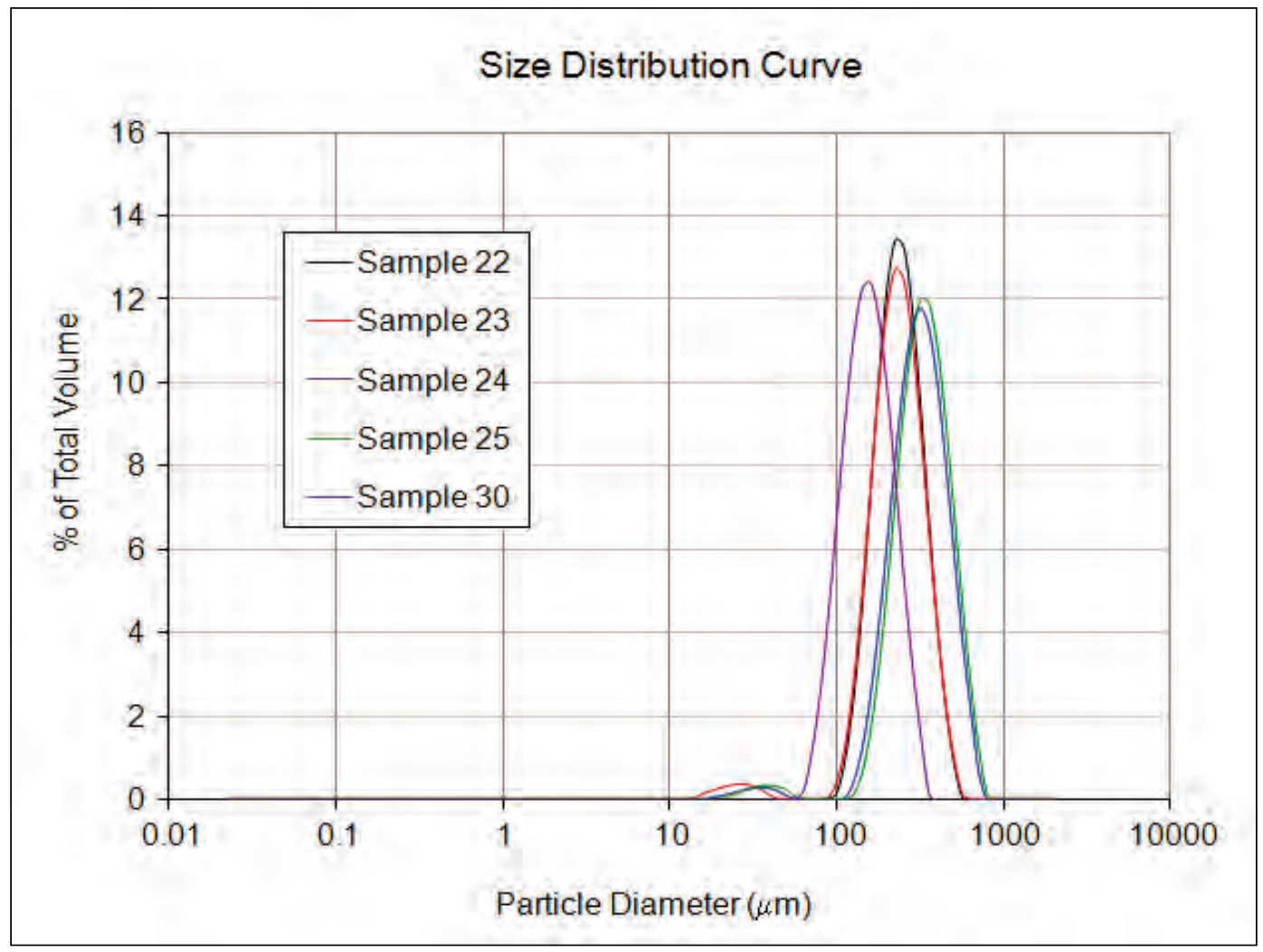

Figure 3-15 Grain-size distribution curves for bottom surficial core samples 31 through 35.

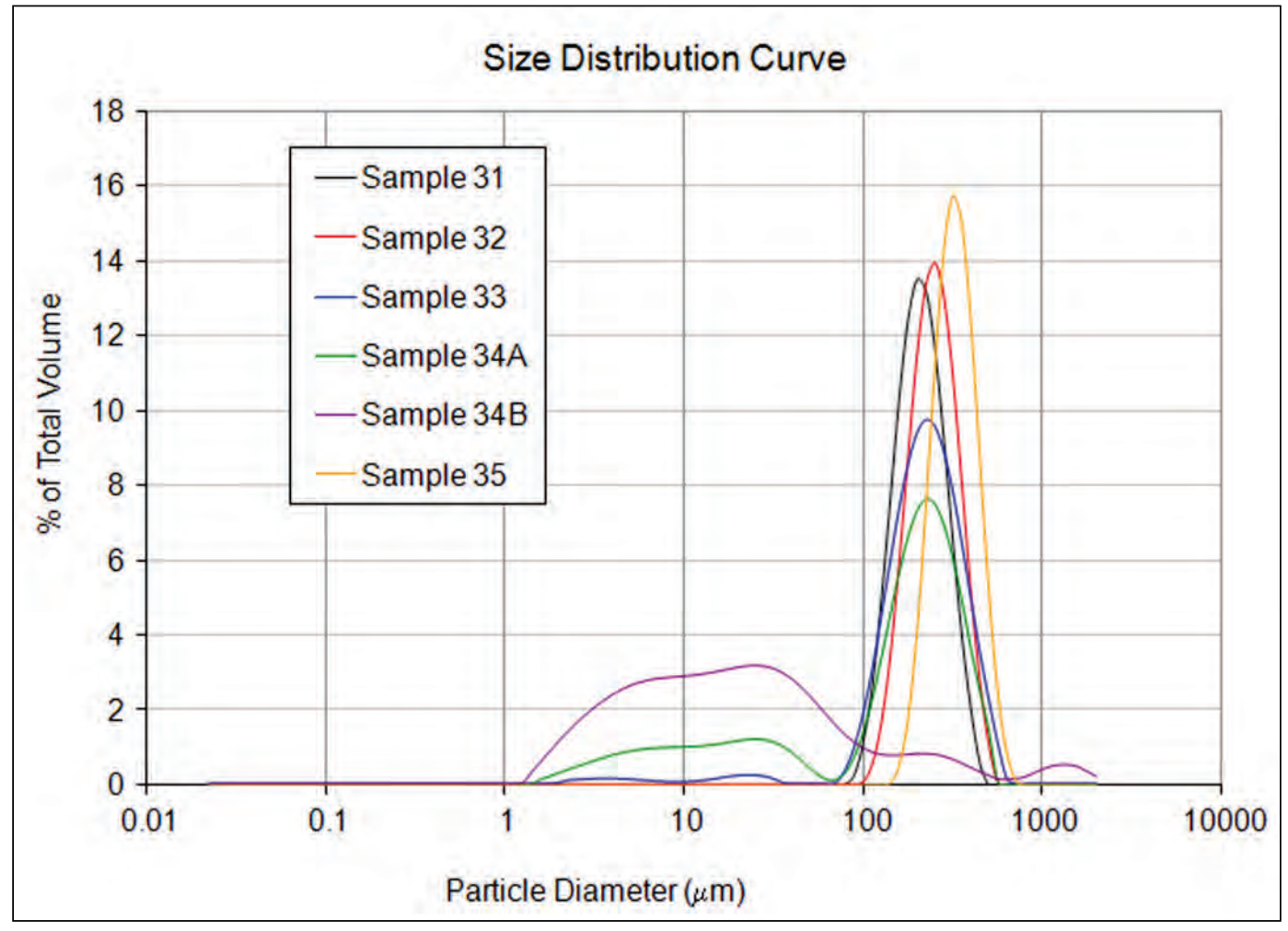


The profile along the Trinity River of the percentage of sediment classes developed from the sediment samples is presented in Figure 3-16. The classes presented are sand ( 0.062 to 2 millimeter $(\mathrm{mm})$ ), silt ( 0.004 to $2 \mathrm{~mm}$ ) and clay $(<0.004 \mathrm{~mm}$ ). The percentage of clay rises sharply as the Trinity River enters Trinity Bay (samples 15 and 16, beyond 8000 meters (m) from the barrier). The profile of sediment classes through ORCO is shown in Figure 3-17. The jump in the percentage of silt and clay at approximately $3000 \mathrm{~m}$ is at the western end of ORCO where it meets Old River.

Figure 3-18 presents the variation along the channel of the sediment sizes associated with percent finer values ranging from $5 \%$ to $100 \%$. The figure shows that there is a general fining of the material in the downstream direction. The significant degree of variability in the vicinity of the channel confluences (2000 to $4000 \mathrm{~m}$ ) is partly the result of more closely spaced sampling locations rather than higher relative variability.

Figure 3-16 Trinity River profile of field-sample sediment class percentages.

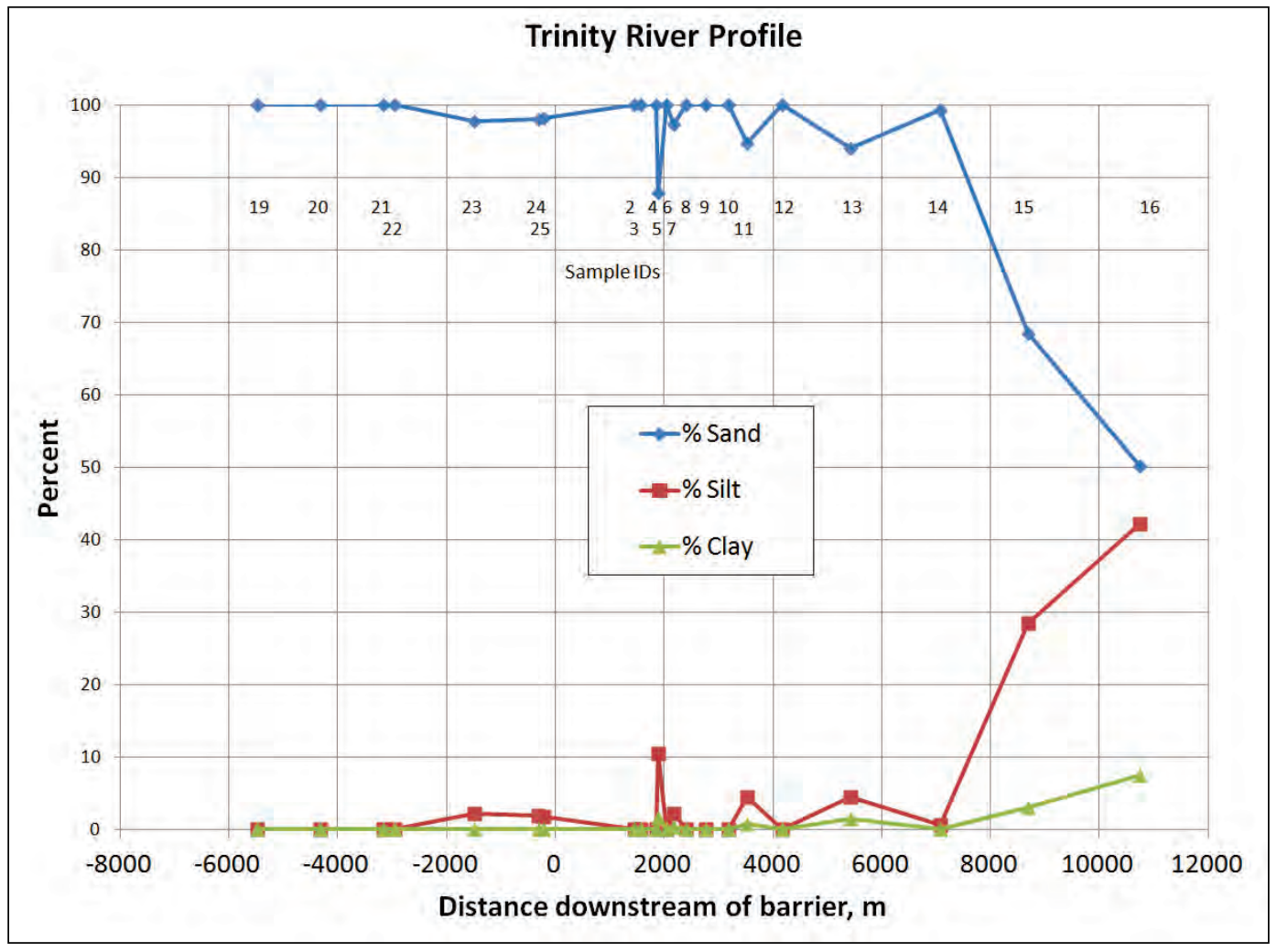


Figure 3-17 ORCO profile of field-sample sediment class percentages.

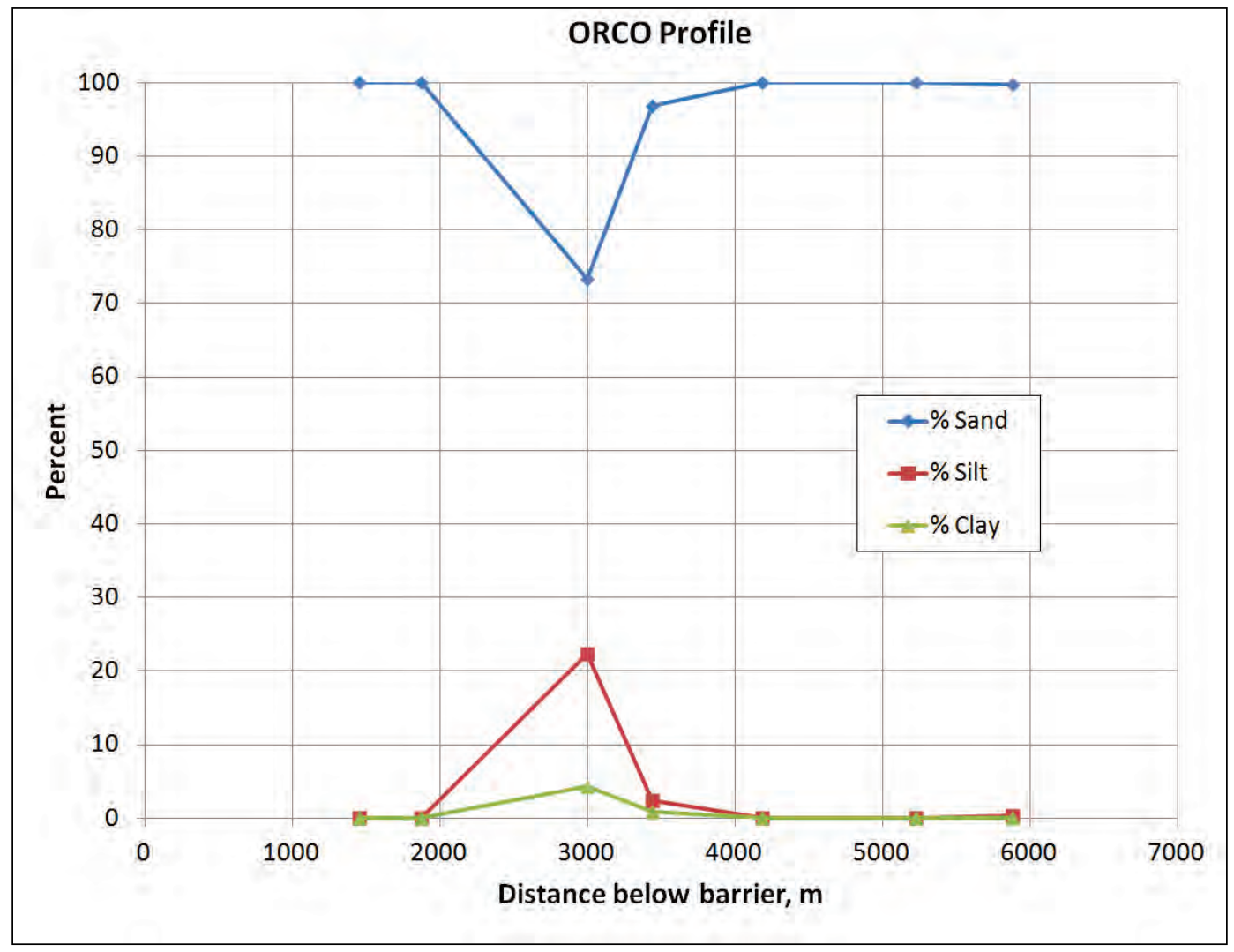

Figure 3-18 Trinity River profile of percent finer fractions of surficial sediments.

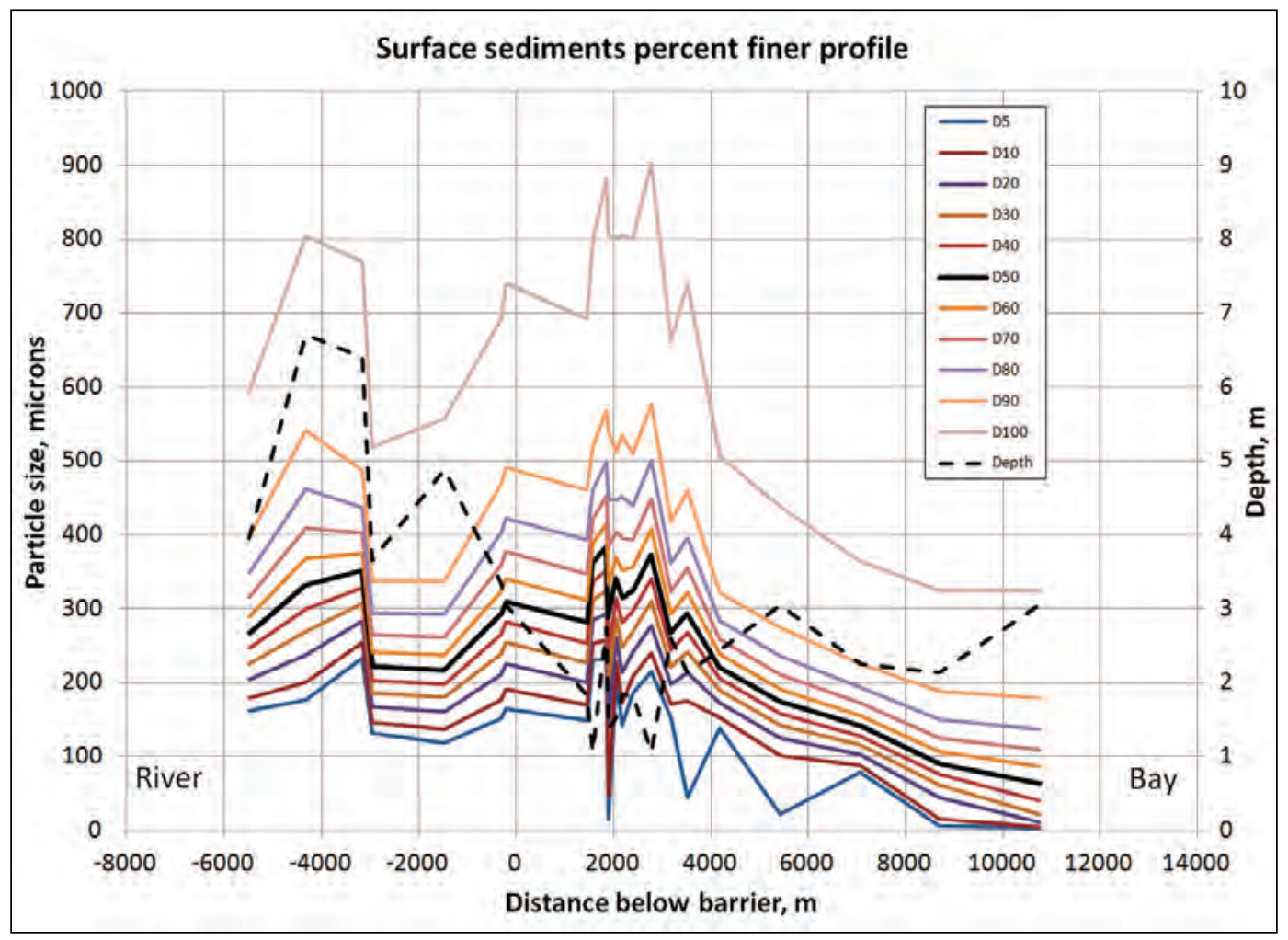




\section{Bathymetry and topography}

The Texas Natural Resources Information System (TNRIS) 10 m LIDAR data were used in the development of the topography in the numerical model (Figure 3-19). In addition, bathymetry was obtained from the National Oceanic and Atmospheric Administration (NOAA) estuarine database for Galveston Bay at a 30 m resolution (Figure 3-20).

The ERDC ADCP data collection effort also included profiling the primary channels and collecting a series of channel cross sections, as shown in Figure 3-21. Details of the bathymetric profiling are shown in Figure 3-22 in the vicinity of the primary channel confluence.

Figure 3-19 TNRIS $10 \mathrm{~m}$ LIDAR Data. Elevations are in meters above MLLW.

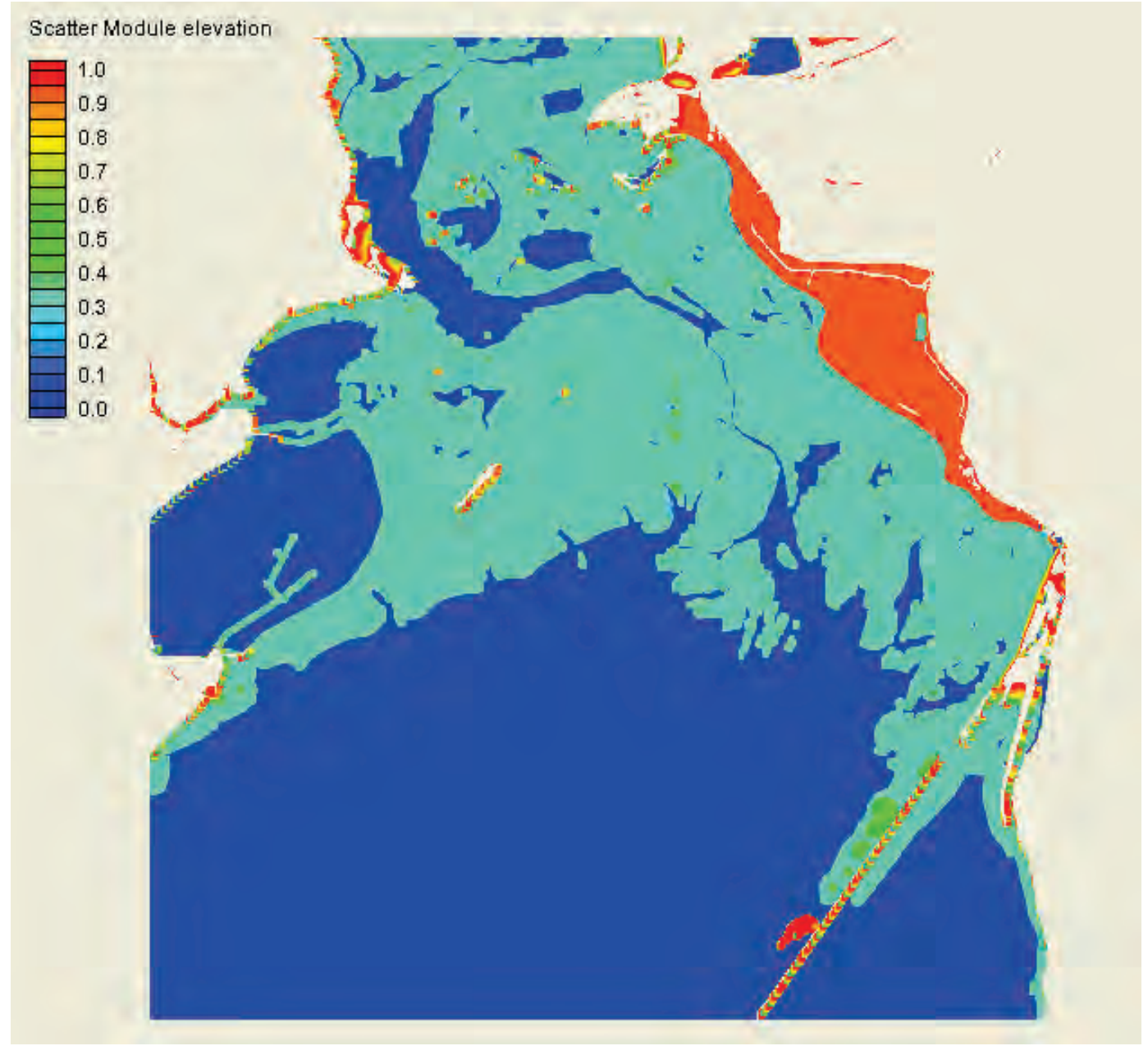


Figure 3-20 NOAA Estuarine Bathymetry (30 m horizontal resolution) in meters above MLLW.

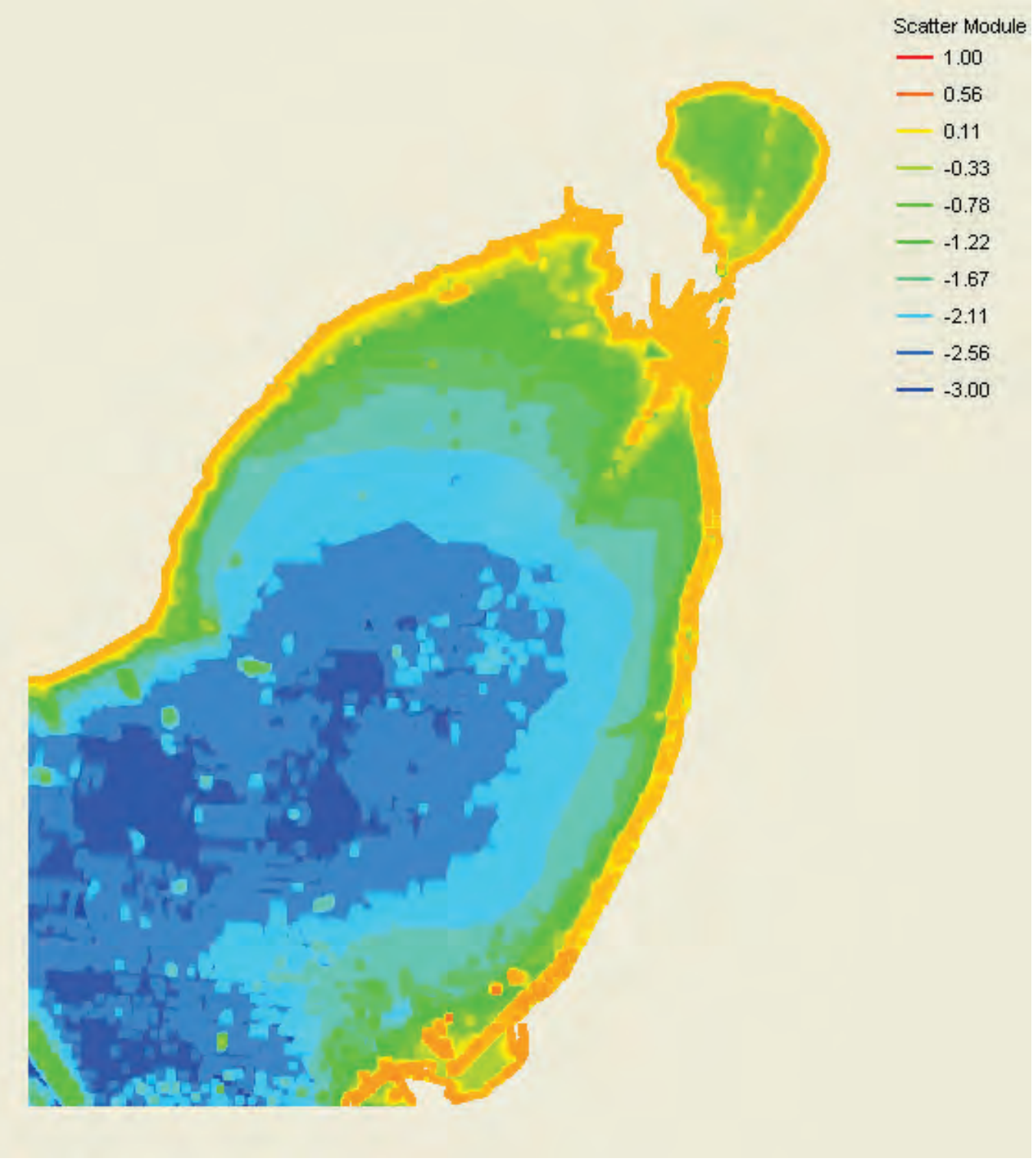

\section{USGS surface water data}

The USGS online National Water Information System (NWIS) was utilized to access river discharge and water surface elevation information used in the verification of the numerical model. The data for the wet-season verification period are summarized in Figure 3-23. 
Figure 3-21 ERDC ADCP profiling and cross-section measurements.

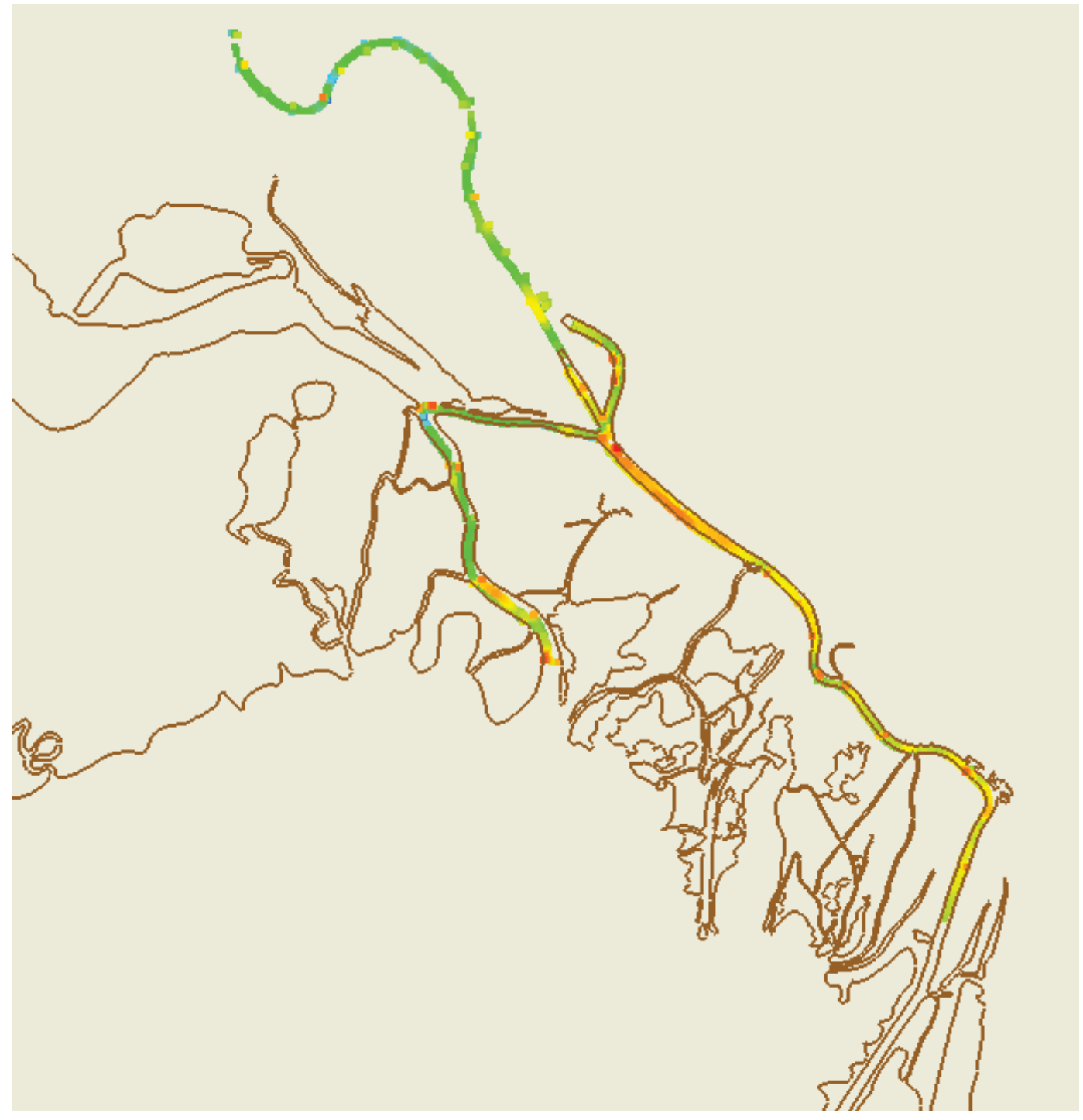

NOAA tide data

Tidal information used for the development of the tidal boundary conditions for the numerical model was obtained from the NOAA Center for Operational Oceanographic Products and Services (COOPS) online database. The tides from Morgan Point in Galveston Bay (Gage Number 8770613) were used to develop model boundary conditions. Tides at Morgan Point are shown in Figure 2-4. 
Figure 3-22 Details of ERDC ADCP bathymetric profiling and cross sections; elevations are in meters above NAVD88.

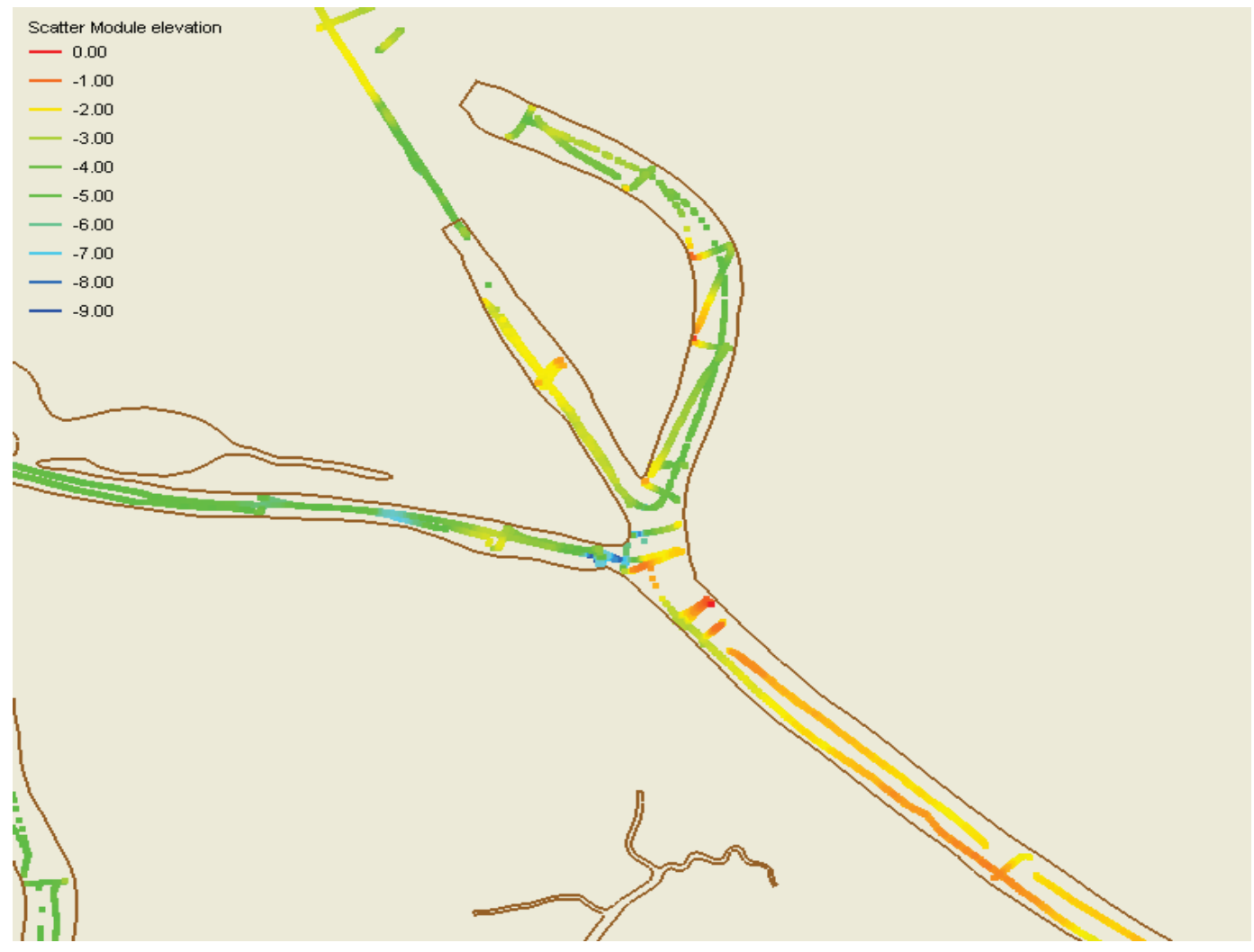

Figure 3-23 USGS NWIS surface-water elevation data for the verification period.

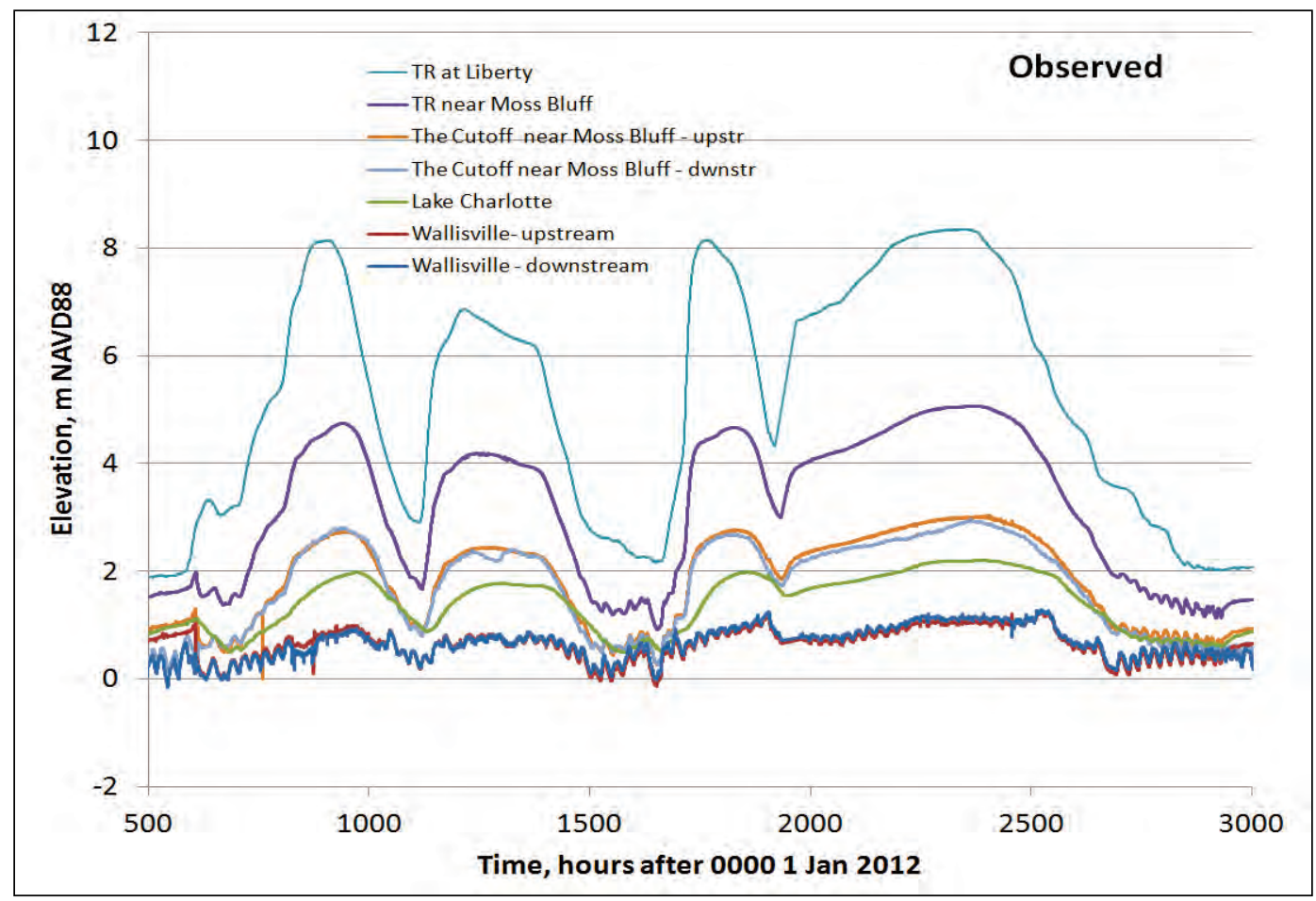




\section{CESWG data and support provided}

The District provided information about the project that facilitated the proper configuration of the numerical model for the system and specification of the flow conditions at the structures at Wallisville, TX.

\section{Rating curves for the salt-barrier tainter gates}

CESWG provided the equations for the rating curves of the tainter gates within the salt-barrier control structure. The rating curve provides an estimation of the discharge through each of the four tainter gates based on the gate opening in feet. The rating curves are presented in Chapter 8 . The dry-season simulations need to reflect the partial gate openings. During the wet-season simulations, the gates were fully raised and free flow was maintained through the salt barrier.

\section{Operational log for salt barrier and navigation lock}

The daily log of the condition of the gates in the salt barrier and lock was provided by CESWG. This information combined with the rating cures for the tainter gates resulted in an estimate of the time history of discharges through the structures. 


\section{Shoaling in the Trinity River Delta}

The increased shoaling in the lower Trinity River is the result of locally reduced transport capacity due to a reduction in flow below the confluence with the ORCO. This redistribution of flows is the result of changes in the overall system at a much larger scale than the local shoal problem, as well as possible local changes.

The Trinity River delta has been progressively growing over the past several decades, as determined by comparing aerial photographs between 1970 (Figure 4-1) and 2011 (Figure 4-2). Delta growth has been documented to occur in two phases. The first is the development of prodelta clays that fill in the receiving basin, followed by the evolution of subaerial land features from sands during flood events that create channel extensions (Coleman and Gagliano 1964; Letter 1982; Wells et al. 1984). The evolution of the delta channels over the past 40 years (yr) is documented by aerial photographs in Appendix A.

The deltaic development within the Trinity River delta follows the general characteristics of similar deltaic systems. The extension of channels by flanking within sand barriers in natural deltas eventually leads to hydraulic inefficiency on a small local scale, leading to local break-out side channels and bifurcations. These processes on the local scalelead to the classical reverse dendritic channel patterns of river deltas. These phenomena are evident within the Trinity River delta.

Eventually, some deltaic systems become so confined within the delta channels that the overall subdelta becomes an inefficient route to open water, and major rerouting occurs as the river finds more hydraulically efficient pathways. Additional subdeltas may form within an overall delta system for similar reasons. Forces such as these on the Mississippi River created a need for the Old River Control Structure and the subsequent replacement structures. These structures on the Mississippi River are required to keep it from rerouting down the shorter route via the Atchafalaya River to the Gulf of Mexico (Americas Wetland Resources 2012). 
Figure 4-1 1970 aerial photograph.

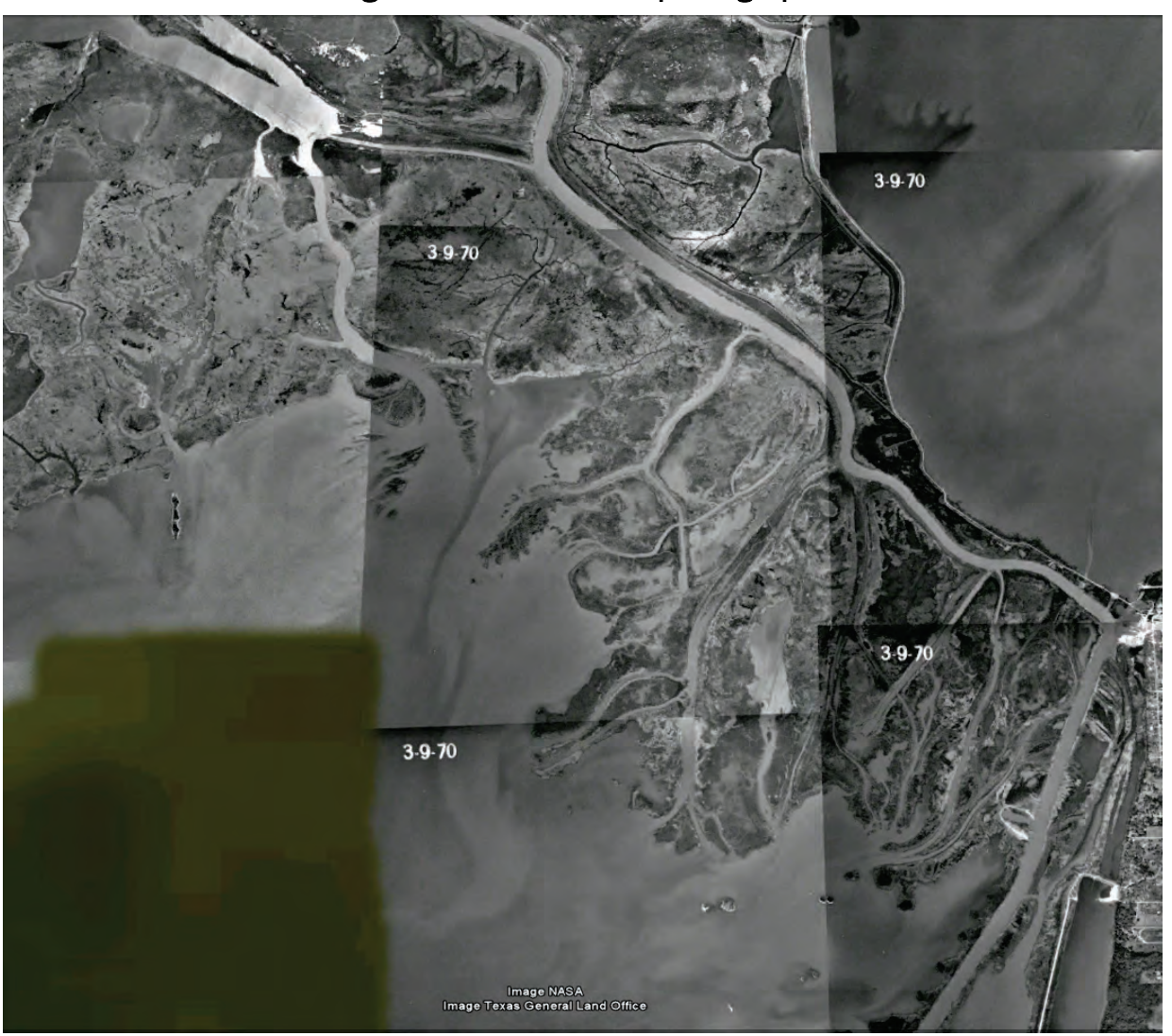

Figure 4-2 2011 aerial photograph.

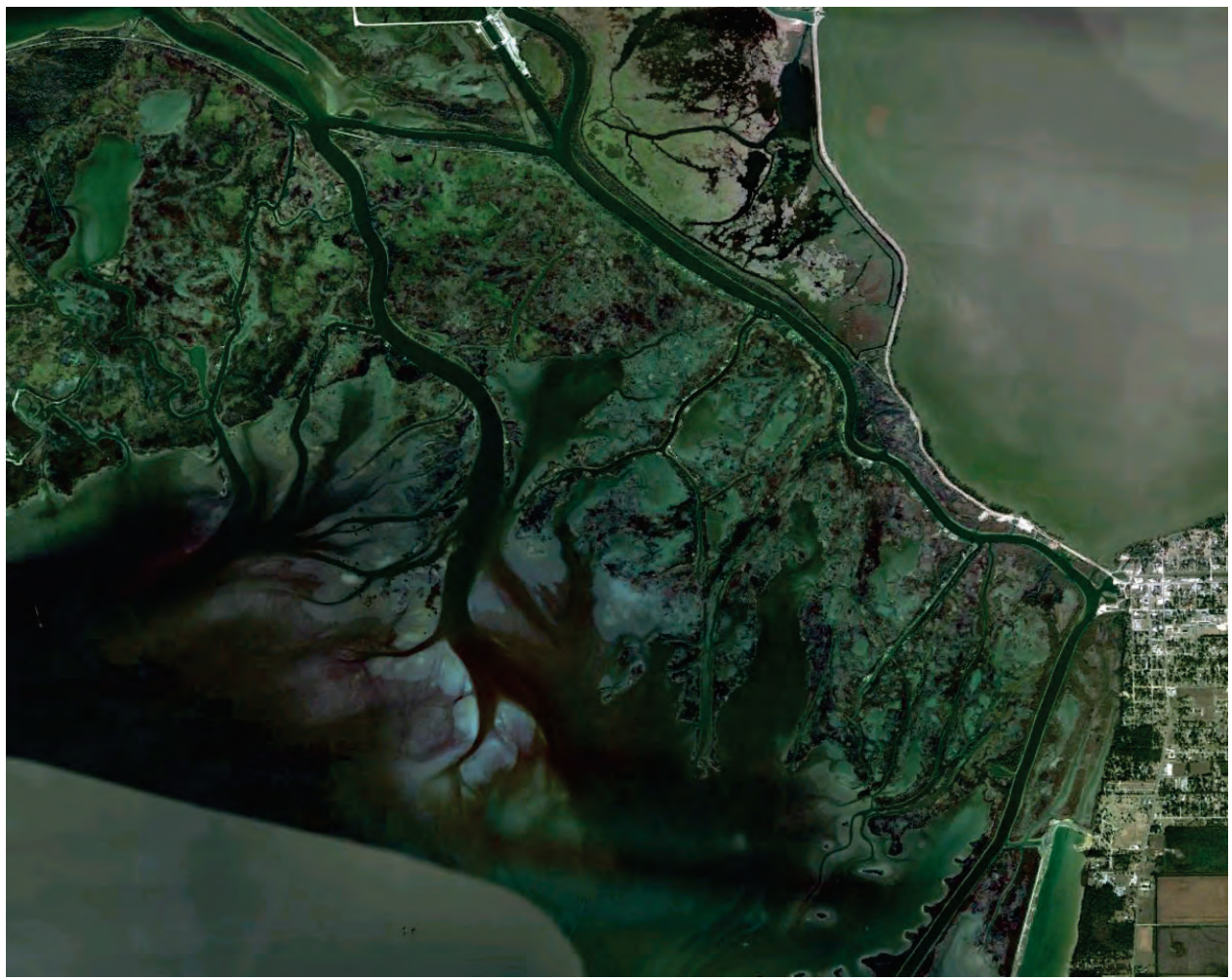


Maintenance of navigation channels through deltaic systems will eventually aggravate the hydraulic inefficiency when the required length of the channel becomes ever longer as prodelta clays are laid down within the receiving bay and are dredged. This is apparently the case within Trinity Bay as the navigation channel length from the confluence of the salt-barrier channel and lock channel (12 km) is significantly longer than the pathway through ORCO and down Long Island Bayou (8 km).

A few computations based on Manning's equation will demonstrate how the Trinity River delta fits into the context of deltaic formation. If the channel friction and geometry of the two flow pathways were the same, then, based on Manning's equation, under uniform flow the ORCO discharge would be $22 \%$ greater than down the navigation channel. To see this, the ratio of Manning's equation for the ORCO and the Trinity River (TR) for this case yields

$$
\frac{Q_{O R C O}}{Q_{T R}} \approx \frac{A_{O R C O}}{A_{T R}} \frac{n_{T R}}{n_{O R C O}}\left(\frac{R_{O R C O}}{R_{T R}}\right)^{2 / 3}\left(\frac{S_{O R C O}}{S_{T R}}\right)^{1 / 2}
$$

where:

$$
\begin{aligned}
& \mathrm{A}=\text { cross-sectional area } \\
& \mathrm{n}=\text { Manning's friction coefficient } \\
& \mathrm{R}=\text { hydraulic radius } \\
& \mathrm{S}=\text { water surface slope }
\end{aligned}
$$

The subscripts refer to the route to open water in Trinity Bay. Because the slopes to open water from the confluence are both based on the same starting and ending water surface elevation, the ratio of the slopes is just the inverse ratio of the two distances along the pathways:

$$
\left(\frac{\mathrm{S}_{\mathrm{ORCO}}}{\mathrm{S}_{\mathrm{TR}}}\right)^{1 / 2}=\left(\frac{\left(\mathrm{z}_{\mathrm{c}}-\mathrm{z}_{\mathrm{b}}\right)}{\mathrm{L}_{\mathrm{ORCO}}} \frac{\mathrm{L}_{\mathrm{TR}}}{\left(\mathrm{z}_{\mathrm{c}}-\mathrm{z}_{\mathrm{b}}\right)}\right)^{1 / 2}=\left(\frac{\mathrm{L}_{\mathrm{TR}}}{\mathrm{L}_{\mathrm{ORCO}}}\right)^{1 / 2}=\left(\frac{12}{8}\right)^{1 / 2}=1.22
$$

The water level difference between the confluence of the Trinity River and the $\mathrm{ORCO}\left(\mathrm{z}_{\mathrm{c}}\right)$ and the open bay $\left(\mathrm{z}_{\mathrm{b}}\right)$ cancels out, making the slope ratio independent of the flow conditions. A reasonable assumption is that the friction between the two pathways is comparable, since the sediments forming the beds are derived from the same sources, so similar channel 
geometries result in a $22 \%$ difference in discharge. If the ORCO channel begins to enlarge and the Trinity River shoals, then the flow ratio can quickly evolve to favor ORCO.

Once the diverting of flow begins, it is very difficult to control. As the flow becomes larger through ORCO, the transport capacity increases, and the channel will begin to enlarge, thereby making that pathway even more hydraulically efficient. Conversely, as the lower Trinity River shoals because its transport capacity is diminished, it becomes even less efficient.

A more precise calculation for the ORCO-Trinity River system can be made using information we have about the two channels. For example, Figure 4-3 shows the aerial photograph of the ORCO from 1970. Comparing that to an aerial photograph of ORCO in 2011 (Figure 4-4) shows that the channel has increased significantly in width. Furthermore, the results of the recent field surveys show the depths in ORCO have increased as well (Figure 3-22).

Assuming that the ratio of the areas of the channels is approximately the product of the ratios of widths and depths and assuming the hydraulic radius is approximately the water depth (D), then

$$
\frac{Q_{O R C O}}{Q_{T R}} \approx \frac{W_{O R C O}}{W_{T R}} \frac{n_{O R C O}}{n_{T R}}\left(\frac{D_{O R C O}}{D_{T R}}\right)^{5 / 3}\left(\frac{L_{T R}}{L_{O R C O}}\right)^{1 / 2}
$$

Figure 4-3 1970 aerial photograph.

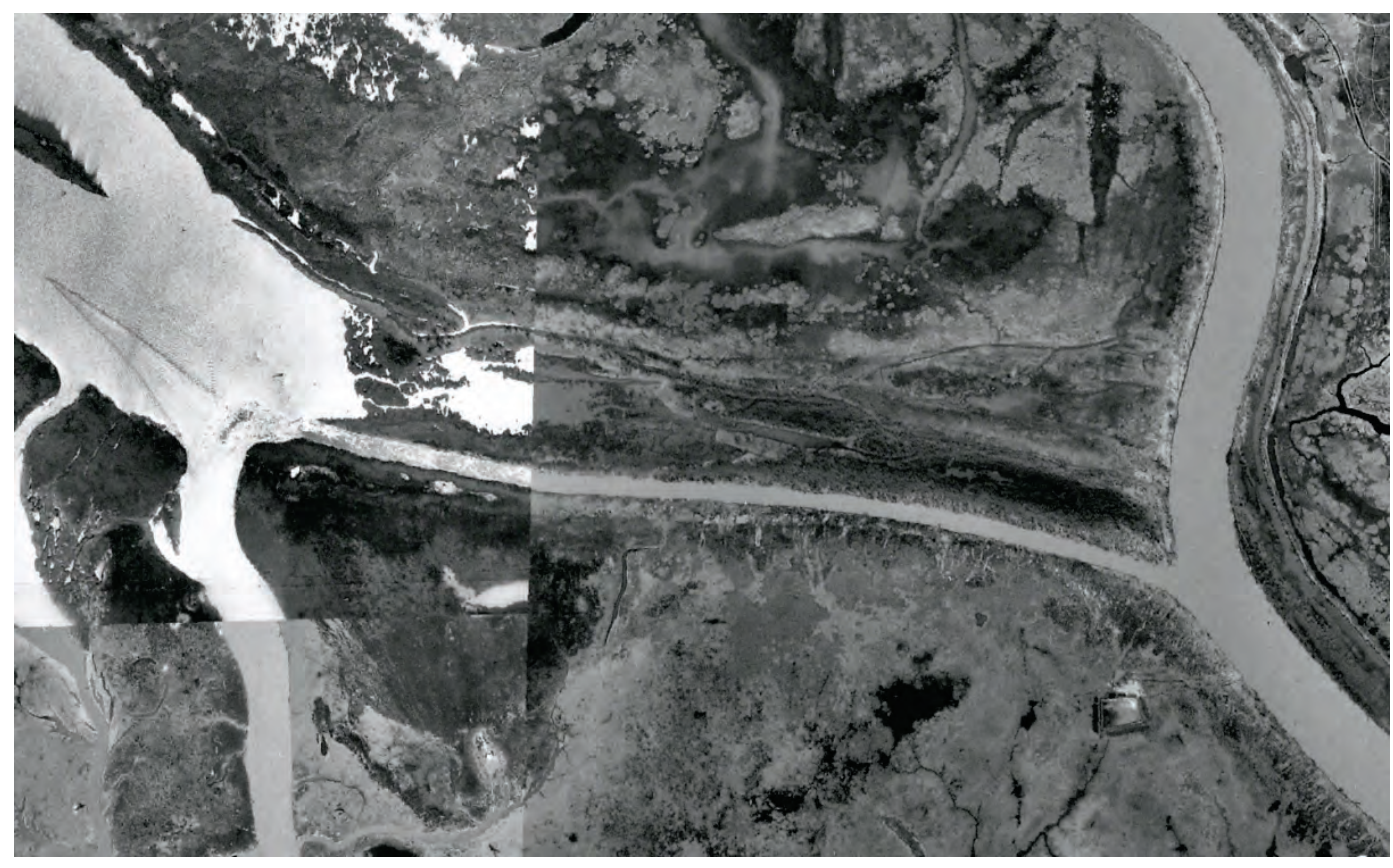


Figure 4-4 2011 aerial photograph.

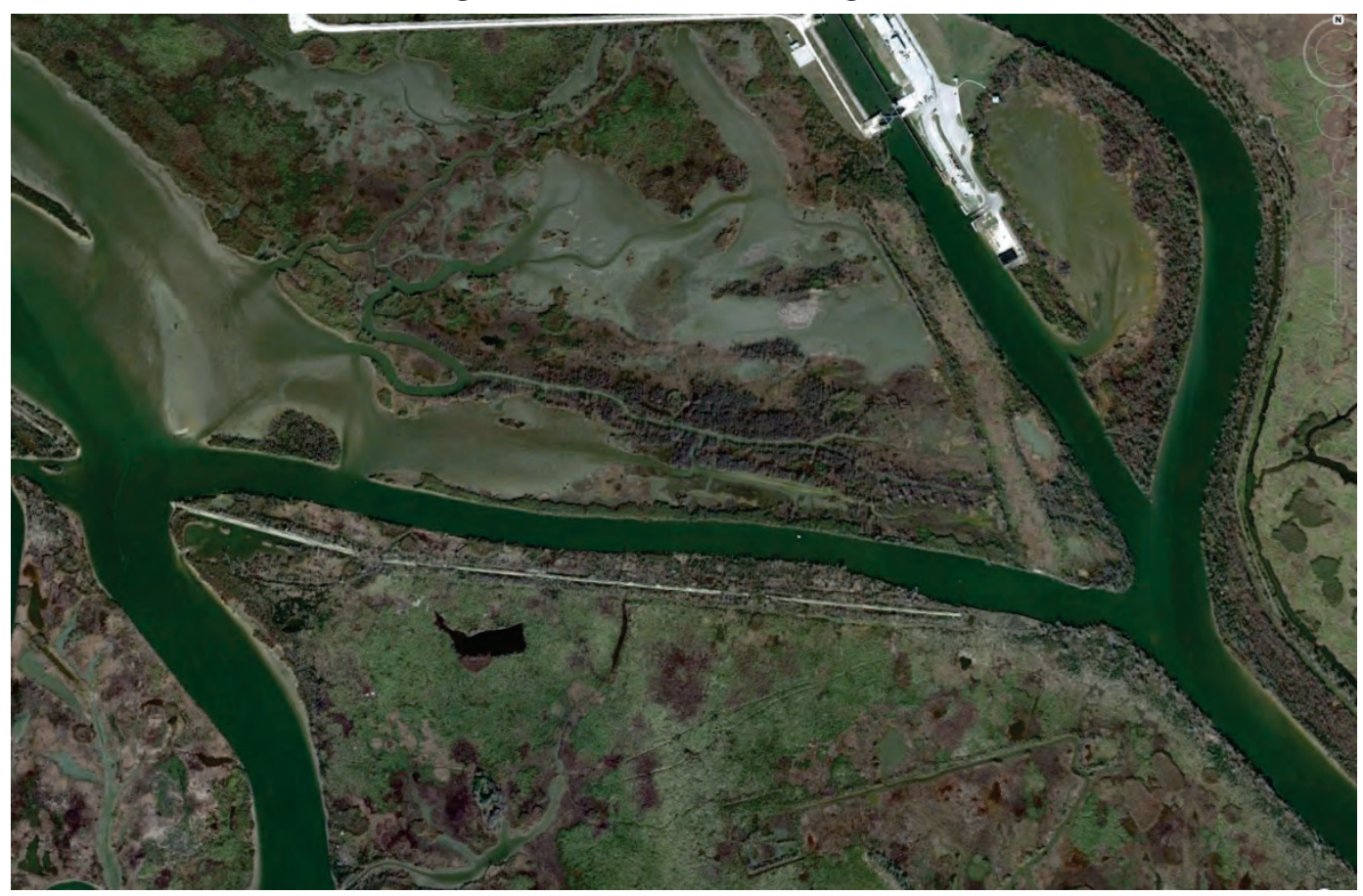

The flow measurements described in Chapter 3 showed that the ratio of the measured flows between ORCO and the lower Trinity River were approximately 3.2 (127.5/40, estimating the correction of the Trinity River flows for the inaccessible portion of the width). The approximate width ratio (taken from aerial photographs) between the two channels is 0.67 , the ORCO still being the narrower. With the assumption that the frictions are the same and knowing the channel length ratio, Equation 4-2 can be solved for the depth ratio. The resulting depth ratio is 2.3, with ORCO being deeper. Inspection of Figure 3-22 shows that the lower Trinity River depths are approximately $2 \mathrm{~m}$ on average, while the ORCO shows the average depth to be approximately $5 \mathrm{~m}$, giving a depth ratio of approximately 2.5. This is a qualitative validation of the applicability of this line of reasoning. The ORCO is the most hydraulically efficient pathway to open water in Trinity Bay and will most likely continue to be due to deltaic processes. 


\section{Approaches for Shoal Removal}

The overall goal of the project is to determine if it is possible, in principle, to remove the Trinity River shoal below the ORCO/Trinity River split by manipulation of the ORCO near the Trinity River. The primary approaches to achieving this goal are, generally,

1. redistributing the flows back into the lower Trinity River so that the existing sediment load can be sustained throughout the channel, thus scouring the Trinity River shoal of interest and/ or

2. reducing the sediment load to the lower Trinity River so that the reduced discharge can sustain the transport of the reduced sediment load.

The methods for accomplishing item 1 above are typically

1. structural (to inhibit the diversion of flows to ORCO),

2. changing the channel alignment to make the diversion very inefficient because of entrance and exit losses at the diversion point,

3. dredging the Trinity River to restore it as a hydraulically efficient pathway,

4. filling the ORCO with sediments along its length to make it less hydraulically efficient, or

5. a combination of 3 and 4 .

The extreme structural case is to dam off ORCO completely. The merits of changing the alignment depend on the relative importance of the local head losses at the diversion compared with the frictional losses along the flow pathways.

The approach of the second primary item above can be accomplished by

1. dredging sediment traps upstream of the problem area to intercept the sediment load at a more efficient location for removing the material and

2. diverting a disproportionately higher fraction of the sediment load into ORCO than the flow distribution would normally dictate. (This alternative would likely involve some structural or channel alignment change.) 


\section{Model Development}

\section{Model code}

The numerical model code used in this study is the U.S. Army Corp of Engineers Adaptive Hydraulics (AdH) code (Berger et al. 2013). AdH is a state-of-the-art modeling system developed by the ERDC Coastal and Hydraulics Laboratory (CHL). It is capable of simulating both saturated and unsaturated groundwater flow, overland flow, three-dimensional Navier-Stokes flow, and two-dimensional (2D) or three-dimensional (3D) shallow-water problems. The current study utilizes the 2D shallow-water module. The 2D shallow-water equations used for this application are a result of the vertical integration of the equations of mass and momentum conservation for incompressible flow under the hydrostatic pressure assumption.

One of the major features of AdH is its ability to automatically adapt the mesh in areas where additional resolution is needed to properly resolve the hydrodynamics and then unresolve the area when the resolution is no longer needed. This feature thus addresses the computational burden issue while allowing adequate resolution for a good simulation. $\mathrm{AdH}$ contains other essential features such as wetting and drying, sediment transport, conservative transport, such as salinity with density coupling, and wind effects. A series of modularized libraries make it possible for $\mathrm{AdH}$ to include vessel movement, vegetative friction descriptions, varying turbulence closures, water quality and ecological modeling, and structures, among other features. AdH can run in parallel or on a single processor and runs on Windows systems and UNIX-based systems.

The application of AdH to this project invoked the simulation of the transport of streamwise vorticity. In a meandering channel this accounts for the effects of secondary currents on the depth-averaged flow distribution within meandering cross sections. This becomes very important for sediment transport.

\section{Model domain}

The model domain was defined to provide the model flexibility to respond to the impacts of remedial alternatives on the hydrodynamics of the overall system. For example, closure of the ORCO channel below Wallisville has the potential to alter the backwater profile along the lower Trinity River. The 
effects could then be seen upstream of the salt barrier at Wallisville and change the overbank flooding and flow losses upstream. These upstream impacts can change the flow distribution, storage in the wetlands, and timing of the flood routing. Consequently, the model domain extends upstream on the Trinity River to Liberty, TX. This location is a gauging station for discharge and was convenient for the development of the inflow boundary condition.

The overall model domain is shown in Figure 6-1. The model includes all of Trinity Bay, Trinity delta, Trinity River, Old River, and all of the primary bayous in the lower system, with the wetland storage on the eastern and western sides of the Trinity River, including Lake Charlotte. The sources of bathymetry were documented in Chapter 3 . The numerical model bathymetry (bed elevation) is presented in Figure 6-2.

\section{Riverine bathymetry approximation}

The development of riverine bathymetry upstream of Interstate 10 (I-10) was developed from an analytical method that took into account the meander of the river, the development of point bars and river crossings. A full description of the methodology is provided in Appendix B. An example of the resulting model bathymetry is presented in Figure 6-3.

\section{Model datum}

The model bathymetry and boundary conditions, as well as analysis, were performed using NAVD88 as the vertical datum. The horizontal datum was set using the UTM NAD 83 projection. The model was developed in metric units. For most of the comparisons to field observations, the results were converted to English units.

\section{Model boundary conditions}

\section{Tides}

The tides for driving the model downstream water surface elevation boundary condition were derived from the 6-minute (min) NOAA tides at Morgan Point in Galveston Bay. The tidal signal was decomposed into the predicted astronomical tide and the residual tide, assumed to be primarily attributed to meteorological effects. The residual tidal signal was then lowpass filtered to remove fluctuations of a period lower than 3 hours (hr). The filtered residual was added back to the predicted astronomical tide for use as the model boundary condition. 
Figure 6-1 Overall model domain.

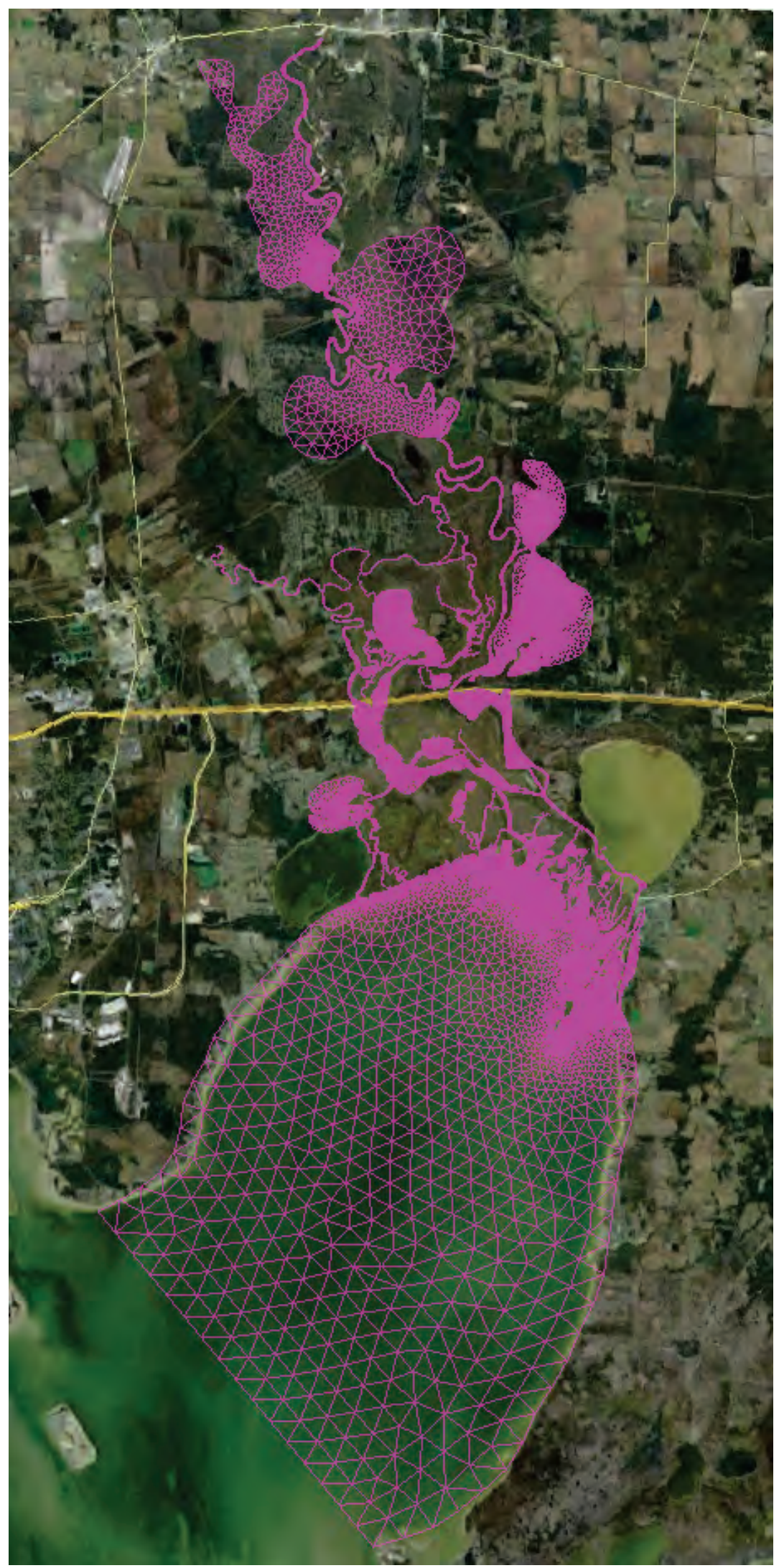


Figure 6-2 Bathymetry of the numerical model; elevations are in meters above NAVD88.

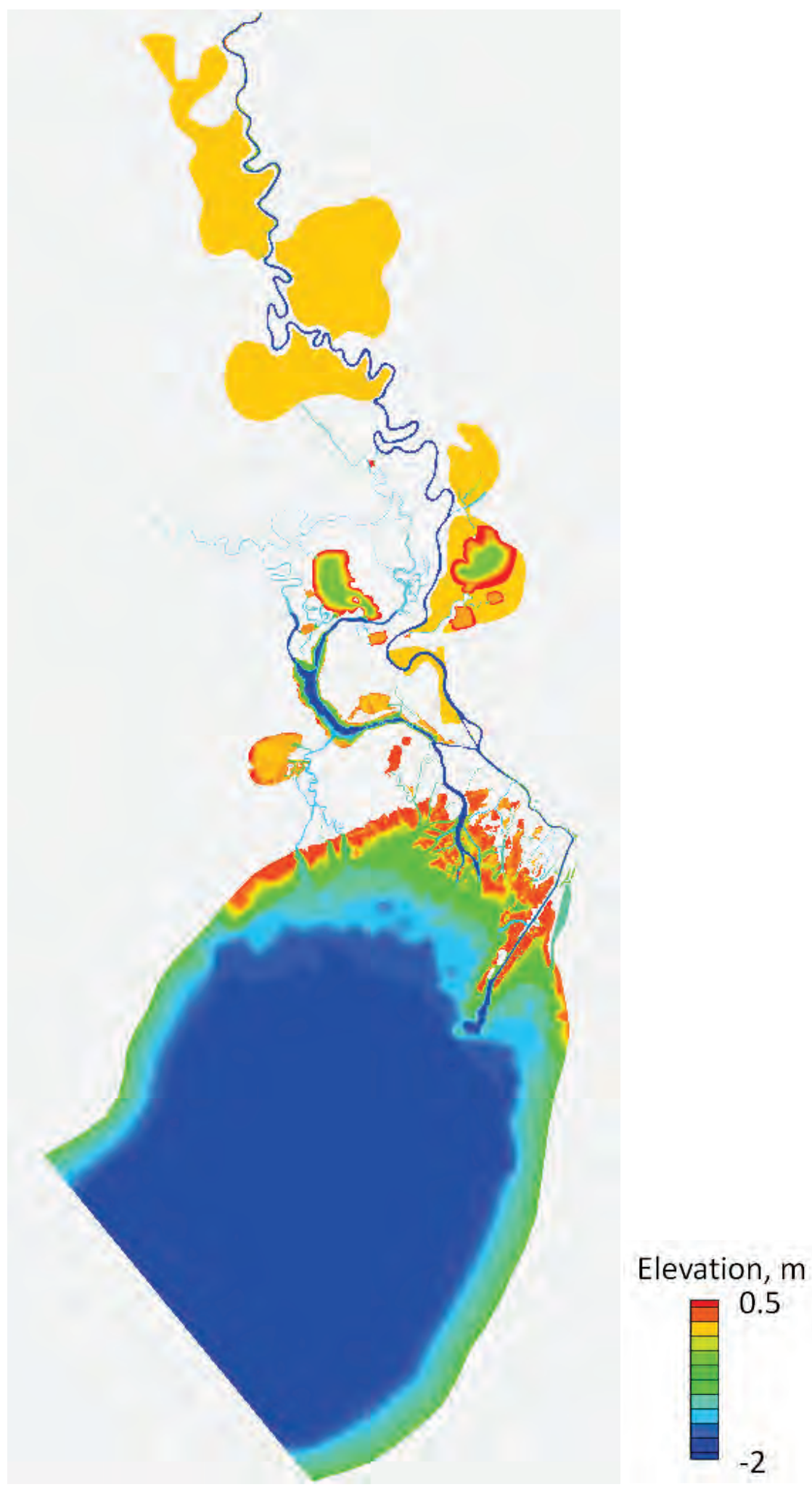


Figure 6-3 Example of the estimation of point bars along the upper meandering Trinity River. Red indicates shallow areas; blue indicates deep areas. See Appendix B for details.
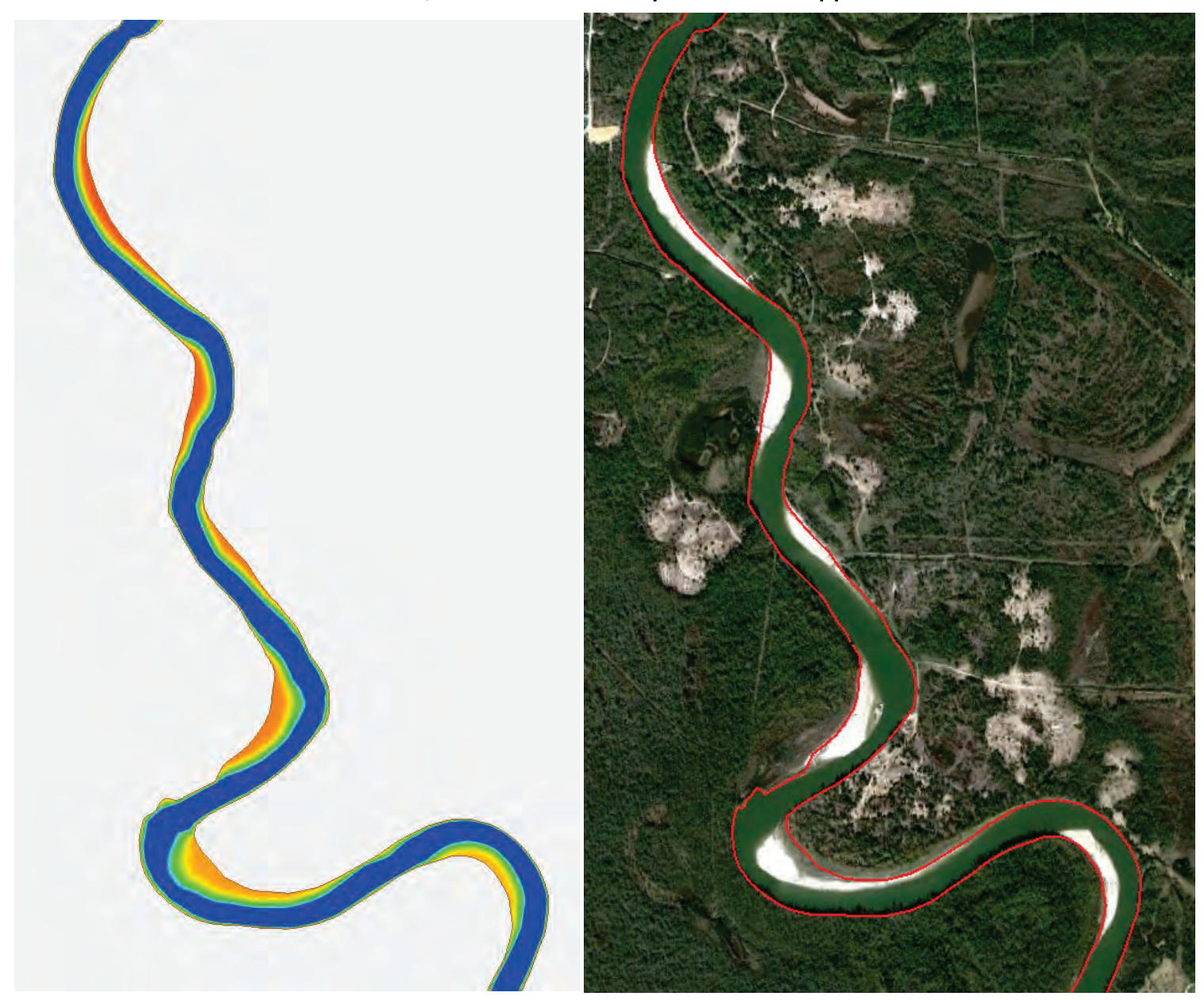

\section{Winds}

Wind data were obtained for Houston Hobby airport, decomposed into east-west and north-south components. Each component was filtered to remove short-term noise (periods less than $3 \mathrm{hr}$ ) and used as a uniform wind over the numerical model domain. Due to the channelization of most of the upper system, only Trinity Bay was expected to have any significant response to the wind stresses. The filtered winds for the wet-season simulation period are presented in Figure 6-4 and for the dry-season period in Figure 6-5. The maximum wind speed during the wet season was $9.7 \mathrm{mps}$ and the average was $3.1 \mathrm{mps}$. During the dry season, the maximum and average wind speeds were 8.6 and $2.5 \mathrm{mps}$, respectively. 
Figure 6-4 Filtered wind components for the wet-season simulation period.

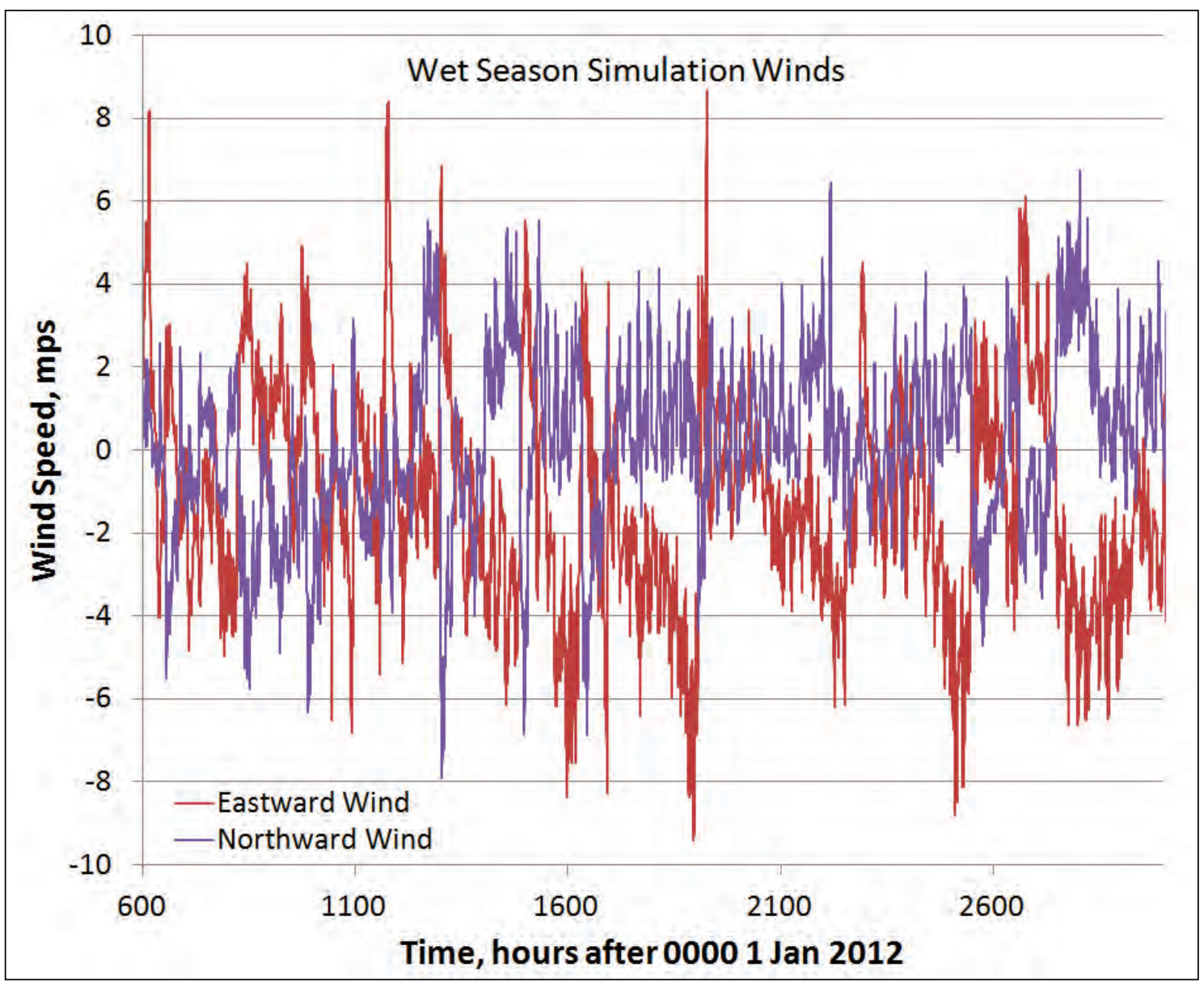

\section{River discharges}

The river discharges at Liberty, TX, are not reported for flows below approximately $283 \mathrm{cms}$. For those periods of very low flow, the flows at Romayor, TX, were used to estimate the flows at Liberty with a time lag. For flows that were falling below $283 \mathrm{cms}$ after a flood event, an exponential decay was applied that matched the slope of the falling discharge. The resulting flows are presented in Figure 6-6. The peak flow at Liberty was just above $1133 \mathrm{cms}$, which is estimated, approximately, as a $12 \%$ exceedance flow (Figure 6-7). The associated stage at Liberty for a $12 \%$ exceedance is approximately $8.29 \mathrm{~m}$, which is associated with moderate flooding (Figure 6-8). The peak stage observed at Liberty during the wet season of 2012 was $8.35 \mathrm{~m}$ (Figure 3-23). 
Figure 6-5 Filtered wind components for the dry-season simulation period.

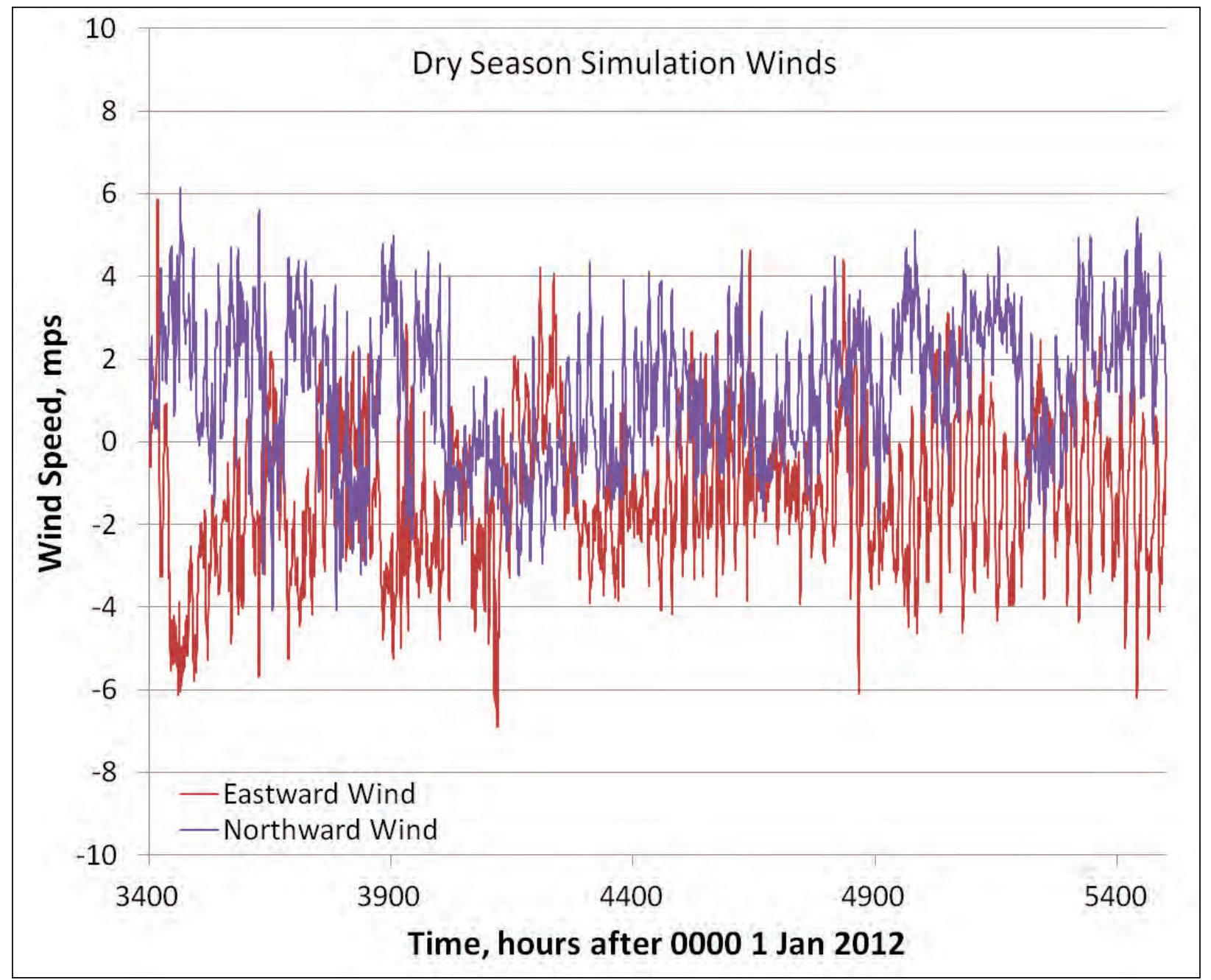

Coastal Water Authority (CWA) canal withdrawals

The CWA canal near Dayton, TX, just south of Liberty, extracts flows from the Trinity River for the water supply in Houston. The extraction flows are nearly constant, near $28 \mathrm{cms}$. That flow was provided to the AdH model as a specified time-varying flow withdrawal, based on the USGS station 08067070.

\section{Boundary condition inflow uncertainties}

As with models of this type in general, there is considerable uncertainty in the freshwater inflows to the model due to measurement uncertainties, ungaged contributions, etc. In addition, precipitation data were lacking for estimation of local contributions to the flow. 
Figure 6-6. Approximated river discharges for the Trinity River at Liberty, TX.

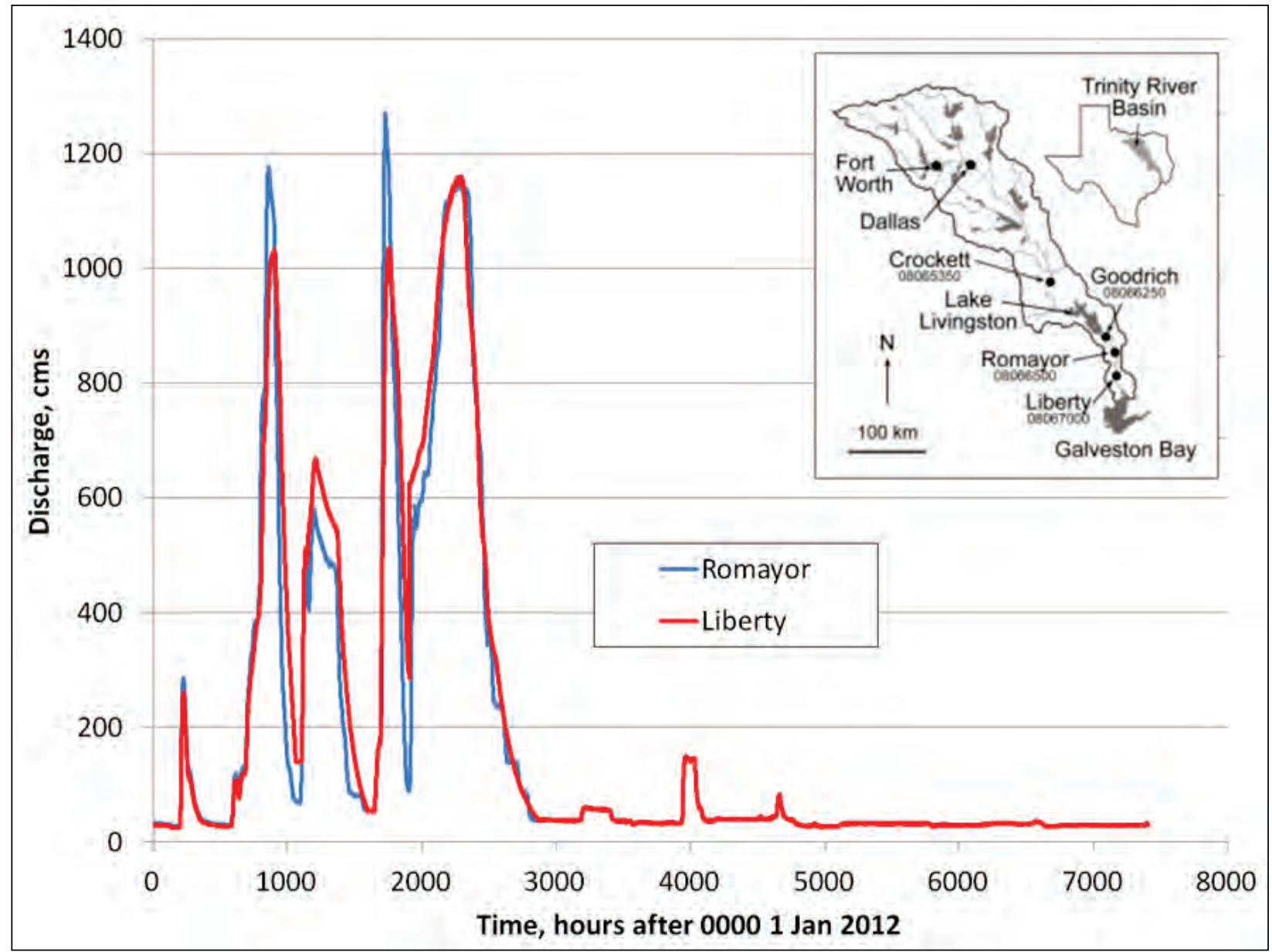

\section{Sediment}

The complexities of sediment sorting within a deltaic system and the lack of comprehensive information to specify either the horizontal distribution of surficial sediments or the vertical structure of an eroding bed make the sedimentation results qualitative. However, comparisons between alternatives remain valid within the constraints of the model assumptions. 
Figure 6-7 Historical exceedance frequency for Trinity River discharge at Liberty, TX (National Weather Service, NOAA, Advanced Hydrologic Prediction Service: http://water.weather.gov).

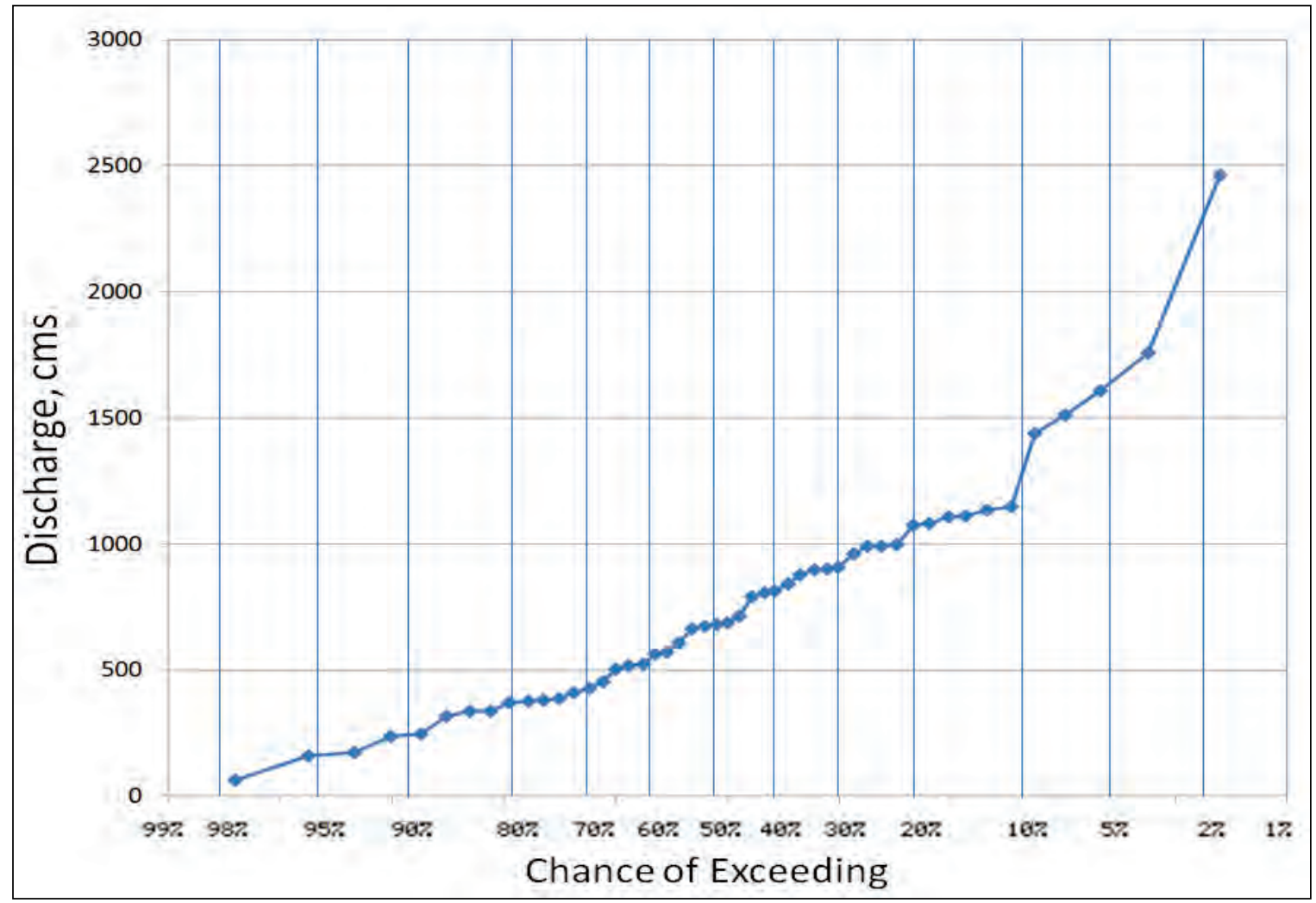

Figure 6-8 Historical exceedance frequency for the Trinity River stage at Liberty, TX (National Weather Service, NOAA, Advanced Hydrologic Prediction Service: http://water.weather.gov ).

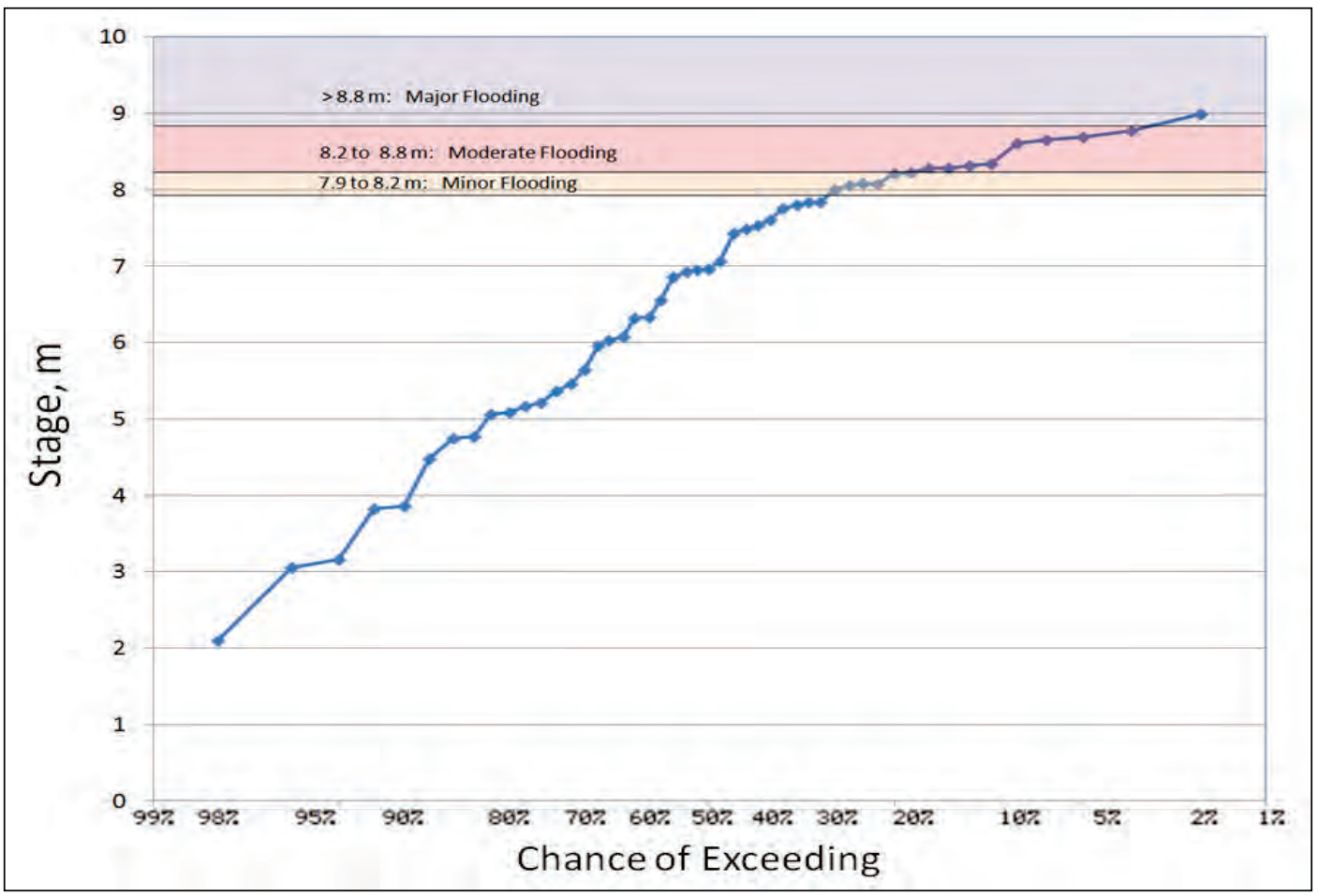




\section{Model simulation periods}

The model was simulated for both a wet season, when the river discharges were high and the lock and salt barrier were generally open to pass flood flows, and the dry season, when the model simulation was greatly complicated by the operation of the structures, which were generally closed. The wet-season simulation as defined by the period of high river discharge at Liberty is shown in Figure 6-9. In addition, inspection of the tide levels across the Wallisville structures provided a fairly clear estimate of when the structures were open and closed. The operation of the structures was later confirmed by CESWG with a detailed description of the operation of the structures. The wet season based on the condition of the structures is defined in Figure 6-10.

The dry season was characterized by the lock and the salt barrier generally closed but with periodic operation of the salt-barrier structure by partially opening multiple gates by just a few feet. The condition of the structures is shown in Figure 6-11, which is based on the detailed log of the operation of the structures combined with estimates of the flow through the structure when partially open. The estimation of the flow through the structure will be discussed in detail in Chapter 8.

Figure 6-9 Simulation periods for wet and dry seasons based on river inflows.

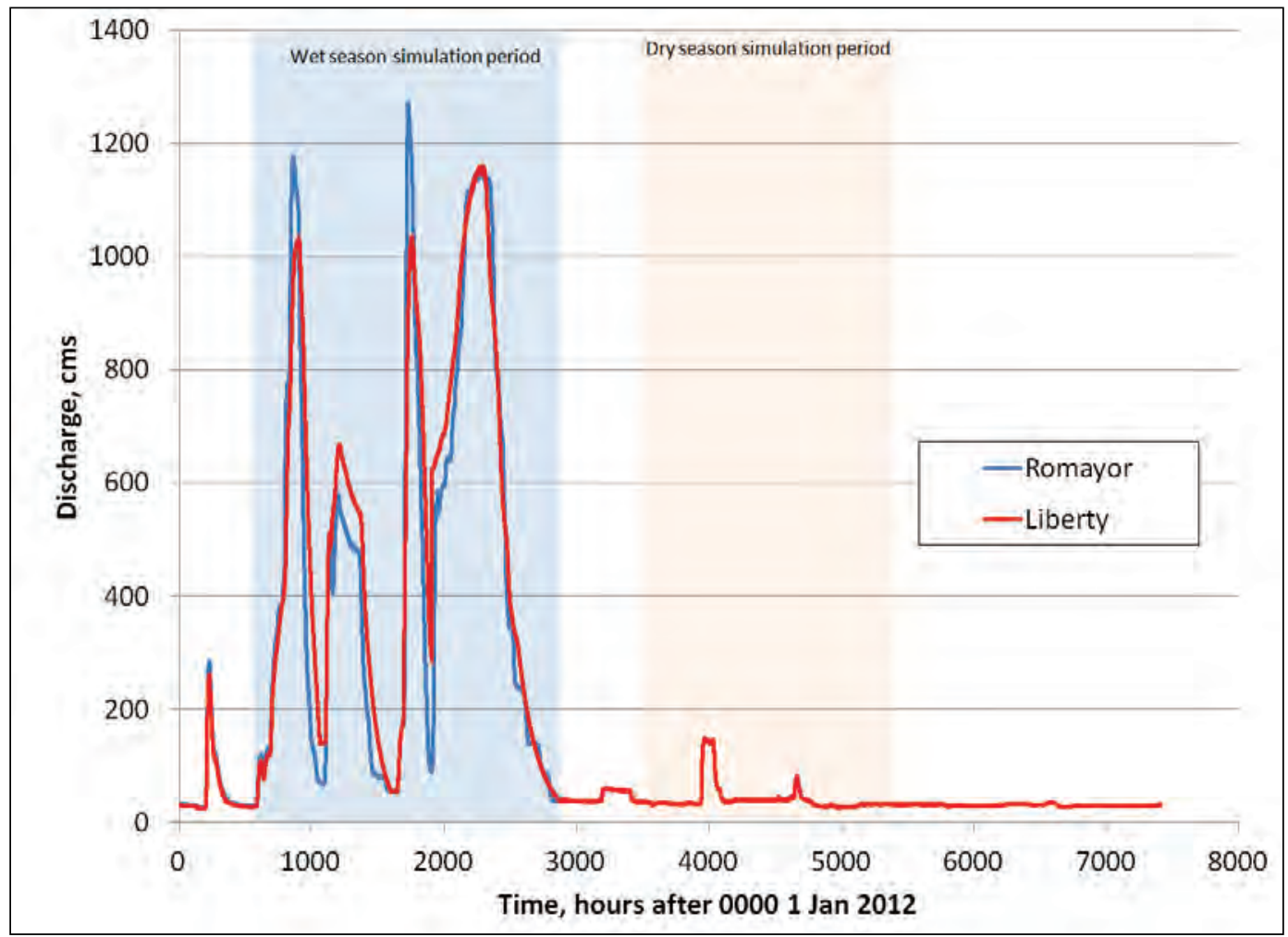


Figure 6-10 Wet-season simulation period; observed tidal signals upstream and downstream of the salt barrier. The barrier open flag (right vertical axis) is equal to 1 when the barrier is open and 0 when closed.

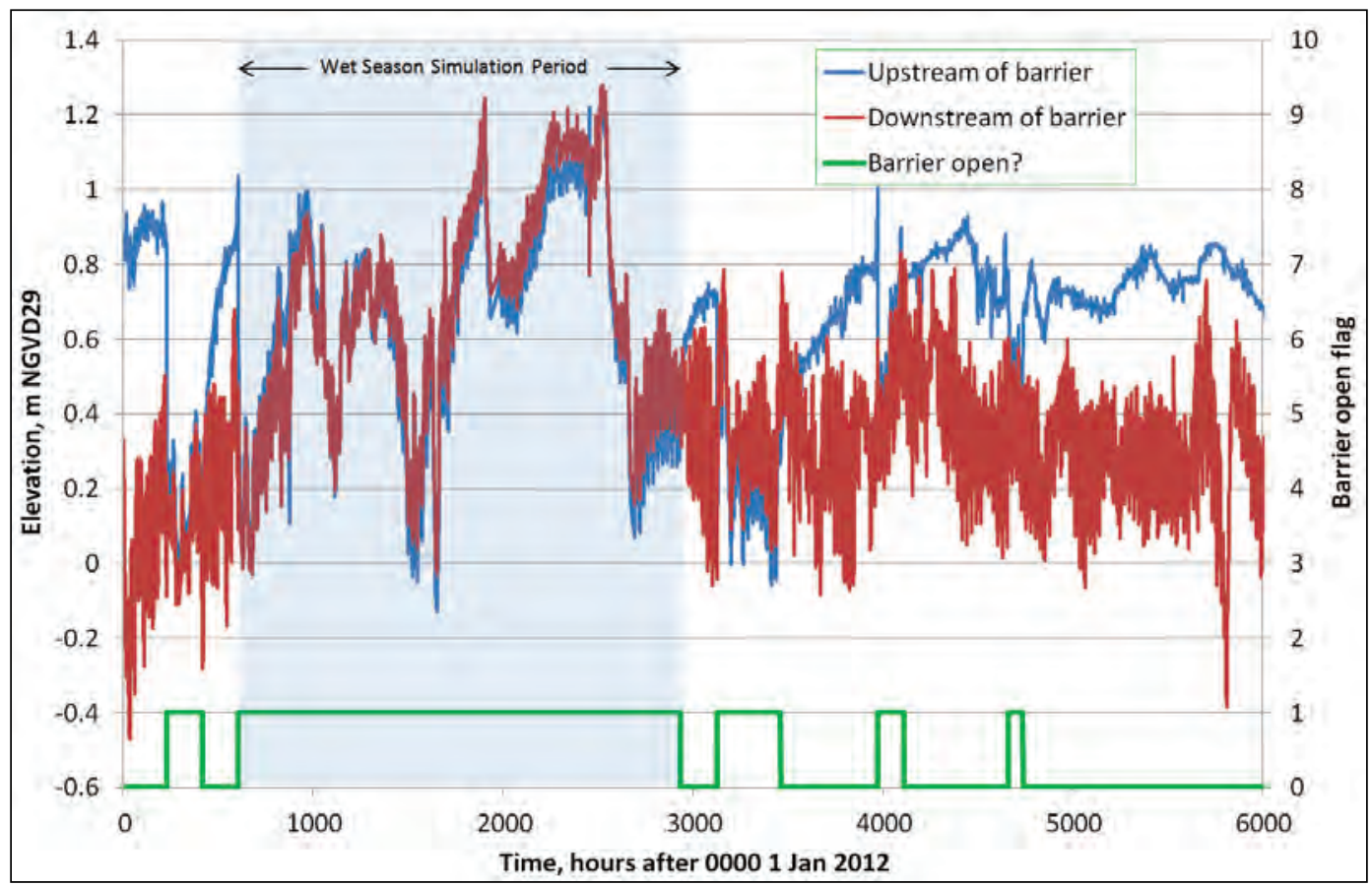

Figure 6-11 Selection of simulation period for dry season. Vertical axis is truncated so details of lower flows can be seen.

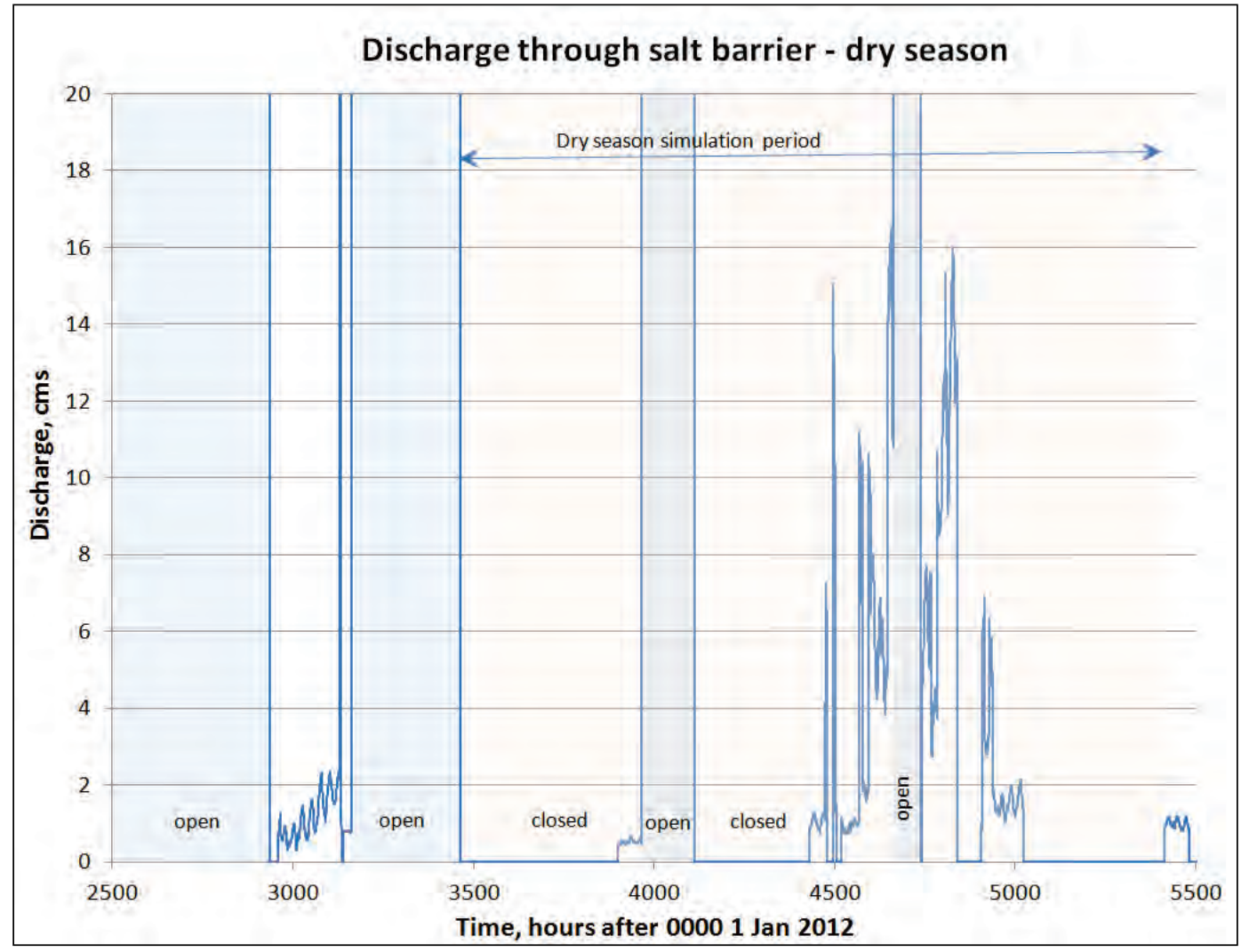




\section{Modeling strategy}

The modeling strategy was to first verify the numerical model to hydrodynamics by matching the backwater effects up the Trinity River (Figure 3-23) as well as the tidal signal downstream of the Wallisville structures. Then a series of sediment-transport-sensitivity simulations were conducted using a common computational mesh and blocking off various flow pathways by turning off elements in the mesh. These sensitivity simulations provide insights into the sediment transport in the study area. Based on the sensitivity simulations and other criteria, a series of design alternatives were developed, in cooperation with CESWG, for which detailed computational meshes were constructed to implement the designs. The design alternatives were simulated for sediment transport and salinity intrusion.

The sediment transport modeling, for both the sensitivity tests and the design alternatives, involved a two-step procedure. The bed surface sediments were initialized uniformly to a grain size distribution that is a general representation of the sediments in the system as derived from the surface cores. The model was then simulated for the wet season with bed displacement turned off. This yielded no net erosion or deposition, but the exchange of sediments to and from the bed resulted in an adjustment of the sediment grain size distribution. With this adjusted sediment grain size distribution in place, the model was rerun with the bed displacement allowed to give the predictive model results for erosion and deposition.

\section{Model hydrodynamic validation}

The model was validated to hydrodynamics for the wet-season simulation. The model was compared to data from the USGS field data stations shown in Figure 6-12. The overall model response during the wet season of 2012 is presented in Figure 6-13 for each of the USGS stations. This general response can be compared to the observed response shown in Figure 3-23.

Direct comparisons between the model and the observations at each station for the wet period are presented in Figure 6-14 through Figure 6-20. The validation comparisons of water surface elevations for each of the USGS stations for the dry-season simulation are shown in Figure 6-21 through Figure 6-27. The dry-season simulations were run with the model coefficients the same as for the wet season, with the exception of the boundary conditions. 
The quality of the model validation in the upper end of the system is poor. The influence of off-channel storage that is only schematized in the model and lack of channel bathymetry to build the model are suspected to be important. The channel friction in the model was set so that the highest peak water level for the maximum discharge was matched.

The distribution of the model discharges at the confluence the Trinity River and the ORCO are presented in Figure 6-28. Because the model validation simulation did not extend into May when the field discharges were monitored, a period during the model simulation for which the total discharge through the Wallisville structures matched the May conditions was used. For comparison during different tidal conditions, the model minimum and maximum discharges are taken over the tidal cycle when the total discharges through the structures matched the measured flows. The model is in very good agreement with the distribution of flows leaving the confluence. 
Figure 6-12 Locations of observed water surface elevation data for model validation.

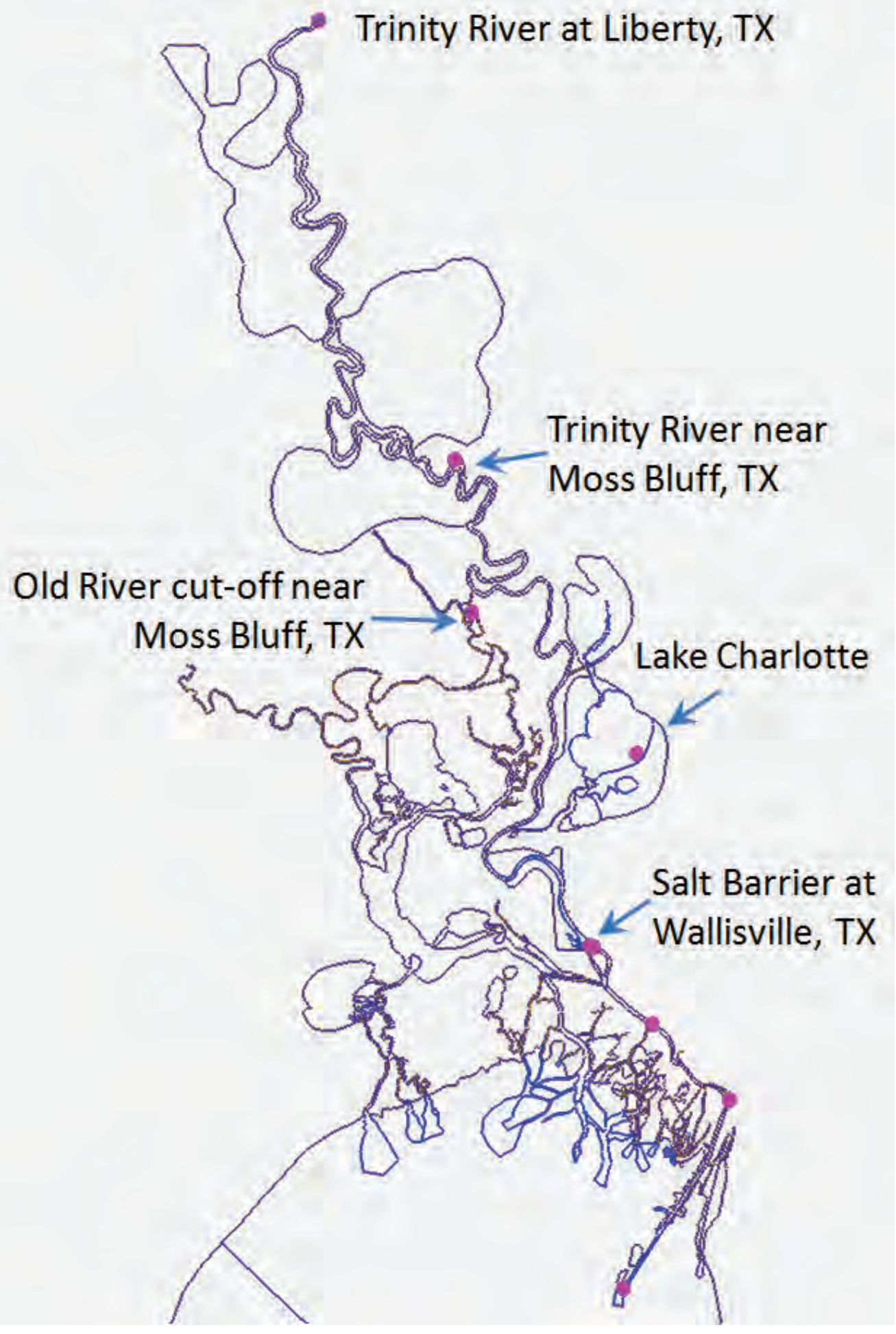


Figure 6-13 Model overall response in water surface elevation during the wet-season validation.

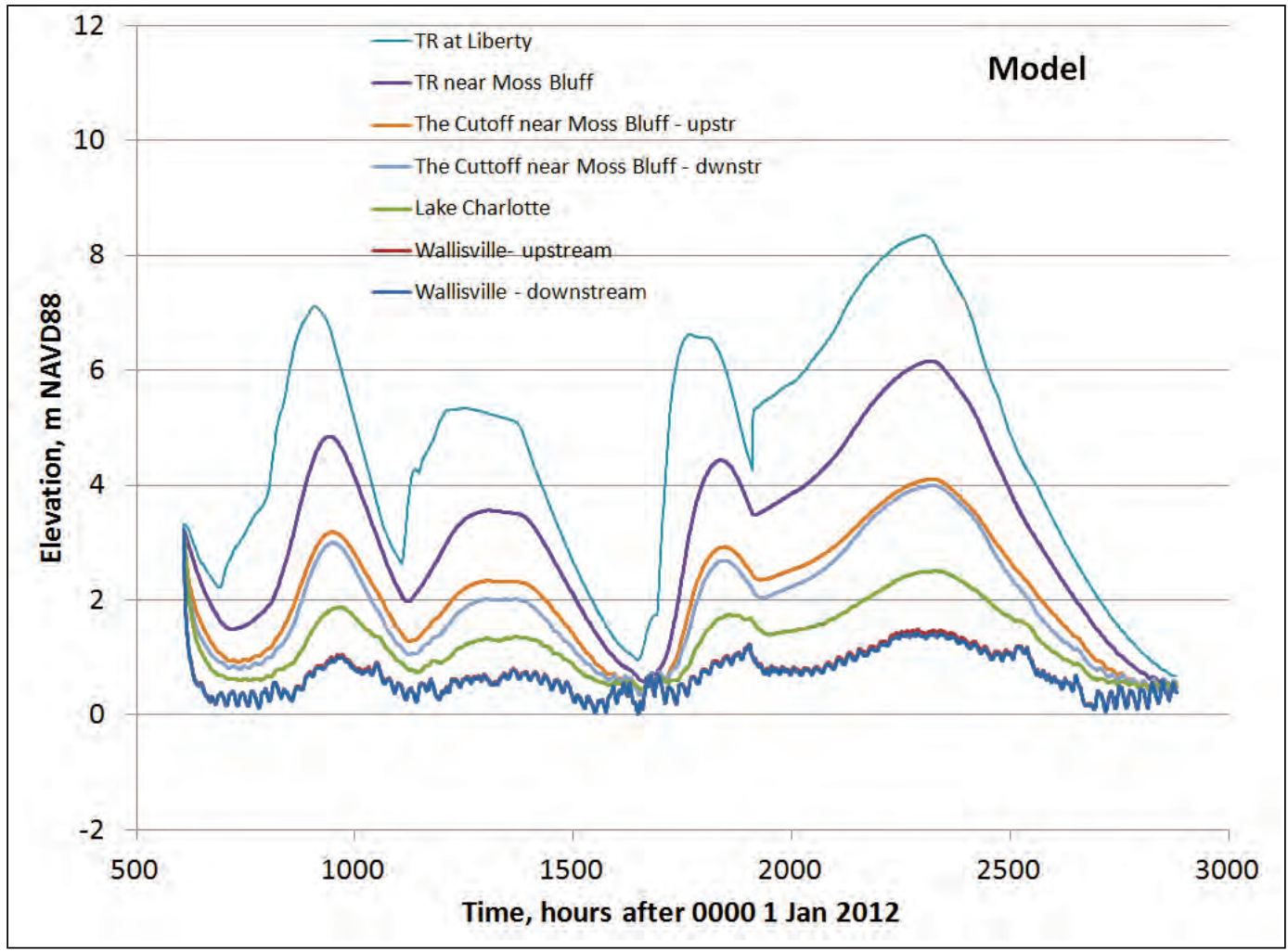

Figure 6-14 Wet-season water surface elevation validation at the downstream side of the salt barrier at Wallisville, TX.

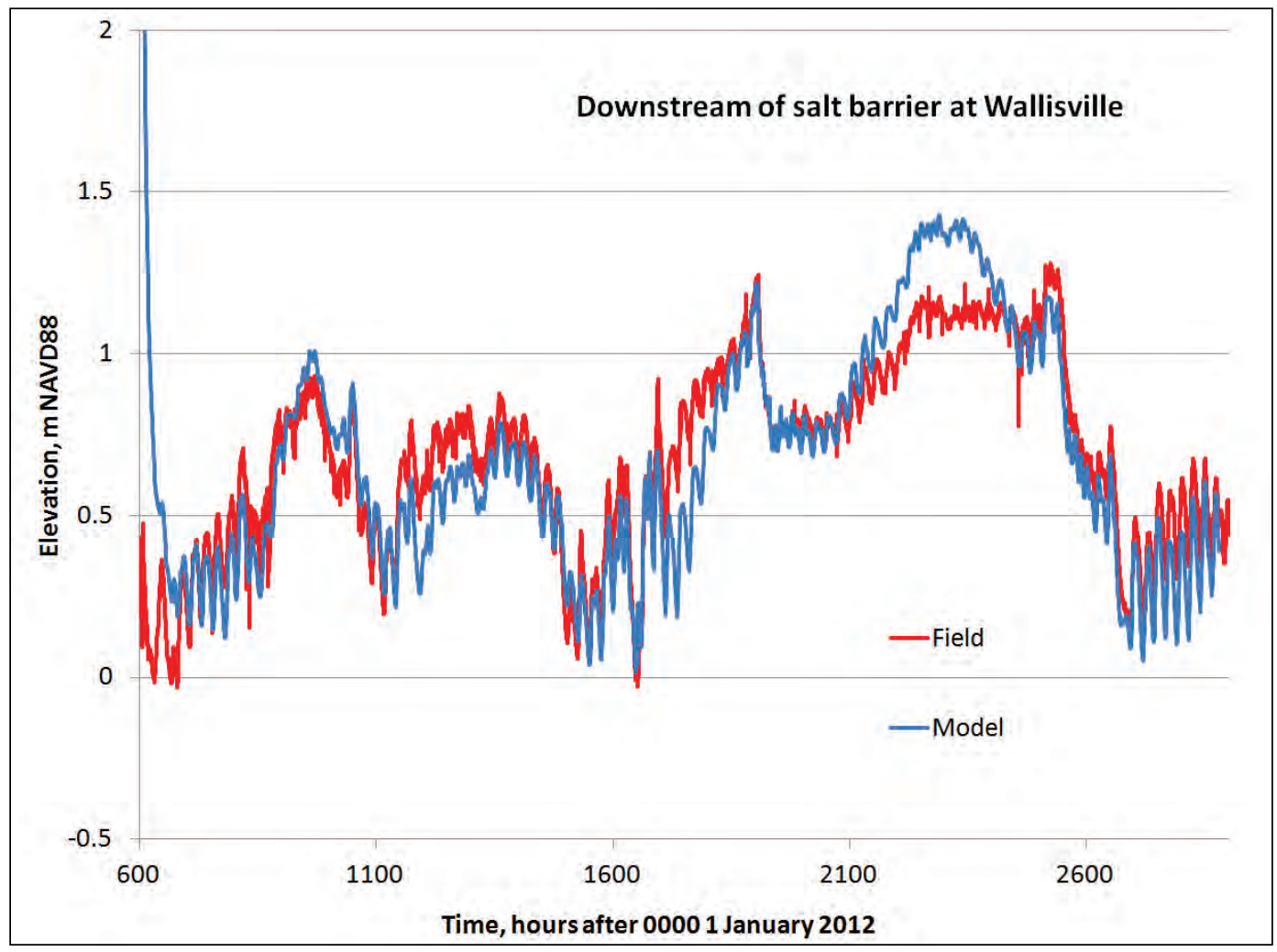


Figure 6-15 Wet-season water surface elevation validation at the upstream side of the salt barrier at Wallisville, TX.

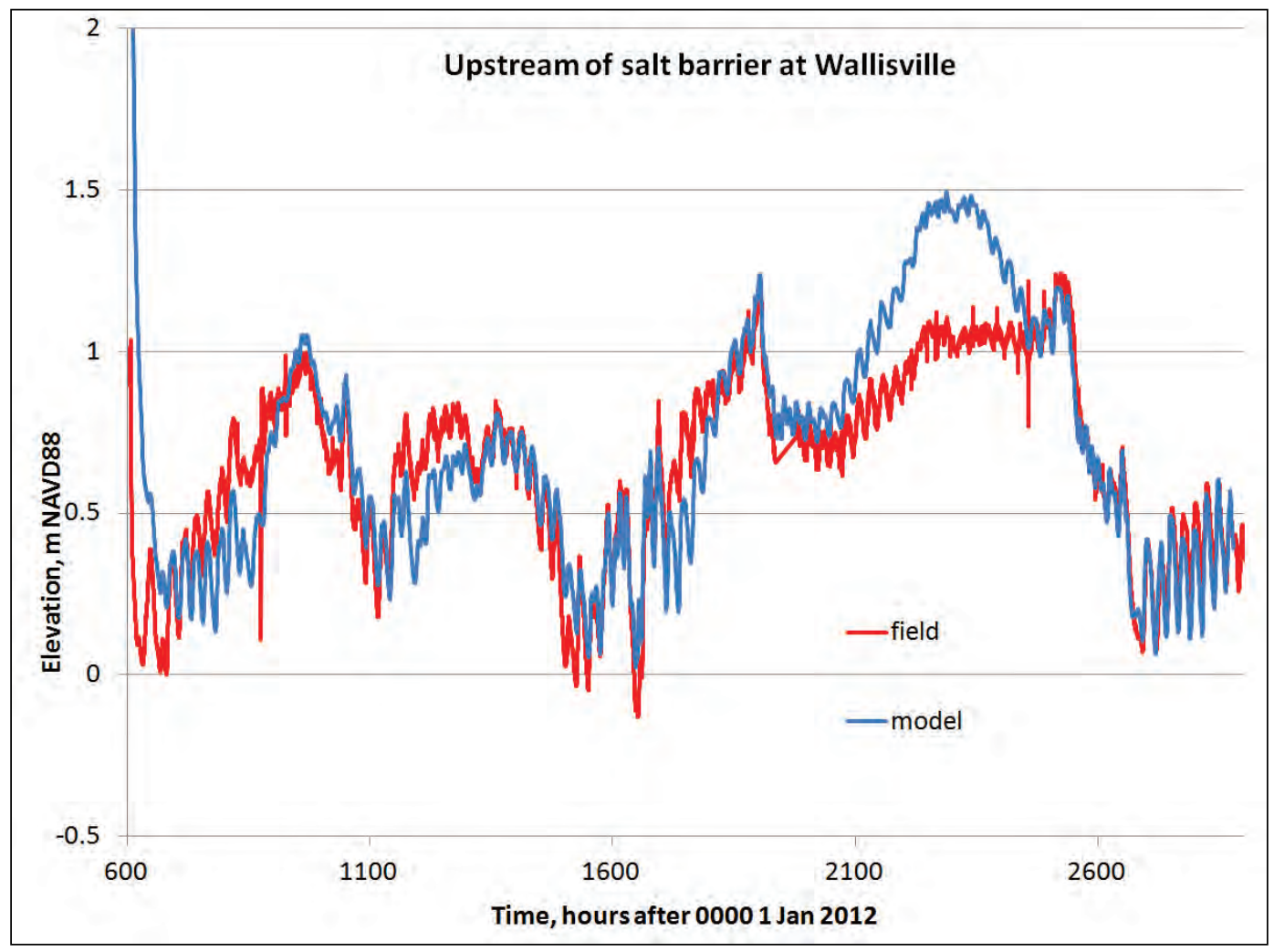

Figure 6-16 Wet-season water surface elevation validation at Lake Charlotte.

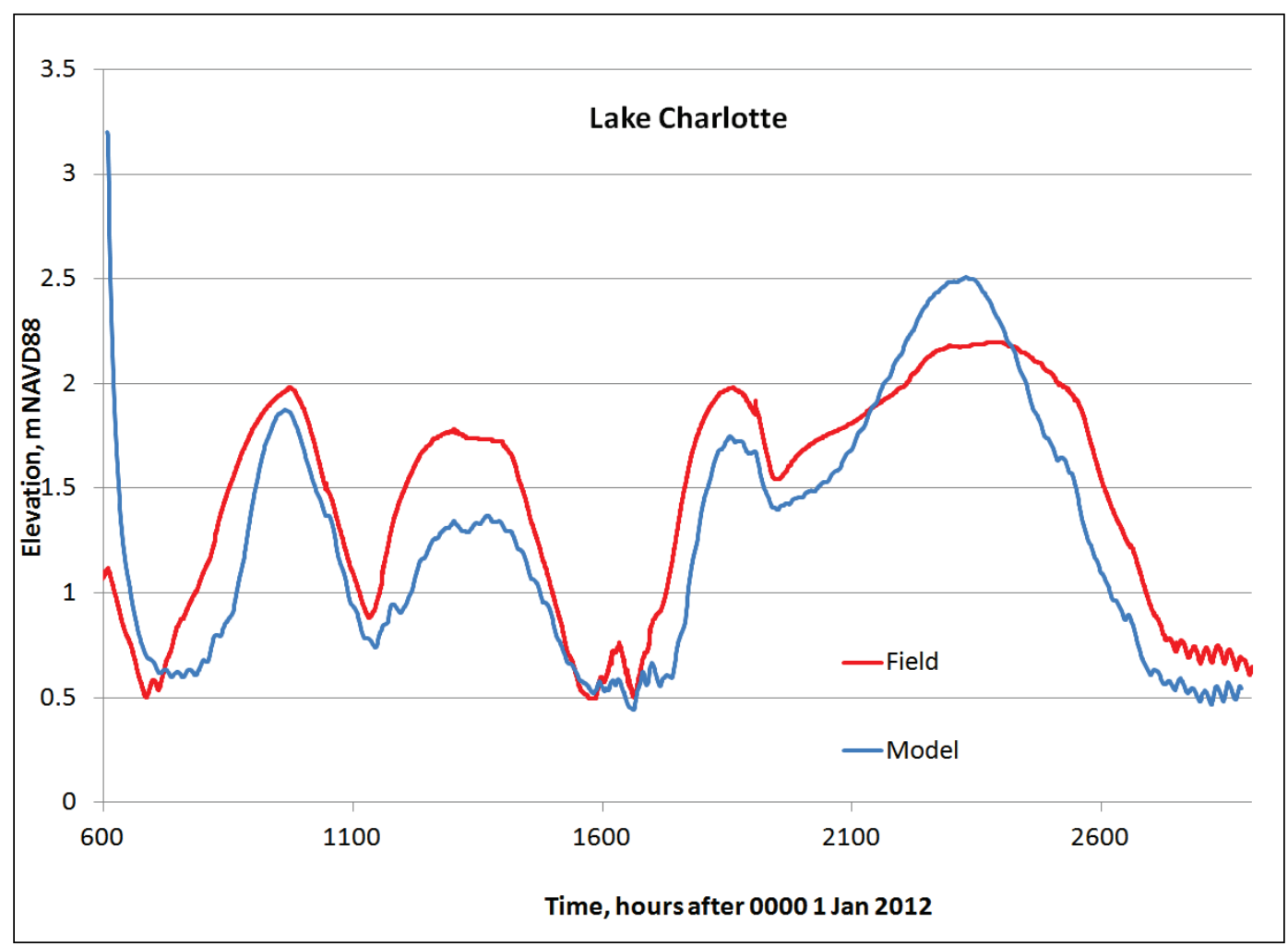


Figure 6-17 Wet-season water surface elevation validation at the downstream side of The Cutoff tide gate near Moss Bluff, TX.

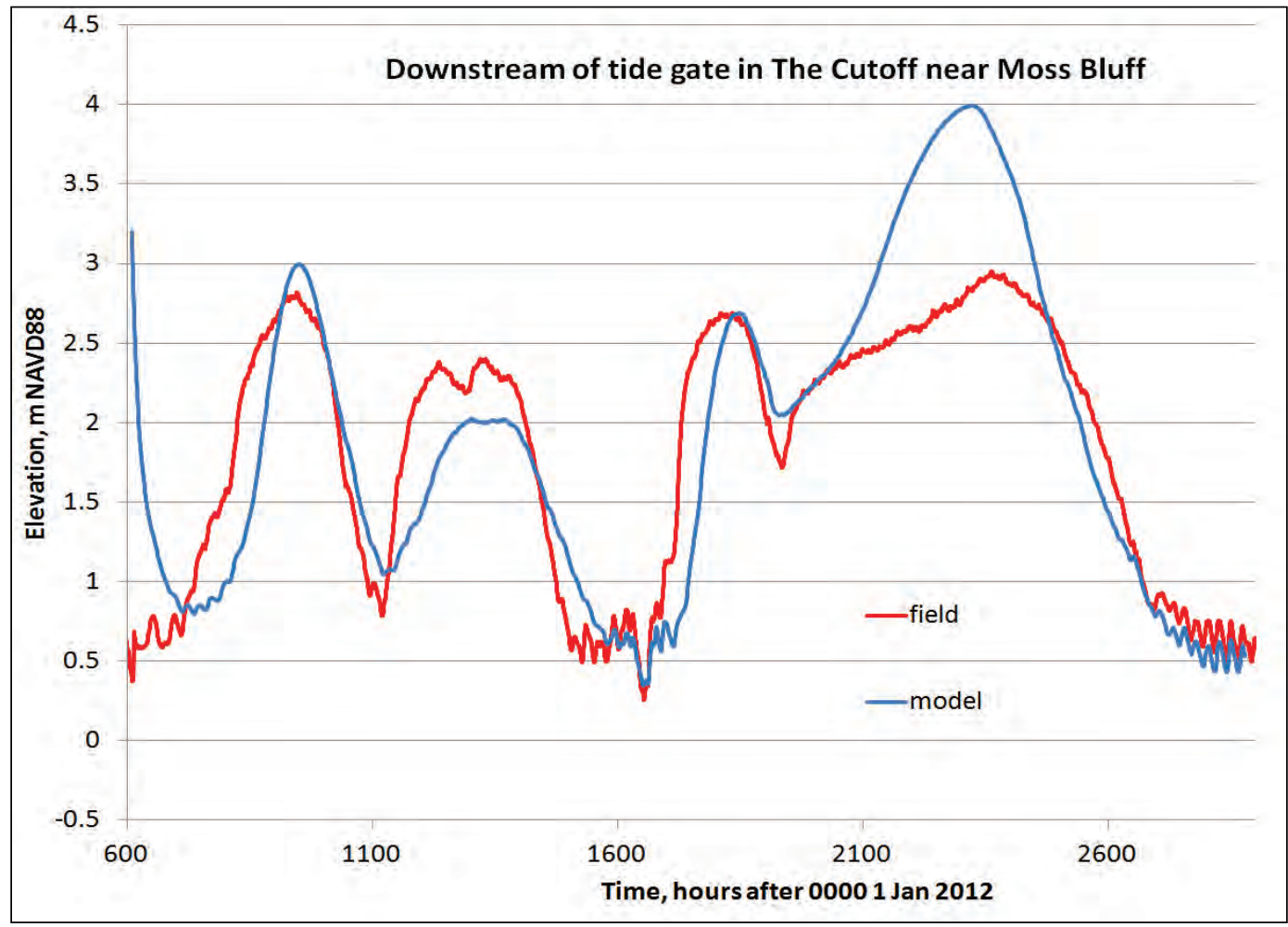

Figure 6-18 Wet-season water surface elevation validation at the upstream side of the tide gate in The Cutoff near Moss Bluff, TX.

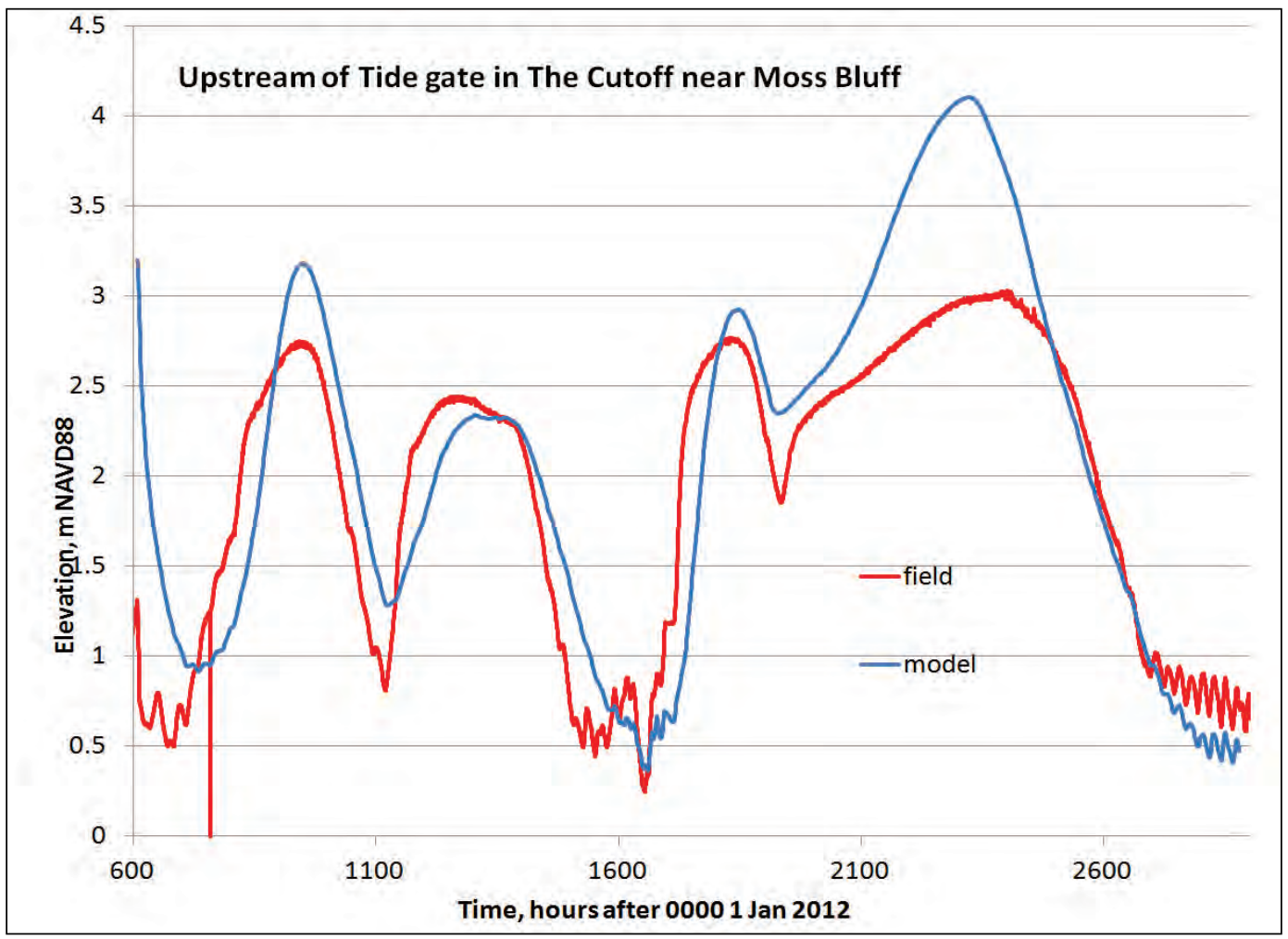


Figure 6-19 Wet-season water surface elevation validation at the Trinity River at Moss Bluff, TX.

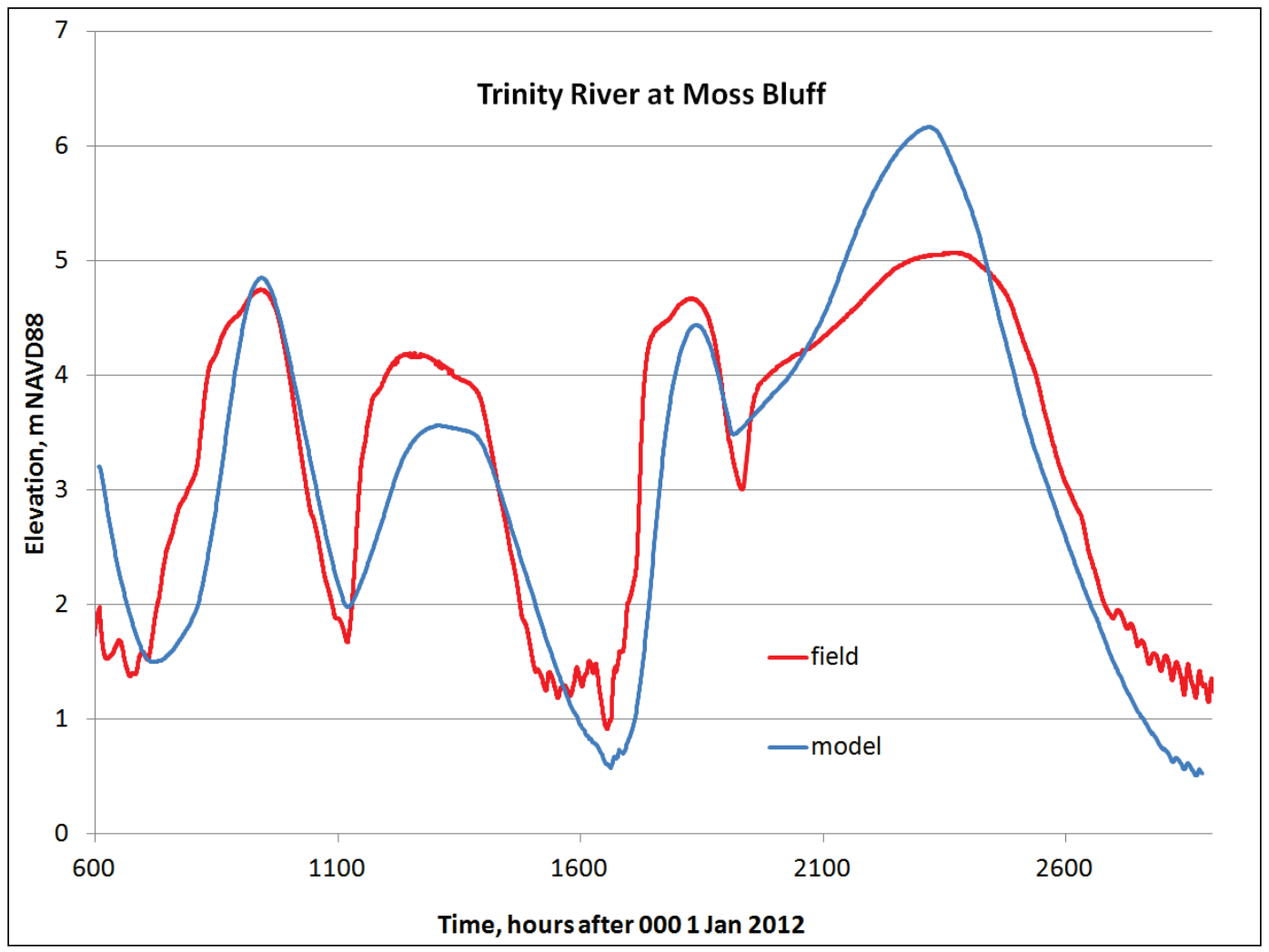

Figure 6-20 Wet-season water surface elevation validation at the Trinity River at Liberty, TX.

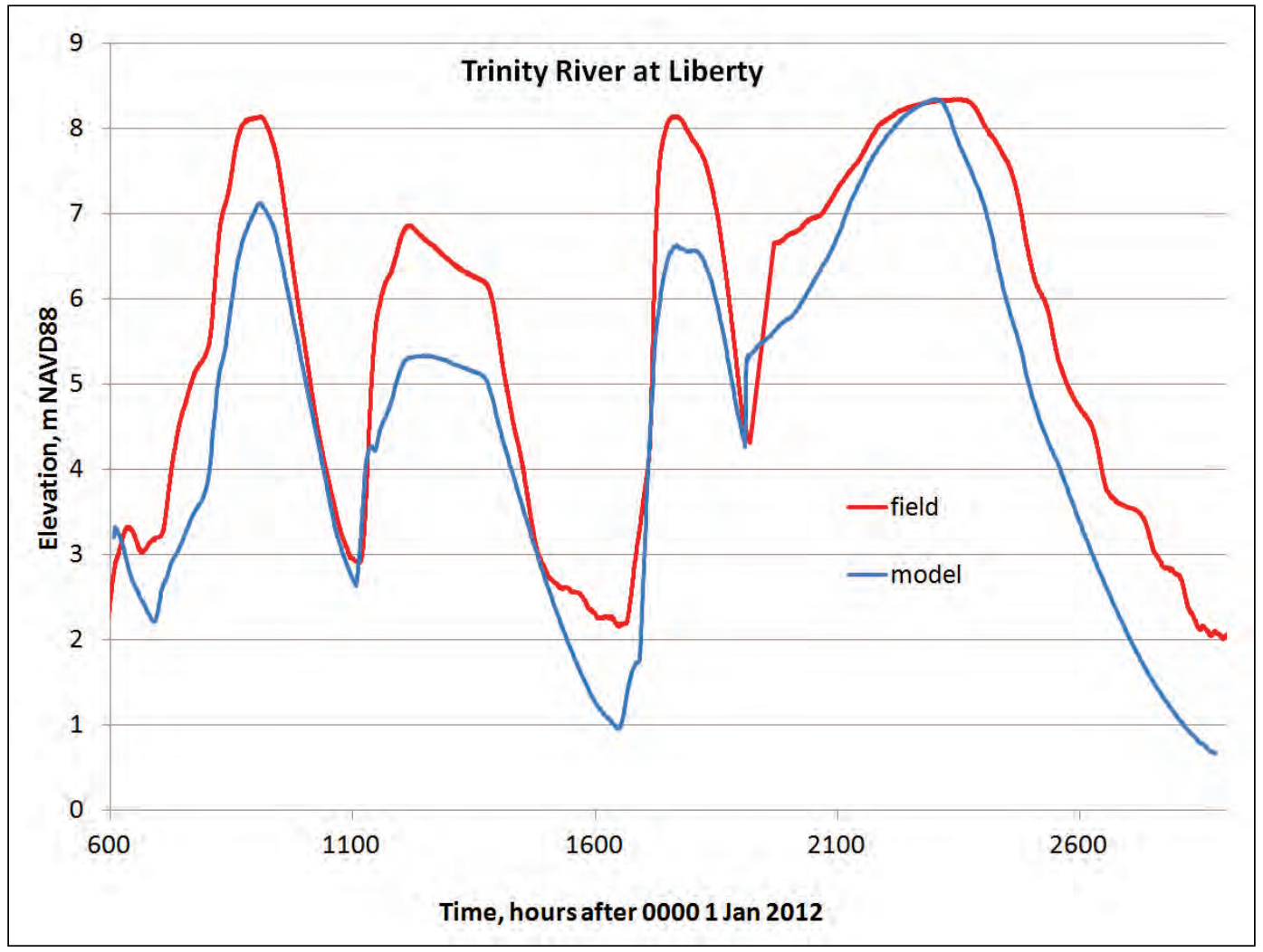


Figure 6-21 Dry-season water surface elevation validation at the downstream side of the salt barrier at Wallisville, TX.

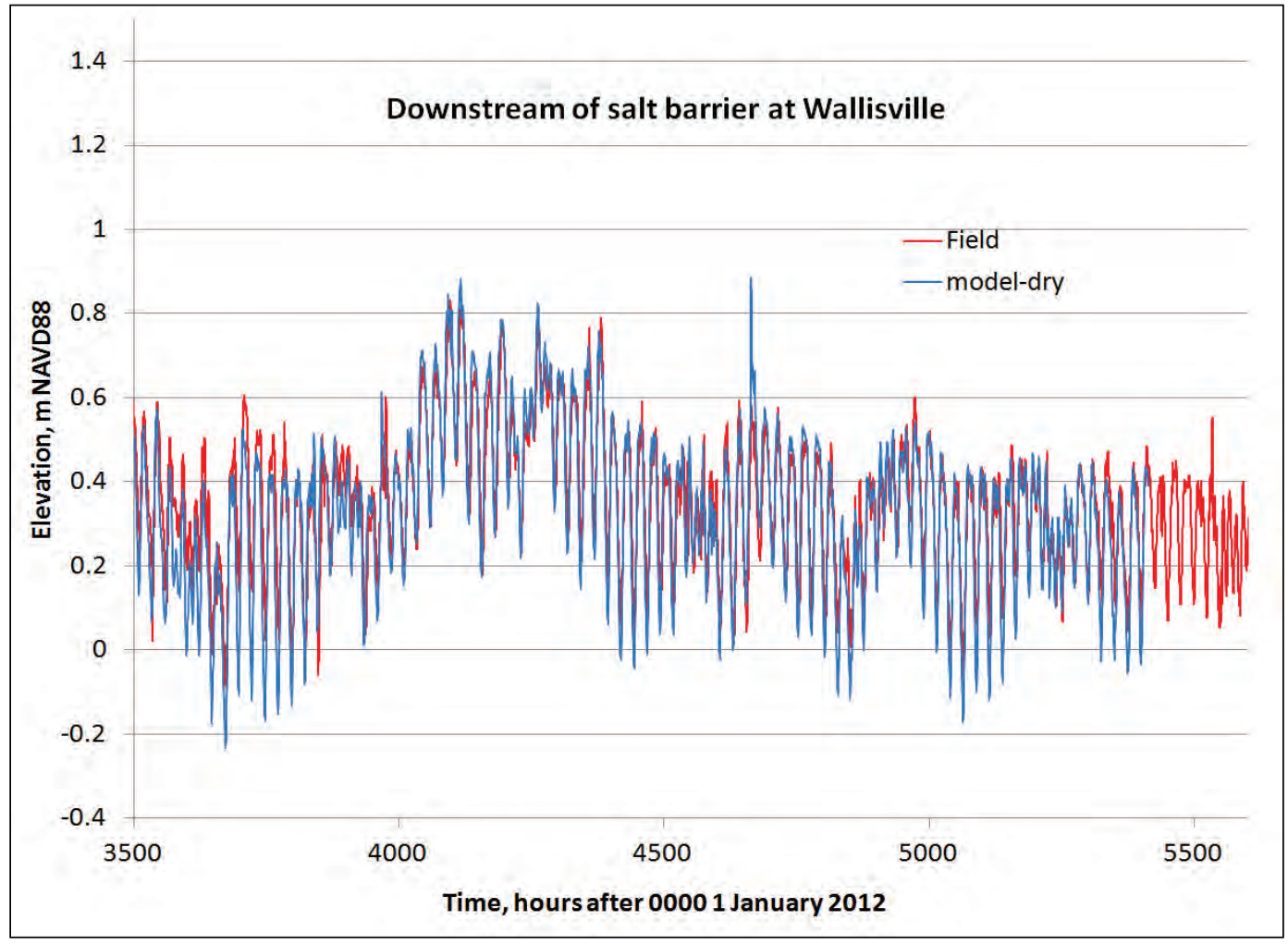

Figure 6-22 Dry-season water surface elevation validation at the upstream side of the salt barrier at Wallisville, TX.

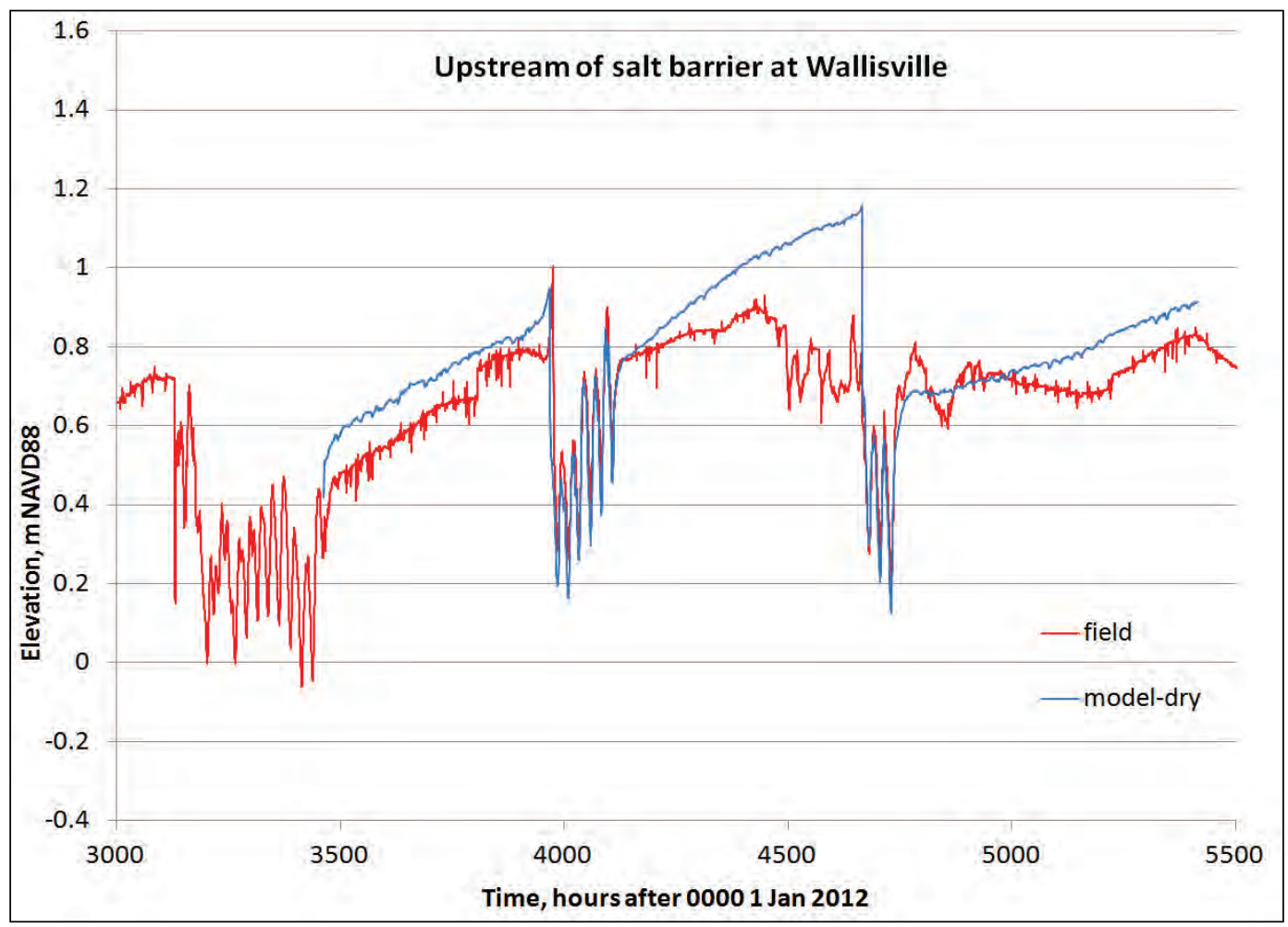


Figure 6-23 Dry-season water surface elevation validation at Lake Charlotte.

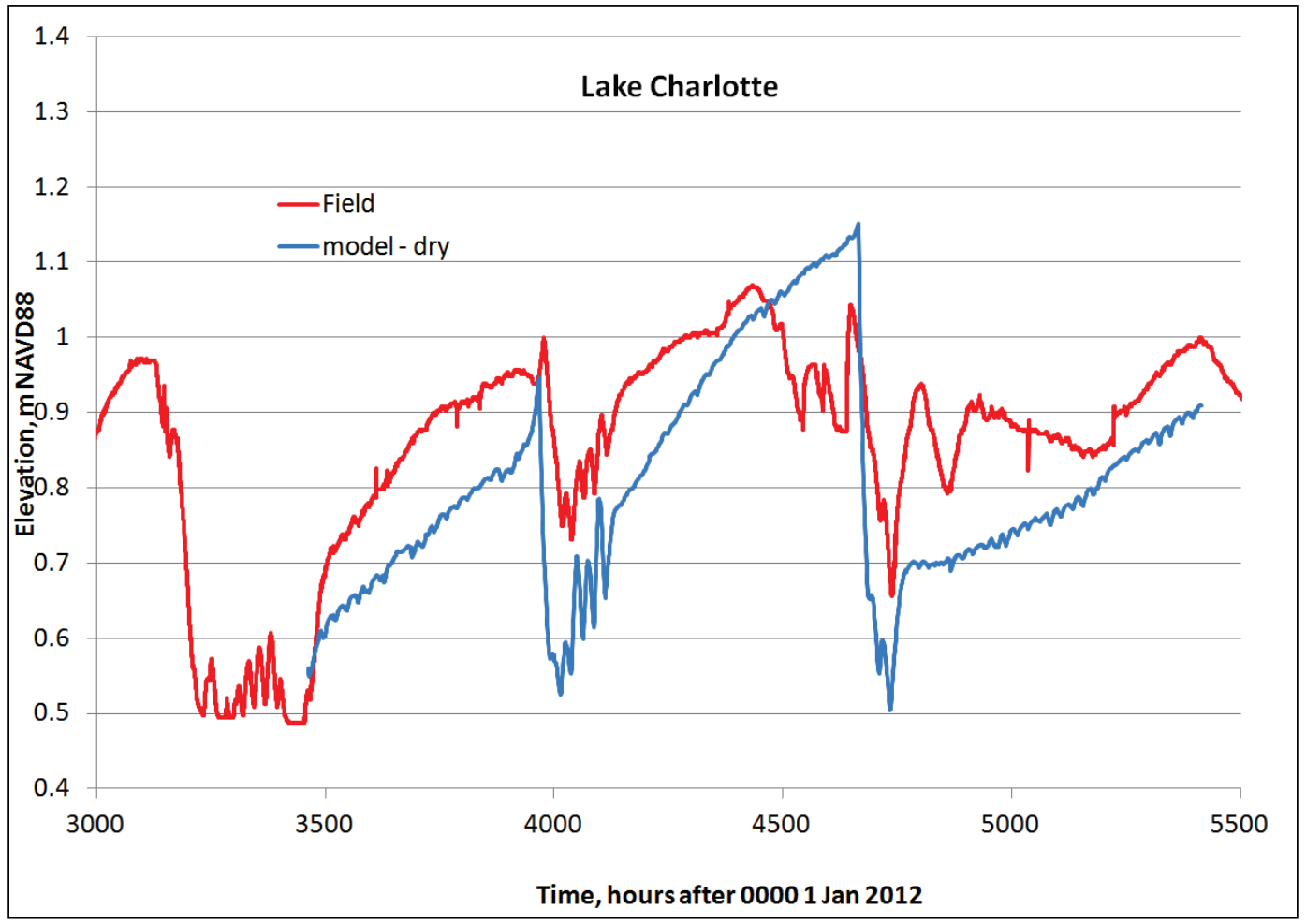

Figure 6-24 Dry-season water surface elevation validation at the downstream side of the tide gate (Structure A) in the Cut Off that runs south from Mark's Bend on the Trinity River near Moss Bluff, TX.

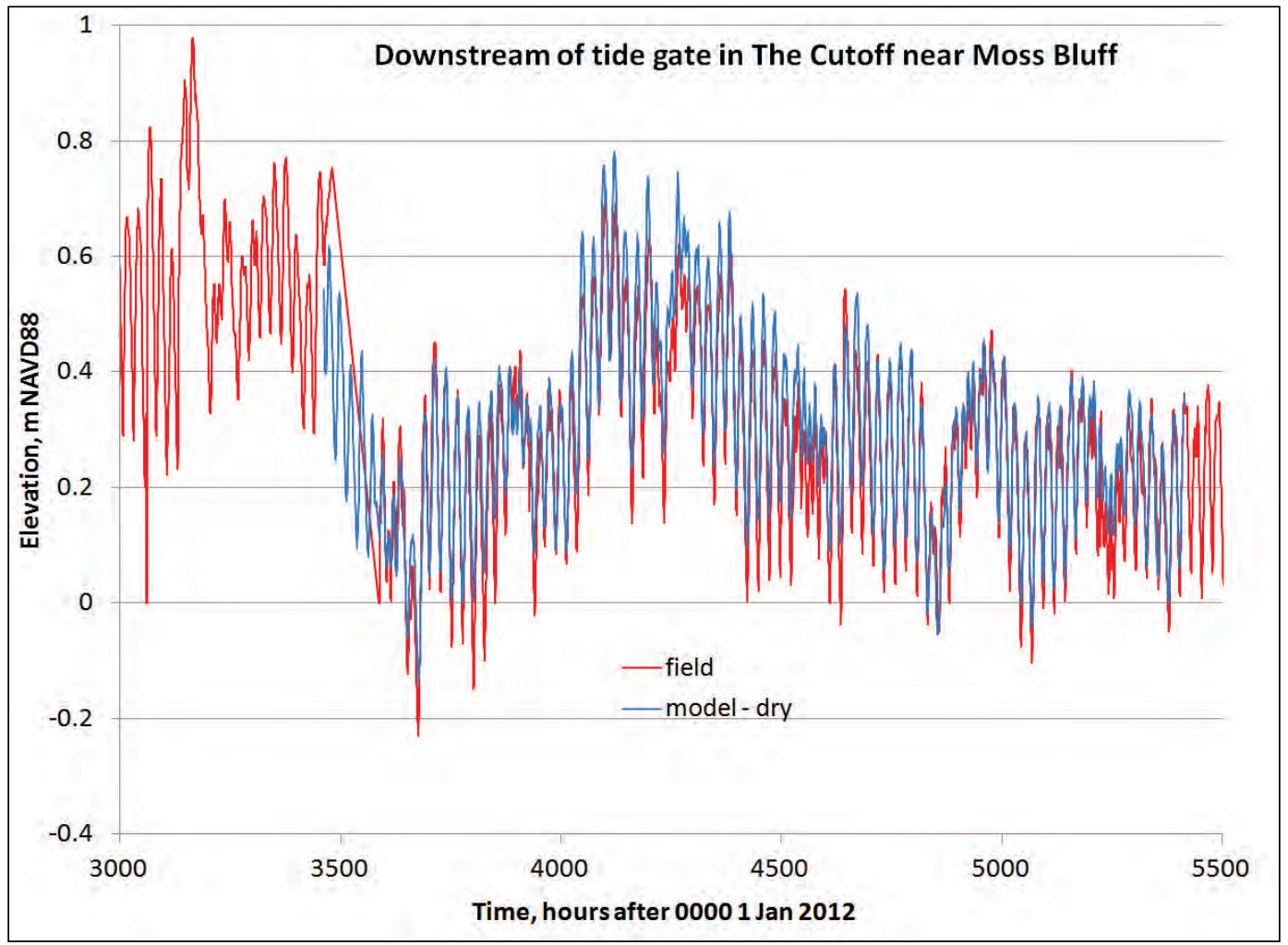


Figure 6-25 Dry-season water surface elevation validation at the upstream side of the tide gate (Structure A) in the Cut Off that runs south from Mark's Bend on the Trinity River near Moss Bluff, TX.

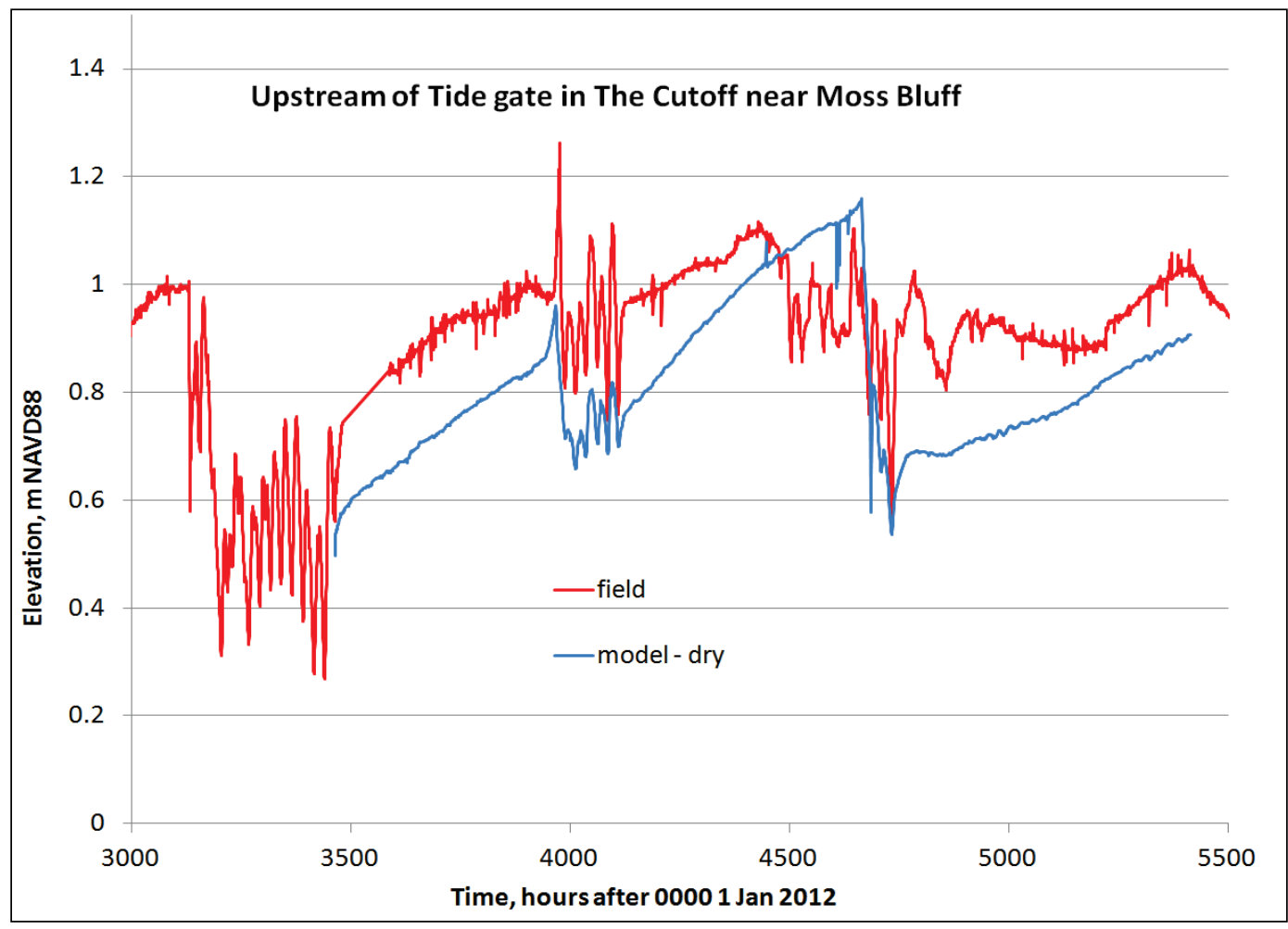

Figure 6-26 Dry-season water surface elevation validation at the Trinity River at Moss Bluff, TX.

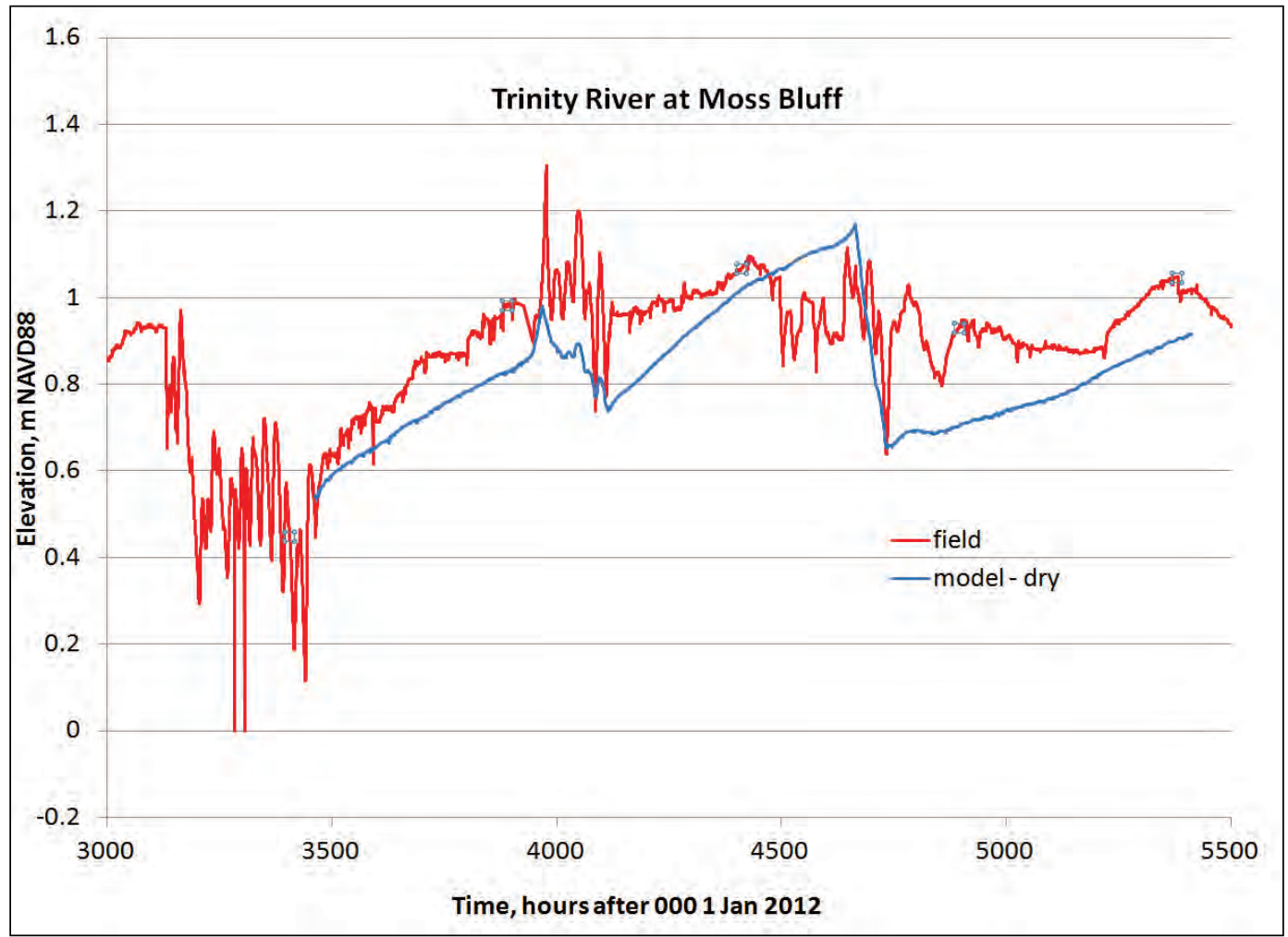


Figure 6-27 Dry-season water surface elevation validation at the Trinity River at Liberty, TX.

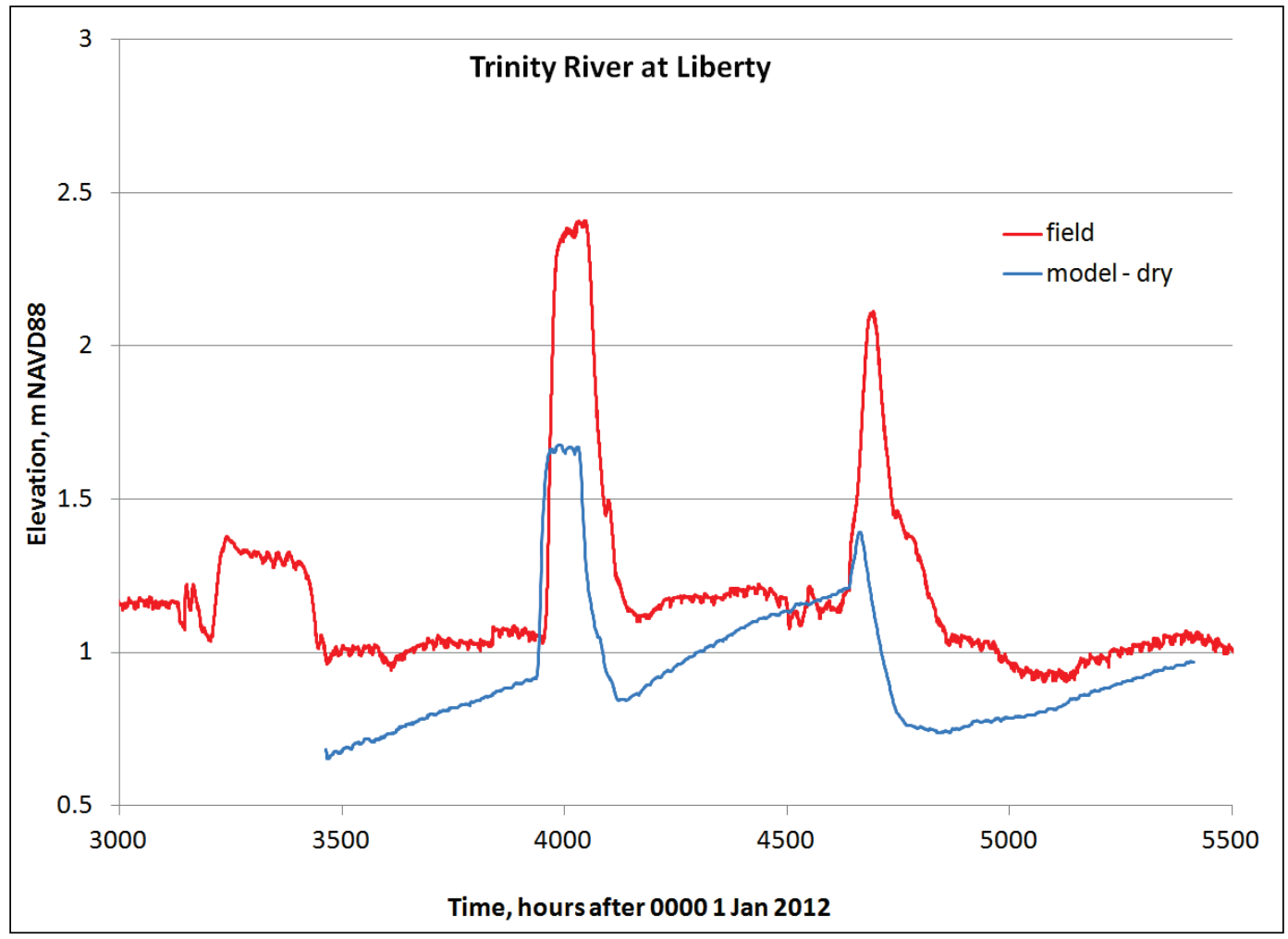

Figure 6-28 Validation of discharges at the confluence.

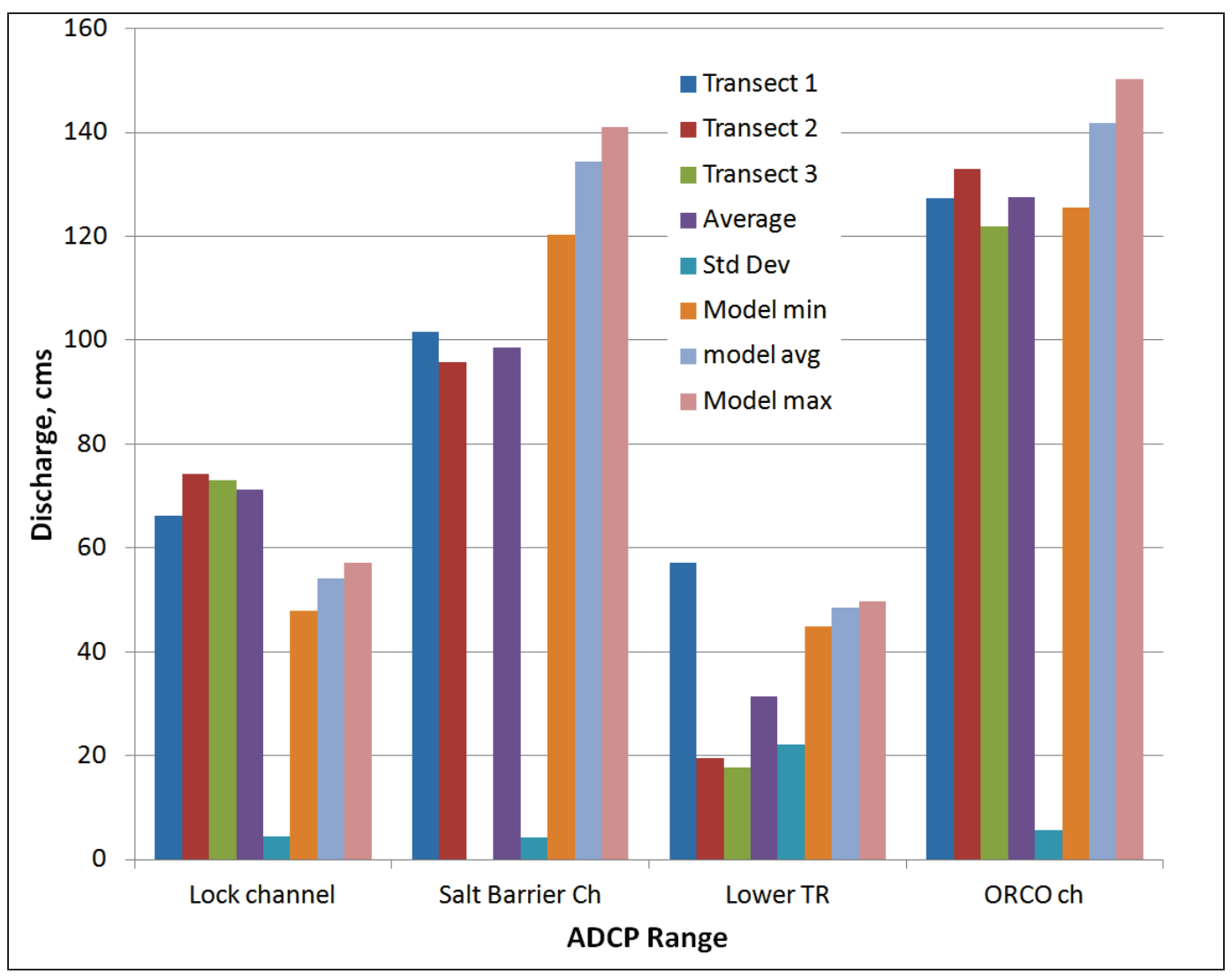




\section{Evaluation of Shoaling}

\section{Sensitivity tests}

The sediment transport model sensitivity tests consisted of running the sediment transport model for combinations of having either or both the navigation lock and the salt barrier open. These combinations were also combined with either having ORCO open or completely blocked. These combinations and their run designations are listed in Table 7-1. The runs are

a. the lock, the salt barrier and ORCO open (run LOBOCO),

b. close the lock channel and put all the water through the salinity barrier keeping ORCO open (run LXBOCO),

c. close the salt-barrier channel and put all the water through the lock channel keeping ORCO open (run LOBXCO),

d. repeat a. with the ORCO closed (run LOBOCX),

e. repeat b. with the ORCO closed (run LXBOCX), and

f. repeat c. with the ORCO closed (run LOBXCX).

In this list and in Table 7-1, $\mathrm{L}=$ lock, $\mathrm{B}=$ salinity barrier, $\mathrm{C}=\mathrm{ORCO}$, and $\mathrm{O}$ and $\mathrm{X}$ are, respectively, open and closed.

Table 7-1 Sediment transport sensitivity simulation run configurations.

\begin{tabular}{|l|l|l|l|}
\hline Designation & Lock & Salinity Barrier & ORCO \\
\hline LOBOCO & Open & Open & Open \\
\hline LXBOCO & Closed & Open & Open \\
\hline LOBXCO & Open & Closed & Open \\
\hline LOBOCX & Open & Open & Closed \\
\hline LXBOCX & Closed & Open & Closed \\
\hline LOBXCX & Open & Closed & Closed \\
\hline
\end{tabular}

These sensitivity simulations were at first run with the existing bathymetry, with the Trinity River shoal. All configurations were then repeated with the shoal removed down to a depth of $2 \mathrm{~m}$. 


\section{Sensitivity simulation procedure}

The procedure for running the sediment transport model was as follows:

1. Define initial bed uniform sediment grain size distribution over the entire model. The initial grain size distribution is presented in Table 7-2 and is compared to all of the ERDC surface core samples in Figure 7-1.

Table 7-2 Sediment model grain size initial specification.

\begin{tabular}{|l|l|l|l|}
\hline Sand Class & Grain size, microns & Specific Gravity & Initial fraction \\
\hline Very Fine Sand & 88 & 2.65 & 0.01 \\
\hline Fine Sand & 177 & 2.65 & 0.15 \\
\hline Medium Sand & 354 & 2.65 & 0.67 \\
\hline Coarse Sand & 707 & 2.65 & 0.16 \\
\hline Very Coarse Sand & 1414 & 2.65 & 0.01 \\
\hline
\end{tabular}

Figure 7-1 Model initial sediment size distribution compared to field sample distributions.

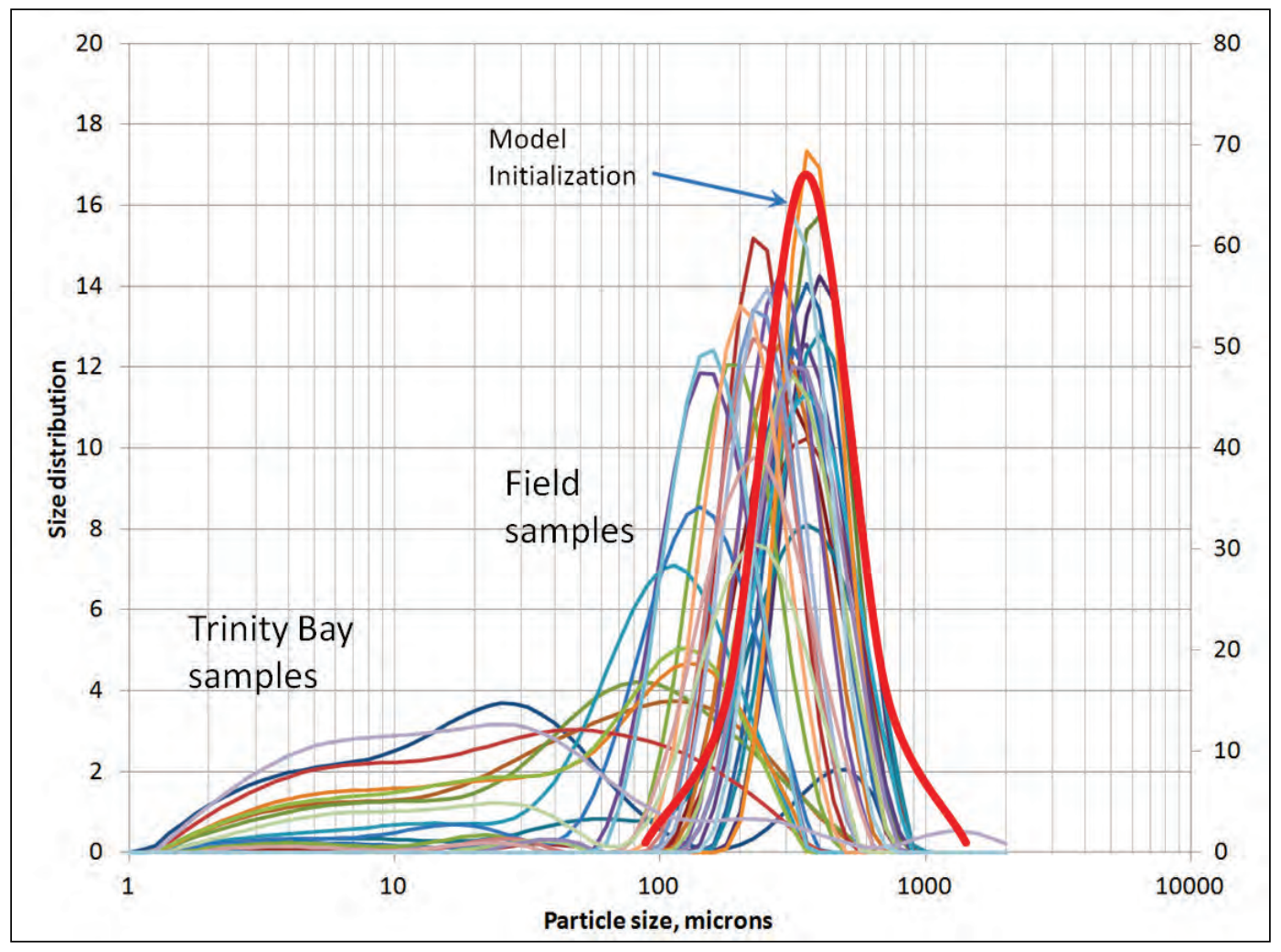

2. Assume equilibrium transport at Liberty, TX, boundary.

3. Simulate wet season with bed displacement restricted so that the grain size distribution is initialized to the existing bathymetry. The distribution of the 
$50 \%$ finer particle size after the bed initialization simulation is presented in Figure 7-2.

4. Use the same bed initialization for all sensitivity simulations. Because all of the sensitivity simulations used the same computational mesh, the bed initialization for the run LOBOCO was applicable for all of the sensitivity tests.

5. Alter bathymetry and/ or configuration as needed for each sensitivity simulation and repeat the wet-season simulation with bed displacement active.

Figure 7-2 Bed initialization results: active layer $D_{50}$ grain size.

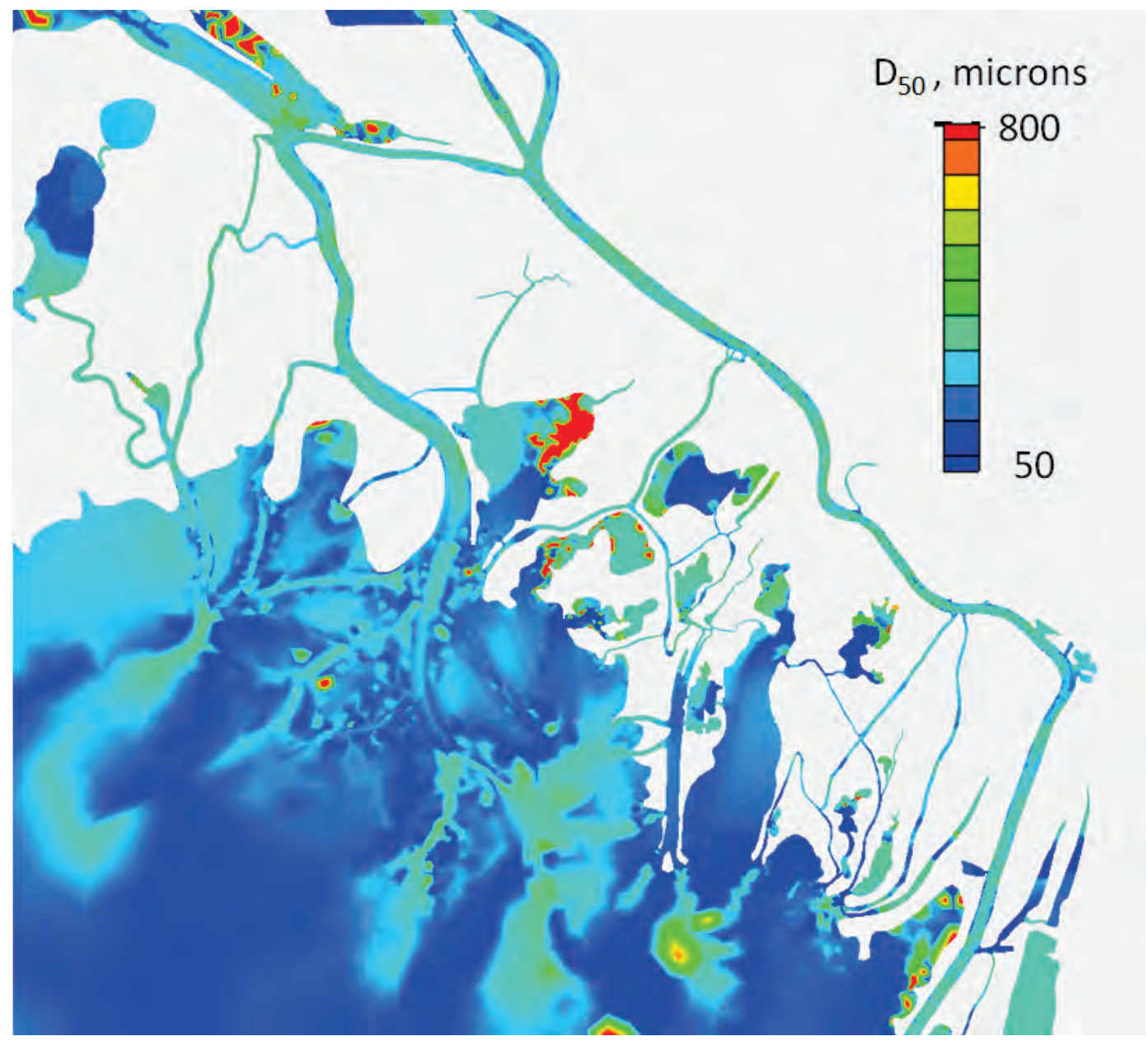

The profile of the $\mathrm{D}_{50}$ grain size after the sediment bed initialization run is presented in Figure 7-3. In this figure, the model is compared to the results from the analysis of the core samples. The observed $\mathrm{D}_{50}$ becomes much finer than the model as the profile enters the bay. This is because the model does not include clays or silts in its specification of sizes (Figure 3-16 and Figure 7-1). The finer material does influence the shoaling problem that is 
the subject of this study, which is dominated by sands. The finer cohesive material may be ignored because any supply that is transported from upstream passes through the project area as wash load during flood events, and during the dry season, normal tidal currents are not sufficient to transport significant fines from the bay into the project area.

Figure 7-3 Profile of $D_{50}$ size after model bed initialization simulation compared to field sediment data.

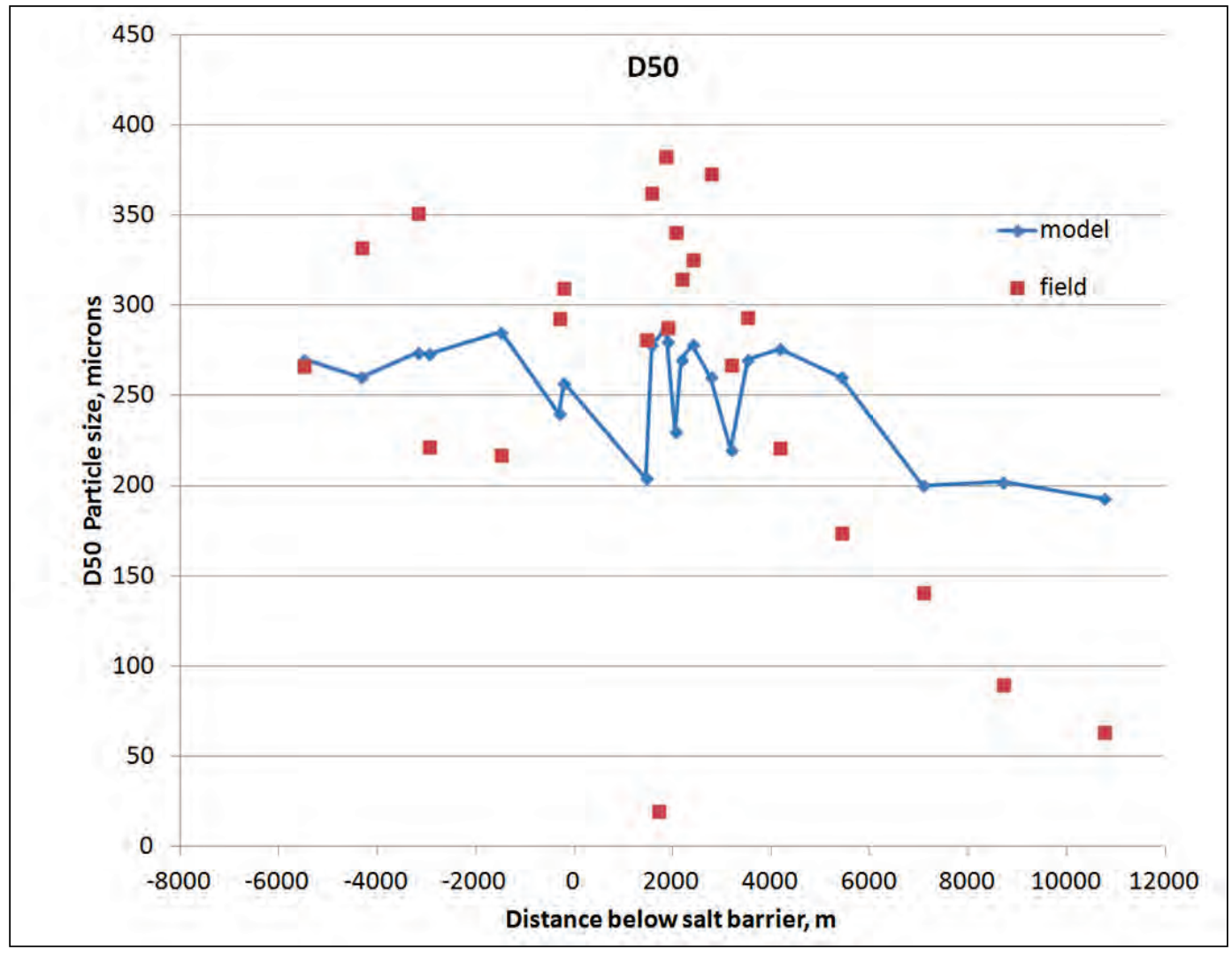

The variability seen in the field sediment sizes is much greater than seen in the model. This is believed to be the result of the heterogeneity of the field bottom sediments. There was insufficient field sampling to defend a more variable sediment size distribution in the model (prior to the bed initialization run). Because of the natural variability, it would not have benefited the project to expand the sediment sampling.

The sediment model was initialized with a single, defined sediment layer $1.0 \mathrm{~m}$ thick with the prescribed grain size distribution. Any erosion extracts bed material from that initial layer. Deposition will, however, overlay the initial bed, and the size distribution will be dependent on the material depositing. The model was set up to accommodate 10 additional layers. 
The original model bathymetry in the vicinity of the confluence of the Trinity River and ORCO is shown in Figure 7-4. The increase in depth from dredging the channel to $-2 \mathrm{~m}$ in the area of the shoal near the confluence and a distance downstream is shown in Figure 7-5. The deepened channel condition used for the sensitivity runs with the shoal removed is shown in Figure 7-6. The volume removed was 65,891 cubic meters $\left(\mathrm{m}^{3}\right)$. Note that this removal area does not extend the entire length of the Trinity River to Trinity Bay and is intended to approximate the removal of the shoal of interest.

\section{Results of sensitivity runs}

The results of the sediment sensitivity run for the LOBOCO condition with the shoal are presented in Figure 7-7. There is localized erosion near the confluence with significant deposition within Old River as a result of the sediment load being sent through ORCO. The locations of the shoals are just downstream of secondary bayous. There is a shoal in the Trinity River just downstream of J ack's Pass in response to loss of transport capacity due to flow losses down Jack's Pass.

Figure 7-4 Original bathymetric elevations (-4, $0 \mathrm{~m}$ contour range).

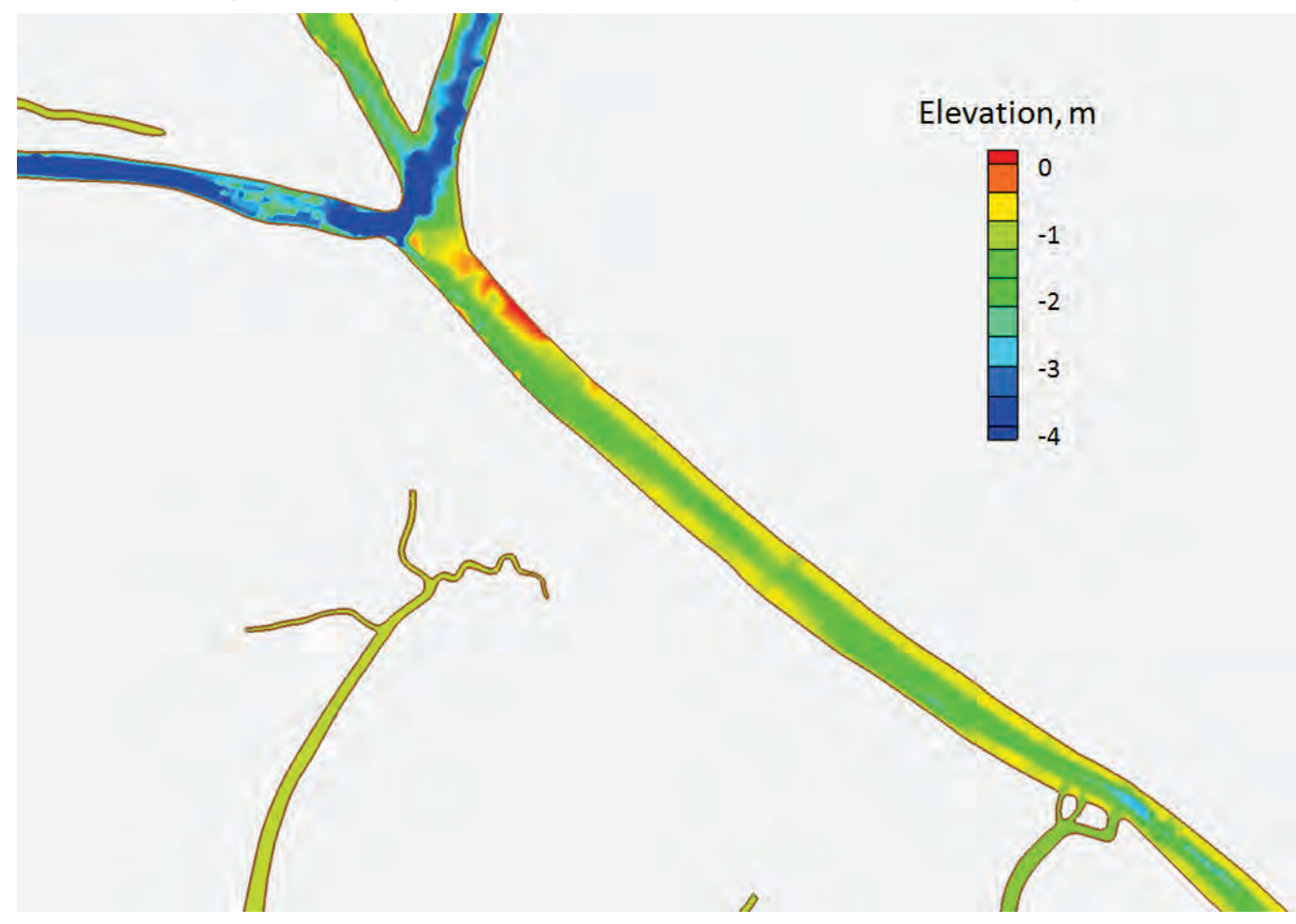


Figure 7-5 Thickness of sediment removed for sediment sensitivity testing $(0,2 \mathrm{~m}$ contour range). Volume removed was $65,891 \mathrm{~m}^{3}\left(86,116 \mathrm{yd}^{3}\right)$.

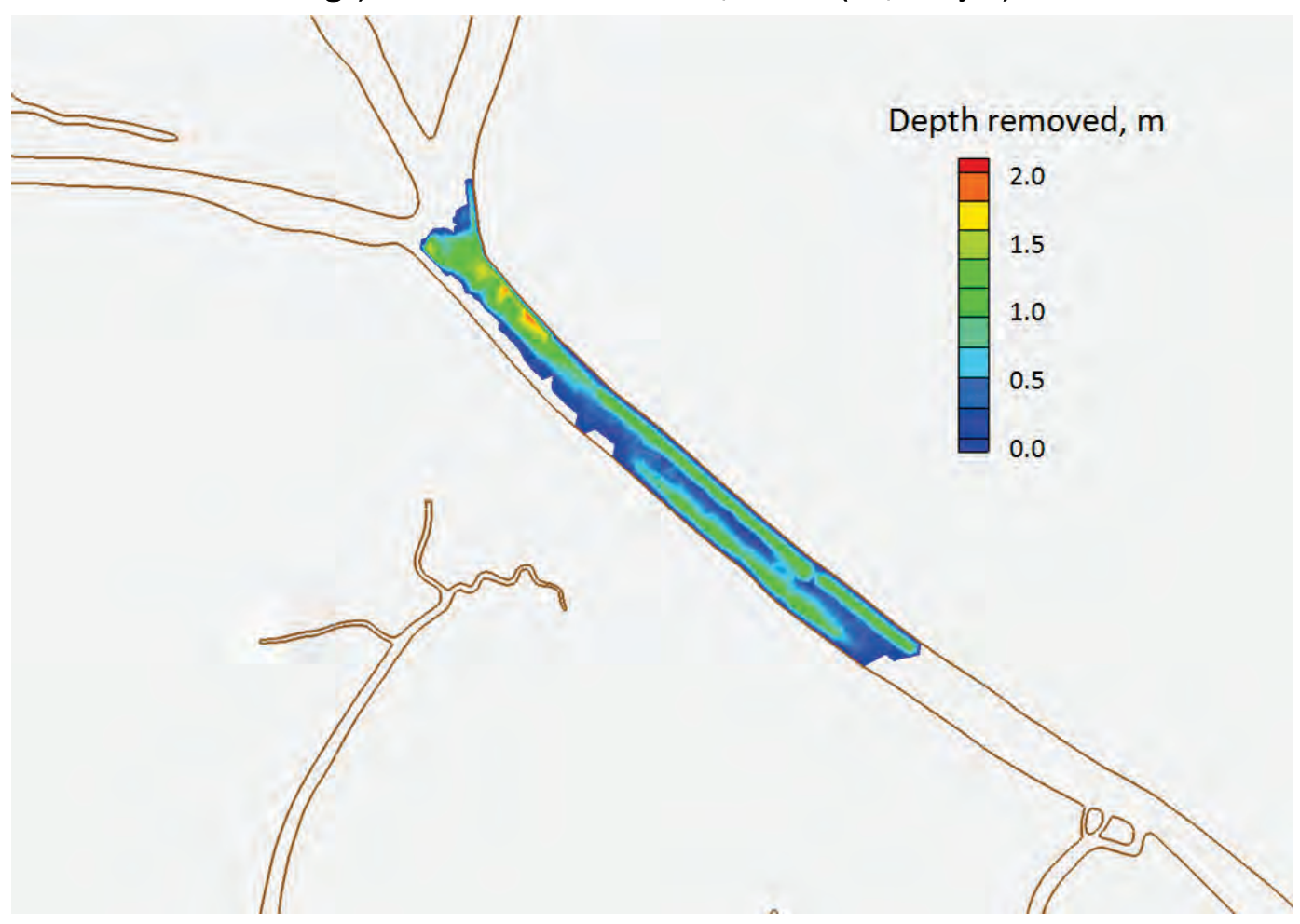

Figure 7-6 Deepened elevations for sediment sensitivity testing ( -4 to $0 \mathrm{~m}$ contour range).

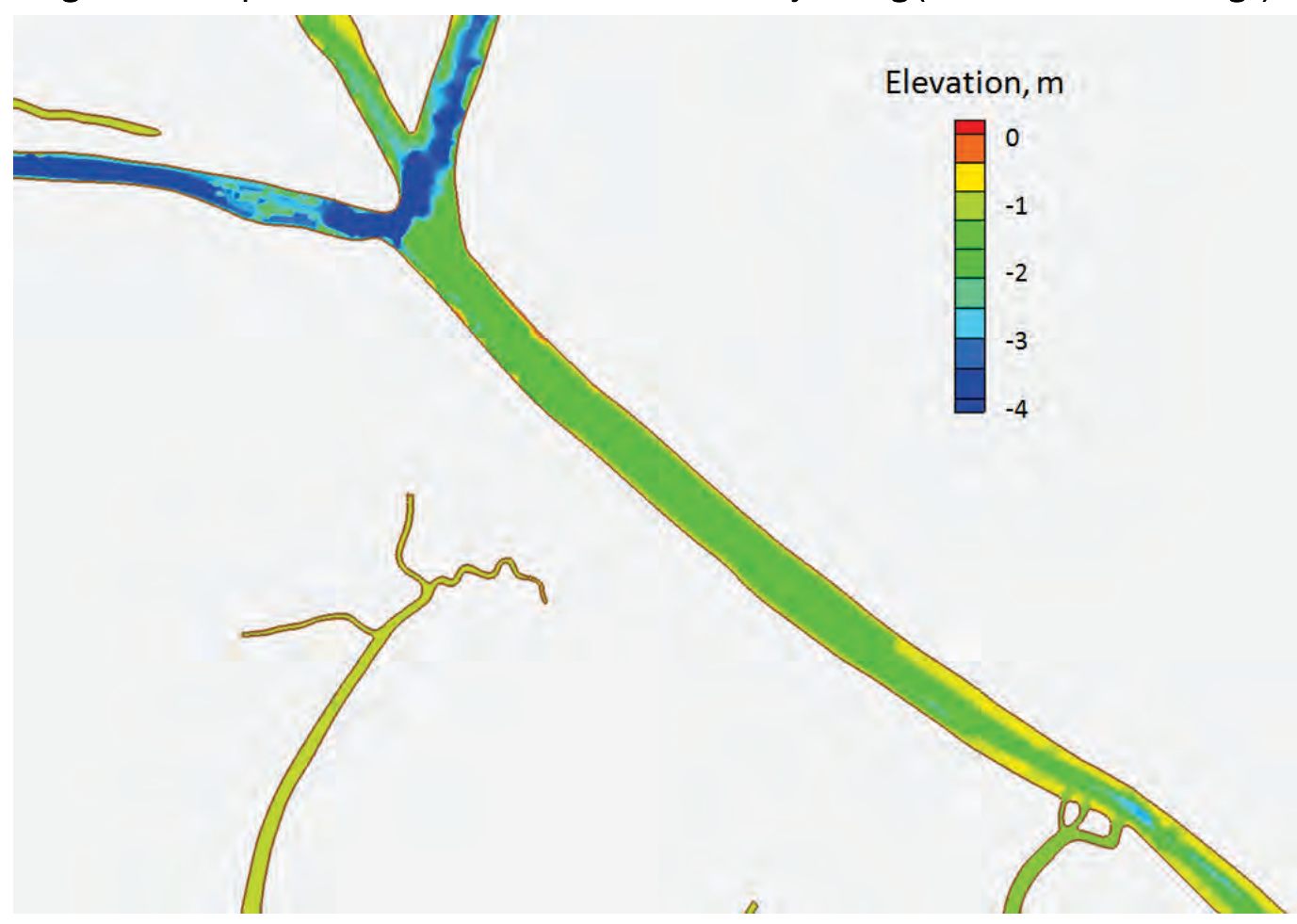


Figure 7-7 Deposition and erosion for sediment sensitivity run LOBOCO with existing depths.

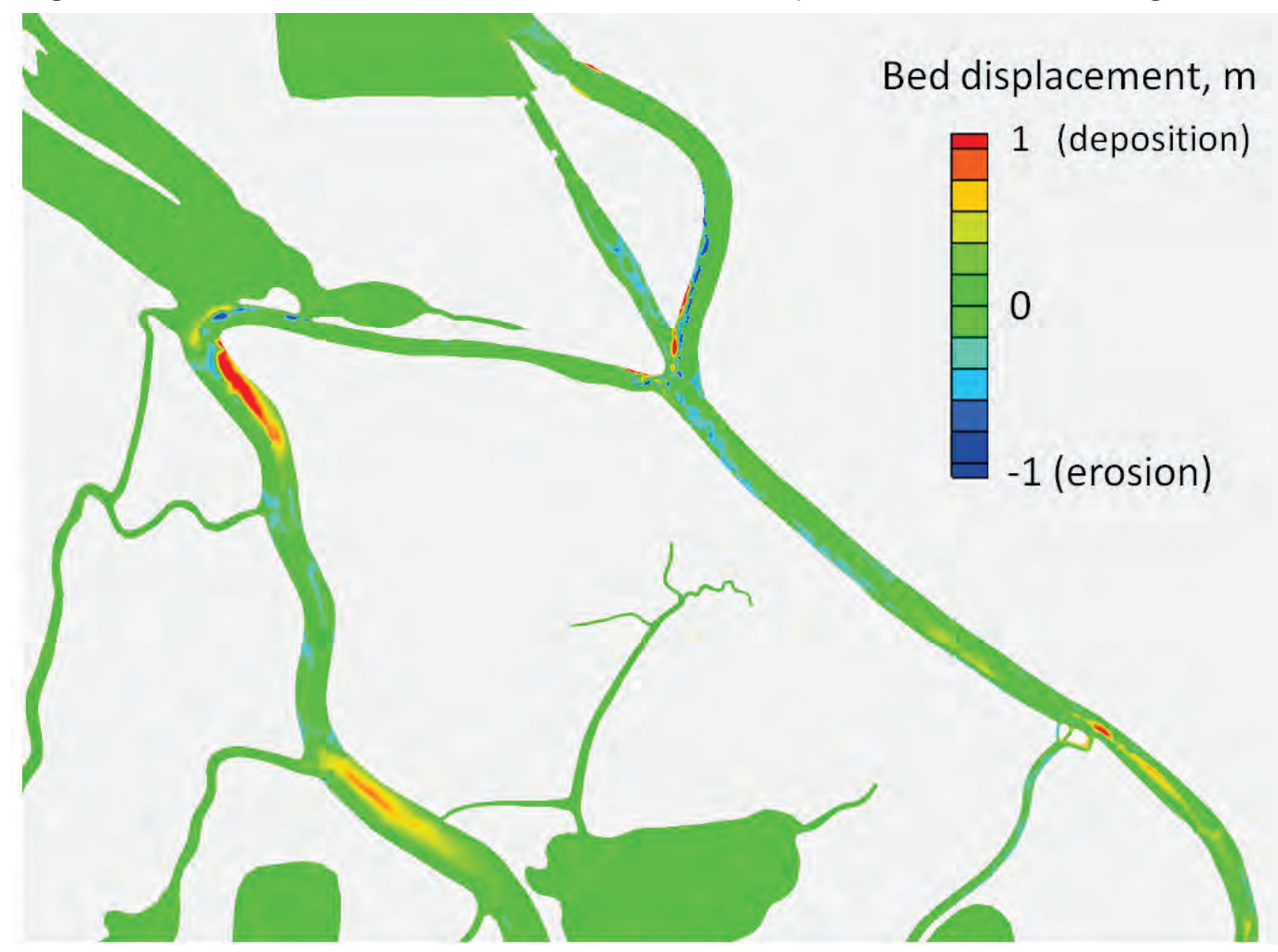

The results of the sediment sensitivity run for the LXBOCO condition with the shoal are presented in Figure 7-8. The only differences between this and LOBOCO are upstream of the confluence, with erosion in the salt-barrier channel and deposition in the mouth of the lock channel, which is closed.

The results of the sediment sensitivity run for the LOBXCO condition with the shoal are presented in Figure 7-9. There is no difference in the distant deposition patterns, but there is now erosion in the lock channel. The shoal that is on the north side of ORCO just west of the confluence is more prominent with all of the water coming through the lock channel. This indicates that benefits will be achieved with channel realignment alternatives. In addition, the scour at the western end of ORCO has disappeared for this configuration.

The results of the sediment sensitivity run for the LOBOCX condition with the shoal are presented in Figure 7-10. The closure of ORCO has a dramatic impact on the erosion and deposition. The Trinity River is now eroding all the way past J ack's Pass and eroding J ack's Pass itself as more flow is diverted there. 
Figure 7-8 Deposition and erosion for sediment sensitivity run LXBOCO with existing depths.

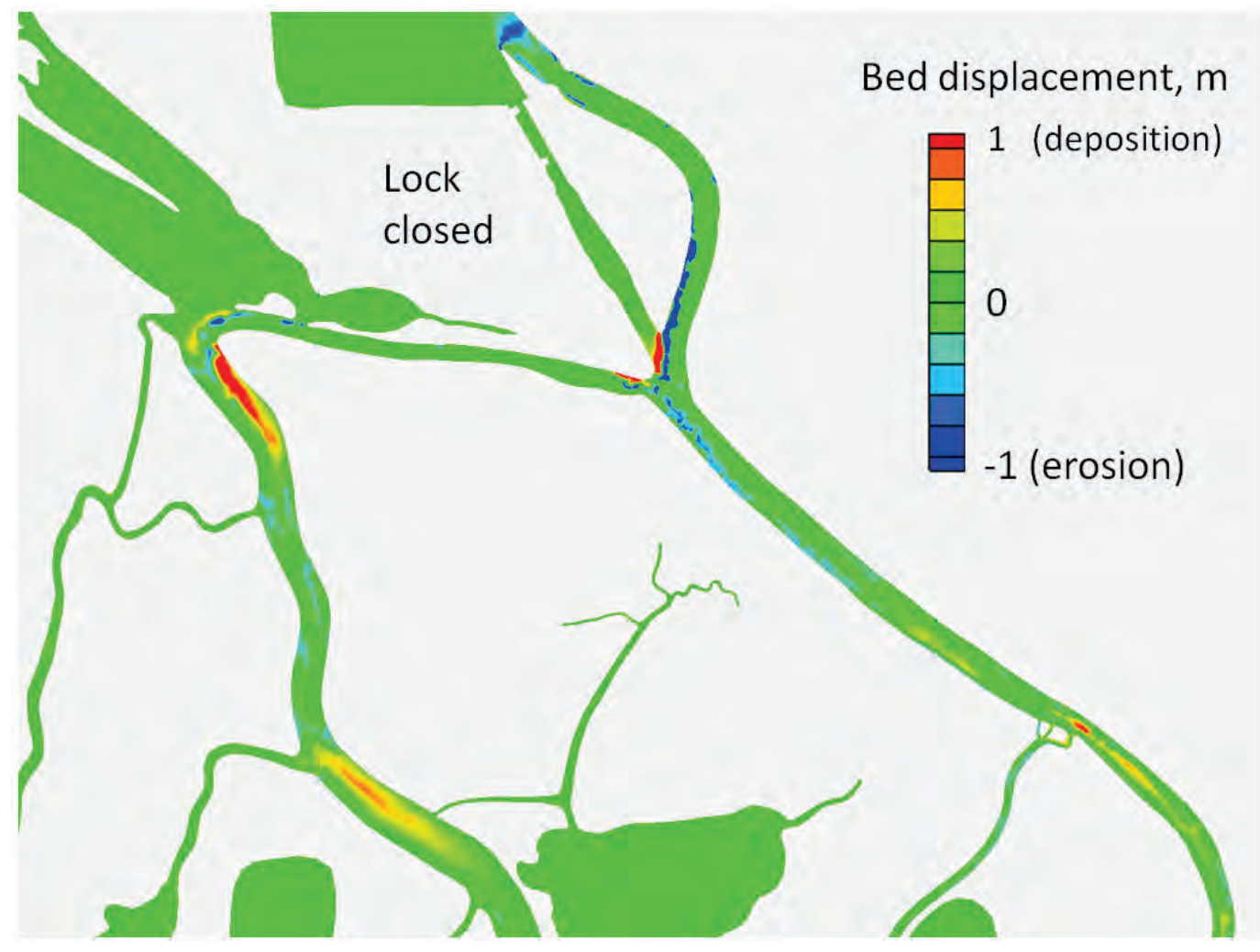

Figure 7-9 Deposition and erosion for sediment sensitivity run LOBXCO with existing depths.

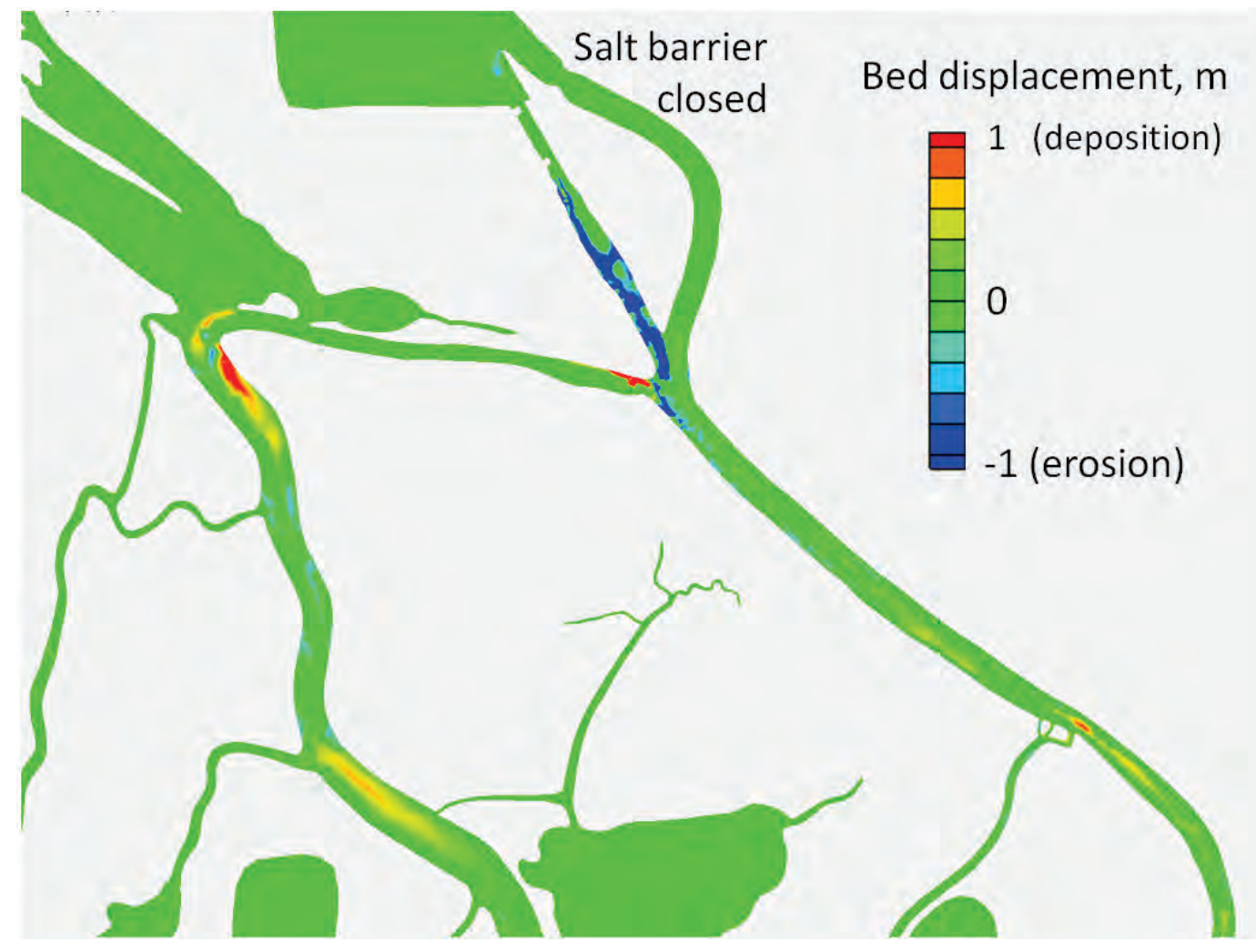


Figure 7-10 Deposition and erosion for sediment sensitivity run LOBOCX with existing depths.

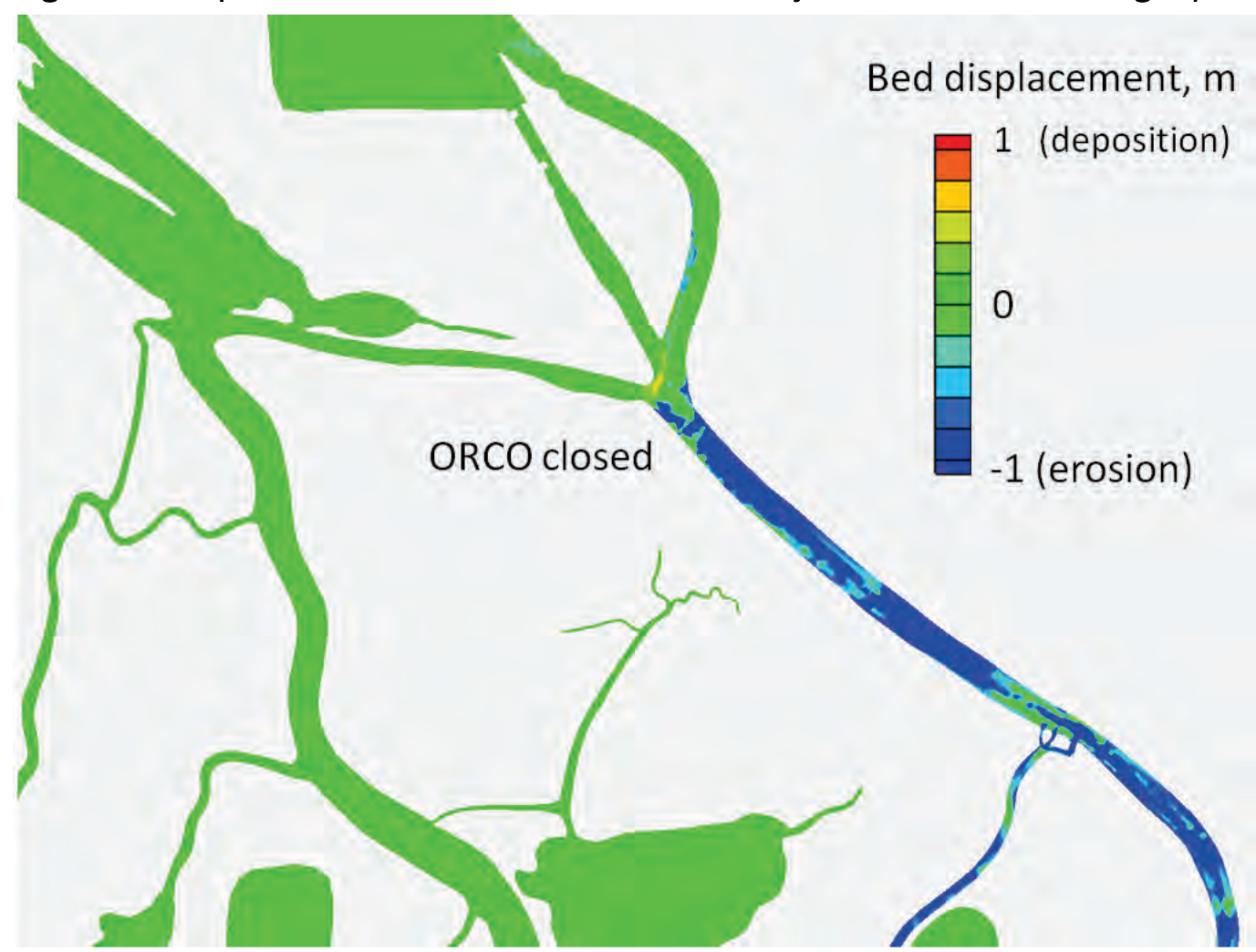

The results of the sediment sensitivity run for the LXBOCX condition with the shoal are presented in Figure 7-11. There is no difference with this configuration over LOBOCX except upstream of the confluence, as was seen with the ORCO open.

The results of the sediment sensitivity run for the LOBXCX condition with the shoal are presented in Figure 7-12. Likewise, there is no difference with this configuration over LOBOCX except upstream of the confluence.

The erosion upstream of the confluence in either channel when all of the flow is routed through that channel is an artifact of the bed initialization. The bed was put in equilibrium with the flow being distributed over both channels, but now the flow is being concentrated in one of the channels. The relative effects are valid, however, pointing to the potential for erosion if the flow distribution is dramatically changed. 
Figure 7-11 Deposition and erosion for sediment sensitivity run LXBOCX with existing depths.

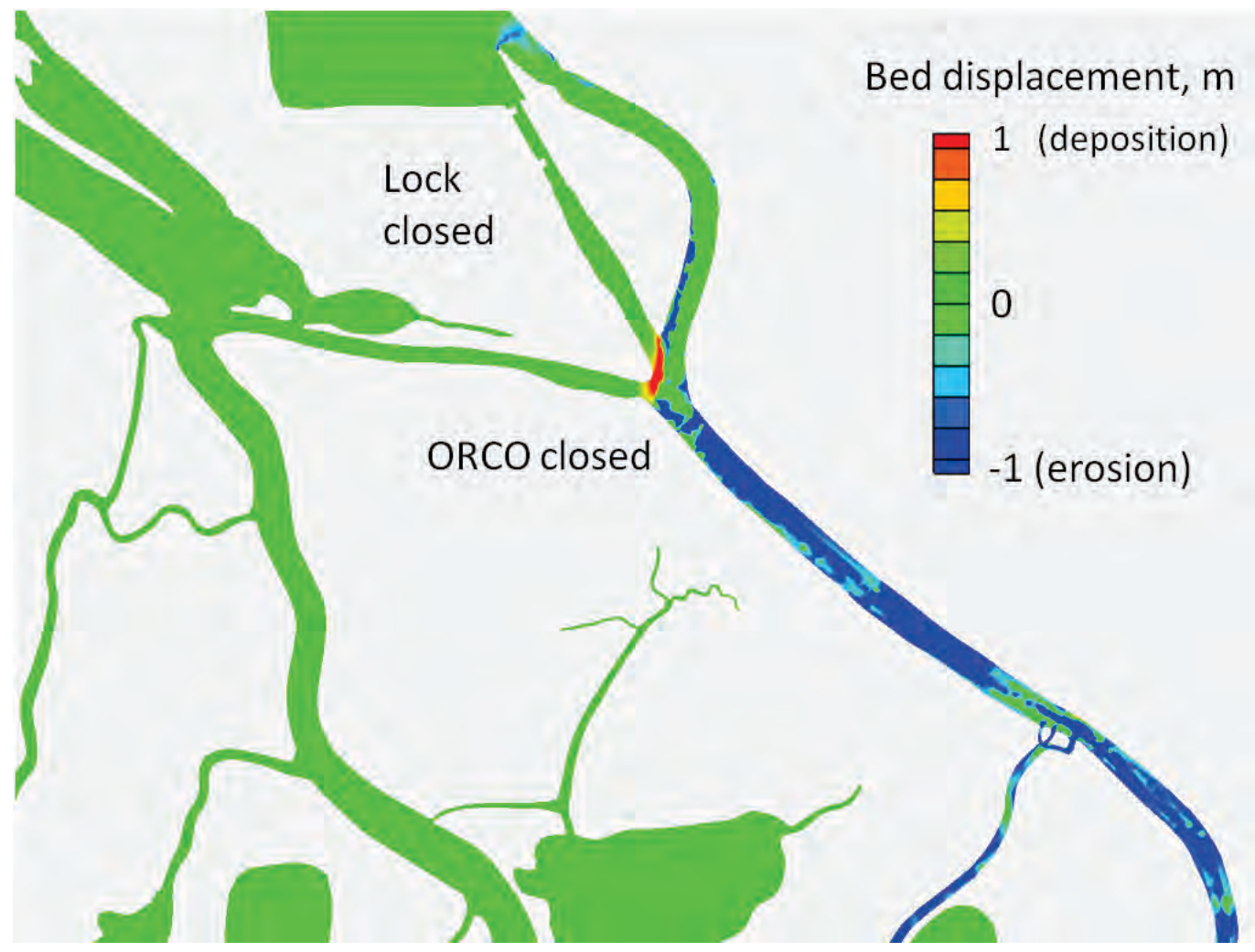

Figure 7-12 Deposition and erosion for sediment sensitivity run LOBXCX with existing depths.

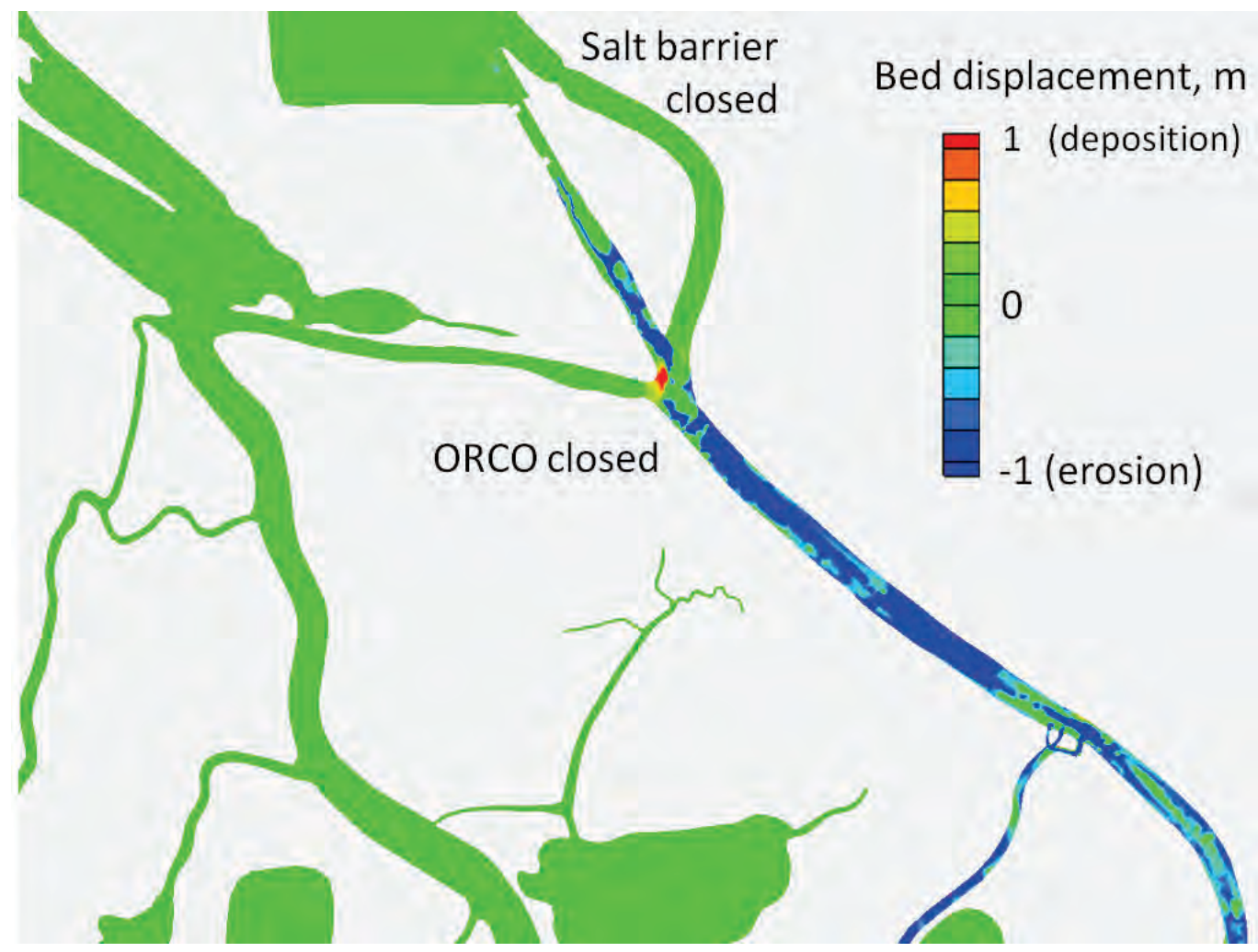




\section{Shoal-removed sensitivity runs}

Results of the sensitivity tests for all configurations with the shoal removed, as represented in Figures 7-5 and 7-6, are presented in Figure 7-13 through Figure 7-18. These simulations were performed to address the question of whether removing the shoal in the Trinity River channel would have an impact on the erosion and deposition patterns. The results show that qualitatively there is no significant difference in the erosion/ deposition patterns due to the various closure options between with and without shoal configurations.

\section{Differences in erosion/deposition with and without the shoal}

In order to get a more quantitative comparison, the two cases were differenced to show the relative erosion and/ or deposition. The differences were computed as "shoal removed- existing." The results of these comparisons are presented in Figure 7-19 through Figure 7-24.

Figure 7-13 Deposition and erosion for sediment sensitivity run LOBOCO with shoal removed.

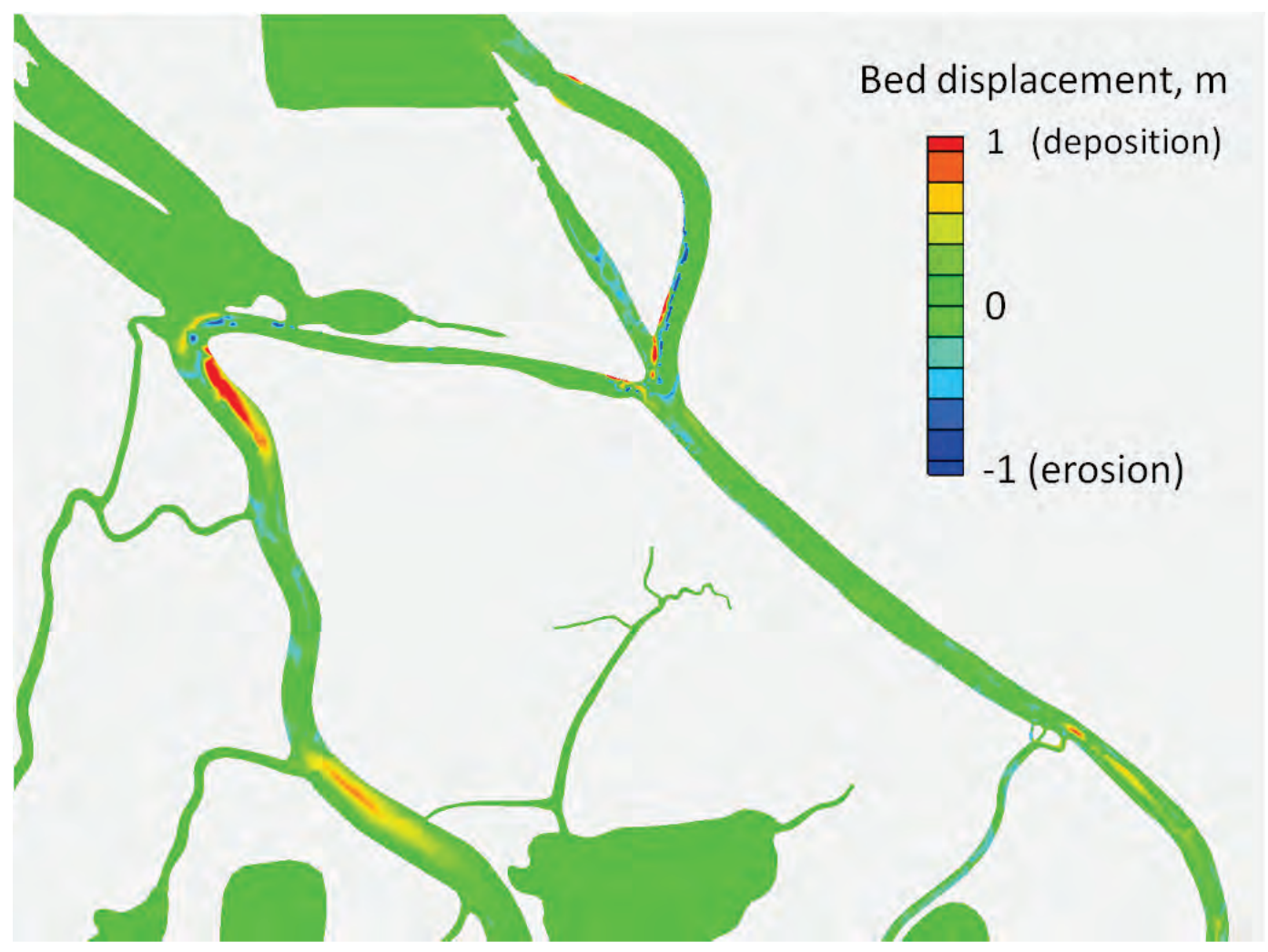


Figure 7-14 Deposition and erosion for sediment sensitivity run LXBOCO with shoal removed.

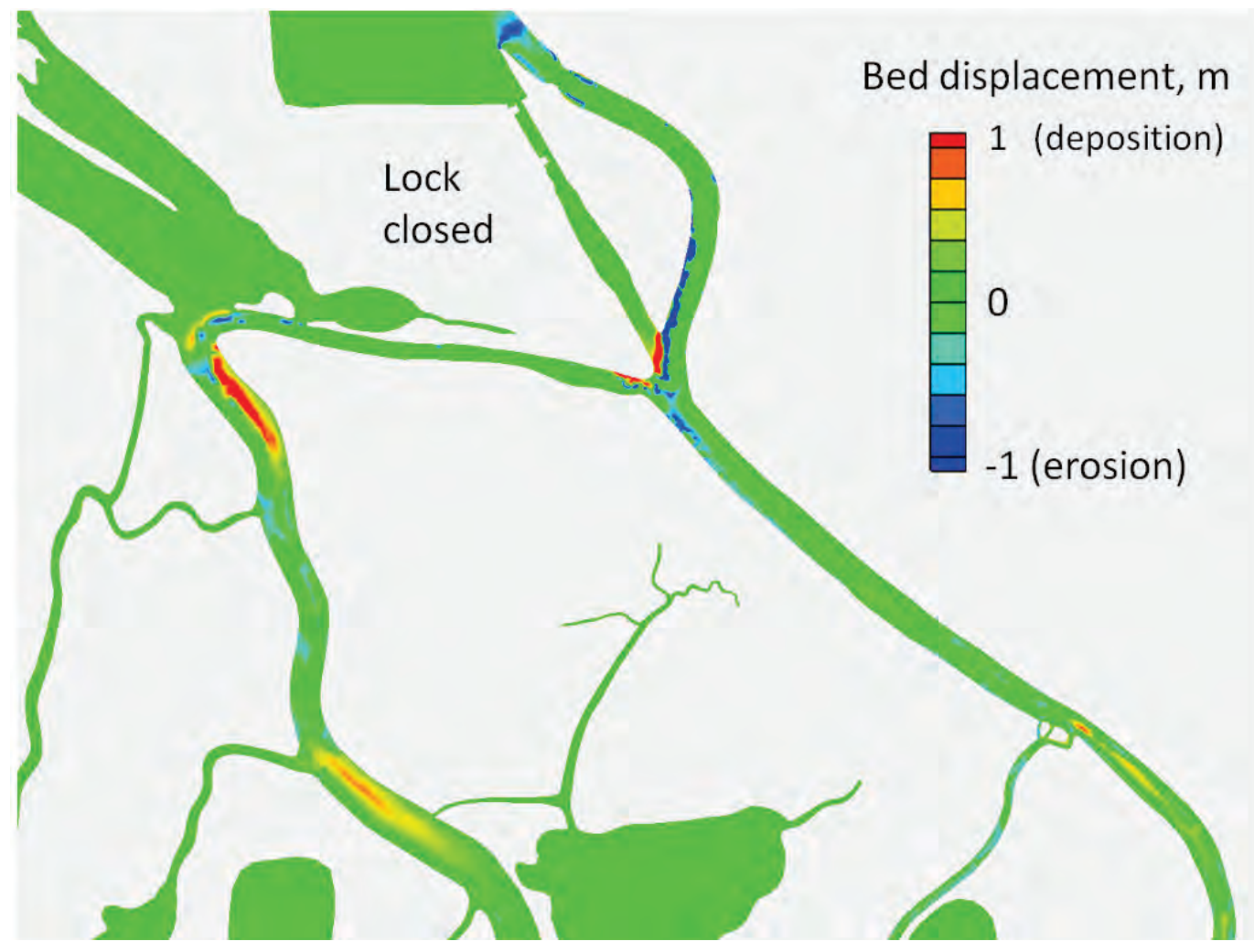

Figure 7-15 Deposition and erosion for sediment sensitivity run LOBXCO with shoal removed.

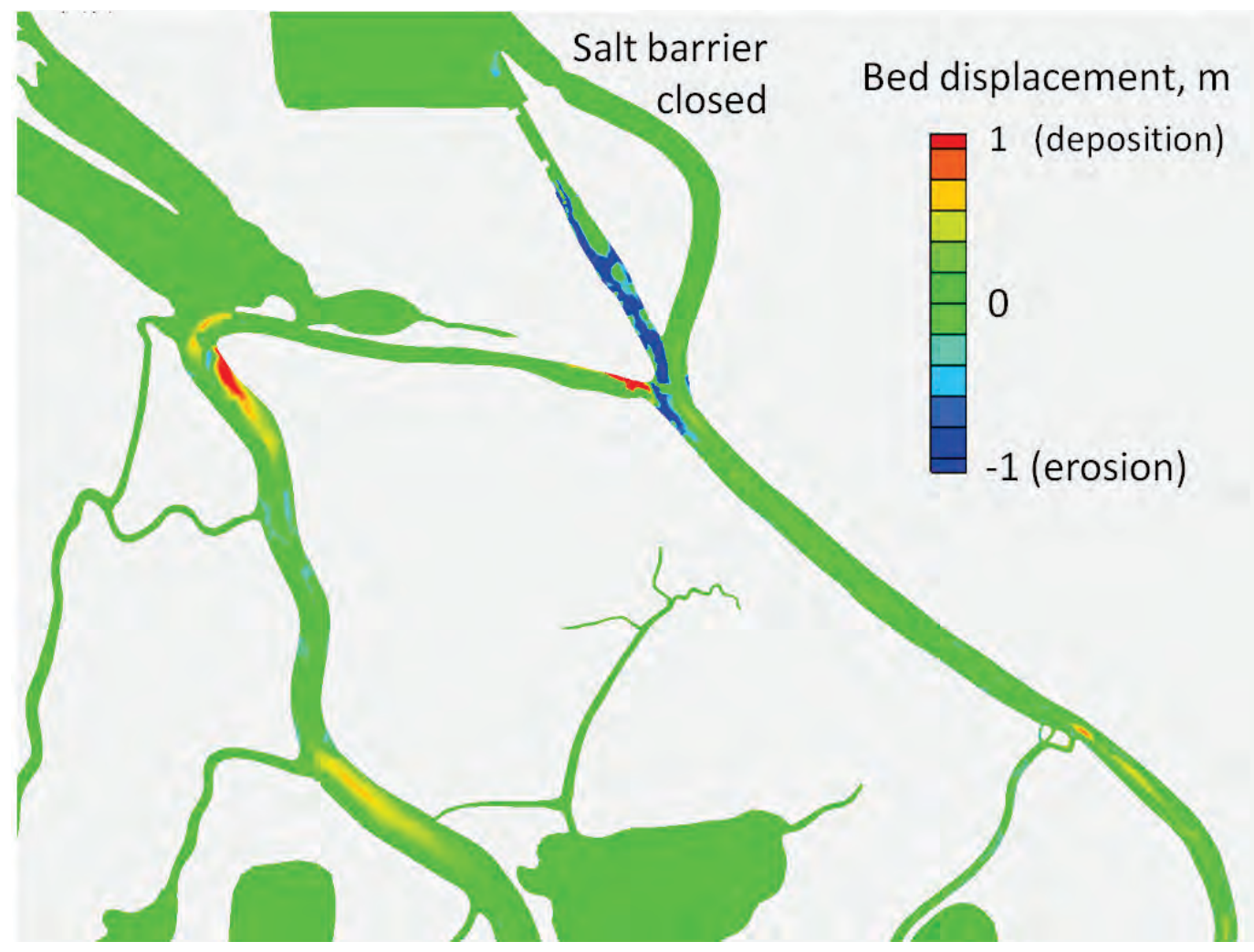


Figure 7-16 Deposition and erosion for sediment sensitivity run LOBOCX with shoal removed.

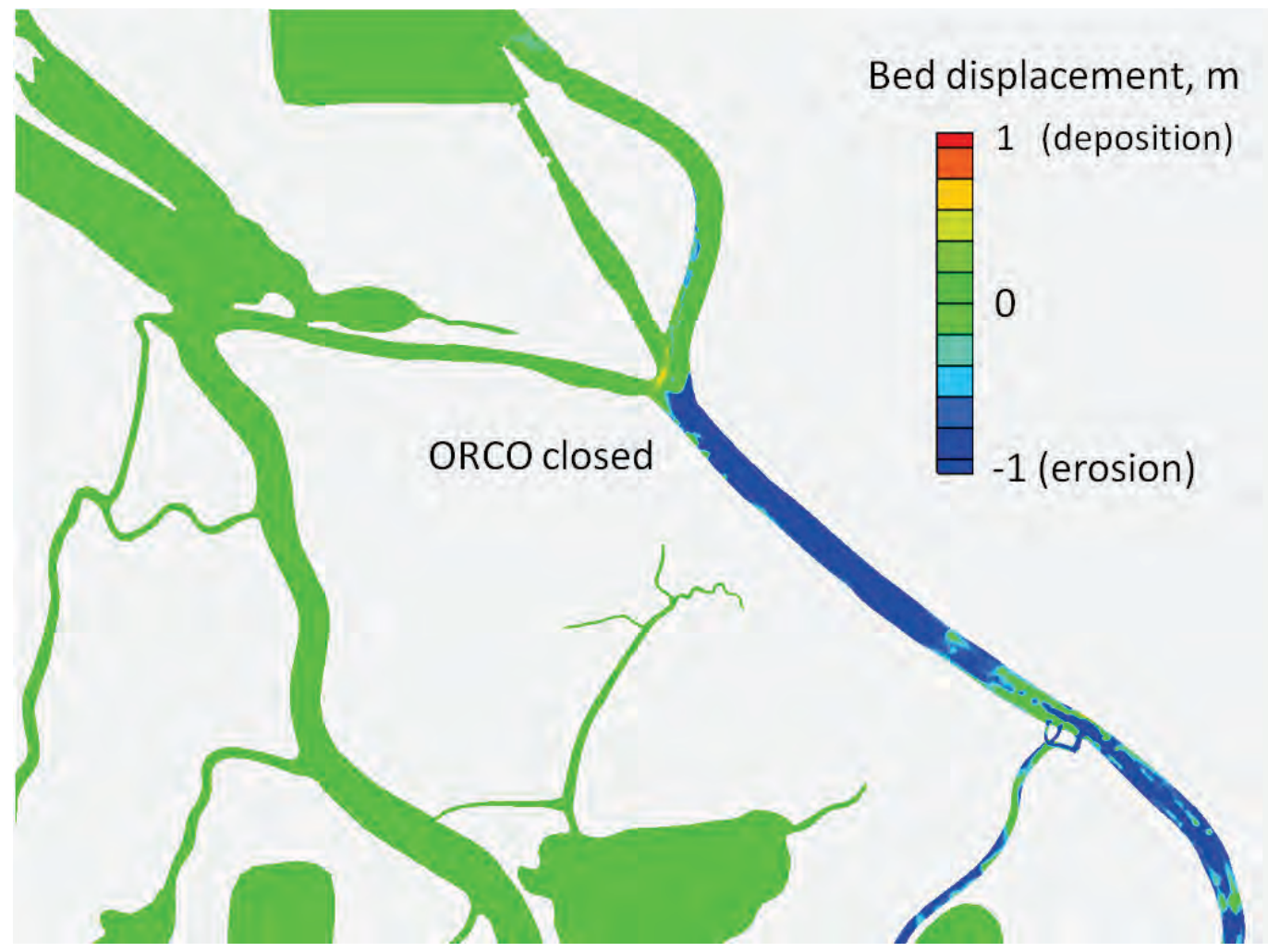

Figure 7-17 Deposition and erosion for sediment sensitivity run LXBOCX with shoal removed.

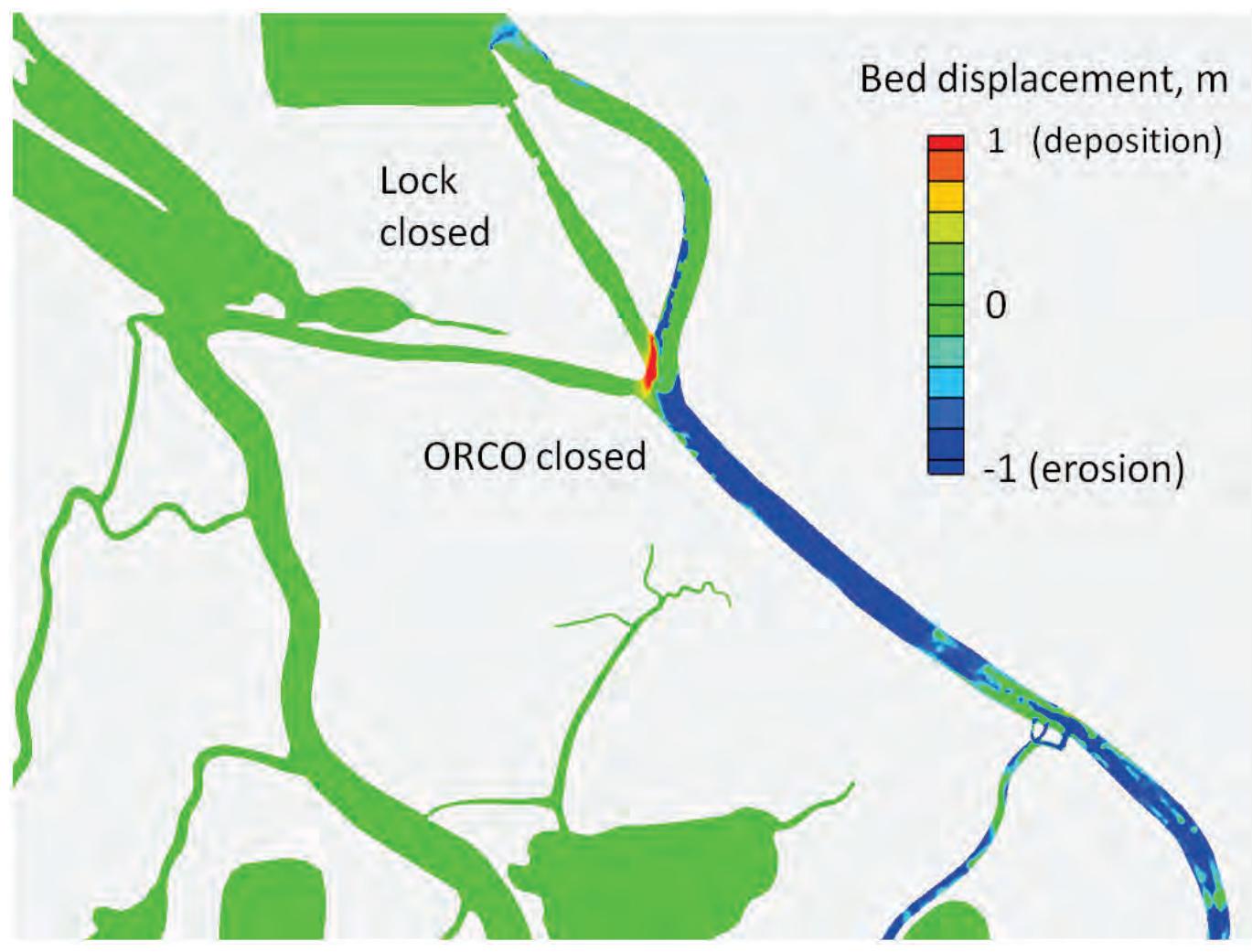


Figure 7-18 Deposition and erosion for sediment sensitivity run LOBXCX with shoal removed.

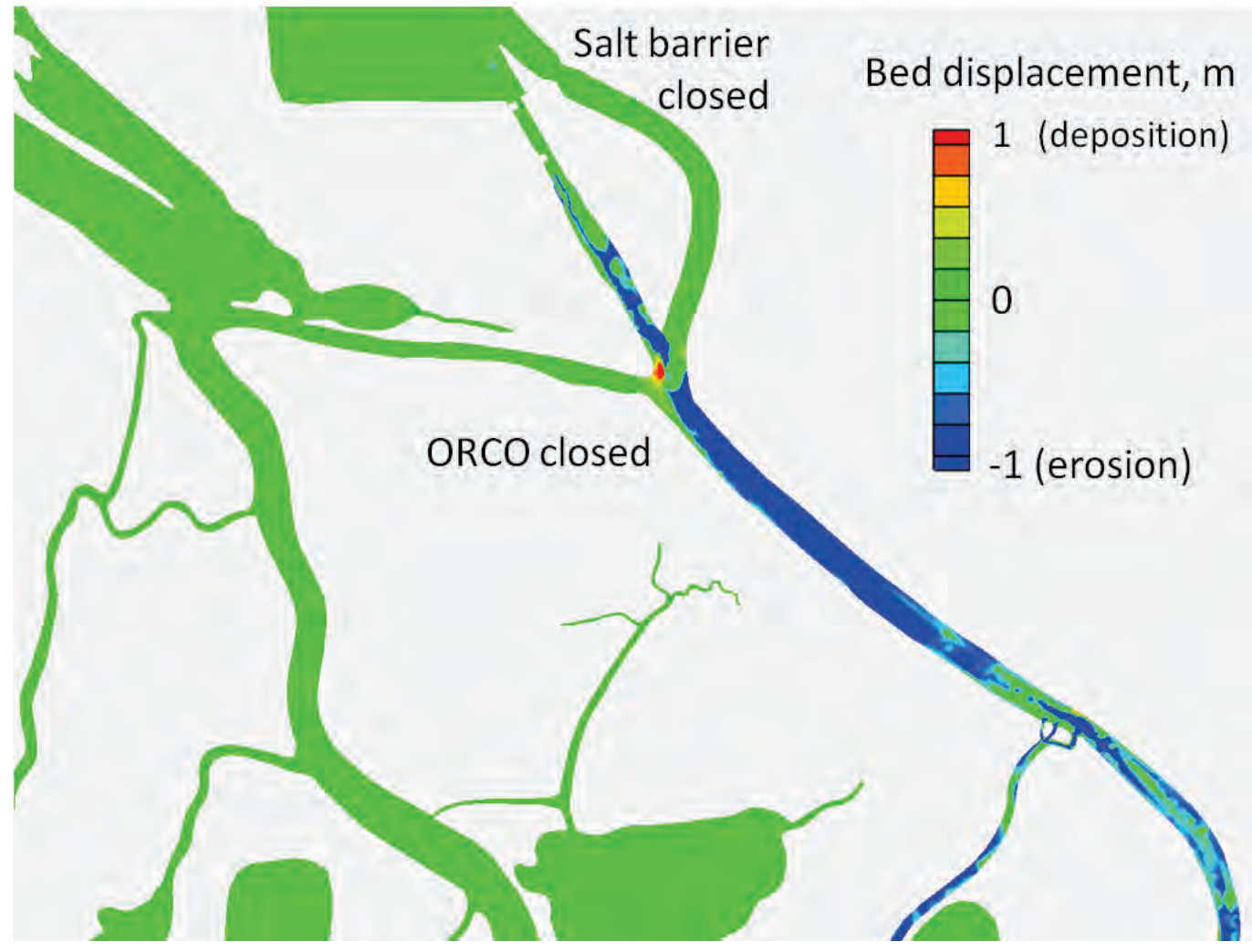

Figure 7-19 Difference in deposition/erosion for sediment sensitivity run LOBOCO (shoal removed-existing).

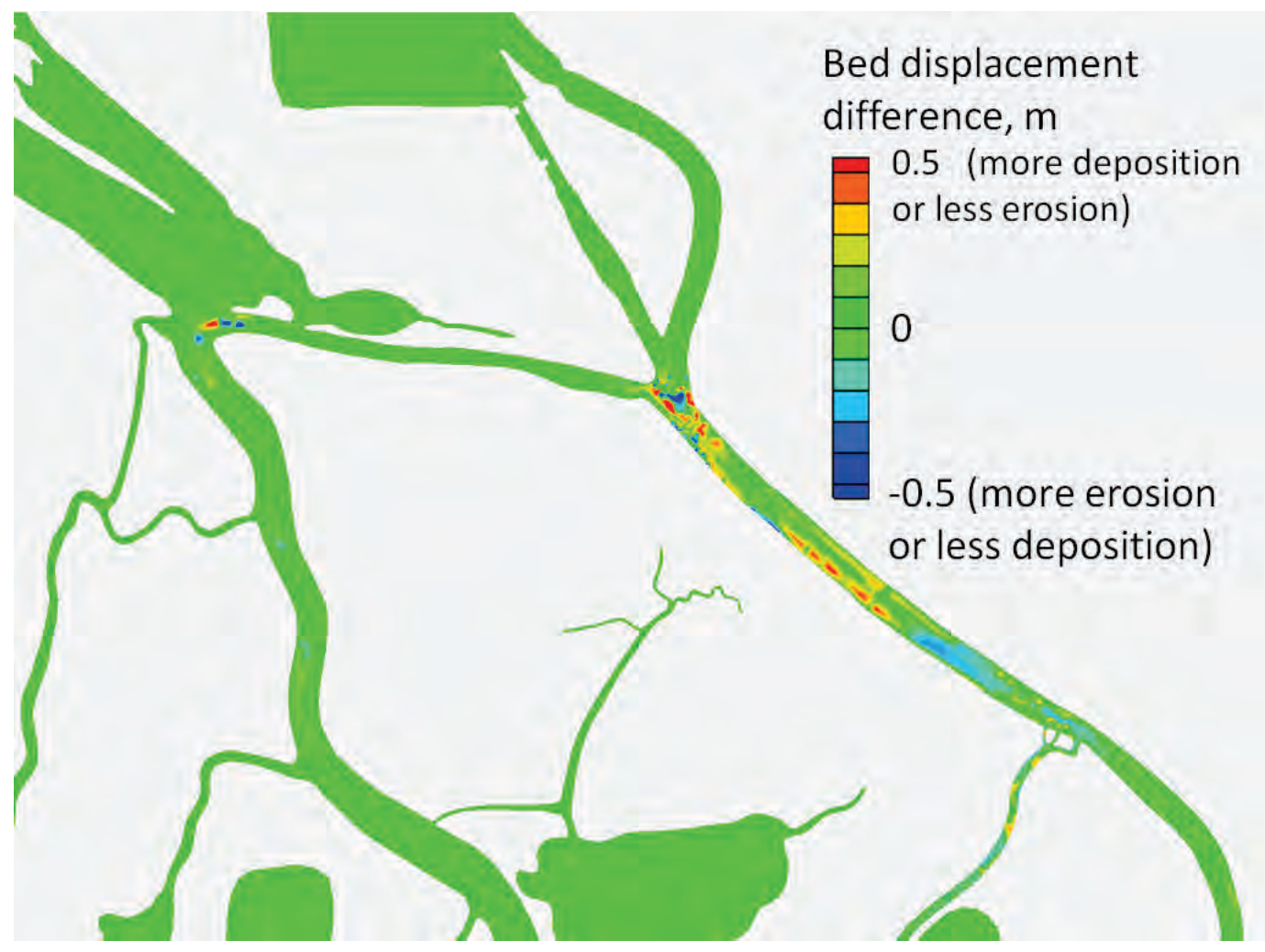


Figure 7-20 Difference in deposition/erosion for sediment sensitivity run LXBOCO (shoal removed-existing).

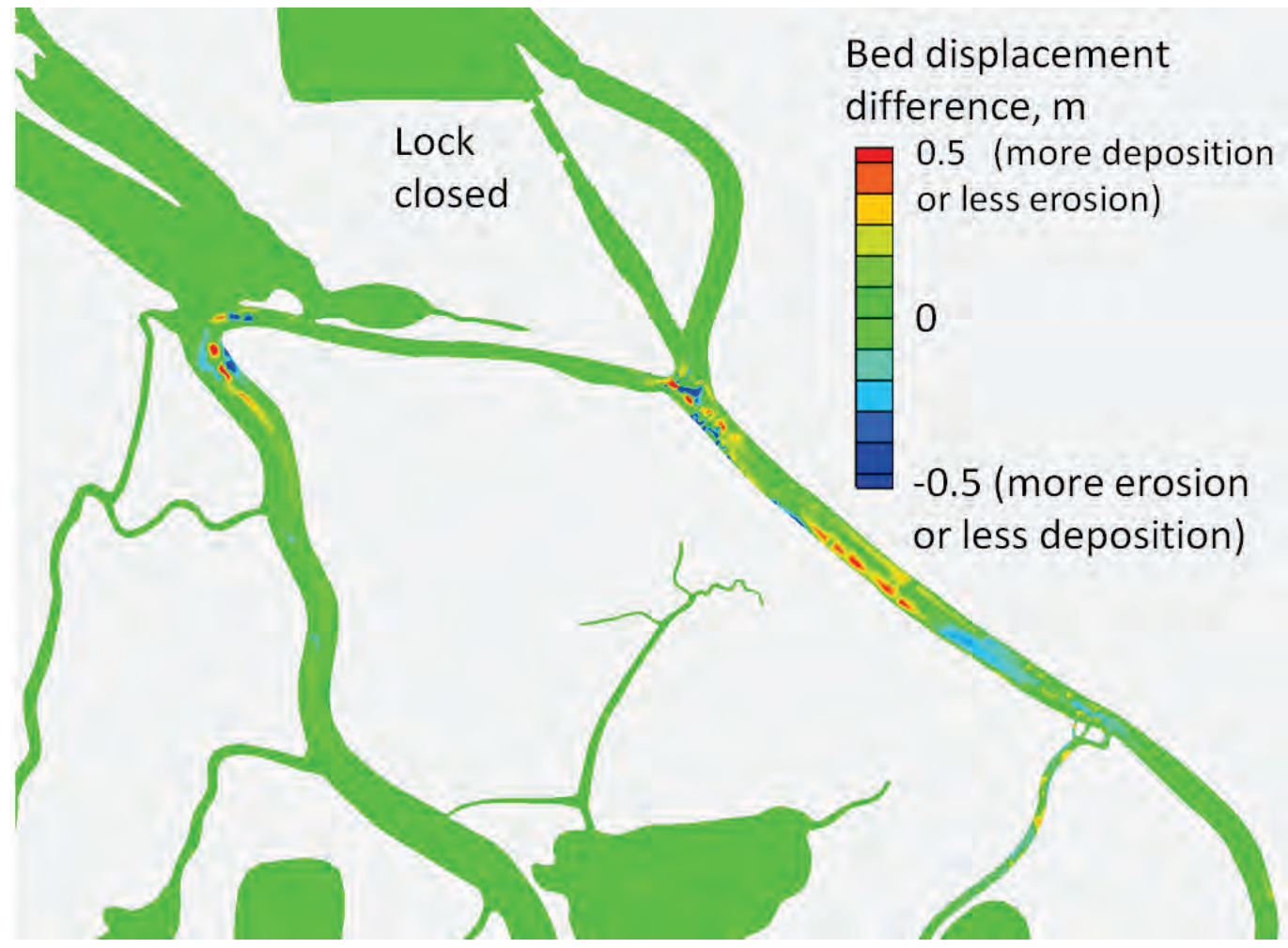

Figure 7-21 Difference in deposition/erosion for sediment sensitivity run LOBXCO (shoal removed-existing).

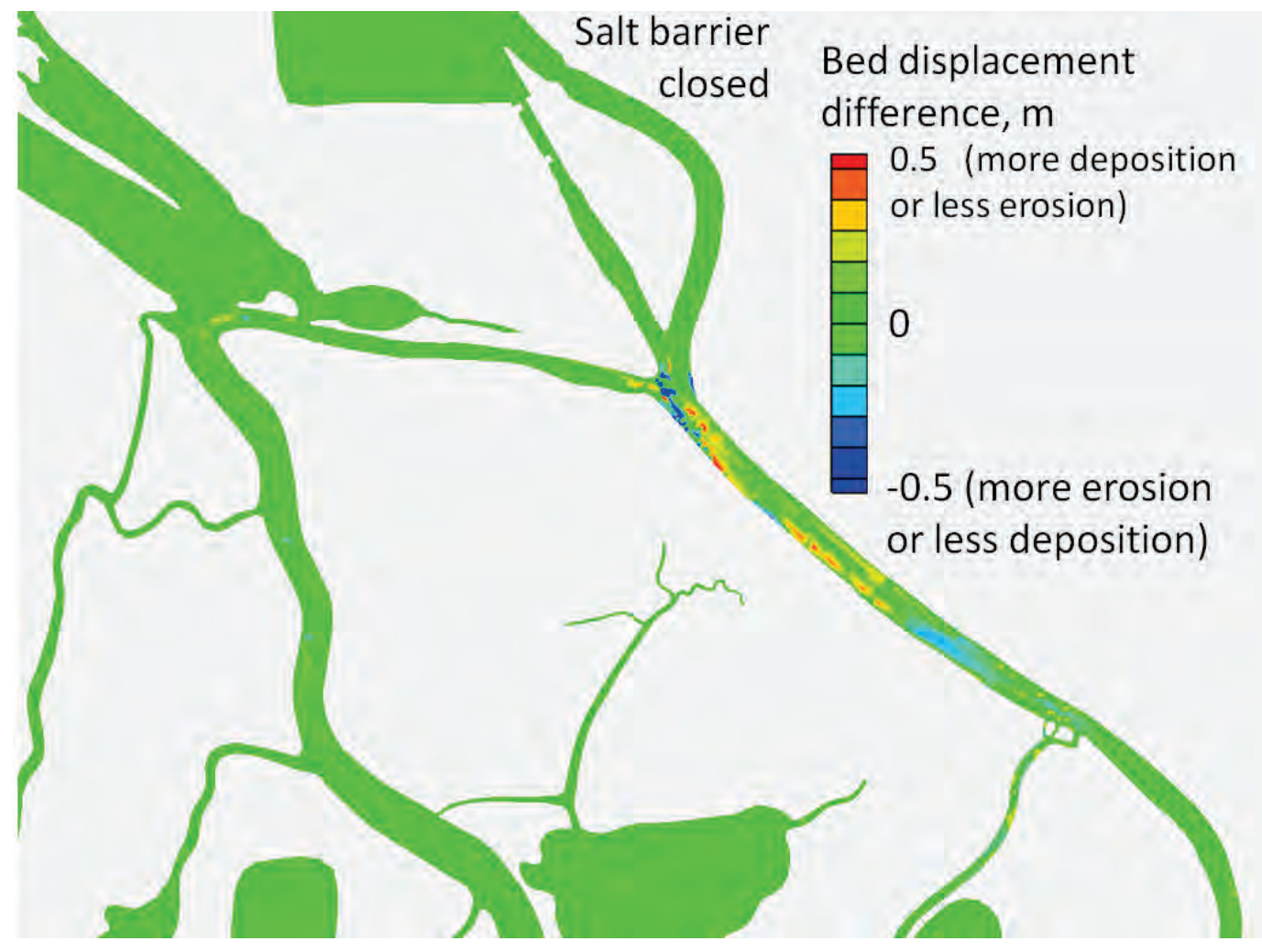


Figure 7-22 Difference in deposition/erosion for sediment sensitivity run LOBOCX (shoal removed-existing).

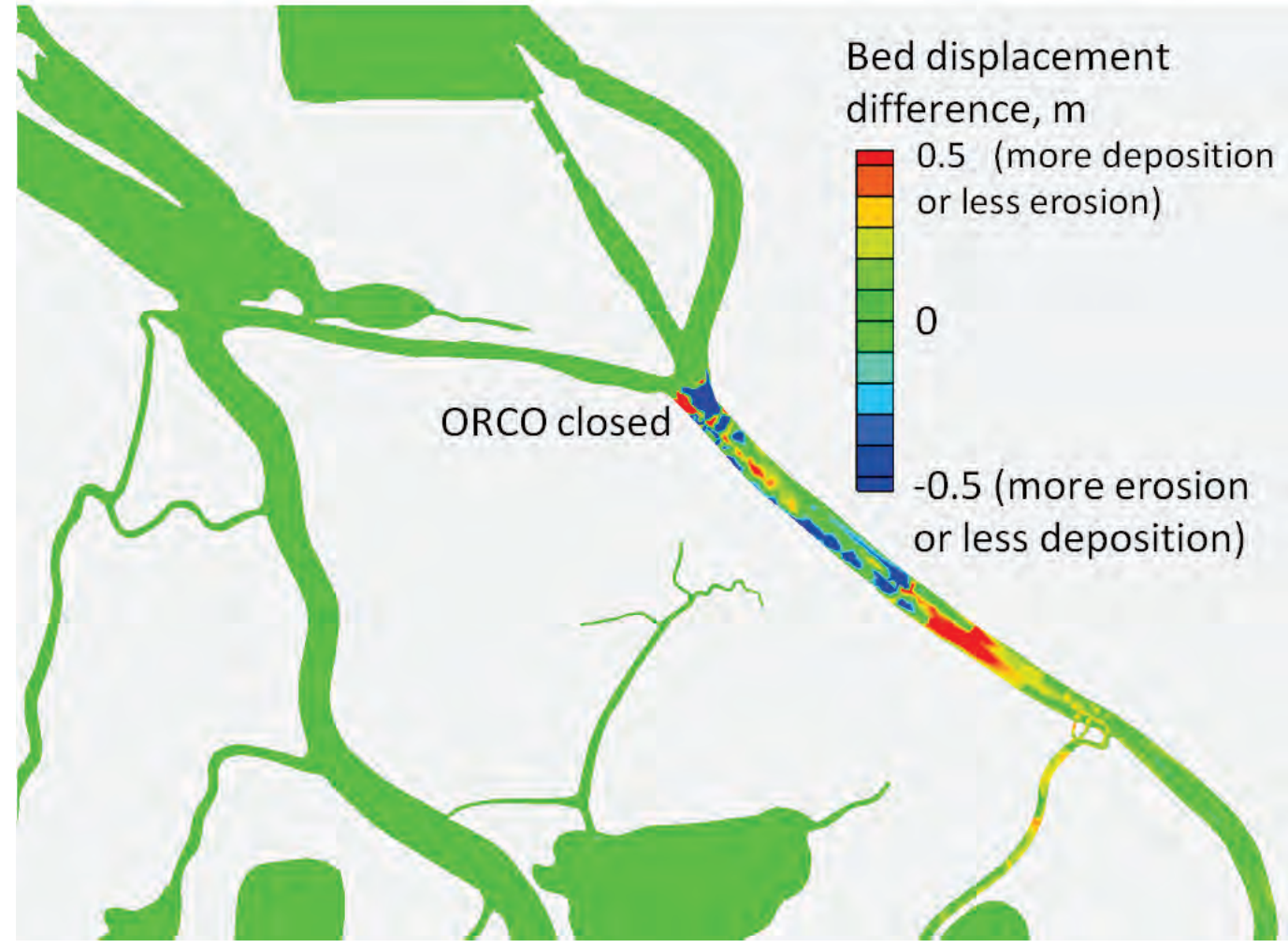

Figure 7-23 Difference in deposition/erosion for sediment sensitivity run LXBOCX (shoal removed-existing).

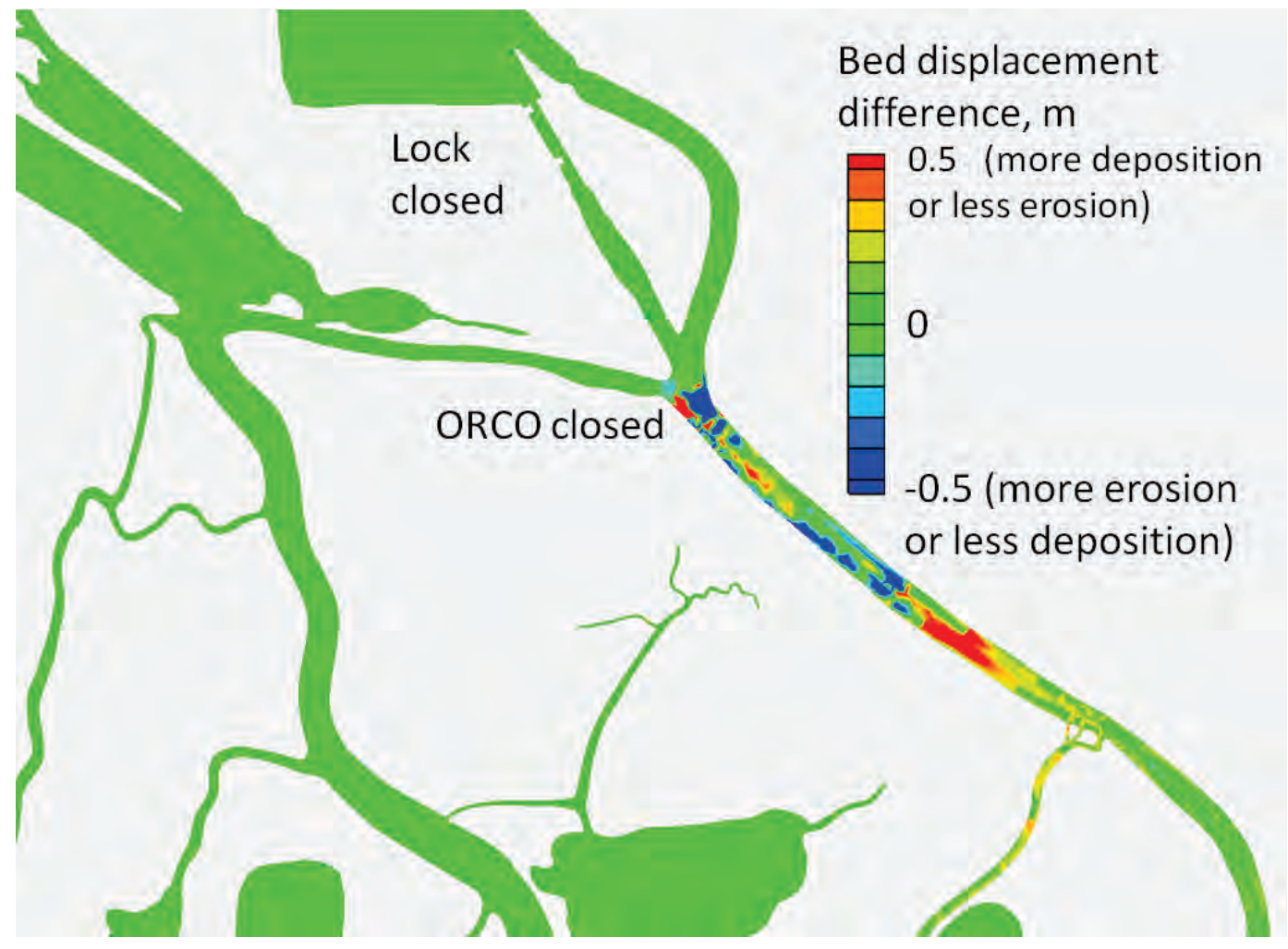


Figure 7-24 Difference in deposition/erosion for sediment sensitivity run LOBXCX (shoal removed-existing).

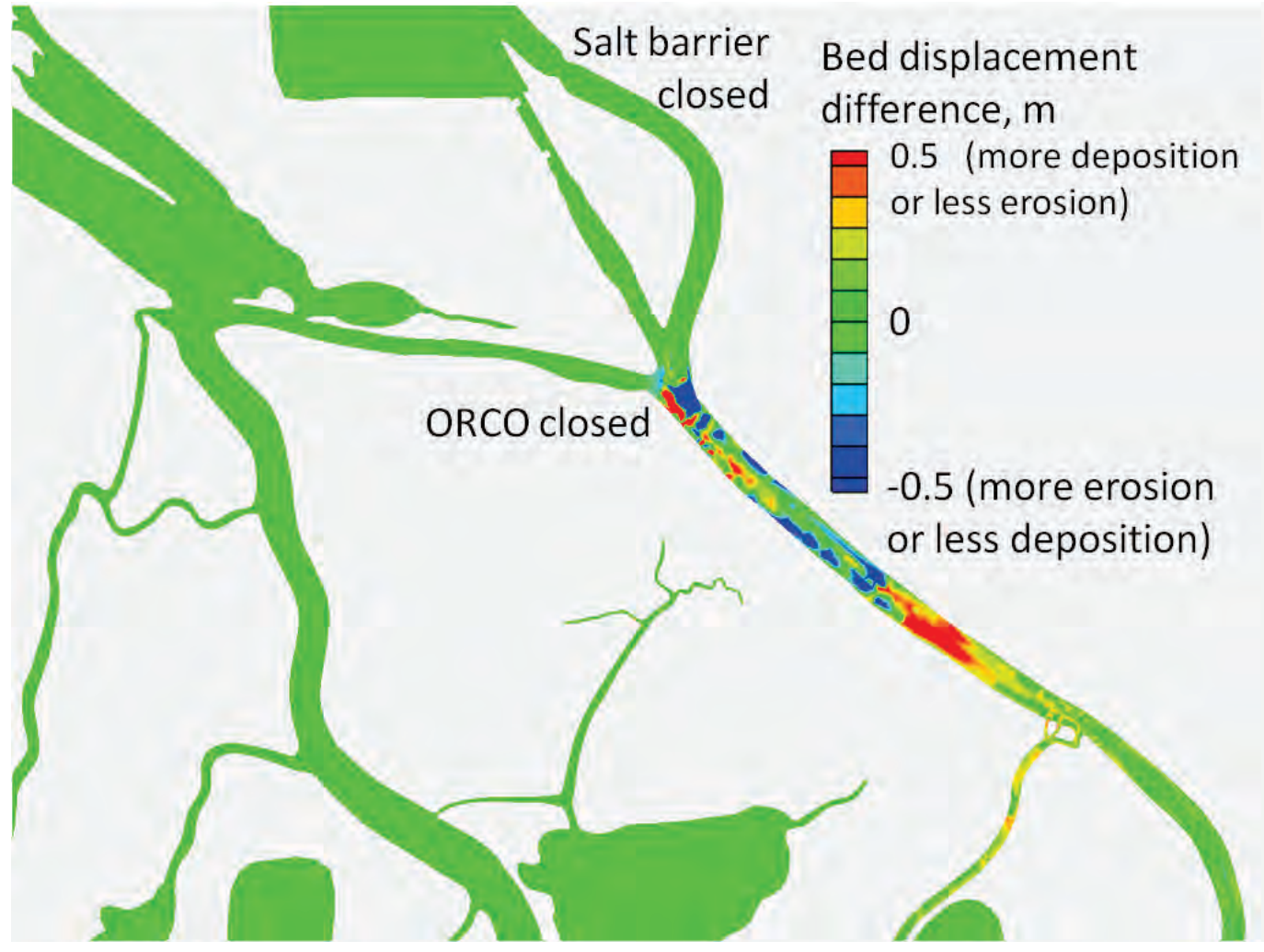

Figure 7-19 shows that for the LOBOCO case, there is greater deposition for the without shoal, as would be expected. Note that a positive difference can be either more deposition, or less erosion, for the without-shoal condition. Conversely a negative difference can be either more erosion or less deposition when the shoal is removed.

Figure 7-20 shows that for closing the lock channel (LXBOCO), there are some differences in the western end of ORCO, but primarily there is more deposition in the Trinity River below the confluence. Figure 7-21 shows similar differences for the closing of the salt barrier (LOBXCO).

The differences for the configurations with ORCO closed (Figure 7-22 through Figure 7-24) are very similar and are all confined to the Trinity River below the confluence. These differences are either more or less erosion.

Figure 7-25 through Figure 7-30 show the erosion and deposition over the entire Trinity delta with side-by-side comparisons of the "existing" and "shoal removed" test results. These show that the only change that results in 
a significant response is the closure of ORCO, which results in erosion of the lower Trinity River down a far as Brown's Pass just west of Port Anahuac. There is also erosion down J ack's Pass, Lighthouse Pass, and Brown's Pass as flow is seeking a more efficient pathway to the bay. There is significant deposition in the Trinity River channel downstream of Brown's Pass, continuing all the way to the end of the navigation channel in Trinity Bay.

General conclusions from this sensitivity analysis are

- closure of either the lock or the salt barrier during the wet season, increasing erosion potential in the other open channel,

- complete closure of ORCO, leading to erosion of the shoal at the head of the Trinity River channel regardless of the direction from which the flows arrive (lock or salt-barrier channel), and

- closure of ORCO, pushing shoaling downstream, with flow being diverted into and promoting erosion of the down-river passes, with increased deposition downstream of the diversions in the Trinity River channel.

Figure 7-25 Deposition/erosion comparison of existing bathymetry vs. dredged condition for LOBOCO.

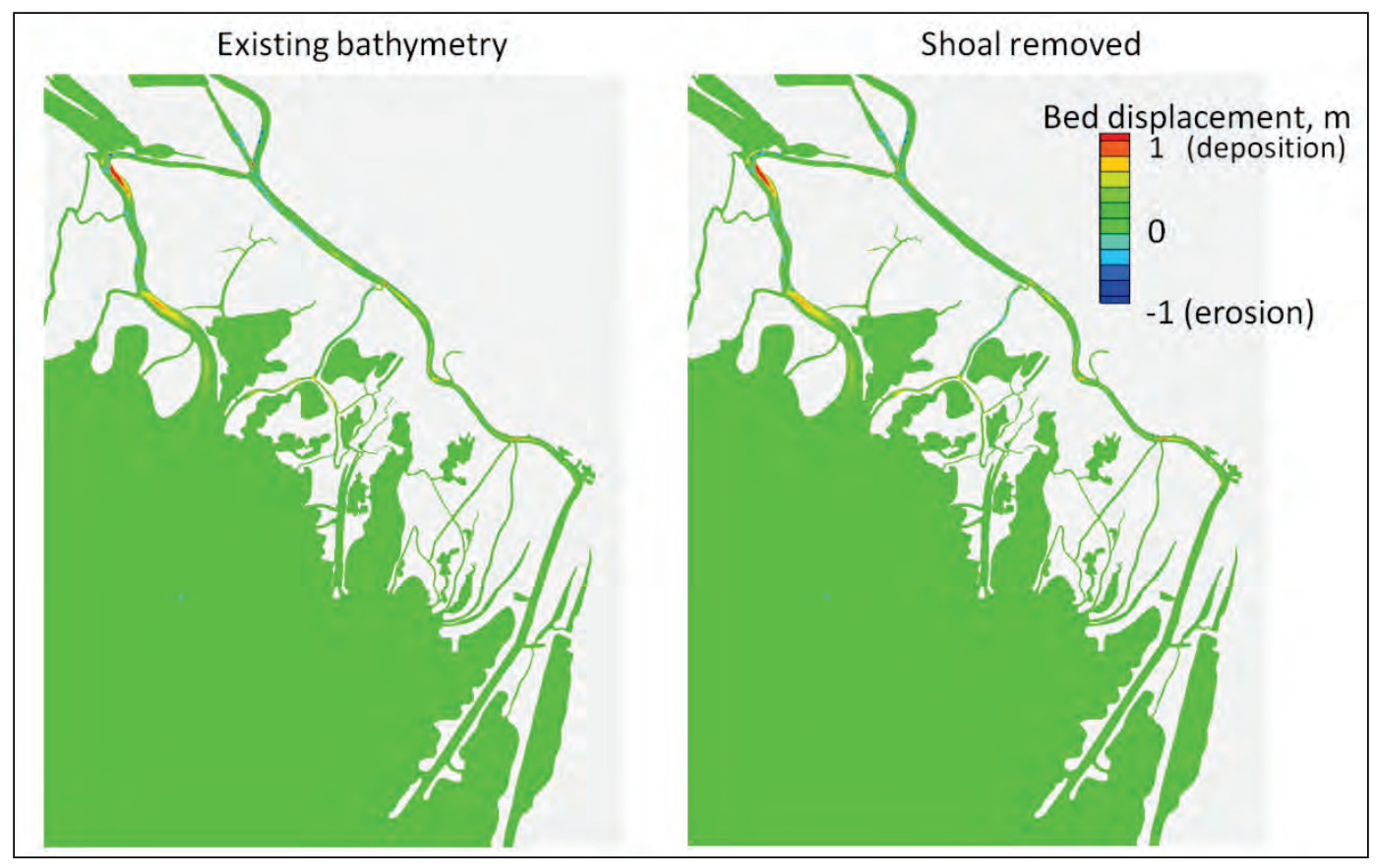


Figure 7-26 Deposition/erosion comparison of existing bathymetry vs. dredged condition for LXBOCO.

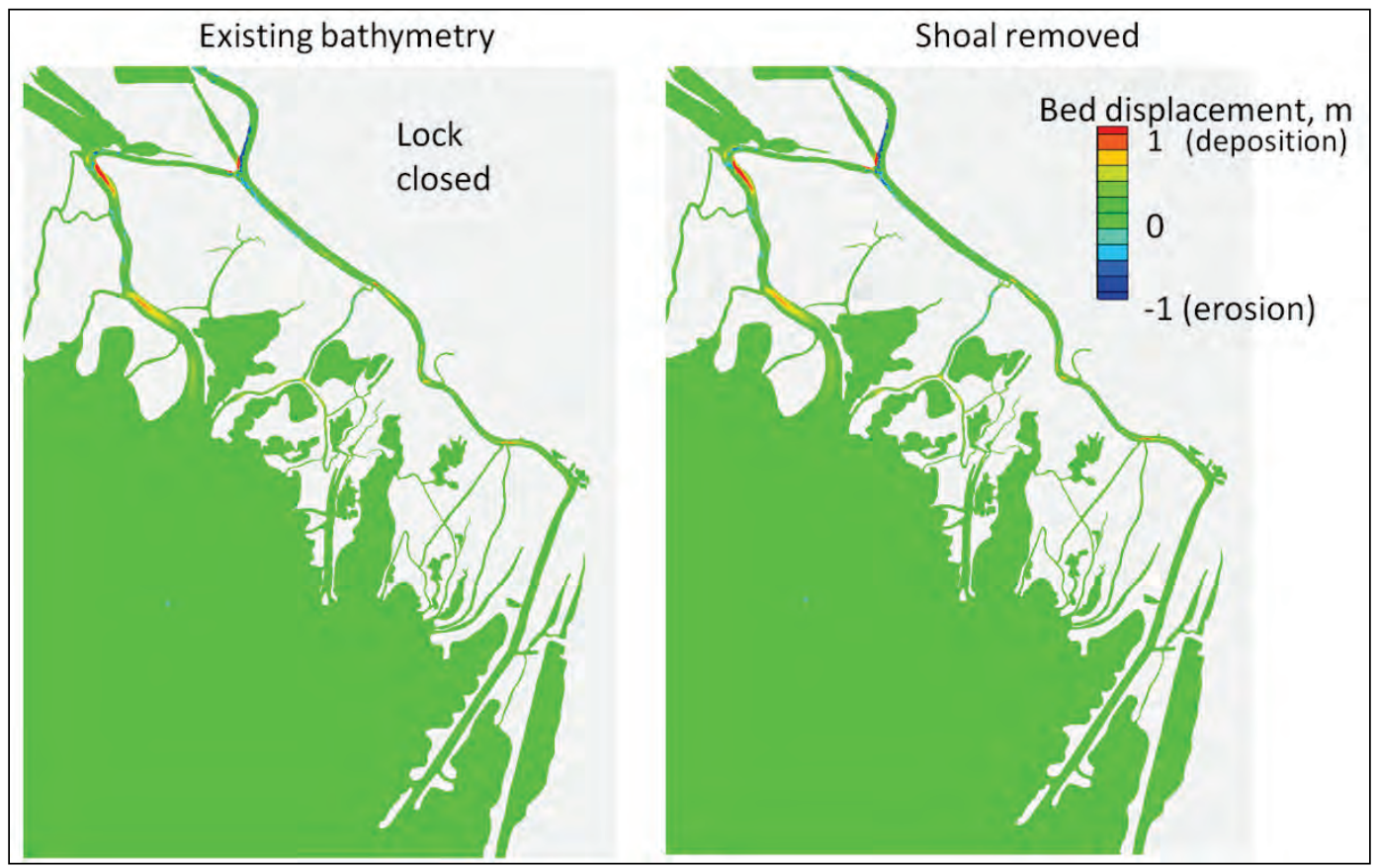

Figure 7-27 Deposition/erosion comparison of existing bathymetry vs. dredged condition for LOBXCO.

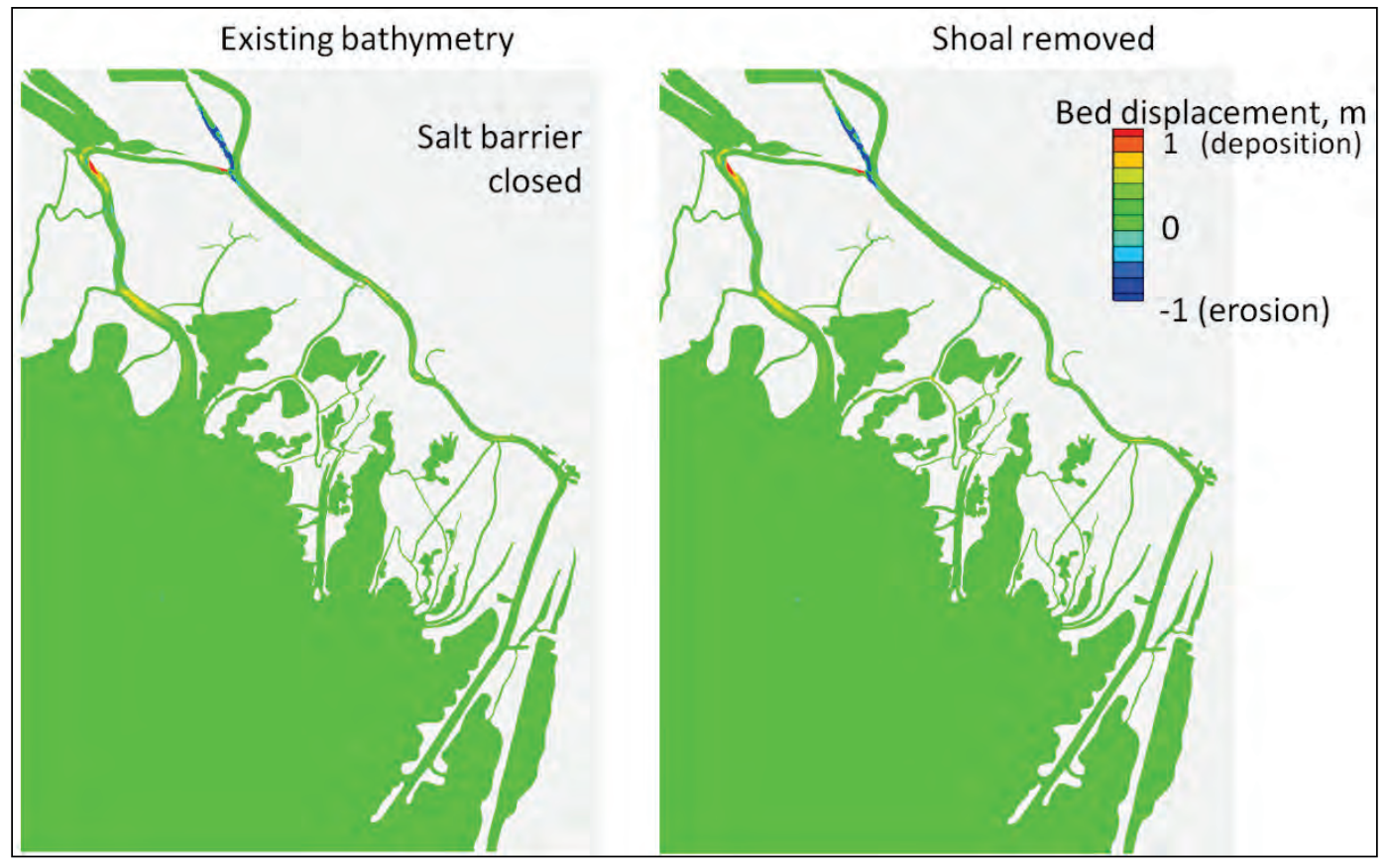


Figure 7-28 Deposition/erosion comparison of existing bathymetry vs. dredged condition for LOBOCX.

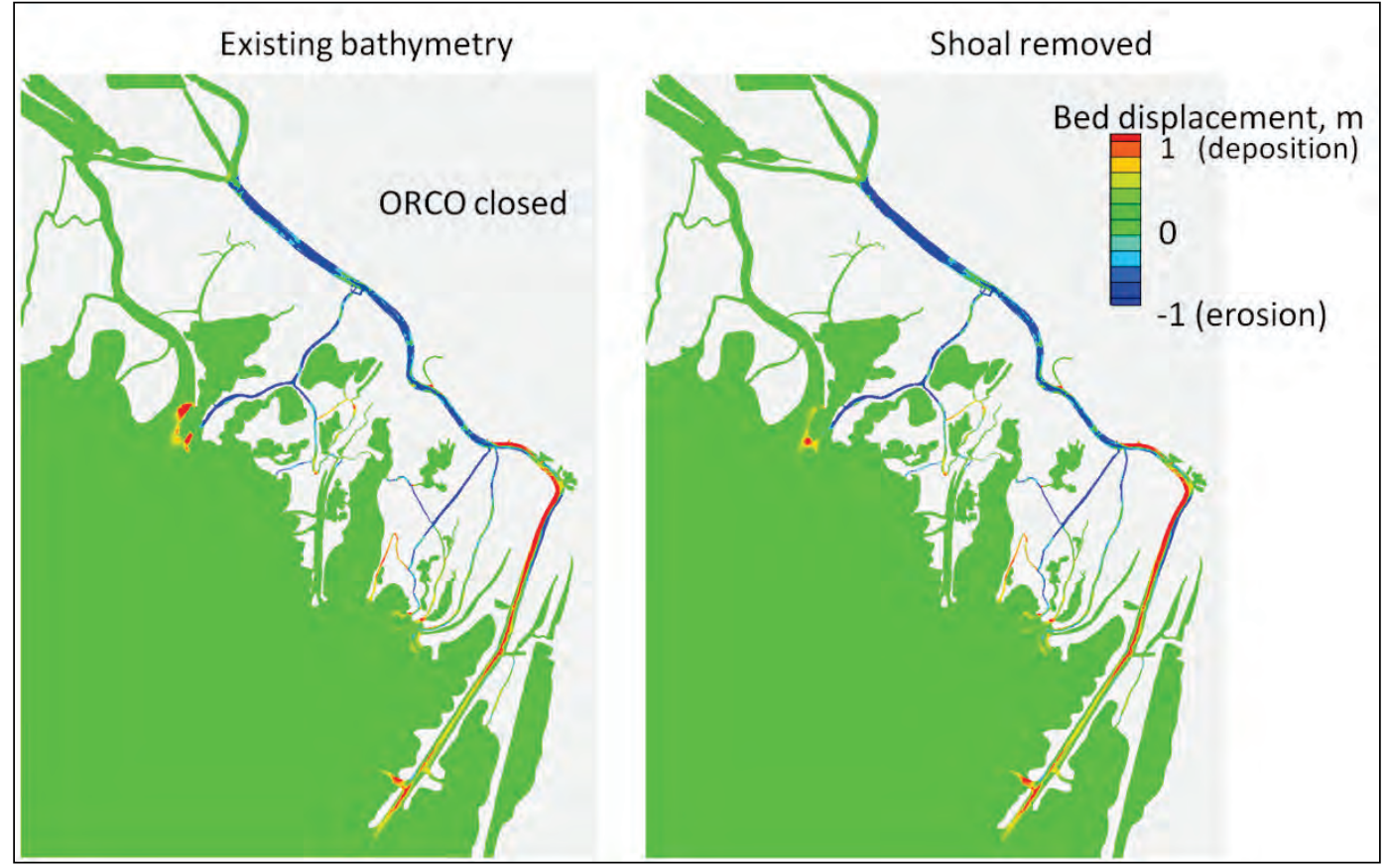

Figure 7-29 Deposition/erosion comparison of existing bathymetry vs. dredged condition for LXBOCX.

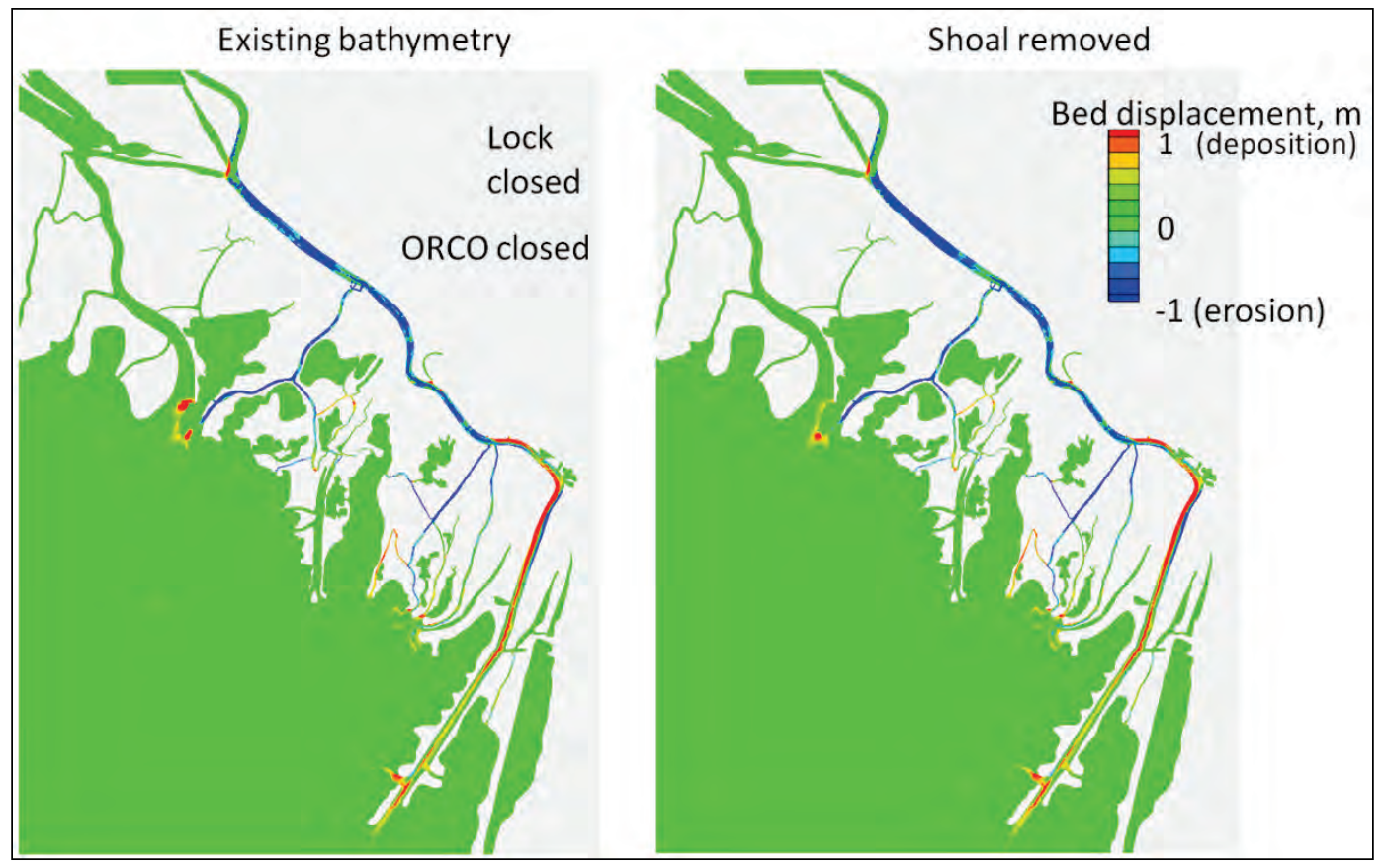


Figure 7-30 Deposition/erosion comparison of existing bathymetry vs. dredged condition for LOBXCX.

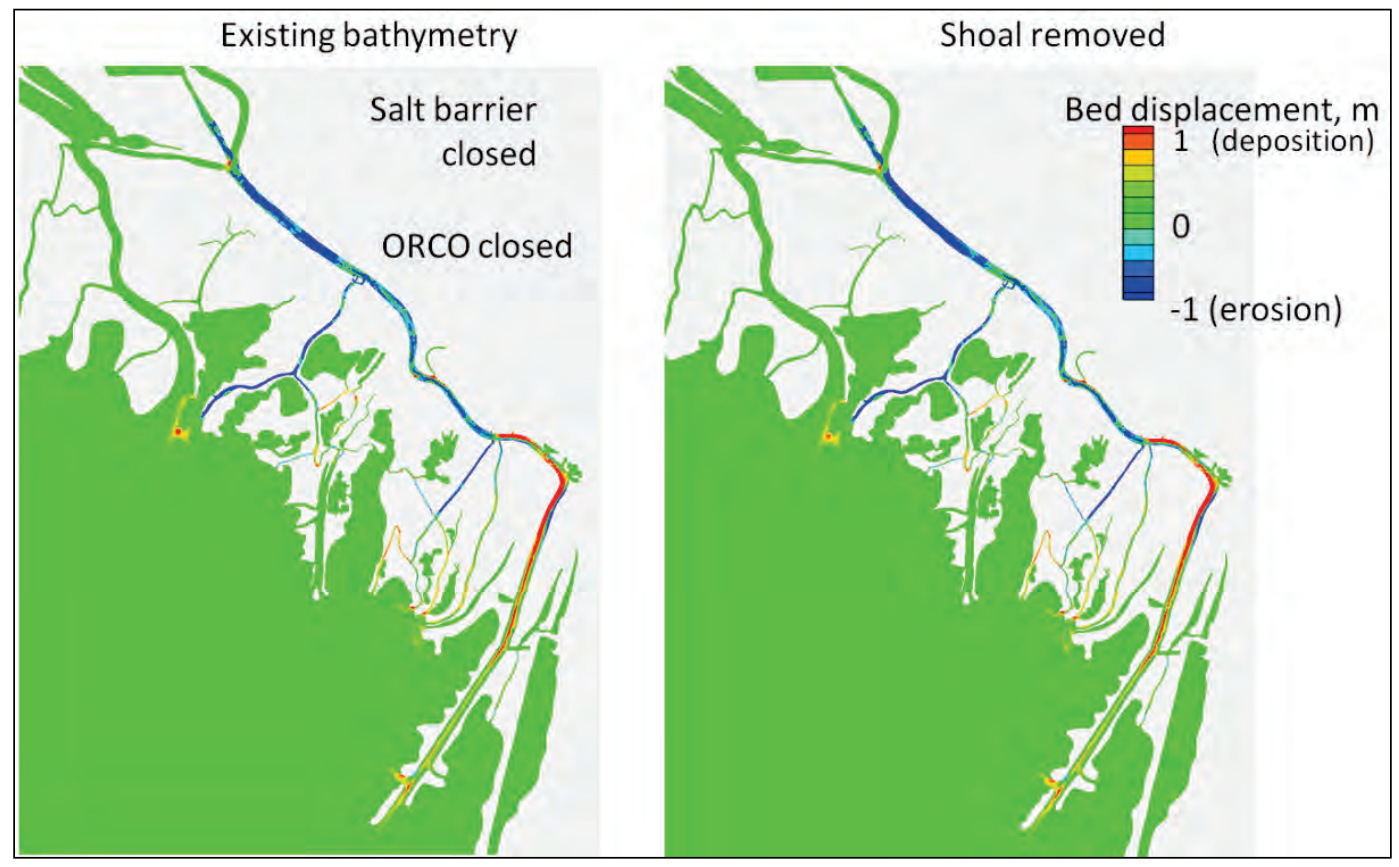




\section{Alternative Testing}

Changes to the system that may help in alleviating the shoal in the lower Trinity River can generally be categorized into the following:

1. Alternatives that redistribute the flows at the confluence of the lock channel, salt-barrier channel, ORCO channel, and the lower Trinity River. These alternatives would attempt to cut off the increasing flows going down the ORCO channel and put them back down the lower Trinity River.

2. Dredging of the shoal to increase depth in the lower Trinity River to promote self scour, including scouring down river. This would be further supported if the dredged material is placed in the ORCO.

3. Some design modification to the channel alignment at the confluence. This would reduce the sediment flux to the lower Trinity River and increase the sediment flux into the ORCO.

4. Construction of a sediment trap. This would reduce the volume of sediment entering the shoal area and trap it in a location that could be more efficiently handled.

\section{Production alternatives}

The production alternatives that have been simulated using the AdH sediment transport model include the following.

\section{Existing conditions}

The existing conditions were the same conditions as run during the sensitivity simulations for the LOBOCO condition. The existing bathymetry in the study area is presented in Figure 8-1.

\section{Dredging of the shoal and placing material into ORCO}

The dredging of the shoal in the Trinity River was essentially the same removal as developed as part of the sensitivity simulations (Figure 7-6). However, for this alternative, the material was returned to the system by placing it into ORCO. The placement was made over the full length of the ORCO, in water depths deeper than $2 \mathrm{~m}$, and distributed proportionally with depth. The bed changes associated with the dredge-and-fill are presented in Figure 8-2, and the final bed condition is shown in Figure 8-3. The volume of material removed was equal to the volume of material placed. 
Figure 8-1 Bathymetry of existing conditions.

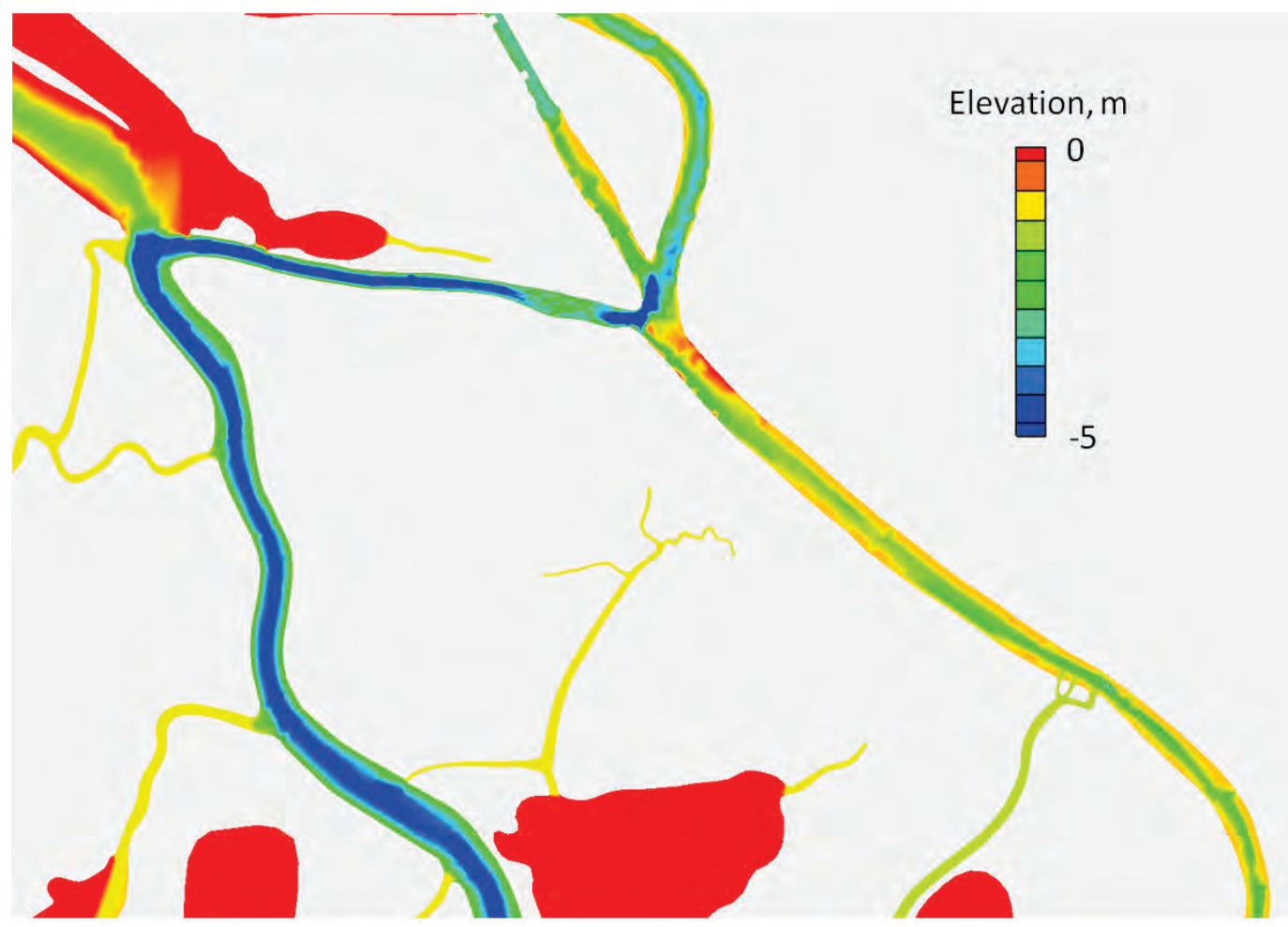

Figure 8-2 Bed changes as a result of dredging Trinity River shoal and placing the material in ORCO.

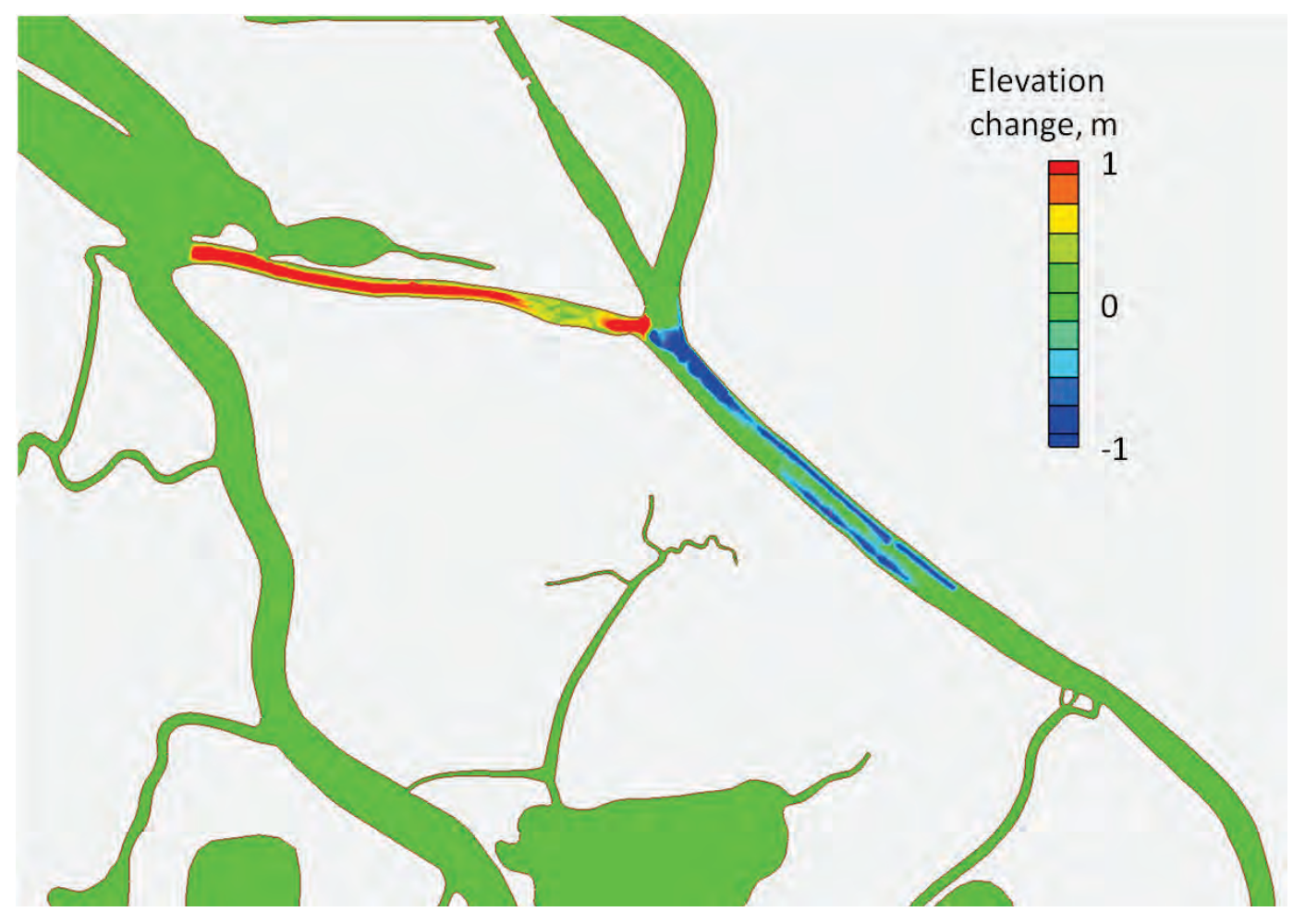


Figure 8-3 Bathymetry after the dredge-and-placement alternative.

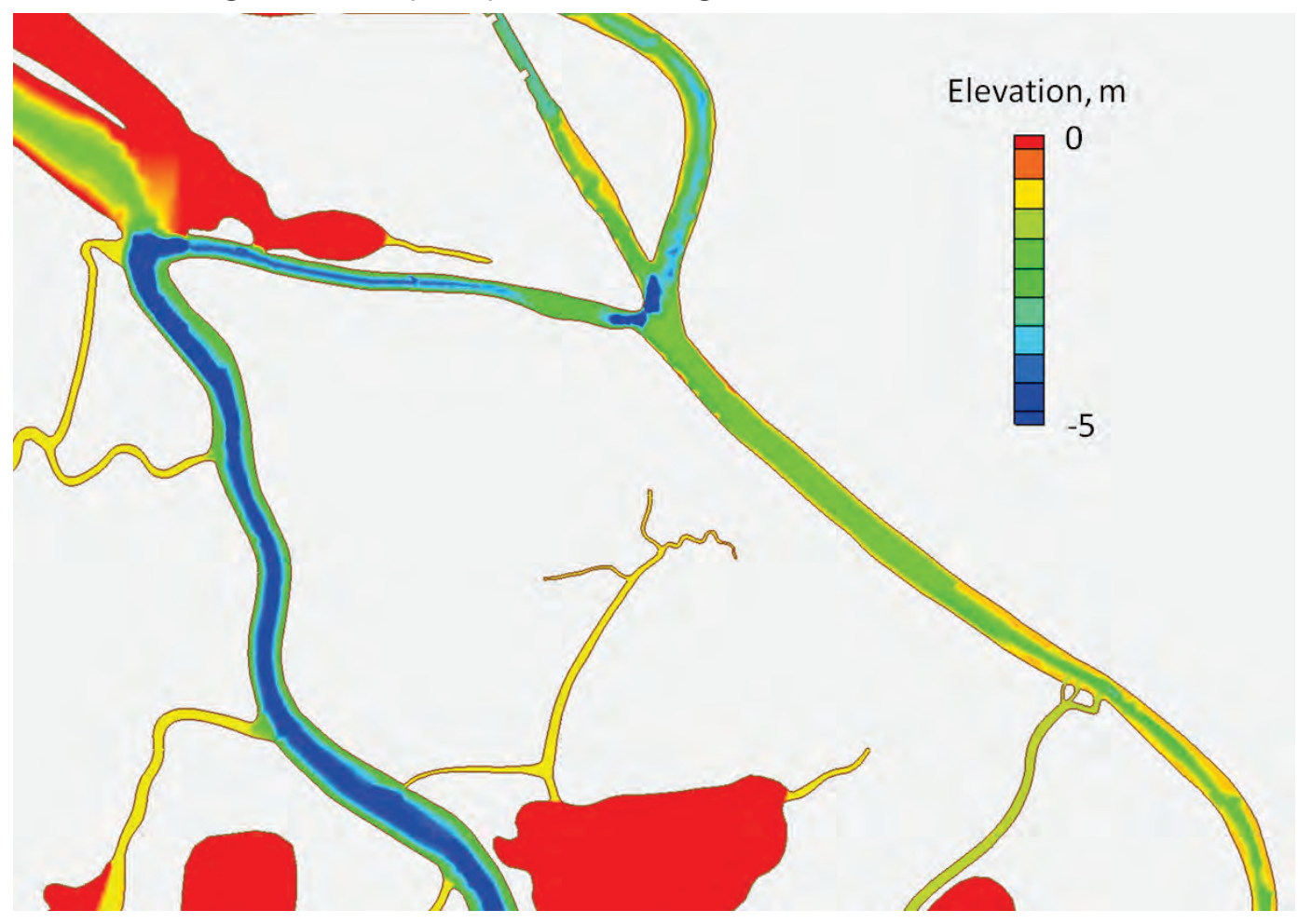

Closure of ORCO by $20 \%$ of the cross-sectional area

The partial closure of ORCO was assumed to be the construction of dikes from each shore in shallow water and encroaching into the cross section until the desired percentage reduction in cross section was achieved. The resulting configuration in the model for a $20 \%$ reduction in flow area is shown in Figure 8-4. The figure presents both the mesh resolution and the bathymetry.

Closure of ORCO by $\mathbf{4 0 \%}$ of the cross-sectional area

The model mesh configuration, resolution, and bathymetry for the $40 \%$ reduction in flow area are shown in Figure 8-5.

\section{Closure of ORCO by $60 \%$ of the cross-sectional area}

The model mesh configuration, resolution, and bathymetry for the $60 \%$ reduction in flow area are shown in Figure 8-6. 
Figure 8-4 Mesh configuration for $20 \%$ reduction in ORCO cross section (top) and bathymetry (bottom).
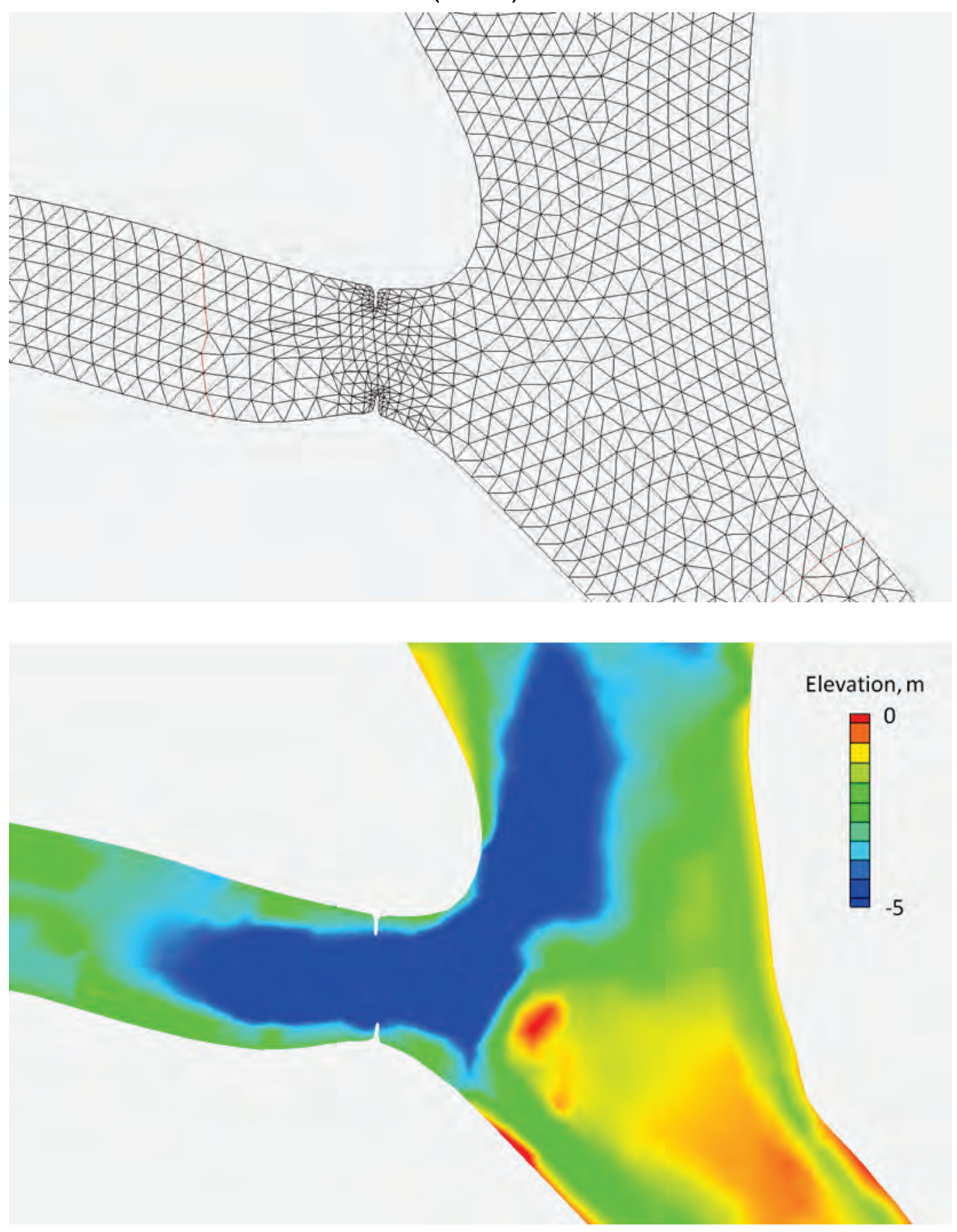
Figure 8-5 Mesh configuration for $40 \%$ reduction in ORCO cross section (top) and bathymetry (bottom).
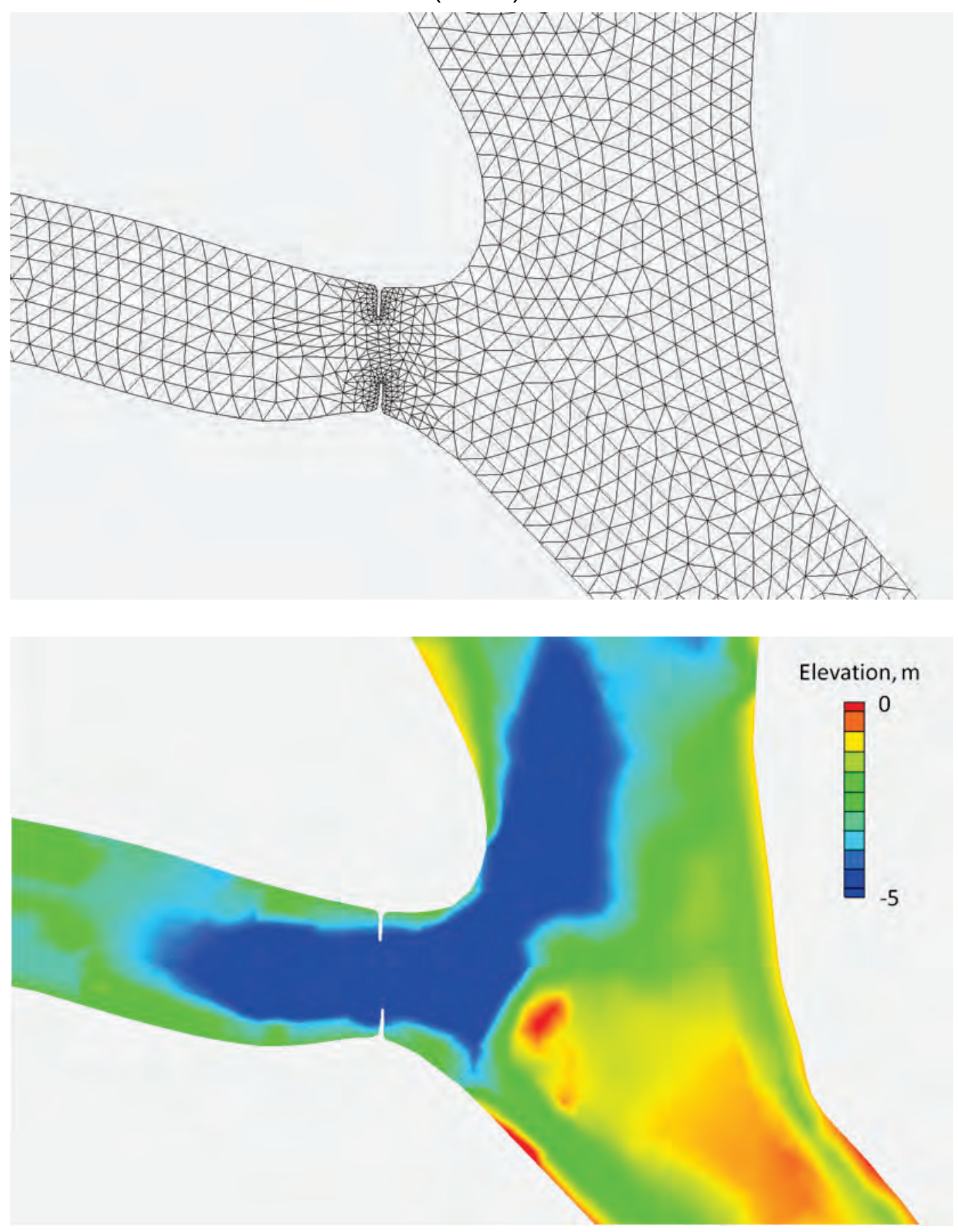
Figure 8-6 Mesh configuration for $60 \%$ reduction in ORCO cross section (top) and bathymetry (bottom).
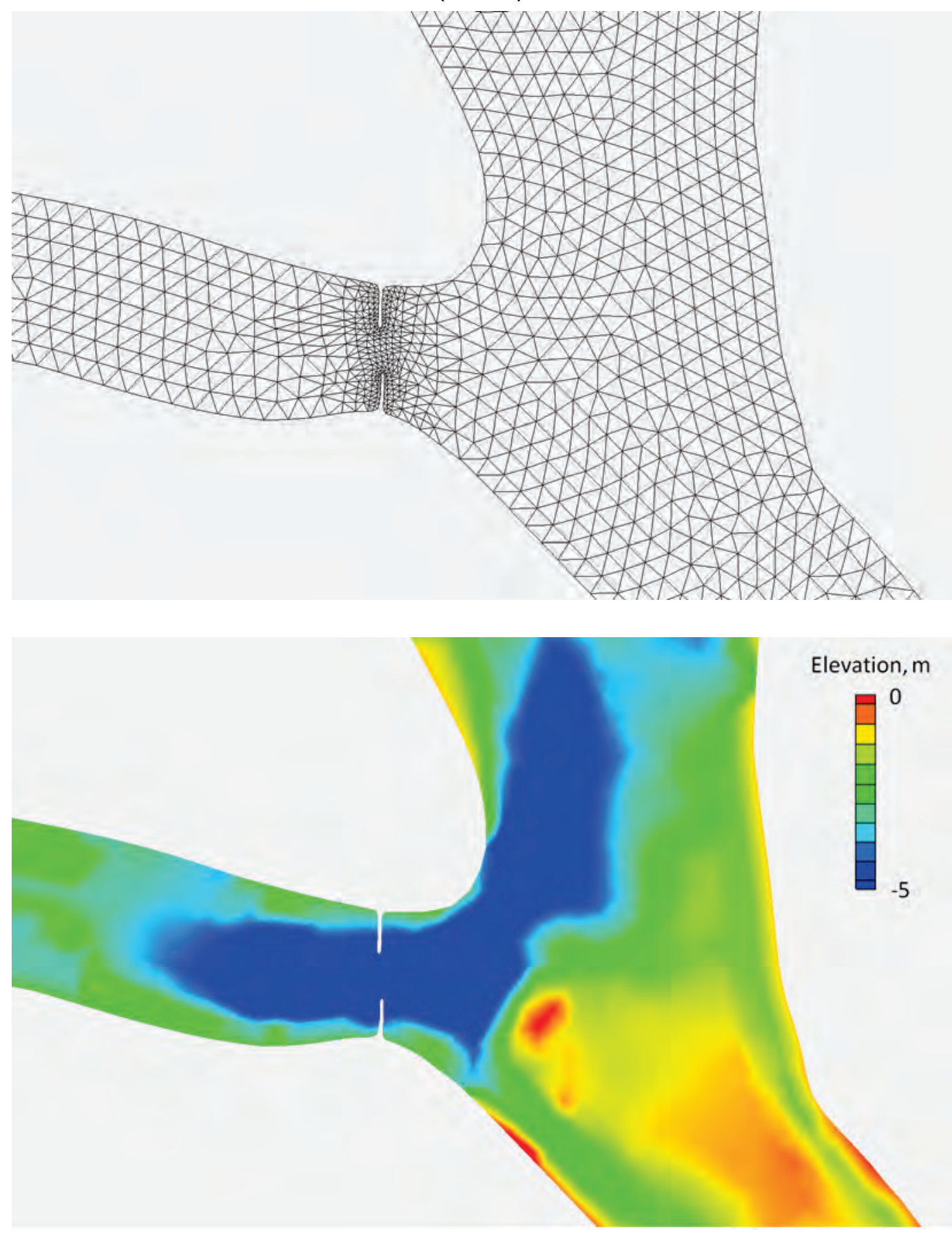

\section{Wet-season simulations}

\section{Sediment transport}

The wet-season sediment transport simulation conditions were similar to the sensitivity simulations for the wet season as described in Chapter 7. 
The main difference is that the shoal material removed is placed into the ORCO channel in the alternative simulations.

\section{Salinity intrusion}

The wet-season salinity intrusion simulation was performed only for the purpose of developing an initial salt field for the dry-season salinity simulation. The initial conditions for the wet-season salinity simulation were a step function across each of the structures, with 30 practical salinity units (psu) downstream and 0 psu upstream, and at certain locations along the other channels to the west. The initial salt field is shown in Figure 8-7.

Figure 8-7 Initial salinities for wet-season salinity simulation. Red is $30 \mathrm{psu}$ and blue is $0 \mathrm{psu}$.

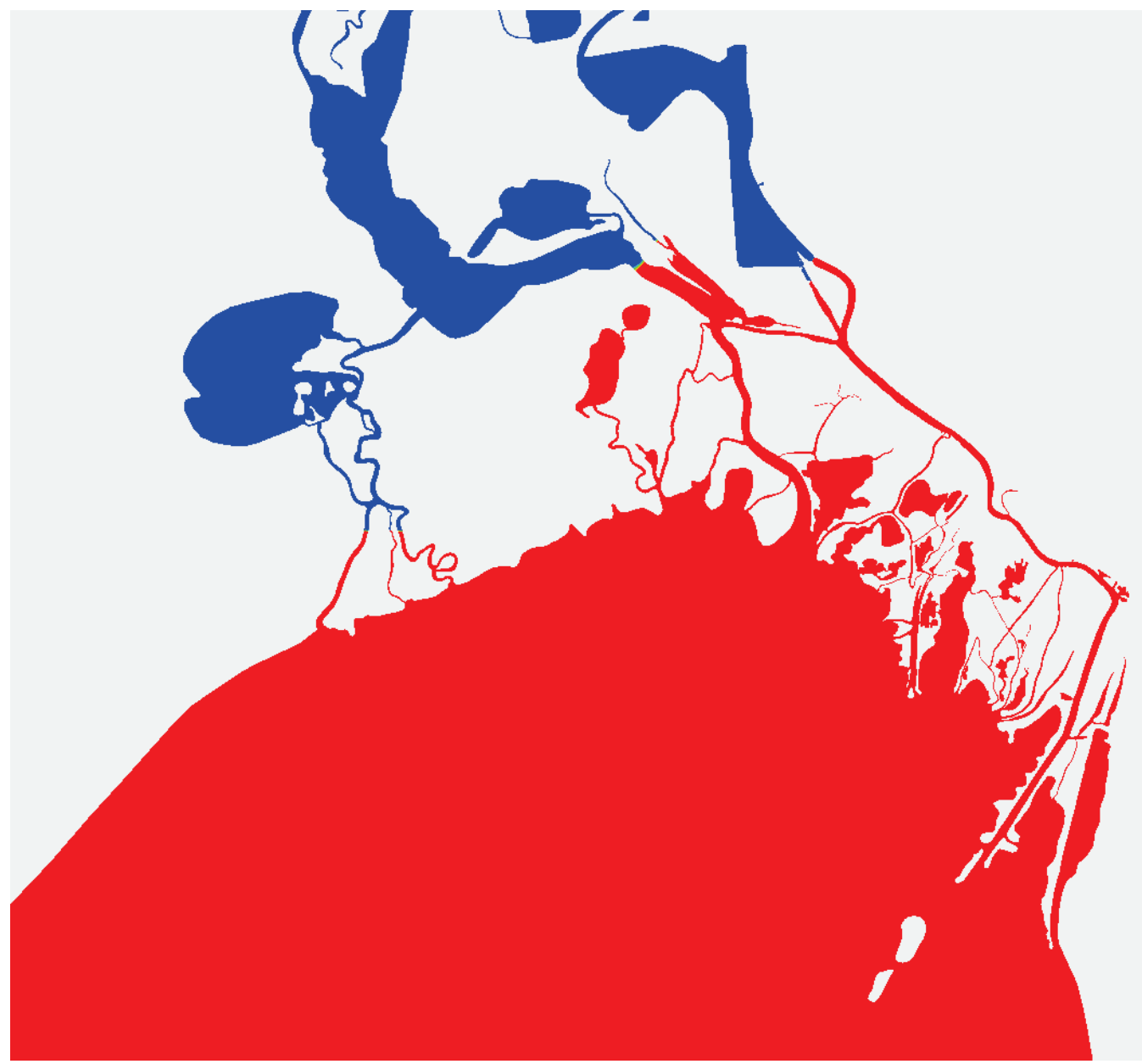

\section{Dry-season simulations}

The simulations of the dry season are more involved because of the various configurations of the structures during the simulation period. These 
include the gate openings of the salinity barrier, the condition of the lock and of Structure A (located in the Cut Off that runs south from Mark's Bend on the Trinity River near Moss Bluff). The possible combinations of status (open or closed) of these three structures are presented in Table 8-1. Similar to the convention of Chapter 7, in Table 8-1, L = lock, B = salinity barrier, $\mathrm{A}=$ Structure $\mathrm{A}$, and $\mathrm{O}$ and $\mathrm{X}$ are, respectively, open and closed. As seen previously (Figure 6-10), the structures at Wallisville were opened periodically during the 2012 dry season for a variety of reasons (salinity control downstream, water-level control upstream, and navigation).

Table 8-1 All possible combinations of configurations for the lock (L), salt barrier (B), and Structure $A(A)$, open $(0)$ and closed $(X)$. Only the configurations shaded blue were used in the dry-season simulation.

\begin{tabular}{|l|l|l|l|}
\hline \multirow{2}{*}{ Configuration ID } & \multicolumn{3}{|c|}{ Structure } \\
\cline { 2 - 4 } & Lock & Salt barrier & Structure A \\
\hline LXBXAX & Closed & Closed & Closed \\
\hline LOBXAX & Open & Closed & Closed \\
\hline LXBOAX & Closed & Open & Closed \\
\hline LXBXAO & Closed & Closed & Open \\
\hline LOBOAX & Open & Open & Closed \\
\hline LXBOAO & Closed & Open & Open \\
\hline LOBXAO & Open & Closed & Open \\
\hline LOBOAO & Open & Open & Open \\
\hline
\end{tabular}

The period of the dry-season simulation was selected as shown in Figure 6-11, spanning from hour 3463 through 5414.5 (model time is referenced to the beginning of 2012). During that period, the operations log for the Wallisville structures showed that the only combinations that occurred were as shown in Table 8-2. Structure A was always closed during the simulation period.

The lock was never opened without having the salt-barrier gates opened as well. When the salt barrier is stated as open, all four of the tainter gates are fully raised out of the water, and free flow occurs through each gate bay. 
Table 8-2 Simulation segments for the dry-season simulation period. The gray shading identifies common mesh configurations.

\begin{tabular}{|l|l|l|l|l|}
\hline $\begin{array}{l}\text { Dry- } \\
\text { Simulation } \\
\text { Segment }\end{array}$ & $\begin{array}{l}\text { Starting Time (hr after } \\
\text { 0000 1 Jan 2012) }\end{array}$ & $\begin{array}{l}\text { Ending Time }(\mathrm{hr} \text { after } \\
\text { 0000 1 Jan 2012) }\end{array}$ & $\begin{array}{l}\text { Duration } \\
(\mathrm{hr})\end{array}$ & $\begin{array}{l}\text { Mesh } \\
\text { Condition }\end{array}$ \\
\hline Dry 1 & 3463 & 3967 & 504.00 & LXBXAX \\
\hline Dry 2 & 3967 & 4111 & 144.00 & LOBOAX \\
\hline Dry 3 & 4111 & 4111.75 & 0.75 & LXBOAX \\
\hline Dry 4 & 4111.75 & 4664.25 & 552.50 & LXBXAX \\
\hline Dry 5 & 4664.25 & 4737.25 & 73.00 & LOBOAX \\
\hline Dry 6 & 4737.25 & 4738.25 & 1.00 & LXBOAX \\
\hline Dry 7 & 4738.25 & 5414.5 & 676.25 & LXBXAX \\
\hline Total Simulation Time & & 1951.50 & \\
\hline
\end{tabular}

Estimation of flow through partially open salt barrier for the dry-season simulations

To perform the dry-season simulations, the flow through a partially closed salt barrier was needed. This flow, during periods when the gates were only partially open, was estimated by using a tainter gate rating curve. The rating curve for the tainter gates is based on WES's Hydraulic Design Criteria Chart 320-8 with its associated narrative (U.S. Army Engineer Waterways Experiment Station (WES) 1952). The Chart and associated narrative apply to tainter gates in open channels discharging submerged flows.

The general tainter gate (Figure 8-8) rating curve (in English units) per gate is

$$
\mathrm{Q}=\mathrm{C}_{\mathrm{s}} \mathrm{Lh}_{\mathrm{s}} \sqrt{2 g h}
$$

where:

$Q=$ discharge, $\mathrm{cms}$

$C_{s}=$ submerged-flow discharge coefficient, a function of the sill submergence-gate opening ratio

$L$ = bay width, $\mathrm{m}$

$h_{s}=$ tail water depth over sill, $\mathrm{m}$

$g=$ acceleration of gravity, $\mathrm{m} / \mathrm{sec}^{2}$

$h=$ total head difference, upstream to downstream, $\mathrm{m}$. 
Figure 8-8 Definition sketch for tainter gate in open-channel flow.

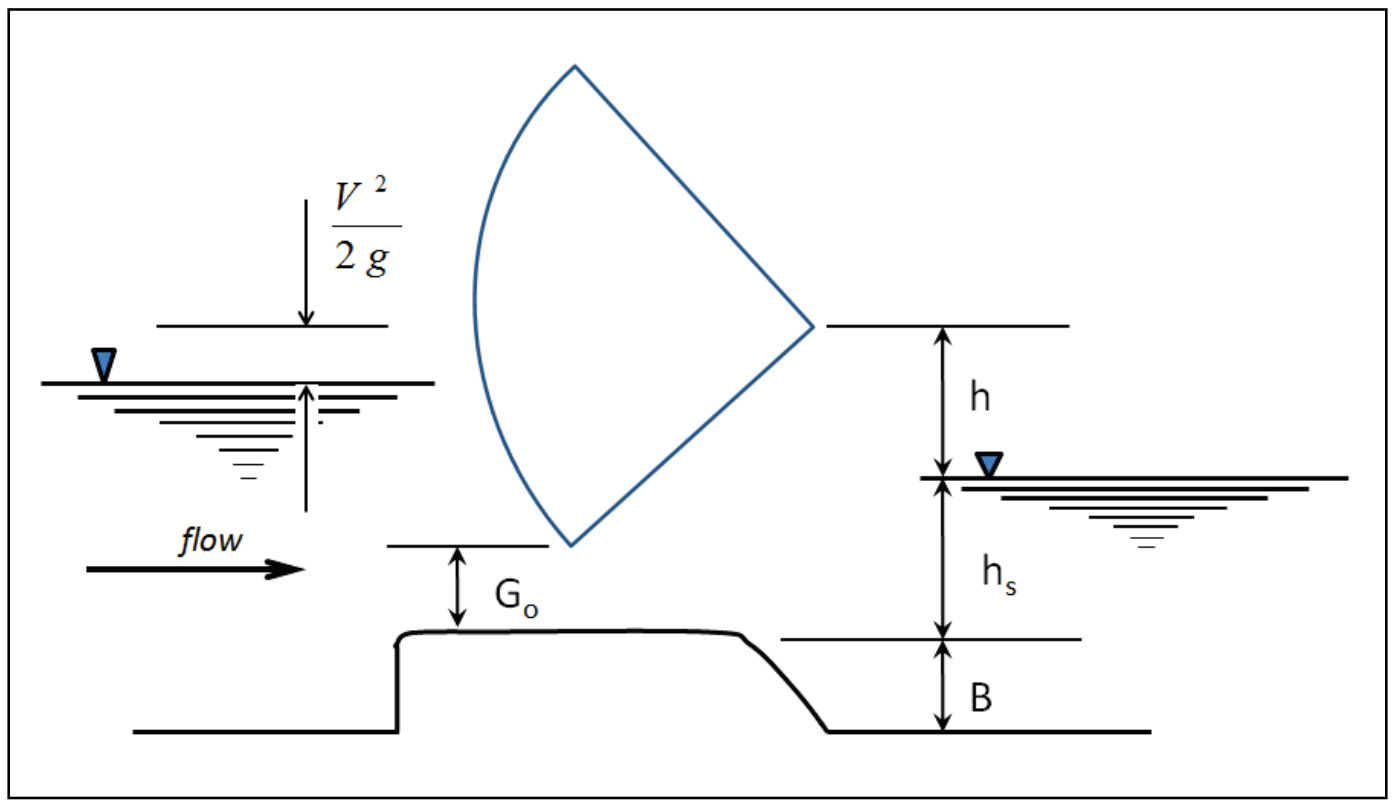

The reference six-curve (prototype) within Hydraulic Design Chart 320-8 (WES 1952) was used to develop an approximate relationship between $h_{s} / G_{o}$ and $C_{s}$, where $G_{o}$ is the gate opening:

$$
\mathrm{C}_{\mathrm{s}}=\left[0.85 /\left(\mathrm{h}_{\mathrm{s}} / \mathrm{G}_{\mathrm{o}}\right)\right]^{0.917}
$$

The applicability of the approximate relationship of Equation 8-2 is limited to when $h_{s} / G_{o}$ is greater than approximately three. The bottom edge elevation of a fully open gate is $2.74 \mathrm{~m}$ National Geodetic Vertical Datum (NGVD), and the sill elevation is $-3.7 \mathrm{~m}$ NGVD. Therefore, the gate opening should be $<2.1 \mathrm{~m}$ for Equation 8-2 to be applicable. For the operation of the gate during the dry season of 2012, the maximum partial gate opening was only $0.91 \mathrm{~m}$. Therefore, Equation 8-2 is appropriate. Substituting Equation 8-2 into Equation 8-1 yields, after expanding terms and rearranging,

$$
\mathrm{Q}=3.816 \mathrm{~L} \mathrm{G}_{\mathrm{o}}^{0.917}\left(\mathrm{G}_{\mathrm{ds}}-\mathrm{SILL}\right)^{0.083}\left(\mathrm{G}_{\mathrm{us}}-\mathrm{G}_{\mathrm{ds}}\right)^{0.5}
$$


where:

$G_{d s}=$ downstream total energy head, $\mathrm{m}$

$G_{u s}=$ upstream total energy head, $\mathrm{m}$

SILL = elevation of the sill, $\mathrm{ft}$ ( $-3.7 \mathrm{~m}$ NGVD).

The discharge estimate from Equation 8-3 is applied to each of the four tainter gates within the Wallisville salt barrier, each with a bay width $\mathrm{L}=$ $14 \mathrm{~m}$.

For the dry season of 2012, the water surface elevations were recorded both upstream and downstream of the structure. Because of the limited flows, the velocity head was assumed to be negligible. The operational sequencing for the season was obtained from CESWG (Charles Scheffler, CESWG-EC) in the form of the gate opening settings for all four bays of the structure. The computed flows through the structure are presented in Figure 8-9. During the summer of 2012, the structure was operated to keep the water levels down for ongoing construction work on bank-protection sheet piling upstream of the structure. The releases between hours 4500 to 5000 were generally for that purpose.

Figure 8-9. Flow through the salt-barrier structure estimated by Equation 8-3.

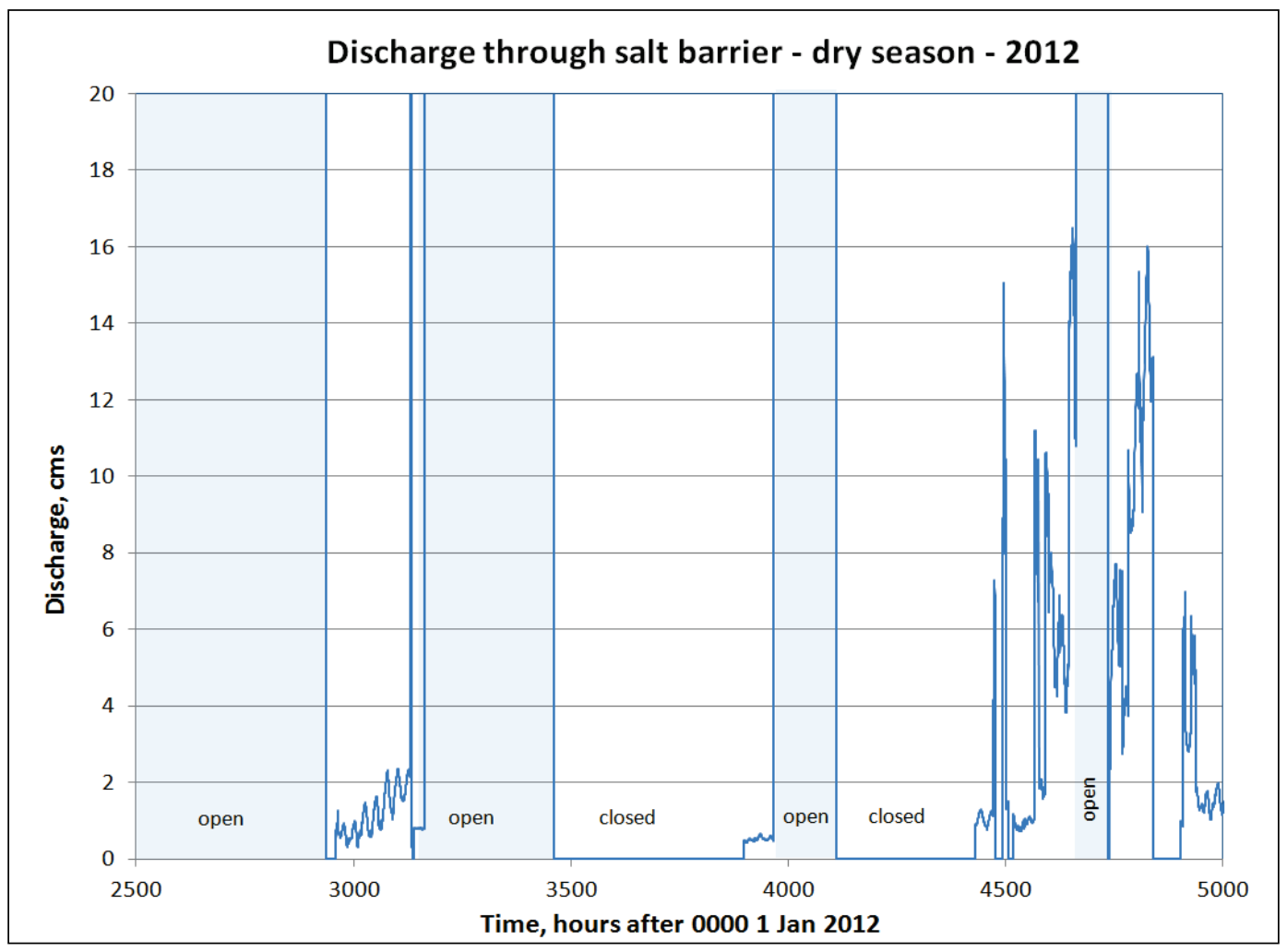


During periods when tainter gates were opened partially, typically one or two gates opened just a few feet. The overall structure in the model was configured as closed, and the estimated discharge through the structure was estimated from analytical equations.

Similarly, when the lock is stated as open, both gates are fully open, allowing free flow through the lock chamber. When the lock is closed, but navigation is locked through the structure, there will be a net flow through the lock that is a function of the head difference across the structure. During daylight hours during the dry season, the lock is operated hourly.

\section{Estimation of flow through lock during operations for the dry-season simulations}

Flow resulting from locking operations was also needed. Conventional lock operation, where one gate is opened to allow boat traffic to enter the lock chamber then closed before the other gate is opened, will result in a net flow through the lock that is the product of the head difference across the lock and the surface area of the lock chamber. The total volume passing through the lock during the day will then be the volume for the locking operation times the locking frequency. This can be converted to an equivalent net uniform discharge that can be applied during the periods of locking operations:

$$
\mathrm{Q}_{\mathrm{eq}}=\mathrm{f}_{\mathrm{o}} \mathrm{A}_{\text {lock }}\left(\mathrm{h}_{\mathrm{us}}-\mathrm{h}_{\mathrm{ds}}\right)
$$

where:

$$
\begin{aligned}
Q_{e q} & =\text { equivalent uniform discharge } \\
f_{o} & =\text { locking frequency, } \text { sec }^{-1} \\
A_{l o c k} & =\text { area of lock chamber }=12,700 \mathrm{~m}^{2} \\
h_{u s} & =\text { water surface elevation upstream of the lock, } \mathrm{m} \\
h_{\mathrm{ds}} & =\text { water surface elevation downstream of the lock, } \mathrm{m} .
\end{aligned}
$$

The area of the locking chamber was estimated via Google Earth. The locking frequency during the periods of operation in the summer of 2012 was on the hour between 7 a.m. and 8 p.m. Expressing once an hour as a frequency would be $\mathrm{f}_{\mathrm{o}}=1 / \mathrm{hr}=1 / 3600 \mathrm{sec}=0.000278 \mathrm{sec}^{-1}$. One 
locking per hour with a $0.3 \mathrm{~m}$ head difference would be an equivalent uniform discharge of $1.08 \mathrm{cms}$. This flow rate is of the same order of magnitude as having one tainter gate bay of the salt barrier open approximately $0.23 \mathrm{~m}$. The time series of the equivalent uniform flows through the lock are presented in Figure 8-10. During the hours of 8 p.m. through 7 a.m. the next morning, the locking frequency was set to zero.

Figure 8-10. The time series of equivalent net flow through the Wallisville lock.

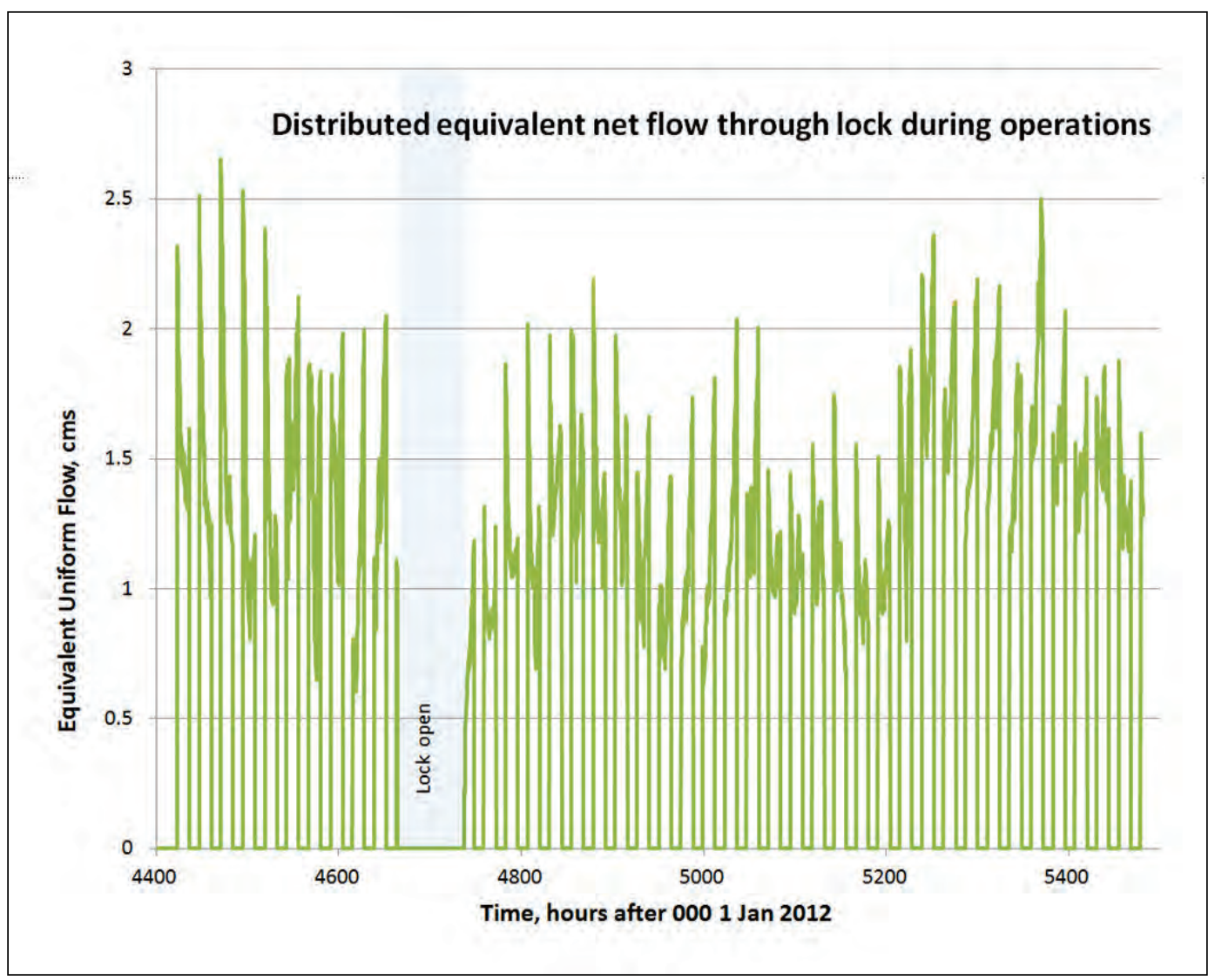

\section{Sediment run initialization for dry-season simulations}

The initial bed was the result of the wet-season bed initialization simulation. By using this condition, a direct comparison between the wetand dry-season effects on the bed can be made. The sediment transport simulations for the dry season involved the construction of a hotstart file from the end of each dry simulation segment (dry-1 through dry-6; see Table 8-2), which included the hydrodynamic conditions as well as the sediment transport variables. These variables included

- water depth,

- water velocities $(\mathrm{x}, \mathrm{y}, \mathrm{z})$, 
- bed layer thickness for layers 1 through 10 ,

- bed layer sediment size distribution for layers 1 through 10,

- concentration in suspension for six constituents (five sediment classes (Table 7-2) and stream-wise vorticity),

- bed displacement,

- active bed layer thickness, and

- active-layer sediment size distribution.

Each of the variables just presented is specified for every computational node within the model mesh.

The hotstart file created from the results at the end of the previous simulation segment becomes the initial conditions file for the next simulation segment. This segmented simulation procedure was developed to address the problem that $\mathrm{AdH}$ does not allow for the boundary condition specifications to change during a simulation (e.g., changing from an open-flow condition through the structures to an internal-discharge specification).

\section{Salinity modeling}

The procedure required for the salinity intrusion modeling during the dry season was identical to that used for the sediment transport, but with fewer variables required for the hotstart file since the sediment and salinity will not be modeled together:

- water depth

- water velocities $(\mathrm{x}, \mathrm{y}, \mathrm{z})$

- salinity. 


\section{Results}

\section{Wet-season sedimentation}

\section{Existing conditions}

Figure 9-1 presents the deposition and erosion contours in the study area, using a contour interval from - 1 to $1 \mathrm{~m}$, with positive (red) denoting deposition and negative (blue) erosion. These results are for the entire wetseason simulation showing the net results after 2274 hours ( 94.75 days) of simulation. There is deposition extending from the point between the lock channel and the salt-barrier channel, on the western side of the salt-barrier channel, and along the northern shore in the eastern end of ORCO. Some erosion is seen in the middle of the lock channel and also in the salt-barrier channel. There was additional deposition in the area of the shoal in upper Trinity River, and moderate erosion is seen at the upstream end of the shoal and along the western side of the Trinity River below the confluence.

Figure 9-1 Deposition and erosion for the wet season for existing conditions in the vicinity of the primary channel confluence.

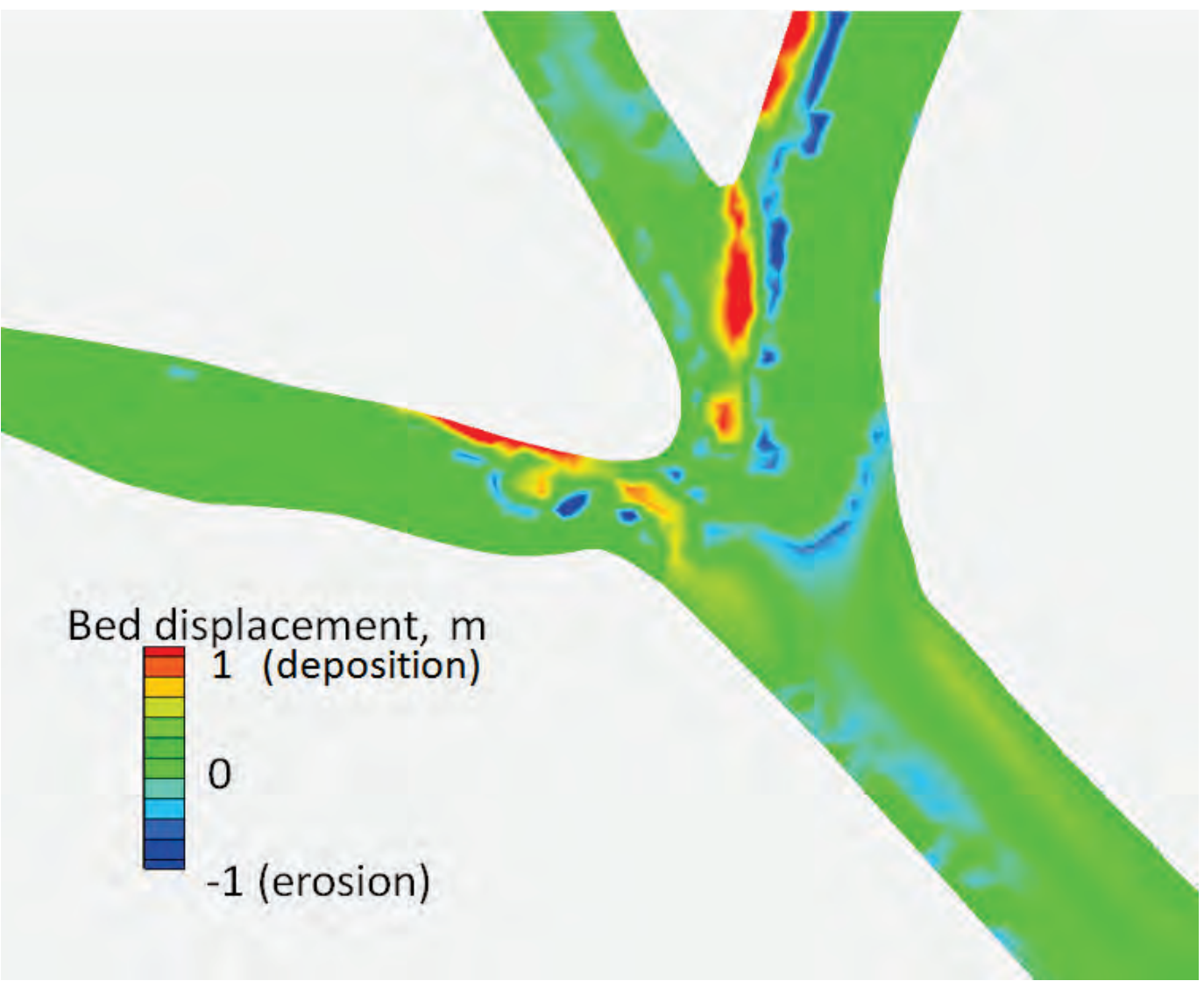


Figure 9-2 shows the existing conditions deposition and erosion patterns over the full Trinity River delta. The flows being diverted down ORCO appear to be transporting the majority of the sediment load. There are significant shoals in Long Island Bayou, just below ORCO on the east bank and again just downstream of the next major bayou. As the flow is diverted, the normal response is a drop in the transport capacity of the remaining flow in the main channel (Letter et al. 2008). Deposition is the result of that loss in transport capacity.

There are additional shoals forming along the lower Trinity River, again just downstream of losses of flow (J ack's Pass, Lighthouse Pass) and in several bends in the Trinity River where the stream-wise vorticity creates deposition potential.

\section{Dredging the shoal and placing material into ORCO}

The alternative of dredging the shoal and placing the material in ORCO has the same general patterns as the existing condition (Figure 9-3). However, the magnitude of the deposition is everywhere diminished. In addition, there is a significant scouring at the entrance to ORCO. The erosion along the western side of the Trinity River below the confluence is more extensive and continuous.

The deposition and erosion patterns over the full delta (Figure 9-4) show that the dredge-and-fill alternative does reduce the sediment transport through ORCO, based on the reduction of the size of the shoal in Long Island Bayou. There is also erosion in J ack's Pass as the result of more flows there, but a local shoal develops in the lower end of J ack's Pass.

\section{Closure of ORCO by $\mathbf{2 0} \%$}

The 20\% closure of the ORCO (Figure 9-5) did not significantly change the deposition patterns outside of ORCO. The dike on the northern side of the ORCO channel acts as a barrier with the development of a shoal on its leeward side that extends well into ORCO.

The overall deltaic erosion and deposition patterns for the $20 \%$ closure of ORCO (Figure 9-6) are not qualitatively different than seen in either the existing or the dredge-and-fill alternatives. The shoals are located in the same places. There are some subtle differences in the erosion and deposition in J ack's Pass, with the $20 \%$ closure having erosion in the upper end of Jack's Pass, with a shoal in the lower end. 
Figure 9-2 Deposition and erosion over the Trinity River delta for the wet season for existing conditions.

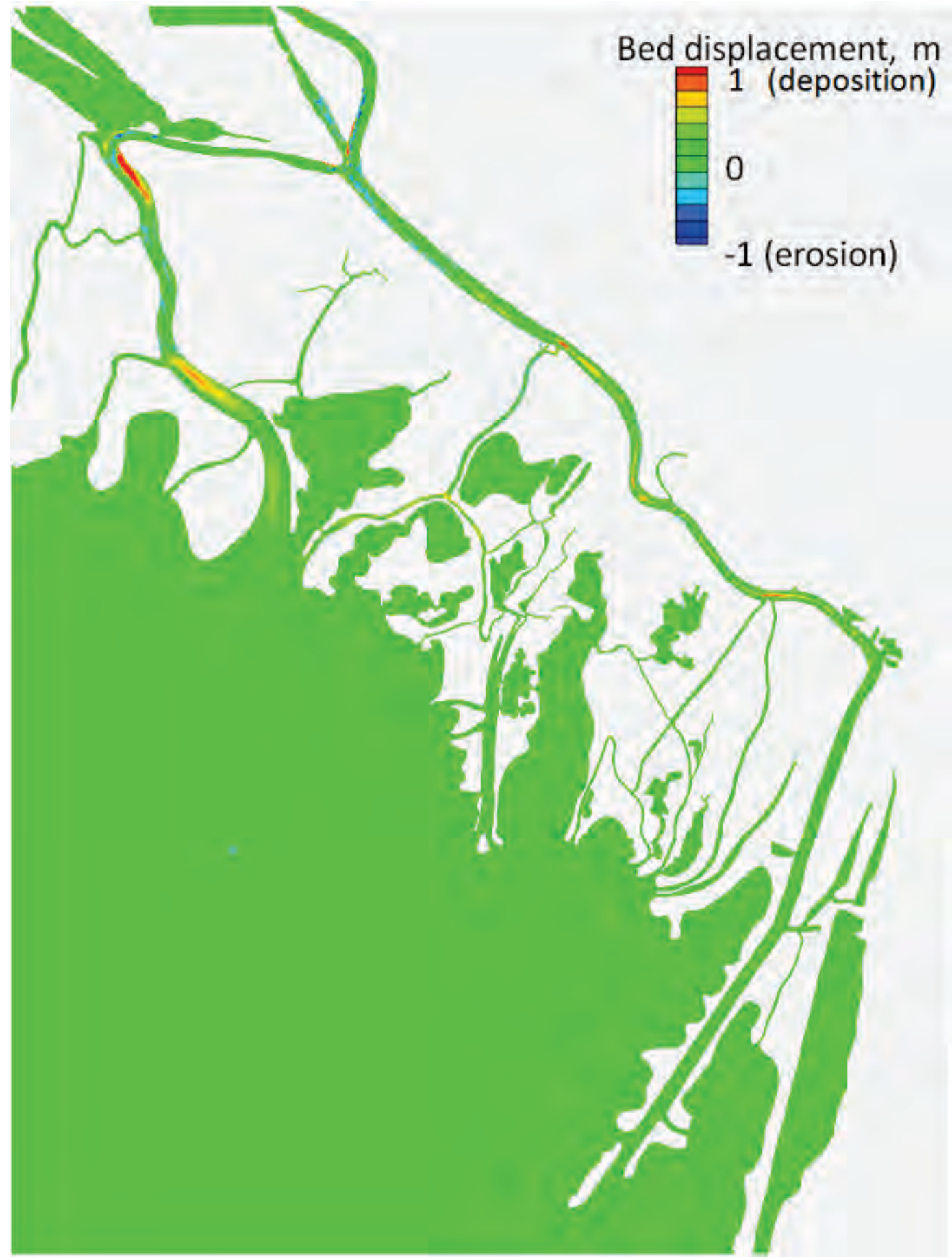


Figure 9-3 Deposition and erosion for the wet season for dredging the Trinity River and placing the material uniformly into ORCO in the vicinity of the primary channel confluence.

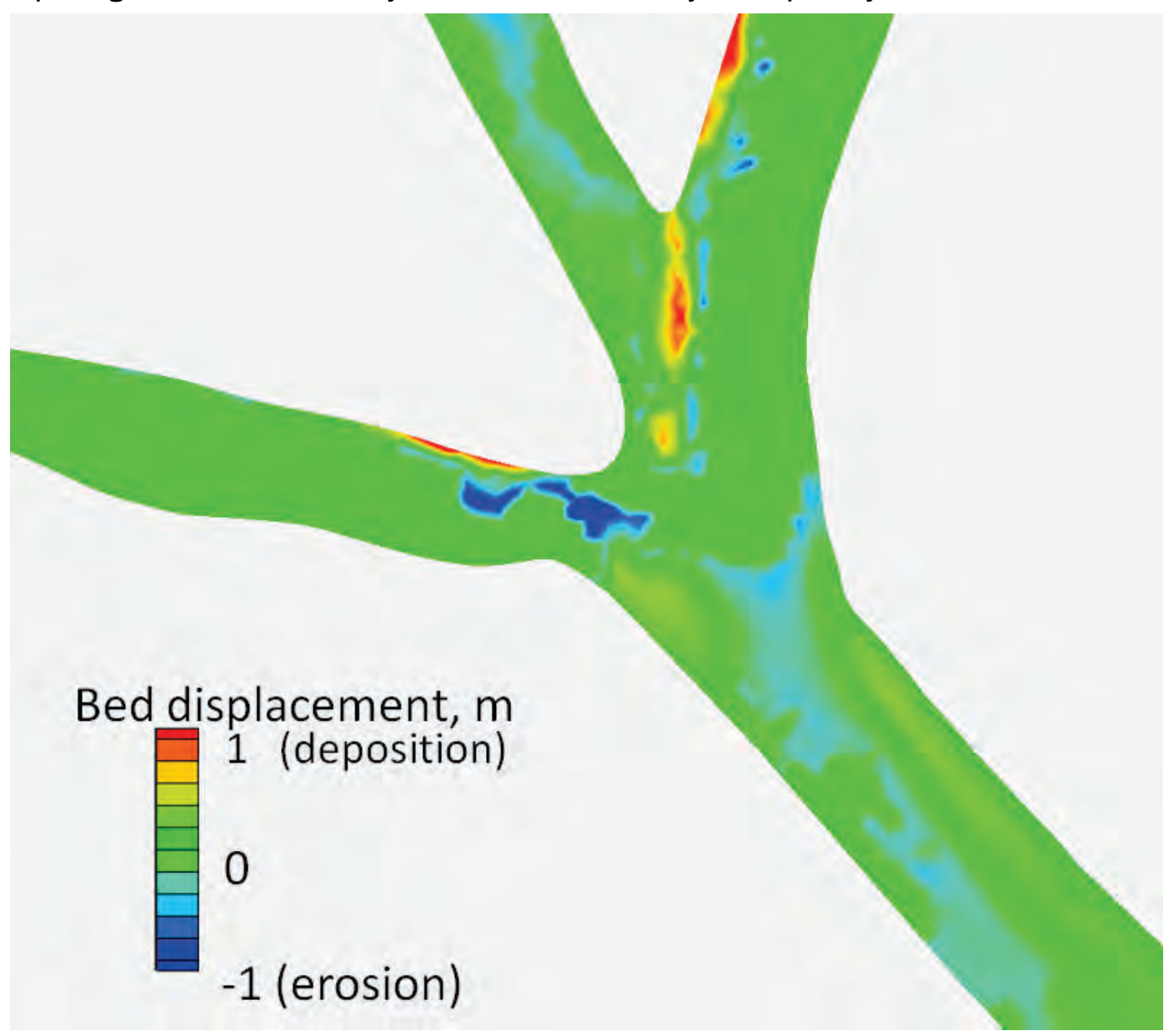

\section{Closure of ORCO by $\mathbf{4 0} \%$}

The $40 \%$ closure of the ORCO seemed to amplify the deposition patterns outside of ORCO seen in the $20 \%$ closure case, making both erosion and deposition more intense without changing the locations (Figure 9-7). The shoal behind the dike on the northern side of the ORCO channel enlarged and extended farther into ORCO.

The overall deltaic bed change patterns (Figure 9-8) are similar to the other alternatives except that the erosion and deposition are becoming magnified. The deposition in the vicinity of Port Anahuac has increased. 
Figure 9-4 Deposition and erosion over the Trinity River delta for the wet season for dredging the Trinity River and placing the material uniformly into ORCO.

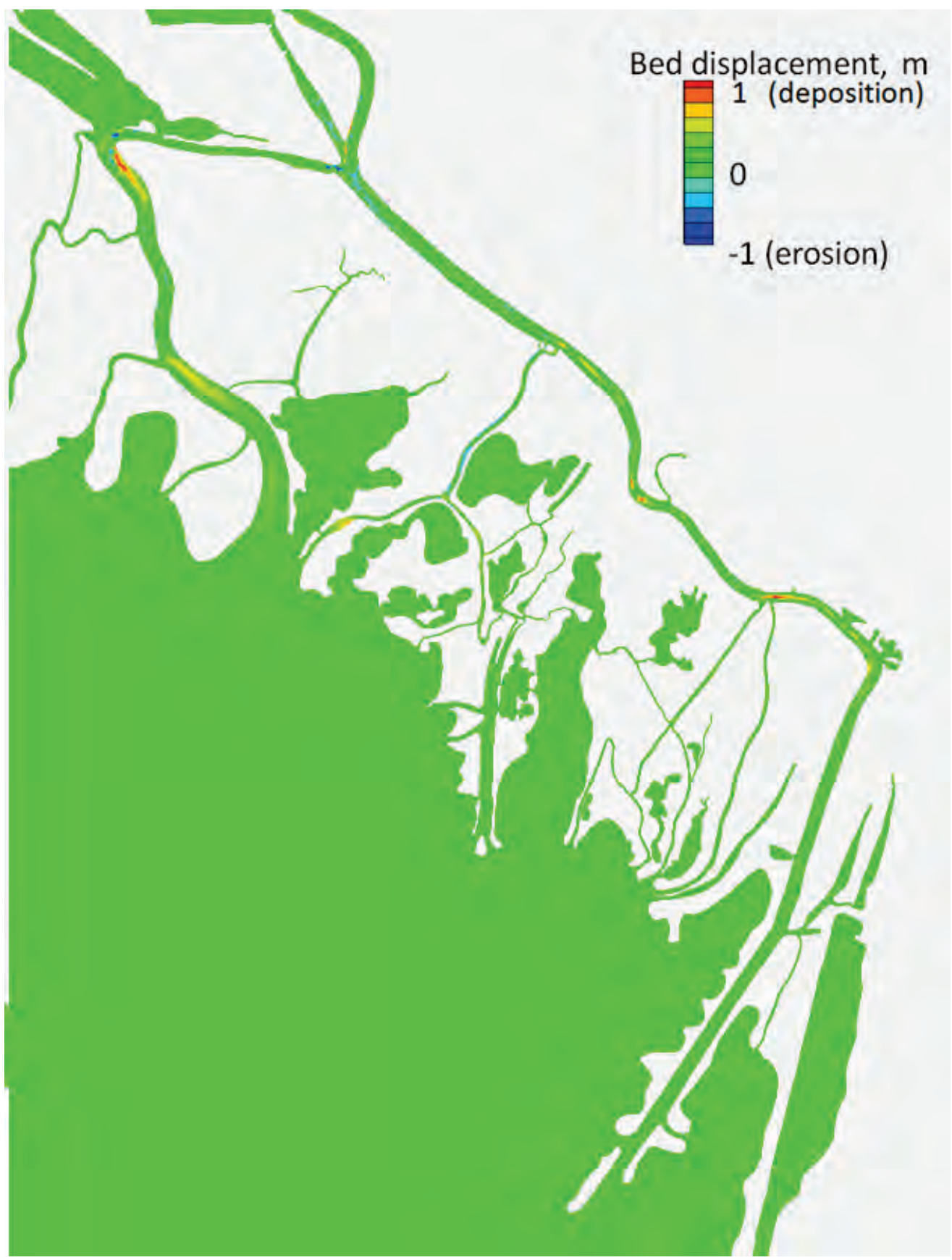


Figure 9-5 Deposition and erosion for the wet season for $20 \%$ closure of ORCO in the vicinity of the primary channel confluence.

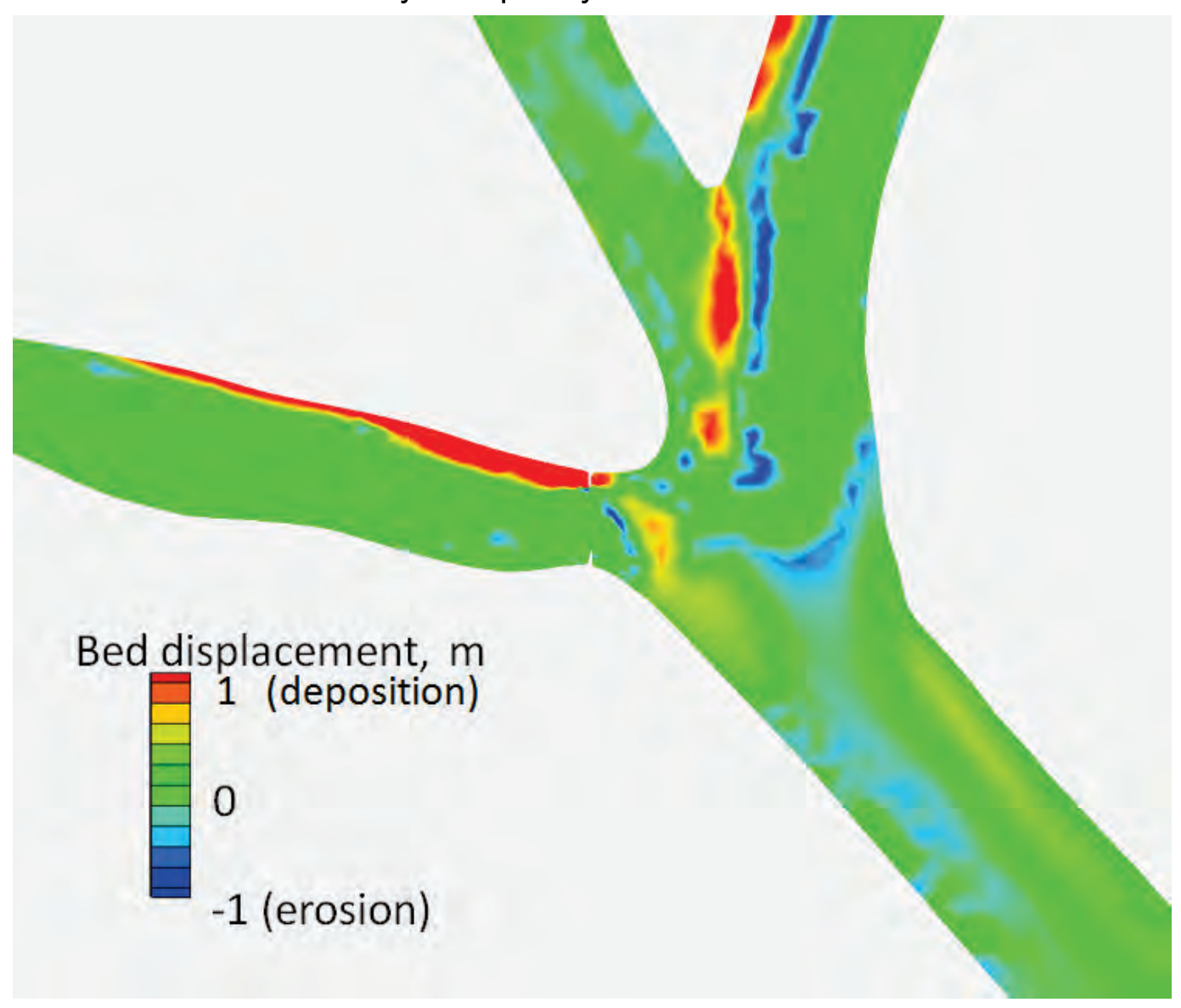

\section{Closure of ORCO by $60 \%$}

With $60 \%$ of the ORCO channel cross section blocked by the dikes (Figure 9-9), there are some significant changes in the erosion and deposition patterns. The crescent-shaped shoal at the head of ORCO just east of the dikes is significant, and the erosion in the upper end of Trinity River has spread through the area where the shoal had formed for existing conditions.

For the overall delta, the bed change patterns for the $60 \%$ closure of ORCO (Figure 9-10) begin to show some more significant differences from the other alternatives. More erosion in the western end of ORCO is seen, and there is increased deposition in the vicinity of Port Anahuac. Erosion in the upper end of J ack's Pass has moved deeper into the pass, beyond the next channel bifurcation. 
Figure 9-6 Deposition and erosion over the Trinity River delta for the wet season for $20 \%$ closure of ORCO.

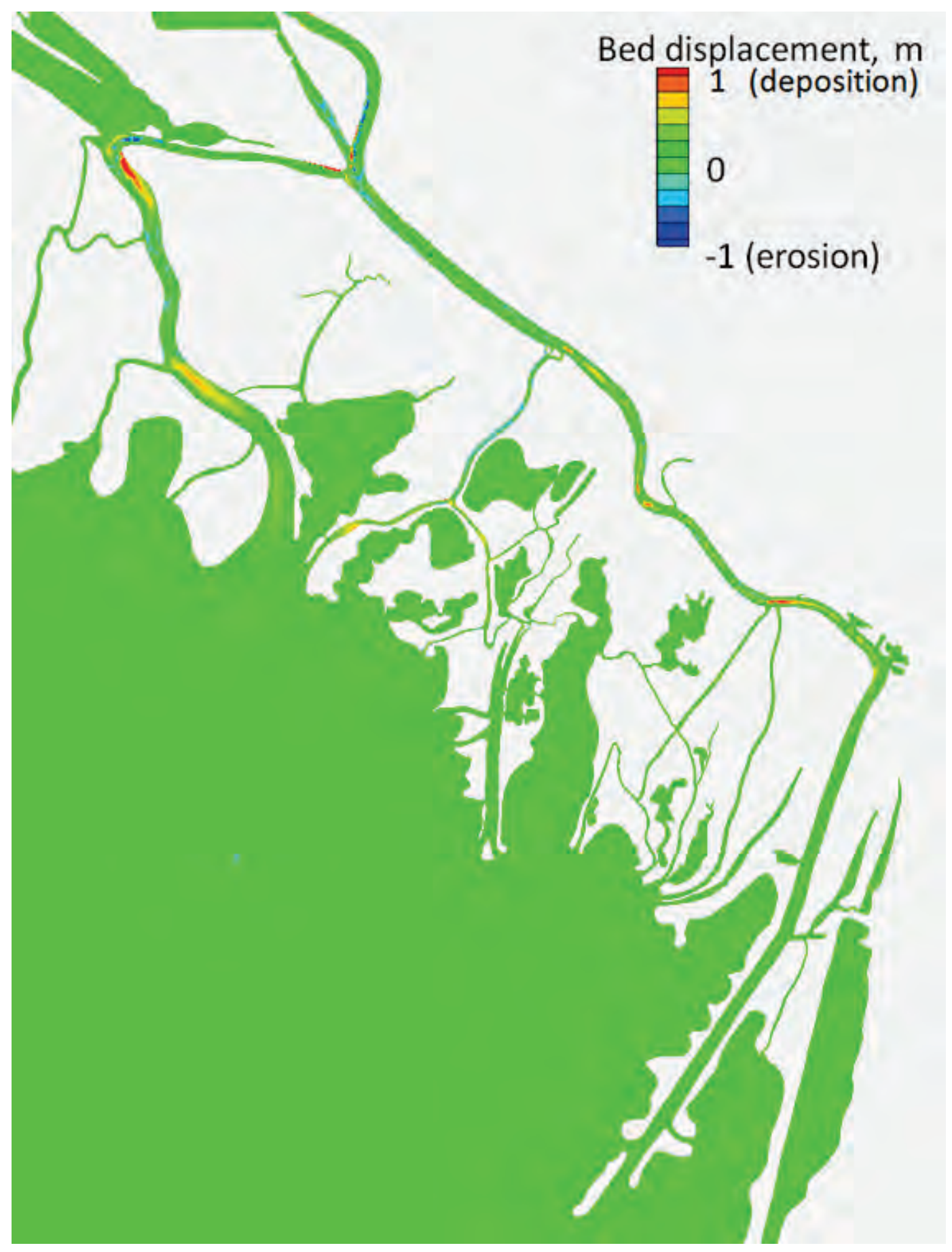


Figure 9-7 Deposition and erosion for the wet season for $40 \%$ closure of ORCO in the vicinity of the primary channel confluence.

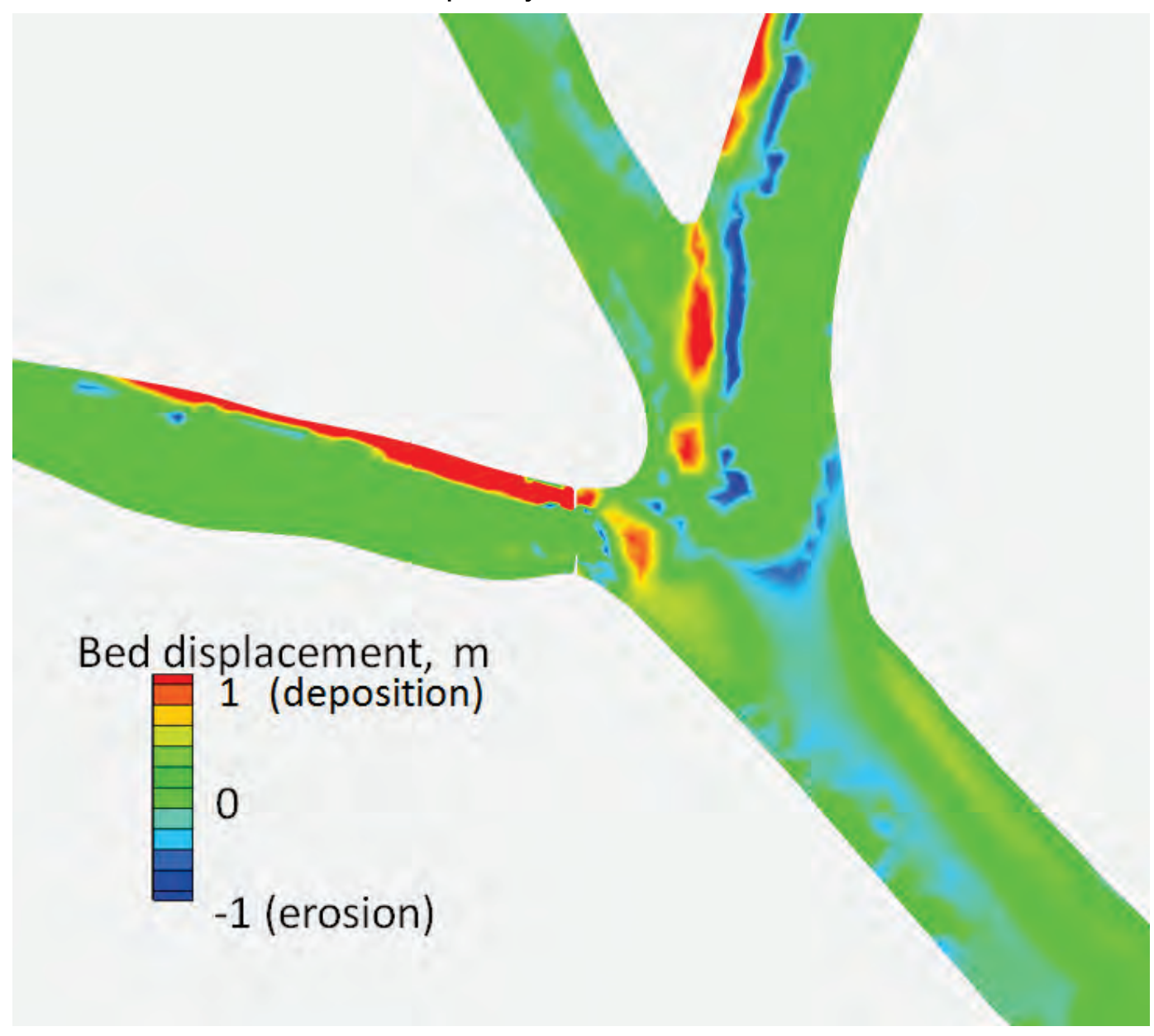

\section{Closure of ORCO by $100 \%$}

The $100 \%$ closure of ORCO (run during the sensitivity tests) is presented in Figure 9-11. The closure clearly provides erosion of the problem shoal well down into the Trinity River. It is anticipated that rerouting the flows completely back down the Trinity River will have far-reaching impacts. The complete closure of ORCO has a dramatic impact on the entire delta (Figure 9-12).

Erosion in the lower Trinity River is over the full cross section through Brown's Pass, and erosion is seen in some part of the cross section well beyond Port Anahuac. Also, there is significant erosion in J ack's Pass, Lighthouse Pass, Brown's Pass, and many of the secondary passes in the eastern part of the delta. The bed changes in ORCO and Long Island Bayou have disappeared. 
Figure 9-8 Deposition and erosion over the Trinity River delta for the wet season for $40 \%$ closure of ORCO.

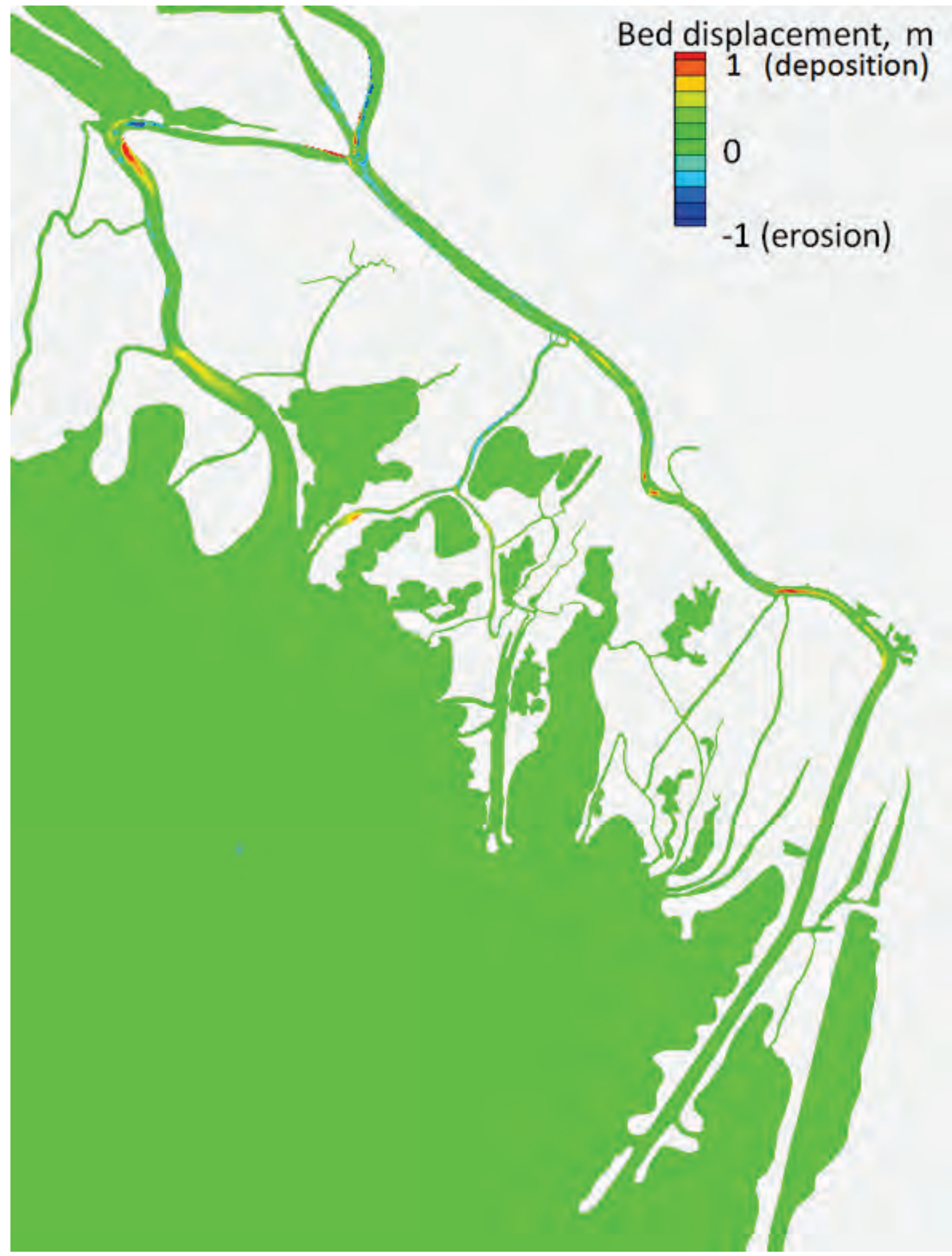


Figure 9-9 Deposition and erosion for the wet season for $60 \%$ closure of ORCO in the vicinity of the primary channel confluence.

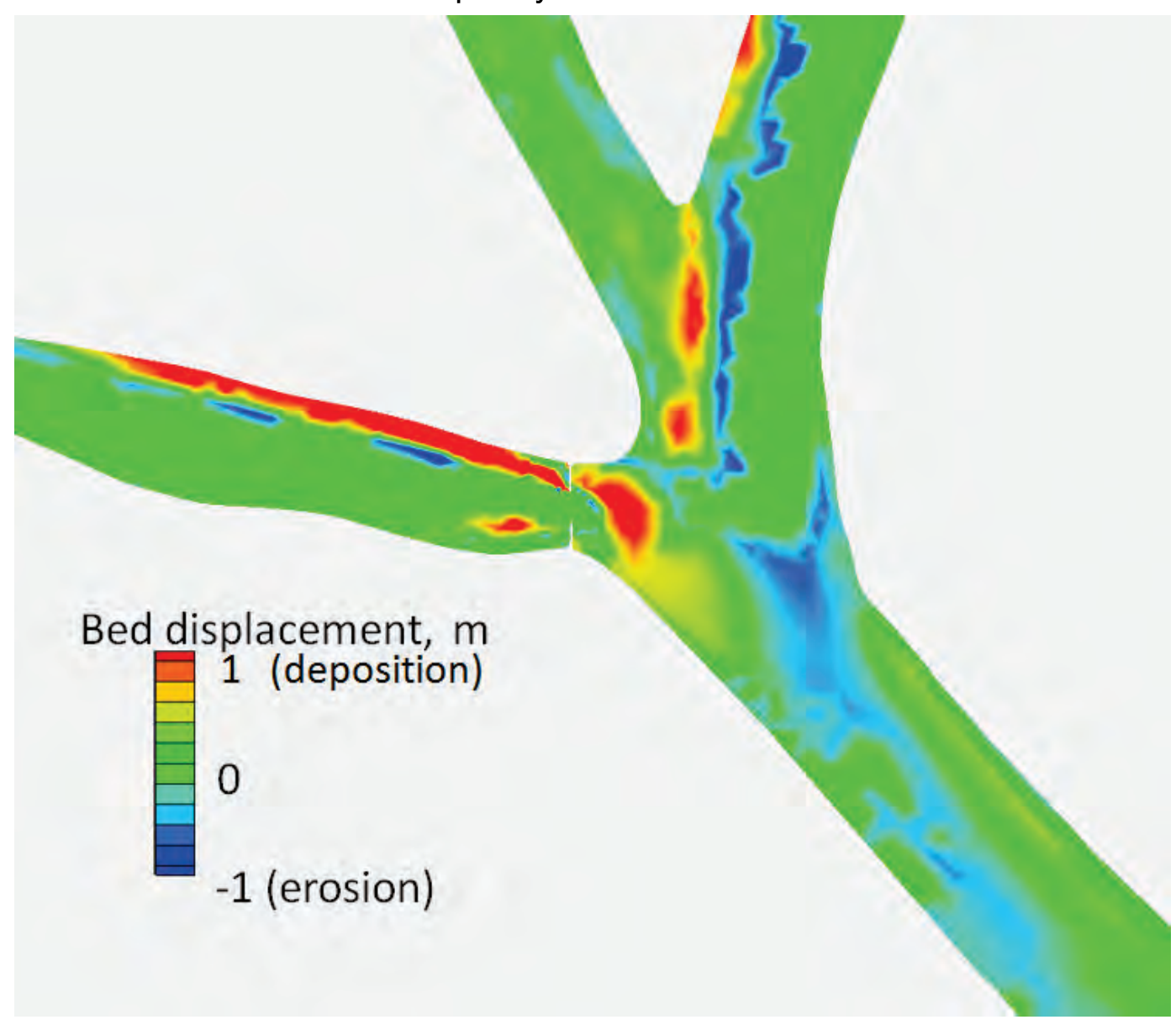

Conclusions from wet-season simulations include the following:

- Partial closure of ORCO may provide some reduction in the shoaling rate in the vicinity of the shoal, without having significant impacts farther downstream on the Trinity River.

- The dredging of the shoal and placement into ORCO does provide some limited reduction in the shoaling rate over the existing conditions.

- Complete closure of ORCO will completely eliminate the shoal at the confluence. The shoaling problem would be moved downstream to near Port Anahuac if no other controls on losses to the flows were made. 
Figure 9-10 Deposition and erosion over the Trinity River delta for the wet season for $60 \%$ closure of ORCO.

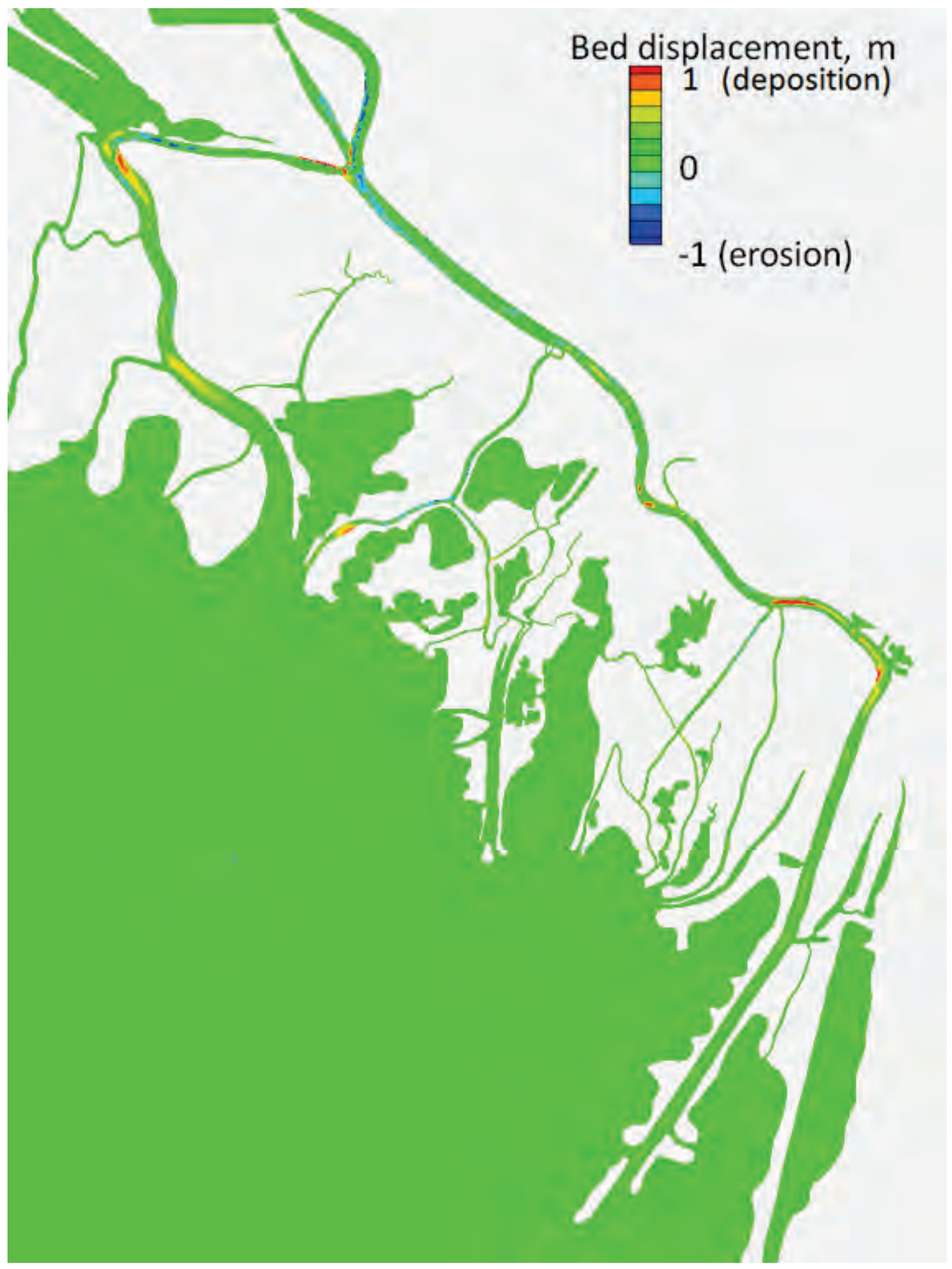


Figure 9-11 Deposition and erosion for the wet season for $100 \%$ closure of ORCO in the vicinity of the primary channel confluence.

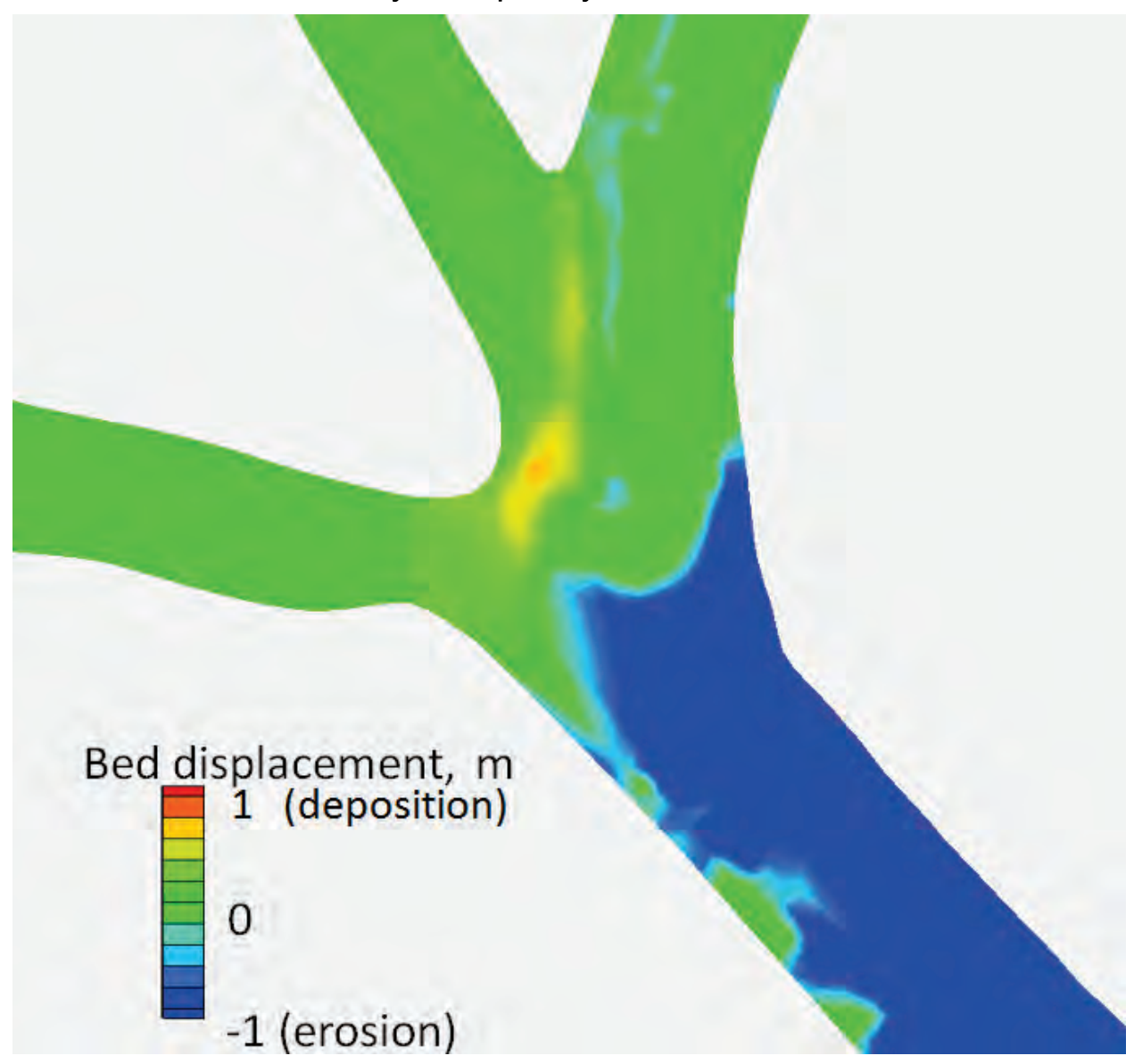

\section{Dry-season sedimentation}

The dry-season sedimentation results showed uniformly that over the duration of the dry season (2-month simulation), no significant cumulative erosion or deposition was observed in the areas of interest, particularly when compared to the wet-season sedimentation. Since the aim is to see to what extent the shoal of interest can be eroded by altering flow paths, this means that these results do not warrant extensive analysis. The magnitude of the erosion and deposition were two orders of magnitude smaller than seen in the wet season.

\section{Existing conditions}

The existing-conditions erosion and deposition in the study area are presented in Figure 9-13. The patterns of erosion and deposition are similar to those seen in the wet-season simulations (Figure 9-1 and Figure 9-2). However, in order to view the patterns, the contour range is 500 times 
smaller ( -0.002 to $0.002 \mathrm{~m}$ ). These level of changes are below the precision of the model and essentially illustrate that there is no significant change in water depths during the dry season.

Figure 9-12 Deposition and erosion over the Trinity River delta for the wet season for $100 \%$ closure of ORCO.

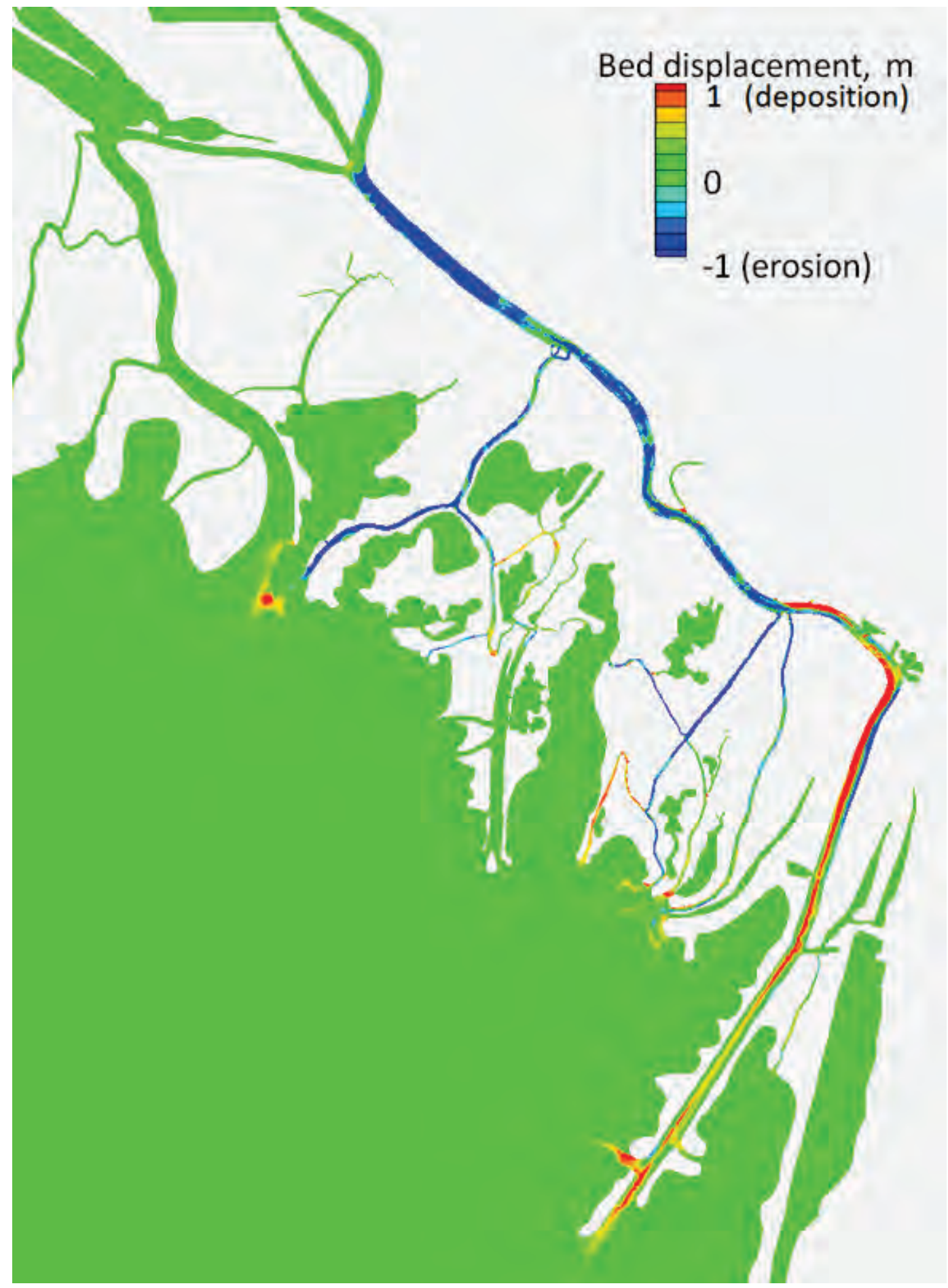


Figure 9-13 Dry-season erosion and deposition for existing conditions.

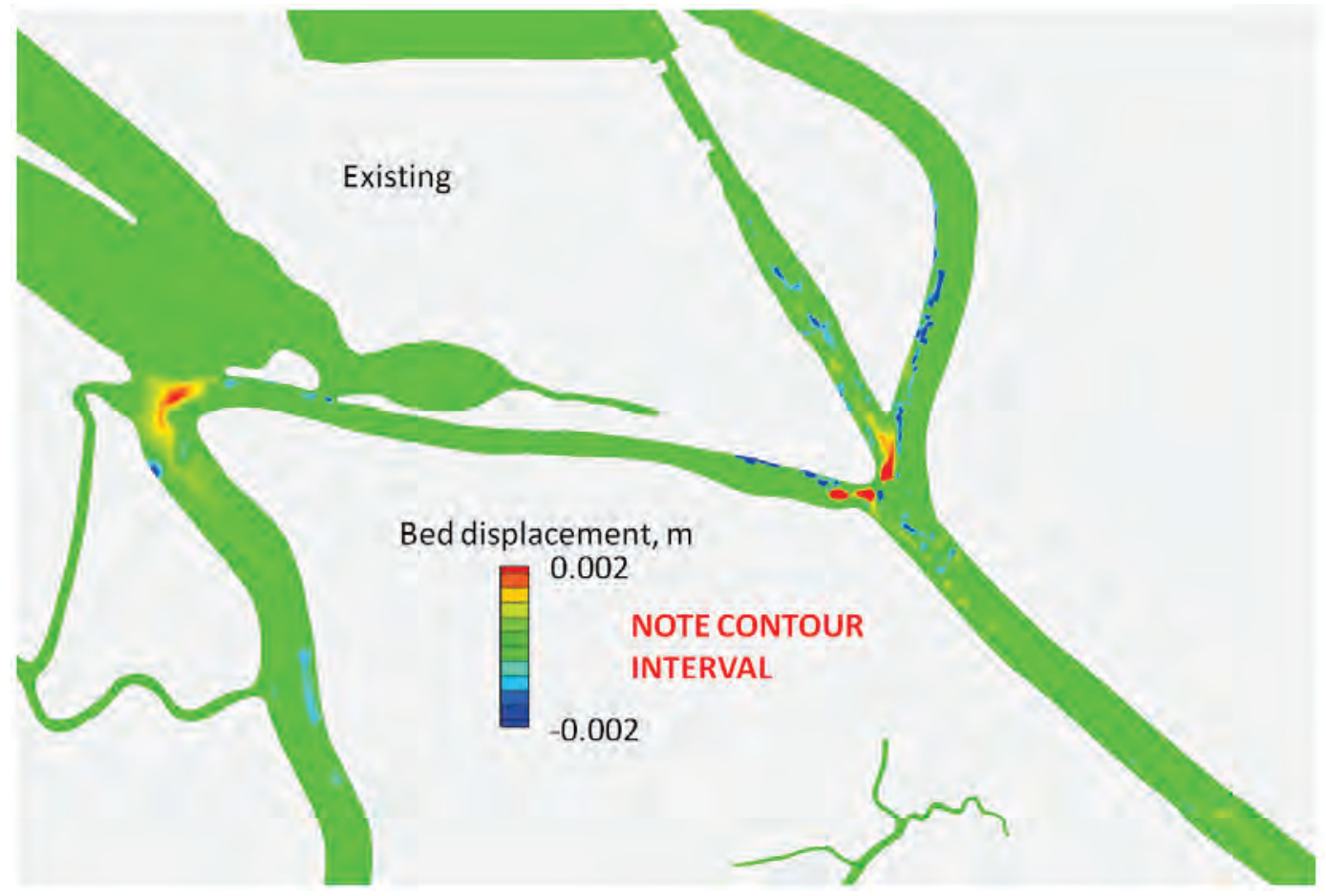

\section{Dredging the shoal and placing material into ORCO}

The dry-season erosion and deposition for the dredge-and-fill condition are presented in Figure 9-14. The bed changes for this alternative are an order of magnitude larger than the other alternatives for the dry season, but that makes them still 50 times smaller than during the wet season. The changes for the dredge-and-fill, though small, extend farther down the Trinity River and the distributary passes (Figure 9-15).

\section{Closure of ORCO by $20 \%$}

The 20\% closure of ORCO had very limited bed change (Figure 9-16). These are limited to very local changes in the vicinity of the confluence and are on the order of millimeters.

\section{Closure of ORCO by $\mathbf{4 0 \%}$}

The $40 \%$ closure erosion and deposition during the dry-season simulation is presented in Figure 9-17. The patterns also are similar to those seen during the wet-season simulation. However, once again, the changes are two orders of magnitude smaller than the wet-season changes. 
Figure 9-14 Dry-season erosion and deposition for dredge-and-fill conditions.

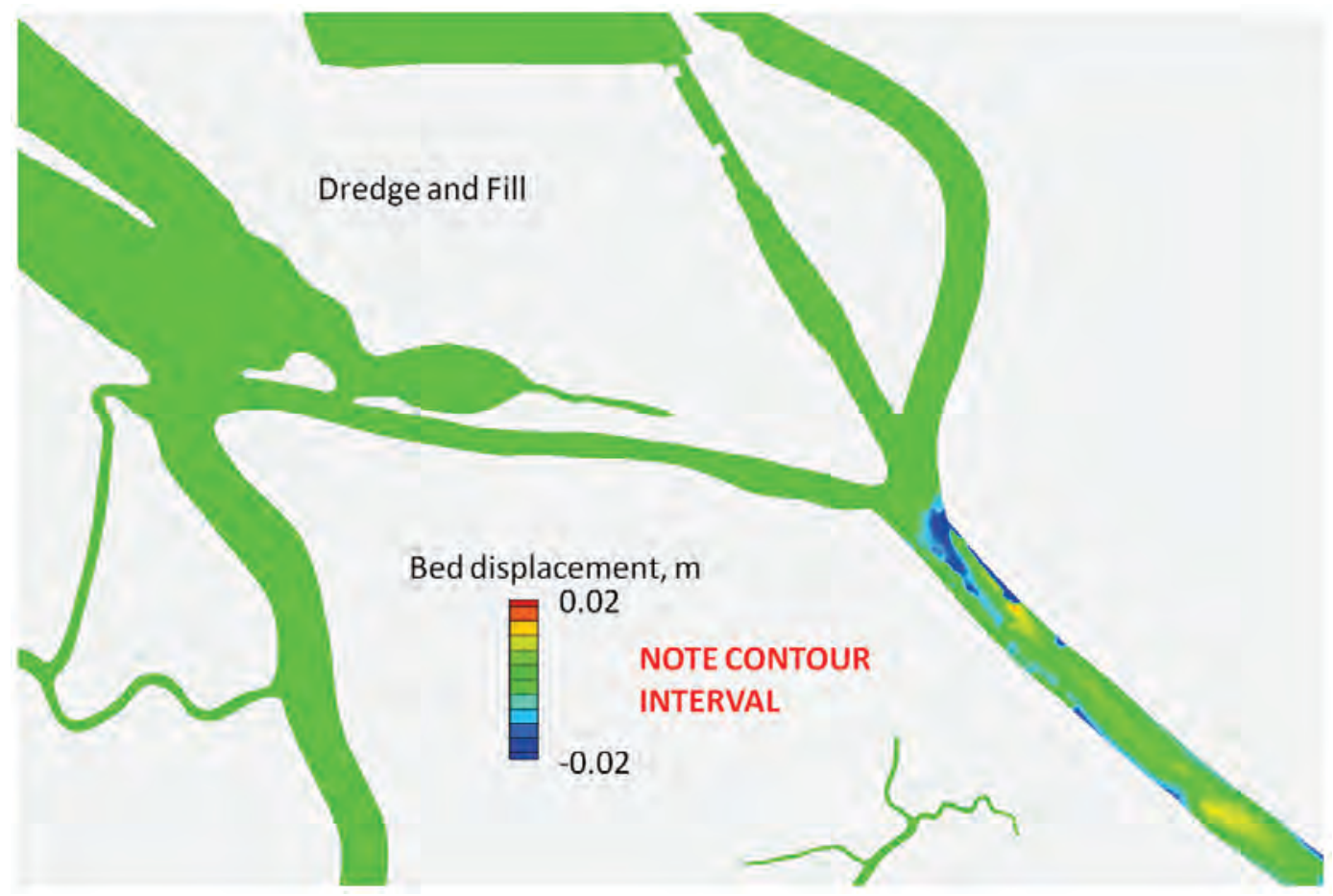

Figure 9-15 System-wide, dry-season erosion and deposition for dredge-and-fill.

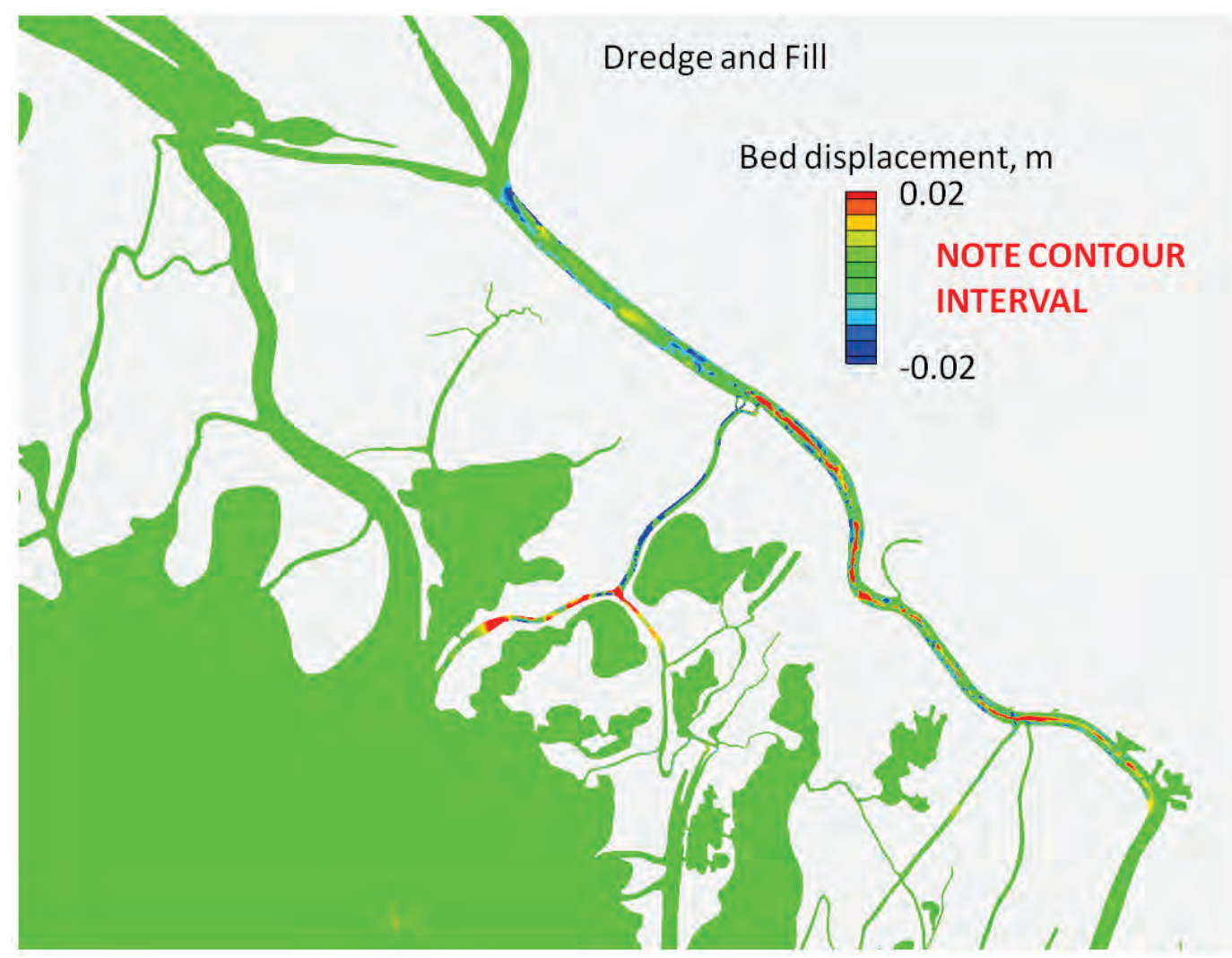


Figure 9-16 Dry-season erosion and deposition for $20 \%$ closure of ORCO.

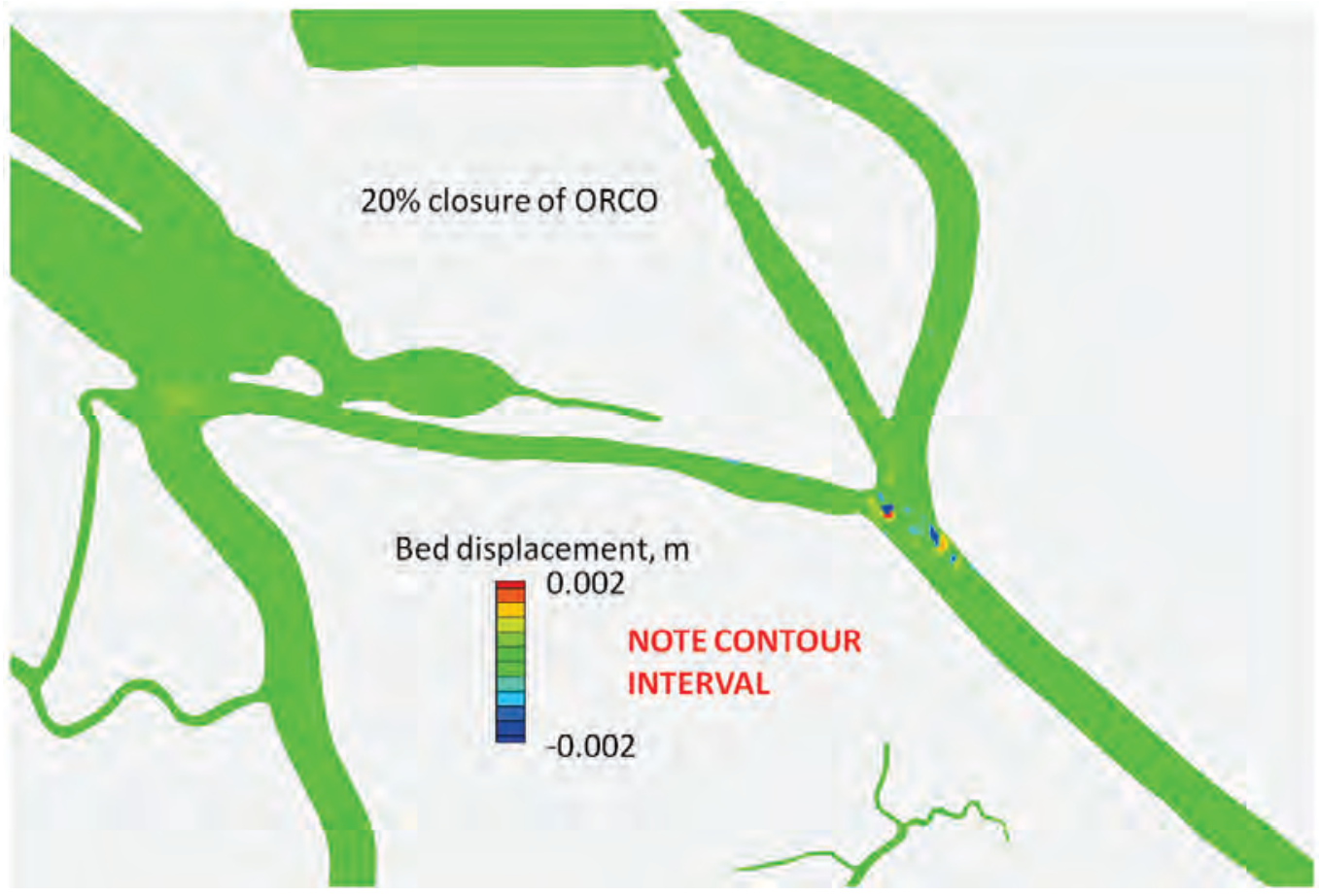

Figure 9-17 Dry-season erosion and deposition for $40 \%$ closure of ORCO.

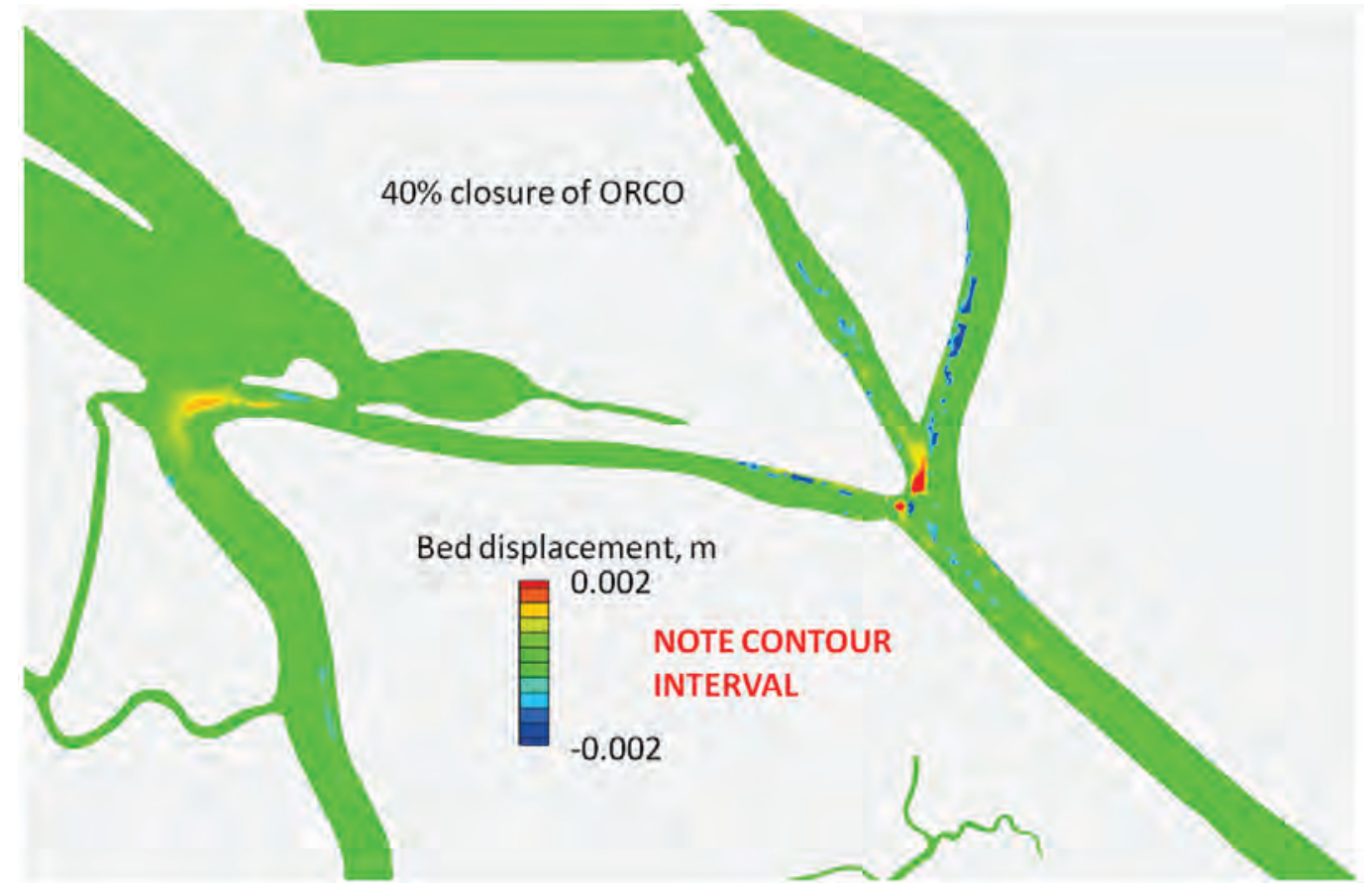




\section{Closure of ORCO by $60 \%$}

Figure 9-18 presents the dry-season erosion and deposition for the $60 \%$ closure of ORCO. These changes are limited to the vicinity of the confluence and are on the order of millimeters.

Figure 9-18 Dry-season erosion and deposition for $60 \%$ closure of ORCO.

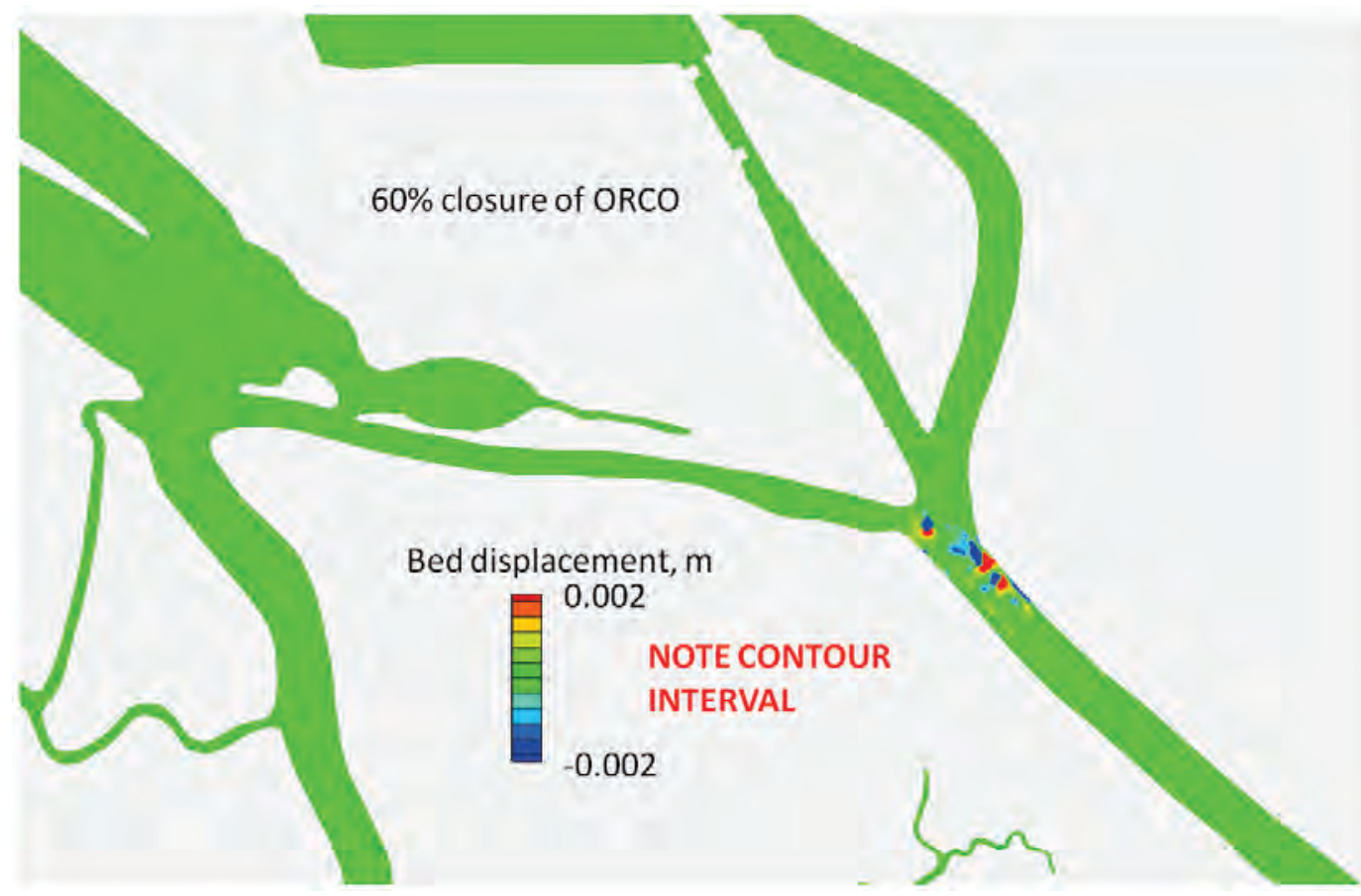

\section{Salinity intrusion}

The primary purpose of the salinity intrusion modeling is to evaluate if any of the alternatives would change the response time for salinity to encroach up the channels to the vicinity of the Wallisville structures to the level that requires operation of the structures to reduce salinity. A variation in the response time will impact the operation of the salinity barrier and lock and should be considered when analyzing the impact of the various alternatives. The 20\% ORCO closure alternative is not included in the salinity intrusion analysis.

\section{Salinity contours}

\section{Existing conditions}

The results of the salinity-intrusion simulations for existing conditions are summarized in the form of salinity contours as shown in Figure 9-19. The figure includes the result at the end of the wet-season simulation, which is 
Figure 9-19 Salinity contours for existing conditions at the end of each simulation period segment.
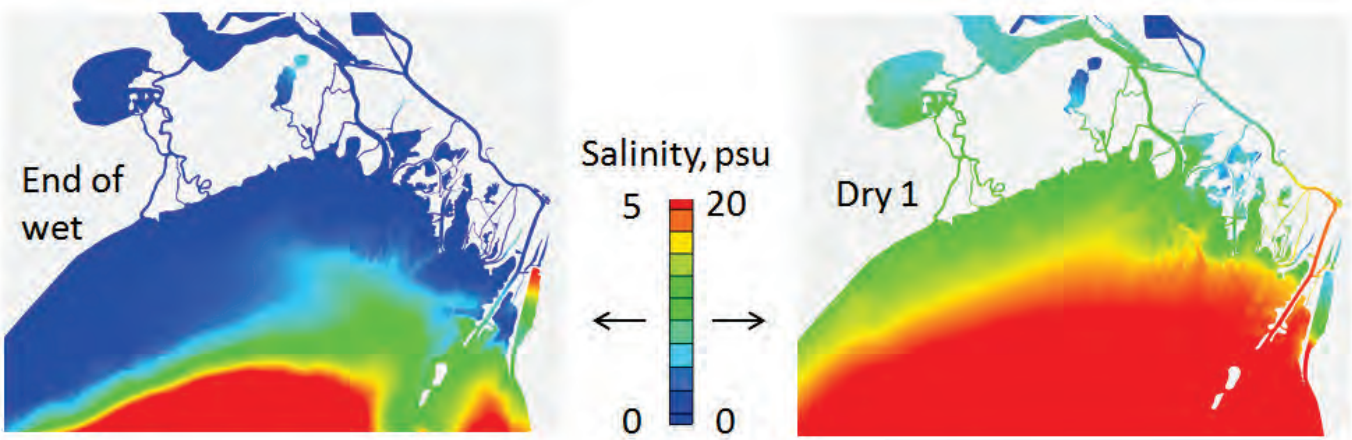

Existing
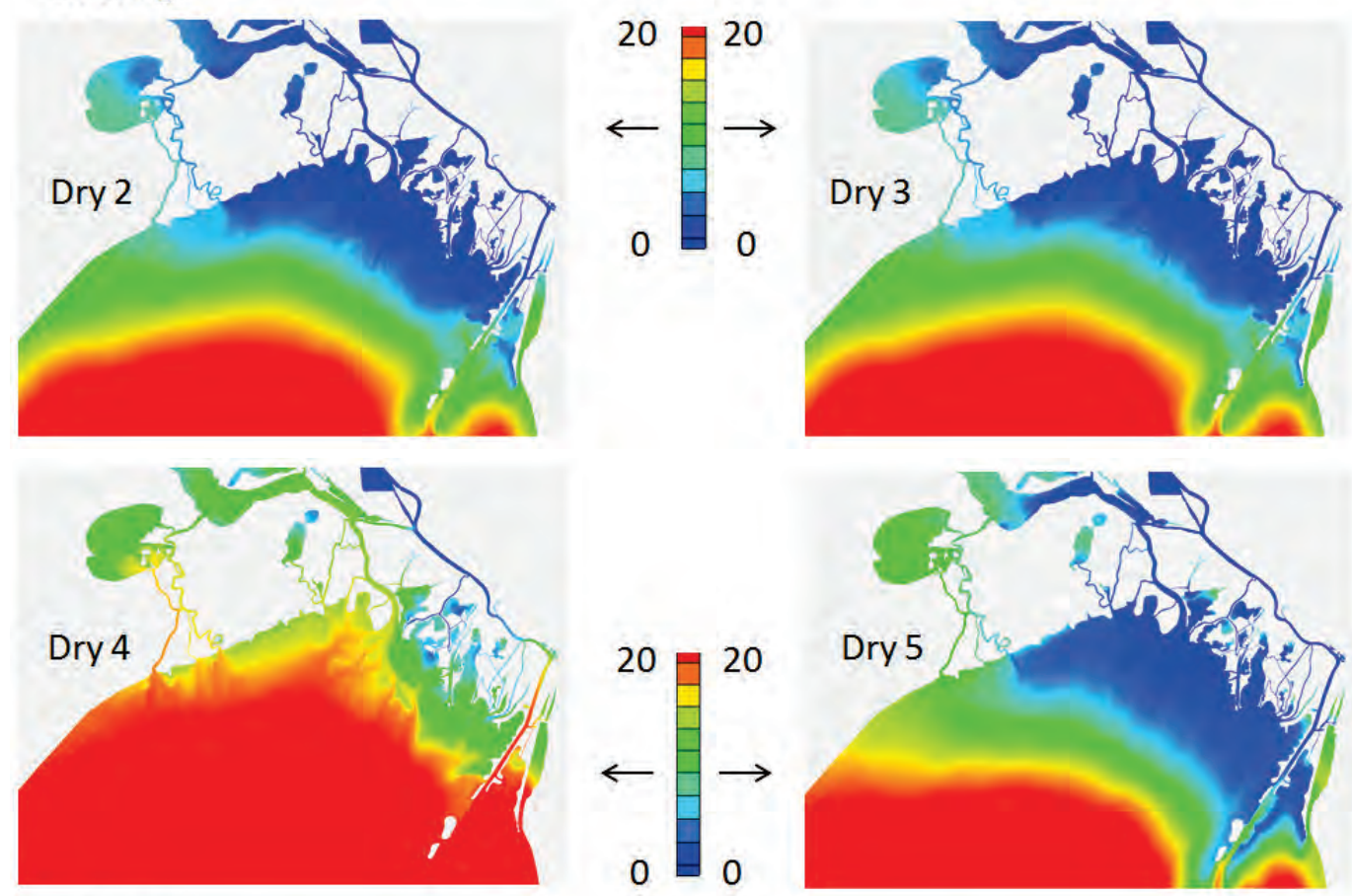

Existing
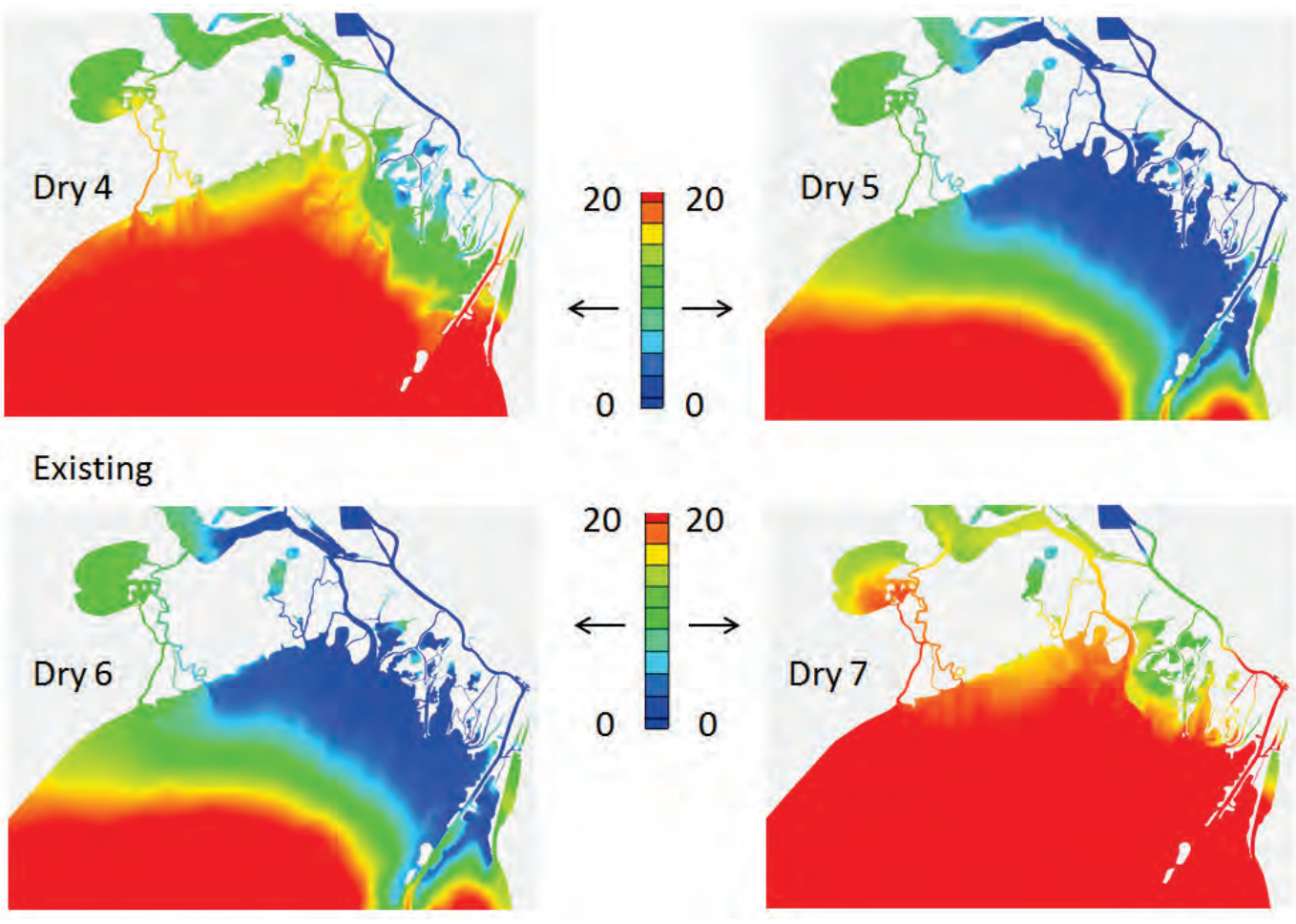
the starting point for the dry season and the contours at the end of each of the seven subsequent simulation segments as detailed in Table 8-2. Note that the contour range for the end of the wet season ( 0 to $5 \mathrm{psu}$ ) is different than for the dry-season segment contours ( 0 to $20 \mathrm{psu}$ ).

The dry-season simulation segments 1, 4, and 7 are periods when the structures are closed. There may have been some operation of the gates, but the lock and tainter gates were generally closed. These periods saw significant salinity intrusion. Simulation segments 2 and 5 were periods when the structures were opened to provide flushing of the salt water from the system. Segments 3 and 6 were very short $(0.75$ and $1.0 \mathrm{hr}$, respectively) and were transition conditions while the structures were being closed.

\section{Dredging the shoal and placing material into ORCO}

The salinity contours for the dredge-and-fill alternative (Figure 9-20) show that there are only very subtle differences between it and the existing conditions. The deepening of the upper Trinity River by dredging creates a more effective route for salt water to work up the channel. This effect can be seen in the Dry 7 contours along the Trinity River, where the dredge-and-fill have higher levels of salinity. The Dry 6 contours, however, show a much more rapid salinity response up Long Island Bayou compared to the existing because of the reduced discharge into the ORCO. When the lock is closed, the immediate reduction in discharge to the confluence of the ORCO and the Trinity River is taken more from the shallowed ORCO than the deepened Trinity River. This results in a surge of saline water eastward through the ORCO and dramatically increases the salinity on the western side of the system.

\section{Closure of ORCO by $\mathbf{4 0} \%$}

The salinity contours for the $40 \%$ closure of ORCO are presented in Figure 9-21. The results are very close to both the existing and the dredgeand-fill alternatives. The subtle difference can be seen along the lower Trinity River. 
Figure 9-20 Salinity contours for dredging the shoal and placing the material into ORCO at the end of each simulation period segment.
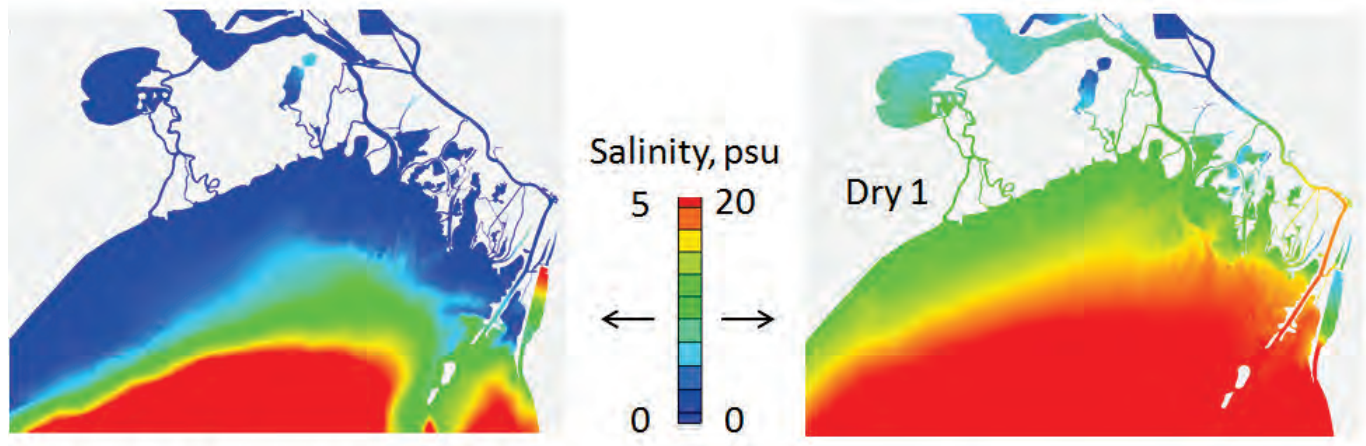

Dredge shoal and place in ORCO
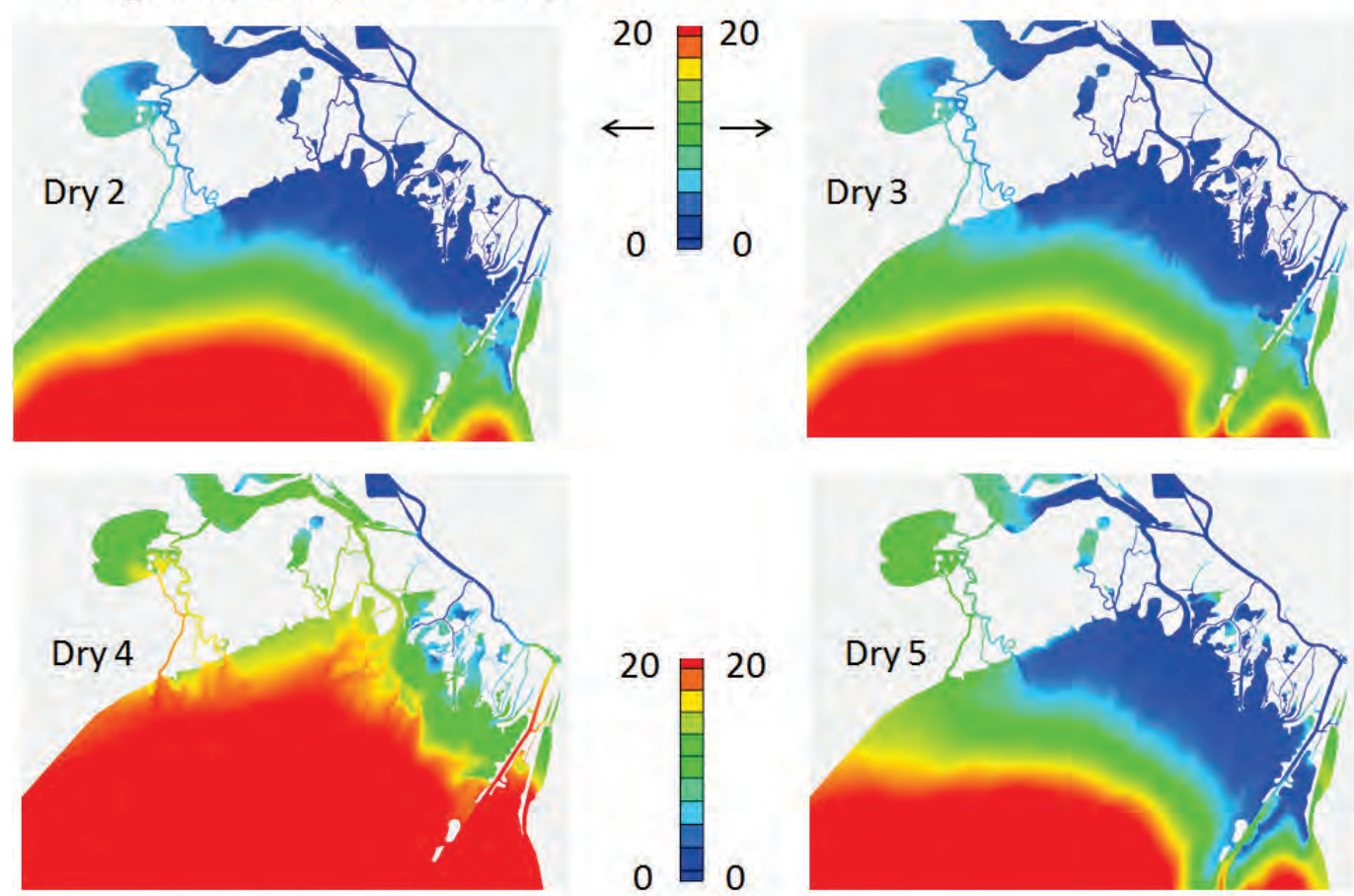

Dredge shoal and place in ORCO
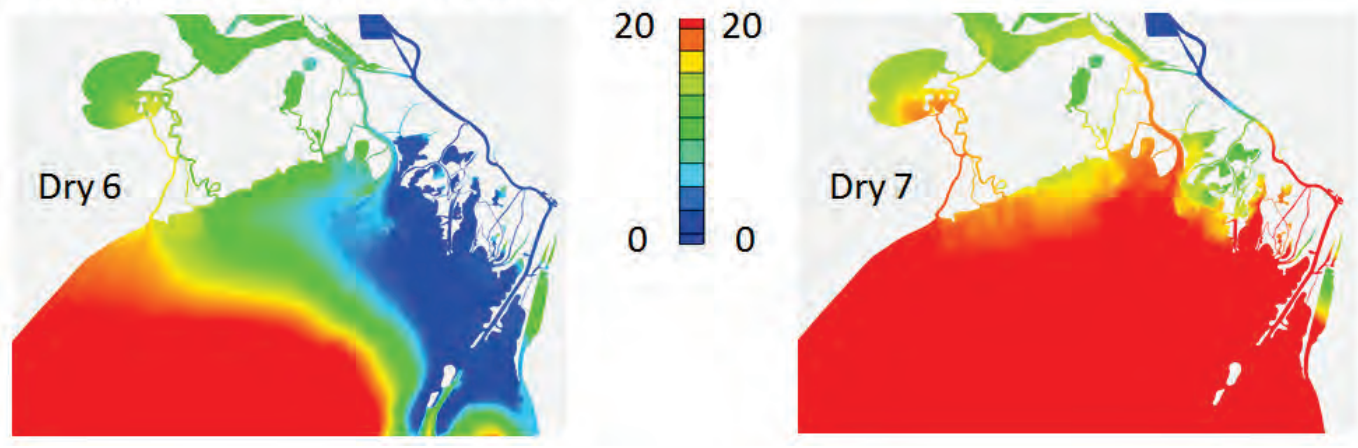
Figure 9-21 Salinity contours for $40 \%$ closure of ORCO at the end of each simulation period segment.
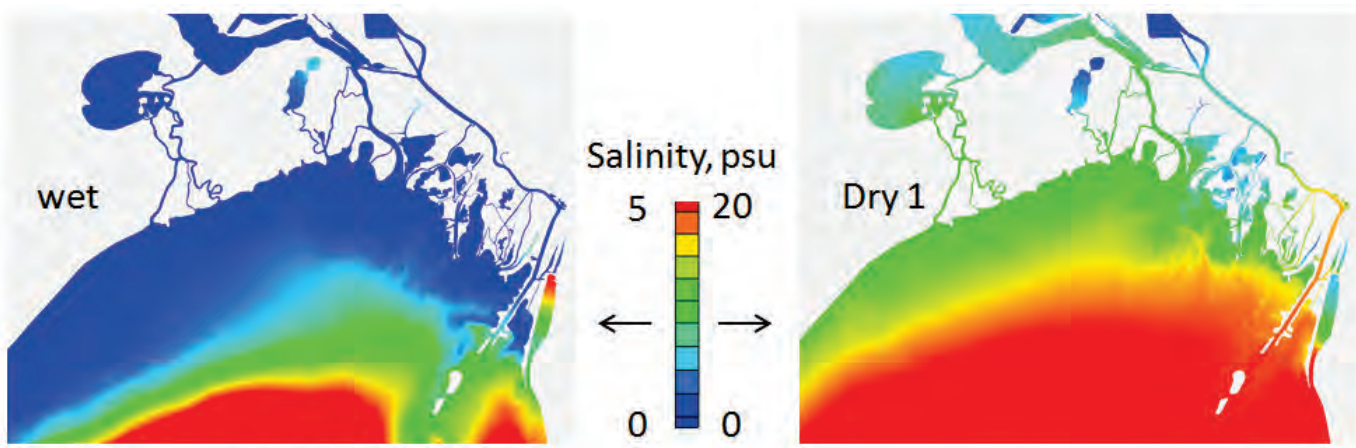

\section{$40 \%$ closure of ORCO}
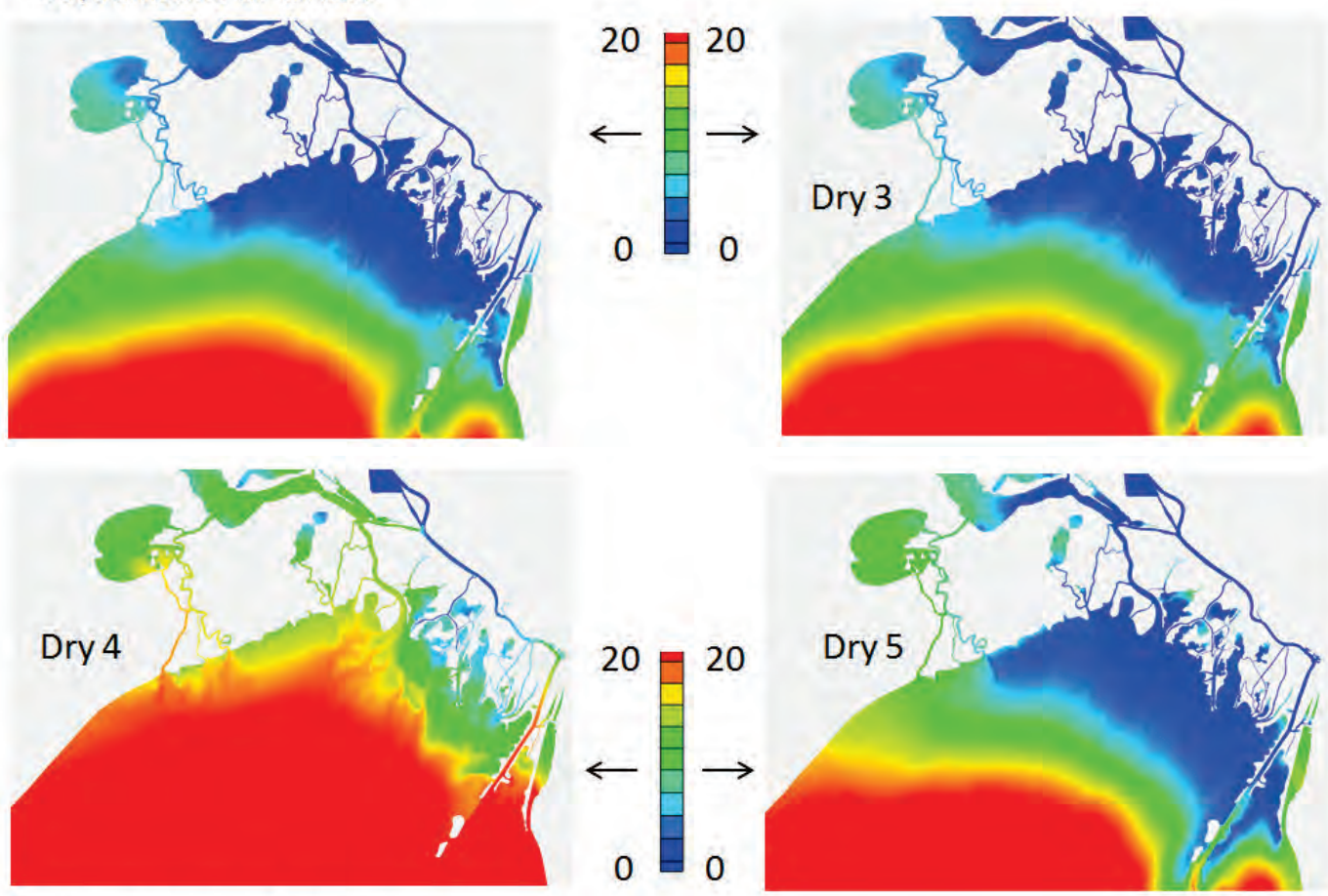

$40 \%$ closure of ORCO

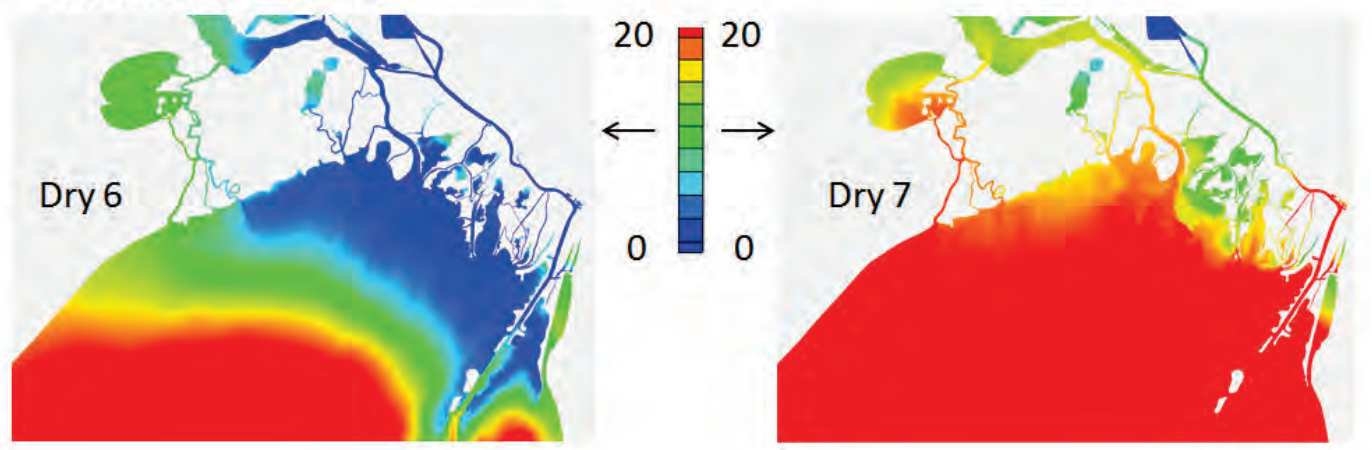




\section{Closure of ORCO by $60 \%$}

The salinity contours for the $60 \%$ closure of ORCO are presented in Figure 9-22. The effect of the alternative of putting a greater fraction of the flushing flow releases down the Trinity River compared to ORCO can be seen in segment 6 results in the middle portion of the delta, where the system is fresher than the existing conditions.

\section{Salinity time-series analysis}

\section{Salinity validation check}

The stations shown in Figure 9-23 were evaluated by plotting the time series of salinity values. The locations are at Port Anahuac, the junction of ORCO and Long Island Bayou, and at the confluence of the channels just above the shoal in the Trinity River. The model did not undergo any adjustment of coefficients in the salinity modeling. The salinity simulations were made with the same mixing coefficients as for the sediment transport simulations. The salinity results were then compared with field data for validation.

The time-series response of the model (existing) salinity levels near the structures is presented with the observed salinity values in Figure 9-24. The qualitative response is comparable between the field data and the model.

The salinity variation during the dry-season simulation involved three pulses of salinity intrusion, separated by periods when the structures were opened to flush the salt away. The first pulse showed that the model arrival time was much later than the field observations. The arrival time is defined as the time when there is a sharp rise in the salinity associated with a salt front. This late arrival in the model is likely associated with the initial conditions being too fresh in the model. The second pulse of salinity has the arrival times much closer, and the overall response is similar. The third pulse has essentially the same arrival times, but the rate of rise is more rapid in the model than in the field. The qualitative agreement between the model and field observations indicates that the model can be used to compare the responses between alternatives. 
Figure 9-22 Salinity contours for $60 \%$ closure of ORCO at the end of each simulation period segment.
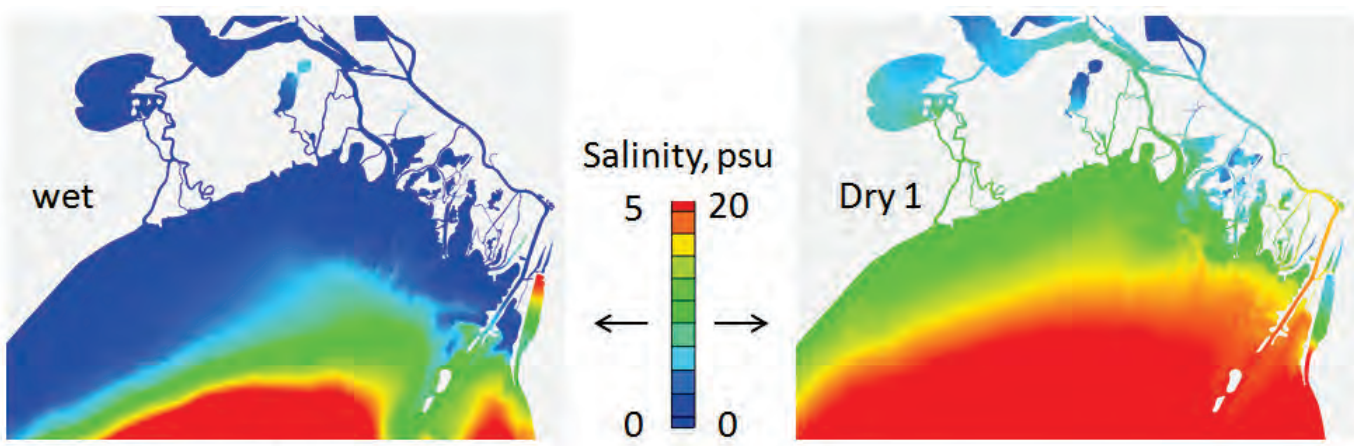

$60 \%$ closure of ORCO
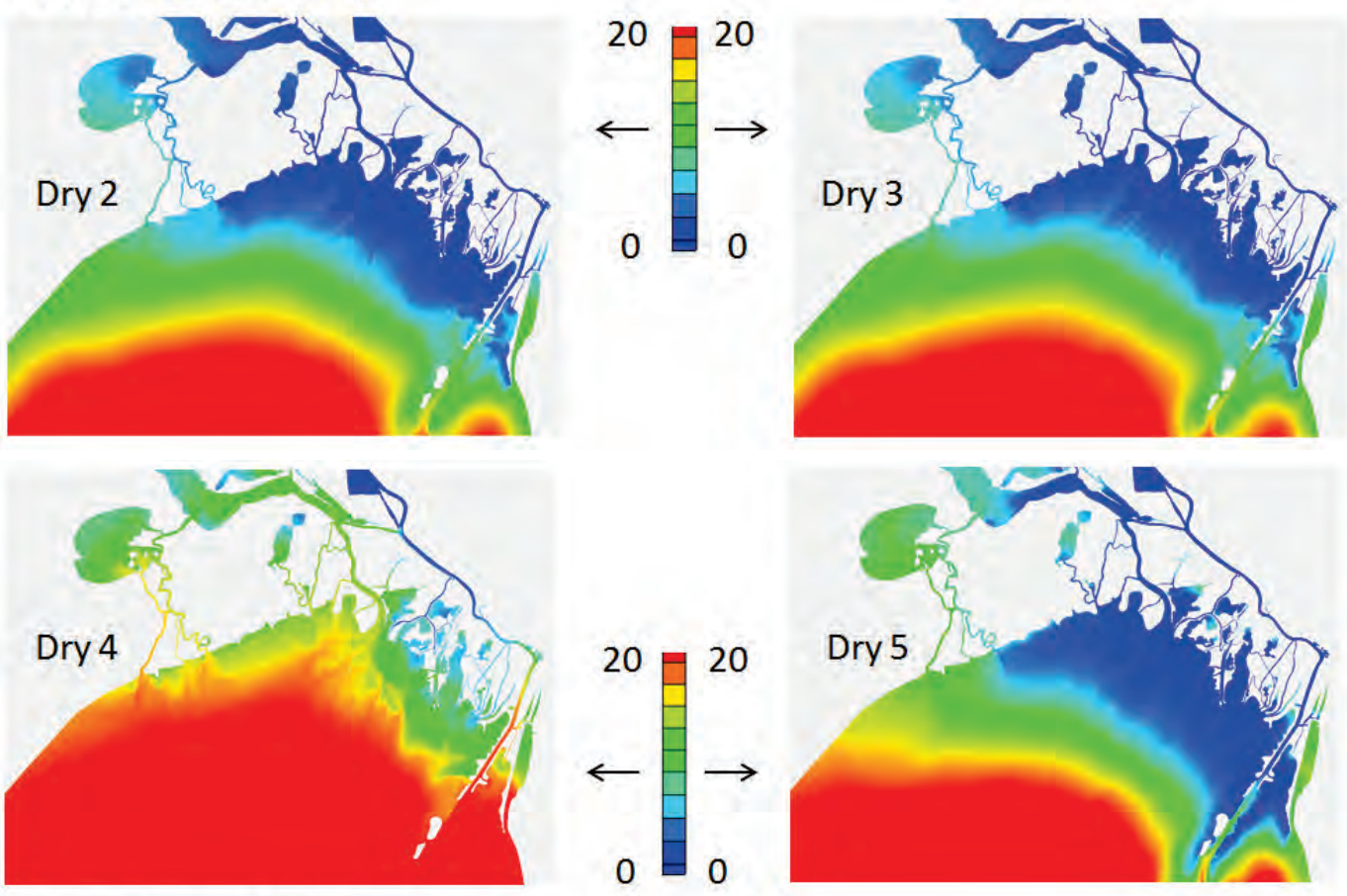

$60 \%$ closure of ORCO
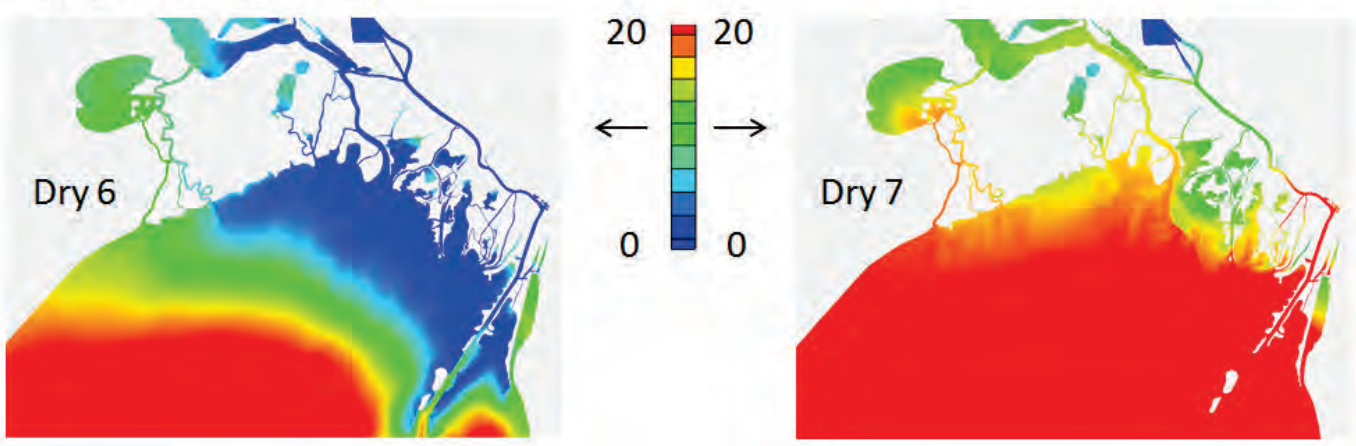
Figure 9-23 Location of stations for salinity time-series analysis.

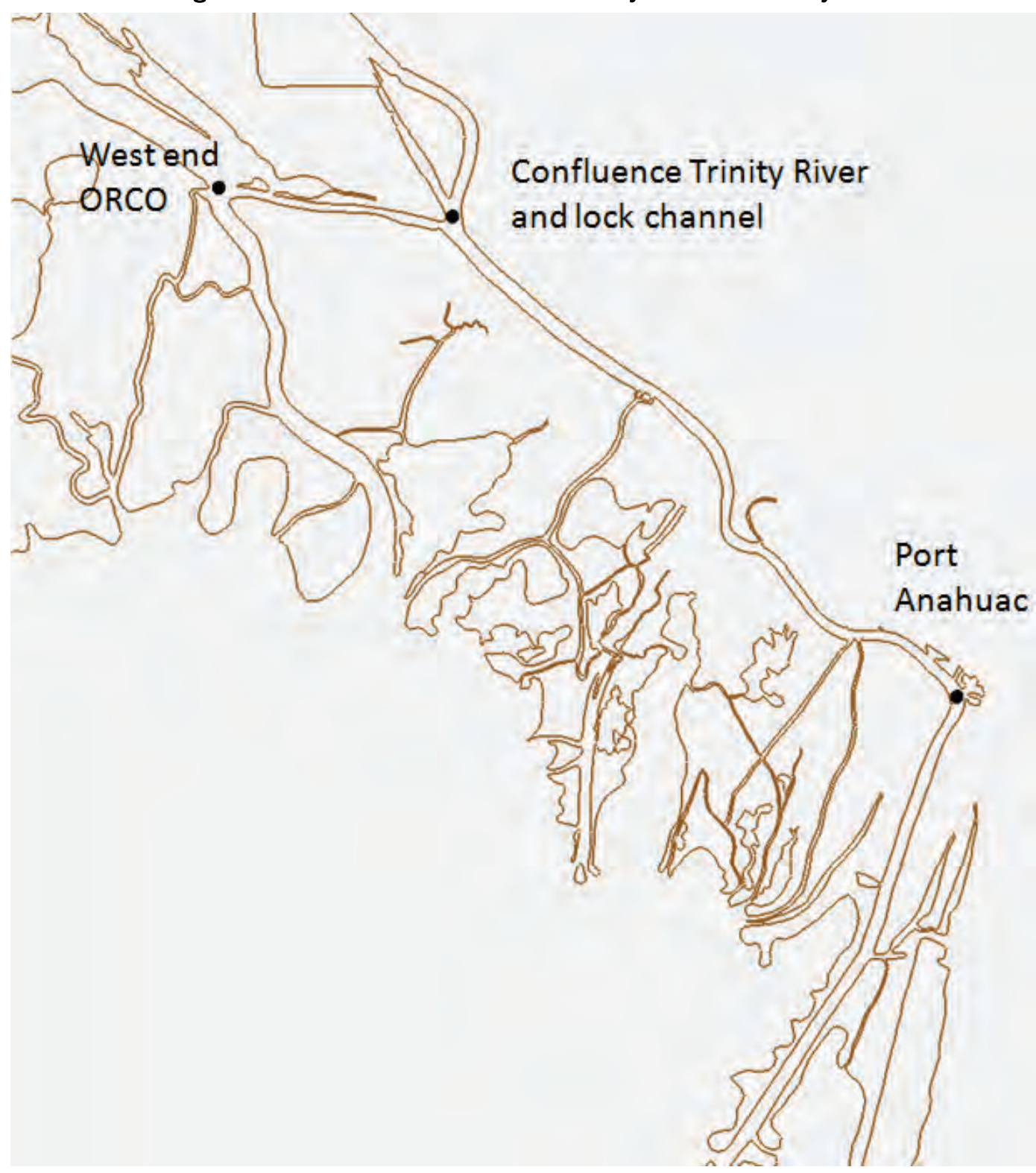

\section{Existing conditions}

The time series at the three locations are presented in Figure 9-25 for the existing conditions. During the three surges of salinity intrusion, the salinity levels at Port Anahuac rise above fresh water levels first, followed by the west end of ORCO, and finally at the confluence in the study area. Salinity levels at the west end of ORCO are consistently about two-thirds of the value at Port Anahuac. The salinity levels at the confluence are 85\% of the levels at the west end of ORCO. 
Figure 9-24 Validation of salinity response.

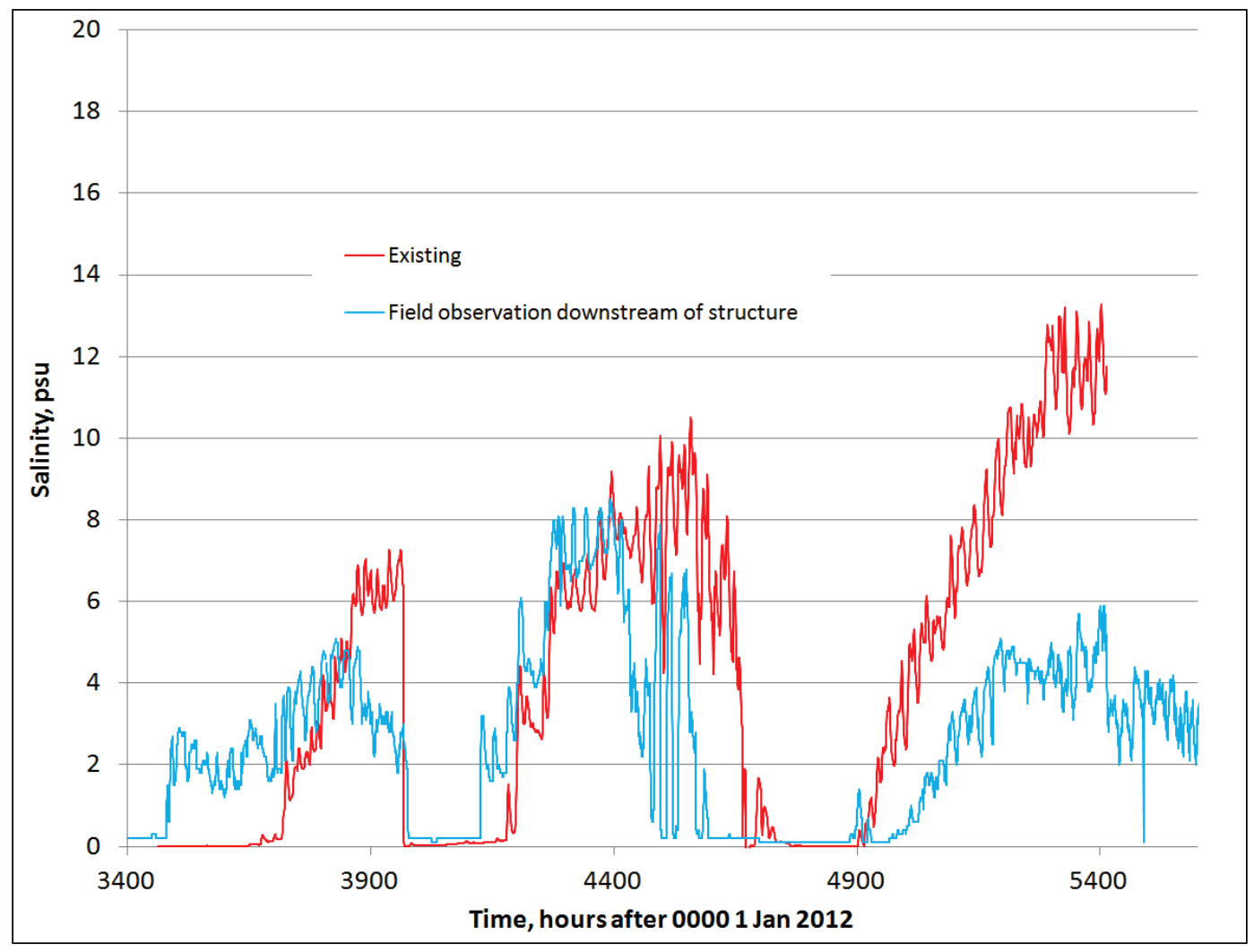

Figure 9-25 Time series of salinity at analysis stations for existing-conditions results.

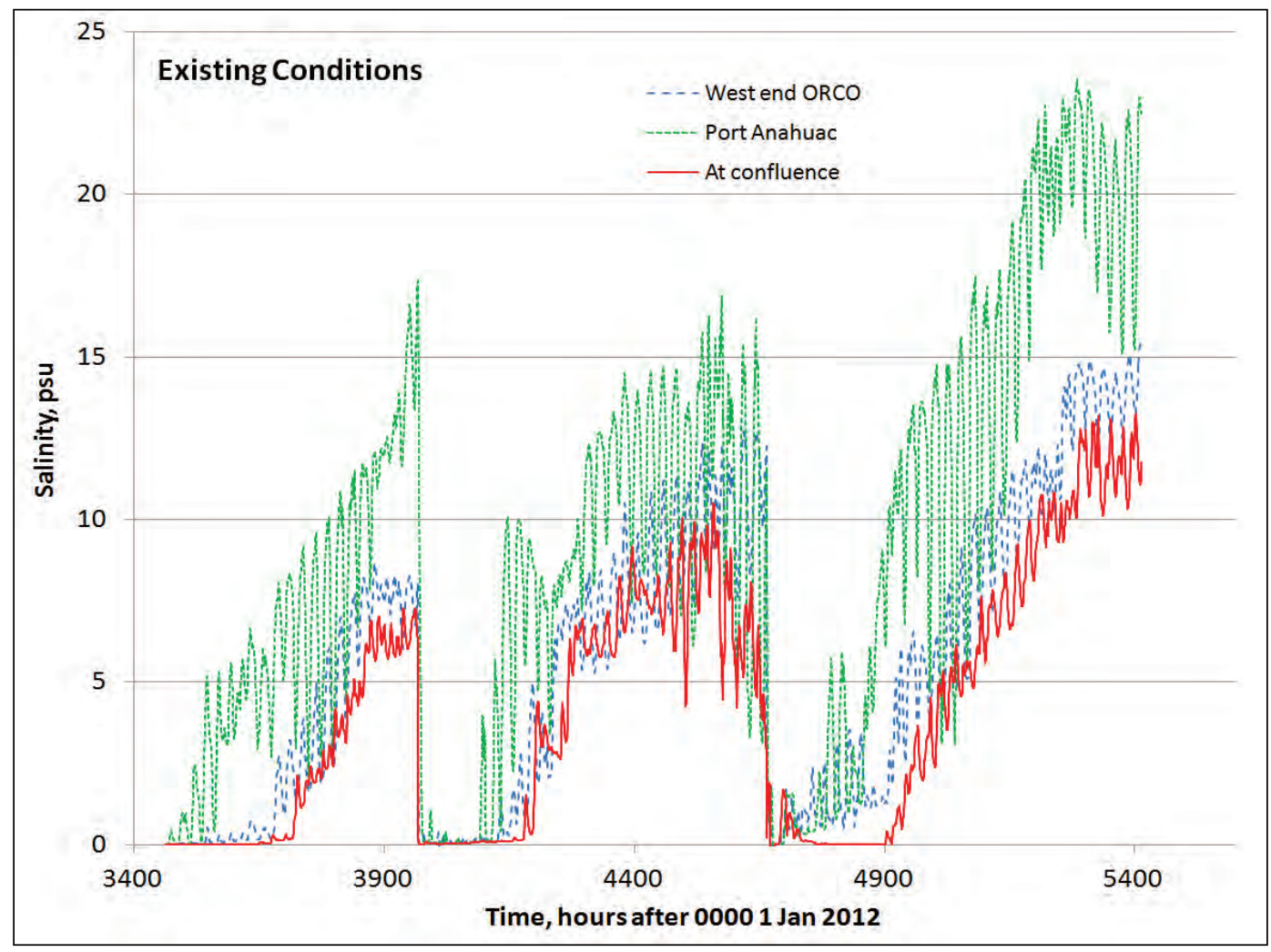




\section{Dredge-and-fill alternative}

Salinity response for the dredge-and-fill conditions are compared for the three stations in Figure 9-26. The salinity responses at Port Anahuac and the west end of ORCO are similar to what was seen in the existing conditions. However, the salinity response at the confluence is dramatically lower. The lower salinity is the result of creating a barrier to salinity intrusion in ORCO with the fill and the increase of flows down the Trinity River to better flush out salinity. Also, the salinity levels at the west end of ORCO are not flushed out during the periods when the structures are open.

Figure 9-26 Time series of salinity at analysis stations for the alternative of dredging the shoal and placing the material into ORCO.

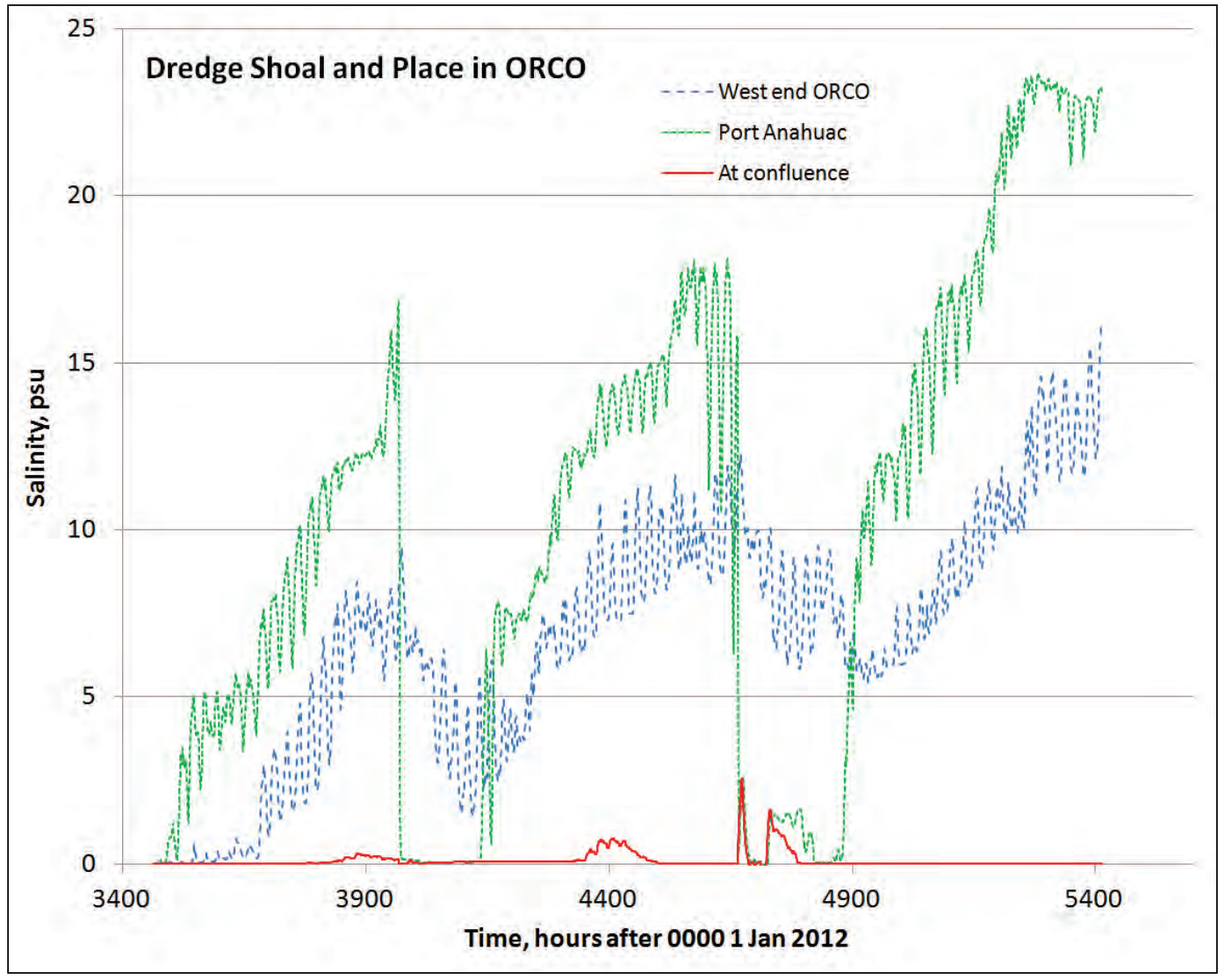

\section{Closure of ORCO by $\mathbf{4 0} \%$}

Figure 9-27 presents the salinity response at the three stations for the $40 \%$ closure of ORCO. These results are more consistent with the existingcondition response, with the relative proportions of the salinity levels at each station maintained. 
Figure 9-27 Time series of salinity at analysis stations for results of $40 \%$ closure of ORCO.

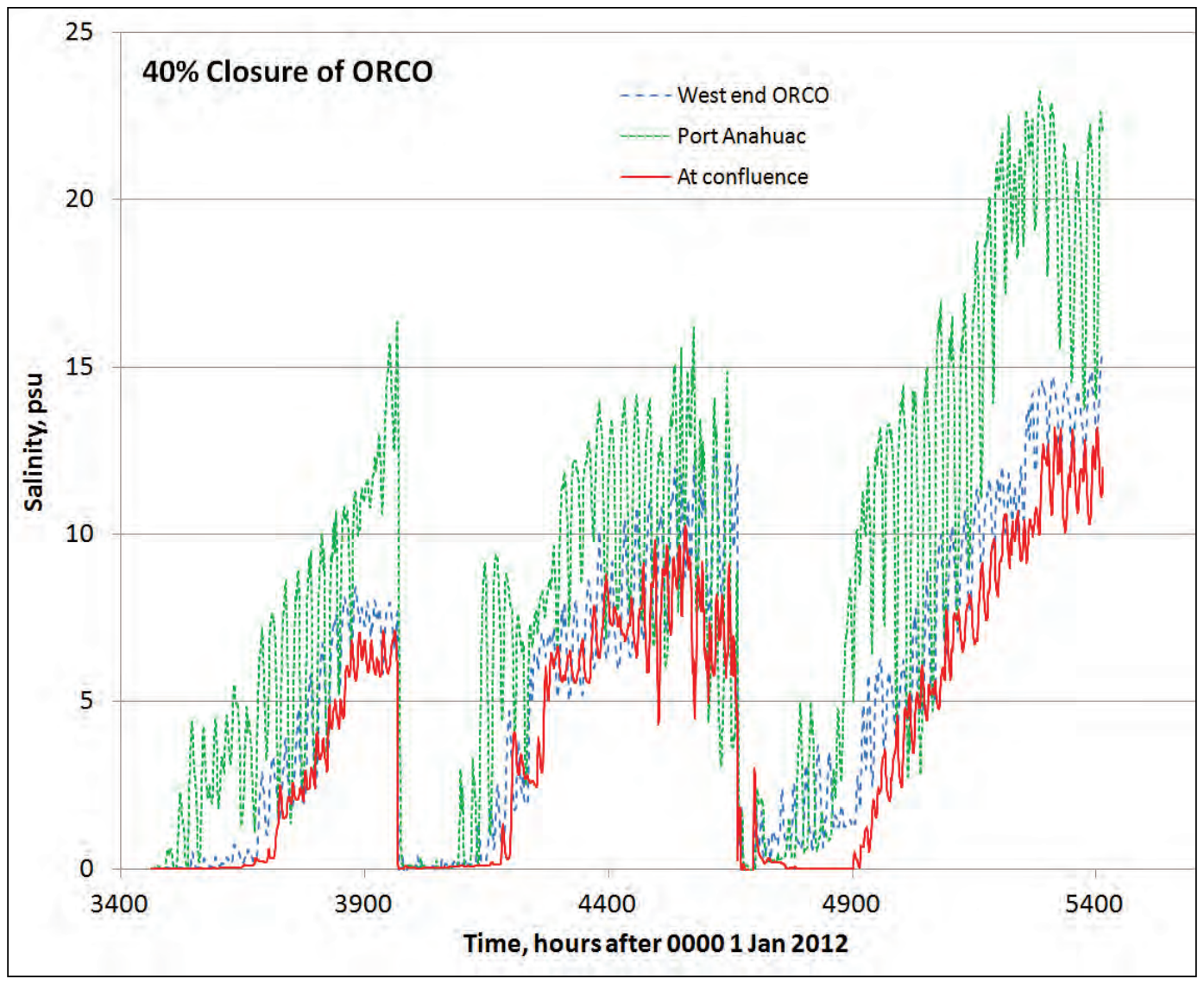

\section{Closure of ORCO by $60 \%$}

Figure 9-28 presents the salinity response at the three stations for the $60 \%$ closure of ORCO. These results are also more consistent with the existingcondition response, with the relative proportions of the salinity levels at each station maintained.

\section{Comparison of responses at the west end of ORCO}

Figure 9-29 presents a comparison of all alternatives at the west end of ORCO. The different response for the dredge-and-fill alternative is evident, with higher salinities being maintained after each intrusion pulse. This is from reduced flushing at the station for the dredge-and-fill alternative relative to the other alternatives associated with a reduction in discharge westward in the ORCO. 
Figure 9-28 Time series of salinity at analysis stations for results of $60 \%$ closure of ORCO.

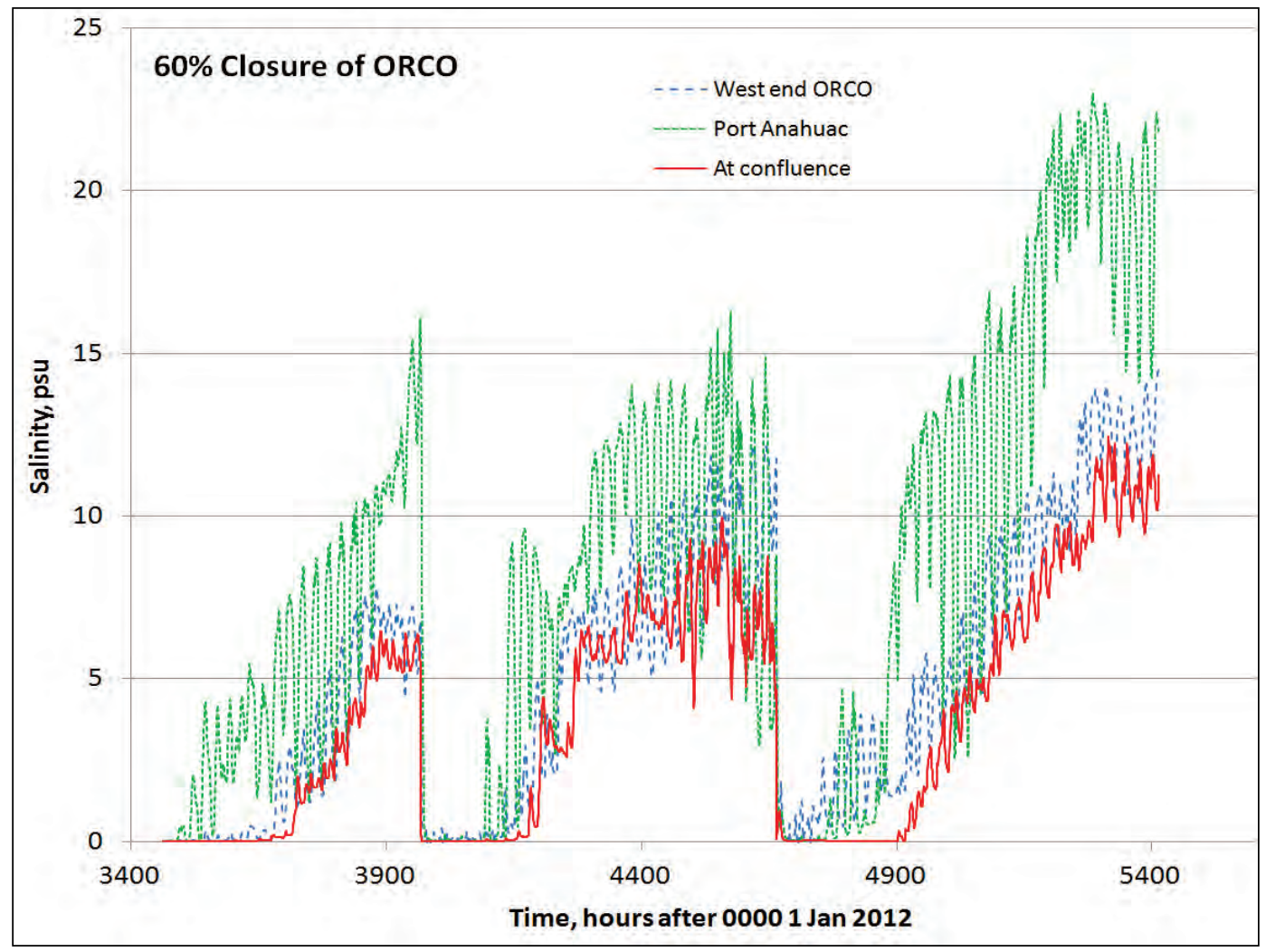

Figure 9-29 Time series of salinity at analysis stations for all alternatives at the west end of ORCO.

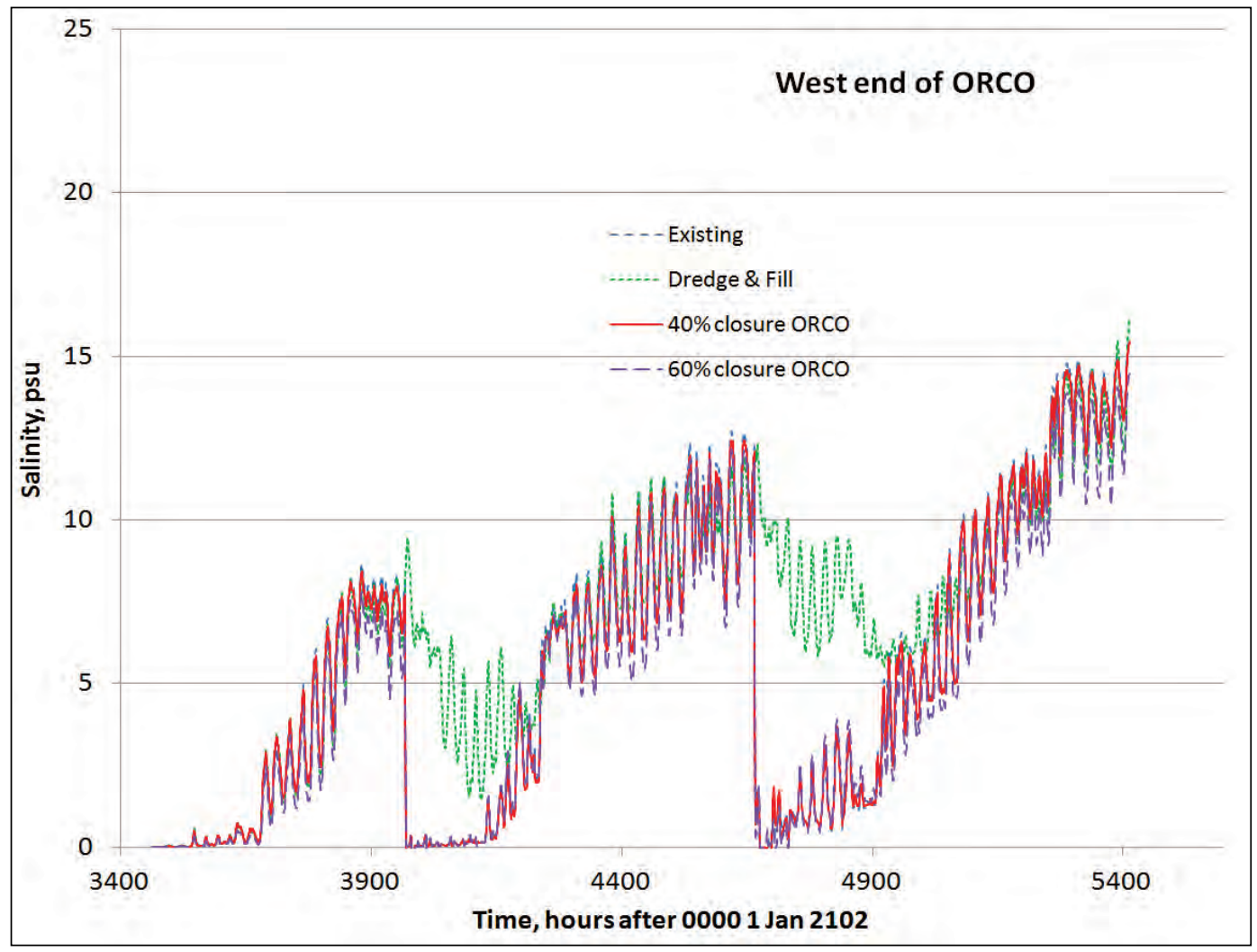




\section{Comparison of responses at Port Anahuac}

The salinity responses at Port Anahuac are presented in Figure 9-30. The response for the dredge-and-fill indicates generally higher salinity levels than seen in the existing conditions. This may be the result of the deepening of the Trinity River, which creates sharper salinity gradients in the salt front because of deeper depths.

Figure 9-30 Time series of salinity at analysis stations for all alternatives at Port Anahuac.

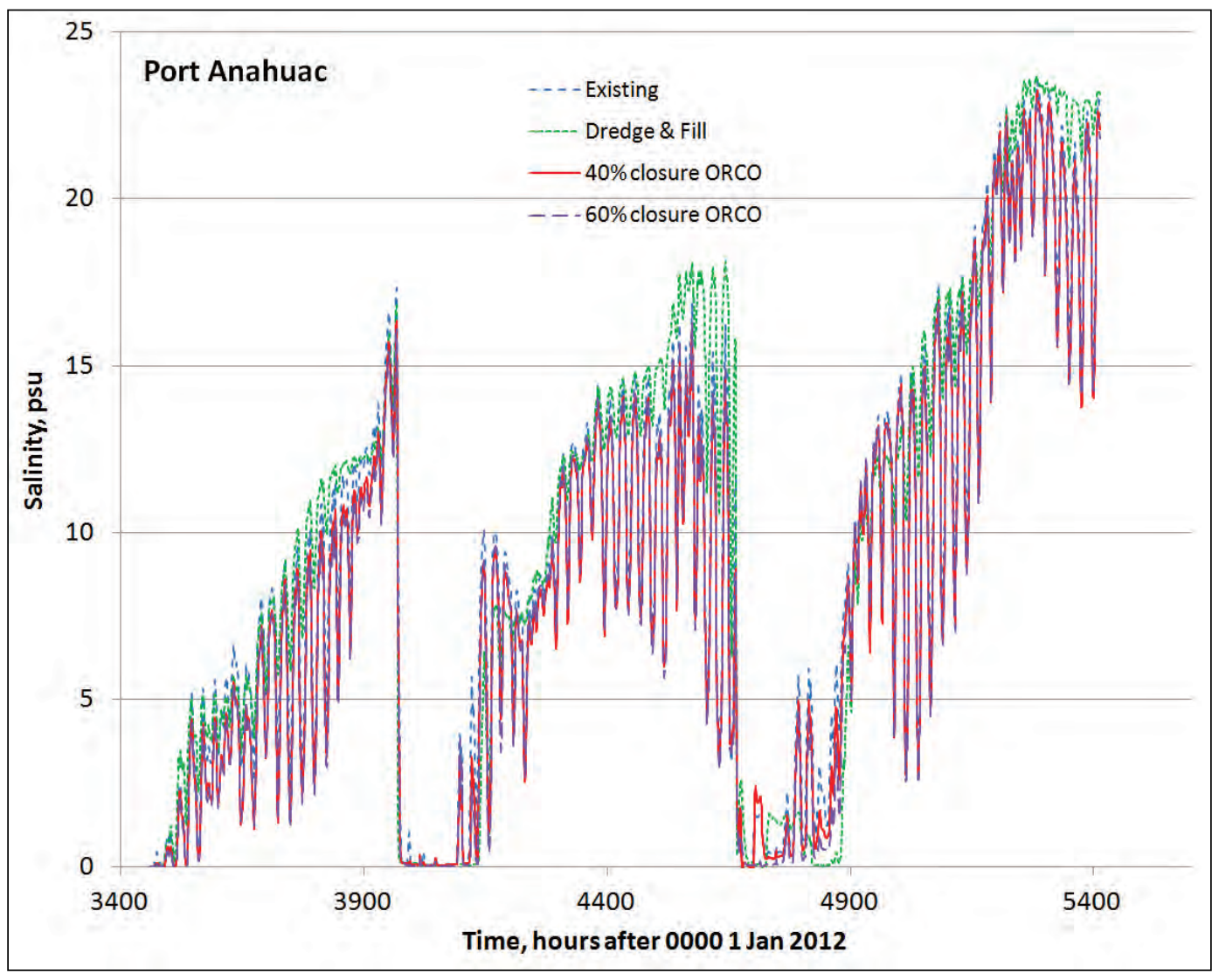

\section{Comparison of responses at the confluence}

The salinity responses at the confluence of channels in the study area for all alternatives are shown in Figure 9-31. The major reduction in the salinity response with the dredge-and-fill alternative is seen. All other alternatives respond comparably to the existing conditions. The field data is presented in the figure to illustrate that the magnitude of the impact of the dredge-and-fill option is significantly greater than the accuracy of the model compared to the field data. 
Figure 9-31 Time series of salinity at analysis stations for all alternatives at the confluence of the Trinity River and the downstream lock channel.

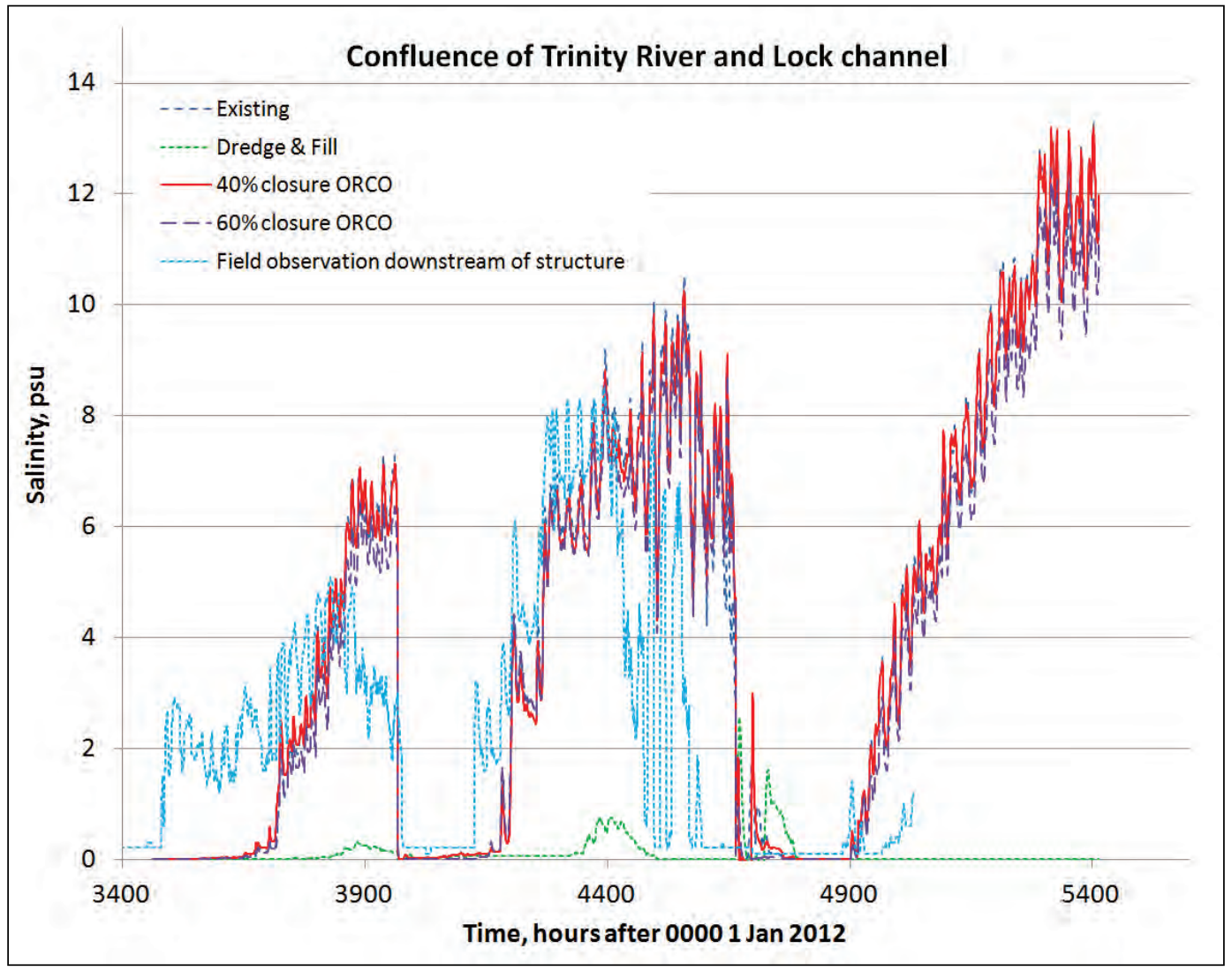

\section{Response time for salinity intrusion}

These time series of salinity response offer a visual impression of the effects of each alternative. In order to simplify and better quantify the responses, the duration of time after the structures were closed for each of the intrusion periods, until a specific salinity threshold was exceeded at the structures, was documented. These results for the three intrusion periods are presented in Table 9-1 for each of the alternatives for threshold salinity levels of 1, 2, and 3 psu. The average response time for all three intrusion periods was calculated, along with the standard deviation. These statistics are plotted in Figure 9-32. Note that for the dredge-and-fill alternative there was essentially no salinity response at the levels chosen. These statistics show that the salinity responses of all the other alternatives are statistically similar. 
Table 9-1. Summary of salinity response.

\begin{tabular}{|c|c|c|c|c|c|}
\hline \multirow[b]{2}{*}{$\begin{array}{l}\text { Intrusion Event } \\
\text { (segment) }\end{array}$} & \multirow[b]{2}{*}{$\begin{array}{l}\text { Threshold Salinity } \\
\text { (psu) }\end{array}$} & \multicolumn{4}{|c|}{ Response Time, hr } \\
\hline & & Existing & $\begin{array}{l}\text { Dredge } \\
\text { \& Fill }\end{array}$ & $\begin{array}{l}40 \% \\
\text { Closure }\end{array}$ & $\begin{array}{l}60 \% \\
\text { Closure }\end{array}$ \\
\hline \multirow[t]{3}{*}{1 (dry 1) } & 1 & 261 & & 255 & 260 \\
\hline & 2 & 263 & & 262 & 288 \\
\hline & 3 & 327 & & 327 & 337 \\
\hline \multirow[t]{3}{*}{2 (dry 4) } & 1 & 70 & 554 & 70 & 70 \\
\hline & 2 & 89 & & 90 & 89 \\
\hline & 3 & 91 & & 91 & 91 \\
\hline \multirow[t]{3}{*}{$3($ dry 7$)$} & 1 & 188 & & 187 & 189 \\
\hline & 2 & 204 & & 205 & 222 \\
\hline & 3 & 223 & & 223 & 248 \\
\hline \multirow[t]{3}{*}{ Average } & 1 & 173 & & 171 & 173 \\
\hline & 2 & 185 & & 186 & 200 \\
\hline & 3 & 214 & & 214 & 225 \\
\hline \multirow[t]{3}{*}{ Standard Deviation } & 1 & 96 & & 94 & 96 \\
\hline & 2 & 88 & & 88 & 101 \\
\hline & 3 & 118 & & 118 & 125 \\
\hline
\end{tabular}

Figure 9-32 Comparison of the salinity response time between alternatives as a function of the threshold salinity level.

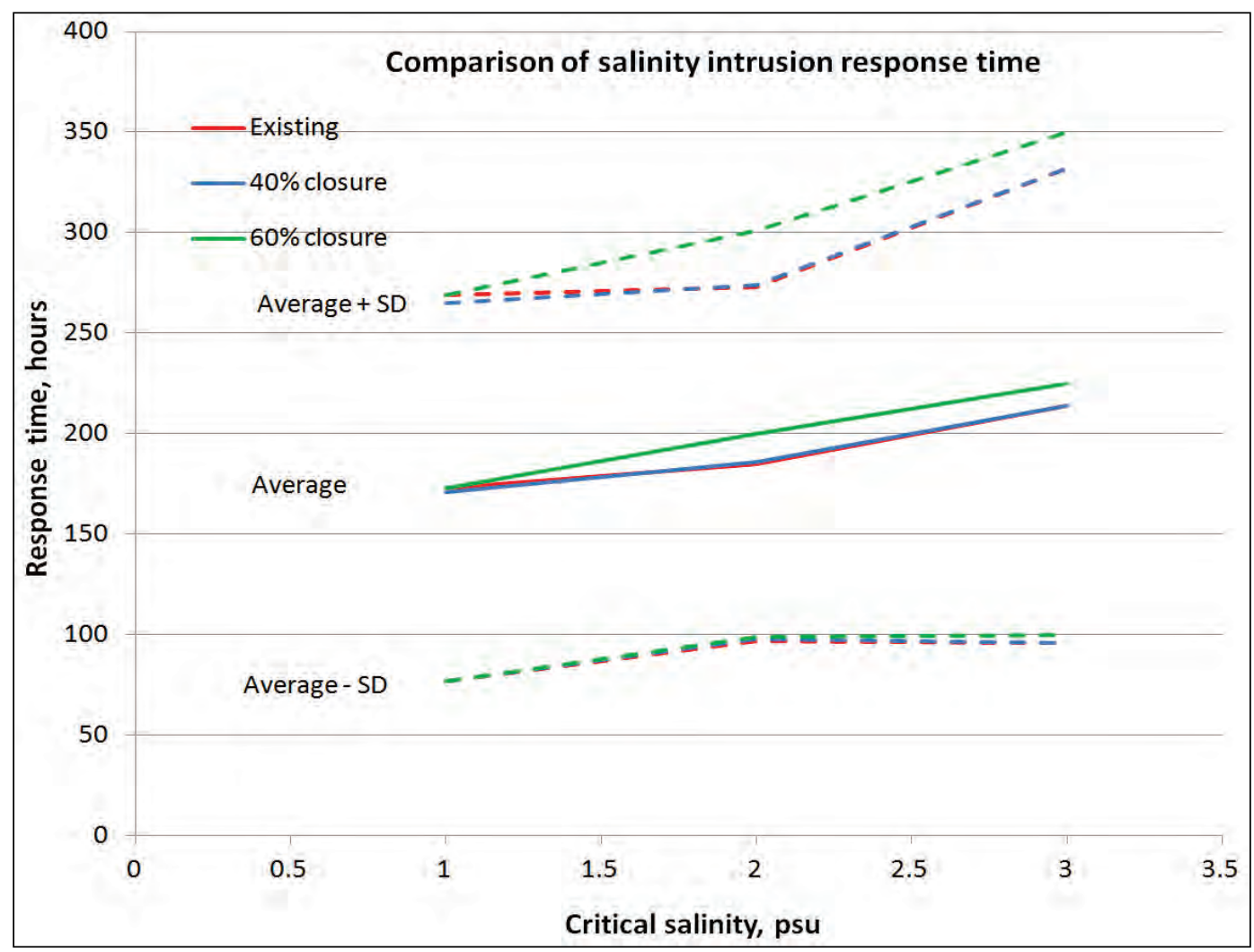




\section{Salinity profile analysis}

The salinity response was also evaluated by plotting the salinity profile along the Trinity River and the ORCO/ Long Island Bayou pathways into open water in Trinity Bay. These profiles are shown in Figure 9-33.

Figure 9-33 Salinity profile alignment for analysis.

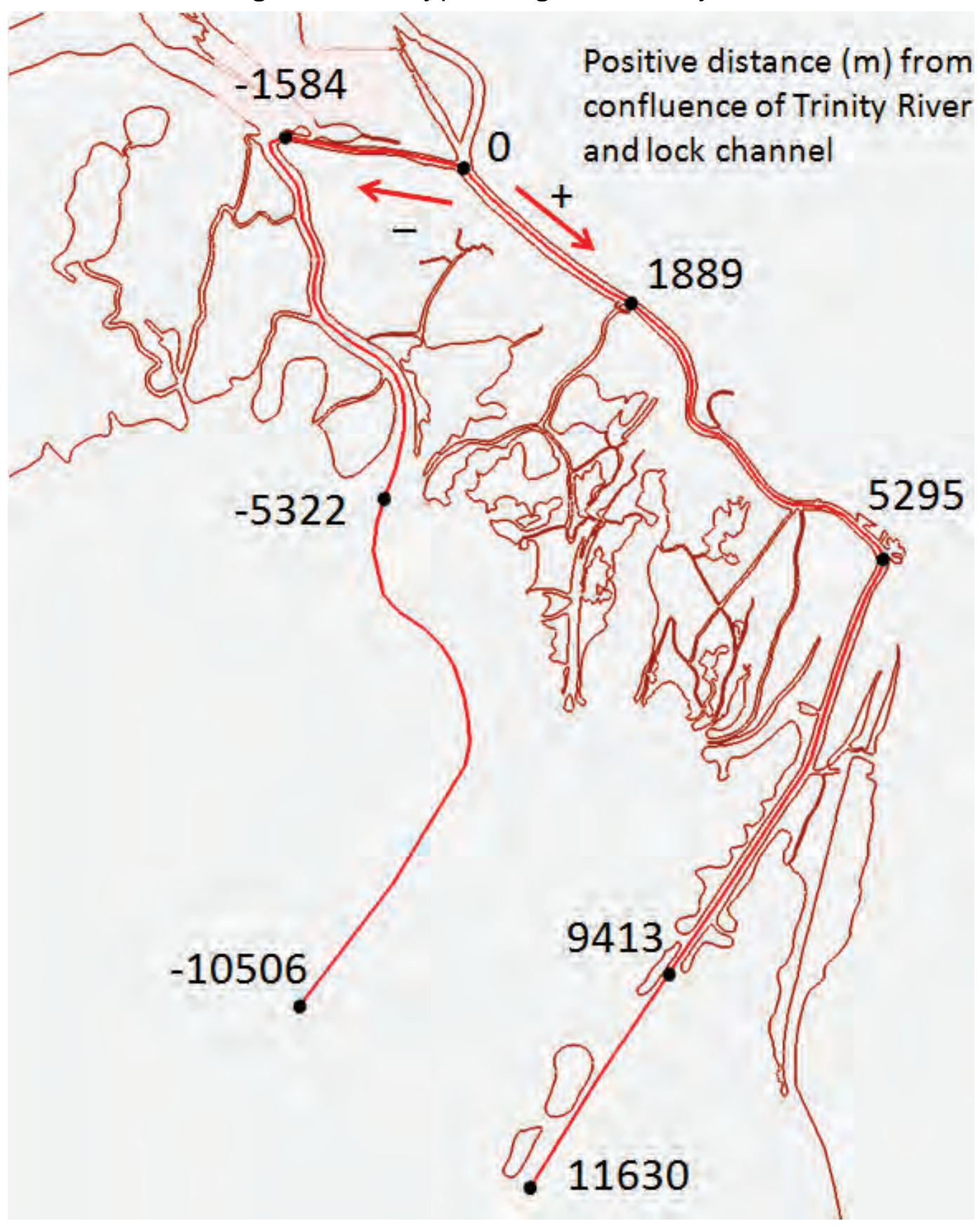




\section{Existing conditions}

The profiles of salinity for existing conditions at the end of each of the seven dry-season simulation segments are presented in Figure 9-34. The profiles for the ends of segments 2, 3, 5, and 6 show that the salinity has been flushed into the bay. The three salinity intrusion periods, segments 1, 4, and 7, show intrusion along both pathways. The distances are referenced to the confluence, with positive distances down the Trinity River and negative distances down ORCO. The first (dry 1) and third (dry 7) intrusion periods show a stronger gradient along Trinity River. The second intrusion period (dry 4) has a sharp gradient along both pathways. The intrusion is greatest overall for the seventh segment, which is the third salinity pulse.

Figure 9-34 Salinity profile for existing conditions at the end of the wet season and all dryseason simulation periods.

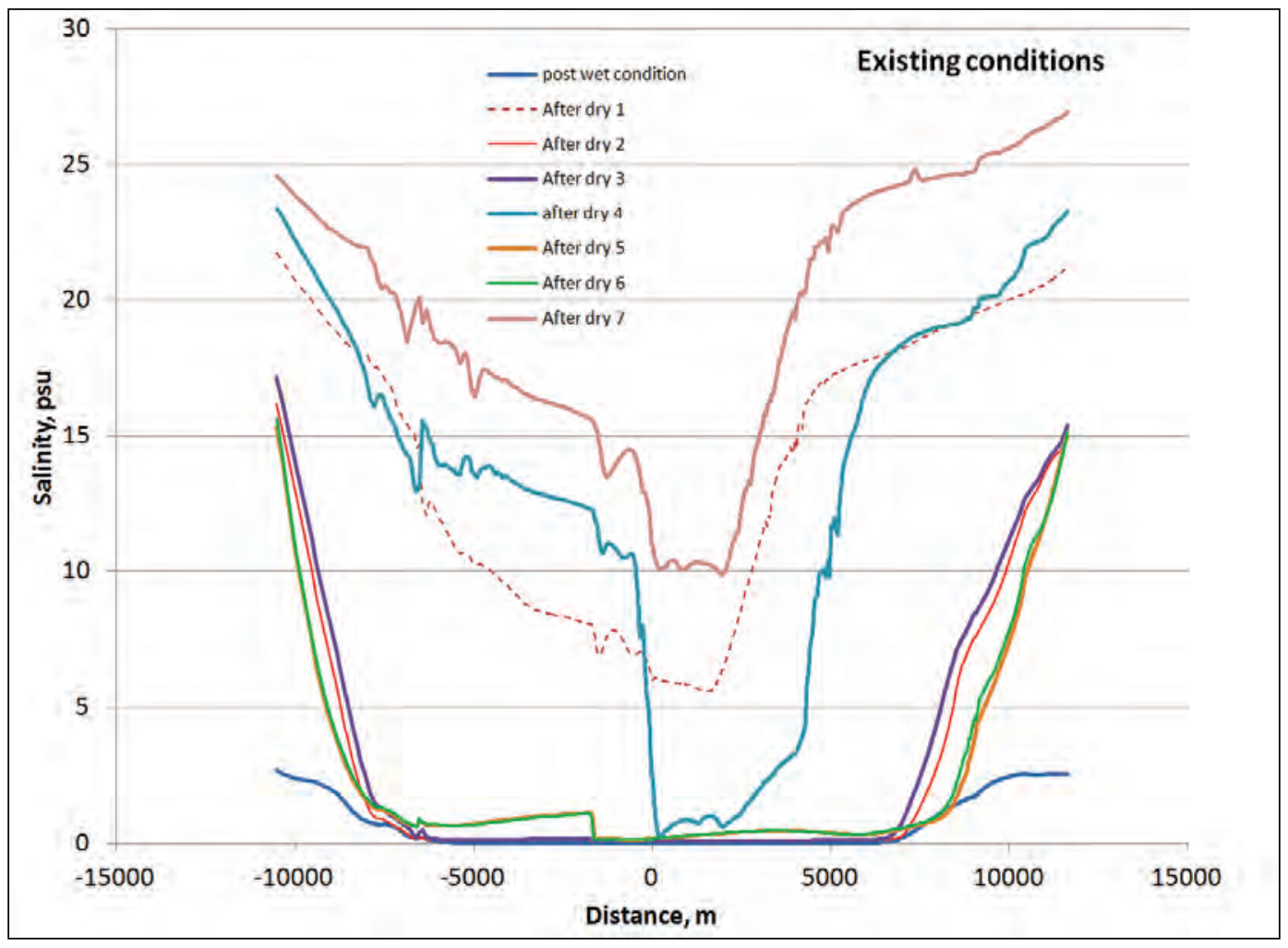

\section{Dredge-and-fill alternative}

The dredge-and-fill alternative salinity profiles are presented in Figure 9-35. The intrusion events (segments 1, 4, and 7) show that the salinities in the vicinity of the confluence remain fresh throughout, with sharp salinity gradients along both pathways. The salinity profiles at the ends of simulation segments 2 and 3 show the salinity has been flushed down the Trinity 
River toward the bay but not completely flushed out of the ORCO. The conditions at the end of segments 5 and 6 also show that intrusion has not been completely flushed out of ORCO.

Figure 9-35 Salinity profiles for the dredge-and-fill alternative at the end of the wet season and all dry-season simulation periods.

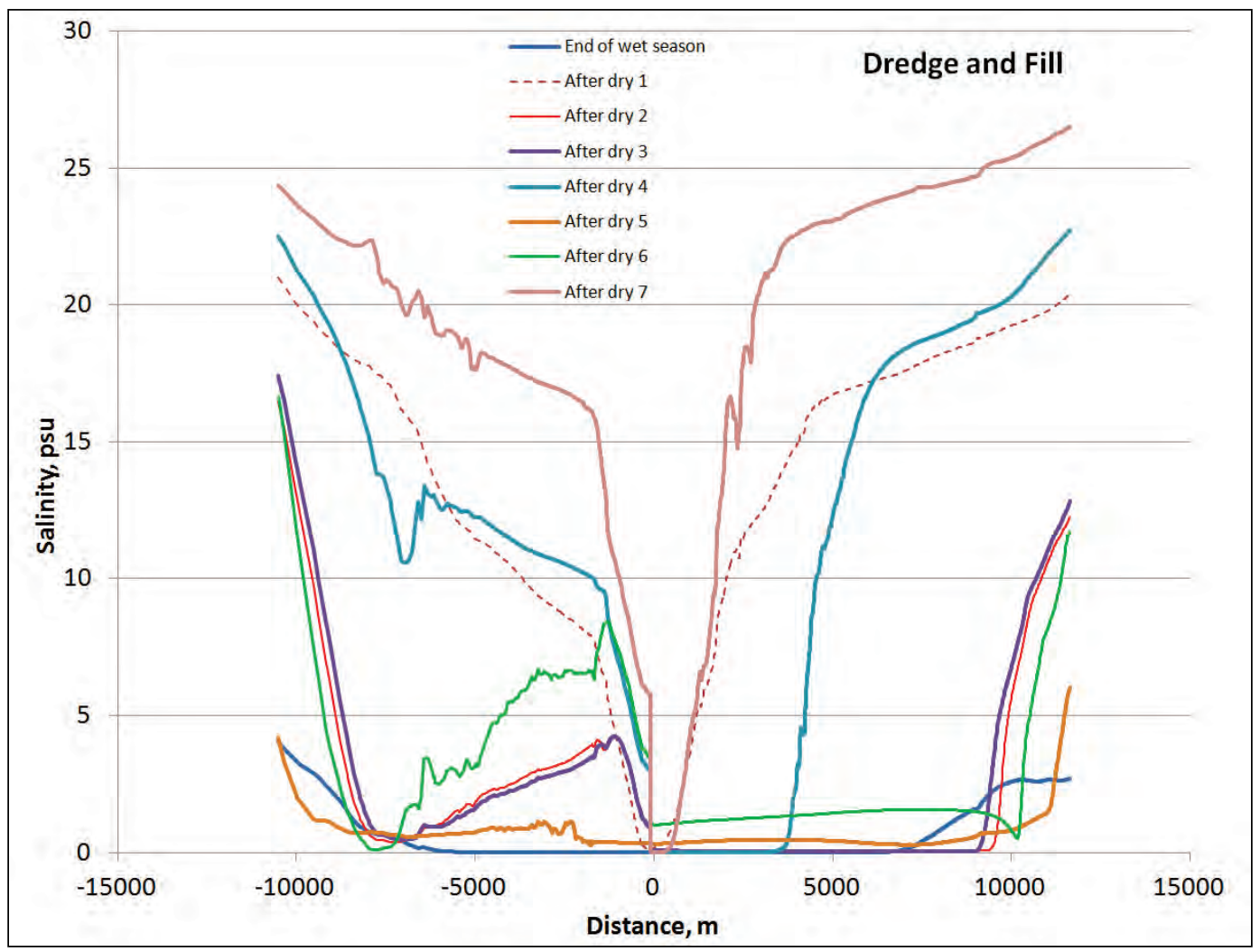

\section{Closure of ORCO by $\mathbf{4 0} \%$}

The salinity profiles for the $40 \%$ closure of ORCO (Figure 9-36) exhibit the same qualitative trends as the existing conditions for all simulation segments. The salinity at the confluence for the first salinity surge (dry 1 ) peaked at approximately $5.5 \mathrm{psu}$. The second surge during segment 4 had salinities below 2 psu in the vicinity of the confluence. The greatest intrusion occurs during the final surge (segment 7), with salinities near the confluence at approximately $10 \mathrm{psu}$.

\section{Closure of ORCO by $60 \%$}

The salinity profiles for the 60\% closure of ORCO (Figure 9-37) exhibit the same qualitative trends as the existing conditions for all simulation segments. The minimum salinities near the confluence during the first 
Figure 9-36 Salinity profile for $40 \%$ closure of ORCO condition at the end of the wet season and all dry-season simulation periods.

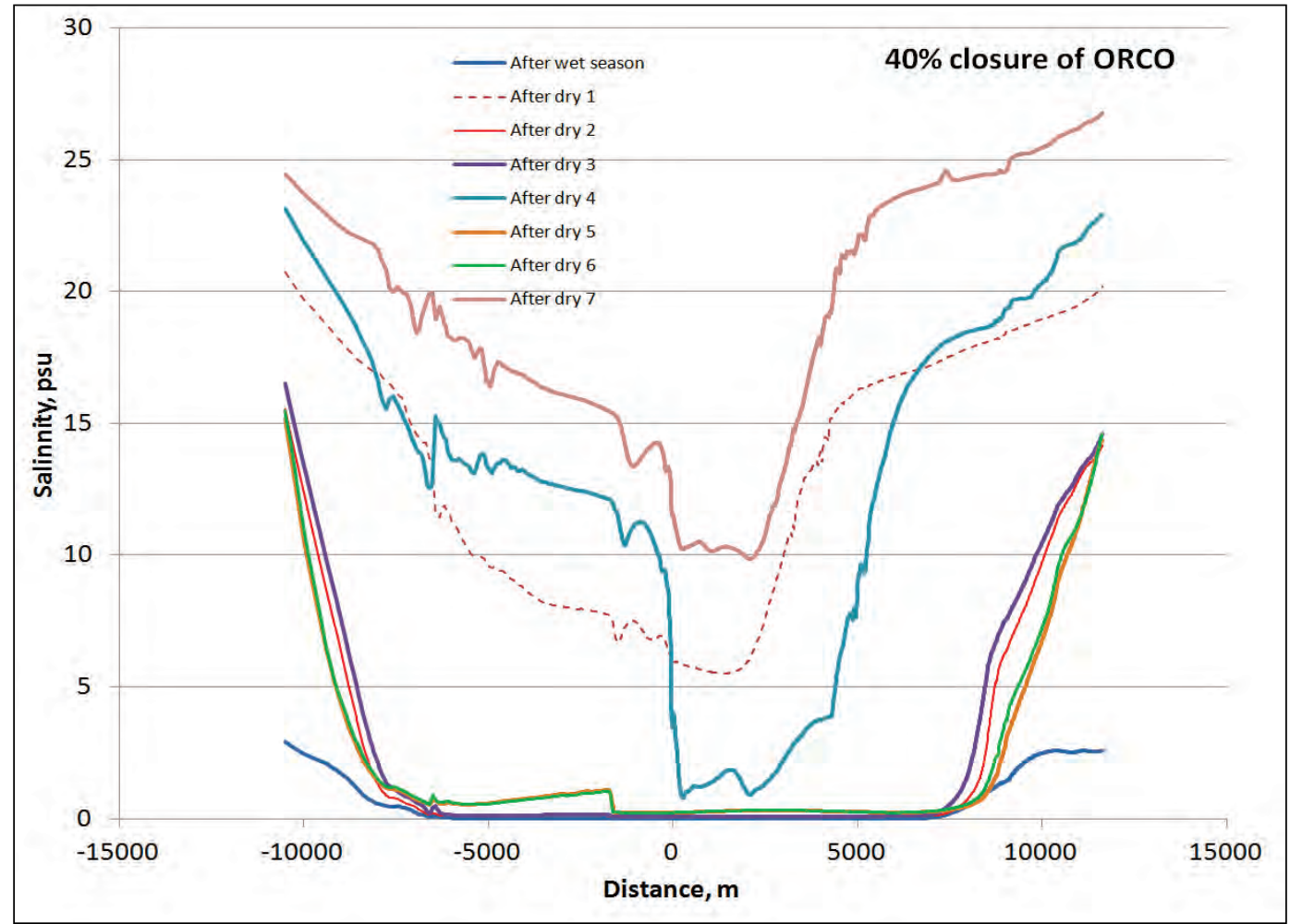

Figure 9-37 Salinity profile for $60 \%$ closure of ORCO condition at the end of the wet season and all dry-season simulation periods.

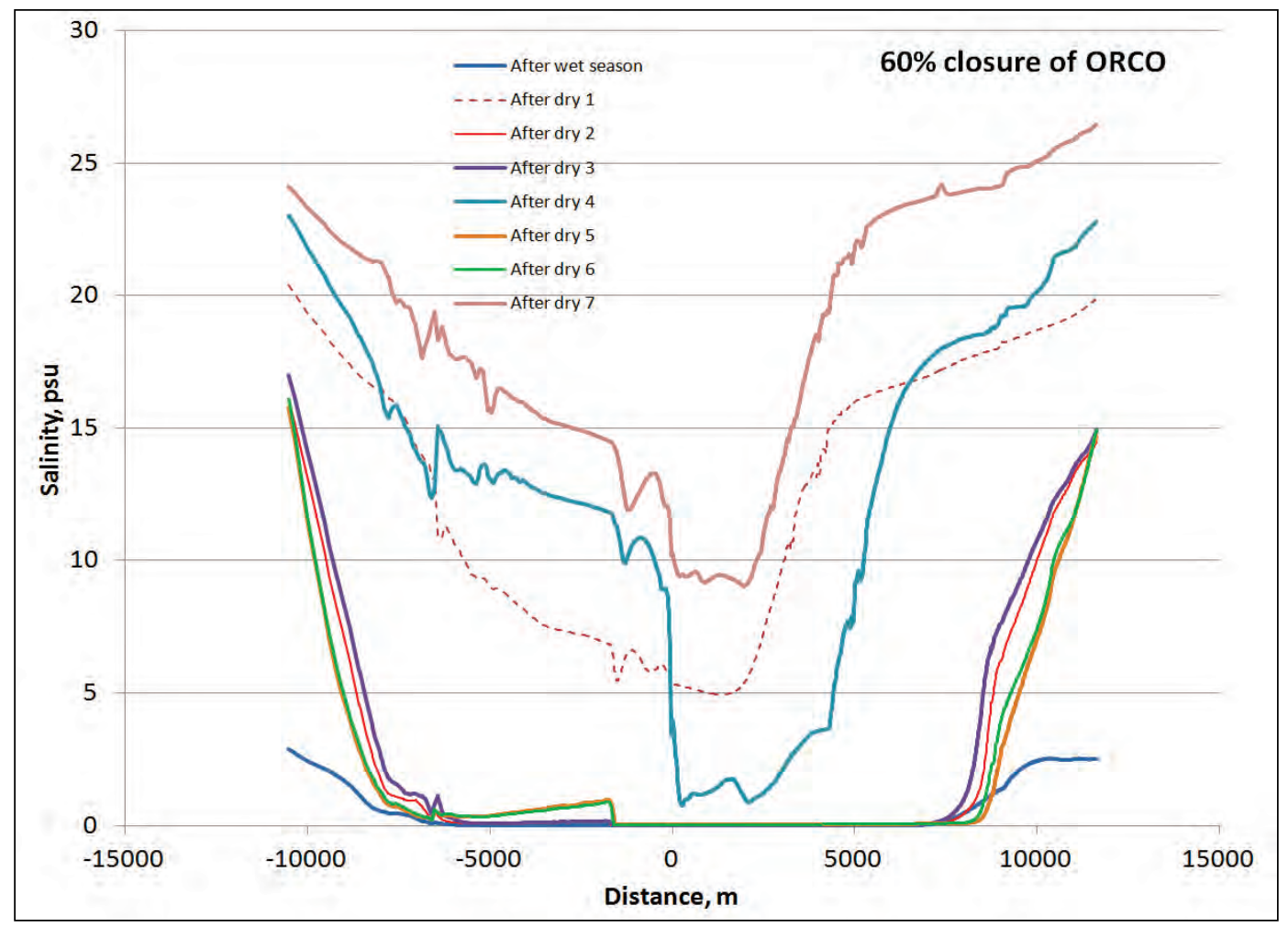


intrusion were 5 psu and below 2 psu for the second surge. The greatest intrusion occurs during the final surge (dry segment 7), with salinities near the confluence at approximately 9 psu.

\section{Comparisons at end of the wet-season simulation}

All alternatives are compared for the profiles of salinity at the end of the wet season in Figure 9-38. All alternatives show that the salinities have been flushed. The positive distance along the Trinity River up to approximately $6600 \mathrm{~m}$ shows fresh water. That is approximately $1000 \mathrm{~m}$ south of Port Anahuac. The salinities are flushed out down ORCO and Long Island Bayou to a distance of $-6000 \mathrm{~m}$, which is all the way to the mouth of the delta. The differences in salinity between alternatives are out in Trinity Bay.

Figure 9-38 Salinity profile for all alternatives at the end of the wet season.

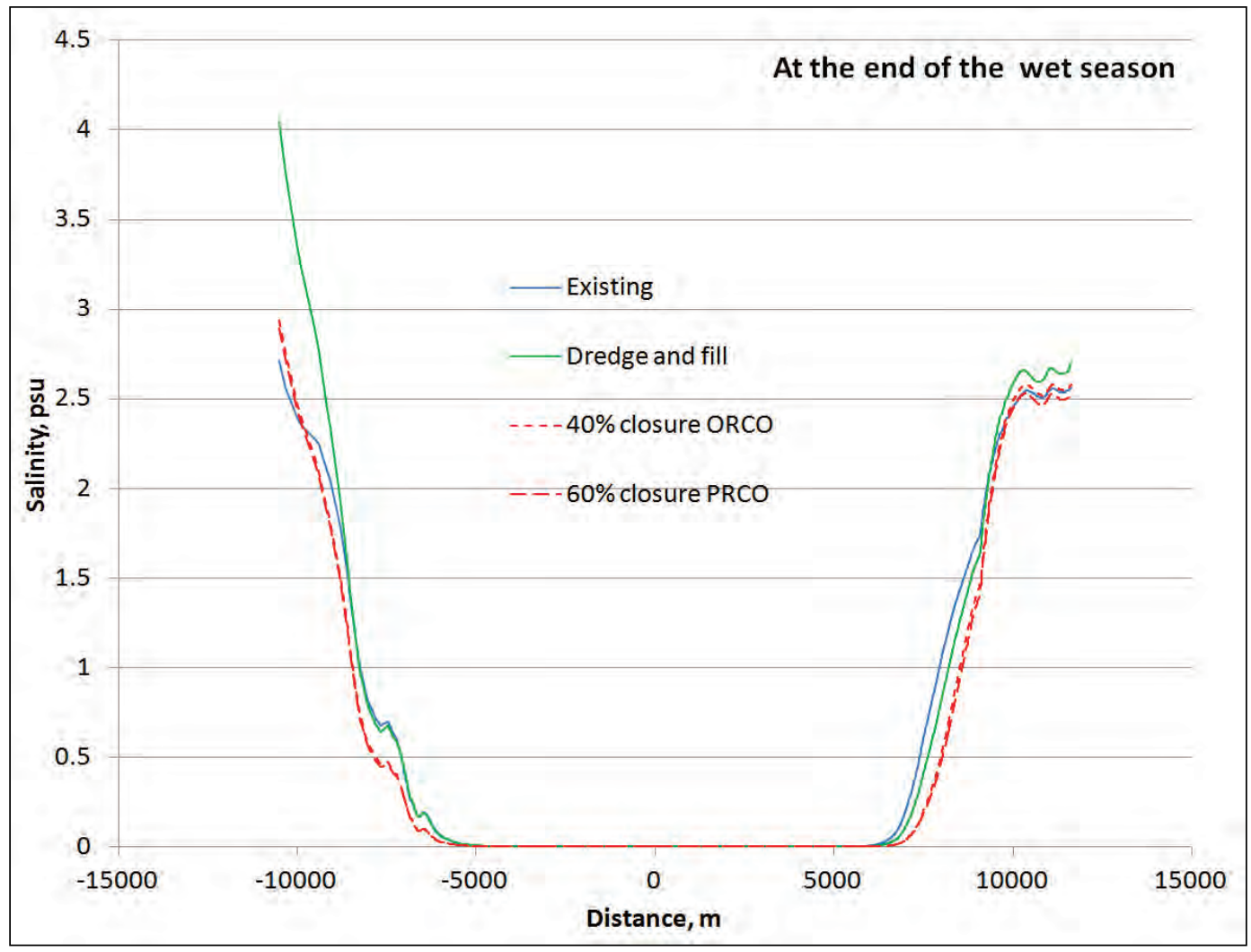

\section{Comparisons at end of dry simulation period 1}

Simulation period 1 was a salinity intrusion period; the structures were closed for the most part, with limited operation of the gates in the salt barrier. The profiles at the end of this period are presented in Figure 9-39. The existing conditions, the dredge-and-fill, the $40 \%$ closure, and the $60 \%$ 
closure all have very similar response profiles. The dredge-and-fill alternative keeps the salinities much fresher over the length of ORCO and near the confluence.

Figure 9-39 Salinity profile for all alternatives at the end of the dry season period 1.

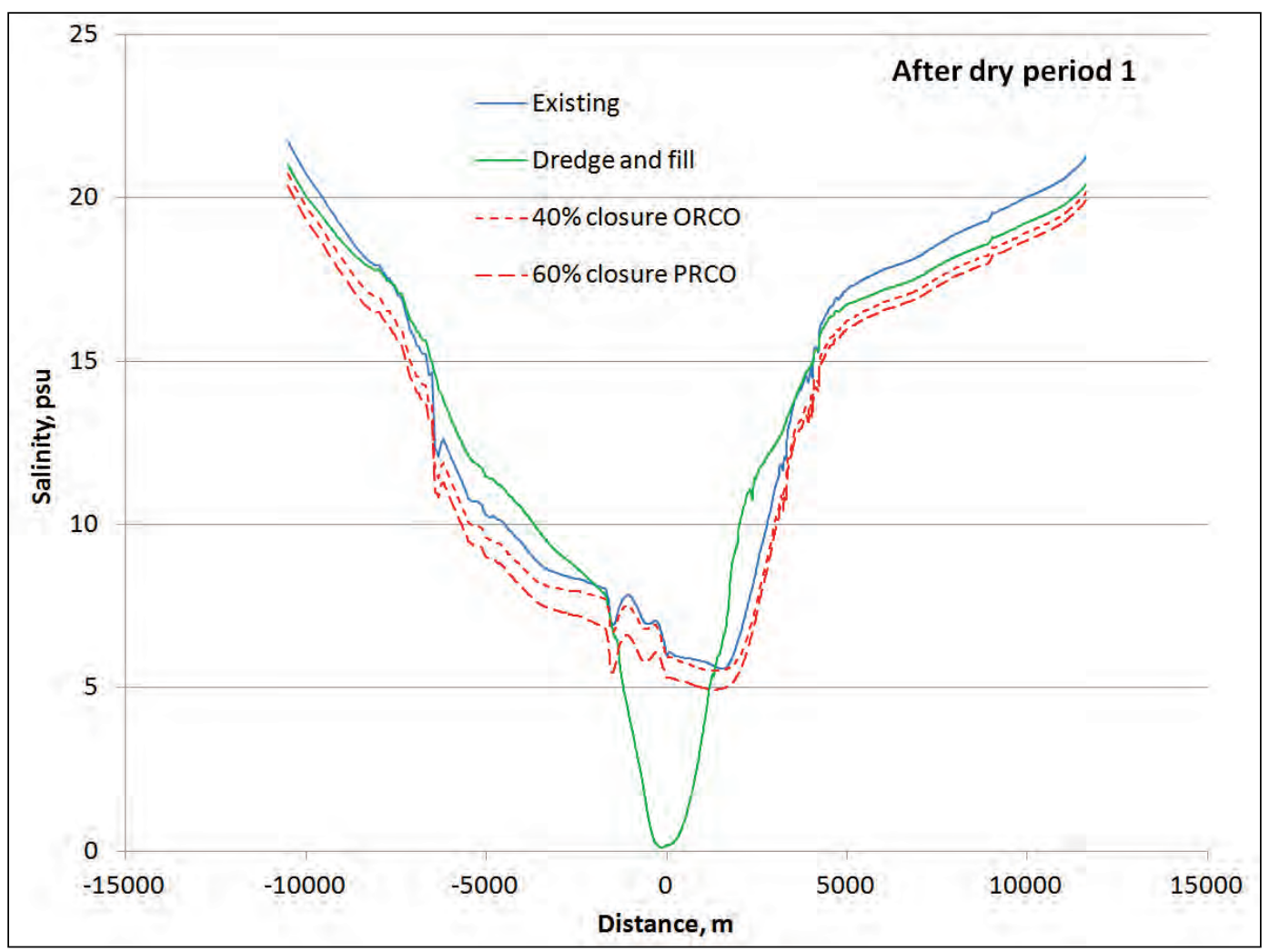

\section{Comparisons at end of dry simulation period 2}

The profiles for all alternatives at the end of the second dry-season simulation period are presented in Figure 9-40. All alternatives are flushed out of the system except for the dredge-and-fill alternative along the ORCO. The dredge-and-fill alternative shows lower salinities in the lower Trinity River channel as it enters the bay.

\section{Comparisons at end of dry simulation period 3}

The salinity profiles at the end of the third period (Figure 9-41) are very similar to the end of period 2 . The third period simulated the closing of a structure and lasted only $45 \mathrm{~min}$, so that is expected. 
Figure 9-40 Salinity profile for all alternatives at the end of the dry season period 2.

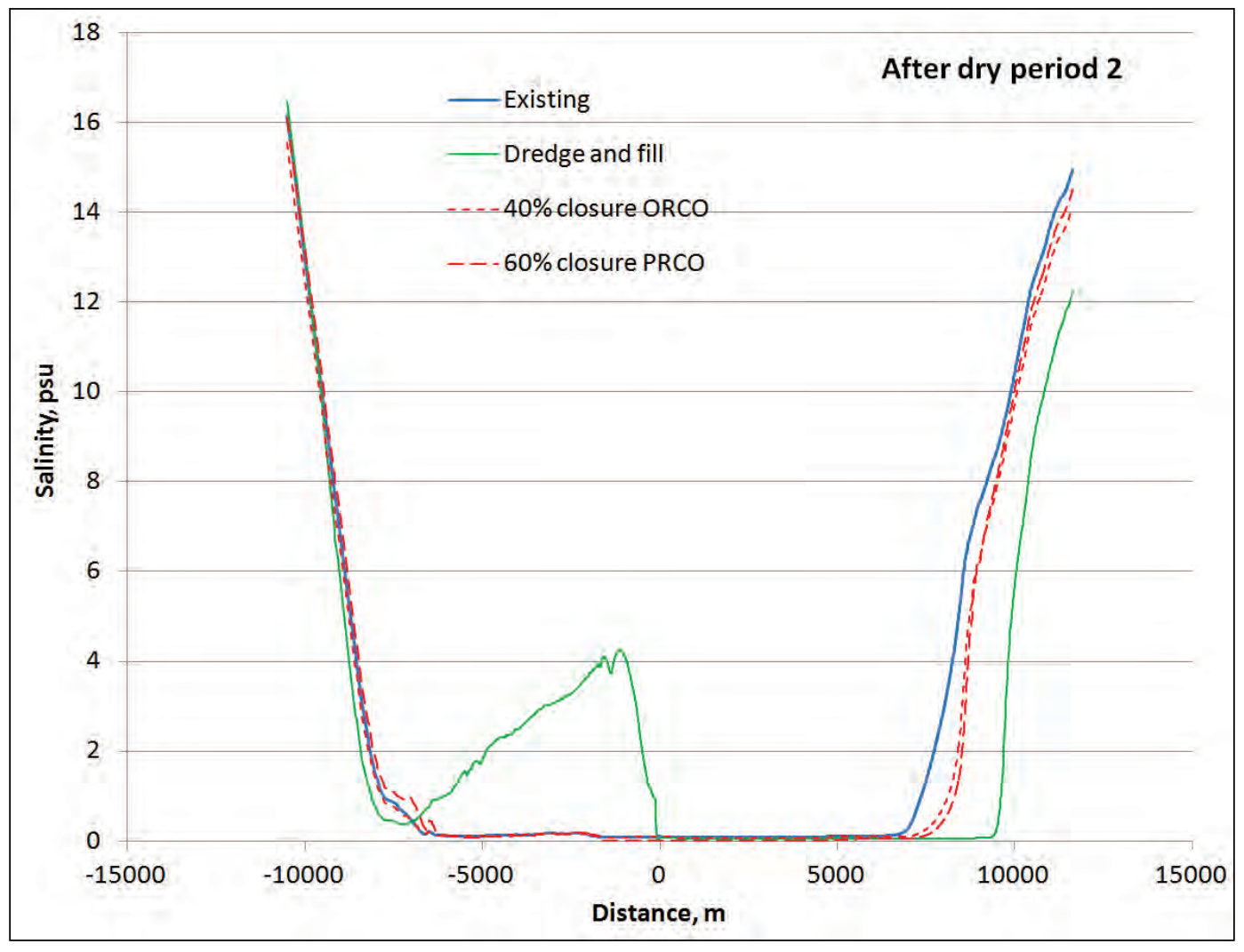

Figure 9-41 Salinity profile for all alternatives at the end of the dry season period 3.

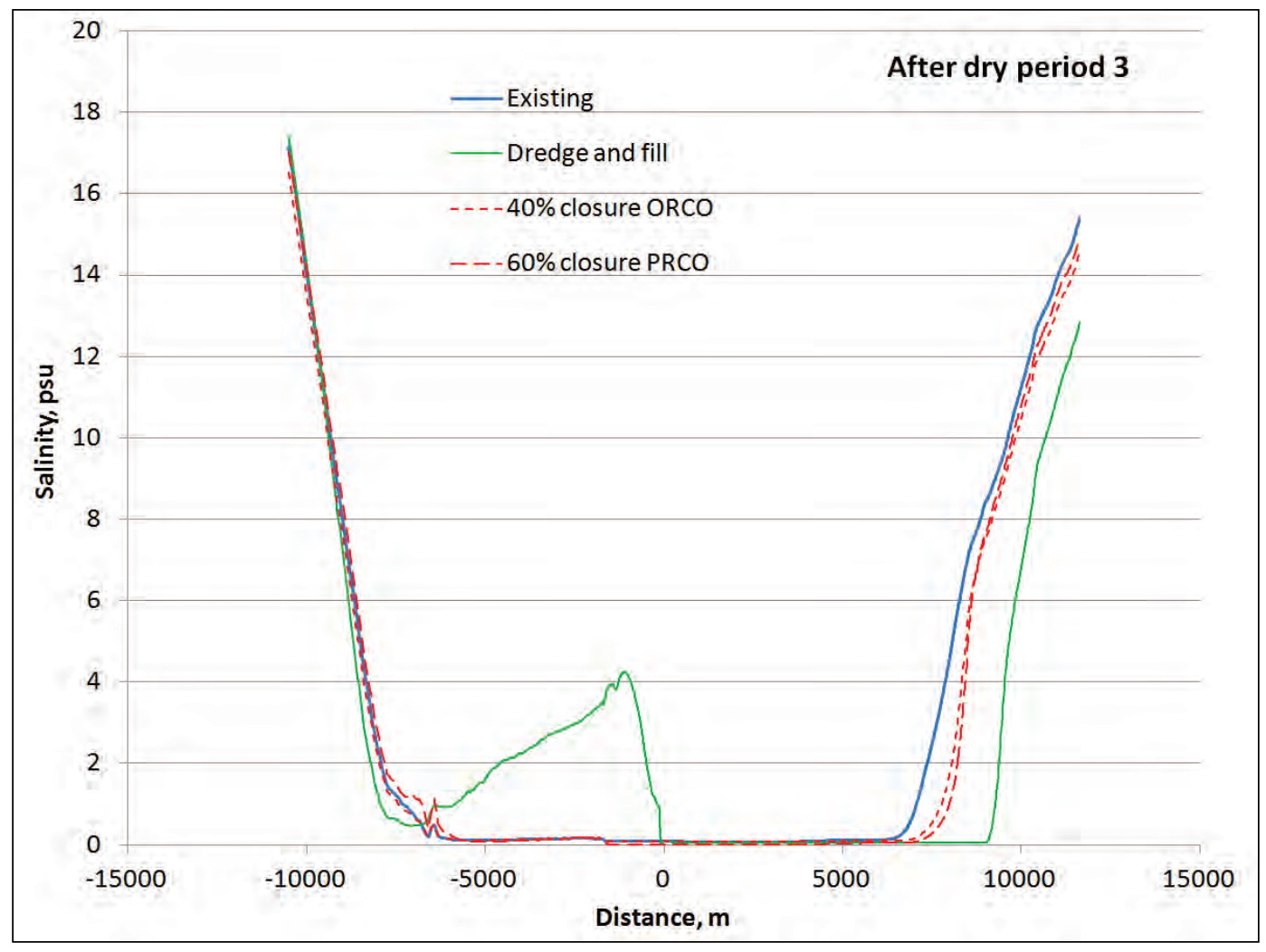




\section{Comparisons at end of dry simulation period 4}

At the end of the fourth dry-season simulation period (Figure 9-42), all alternatives have similar intrusion except for the dredge-and-fill. The dredge-and-fill has lower salinities along the ORCO path and slightly higher salinities along the Trinity River, except near the confluence, where it is fresher.

Figure 9-42 Salinity profile for all alternatives at the end of the dry season period 4.

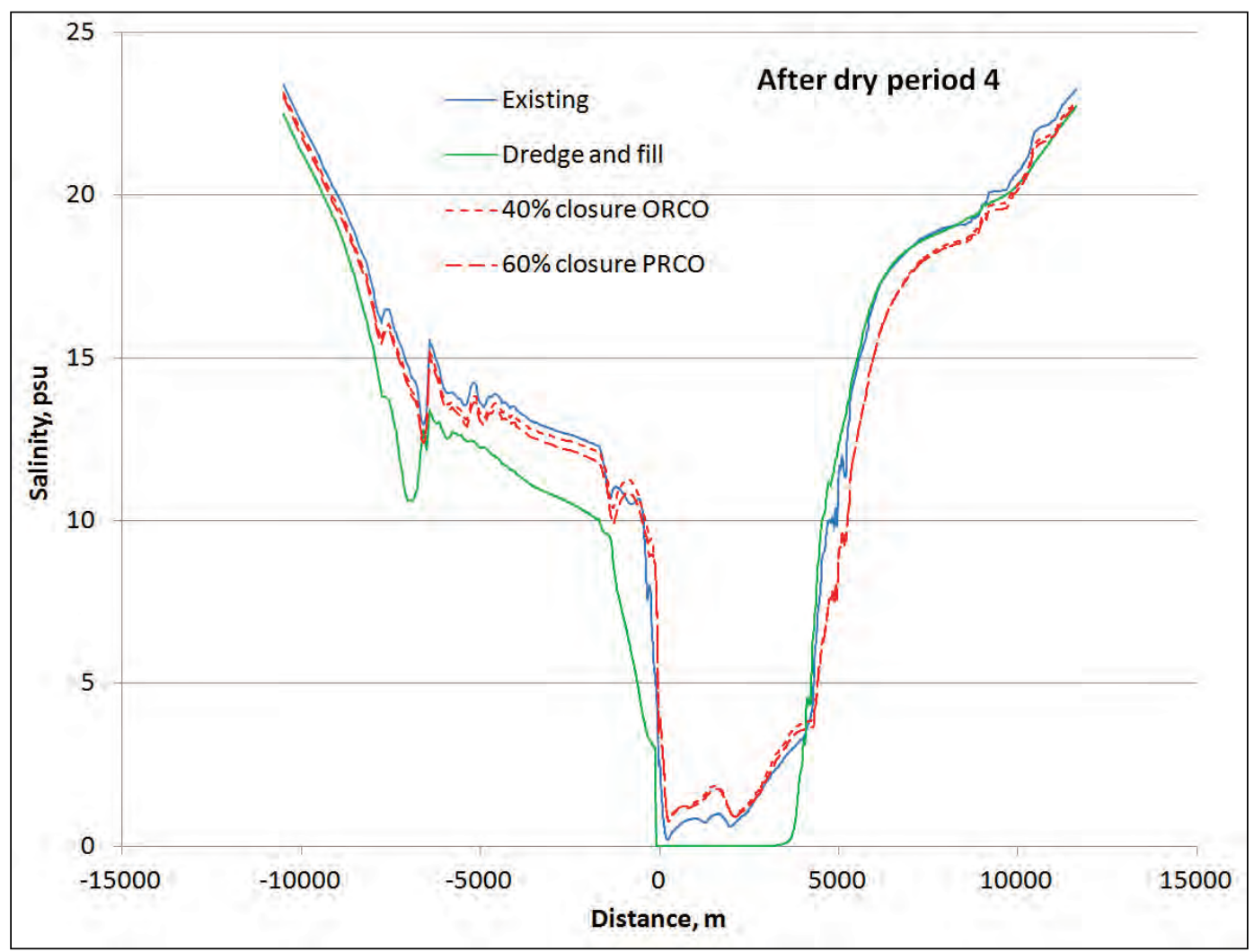

\section{Comparisons at end of dry simulation period 5}

The flushing of the system during the fifth dry-season simulation period, when both of the structures were open, is illustrated in Figure 9-43. The dredge-and-fill alternative shows the lowest salinities, particularly along ORCO. The higher salinities persist down the Trinity River as well.

\section{Comparisons at end of dry simulation period 6}

The end of the sixth simulation period (Figure 9-44) shows results are very close to those seen after the fifth period for all alternatives except the dredge-and-fill option. Again, this is due to the short duration (1 hr) of the 
Figure 9-43 Salinity profile for all alternatives at the end of the dry season period 5.

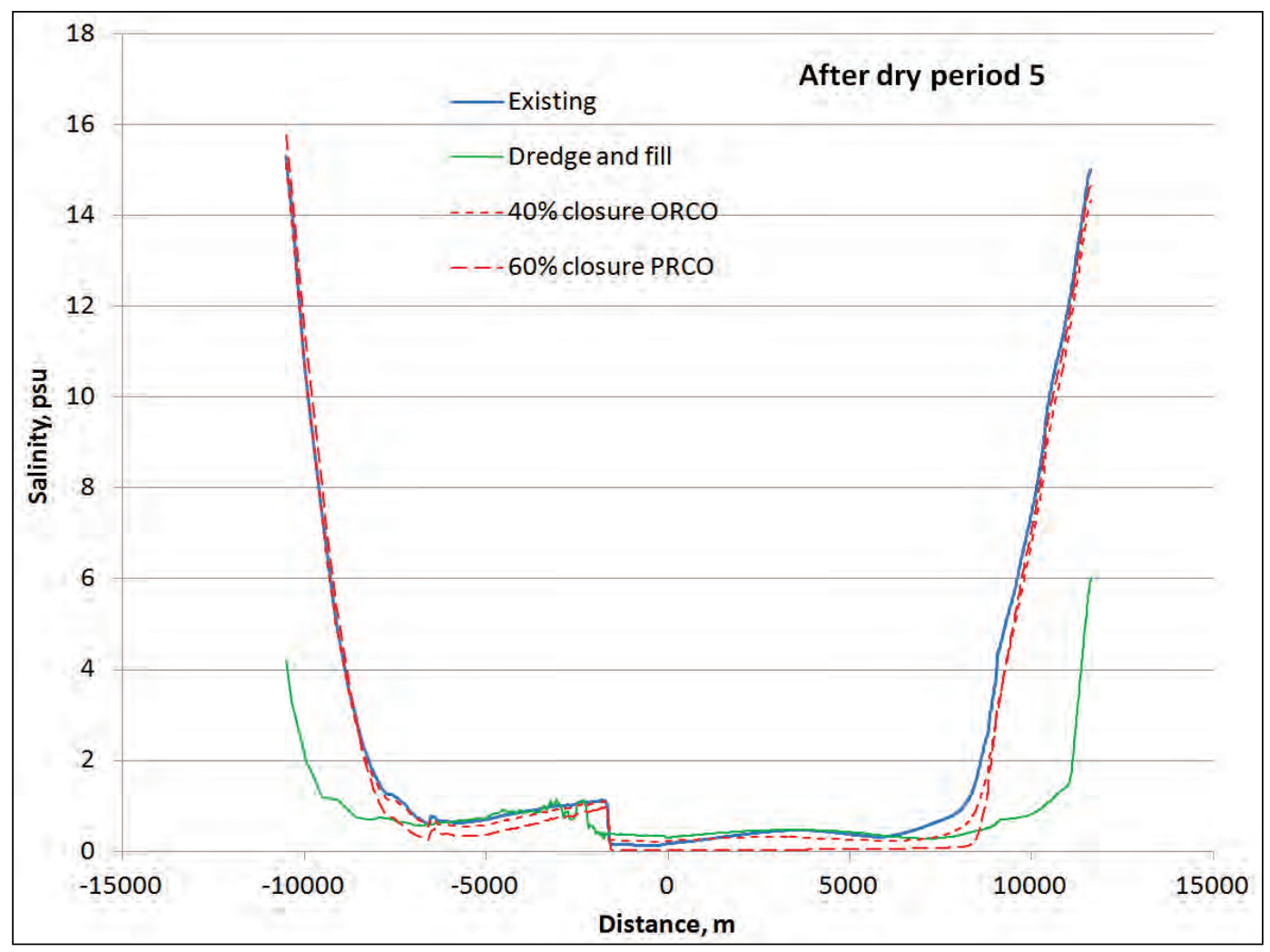

Figure 9-44 Salinity profile for all alternatives at the end of the dry season period 6.

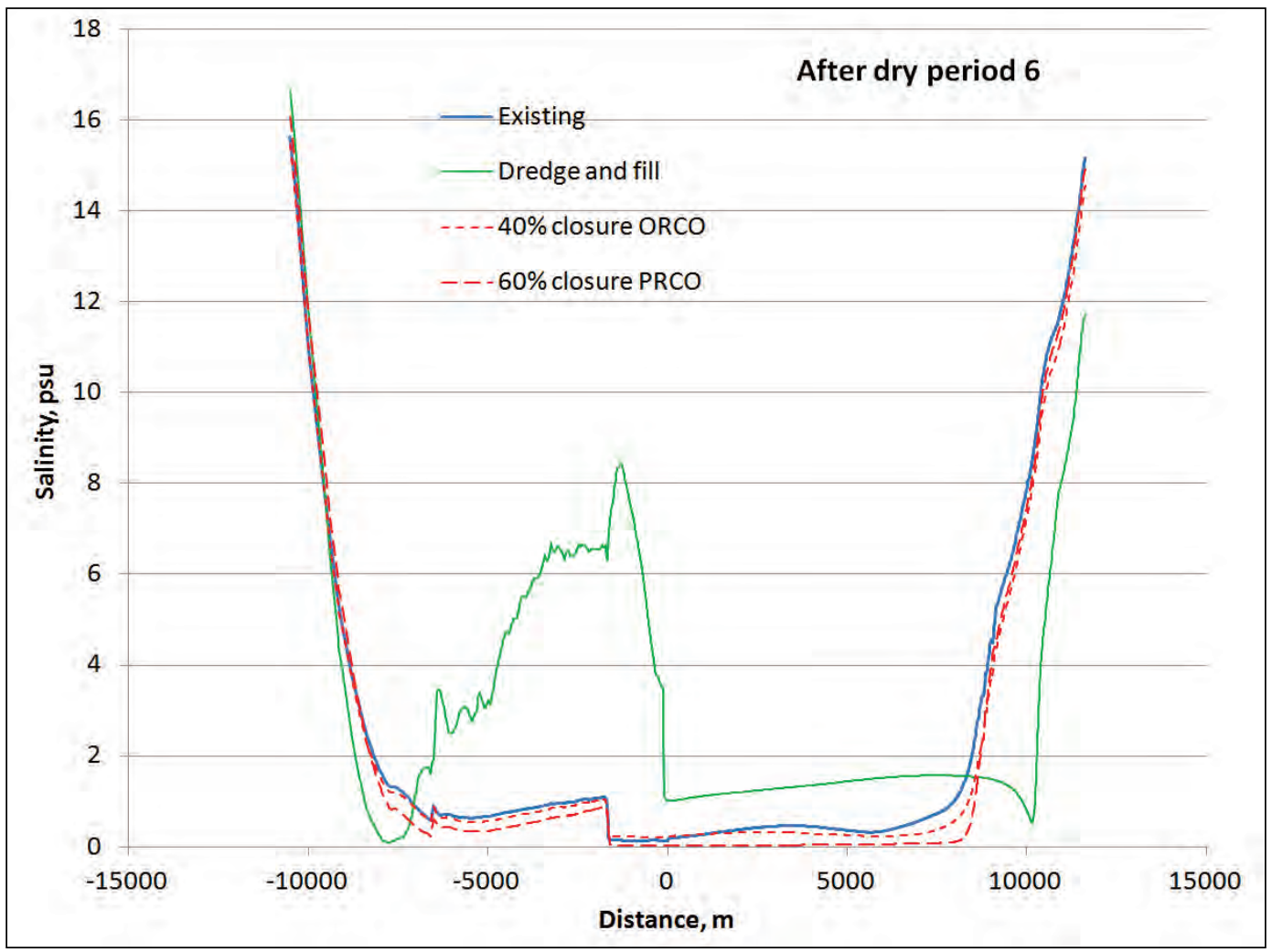


sixth period. However, the dredge-and-fill option reflects the eastward circulation induced in the ORCO by the dredging of the Trinity River and the opening of the structures during segment 6.

\section{Comparisons at end of dry simulation period 7}

The salinity intrusion along the profile at the end of the seventh dryseason simulation period is presented in Figure 9-45 for each of the alternatives. Again, the alternative that deviates from the closely similar trends is the dredge-and-fill. The dredge-and-fill case is fresh at the confluence and slightly saltier than the other alternatives along the rest of the profile. Each of the partial-closure alternatives shows a general reduction in salinities along the profile.

Figure 9-45 Salinity profile for all alternatives at the end of the dry season period 7.

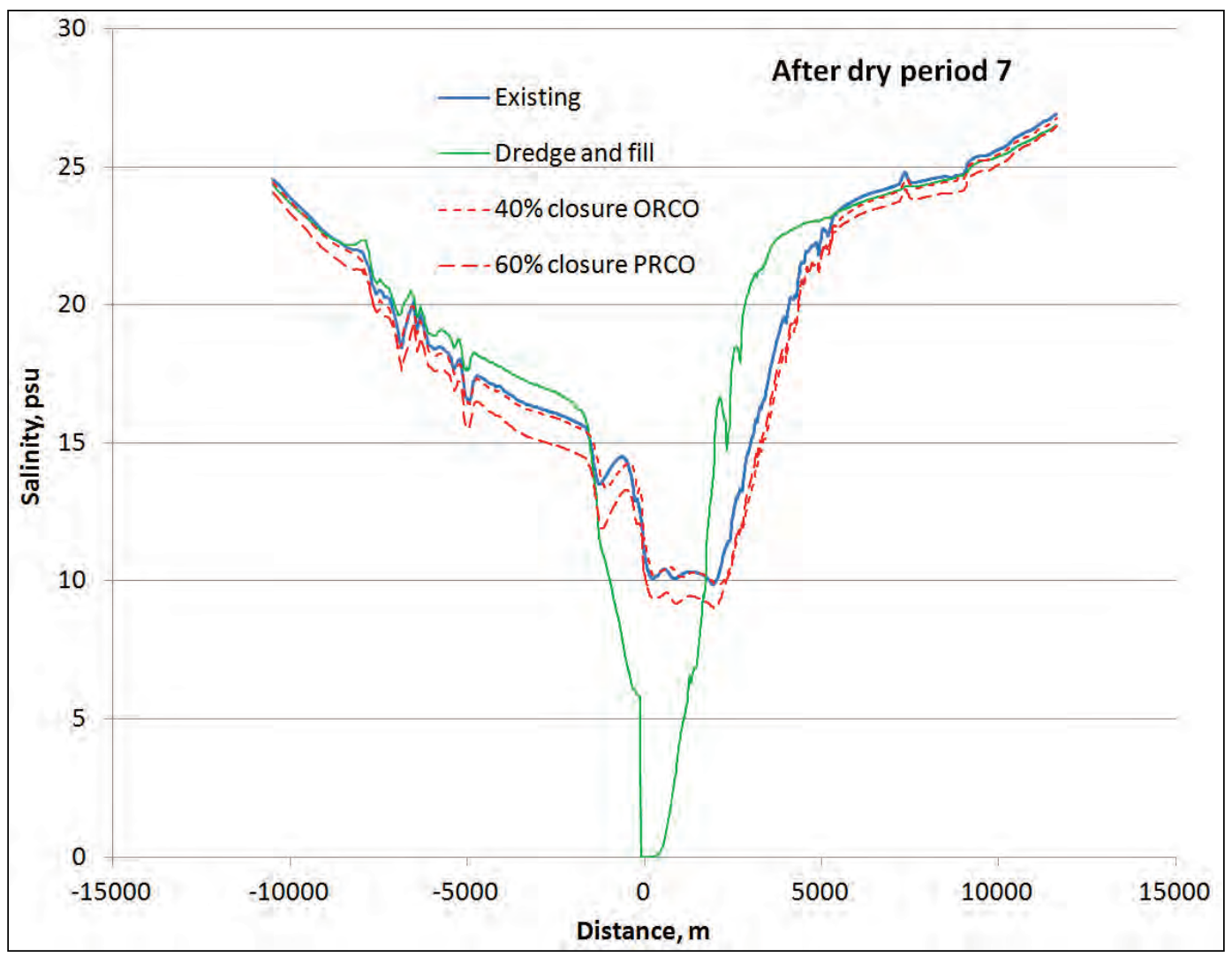




\section{Conclusions}

The following conclusions have been drawn from the numerical modeling performed and documented within this report:

- The AdH model developed for the project has been shown to reliably reproduce observed behavior of hydrodynamics and sedimentation trends within the lower Trinity River sufficiently to answer the basic study question: Is it possible, in principle, to remove the Trinity River shoal below the ORCO/Trinity River split by manipulation of the ORCO near the Trinity River?

- The shoaling below the Wallisville structures is a sand-transportcapacity problem and can be studied without consideration of fine sediments (silts and clays).

- The shoaling is the result of deltaic processes seeking a more hydraulically efficient route for the river water.

- The sedimentation bathymetric changes occur primarily during the wet season. Very limited changes occur during the dry season.

- Complete closure of ORCO will erode the shoal at the head of the Trinity River channel regardless of the direction from which the flows arrive (lock or salt-barrier channel).

- Closure of ORCO pushes shoaling downstream, with flow becoming diverted into and promoting erosion of the downstream passes, which then results in deposition downstream of the diversions in the Trinity River channel.

- Partial closure of ORCO provides some reduction in the shoaling rate in the vicinity of the shoal, without having significant impacts farther downstream on the Trinity River.

- The $60 \%$ closure of ORCO provided the greatest shoal removal for the partial-closure cases tested.

- The dredging of the shoal and placement into ORCO provides only limited reduction in the shoaling rate over the existing conditions.

- The salinity modeling suggested that none of the tested partial-closure alternatives changed the statistical response of the system to salinity intrusion during the dry season compared to the existing conditions.

- The dredge-and-fill alternative altered the salinity regime in a complex manner that increased salinities to the west and generally freshened the eastern portion of the delta. 


\section{References}

Americas Wetland Resources. 2012. Louisiana Old River Control Complex and Mississippi River flood protection. New Orleans, LA: Loyola University. http://www.americaswetlandresources.com/background_facts/detailedstory/LouisianaRiverCon trol.html

Berger, R. C., J . N. Tate, G. L. Brown, and G. Savant. 2013. Adaptive hydraulics; Users manual. Vicksburg, MS: U.S. Army Engineer Research and Development Center. http://chl.erdc.usace.army.mil/Media/1/2/9/9/AdH_Manual_4.3.pdfor http://AdH.usace.army.mil

Coleman, J . M., and S. M. Gagliano. 1964. Cyclic sedimentation in the Mississippi River deltaic plain. Gulf Coast Association of Geologic Society Transactions 14: 67- 80.

Dellapenna, T. M., M. A. Allison, G. A. Gill, R. D. Lehman, K. W. Warnken. 2006. The impact of shrimp trawling and associated sediment resuspension in mud dominated, shallow estuaries. Estuarine, Coastal and Shelf Science 69(3-4): 519- 530. Elsevier. http://dx.doi.org/10.1016/j.ecss.2006.04.024

Letter, J . V., Jr. 1982. The Atchafalaya River delta; Report 3, extrapolation of delta growth. Technical Report HL-82-15. Vicksburg, MS: U.S. Army Engineer Waterways Experiment Station.

Letter, J . V., J r., C. F. Pinkard, J r., and N. K. Raphelt. 2008. River diversions and shoaling. ERDC/ CHL CHETN-VII-9. Vicksburg, MS: U.S. Army Engineer Research and Development Center. http://chl.erdc.usace.army.mil/chetn.

National Ocean Service. 2006. Tide tables 2006, High and low water predictions, East Coast of North and South America, including Greenland. Washington, DC: U.S. Department of Commerce, National Oceanic and Atmospheric Administration.

Phillips, J . D., M. C. Slattery, and Z. A. Musselman. 2004. Dam-to-delta sediment inputs and storage in the lower Trinity River, Texas. Geomorphology 62: 17- 34.

Phillips, J . D., and M. C. Slattery. 2007. Downstream trends in discharge, slope, and stream power in a lower coastal plain river. J ournal of Hydrology 334: 290- 303.

Trinity Waters. 2011. Trinity River basin characteristics. http://trinitywaters.org/trinityriver/trinity-river-basin-characteristics/

U.S. Army Engineer Waterways Experiment Station. 1952. Hydraulic design criteria. Vicksburg, MS: U.S. Army Engineer Waterways Experiment Station. http://chl.erdc.usace.army.mil/hdc

Wells, J. T., S. J . Chinburg, and J. M. Coleman. 1984. The Atchafalaya River delta; Report 4, generic analysis of delta development. Technical Report HL-82-15. Vicksburg, MS: U.S. Army Engineer Waterways Experiment Station. 


\section{Appendix A: Aerial Photographs of Trinity River Delta Evolution}

Figure A-1. Condition of the system in 1970.

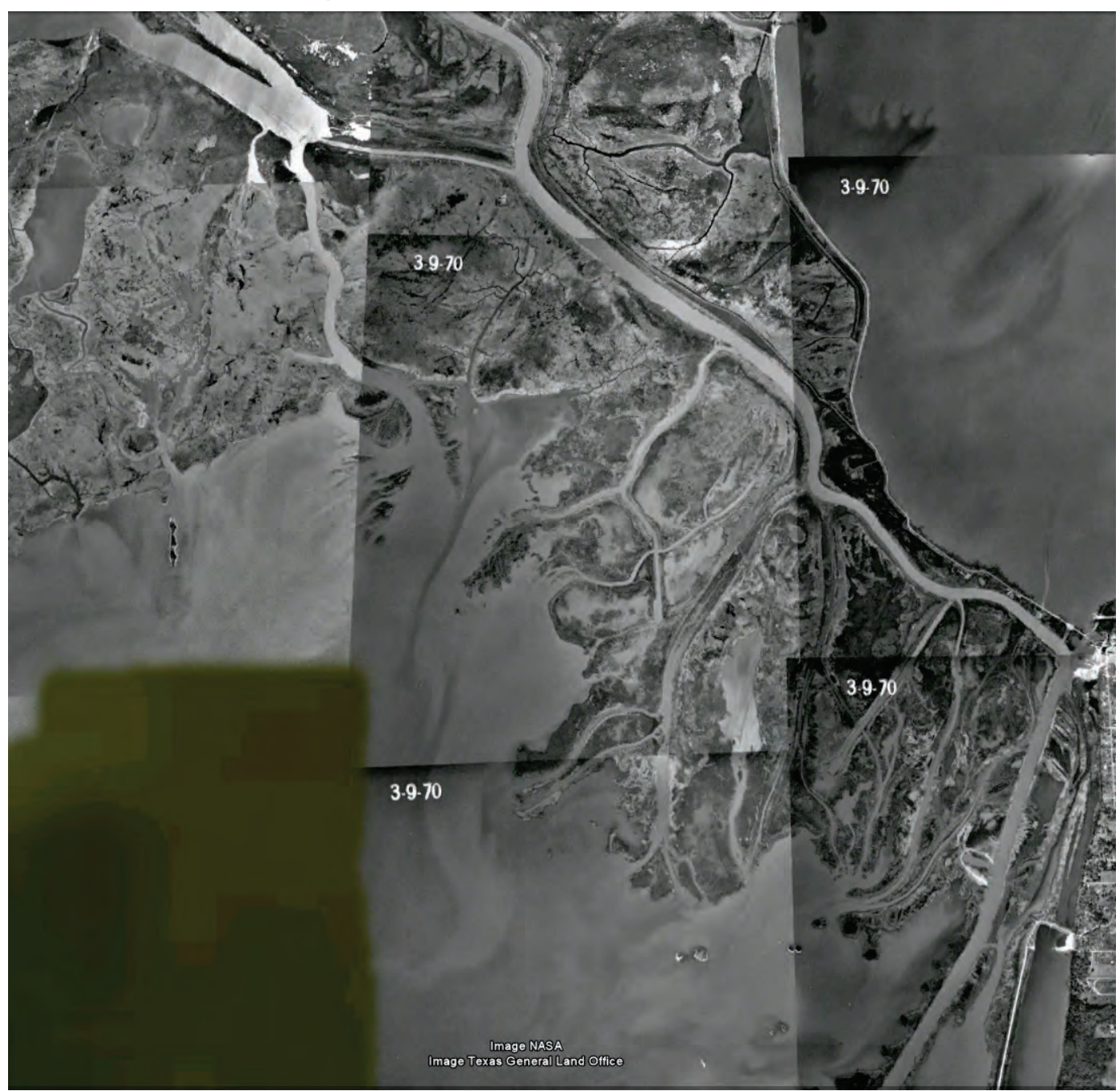


Figure A-2. Aerial photograph from 18 January 1995.

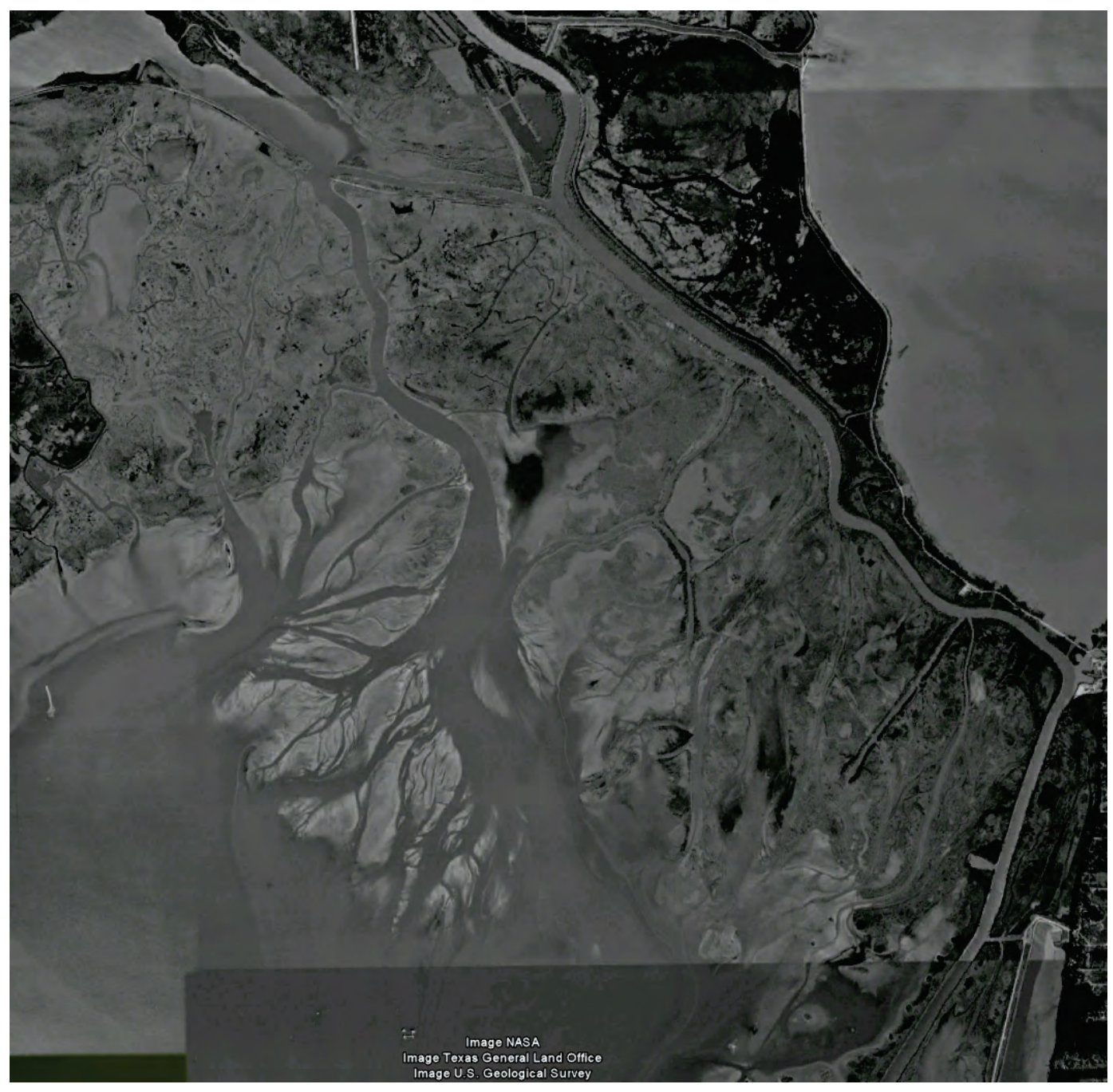


Figure A-1 Aerial photograph from 30 August 2002.

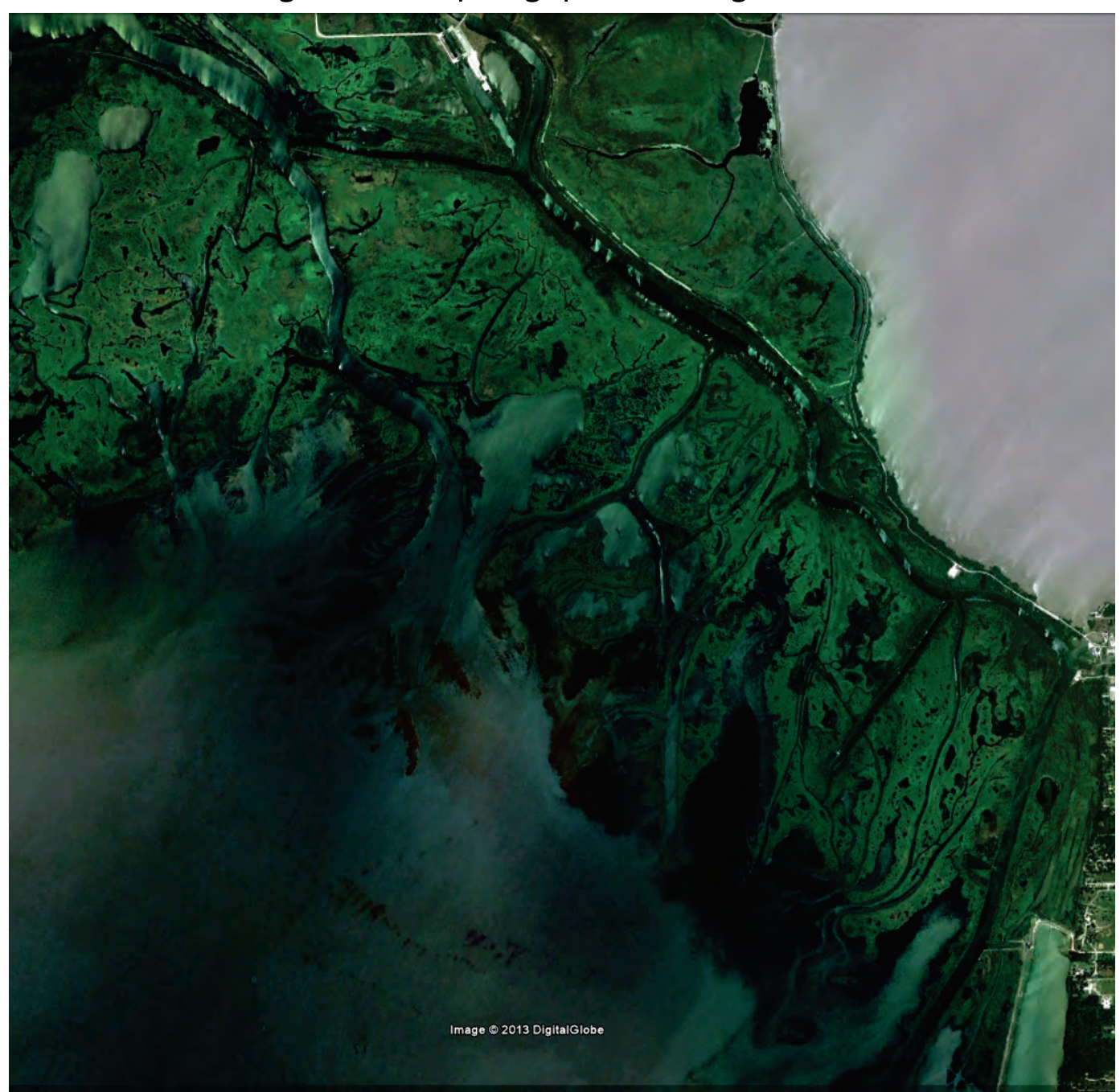


Figure A-4. Aerial photograph from 27 June 2005.

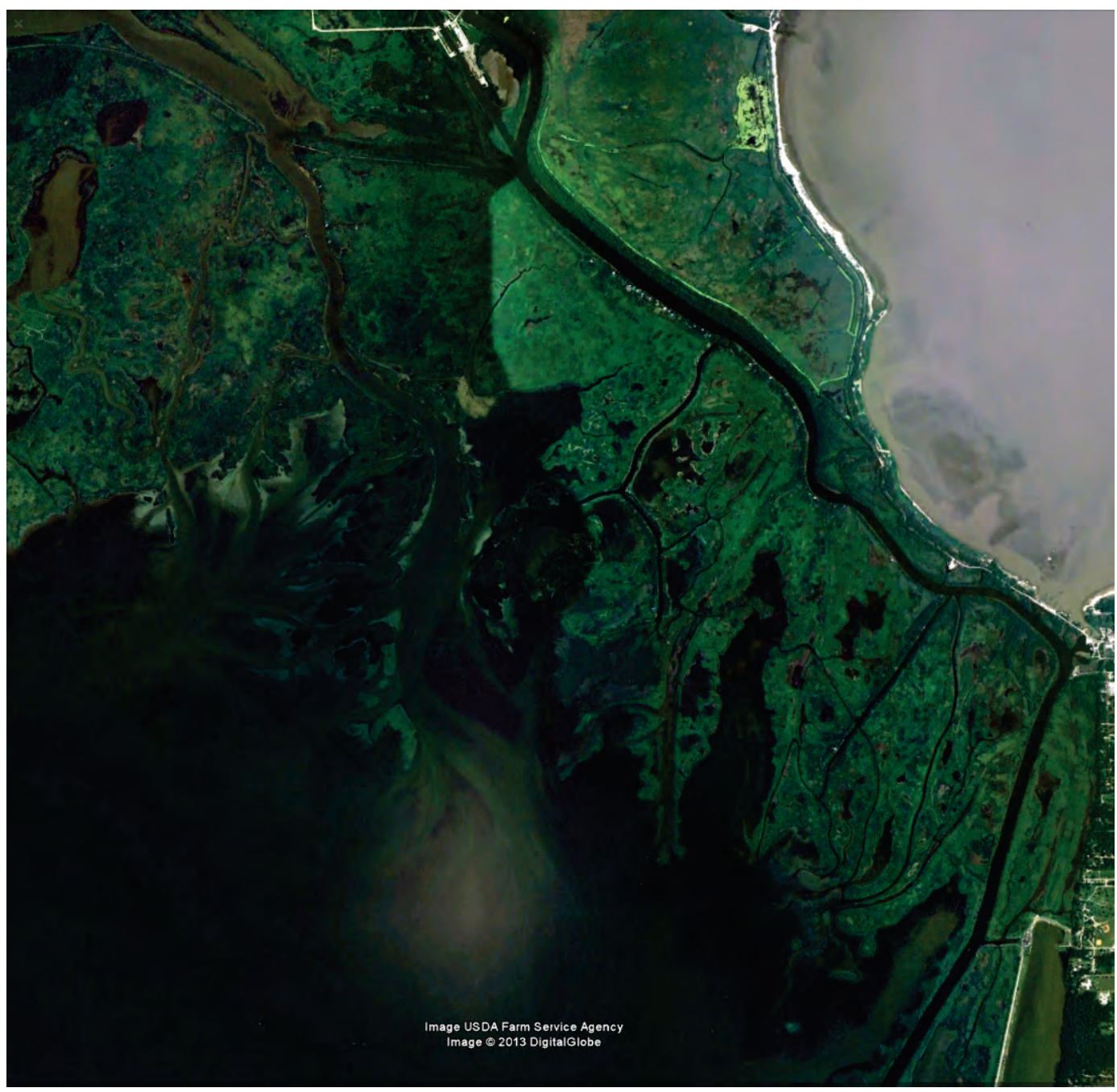


Figure A-5. Aerial photograph from 31 March 2006.

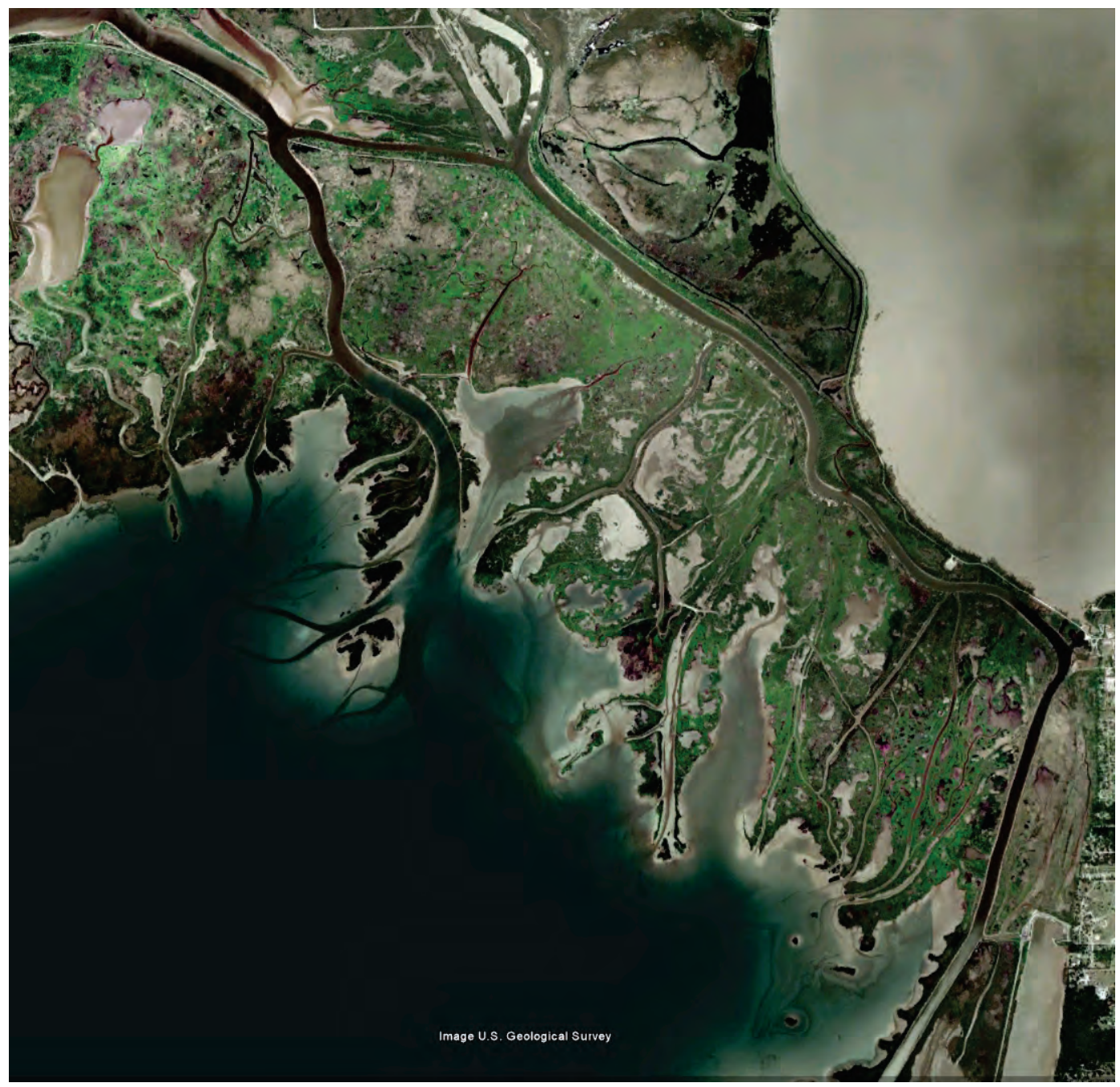


Figure A-6. Aerial photograph from 31 October 2006.

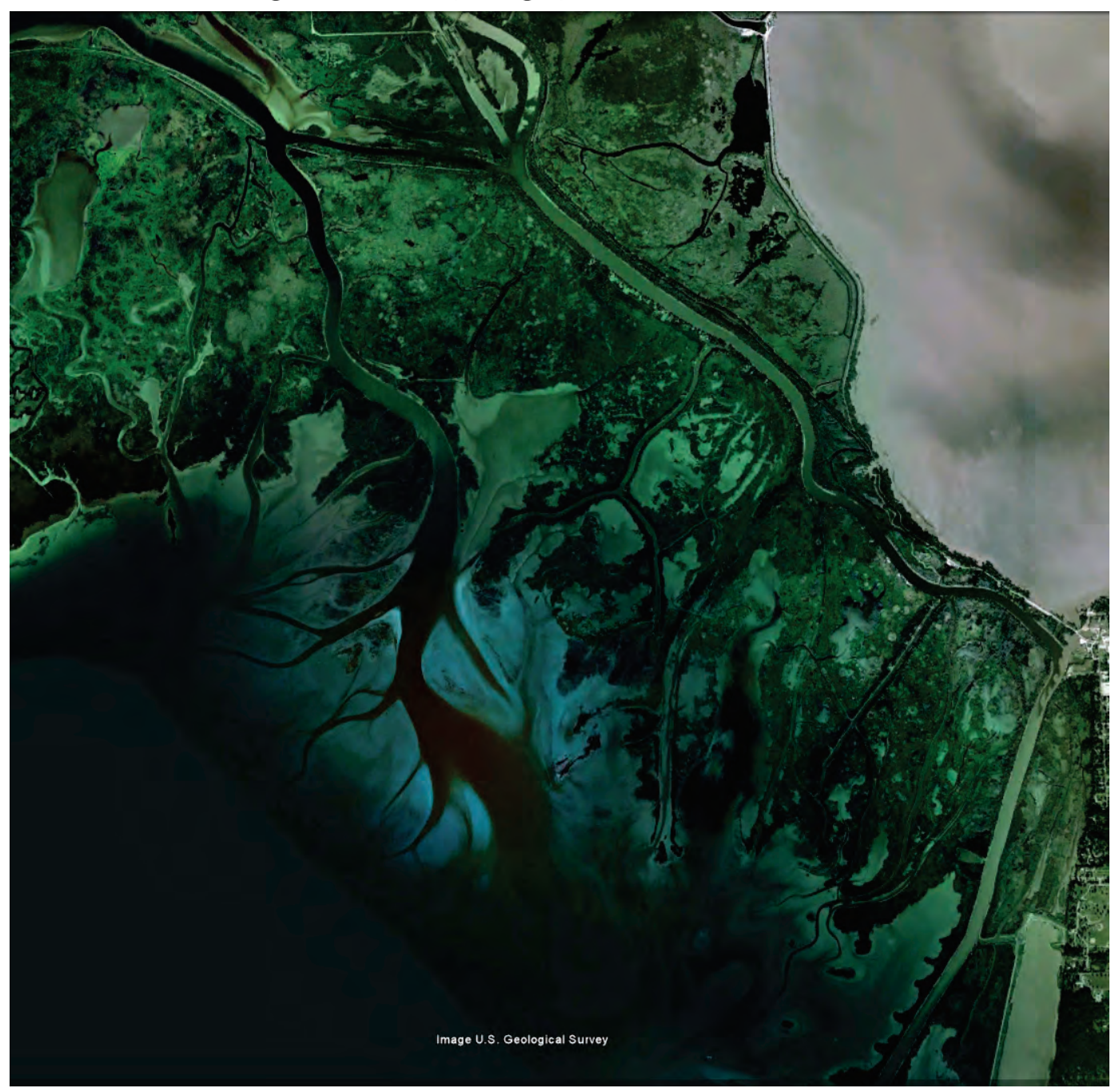


Figure A-7. Aerial photograph from 31 March 2008.

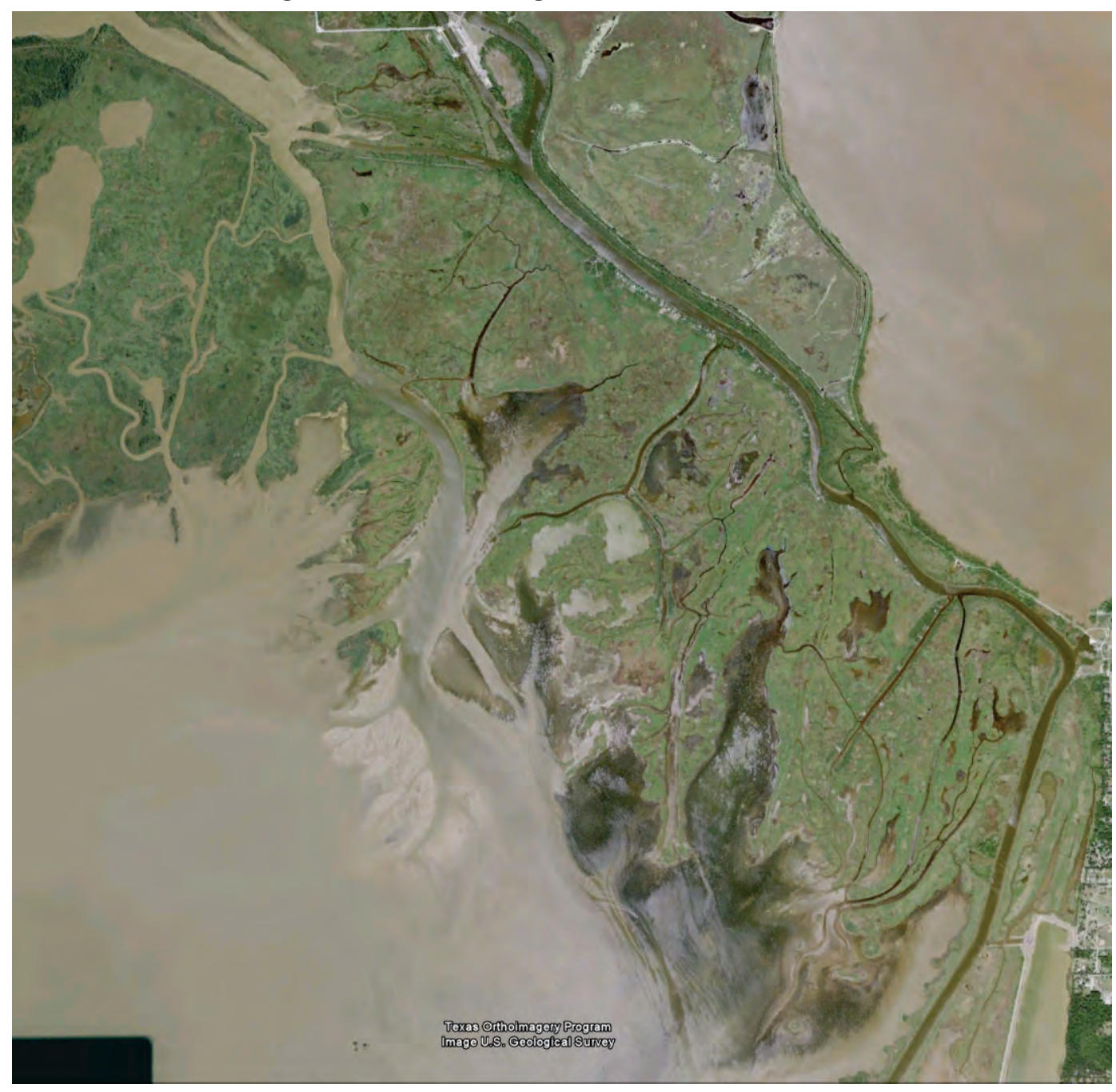


Figure A-8. Aerial photograph from 31 December 2008.

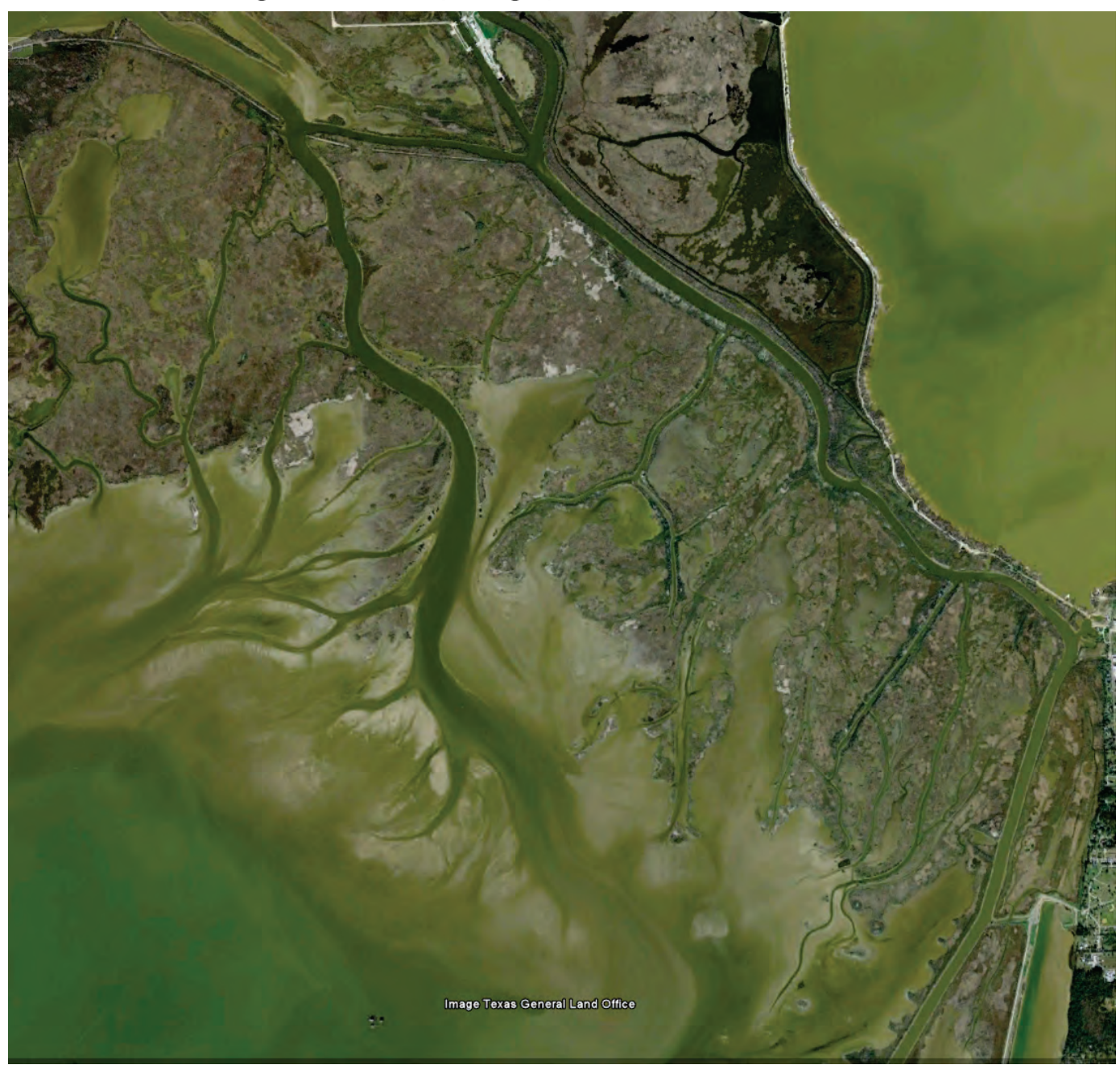


Figure A-9. Aerial photograph from 8 January 2010.

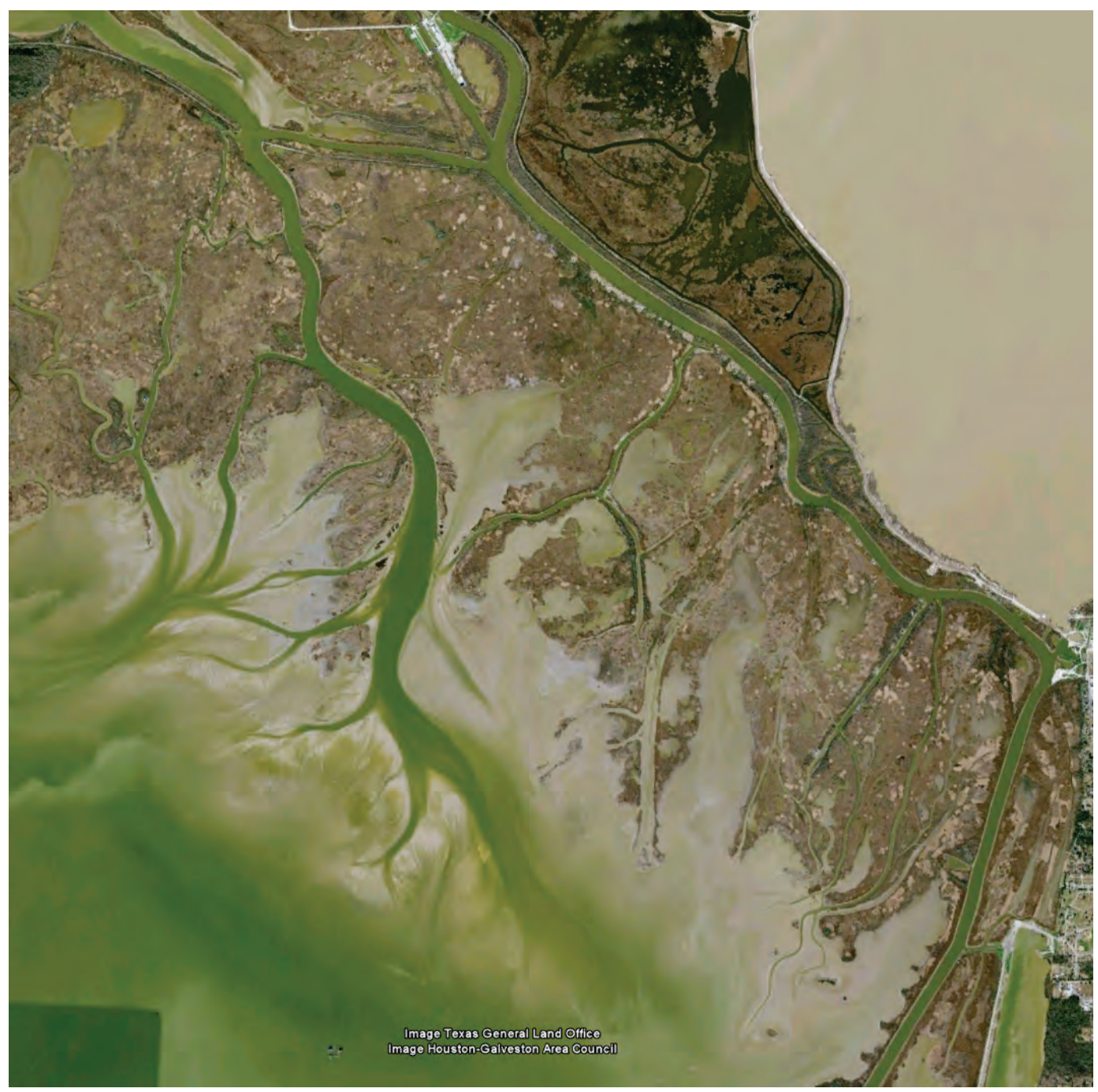


Figure A-10. Aerial photograph from 12 March 2010.

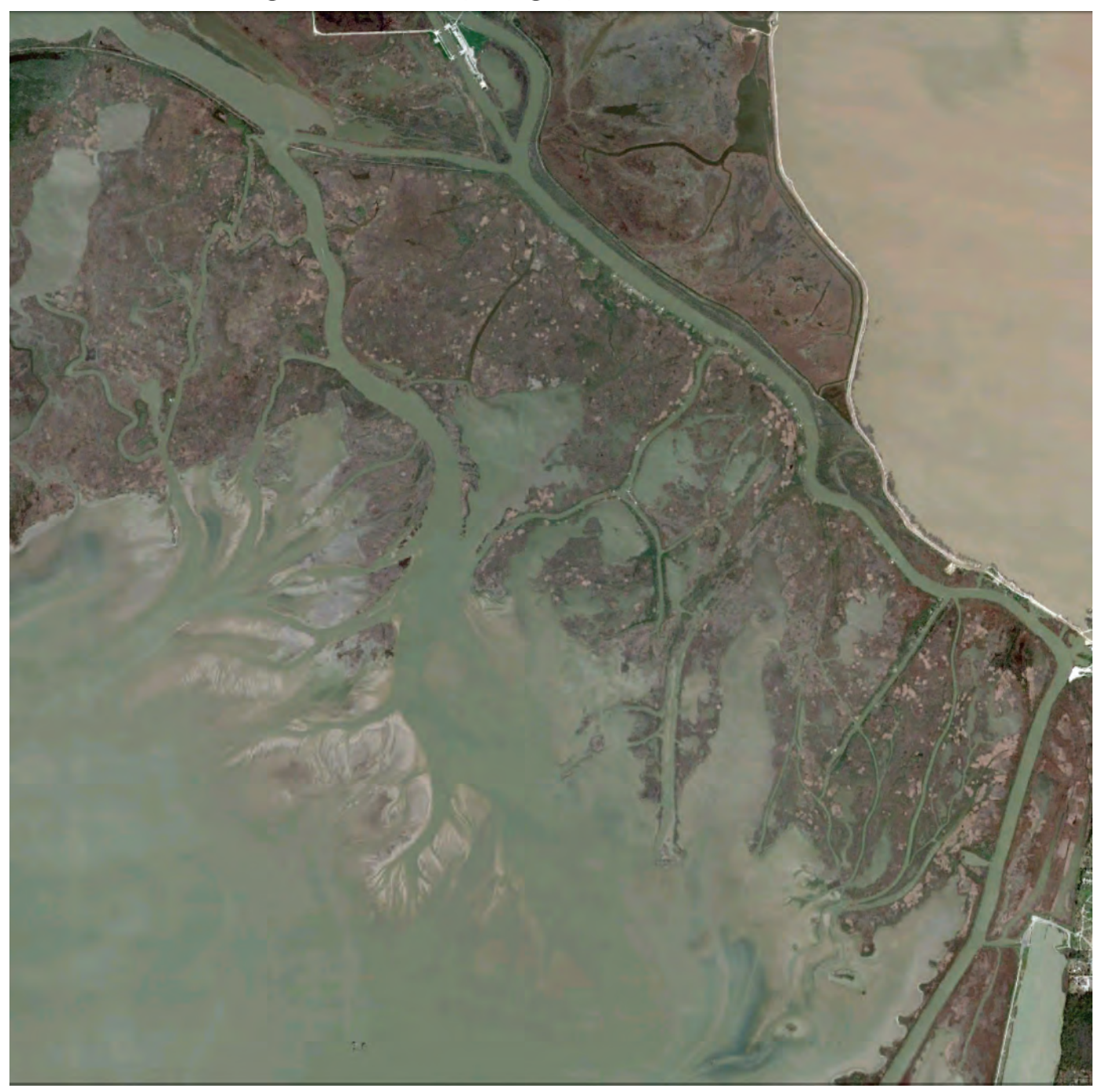


Figure A-11. Aerial photograph from 28 November 2011.

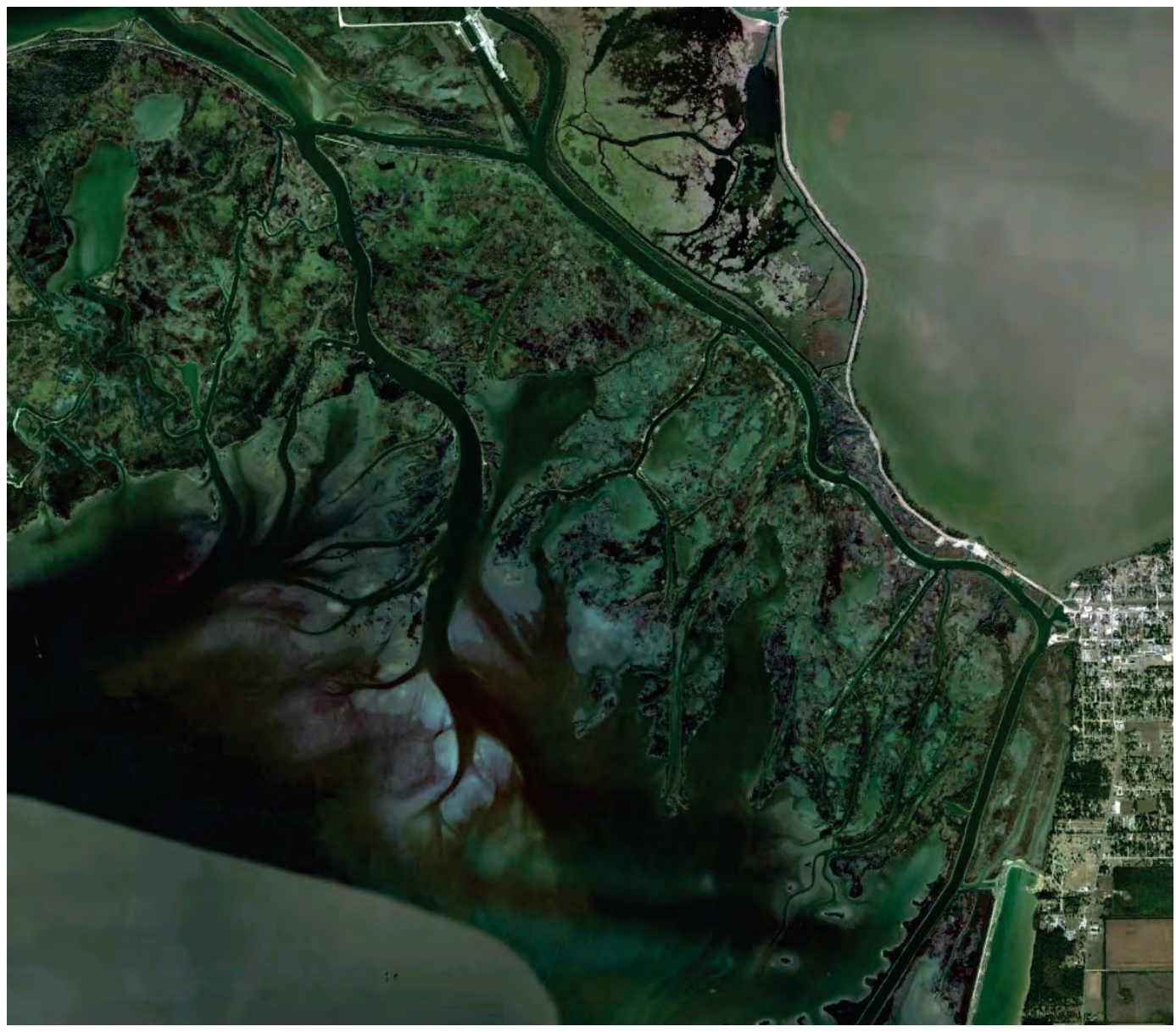

Figure A-12. Aerial photograph from 1970.

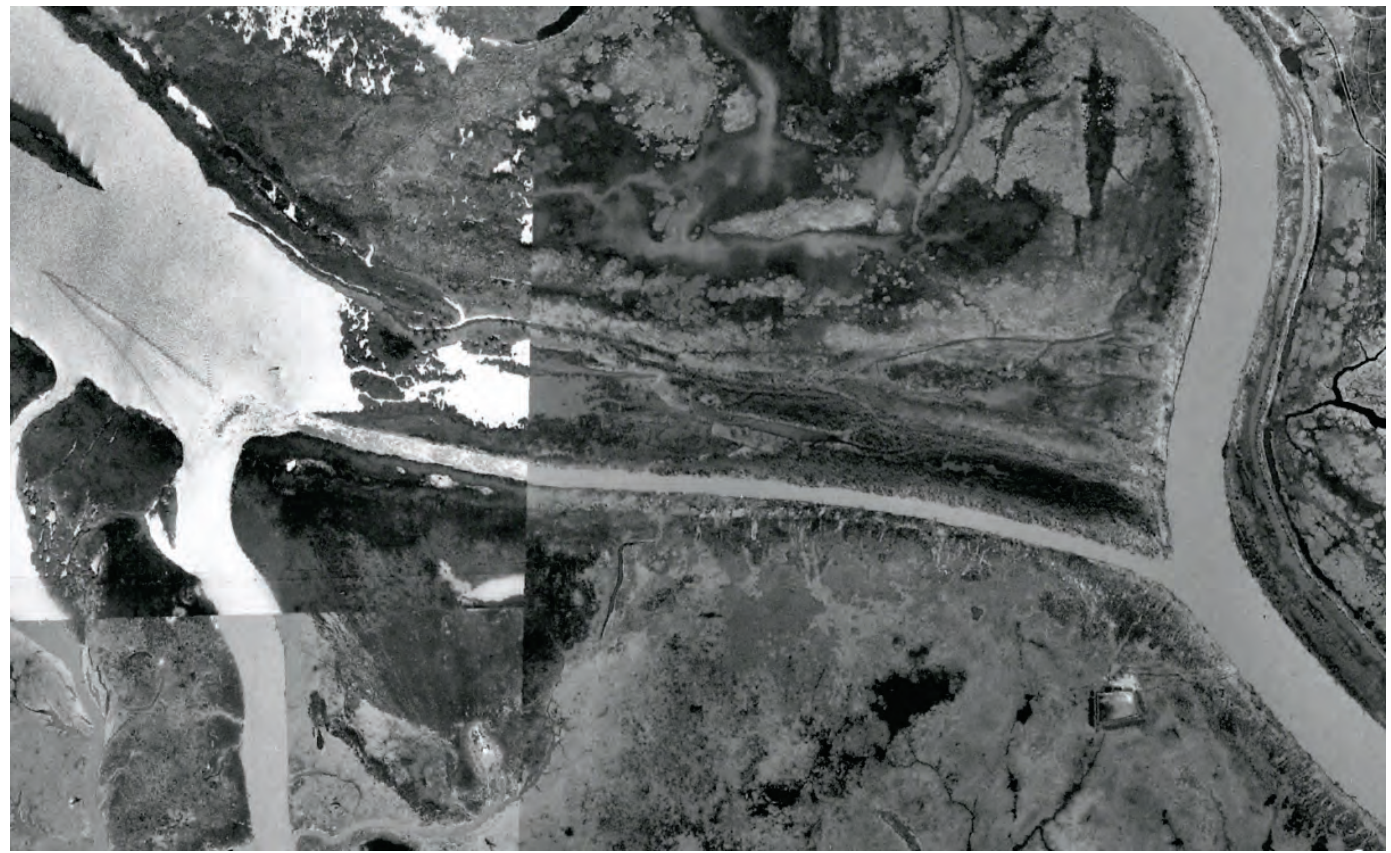


Figure A-13. Aerial photograph from 28 November 2011.

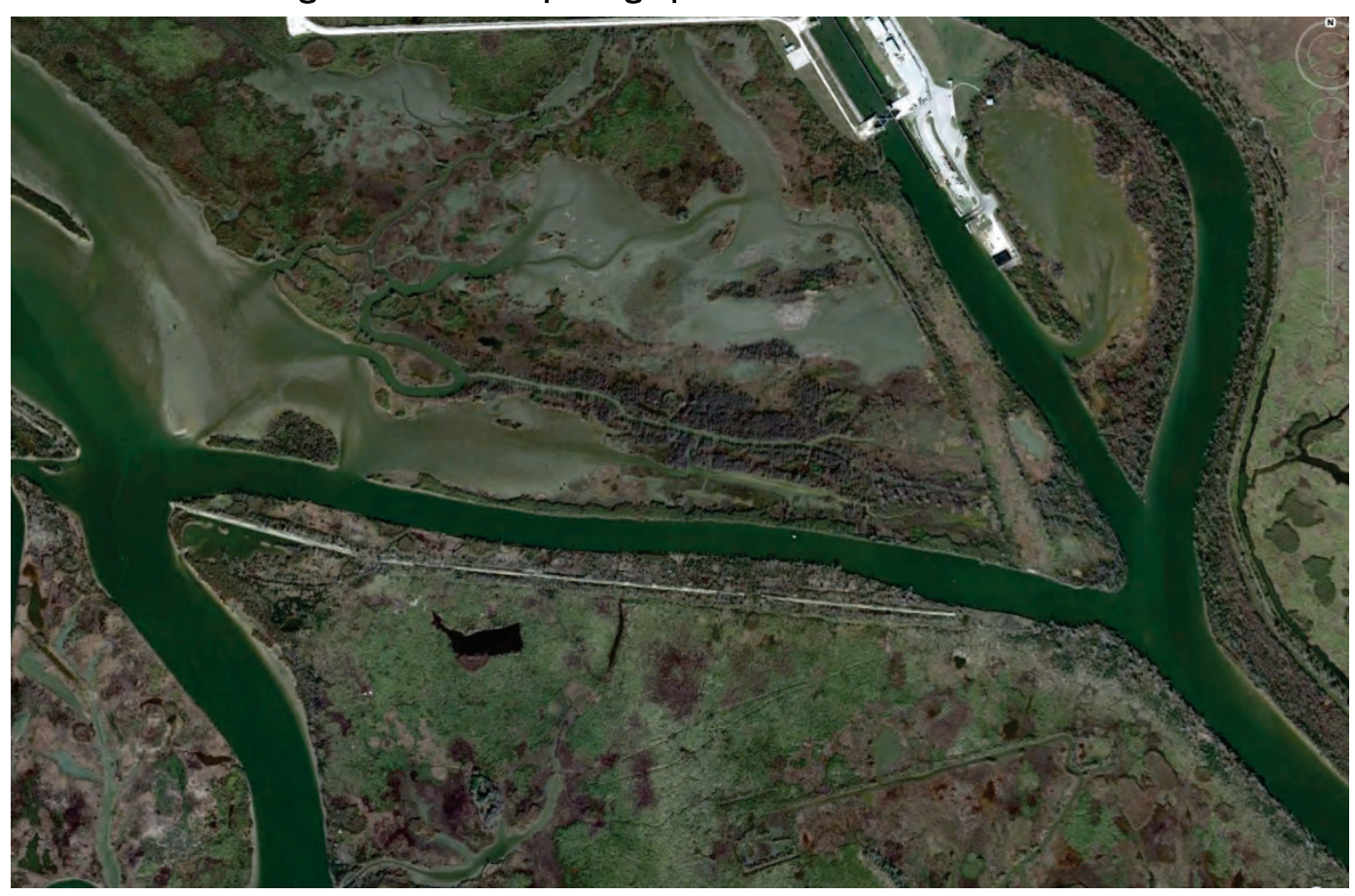




\section{Appendix B: Development of Upper River Bathymetry}

The Trinity River above Wallisville up to Liberty, TX, was identified as key to the response of the system to changes in backwater and redistribution of flows to the west. There are no comprehensive bathymetric data available for the upper system, but the sinuosity of the river within that reach was expected to be significant in the development of point bars with deep outer banks and cross-over bars between river bends. It was anticipated that if simplistic geometry were prescribed over the sinuous reach, dramatic bathymetric adjustments would ensue during the sediment modeling that would greatly complicate the overall modeling effort and the sediment supply to the Wallisville structures. Therefore, an effort was made to provide an approximation of the geometry with prescribed point bars and distorted cross sections associated with the sinuosity of the river. Figure B-1 presents a typical combination of turns in the river just below Liberty with prominent point bars.

Figure B-1 Example bendway on the lower Trinity River below Liberty, TX.

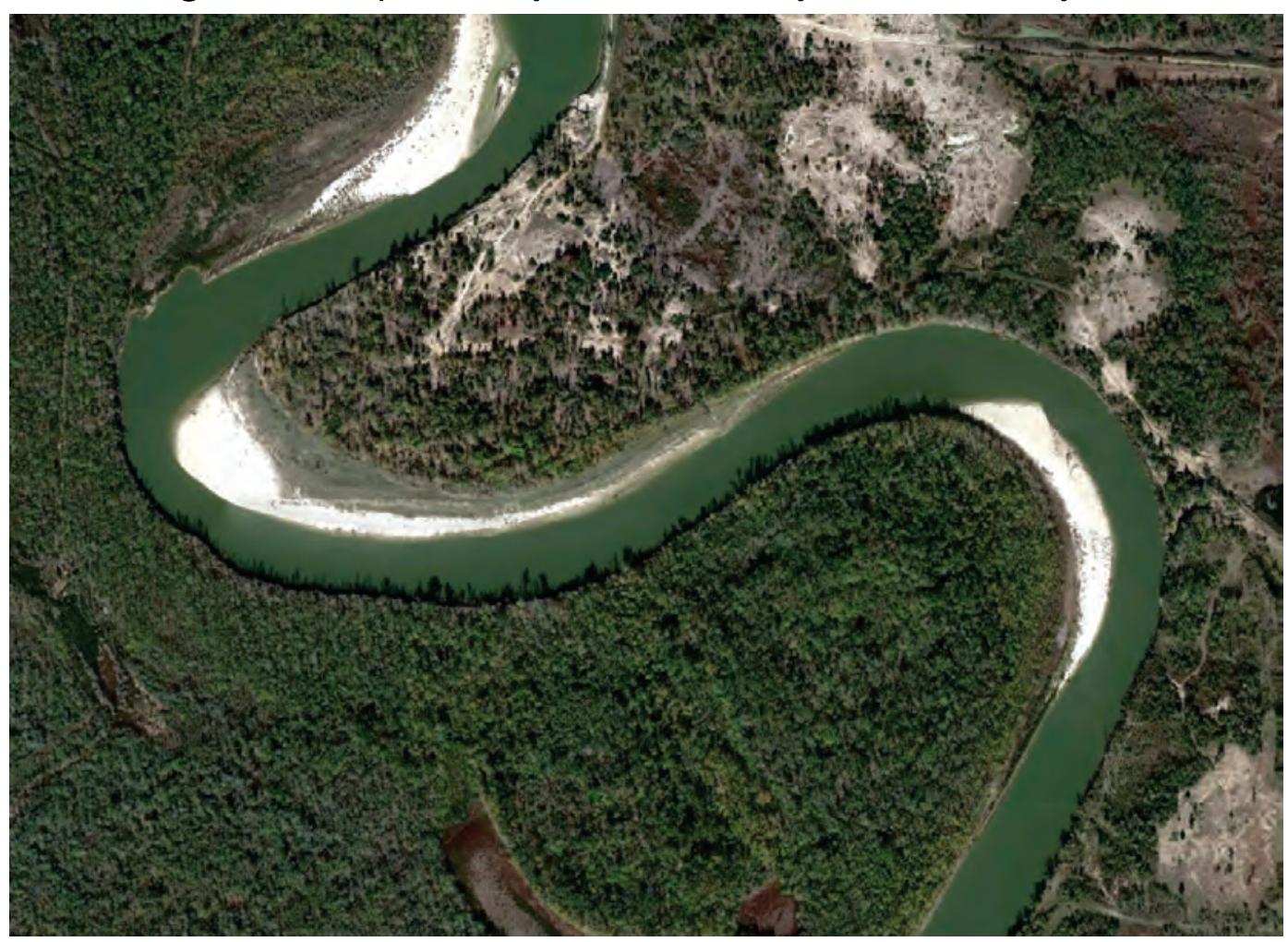




\section{The distorted channel}

The following is a heuristic approach to treating the bathymetry in response to a meandering channel.

Assume that there is a channel with a parabolic cross section, where the local depth is defined as

$$
\mathrm{d}=4 \mathrm{~d}_{\mathrm{m}} \mathrm{s}(1-\mathrm{s})
$$

and $\mathrm{s}=\mathrm{y} / \mathrm{W}$ is the nondimensional distance from the inner bank toward the outer bank:

where:

$$
\begin{aligned}
\mathrm{d} & =\text { local depth } \\
\mathrm{d}_{\mathrm{m}} & =\text { maximum depth in the cross section } \\
\mathrm{W} & =\text { channel width } \\
\mathrm{y} & =\text { distance from the inner bank toward the outer bank }
\end{aligned}
$$

and the normalization " 4 " assures that the depth at the deepest location along $s$ is $\mathrm{d}_{\mathrm{m}}$.

The cross-sectional area of the channel is computed as

$$
A=\int_{0}^{\mathrm{W}} \mathrm{d} d \mathrm{dy}=\mathrm{W} \int_{0}^{1} \mathrm{dds}=4 \mathrm{Wd} \mathrm{d}_{\mathrm{m}} \int_{0}^{1} \mathrm{~s}(1-\mathrm{s}) \mathrm{ds}=\frac{2}{3} \mathrm{~W} \mathrm{~d}_{\mathrm{m}}
$$

If the cross section is distorted due to the effects of channel meandering and helical flows in such a way that the cross section can be approximated as a quadratic equation in $\mathrm{s}^{\alpha}$ rather than $\mathrm{s}$, then

$$
\mathrm{d}=4 \mathrm{~d}_{\mathrm{m} \alpha} \mathrm{s}^{\alpha}\left(1-\mathrm{s}^{\alpha}\right)
$$

where $\alpha$ is an undetermined exponent, the distortion factor that determines the shift of the deep point of the cross section from midchannel, and $\mathrm{d}_{\mathrm{m} \alpha}$ is the maximum depth for a given $\alpha$. 
The area under the distorted cross section is

$$
\mathrm{A}=\int_{0}^{\mathrm{W}} \mathrm{d} d \mathrm{y}=\mathrm{W} \int_{0}^{1} \mathrm{~d} \mathrm{ds}=4 \mathrm{Wd} \mathrm{d}_{\mathrm{m} \alpha} \int_{0}^{1} \mathrm{~s}^{\alpha}\left(1-\mathrm{s}^{\alpha}\right) \mathrm{ds}=\frac{4 \alpha W d_{\mathrm{m} \alpha}}{(\alpha+1)(2 \alpha+1)}(\mathrm{B}-4)
$$

It is reasonable as a first approximation that the area of the distorted cross section is the same as the undistorted cross section. Equating the areas of the undistorted (Equation B-2) and distorted cross section (Equation B-4) gives

$$
\frac{4 \alpha W d_{\mathrm{m} \alpha}}{(\alpha+1)(2 \alpha+1)}=\frac{2}{3} \mathrm{Wd}_{\mathrm{m}} \Rightarrow \frac{d_{m \alpha}}{d_{\mathrm{m}}}=\frac{(\alpha+1)(2 \alpha+1)}{6 \alpha}
$$

This can be checked for consistency; with $\alpha=1$, then $\mathrm{d}_{\mathrm{m} \alpha} / \mathrm{d}_{m}=1$. When $\alpha=$ 2 , then $\mathrm{d}_{\mathrm{m} \alpha} / \mathrm{d}_{m}=5 / 4=1.25$. When $\alpha=3$, then $\mathrm{d}_{\mathrm{m} \alpha} / \mathrm{d}_{m}=14 / 9=1.56$. The distortion in the cross section for this analytical expression is presented in Figure B-2 for values of $\alpha$ of 1, 2, 3, 4, and 5.

Figure B-2 Distortion of the parabolic cross section for increasing values of $\alpha$ greater than 1.

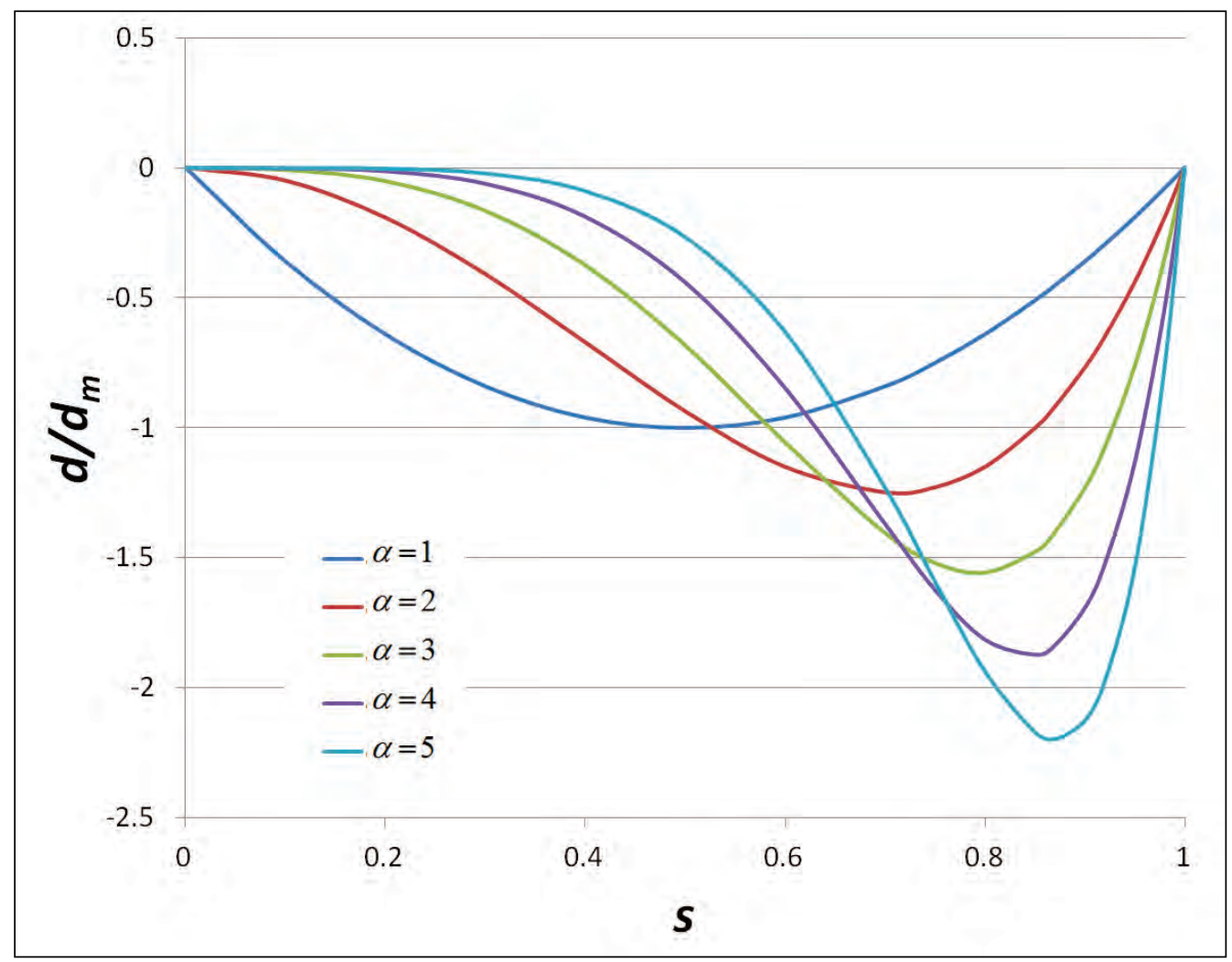


The effect of $\alpha$ on the ratio of the maximum depths $\left(\mathrm{d}_{\mathrm{m} \alpha} / \mathrm{d}_{m}\right)$ is presented in Figure B-3. The relationship is almost linear. Taking the derivative of the expression above with respect to $\alpha$ gives

$$
\frac{\mathrm{d}}{\mathrm{d} \alpha}\left(\mathrm{d}_{\mathrm{m} \alpha} / \mathrm{d}_{\mathrm{m}}\right)=\frac{1}{3}-\frac{1}{6 \alpha^{2}}
$$

For a value of $\alpha$ of 1 , the slope of the curve is $1 / 6$; with increasing value of $\alpha$, the slope of the relationship asymptotes to a slope of $1 / 3$. These slopes are plotted in Figure B-3. This illustrates that the dependence of the ratio of the peak depths in the cross section is almost linear with $\alpha$.

Figure B-3 Effect of the distortion exponent on the ratio of maximum water depths.

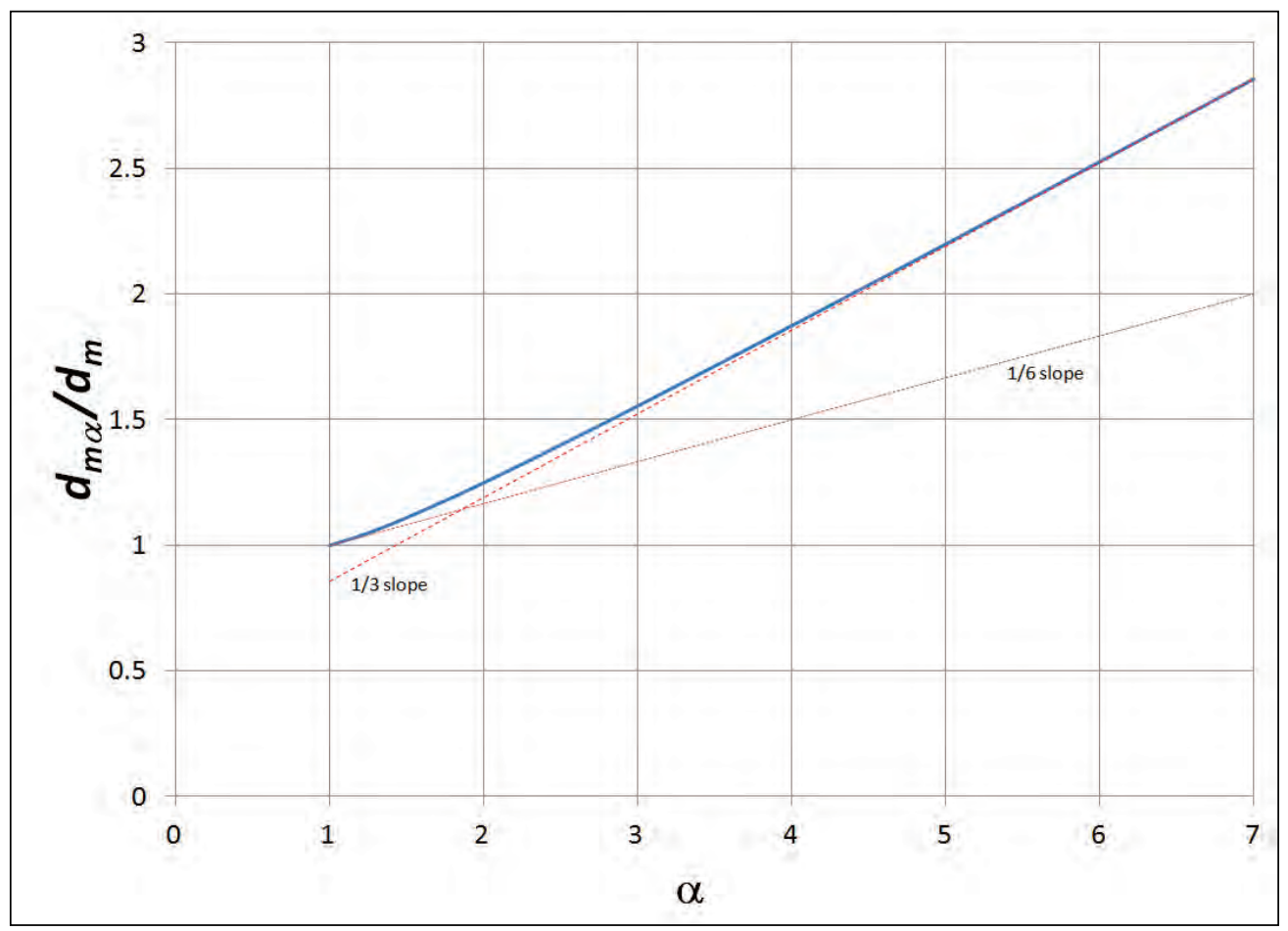

Substituting Equation B-5 into B- 3 yields an expression for the distorted cross section relative to the maximum depth of the undistorted cross section:

$$
d=4 d_{m} s^{\alpha}\left(1-s^{\alpha}\right) \frac{(\alpha+1)(2 \alpha+1)}{6 \alpha}
$$


The depth variation above is referenced to an elevation such that all depths are positive. In order to see a point bar emerge, the water level needs to be referenced as some fraction of the peak depth of the positive depth distribution (Figure B-4). Setting the threshold depth for bar emergence to a fraction $(\beta)$ of the peak depth (of the undistorted cross section), then the distance across the section to that depth can be solved iteratively using the following equation:

$$
\mathrm{S}_{\beta}=\left\{\frac{1}{\left(1-\mathrm{s}_{\beta}{ }^{\alpha}\right)} \frac{3 \alpha \beta}{2(\alpha+1)(2 \alpha+1)}\right\}^{\frac{1}{\alpha}}
$$

Figure B-4 Illustration of depth sensitivity for point-bar emergence.

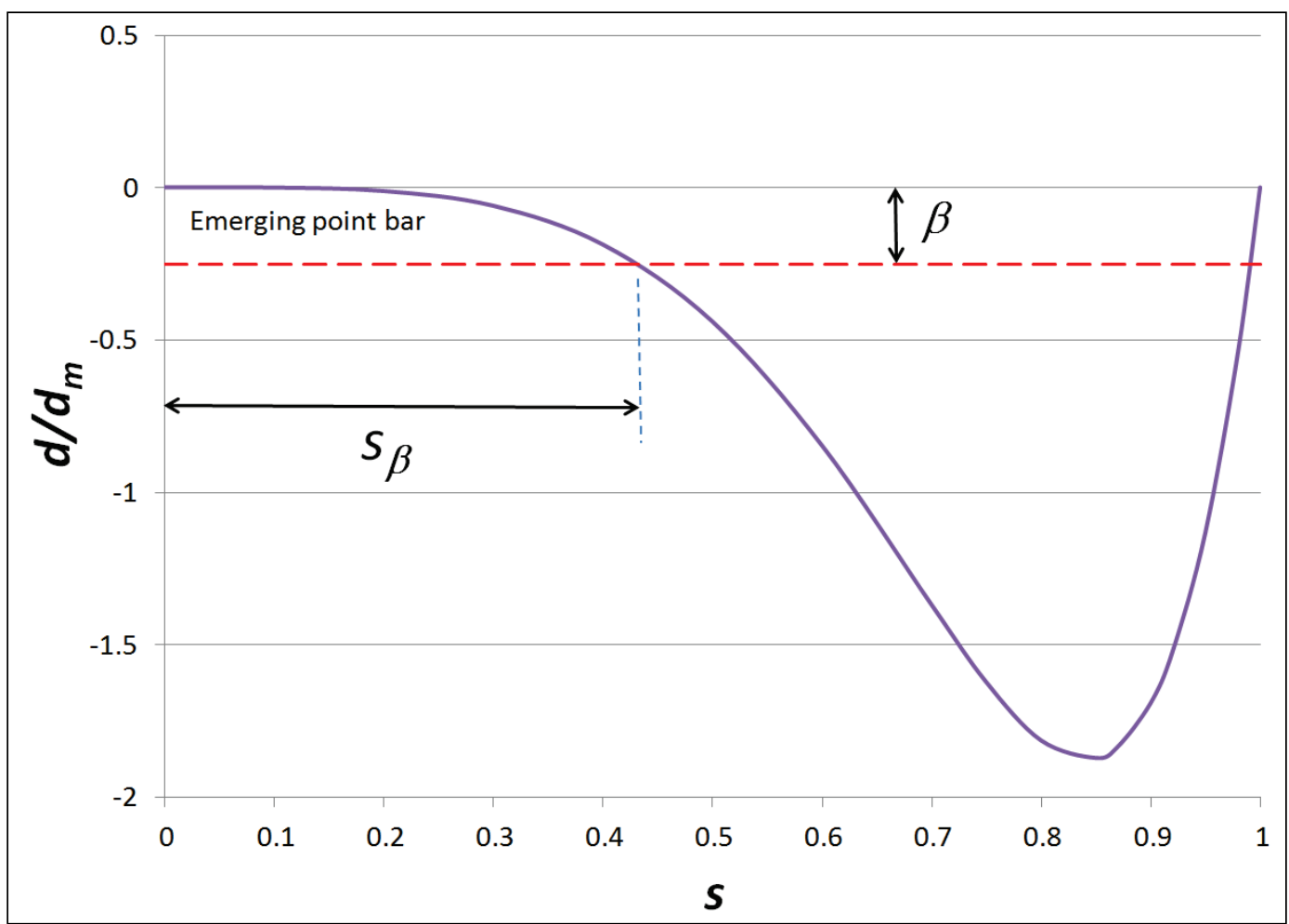

The point bar in the lower right in Figure B-1 extends approximately $40 \%$ across the channel width. That corresponds to a value of $\mathrm{s}_{\beta}=0.40$. Solving Equation B-8 for $\alpha$ is not simple. Another approach is to set $\beta$ and calculate the value of $\mathrm{s}_{\beta}$ for varying values of $\alpha$ and then inspect the results. This was done in Table B-1. For a distance across the channel of $40 \%$ (s = $0.40)$, the results in the table suggest that the distortion factor $(\alpha)$ for that cross section may be between 4 and 6 . 
Table B-1 Point-bar encroachment into cross section.

\begin{tabular}{|l|l|l|l|}
\hline \multicolumn{4}{|c|}{ Distance $\left(\mathbf{S}_{\beta}\right)$ to $\beta d_{m}$ is determined by $\alpha$ and $\beta$. } \\
\hline$\alpha$ & $\beta=0.05$ & $\beta=0.1$ & $\beta=0.25$ \\
\hline 2 & 0.1005 & 0.1429 & 0.2298 \\
\hline 3 & 0.2008 & 0.2537 & 0.3474 \\
\hline 4 & 0.2862 & 0.3410 & 0.4311 \\
\hline 5 & 0.3556 & 0.4094 & 0.4935 \\
\hline 6 & 0.4131 & 0.4641 & 0.5421 \\
\hline
\end{tabular}

\section{Application to field data}

The method just described was applied to the cross-section data collected by ERDC using ADCP as described in Chapter 5. It was discovered that in order to fit the field data more reasonably, a uniform depth offset was needed in Equation B-3, giving

$$
\mathrm{d}=\mathrm{d}_{0}+4 \mathrm{~d}_{\mathrm{m} \alpha} \mathrm{s}^{\alpha}\left(1-\mathrm{s}^{\alpha}\right)
$$

This offset is possibly the result of the pooling effect behind the Wallisville structures. Observations from aerial photographs show no point-bar emergence until above I- 10 . The locations of the ADCP cross sections measured by ERDC are shown in Figure B-5, located between the Wallisville structures and I- 10 .

The results of fitting Equation B-9 to the 18 transects are presented in Figure B-6 through Figure B-23. The fitting of Equation B-9 to the field cross sections was performed iteratively, using general visual judgment of the relative quality of the fit. Within each cross section, the equations were applied with the distance relative to the shoreline considered on the pointbar side of the river. 
Figure B-5 Locations of ADCP cross sections.

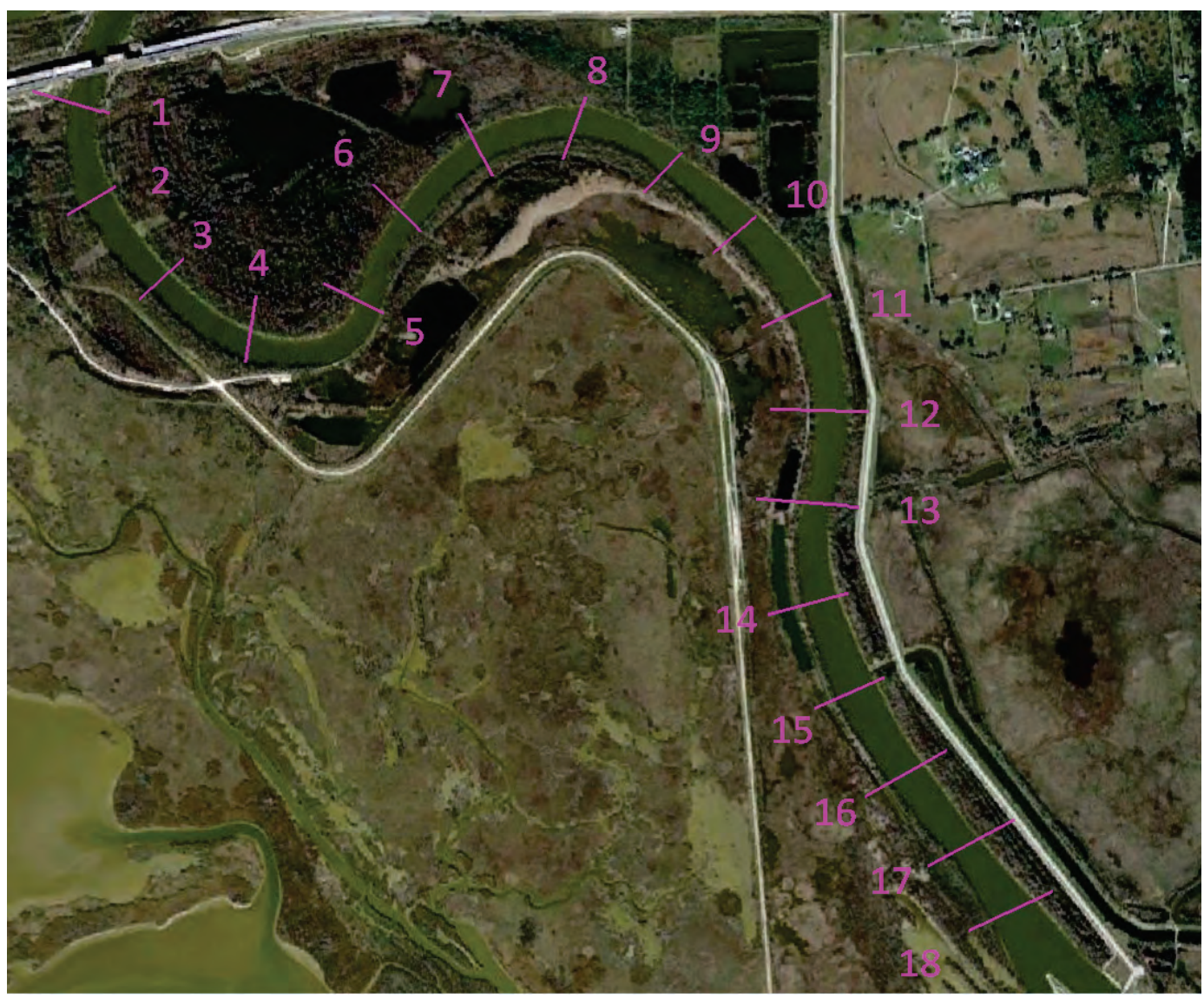

Figure B-6 Fit of Equation B-9 to ADCP cross section 1.

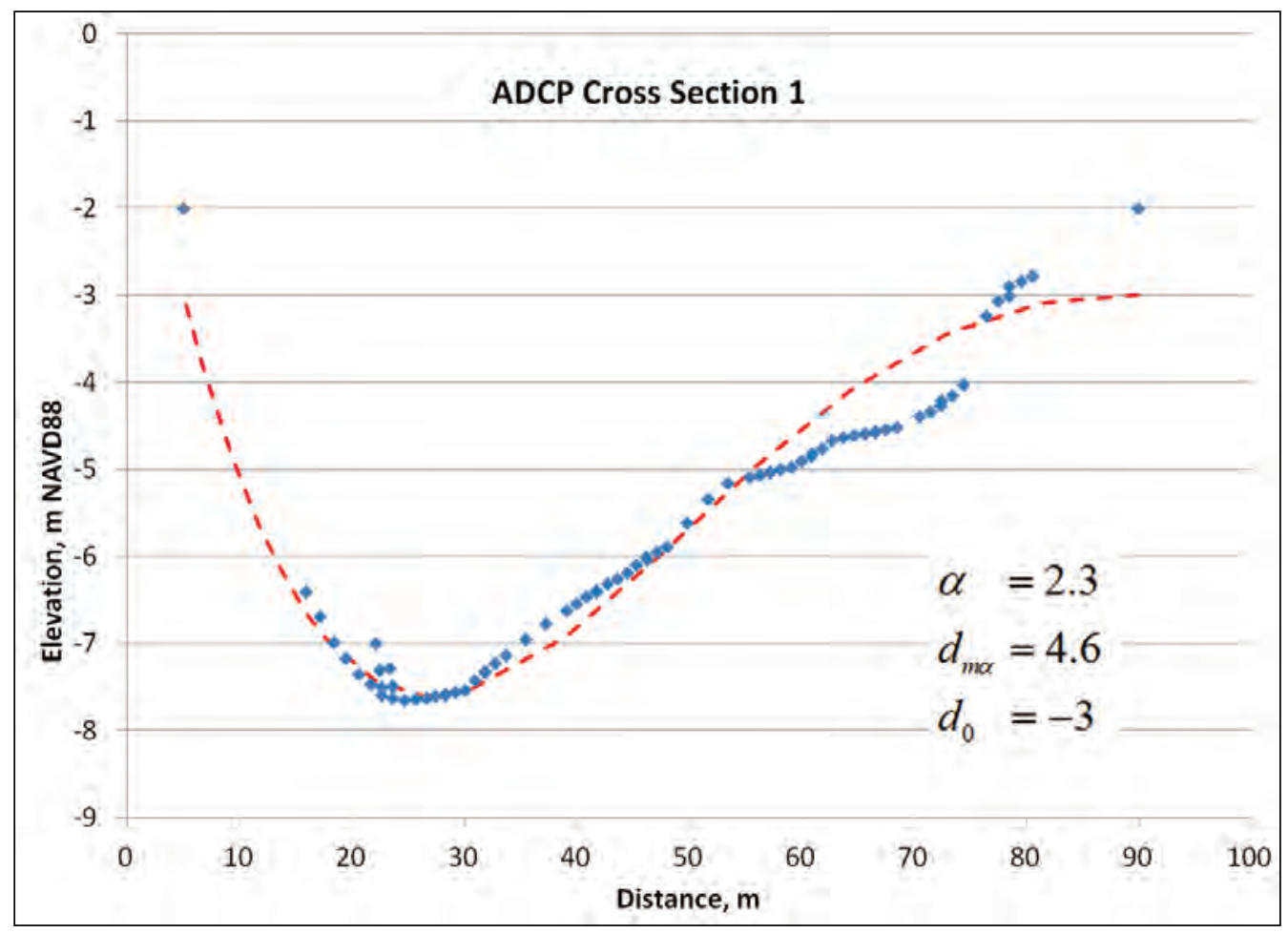


Figure B-7 Fit of Equation B-9 to ADCP cross section 2.

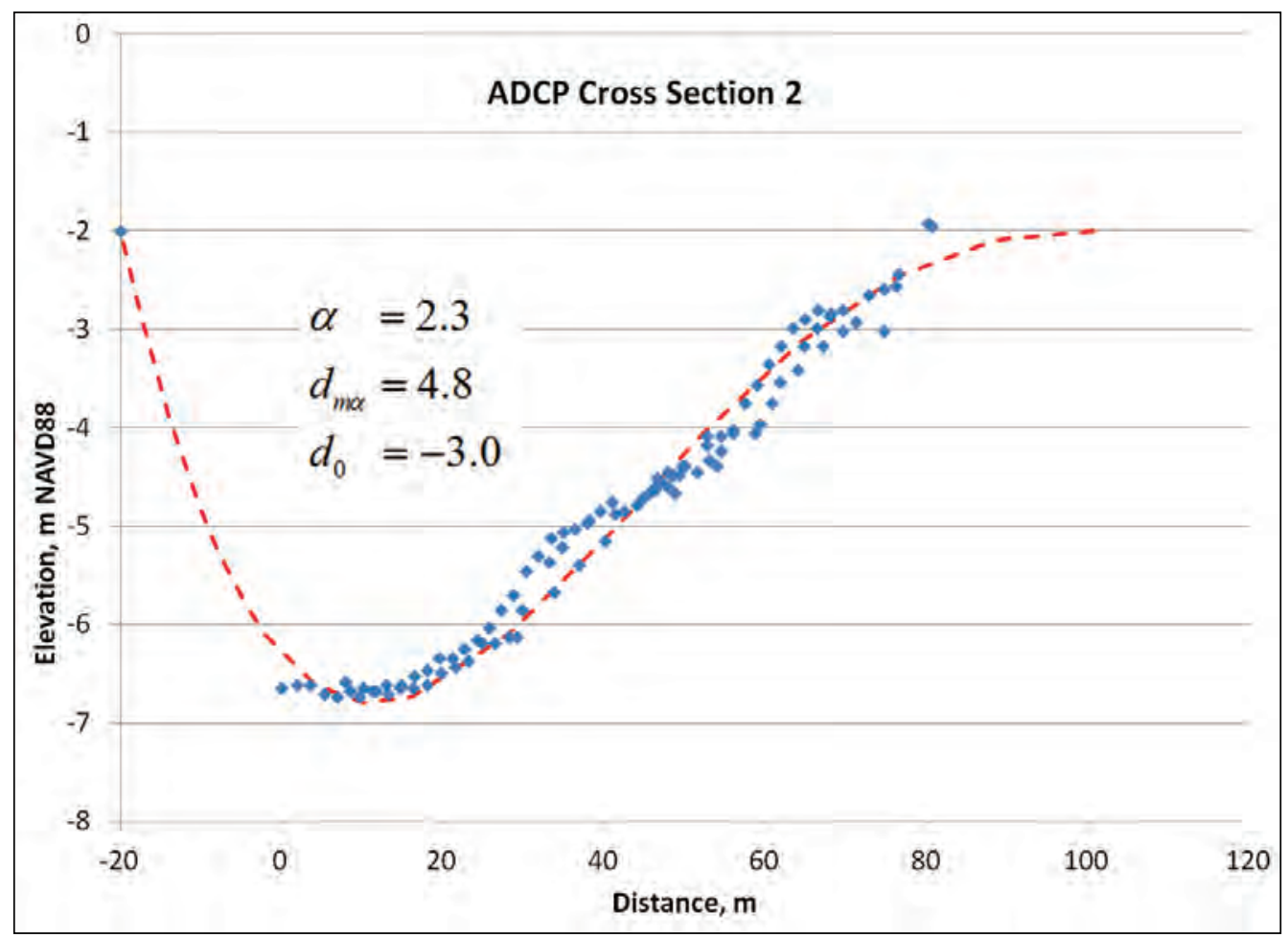

Figure B-8 Fit of Equation B-9 to ADCP cross section 3.

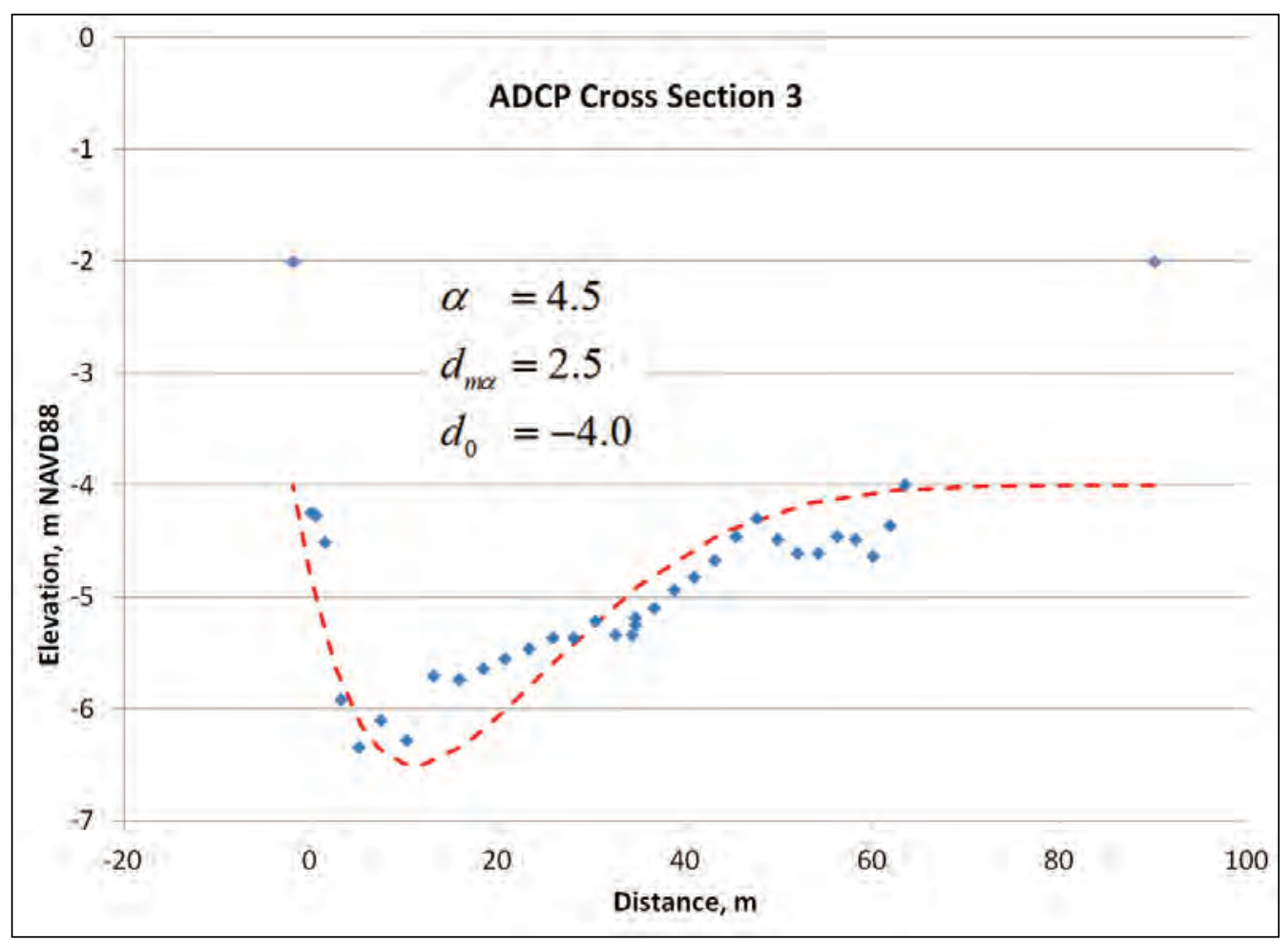


Figure B-9 Fit of Equation B-9 to ADCP cross section 4.

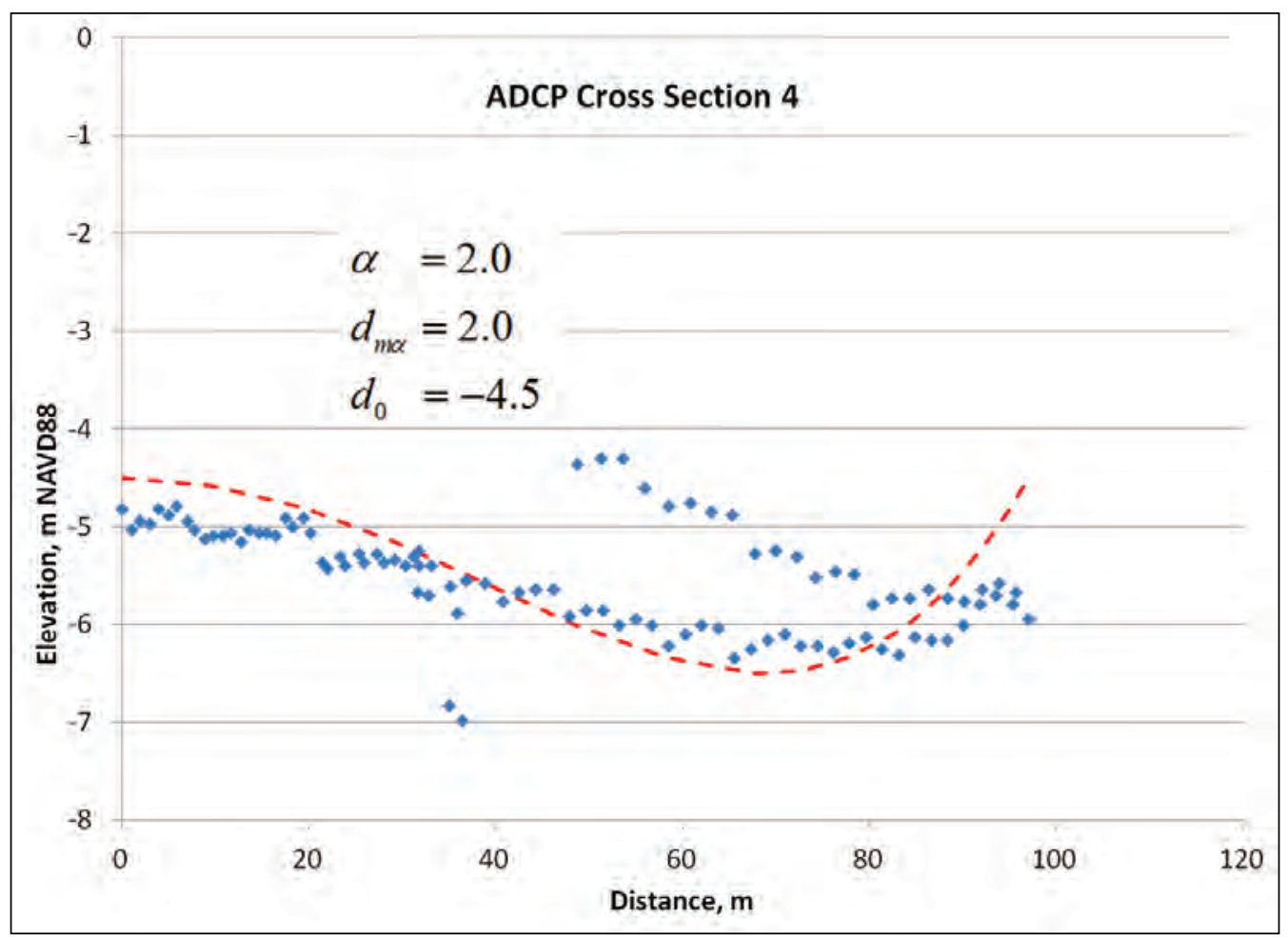

Figure B-10 Fit of Equation B-9 to ADCP cross section 5.

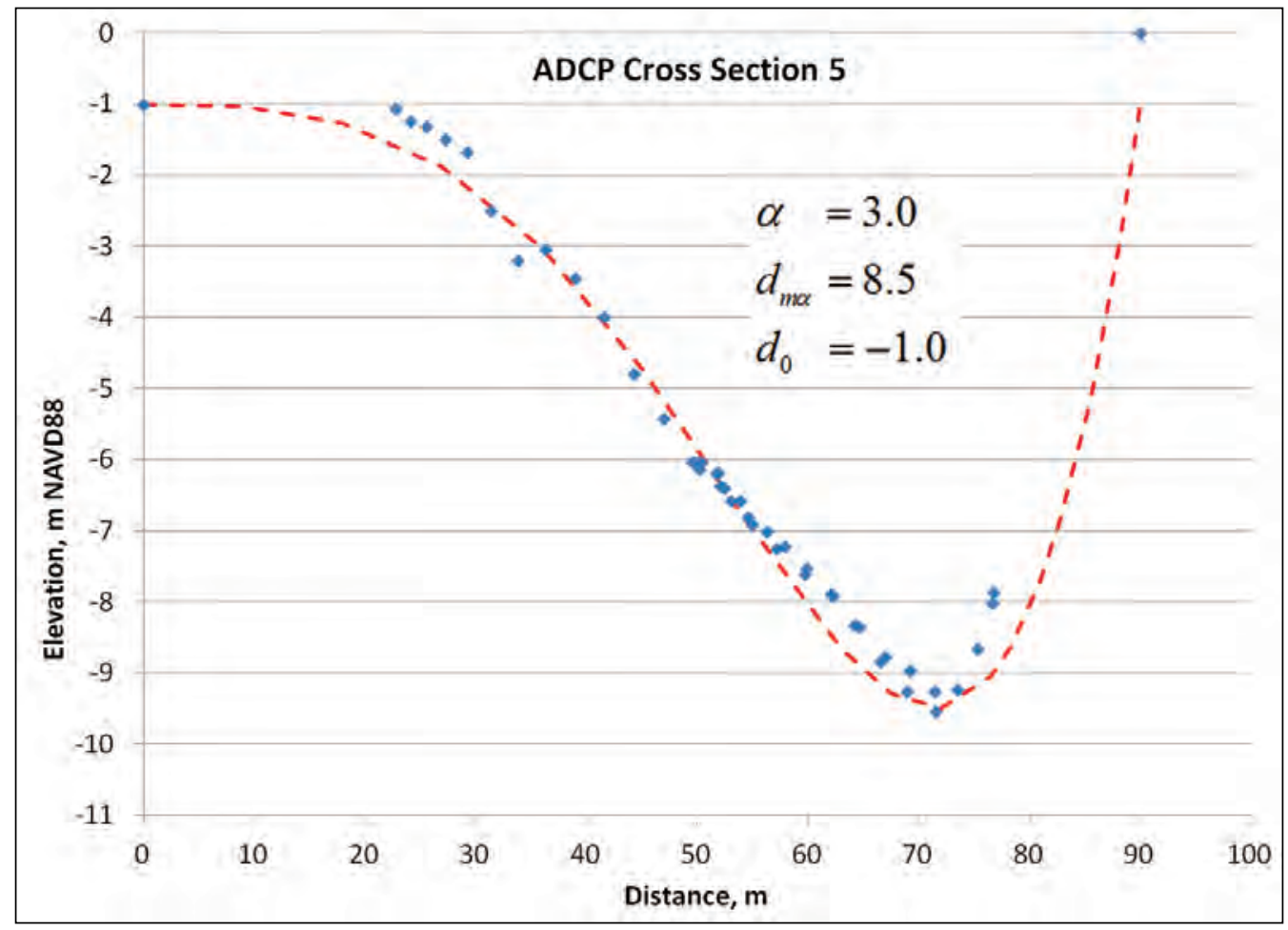


Figure B-11 Fit of Equation B-9 to ADCP cross section 6.

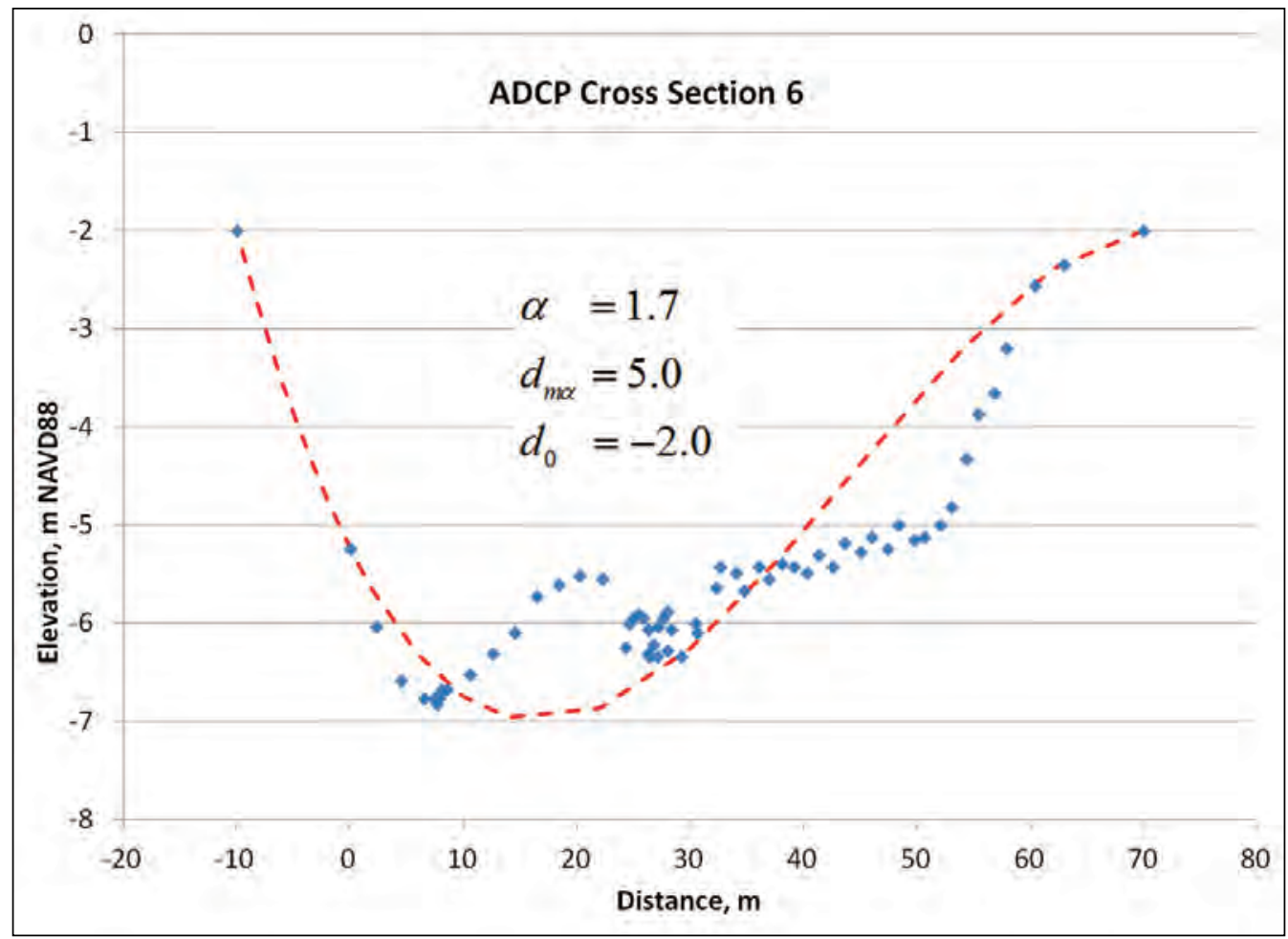

Figure B-12 Fit of Equation B-9 to ADCP cross section 7.

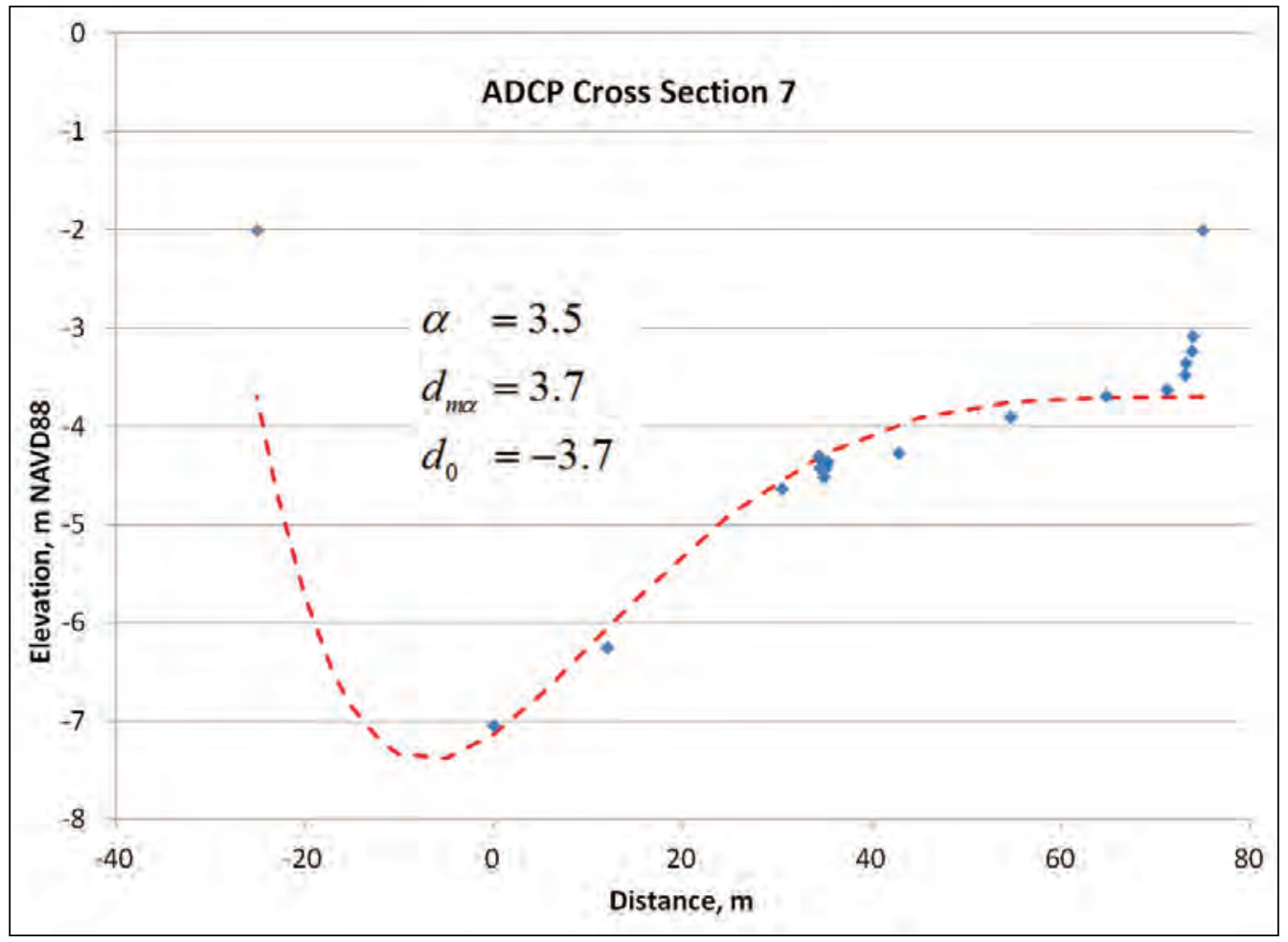


Figure B-13 Fit of Equation B-9 to ADCP cross section 8.

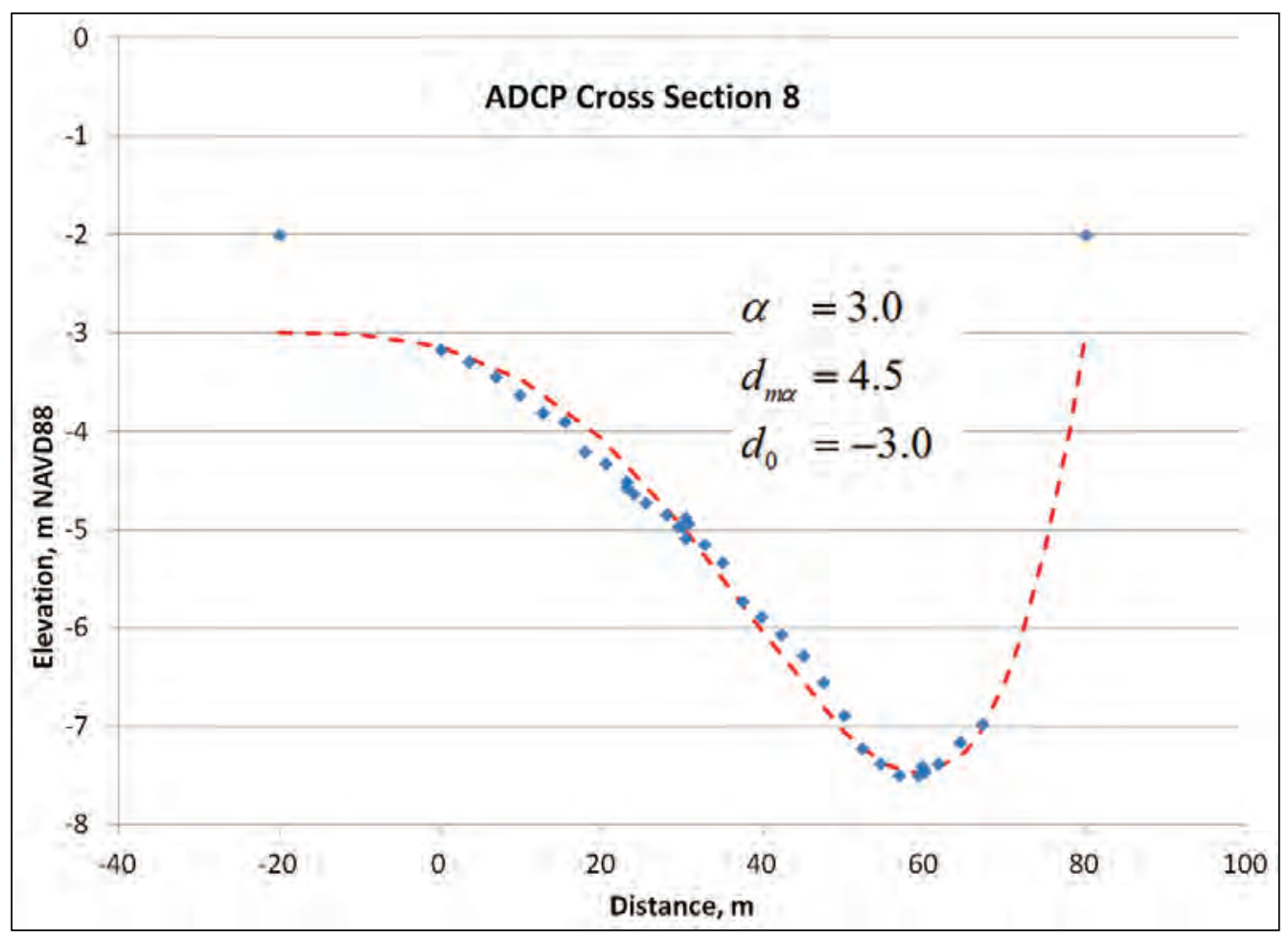

Figure B-14 Fit of Equation B-9 to ADCP cross section 9.

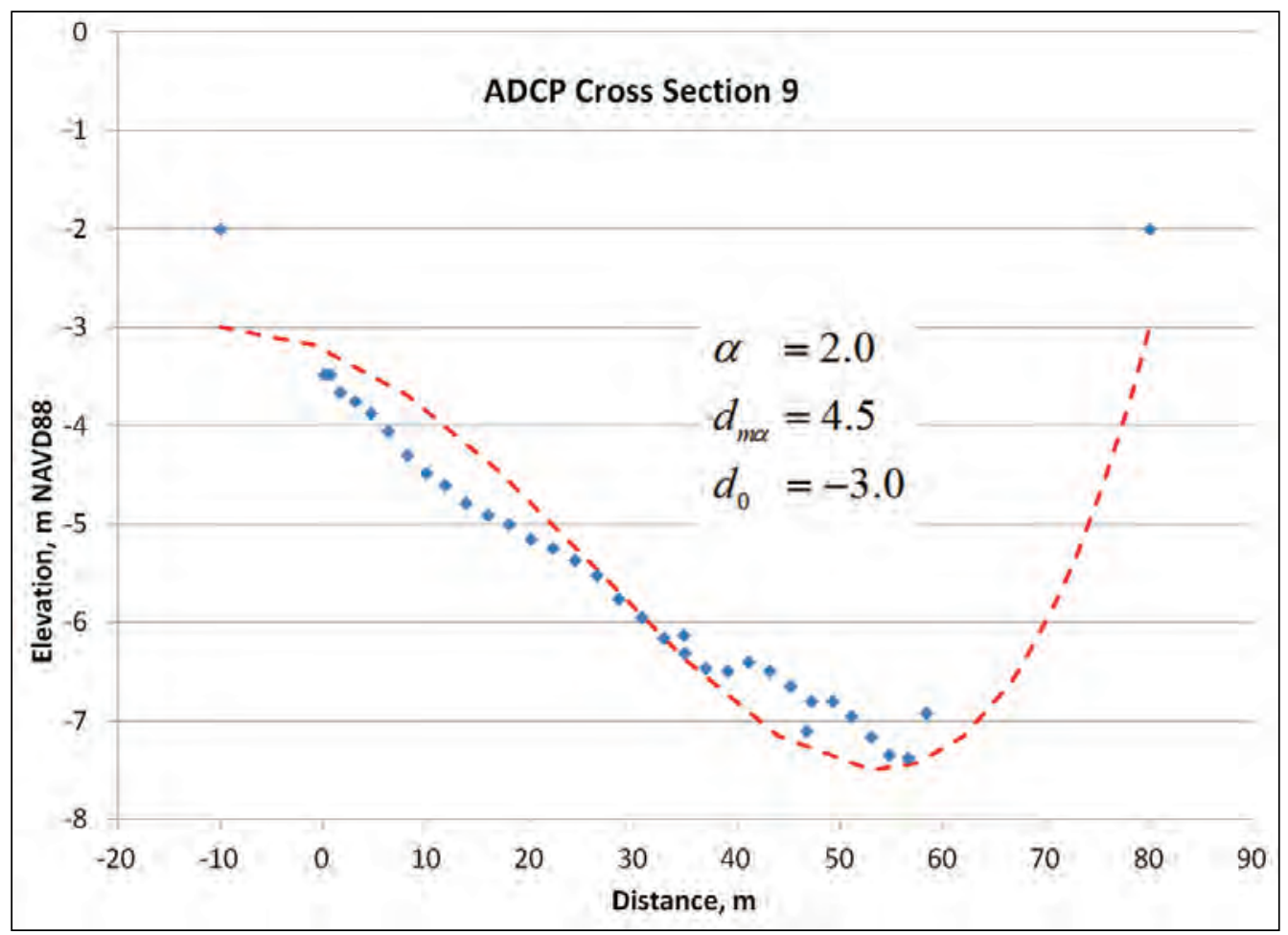


Figure B-15 Fit of Equation B-9 to ADCP cross section 10.

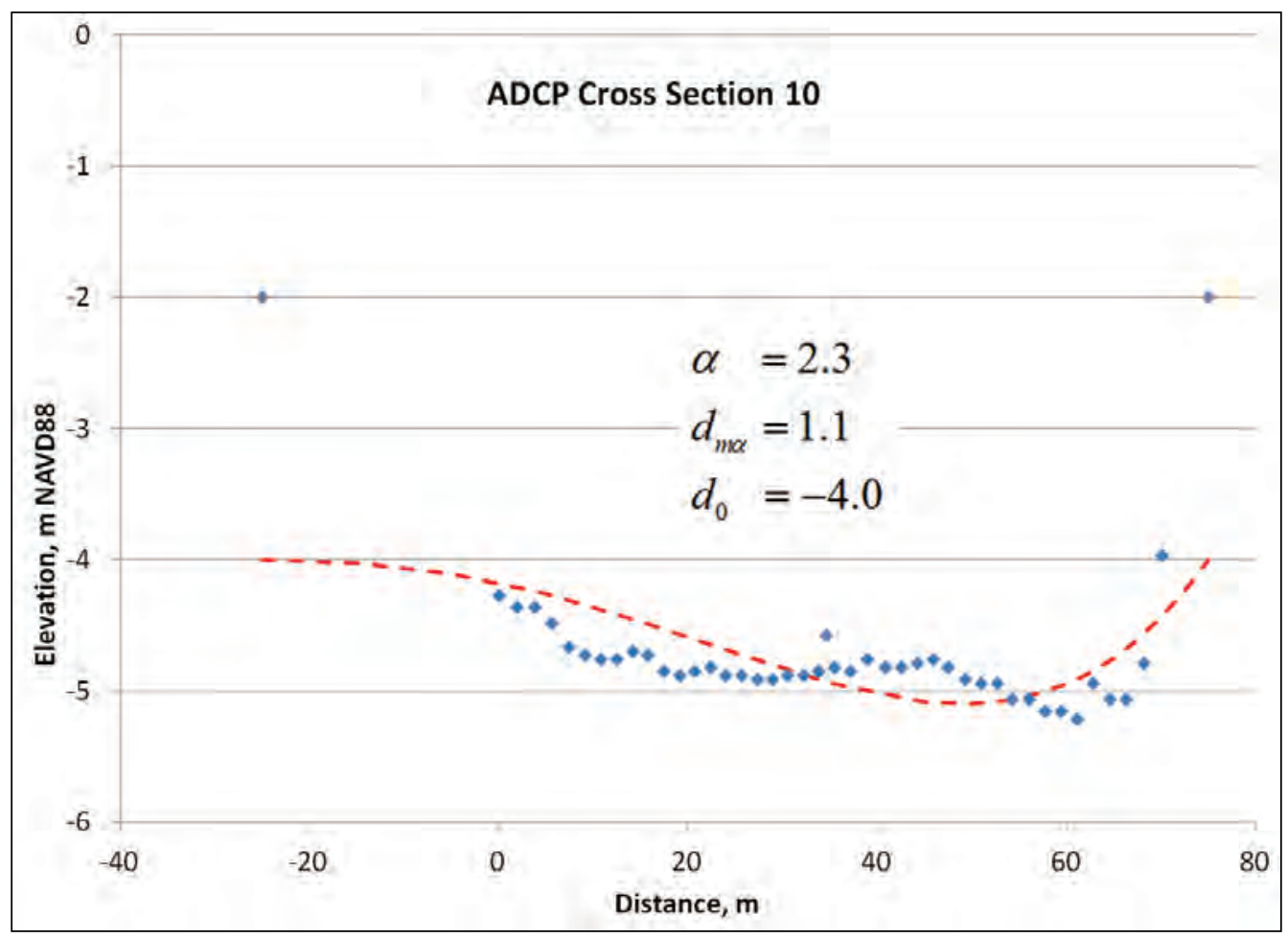

Figure B-16 Fit of Equation B-9 to ADCP cross section 11.

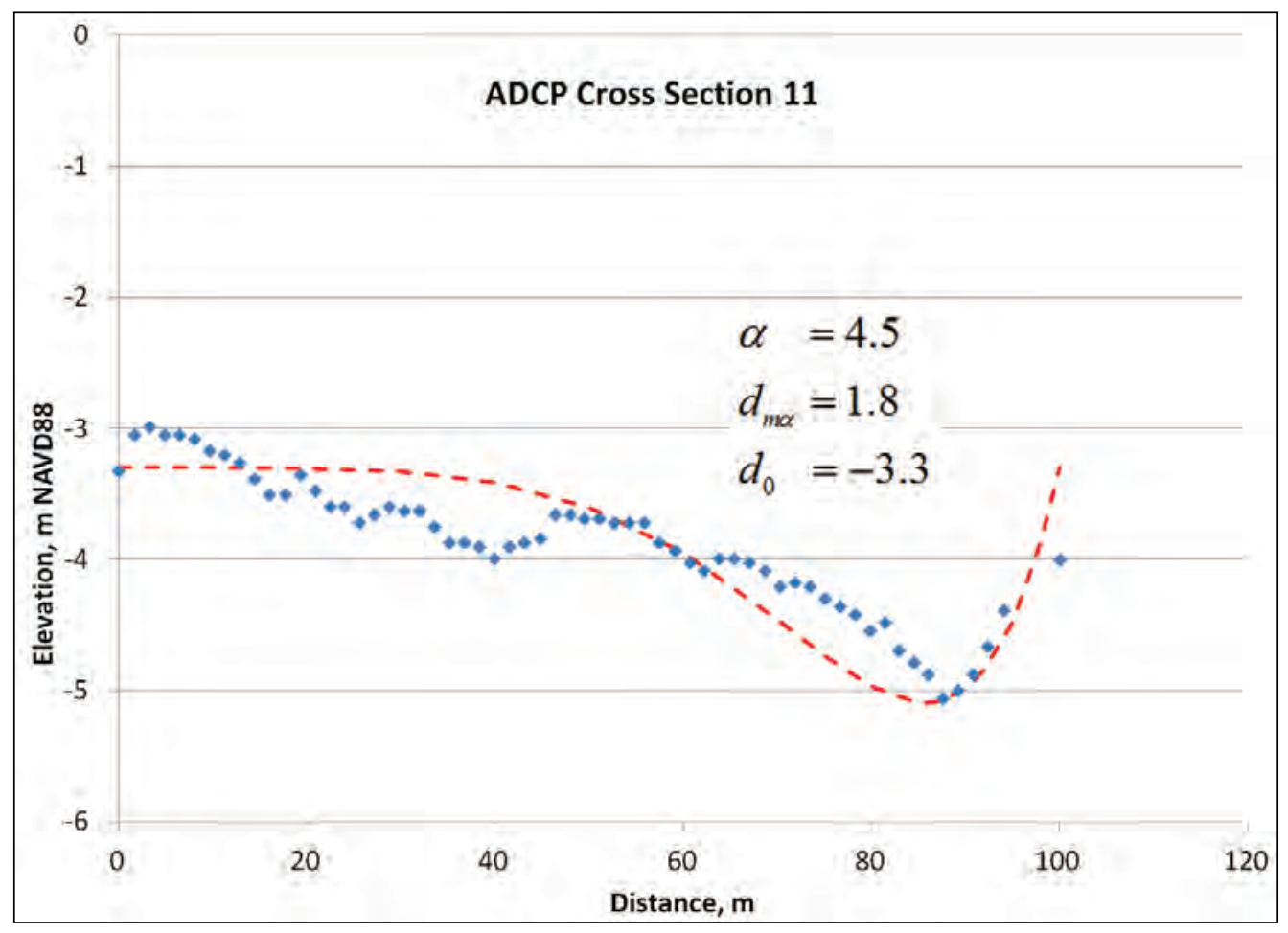


Figure B-17 Fit of Equation B-9 to ADCP cross section 12.

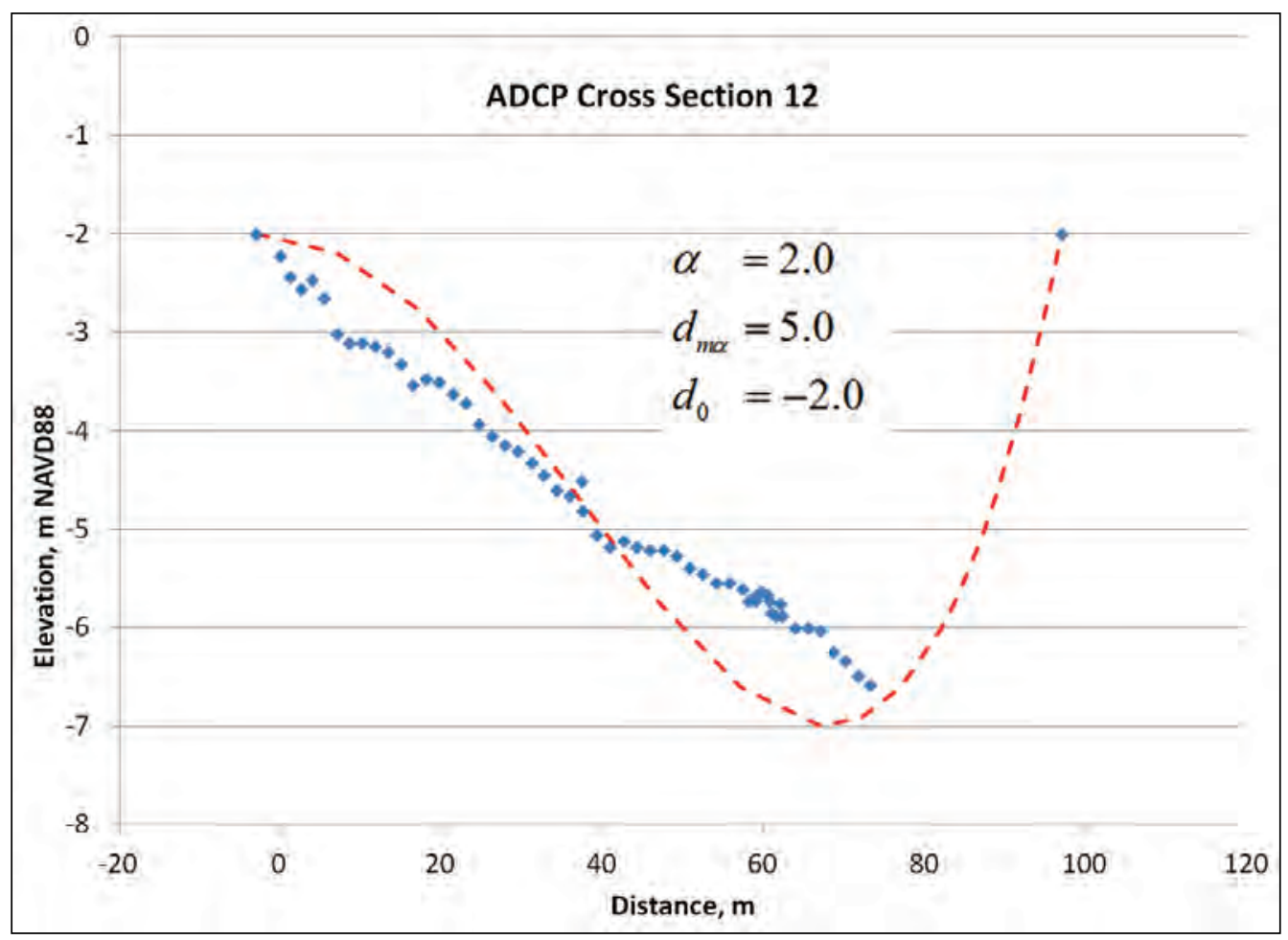

Figure B-18 Fit of Equation B-9 to ADCP cross section 13.

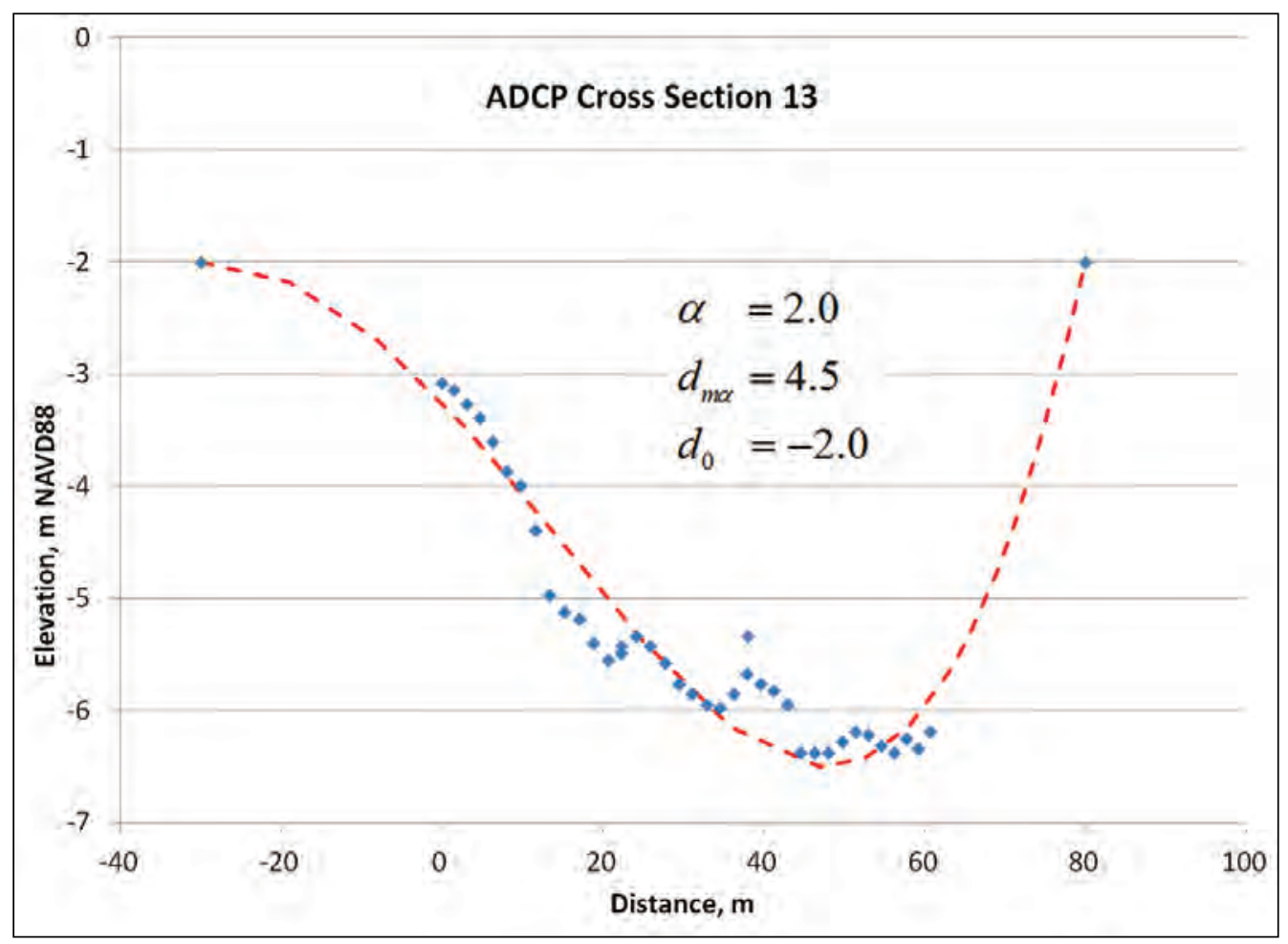


Figure B-19 Fit of Equation B-9 to ADCP cross section 14.

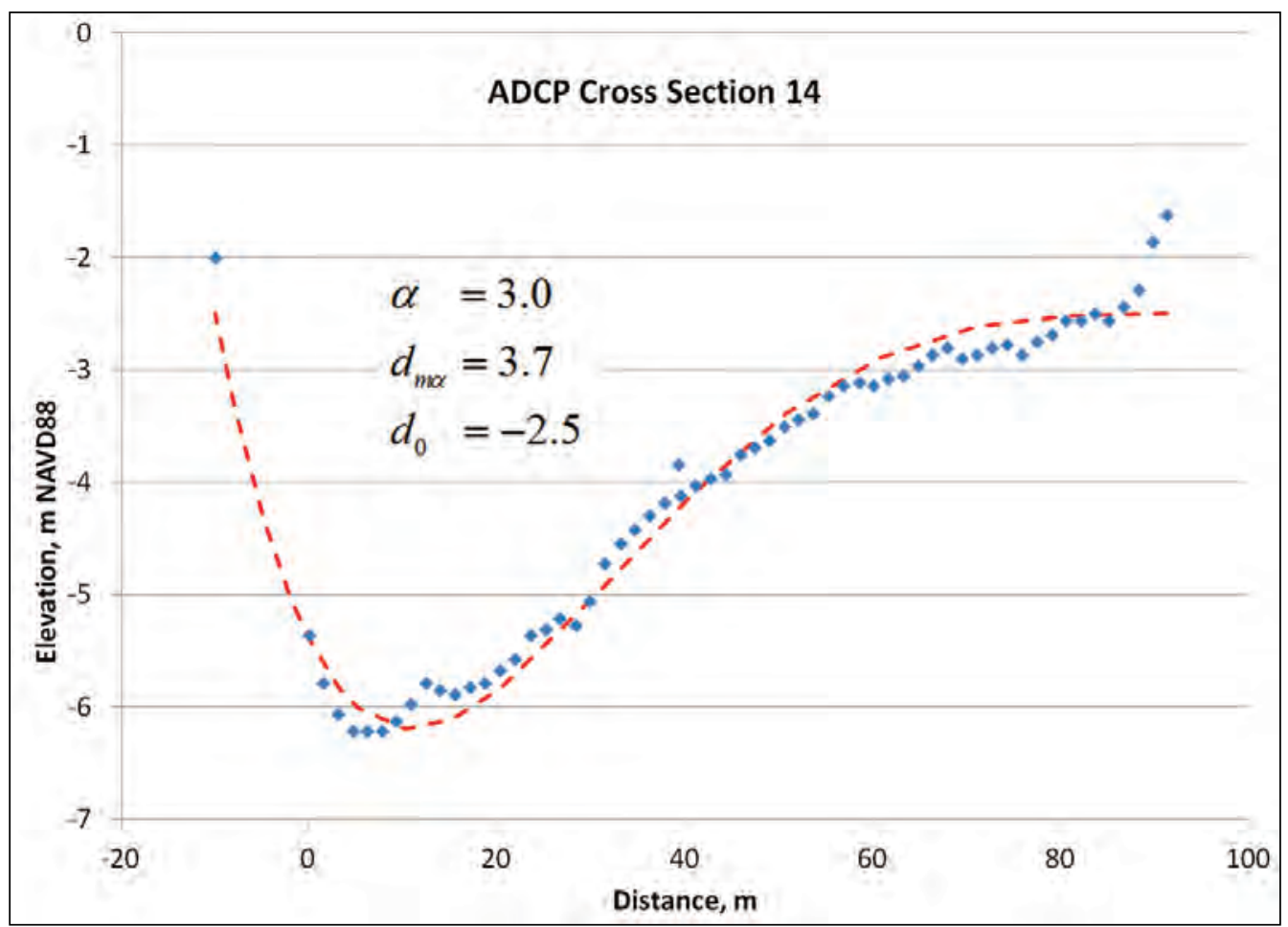

Figure B-20 Fit of Equation B-9 to ADCP cross section 15.

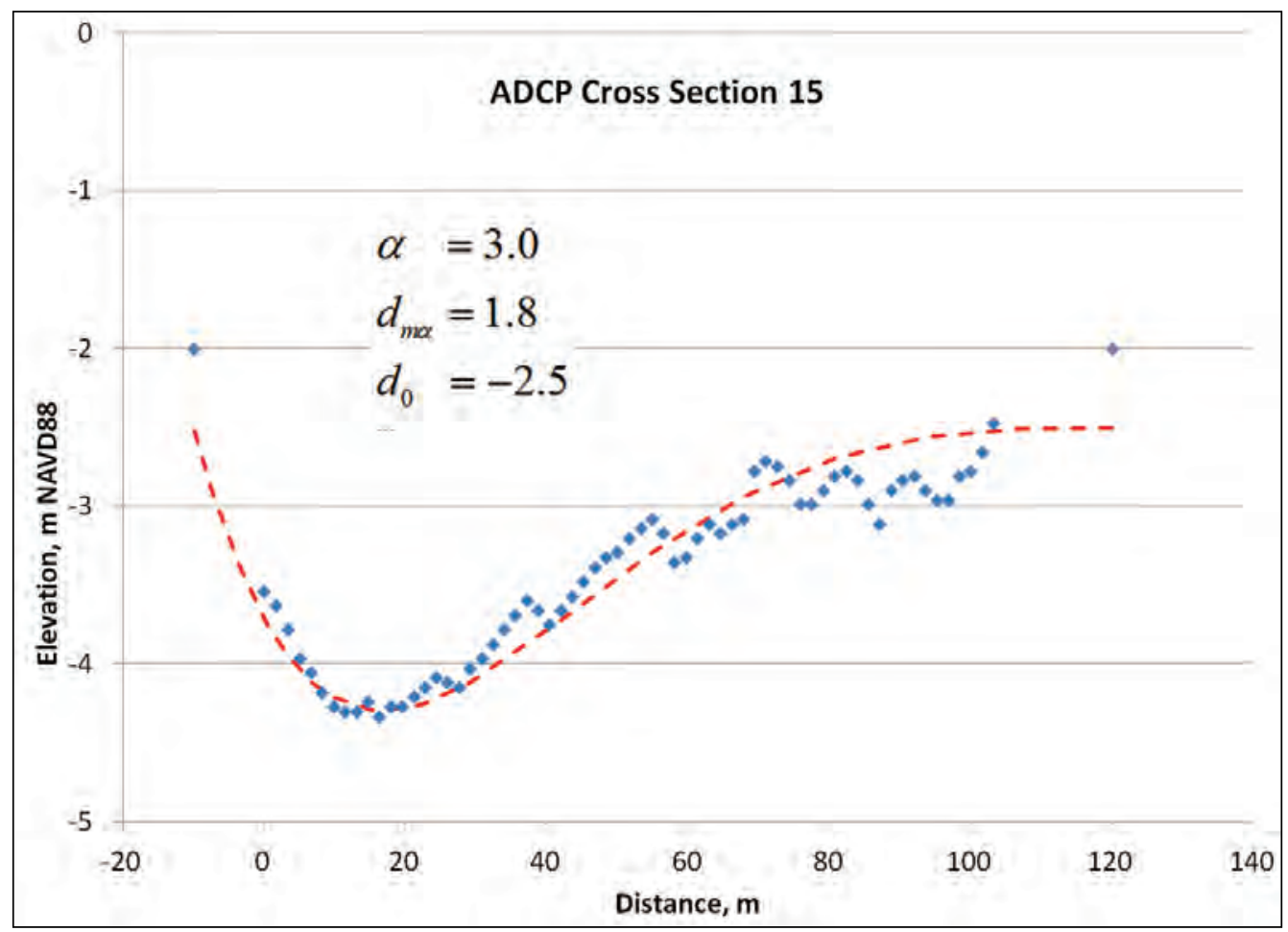


Figure B-21 Fit of Equation B-9 to ADCP cross section 16.

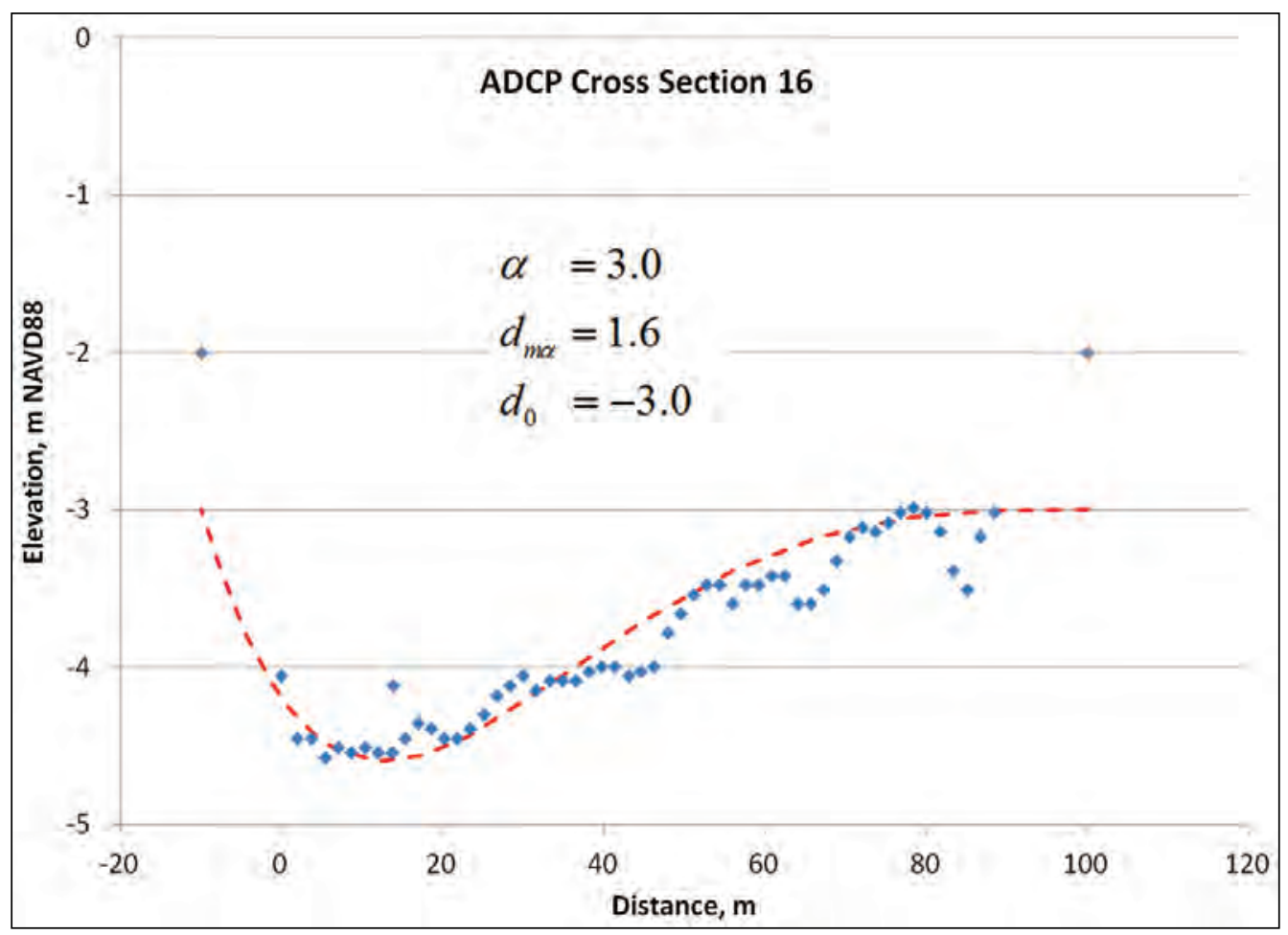

Figure B-22 Fit of Equation B-9 to ADCP cross section 17.

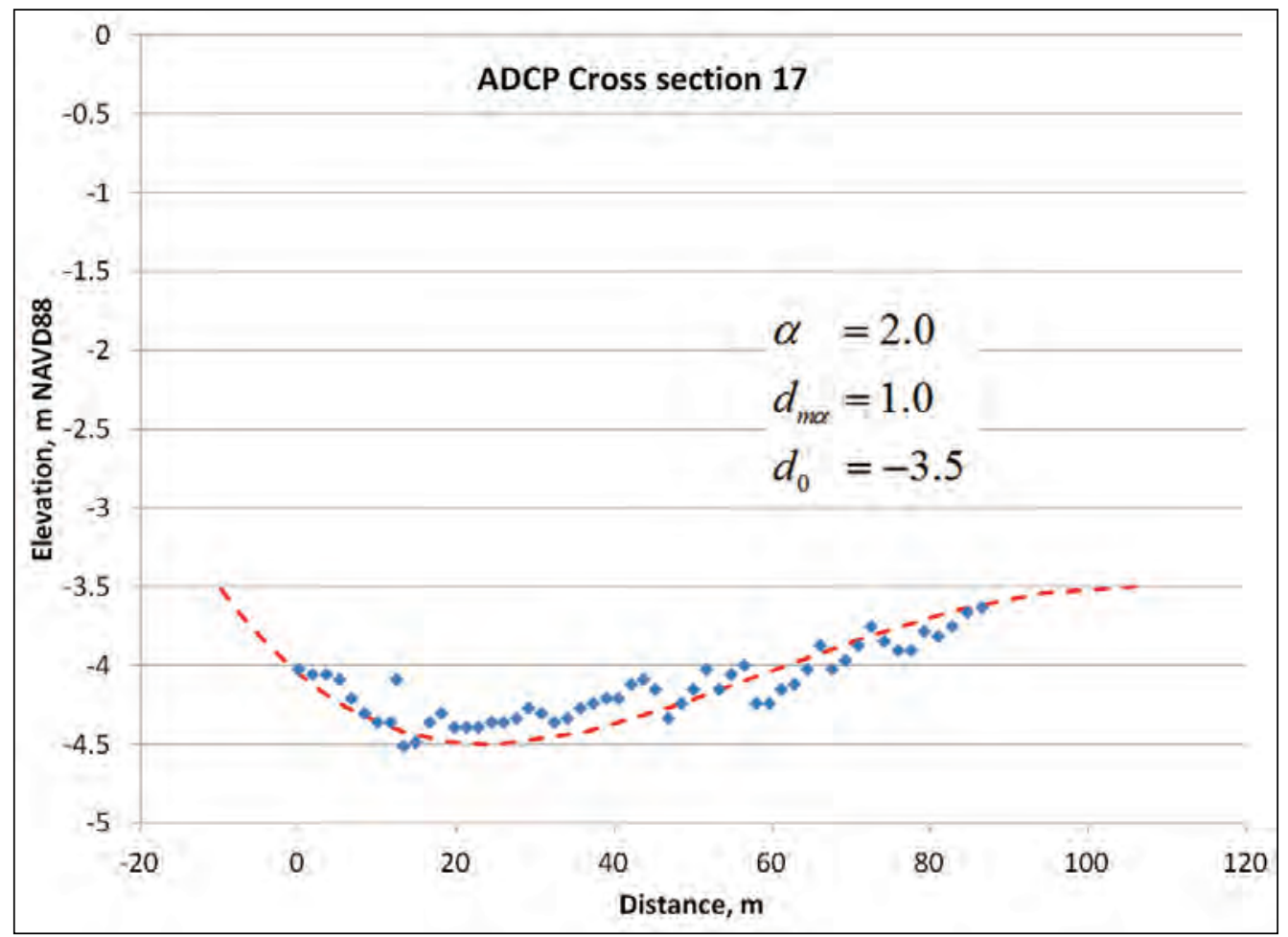


Figure B-23 Fit of Equation B-9 to ADCP cross section 18.

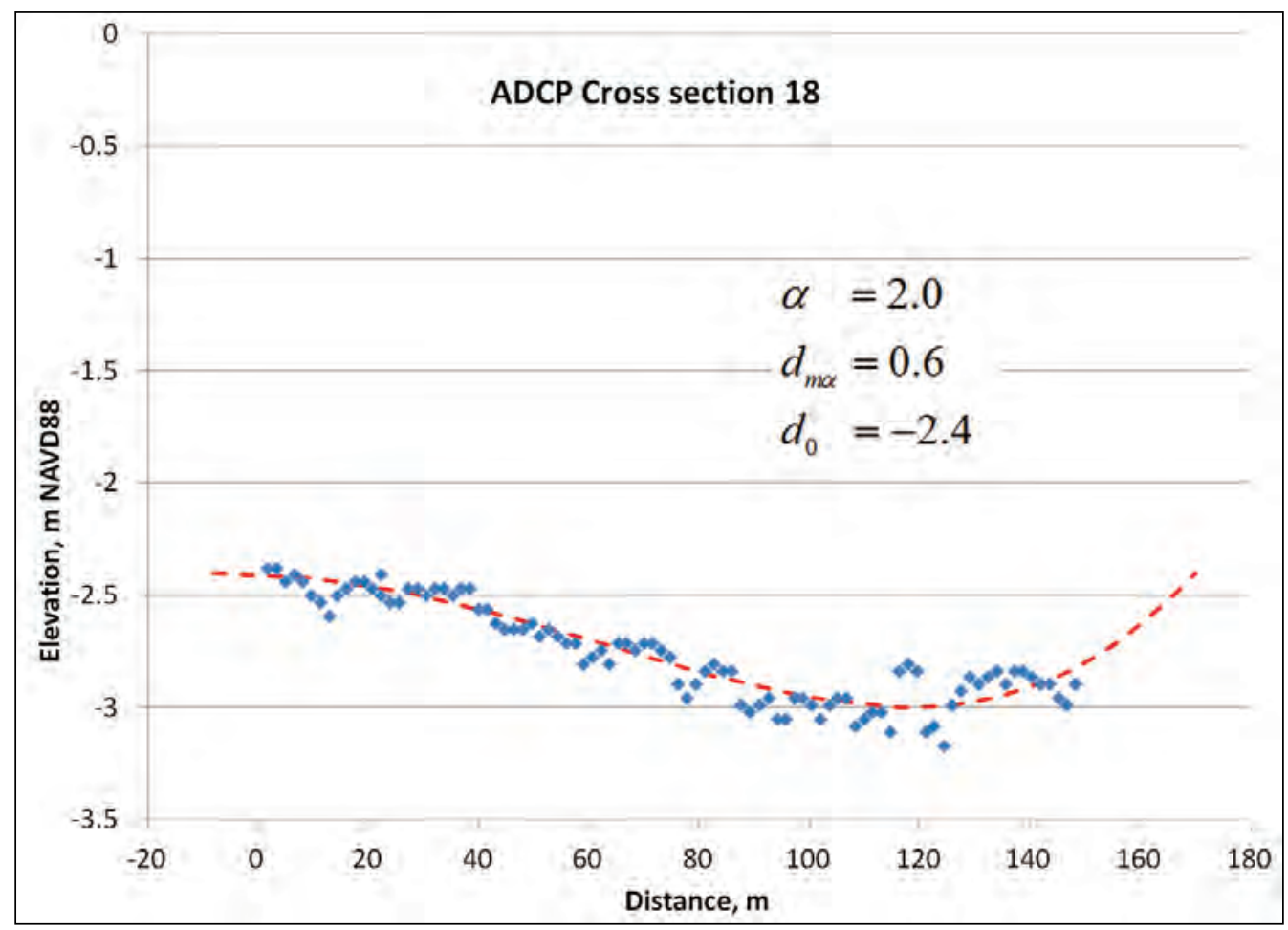

\section{Application north of I-10}

The application of the methodology to the reaches above I-10 required that the local distortion factors be related to the approximate radius of curvature of the river bends. Inspection of aerial photographs over the entire river shows that the greatest extent of point bars tends to occur slightly downstream of the sharpest shoreline radius of curvature. The maximum distortion was inferred from the extent of the point bars. The peak distortion was applied just downstream of the apex of the bends in the river and assumed to vary linearly along the axis of the river, diminishing toward the crossings on either side. The crossings were assumed to have no distortion, having a distortion factor of 1.0.

The application of the distorted bathymetric fit was performed to a series of segments along the river. The example reach shown in Figure B-1 is illustrated in Figure B-24, showing the division of the river into segments assumed to run from crossing to crossing or over an extended crossing. The general methodology is shown in Figure B-25. The ends of each river segment are assumed to have no cross-sectional distortion $(\alpha=0)$. The shoreline side of the reach marked with the red dot is considered the pivot point for the application of the distortion, with the peak distortion $\left(\alpha_{\max }\right)$ 
Figure B-24 AdH model mesh development in the vicinity of the observed Trinity River bendway. The division of the river channel into segments for the application of the analytical bathymetric bendway distortion is illustrated.

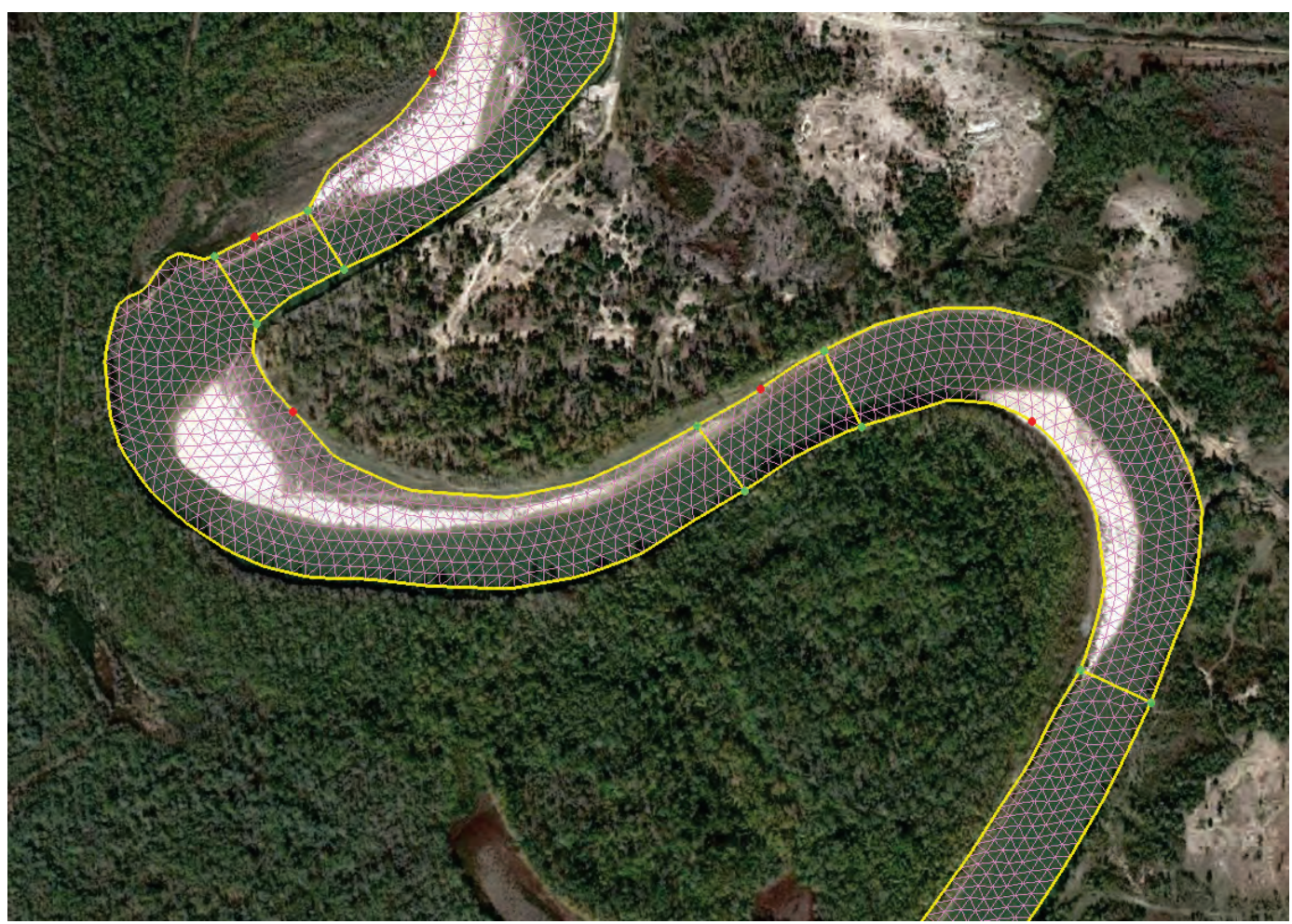

Figure B-25 Methodology for the application of the cross-section distortion above I-10. Cross sections were generated at vertices along the shoreline arcs.

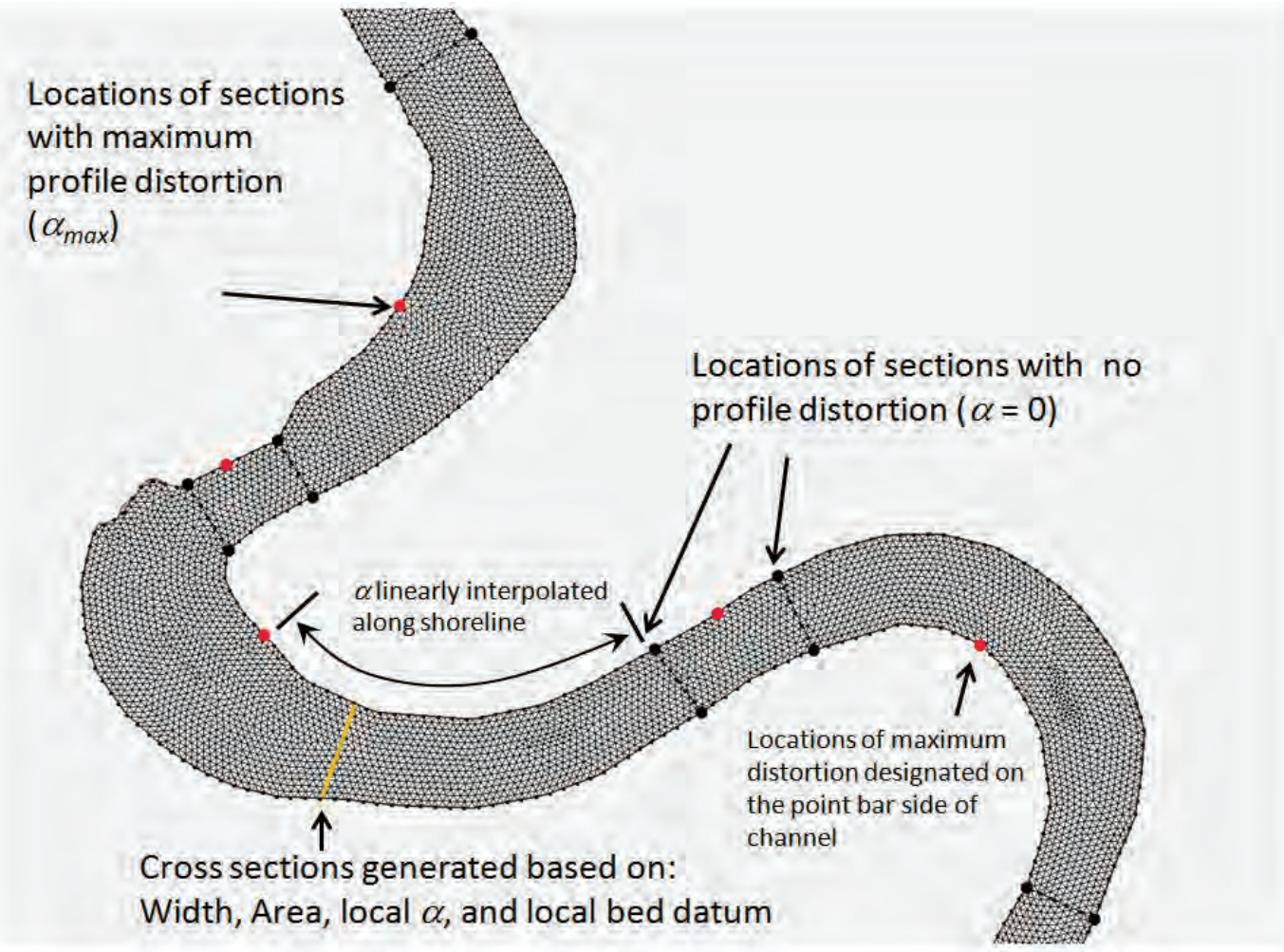


within the cross section at that point. The value of $\alpha$ is linearly interpolated between the pivot points and the crossings at the ends of the reach segment. Within each cross section, the width is defined from the horizontal geometry. With an assumed value of $\alpha$ and a constant crosssectional area (reasonable as a first approximation), the peak depth in the distorted cross section can be solved from Equation B-4 as

$$
\mathrm{d}_{\mathrm{m} \alpha}=\frac{\mathrm{A}(\alpha+1)(2 \alpha+1)}{4 \alpha W}
$$

The bed elevation offset $\left(\mathrm{d}_{0}\right)$ as included in Equation B-9 was applied as a general bed slope that varies between $-3 \mathrm{~m}$ at Wallisville to $+0.5 \mathrm{~m}$ at Liberty. The sinuous distance along the river is approximately $54 \mathrm{~km}$ between Wallisville and Liberty, giving a bed slope of 0.00006 . The full extent of the segments over which this analytical method was applied is shown in Figure B- 26.

Figure B-26 Overall extent of river segments with analytically generated bathymetry using the bendway distortion methodology.

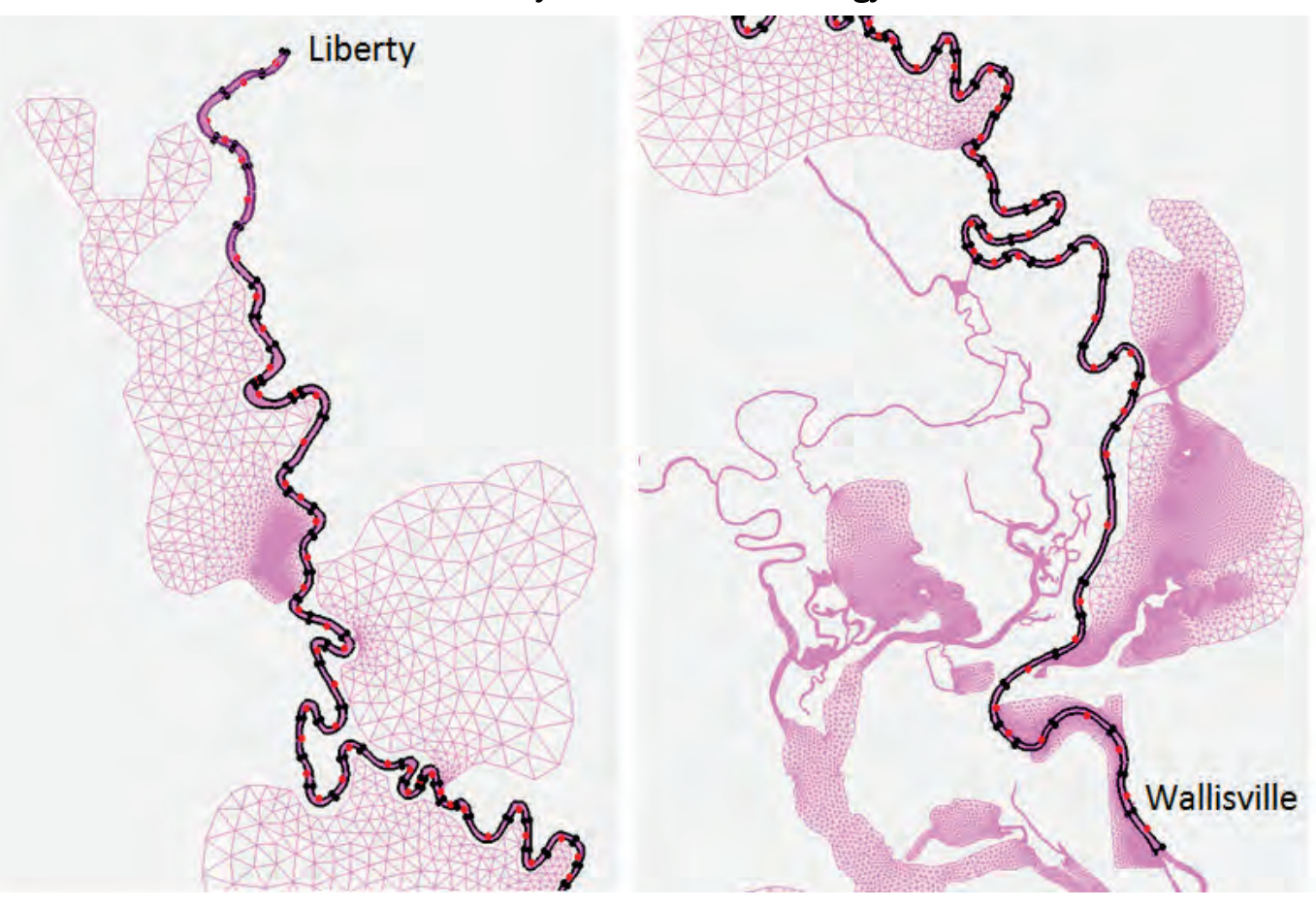

The generation of the cross sections was accomplished by a task-specific computer code, developed for this project, that generated data values for all cross sections from which values were interpolated to the prescribed mesh resolution via the Surface-water Modeling System (SMS). 
Model bathymetry for the river reach shown in Figure B-24, as computed, is shown in Figure B-27. This, and other computed bathymetries, was interpolated onto the model mesh from the calculated distorted cross sections.

Figure B-27 Example of the analytically developed bathymetry in the numerical model.

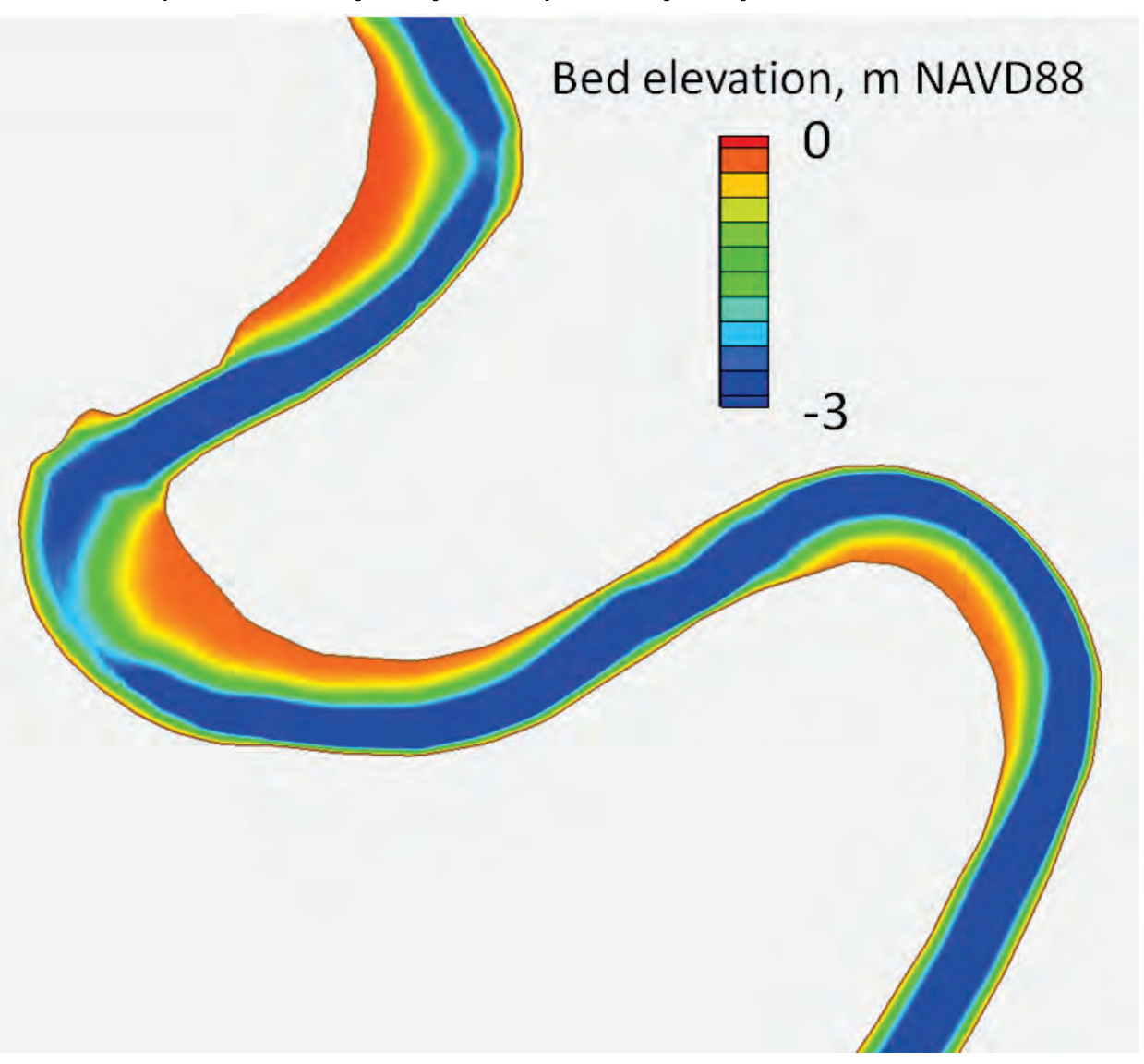




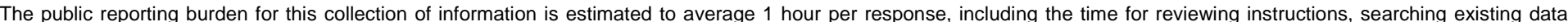

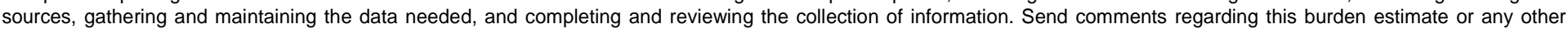

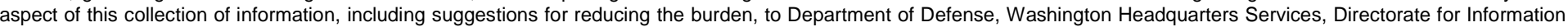

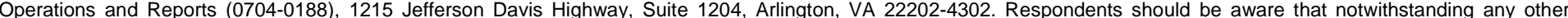
provision of law, no person shall be subject to any penalty for failing to comply with a collection of information if it does not display a currently valid OMB control number. PLEASE DO NOT RETURN YOUR FORM TO THE ABOVE ADDRESS.

\begin{tabular}{l|l|l}
\hline 1. REPORT DATE & 2. REPORT TYPE & 3. DATES COVERED (From - To) \\
February 2015 & Final report & May 2012 - May 2014
\end{tabular}

\section{TITLE AND SUBTITLE}

5a. CONTRACT NUMBER

Numerical Modeling of Trinity River Shoaling below Wallisville, TX

5b. GRANT NUMBER

5c. PROGRAM ELEMENT NUMBER

6. AUTHOR(S)

5d. PROJECT NUMBER

Joseph V. Letter, Jr., Gary L. Brown, Robert McAdory,

and Thad C. Pratt

5e. TASK NUMBER

5f. WORK UNIT NUMBER

7. PERFORMING ORGANIZATION NAME(S) AND ADDRESS(ES)

U.S. Army Engineer Research and Development Center

Coastal and Hydraulics Laboratory

3909 Halls Ferry Road

Vicksburg, MS 39180

9. SPONSORING/MONITORING AGENCY NAME(S) AND ADDRESS(ES)

U.S. Army Corps of Engineers

Galveston District

2000 Fort Point Road

Galveston, TX 77550

8. PERFORMING ORGANIZATION REPORT NUMBER

ERDC/CHL TR-15-1

10. SPONSOR/MONITOR'S ACRONYM(S)

\section{DISTRIBUTION/AVAILABILITY STATEMENT}

Approved for public release; distribution is unlimited.

\section{SUPPLEMENTARY NOTES}

\section{ABSTRACT}

The Trinity River below the navigation lock and salinity control structure at Wallisville, Texas has experienced significant shoaling in recent years. The location of the shoal is immediately downstream of the confluence with the Old River Cut Off channel (ORCO), which has been enlarging and progressively carrying a greater fraction of the discharge at the expense of the Trinity River. The reduction in flow in the Trinity River below the ORCO has resulted in reduced sediment transport capacity which created the shoaling problem. This report presents the results of a numerical model study to evaluate alternatives for potential mitigation of the shoaling problem. The alternatives include dredging the shoal and placing the material into the ORCO, damming the ORCO and partial closure of the ORCO. The model results illustrate the basic problem of an elongated navigation channel with numerous distributary pathways for water and sediment within a deltaic system. The routing of all flow down the Trinity River will result in erosion of the current shoal, but shoaling will then occur below the next bayou that extracts flow from the river.

\section{SUBJECT TERMS}

Adaptive Hydraulics (AdH)

Hydrodynamic modeling

16. SECURITY CLASSIFICATION OF:

\begin{tabular}{|c|c|c|c|}
\hline & & & $\begin{array}{l}\text { 17. LIMITATION OF } \\
\text { ABSTRACT }\end{array}$ \\
\hline a. REPORT & b. ABSTRACT & $\begin{array}{ll}\text { c. } & \text { THIS } \\
& \text { PAGE }\end{array}$ & ABSTRACI \\
\hline UNCLASSIFIED & UNCLASSIFIED & UNCLASSIFIED & UNL \\
\hline
\end{tabular}

Navigation structures

Salt barrier

Sediment transport

17. LIMITATION OF

18. NUMBER OF PAGES

182
Trinity River

USACE Galveston District

9a. NAME OF RESPONSIBLE PERSON

Robert McAdory

19b. TELEPHONE NUMBER (Include area code) 601-634-3057 